\title{
Architecture and Community Variability within the Antelope Creek Phase of the Texas Panhandle
}

Christropher Ray Lintz

Texas State University

Follow this and additional works at: https://scholarworks.sfasu.edu/ita

Part of the American Material Culture Commons, Archaeological Anthropology Commons, Environmental Studies Commons, Other American Studies Commons, Other Arts and Humanities Commons, Other History of Art, Architecture, and Archaeology Commons, and the United States History Commons

Tell us how this article helped you.

This Article is brought to you for free and open access by the Center for Regional Heritage Research at SFA ScholarWorks. It has been accepted for inclusion in Index of Texas Archaeology: Open Access Gray Literature from the Lone Star State by an authorized editor of SFA ScholarWorks. For more information, please contact cdsscholarworks@sfasu.edu. 


\section{Architecture and Community Variability within the Antelope Creek Phase of the}

Texas Panhandle

\section{Creative Commons License}

(c) (i) (8)

This work is licensed under a Creative Commons Attribution-NonCommercial 4.0 International License 


\section{5}

Lintz, Christopher Ray

ARCHITECTURE AND COMMUNITY VARIABILITY WITHIN THE ANTELOPE CREEK PHASE OF THE TEXAS PANHANDLE

The University of Oklahoma

PH.D. 1984

\section{University}

Microfilms

International $300 \mathrm{~N}$. Zeeb Road. Ann Arbor.M1 18106

\section{Copyright 1984}

by

\section{Lintz, Christopher Ray}

All Rights Reserved 
THE UNIVERSITY OF OKTAHOMA

GRADUATE COTLEGE

ARCHITECTURE AND COMMUNITY VARIABILITY

WITHIN THE ANTELOPE CREEK IUHASE

OF THE TEXAS PANHANDLE

A DISSERTATION

SUBMITHED TO THE GRADUATE FACULTY

in partial fulfillment of the requirements for the

degree of

DOCTOR OF PHILOSOPHY

By

CHRISTOPHER RAY IINTZ

Norman, Oklahoma

1984 


\section{ARCHITECTURE AND COMAONITY VARIABIIITYY}

WITHIN THE ANTELOPE CREEK PHASE

OF THE TEXAS PANHANDLE

A DISSERTATION

APPROVED FOR THE DEPARTMIENT OF ANTHROPOLOGY

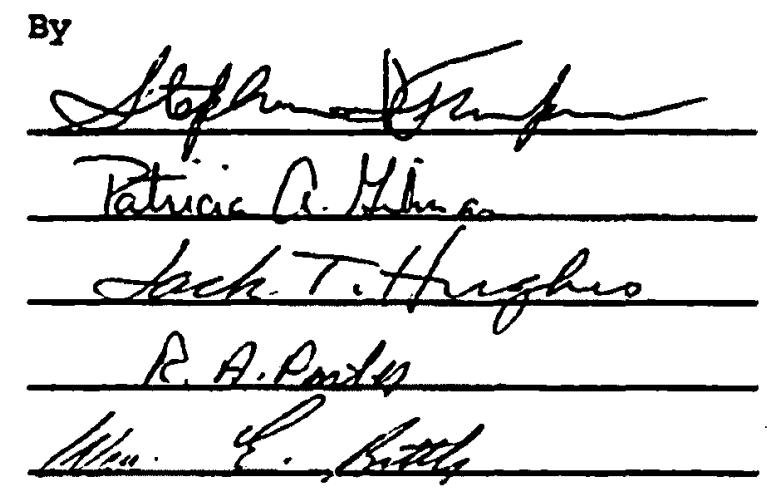

DISSERTATION COMMITTEE 
(C) 1984

CHRISTOPHER RAY LINTZ

\section{ALL RIGHTS RESERVED}


ARCHITECTURE AND COMPUNITY VARIABILITY

HITHIN THE ANTELOPE CREEK PHASE

OF THE TEXAS PANHAHDLE

BY: CHRISTOPHER R. LINTZ

MAJOR PROFESSOR: STEPHEN I. THOMPSON, Ph.D.

\section{Abstract}

This study is concerned with examining the causes underlying cultural variation. The rationale for examining cultural variation is to elucidate the adaptative relationship of the cultural system within its natural and social environmental contexts. Changes in the environment will engender fundamental modifications of the entire cultural system, which in preindustrial semisedentary cultures will be manifested by alterations in architectural, community and settlement patterns, along with other tangible aspects of the cultural system.

The study focuses on delineating cultural variability of the Antelope Creek phase, a late prehistoric village manifestation on the Southern High Plains of North America. Architectural remains from 28 extensively excavated sites from an 80 kilometer segment of the Canadian River are used to delineate the range of household and community patterns within the settlement system. Artifactual, mortuary, chronometrical and physical environmental information are used in conjunction with the architectural data to examine functional, social, temporal and spatial factors potentially contributing to the household and comnunity variability. 
Many community trends not reconciled by these factors are comprehensible when the natural and social context of the larger region is considered. The present environmental conditions are marginal for dependable maize production, and paleoenvironmental reconstructions indicate that xeric conditions were intensifying throughout the duration of the manifestation. The presence of springs issuing fossil water from the Ogallala aquifer during the on-set of drought conditions underlies the development of the Antelope Creek cultural system. Intensification of drought conditions adversely affected the economic base. In an attempt to alleviate the resulting population stress, a series of "buffering mechanisms" were implemented in a futile attempt to maintain the Plains Village pattern. A break down in social cohesion, shifts in settlement patterns towards lateral tributaries, expansion of trade networks :ith adiacent groups, and the development of raiding behavior were unsuccessfully employed to retain the Antelope Creek cultural system. Ultimately these measures proved to be inadequate, and by the sixteenth century, other major alterations in settlement and subsisterce patterns were required, which radically changed the cultural system. 


\section{PREFACE}

As a relatively new graduate student with some experience in southwestern archaeology, I served as the foreman on the 1972 and 1973 University of Oklahoma sumer archaeological fieldschools, which were conducted at two Antelope Creek component sites in the Oklahoma panhandle. One of these, the McGrath site, was analyzed as part of my Masters research. I intended to incorporate materials from the more extensively excavated Two sisters site into a doctoral dissertation. Accordingly, in excess of 96,000 items from the Two Sisters site were washed, restored and catalogued during spare time, while I was engaged in course work towards the degree. A alescriptive report on the two sisters site could have been quickly generated; however, in lieu of broader comparative base in the Oklahoma panhandle, many of the research problems seemed to be site specific. No systematic surveys had been conducted in the oklahoma panhandle, and only two other architectural sites had been reported.

In 1976, I was hixed by the Oklahoma Axchaeological Survey to conduct an extensive reconnaissance in the Oklahoma panhandle of the known axchaeological sites in order to determine their potential elegibility for nomination to the National Register of Historic Places. The constraints of the survey required that only previously recorded sites be evaluated. Nevertheless, seven other sites with comparable architectural remains were visited during this four county survey. Most of these Antelope Creek architectural sites had been severely vandalized, yet considerable variation was observed in the size, spatial relationships of rooms, and site settings. These 
architectural remains were thought to reilect in some way the needs of the people using the structures. But did the architectural differences reflect temporal, spatial, functional, social or environmental differences?

Faced with the prospects of a dwindling cultural resource base, the wisest approach to the problem of architectural variation required the compilation of the range of variation discerned from excavated features, and a synthesis and test of explanations for the variations observed. Since few of the sites in Oklahoma had been professionally excavated, and they seemed to have close affiliations with sites in Texas, the quickest means of documenting Antelope Creek architectural and community variation was believed to be through an examination of records from numerous excavated sites along the Canadian River in Texas. This undertaking was not accomplished as simply as envisioned. Soon, the problem of cultural variation among Antelope Creek sites in Texas took precedence over the continued study of the Two sisters materials in Oklahoma.

A review of the published literature on the Antelope creek focus in Texas revealed three alarming facts: 1) most of the excavation results existed as unpublished manuscripts, theses or fieldnotes at widely scattered institutions: 2) the existing culturai syntheses rarely specified the provenience and frequency of the observed architectural variations; and 3) little consensus existed concerning the meaning of the variations. Thus a thorough understanding or cultural variation based on primary documents was deemed crucial for clarifying these ambiguities. This study pulls together and documents the reported range of architectural and community variability within a single locality in Texas, and examines a series of factors underlying the range of variation. It provides the groundwork for 
future research in the Canadian River valley of Texas, and serves as a comparative information base for understanding the archaeological remains in adjacent localities.

Since I claim no first-hand excavation experience at any of the sites examined in this study, I have amassed a considerable debt to numerous individuals who have helped in guiding, compilirg, integrating and interpreting the diverse pieces of information. The organization and writing of this study has benefited from advice and constructive criticism of my dissertation comittee. My original comittee consisted of Drs. Rohert E. Bell, William E. Bittle, Jack T. Hughes, Richard A. Pailes, and Sieghen I. Thompson. I deeply appreciate their help throughout all stages of this study and particularly their patience during the time I was fully employed in contract archatology in other parts of Oklahoma. Upon Dr. Bell's retirement and subsequent resignation from all committee duties, Dr. Patricia A. Gilman joined the comittee and provided guidance and moral support during the final stages of the research. I am also grateful to Dr. John Dunn, Chairman of the Department of Anthropology, for providing office space at the University during the writing stage of this dissertation. Dr. Don Wyckoff, Director of the Oklahoma Archaeological Survey, permitted access to the Survey's extensive library.

The compilation of field records involved several trips to the study area, personal interviews with some of the active participants in Antelope Creek archaeology, and correspondence with archivists at distant institutions. Transportation for two of these trips was provided by Richard Pailes and Terry Mcclung, and free lodging in Canyon, Texas, has always been available in Meeks and Mary Etchieson's home. Jack Hughes and Bill Harrison 
allowed me open access to their personal records and documents and materials on file at the Killgore Research Center and the Panhandle-Ylains Historical Society Museum in Canyon, Texas. Jack's records, fieldnotes and recollections have been invaluaile in integrating and interpretiig information from the various documentary sources. Dr. Eileen Johnson iso permitted an unannounced inspection of the records and collections on file at the Texas Tech University Museum in Lubbock. Acting Superintendent John Sponsel, and Park Service Rangers Ed Day and Wes Phillips provided both access to Floyd Studer's fieldnotes on file at the National Park Service Offices at Fritch, Texas, and an escort to some of the sites neax Lake Meredith. On other occasions, Jack Hughes, Bobby Speers, Meeks Etchieson and Jim and Beverly Couzzourt were willing companions on various field excursions, and generously shared their insights about the archaeology of the Texas panhandle. The WPA field archaeologists, Ele and Jewel Baker, and Norpan Archaeological Society members, Dick and Mary Carter, and William and Clara Dumas submitted to personal interviews and provided documents from their files concerning the projects with which they participated. Finally, various archivists located and forwarded records from eariy fieldwork on file at a number of distant institutions. Valuable information was obtained from Ms. Goodman at the Americen Museum of Natural History, New York, Sharon Urban at the Arizona State Museum, Tucson, Carolyn Spock at the Texas Archaeological Research Laboratory, Austin, and Elizabeth Ruwell at the University of Pennsylvania Museum, Philadelphia. I would like to thank Ms. Ruwell for her help in obtaining permission to reproduce J. Alden Mason's map of Alibates Ruin 28, Unit 2 (Figure 44) from copyrighted fieldnotes at the University of Pennsylvania Museum. In addition, I would 
I would particularly like to thaik Darrell Creel, who just happened to be researching E. B. Sayles' records, and was able to provide documents from both the Arizona Stiate Museum, and the Texas Archaeological Research Laboratory. Other colleagues who have shared information or were willing to listen to problems encountered during this study include Tim Baugh, Robert Brooks, Nancy Etlinger, Peggy Flynn, David and Alicia Hughes, Ron Ice, Harold Katchell, Mike Mayo, Dan Reff, Terry Steinacher, Fern Swenson, Bill White, and the late vincent Dale.

Support for this research was provided by Safeway Stores, Inc., and the Coca-Cola Bottling Company, and of course, my wife. Major segments of the initial draft of this study were typed by Jane Dye, Phillis Neeley, and David and Alicia Hughes. The final report was typed by Estis Wynn.

It is impossible to completely acknowledge the contribution, support and sacrifices made to this study by wy wife, Roberta, and family.- They, above all, patiently endured the frustrations, neglect and hardships of a husband and father who became deeply immersed in this study. Yet somehow they maintained that special environment necessary for completing the dissertation. Finally, I wish to thank those persons who I have neglected to mention, but who contributed to the realization of this study. 


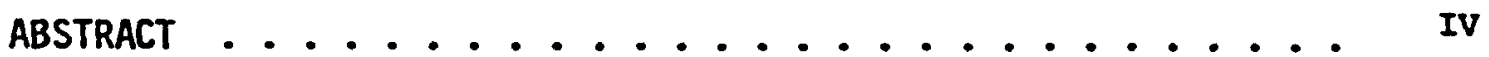

PREFACE ........................ vI

LIST OF TABLES ...................... XXVI

LIST OF FIGURES ....................... CHAPTER

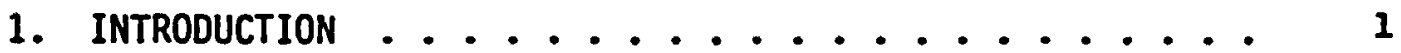

2. CULTURAL TAXONOMIES AND THE RECOGNITION OF ANTELOPE

CREEK CULTURAL VARIABILITY ............. 8

Introduction ............... 8

Overview of Antelope Creek Archaeological

Fieldwork ............... 8

Pre-1928 Period ................ 9

1928-1945 Period ............. 15

1945-1961 Period .............. 24

1961-1980 Period ................ 27

Summary and Critique of Cultural Classifications . . 34

Taxonomic Units Redefined ............ 41

The Upper Canark Regional Variant ....... 44

The Apishapa Phase ........... 46

The Antelope Creek Phase .......... 52

Summary ................... 64

3. ENVIRONMENTAL DIVERSITY OF THE STUDY AREA . . . . . . 67

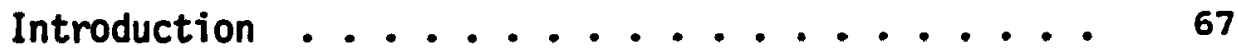

General Setting and Definition of the Study Area . . 68

Natural Diversity of the Study Area . . . . . . 74

Geology............... 74

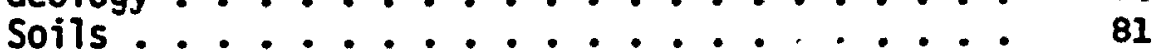

Climate .................. 89

Hydrolcgy .............. . . 95 
Flora .................... 99

Fauna ................... 103

Paleoenvironment ............. 105

Aspects of Human Ecology ............ 110

Summary . . . . . . . . . . . . . . 123

4. ANALYTICAL liETHODS AND SAMPLE LIMITATIONS . . . . . 126

Introduction .............. 126

Methodological Approach ........... 126

Sampling Strategies . . . . . . . . . 130

Capabilities and Limitations of the Data Base . . . 132

Summary . . . . . . . . . . . . . 137

5. INTRA-SITE SPATIAL VARIATIONS: ARCHITECTURE AND

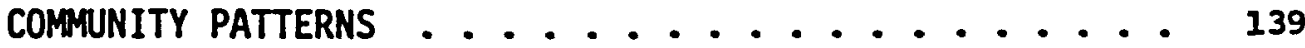

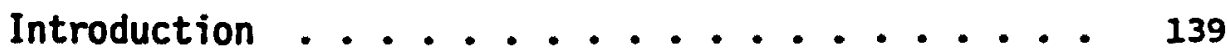

Nature of Architectural Variations ....... 139

Patterns of Architectural Units ......... 140

Miscellaneous Unit Forms ........... 216

Summary of Unit Types ............. 220

Spatial Aspects of Community Patterning . . . . . 223

Patterns of Aggregation ............ 223

Summary of Aggregate Types .......... 236

Patterns of Isolated Rooms ......... 236

Summary of Spatial Aspects of Community
Patterning ................ 243

Architectural Site Types . . . . . . . . . 244

Summary . . . . . . . . . . . . . . 247

6. FUNCTIONAL CORRELATES OF ARCHITECTURAL UNITS AND

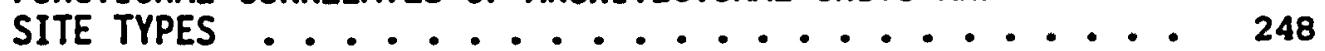

Introduction ................... 248

Functional Aspects of Architectural Unit Types . . 249 
Functional Aspects of Subhomesteads,

Homesteads and Hamlets ............ 259

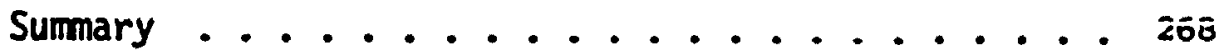

7. SOCIO-POLITICAL DIFFERENTIATION AS REFLECTED BY

ANTELOPE CREEK MORTUARY PRACTICES ........... 270

Introduction ............... 270

Nature of Mortuary Variability ......... 271

Patterns of Body Disposal ........... 271

Patterns of Symbolic Expressions of Respect . . . 283

Interpretations ............. 287

Summary .................. 289

8. CHRONOLOGICAL AND TEMPORAL DIVERSITY IN ARCHITECTURE

AND COMMUNITY PATTERNING .............. 292

Introduction ............... 292

Absolute Dating and Initial Site Ordering ..... 293

Relative Dating and Final Site Ordering ...... 300

Temporal Variations in Arcinitecture and Community

Patterns................. 307

Summary .................. 313

9. SPATIAL DIVERSITY IN ARCHITECTURE AND COMMUNITY

PATTERNING . . . . . . . . . . . . . . 315

Introduction ................ 315

Macrospatial Diversity ............ 318

Geology, Soils and Topography ........ 319

Hydrological Setting........... 329

Microspatial Diversity ............ 335

Summary ................. . 346

10. SYSTEMIC CHANGE AND INTERREGIONAL RELATIONSHIPS . . . . 349 
Chapter

Page

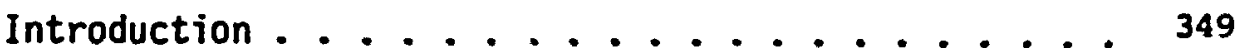

The Origins of Antelope Creek ......... 351

Immigration ............. 351

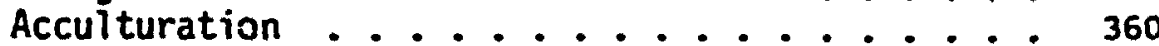

Summary of Trait Origins ............. 382

Ecological Systemics and Cultural Dynamics ...... 385 The Ecological Systemics of Population

Pressure ............. . 385

Evidence for Population Stress during the

Antelope Creek Phase - * * * - • • 390

Creek People...............4 400

Summary .................... 414

11. SUMMARY AND CONClUSIONS ............... 417

Introduction ............... 417

Study Synopsis . . . . . . . . . . . . 417

Future Directions ............. 431

REFERENCES CITED .................... 438

APPENDIX

A. THE SITES ................................ 471

McMurry College/Texas Technical College Sites

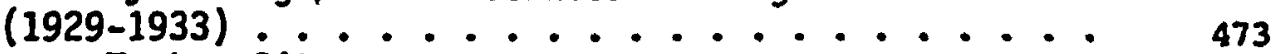

Tarbox Site ............... 474

Lookout Ruin ............... 479

The Panhandle-Plains Historical Society (1930-1935) . 481

Coetas Creek Ruin $55 . . . . . . . . .4882$

The Works Progress Administration Sites (1938-1941) . 486

Antelope Creek 22 ............ 490

Antelope Creek 22A ............. 498

Antelope Creek 23 ........... . 500

Antelope Creek 24 ............ 502

Alibates 28 .................. 505

Alibates $28 \mathrm{~A}$................... 524

Alibates 30 . . . . . . . . . . 526

Chimney Rock Ruin 51 ............ . 528

Chimney Rock Ruin 51A ............ 529 
Panhandle-Plains Historical Museum (1951-1980) . . 531

Sanford Ruin ............. 533

Roper Site .............. 538

Pickett Site .............. 542

Cottonwood Creek Ruins ............. 544

Marsh Site ............... 548

Jack Allen Site . . . . . . . . 549

Zoilars Site................ 553

University of Texas--Texas Archaeological Salvage

Projest (1961-1962) ..................... 555

Conner Site ............. 556

Medford Ranch :...................... 558

Spring Canyon ............. 561

Texas Tech University Sites (1963-1967) . ...... 564

Arrowhead Peak ............. 565

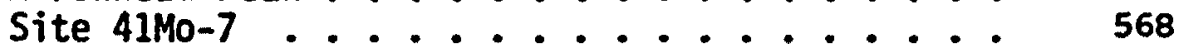

Turkey Creek Site ............ 570

Footprint Site.............. 572

Texas Archaeological Society Excavations (1969) . . 576

Big Blue Creek Burials ........... 577

Texas Highway Department (1973) ......... 580

Black Dog Village ........... 580

B. ARCHITECTURAL ATTRIBUTES AND VARIABLES . . . . . . . 585

C. ARCHITECTURAL UNIT REFERENCE SOURCES . . . . . . . . 626

D. BURIAL ATTRIBUTES AND VARIABLES ........... 631 


\section{LIST OF TABLES}

TABLE

Page

1. Cultural Taxonomies Applied to Late Prehistoric

Manifestations in the Texas Panhandle ........ 36

2. Radiocarbon Dates from Apishapa Phase Sites ....... 49

3. Radiocarbon Dates from Antelope Creek Phase Sites .... 55

4. Archaeomagnetic Dates from Antelope Creek Phase

Sites...................... 57

5. Cross-dated Southwestern Trade Sherds from Antelope

Creek Phase Sites............... 58

6. Origins and Characteristics of Soil Series from the Study Area ...................

7. Percent Effective Solar Radiation for Various North and South Slope Surfaces during Summer and Winter Solstices.

8. Late Holocene Climatic Changes on the Southern Plains . . 107

9. Economically-Useful Plants Indigenous to the Study Area ..................

10. Extant of Excavations and Kinds of Features Encountered - 133

11. Association of Doorway Attributes from Type 1 Units . . 154

12. Association of Unit Size, Wall Footing Type, and Roof Support Systems for Type 1 Units .......... 157

13. Association of Interior Feature Attributes for Type 1

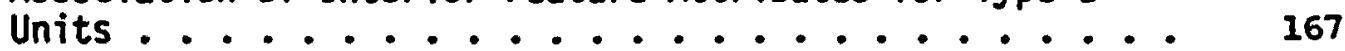

14. Association of Support Posts, Wall Footings, and Doorway Types for Type 2 Units ............

15. Association of Interior Hearths and Cists for Type 2

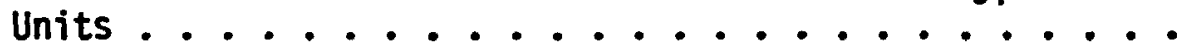

16. Association of Support Posts, Wall Footings, and Doorways for Type 2 Units ..............

17. Association of Unit Shape, and Interior Features for Type 3 Units .................... 
18. Association of Interior Features for Type 4 Units . . . 187

19. Association of He?? Foctings, Docrwäys, and Interior Pit Location for Type 5 Units . . . . . . . 191

20. Association of Unit Shape, Hall Footings, Doorways, and Hearth Locations for Type 6 Units .......... 195

21. Association of Unit Shape, Wall Footings, and Subterranean Placement of Type 7 Units .........

22. Association of Wall Footings, and Contiguous Room Arrangement for Type 8 Units . . . . . . . . . 204

23. Association of Wall Footings, and Subterranean Placement of Type 10 Unites .............

24. Frequency of Room Potential and Actual Occurrence in Subordinate Positions within Aggregate Type II . . . . . 230

25. Chi Square Test of the Placement of Oversized Subordinate Rooms with in Aggregate Type II. . . . . . 232

26. Distribution of Architectural Units and Aggregates by Site. ............. 238

27. Spatial Relationship of Free-Standing Dominant and Subordinate Features at Simple ïulicstead Sites. . . . .

28. Distribution of Dominant and Subordinant Rooms and Pits/Cists by Site Type ............. 246

29. Artifacts Associated with Architectural Unit Types 1-8.................. 252

30. Select Artifacts from Isolated, Paired and Contiguous Type 8 Units ............. 257

31. Density of Select Artifacts by Site Type. . . . . . . 261

32. Antelope Creek Phase Burial Provenience . . . . . . . 274

33. Grave Goods Associated with Single Interment Sex/Age Groupings ................. 284

34: Distribution and Quantity of Grave Goods by Sex and Gender. .................. 
35. Mean Feature and Site Age Based on MASCA

Calibrated Radiocarbon Dates .............

36. A Two Tailed t-Test for Contemporaneity of Radiocarbon Dated Features .............

37. Initial Temporal Ordering of Sites Based on MASCA Calibrated Radiocarbon Dates .......... 301

38. Final Temporal Ordering of Sites by Subphase . . . . . 308

39. Temporal Trends in Antelope Creek Phase Architecture . . 309

40. Relationship of Site Types to Geology, Soil Texture and Topographic Settings..............

41. Correlation of Wall Construction Methods in Main Residential Units with Geological Deposits .......

42. Correlation of Site Types with Soil Association

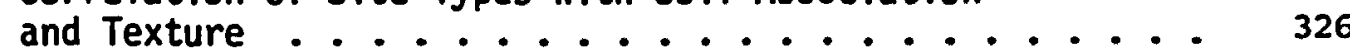

43. Correlation of Site Types by Topographic Setting . . . . 327

44. Relationship of Antelope Creek Phase Sites to Canadian River and Nearest Tributary .........

45. Chi-square Test of Site Type by Distance from

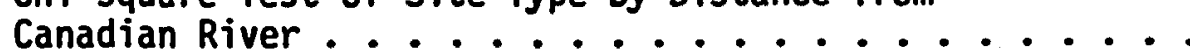

46. Rangeland Productivity of Soil Types in Hutchinson and Potter Counties. .............

47. Percent Soil Types inside One Kilometer Site

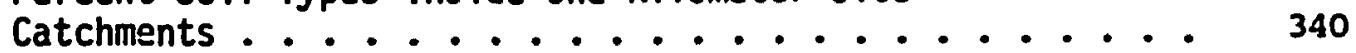

48. Productivity of Site Catchment Areas . . . . . . . . 341

49. Comparison of Percent Preferred Faunal Habitat and Percent Topographic Features within Site Catchments. . .

50. Distribution of Select s.rchitectural Traits in Pueblo II Period Southivestern Complexes ........

51. Summary of Metric Observation t-tests of Male and Female Skeletal Remains from Alibates Ruin, Antelope Creek Ruin, and the Footprint Site. . . . . .

52. Number of Household Clusters and Size of Structures at Early and Late Subphase Sites 
53. Distribution of Burned Structures at Antelope

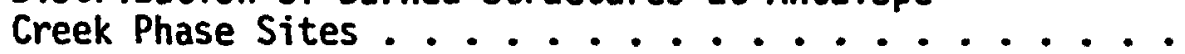

54. Correlation of Site Designations and Map

References ................. 472

55. Correlation of Unit Designations and Original

Feature Numbers to Unit Types ........... 586

56. Room Attributes and Variables ............. 601

57. Antelope Creek Phase Mortuary Information . . . . . . 632 


\section{LIST OF FIGURES}

FIGURE

Page

1. Distribution of Archaeological Sites

on the Southern Plains ............. 11

2. Histogram of Antelope Creek Phase Radiocarbon,

Archaeomagnetic, and Ceramics Cross-dates. . . . . . 60

3. Topography of the Southern High Plains ......... 69

4. Topography of the Study Area and the Distribution of Sites ............ 73

5. Geology of the Study Area .............. 75

6. Canadian Valley Topographic Features and their Relationship to Geological Deposits. . . . . . . 76

7. Cross Sections of the Canadian River Valley ...... 77

8. Generalized Soil Associations within the Study Area ................ 85

9. Lateral Tributaries within the Study Area . . . . . . 97

10. Variations in Architectural Unit Tupes .......... 142

11. Variations in Size Range of Architectural

Unit Types ................. 143

12. Generalized Example of Unit Type 1 . . . . . . . 145

13. Generalized Example of Unit Type 2 . . . . . . . . 169

14. Generalized Example of Unit Type 3 . . . . . . . . 177

15. Generalized Example of Unit Type 4. . . . . . . . 184

16. Generalized Example of Unit Type 5 . . . . . . . . 189

17. Generalized Example of Unit Type 6 . . . . . . . 193

18. Generalized Example of Unit Type 7 . . . . . . . 196

19. Generalized Example of Unit lyf - 3.......... 200 
20. Generalized Example of Unit Type 9 . . . . . . . 208

21. Generalized Example of Unit Types 10 and 11 ...... 211

22. Miscellaneous Unit Forms ................ 216

23. Unit Arrangements in Aggregate Types I-IV ........ 225

24. Stylized Layout of Potential and Actual Rooms, Aggregate Type II .............. 228

25. Multiple Interments inside Structure 1 at the Footprint Site............... 277

26. Average Feature and Site Age Based on MASCA Calibrated Radiocarbon Dates ............ 298

27. Distribution of Early and Late Sites in the Study Area.....................

28. Elevations and Distances of Sites from the Canadian River and Adjacent Tributaries

29. Southwestern Districts Adjacent to the Antelope Creek Phase.............. 367

30. Plan of Tarbox Ruin .................. 476

31. Structure B at Tarbox Ruin .............. 478

32. Plan of Lookout Ruin ................ 480

33. Plan of Coetas Creek Ruin .............. 484

34. Details of Architectural Remains at
Coetas Creek Ruin ................... 485

35. Location of Excavation Areas at Antelope

Creek Ruin 22 ....................... 491

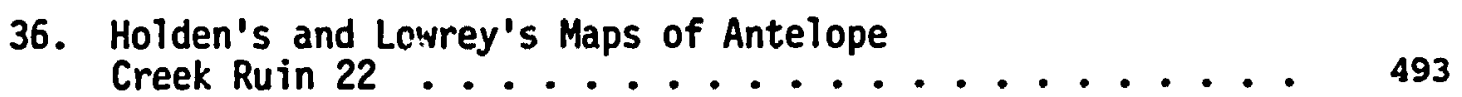

37. WPA Map of Antelope Creek Ruin 22 . . . . . . . . 495

38. Composite Map of Antelope Creek Ruin 22 . . . . . . 496

39. Plan of Antelope Creek Ruin 22A . . . . . . . . . 499 
40. Plan of Antelope Creek Ruin 23 ........... 501

41. Skematic Map of Antelope Creek Ruin 24 ......... 504

42. Plan of Alibates Ruin 28 ............ 506

43. Map of Studer's Excavations at Al itates

Ruin 28, Unit I.................. 508

44. Mason's Map of Al ibates Ruin 28, Unit I ........ 510

45. Alibates Ruin 28, Unit I, Composite Map ......... 513

46. Mound at Alibates 28 , Unit I, as Indicated by Wall Heights ............... 514

47. Stratigraphy of Mound at Alibates Ruin 28, Room 19 .................... 515

48. Cross Sections of Mound at Alibates Ruin 28,

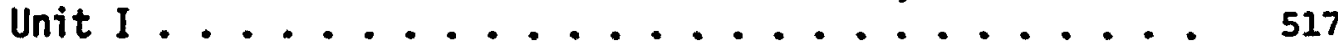

49. Density of Artifacts in Excavation Unit I, Al ibates Ruin 28 .............. 519

50. Al ibates Ruin 28, Unit II ............ 521

51. Density of Artifacts in Excavation Unit II,

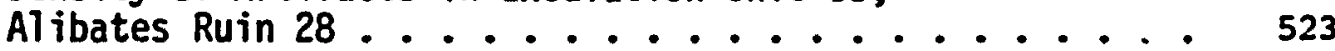

52. Site Map and Tool Densities at Alibates Ruin 28A . . . 525

53. Architectural Remains at Alibates Ruin 30 ....... 527

54. Chimney Rock Ruin 51 .............. 530

55. Architectural Remains at Chimey Rock Ruin 51A ..... 532

56. Plan of Sanford Ruin ............... . 534

57. Details of Main Room Block at Sanford Ruin . . . . . . 536

58. Plan of the Roper Site ............. 540

59. Plan and Profile of the Pickett Site .......... 543

60. Moorehead's Map of the Cottonwood Creek Ruin . . . . . 546

61. Norpan Excavations at the Cottonwood Creek Ruin ..... 547 
62. Plan of the Marsh Site ............. 550

63. Plan of the Jack Allen Site ............. 552

64. Plan of the Zollars Site ............... 554

65. Plan of the Conner Site ............. 557

66. Plan of the Medford Ranch Site . . . . . . . . . 560

67. Plan of the Spring Canyon Site . . . . . . . . 563

68. Plan of the Arrowhead Peak Site .......... 566

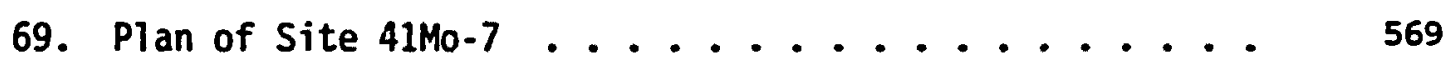

70. Plan of the Turkey Creek Site ............ 571

71. Plan of the Footprint Site . . . . . . . . . . 574

72. Plan of Big Blue Cenetery, SARE-242 . . . . . . . 579

73. Plan of Black Dog Village ............ 582 


\section{CHAPTER 1}

\section{INTRODUCTION}

This study is concerned with the examination of causes underlying cultural variation evident within a single late prehistoric village complex on the Southern High Plains of North America. By cultural variation, I mean those readily distinguishable differences in form, condition and appearance of elements composing the cultural system. The rationale for examining cultural variation is to elucidate the adaptive relationship of the cultural system within its natural and social environmental contexts. Archaeologically, variation is most easily observed in such tangible aspects of the prehistoric cultural system as architecture, community and settlement-subsistence patterns, burial practices, crafts and trade goods. The basic tenet of this study is that architecture, comunity and settlement patterns are sensitive indicators of the natural and social environmental conditions confronting pre-industrial people in their search to satisfy basic needs for survival. Furthermore, changes in the physical and social environment will necessarily be reflected by modifications in the methods used to satisfy these basic needs. This study focuses primarily on architectural and community variations, since the household and community are considered to be the fundamental unit in the subsistencesettlement pattern among semisedentary groups. Even though architectural sites make up only a small part of the entire settlement-subsistence system, they constitute the focus of activities within semisedentary cultures. 
The products from less permanent procurement and processing sites within the settlement-subsistence system eventually end up at architectural sites where these goods, are modified, consumed, traded, or discarded. Thus, the repertoire of activities at these architectural sites is sufficiently broad and patterned to leave behind a substantial amount of patterned material remains. It is for this reason that a detailed study of architecture and community variation, in conjunction with the other tangible aspects of the cultural system, will reflect changes in the natural and social environmental conditions facing the population.

The main puxpose of this study is to show how the seemingly complex range of architectural and community variation evident in a single locality of a prehistoric culture reflects consistency in feature/structural, social, temporal, and spatial patterning. Furthermore, many of these trends or patterns are comprehensible when the natural and social context of the region is considered. The argument developed in this study maintains that the fundamental cause underlying many of the patterns in material remains is related to buffering mechanisms initially employed in an attempt to alleviate population stress induced by the deteriorating environmental conditions which occurred during the fourteenth century. It is further argued that these initial buffering mechanisms were insufficient to permit the maintenance of the existing cultural system, so that by the sixteenth century, radical readjustments were required. Although the precise nature of these changes remains unclear, the transformation of the cultural system was so extensive that the continuity of cultural development into the historic period is unclear.

The culture selected for scrutiny in this case study is the intelope Creek manifestation found along the major river systems cross-cutting the 
Southern High Plains in the Texas and Oklahoma panhandles. The boundaries of the culture are roughly delineated by the Llano Estacado escarpment to the east and west, and the North Canadian and Red River drainages to the north and south. In order to maintain a manageable and comprehensive unit for anaiysis, an $80 \mathrm{~km}$ long segment of the Canadian River Valley in Texas, between Spring Canyon on the east and Tecovas Creek on the west was selected for study. This area was chosen for the following reasons:

1) This study locality has been the focus on a considerable amount of intermittent archaeological fieldwork by both professionals and amateurs since the 1920 s.

2) Numerous Antelope Creek architectural sites have been investigated in this area. At least 34 of these sites have received some form of testing, and reports, manuscripts, field notes and journals are available at various archives and repositories for 28 of these projects. The sites vary in size, topographic placement and architectural type. In excess of 200 architectural room-like features have been exposed.

3) The reports indicate considerable heterogeneity in site size, community patterning and architectural details (Krieger 1946; Duffield 1964; Green 1967; Lintz 1984).

4) Good chronological control from radiocarbon and cross-dated Southwestern ceramics is available for many of the sites in the study area. Available evidence indicates that the culture flourished between A.D. 1200 and 1500 (Lintz 1984).

5) The study area displays considerable natural diversity in geology, soils, topographic settings, hydrology, and the distribution of floral, faunal and mineral resources. Also, the famed Alibates chert, 
which was intensively quarried and extensively traded by Antelope Creek people, outcrops in the middle of the study area.

Despite the extensive amount of fieldwork and dating of the culture, Antelope Creek is poorly understood, since most of the excavation results are hidden in obscure manuscripts or exist in field journals. The cultural system is enigmatic, since it appears to be a blend of plains and Southwestern influences. The Antelope Creek subsistence orientation and material assemblages conform to the Plains village Pattern (Wedel 1961), but the architectural and community patterns show strong similarities with the Southwestern Puebloan pattern.

Most syntheses describe the architectural remains in terms of typical generalized characteristics. The Antelope Creek phase architectural sites range from single structures to villages containing in excess of 80 buildings. The rooms range from circulax to rectangular in shape, and can occur as isolated free-standing structures, or are incorporated with other rooms into contiguous room block structures. Walls typically are made of coursed masonry liberally set in adobe and built upon a foundation of up right masonry slabs. Relatively common and most elaborate is a large rectangular room with an eastward extended entryway. Interior features include a channel (consisting of a depression encompassing the central third of the floor surface), four roof support posts around a certral hearth, occasionaliy a raised platform within the channel area, and storage pits and cists located adjacent to the channel. Other room features vary considerably in size, shape, and interior morphology. Most of these syntheses provide an adequate description of th.e architectural and material remains, but suffer from poor quantification 
and lack of references. It is cften impossible to determine whether the "common trait" occurrences were identified frnm impressionistic intuitions, or are grounded in quantitative analyses. Furthermore, the provenience and frequency of variations from the normal forms are not indicated or linked to specific site features. Thus the delination of factors underlying variations in Antelope Creek architecture and community patterns requires an extensive and detailed description of the distribution and fxequency of st.nuard and exceptional cases. By necessity, a major portion of this study is concerned with describing variation and discerning patterned trends in the morphological differences found in the architectural remain from the 28 sites used in this study.

In order to examine the problem of Antelope Creek variability, I review the Antelope Creek literature in Chapter 2 to show how variations were perceived and explained by earlier archaeologists, and to demonstrate that the Antelope Creek focus concept as used in recent publicatious has evolved into something quite different from the intent expressed in the original definition. Furthermore, I argue that this culture construct is ill suited for the study of variability and that conceptual reorganization is required. It is for these reasons that the Upper Canark regional variant is defined for the late prehistoric complexes in the western portion of the Southern plains. Two contemporaneous but spatially and materially distinct cultures recognized within the Upper Canark Regional Variant include the Apishapa phase of the mesa and canyon lands of southeastern Colorado, and the Antelope Creek phase of the High Plains in the Texas and Oklahoma panhandles.

Chapter 3 explicitly defines and describes the study area. The high Plains-Canadian Valley locality, a portion of the Canadian Valley 
trench in the Texas panhandle, serves as the focus for this study of variation within the Antelope Creek phase. A detailed description of the microenvironmental differences of the natural setting within the study area is presented as a foundation for examining the architecture and community diversity.

Chapter 4 discusses the methods of compiling the architectural information used in the analysis from archival documents. Furthermore, the chapter indicates the limitations of the study sample.

The range of architectural and community variations are described in Chapter 5. A total of 11 architectural unit types are identified on the basis of morphological differences evident from an attribute analysis of information derived from 28 excavated architectural sites. Furthermore, six different kinds of contiguous room aggregate patterns are delineated, and some consistency in the spatial patterning of isolated structures at smaller sites is discerned. Finally, three basic architectural site types are recognized by the association of select kinds of room forms.

Chapter 6 examines the artifactual remains in an attempt to identify functional differences both among morphologically defined architectural unit types and among specific site types. The available mortuary information is examined in Chapter 7 in order to discern the nature of social differentiation among Antelope Creek phase people. The patterns of body disposal and grave good associations are examined from several different cemeteries to indicate the extent of prehistoric social differentiation, which potentially could sccunt for architectural and comminity differences. Chapter 8 is concerned with discerning architectural and community pattern changes through time. Radiocarbon dating and artifact seriation 
methods are used to assign most sites to an early subphase (A.D. 1100 to 1350), or to a late subphase (A.D. 1350 to 1500). A comparison of the architectural remains assigned to the two subphases reveals dynamic trends in Antelope Creek architectural and comunity patterns. The spatial diversity of architecture and comunity patterns relative to the distribution of natural resources of the study area is examined in Chapter 9.

Chapter 10 transcends the boundaries of the High Plains-Canadian Valley locality and examines two facets of Antelope Creek variability in light of broader temporal and spatial contexts. Although this study is not intended to be culture historical, the origins of Antelope Creek architectural and community variability are examined in order to discern both the potential sources of inspiration and the mechanisms of cultural transmission and to refute some previously published ideas about Antelope Creek origins. Next, the cultural dynamics are considered from an ecological perspective. Available evidence suggests that the Antelope Creek population may have been increasing during a time when climatic changes caused disruptions in the availability and predictability of the main food resource base. I argue that the fundamental changes evident in Antelope creek community and settlement patterns reflect various attempts to implement buffering mechanisms in a futile effort to cope with population stress. The implications of these changes are summarized in Chapter 11. Finally, the basic supporting information from the 28 sites, and the architectural and morphological details are presented as appendixes in this study. 


\title{
CHAPTER 2
}

\section{CULTURAL TAXONOMIES AND THE RECOGNITION OF ANTELOPE CREEK CULTURAL VARIABILITY}

\begin{abstract}
Introduction
This chapter reviews previous research conducted at sites attributed to the Antelope Creek manifestation. It is not so much concerned with a detailed chronological recitation of who worked where, but with summarizing the major contributions and showing how the Antelope Creek conceptual and research orientations have changed. In addition, it is concerned with tracing how cultural and specifically architectural variability was perceived and with reviewing the models developed to account for these differences. As such, it provides an historical perspective of the culture and indicates the extent of the available information. The cultural terminology largely reflects how the various researchers have perceived the assemblage composition and its relationship with adjacent assemblages. In addition, an historical overview of previous investigations shows how the same terminc_ogy has been applied to quite different cultural models. Underlying implications of these taxonomic systems will be assessed later in this chapter, leading to a redefinition of the cultural taxonomy of the Plains Village Tradition in the western portion of the Southern Plains.
\end{abstract}

\section{Overview of Antclope Creck Archaeological Work}

The 75-year history of Antelope Creek research has experienced four phases of research intensity: Pre-1928; 1928 to $1945 ; 1945$ to 1961 ; 1961 
to present.

PRE-1928: PERIOD OF REGIONAL RECONNAISSANCE BY EASTERN ARCHAEOLOGISTS

Prior to 1928 field work was mainly characterized by extensive whirlwind surveys and limited excavations sponsored by Eastern institutions. These projects uniformly lacked a sustained commitment to the investigation of questions raised by the field work. The cultural nomenclature preceded formal guidelines for the designation of archaeological cultures, and the names largely reflect geographical arsas. Most field work was directed towards the identification of interregional relationships. Consequently, local variability was largely ignored.

Bandelier (1892:137) was one of the first to record ancient ruins in the Canadian River drainage, approximately 25 miles west of Wagon Mound, New Mexico. He concluded that the ruins may have been related to similar sites in the Pecos River drainage. Although the sites were not affiliated with the Antelope Creek manifestation, Bandelier's work documented the presence of late prehistoric sites at the headwaters of the Canadian River. The earliest reported exploration of an Antelope Creek component was by Dr. T. L. Eyerly in 1907, at the "Buried City" (Handley Ruins) on Wolf Creek in Texas (Figure 1). Dr. Eyerly, a history professor, and his students from the Canadian Baptist Acadeny located 12 mounds and conducted limited excavations in several of them. A series of short descriptive reports resulting from this work primarily called attention to the archaeological resources in the Texas panhandle (Eyerly 1907a, 1907b, 1910, 1912). Eyerly was the first to note the distinctive use of vertically oriented stone slabs as structural foundations.

During the next two decades, a series of nationally prominent 
Key to Late Prehistoric Southern Plains Sites and Complexes.

Undesignated Regional Vartant

$\nabla$ Great Bend Sites

1. Mniteford

2. Paint Creek

3. Tobias

4. Thompson

5. Malone

6. Saxman

7. Eldorado

8. Augusta

8. Hood

9. Belle Plaín

10. Zyba

11. Douglas

12. Arkansas City

13. Country Club

14. Pratt

15. Kinsiey

C Custer Phase Sites
16. Hodge
17. Phtilips
18. Hilliams
19. Mouse
20. Goodian :
21. Shahan II

$\Delta$ Mashita River Phase Sites

22. Shahan I

23. Goodman II

24. HeLaughiln I \& II

25. McLemore

26. Duncan-Hilison

27. Max Thomas

28. Brown

29. Lee I

30. Lacy

- Henrfetza Sites
31. Bennett
32. Coyote
32. Glass
33. Onion Creek
34. Littie Nichita
35. Harrell
36. Pllot Creek
36. Irish
36. Hackberry
37. Farmersville
38. Ragland
39. Campell Hole

Upper Canark Regional Variant

Antelope Creek Phase Sites

40. A-739

41. Saddleback Mesa

42. Landergin Mesa

43. Handley's Ruin (Buried City)

44. Stamper Site

45. Two Sisters

45. MeGrath

46. Roy Suith

See Figure 4

- Apishapa Phase Sites

47. Kenton Caves

48. Tecla Hogtiewicz

Q. Umbart Cave

50. Trincheras Cave

51. Medina Rocksheiter

51. Pyeate Rockshelter

52. Line Junction

53. Metate Cave

53. Homestead Enclosure

54. Snake Blakeslee I

Undesignated Possibiy Upper Canark

55. Dead Man's Mesa

56. Gallegos

57. La-1994

58. Congdon's Butte

59. La-i701

60. La-1996

61. La-12264

62. Magon Hound

63. Sitio Creston

63. Tinsiey stees

- Possible Antelope Creek Sites

64. 2froms Stte

65. Hedding Site 


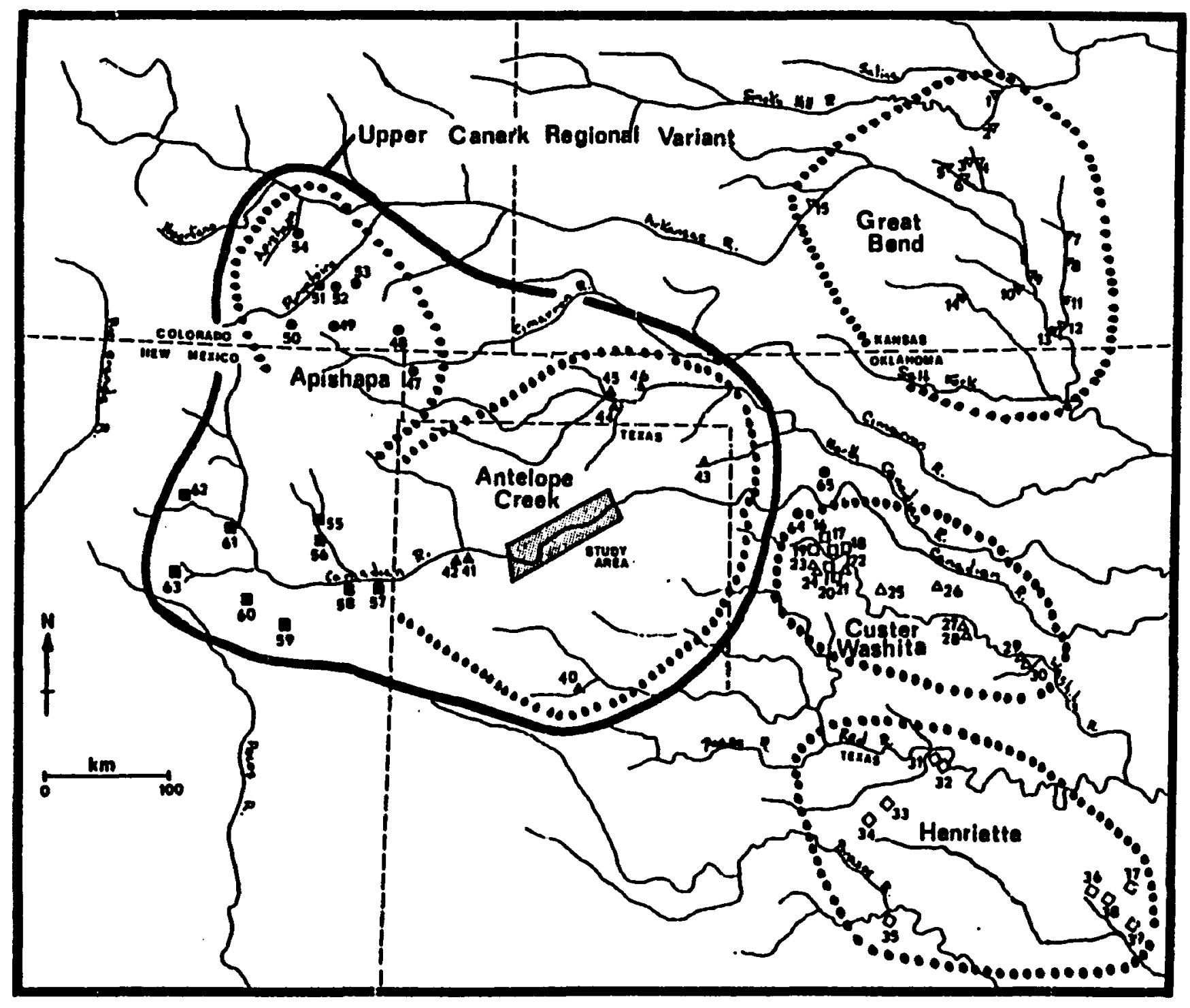

Figure 1. Distribution of Archaeological Sites in the Southern Plains. 
archaeologists conducted brief surveys and limited test excavations in the Texas panhandle. Despite the extent of digging, there is no evidence that any struct:ares or rooms were completely excavated during this period. Initially, the excavations were focused on the Wolf Creek drainage, but later they were shifted to the Canadian River valley. In 1914 or 1915, J. Walter Fewkes visited Handley Ruins and excavated a burial. Nothing is known about its condition or the grave associations (Moorehead 1931:94). Cursory visits to Handley Ruin were made by Joseph Thorburn and Fred Sterns in 1917 and by C. B. Franklin in 1919 during the successive extensive surveys of the North Canadian and Arkansas Rivers by the Phillips Academy of Andover, Massachusetts (Moorehead 1921:1; Wedel 1981:27). Thoburn recorded over 30 sites in Oklahoma, whereas Franklin noted over 70 in south central Kansas. There is no indication that either Thorburn or Franklin recorded sites in the Texas panhandle (Moorehead 1921, 1931). Both surveys were important in documenting the presence of prehistoric sites with cordmarked pottery in the Prairie-Plains border region to the northeast of the Texas panhandle. The mention of complex structures at Handley Ruins prompted Franklin's colleague at Phillips Academy, Warren K. Moorehead, to initiate a survey and testing program in the Texas panhandle.

Moorehead conducted a brief survey of Wolf Creek and the Canadian River Valley in 1919 and made a more extensive expedition in 1920. Although descriptions are not adequate by present standards, the survey reports hint at considerable diversity in settlement locations and architecture. In three months, Moorehead located over 100 sites between Handley Ruin and Lande:-gin Mesa. He mentions a cluster of over 109 "stone graves" and more than 40 buildings on Tarbox and Cottonwood Creeks. Although some burials occur on high points away from the occupation sites, Moorehead's 
identification of some graves rests on uncertain eriteria. Some isolated small stone-lined features contajned flexed burials, but others were empty and have been interpreted as storage cists (Baker and Baker 1941a). On Antelope Creex, the ruins were found scattered over three miles of mesa top, second terrace, and lower terraces (Moorehead 1921). Within this drainage, Worehead recorded one large contiguous room structure (Antelope Creek Ruin 22), 14 one-room buildings, and one building surrounded by an earthpebble embankment nearly 50 feet in diameter (Moorehead 1931:106).

During Hoorehead's 1920 expedition, five structures were tested at Handley's Ruin. In the Canadian River valley, he "... did not have time to examine more than fifty or sixty graves and excavate in twenty to twentyfive buildings." (Moorehead 1921:7). Details of his findings have never been published, although a belated summary appeared in 1931.

Moorehead was the first to correctly perceive that the cultural remains were neither Mississippian nor Puebloan in form. Instead, he attributed the materials to a Plains tribe which changed as it spread up the Canadian River (Moorehead 1921:11). Consequently, he variously employed such geographical names as "Canadian Valley Culture," "Texas Panhandle Culture," or simply the "Panhandle Culture" when referring to the remains (Hoorehead 1921:10; 1931:122, 128). His concept of "culture" was loosely applied. While he does not explicitly state what is meant by the interchangeable cultural terms, apparently formal and spatial criteria were defined only through contrasts with brtter known "Mississippian" and "Puebloan" cultures. The content and spatial parameters were only mentioned in passing. Through interviews with elderly Apache, Kiowa, and Comanche, Moorehead determined that the ruins were not recently occupied, but he was unable to ascertain the age of the culture. 
In 1929 Ronald Olson from the American Museum of Natural History and J. Alden Mason from the University of Pennsylvania Museum independently conducted brief surveys of the Canadian River valley and tested structures at the Alibates 28 Site (Mason 1929). The results of Dr. Olson's survey were never pubiished; however, his brief field notes indicate that he visited Landergin Mesa and the Alibates Quarries and conducted partial exca-. vations on two structures at Alibates 28 (Olson n.d.). Mason's party conCucted excavations in three structures at Alibates 28 and briefly visited Landergin Mesa and sites on Gxapevine Creek and Palo Duro Canyon (Mason 1919, n.d.a). Mason recognized that the axtifact assemblage exhibited many Plains characteristics, hut he felt that the architecture was strikingly puebloan. He initially attributed the combination to "cultural hybridization," but in a later work, conceded that the Canadian Valley ruins were distinctly plains rather than Puebloan or Mississippian in origin (Mason 1919; 1935:31). By this time reports by local researchers demonstrated that the remains were relatively late (Holden 1933:50). Mason was primarily concerned with initial influences between the "high cultural centers" in the Southwest and Mississippi Basin, and he felt that the Canadian Valley culture was not involved with early cultural diffusion between the two regions.

The early explorations : vere thus marked by short term field work designed to identify quickly the nature and extent of cultural remains in the Texas panhandle. Both Moorehead (1933) and Mason (1935) later advocated the need for additional field work, but, perhaps significantly, neither conducted further work in the Texas panhandle. The variability encountered was primarily examined on the intercultural rather than intracultural level. No attempts were made to define or explain the nature of variability. These early explorations nevertheless sparked considerable 
interest on the local level.

1928 TO 1945: PEKIOD OF LOCAL LARGE-SCALE PROTECTS.

Between 1928 and 1945, many large-scale excavations were conducted by local archaeologists at major sites along the Canadian and North Canadian Rivers. Unlike the previous expeditions, the field work represented fairly long-term commitments, as is indicated by Holden's intermittent four-year excavation prẹ:=in, Baker's continuous three-year excavation program, and Studer's informai 50-year survey and excavation program. Research of the early 1930s was supported by local institutions, but by the late 1930s, the projects were funded by the Federal Emergency Relief Administration (FERA) and the Works Progress Administration (WPA).

Most field work of this period focused on the largest sites in the region. Published reports stressed architectural details. Since many of the architectural features have no correlates with features in adjacent cultures, the early workers encountered considerable difficulty in recognizing, excavating, and describing the nature of architectural remains. Other aspects of material culture were hastily summarized, but seldom quantified, and rarely provenienced. Major concerns involved chronological placement of the culture, the reconstruction of past lifeways, and examining the relationship of the Canadian Valley culture with the Puebloan area. Throughout, the local archaeologists showed little concern for using any of the cultural taxonomic system what were developed and being utilized in adjacent regions. No taxonomic consensus was reached, and often an archaeologist used several terms interchangeably when referring to the culture in the Canadian valley. The earliest large-scale excavation program in the canadian River valley was conducted between 1929 and 1932 by Dr. William C. Holden and his 
students. Dr. Holden was interested in ascertaining the nature of plainsSouthwestern relationships by systematically excavating a sexies of sites extending from the Texas panhandle to eastern New Mexico. Extensive testing was conducted at large, mostly contiguous room sites, such as Tarbox Ruin (Holden 1929), the A-C Antelope Creek 22 Ruin (Holden 1930), Tierra Blanca Ruin (Holden 1931), and the B.T.K. or Saddleback Ruin (Holden 1932a, 1933). In New Mexico, he worked at Tecolote Ruin near Las Vegas in 1930 and 1931 (Holden 1931, 1932b). Between 1930 and 1932, the excavations at Antelope Creek 22 and an adjacent site, Lookout Ruin, were continued by E. J. Lowrey. Architectural details and artifacts of these two sites and Saddleback Ruins formed the basis for three Masters of Arts theses (Lowrey 1932; Haynes 1932; Holden, T.C. 1934). The excavations at Saddleback Ruin completely exposed 33 small irregularly-shaped contiguous rooms on top of a mesa, but the excavations at Antelope Creek 22 and Lookout Ruins consisted primarily of trenches through portions of the room block.

Holden's reports provided the first substantial details of architecture and community patterning. He recorded, but did not always accurately interpret, details and variations in room construction, the location of interior features, and some artifact concentrations. For example, the curbing along the depressed floor channel was interpreted as walls or interior partitions, and the depressed channel was interpreted as floor surfaces reflecting multiple occupations. Nevertheless, he noted differences in wall construction methods and the shapes of rooms, and he ascribed possible functional differences to small "cists" and larger, circular ....monial" rooms. Holden's research program also recovered small quantities $;-$ Southwestern trade ceramics which, for the first time, demonstrated that the sites dated between A.D. 1350 and 1450. These late dates meant that the material 
remains could no longer be viewed as evidence of Puebloan groups expanding eastward on to the plains. Instead, William Holden postulated that the antecedents were Plains or Eastern groups (cf. Tom Holden 1934). Holden found nothing to indicate what had happened to the culture. He postulated that droughts or raids forced the Panhandle residents to either move westward and become amalgamated with the Rio Grande Pueblos, or to become nomisis and drop their distinctive material assemblage.

Holden and his students frequently used Moorehead's term "Panhandle Culture" when referring to the sites. On other occasions he employed his own geographically- or descriptively-based terms: The "Canadian Culture," the "Panhandle-Canadian Culture," or the "Slab House Culture" (Holden 1931: 43; 1933:39). He apparently resisted the adoption of the proposed Pecos Classification (Kidder 1927), presumably because he apparently recognized that the Panhandle culture was distinctively different from the Southwest manifestations.

During this period other institutions were also concerned with the eastern boundaries of the Southwest. In 1932, E. B. Sayles located 21 sites in the region during his survey of Texas for the Gila Pueblo Institute (Sayles 1935). With the consent of Holden and Studer, Sayles excavated one room and three trenches at Antelope Creek Ruin 22 and was involved with excavations at Alibates 28 and Saddleback Ruins. Sayles' unpublished notes clearly indicate that he thought the sites represented an eastward expansion of Puebloan groups; however, most of his conclusions were made "without regard to previous publications on this site or this area" (Sayles 1932). He postulated an internal architectural development from post-reinforced walls to masonry walls as a response to the local scarcity of timber. He also suggested that rectangular rooms preceded circular rooms, but gave no 
reasons to account for the change. Sayles was undoubtedly in communication with Holden and probably profoundly influenced Studer. In a subsequent publication, Sayles (1935) employed the Gladwin and Gladwin taxonomic system and attributed the Canadian Vailey materials to a "Panhandle Phase." The term was apparently never formally adopted by local archaeologists since the content of the phase was not formally defined, and the use of the system implied some Southwestern relationships.

The most sustained investigations of the Canadian valley ruins was by a local resident, Floyd v. Studer. As a student at the Canadian Baptist fcademy, Studer claimed responsibility for arousing Dr. Eyerly's interest in excavating the "Buried City" in 1907 (Studer 1955:88). Studer surveyed the panhandle for nearly a quarter of a century before he published his first report. By 1930 , he had located 110 major ruins and conducted test excavations on Saddleback Mesa (Studer 1931a, 1931b). More importantly, he was able to secure "scientific leases" from many landowners along the Canadian River, thereby controlling access to most of the sites (Holden 1932a: 288). In 1931 Studer was appointed to an honorary post as director of the newly created Department of Archaeology and Paleontology at the PanhandlePlains Historical Society. During the early 1930s, Studer initiated excavations at several sites, including Alibates 28 and the Francis Site, the later better known as Ruin 55 on Coetas Creek (Studer 1934). He later "directed" the WPA excavations at several sites along Alibates and Antelope Creeks. Although an insurance salesman by vocation, Studer's archaeological interests span more than 50 years. His personal files contain notes on more than 212 sites (Studer 1955:87; n.d.).

Throughout his writings, Studer consistently employed such Southwesterı terminology as "Post-Basketmaker Culture," "Texas Panhandle Pueblo 
Culture," and "Panhandle Pueblo Indians" in reference to the people and their material remains (Studer 1931a, 1931b, 1931c, 1934:80, 1239:94, 1955:94, 1963). His initial use of these terms reflected a seneral trend of his time. After the development of the Pecos Classification, it became fashionable to refer to complexes in eastern New Mexico and the Texas-Oklahoma panhandles region in reference to the Southwestern Classification (cf. Renaud 1930; Sayles 1935; Baker 1929; Antle 1939). Furthermore, as archaeologists from the eastern institutions became uninterested in the area, studer developed a strong reiationship with Southwestern archaeologists and became deeply influenced by their interpretations and terminology. Studer's reports often mention "sipapus," "ventilators," "antechambers," "deflectors," "kivas," "clan houses," and other Southwestern architectural traits when discussing the panhandle sites. Underlying the use of these terms was a conviction that all plains Indian societies were nomadic, whereas Southwestern societies were sedentary (Studer 1931a:131). Studer failed to recognize the significance of strong material assemblage and architectural parallels between the Texas panhandle sites and those in the Central plains, even though he was aware of Central Plains research and was vis: ced by Nebraska archaeologist, Earl Bell (Studer 1942:67-72). The presence of prehistoric structures in the panhandle, by definition, meant that they were involved in a Southwestern mode of life. This mistaken notion accounts for Studer's paradoxical position of using Southwestern architectural and cultural terminology, yet insisting on a Plains or Eastern origin for the Panhandle culture (Studer 1934:81; 1955:94).

Studer's archaeological legacy consists of several excellent cultural syntheses (Studer 1931a, 1931c, 1955, 1963). Since his acquaintance with the cultural remains was based on materials recovered from excavations and 
surveys, his syntheses are fairly detailed and record a wide range of circular and rectangular architectural forms of various sizes and configurations. Studer also noted differences in mortuary practices, including burials inside structures as well as in discrete areas away from the villages.. Studer offered little explanation for these differences. Much to his credit, Studer advocated and largely practiced conservation archaeology through his control of scientific leases, development of a crude site file system, and his intentional publication of erroneous site location information to discourage vandalism (Studer n.d.; Speer 1980:44).

During the early 1930s, the Federal Emergency Relief Administration (FERA) supported archaeological excavations at two slab house sites in the Oklahoma panhandle. The results on occasion, have been misinterfreted (Clements, 1945:108) and are still not well understood. In 1933 and 1934, excavations were conducted at the stamper site, a large village consisting primarily of isolated room structures, on the North Canadian River. The major excavations were directed by C. Stuart Johnson in the summers of 1933 and 1934; and were briefly continued by Fred Carder in the winter of 1934 . At least 12 rooms were tested, and most of the burials from the site came from inside a single room. Johnson (1934) prepared a short manuscript summarizing his field work, and a more thorough analysis was completed 15 years later (Watson 1950). The results of Carder's work, which employed a different grid system, have never been published. The second slab-house site excavated by FERA support was the Roy Smith or Sharp's Creek Crossing Site near Turpin, Oklahoma. Joseph Thoburn of the Oklahoma Historical society, spent considerable effort in 1934 excavating an historic stone corral at the Roy Smith site. However, he also trenched a prehistoric contiguous room block and dynamited an adjacent small cave (Thoburn 1935). The results of 
Thoburn's work went largely unnoticed until additional work was conducted in the prehistoric room block during the late 1960s (Schneider 1969). Thus, despite extensive excavations at two sites in Oklahoma, the results of the FERA excavations went unpublished. Stuart Johnson moved to Texas in 1934 and continued archaeological work on slab house sites and paleontology until his untimely death in 1939. His unpublished manuscript on the Stamper site provided important documentation for the presence of villages consisting of isolated room structures in the oklahoma panhandle.

Between February 1938 and July 1941, three large scale Works Progress Administration (WPA) projects were conducted at eight sites along Antelope Creek, Alibates Creek, and Corral Creek under the supervision of Ele and Jewel Baker (1941a, 1941b, 1941c, 1941d; Studer 1942). Although Antelope Creek Ruin 22 had been previously excavated by Studer, Holden, Lowrey, and Sayles, the WPA crews excavated the remaining 17 of the 27 contiguous rooms, found one burial, and opened at least 86 ten-by-ten-foot exterior "sections." In addition, five contiguous rooms, two isolated rooms, 16 burials, and three exterior "areas" were excavated at Antelope Creek Ruin 22A at the base of the bluff; one room was excavated at Antelope Creek Ruin 23; and 15 rooms and 17 "sections" were excavated at Antelope Creek Ruin 24. In the Alibates Creek drainage the WPA excavazors unearthed nine rooms at Alibates Ruin 30; one room and 42 ten-by-ten-foot "sections" at Alibates Ruin 28A; and a total of 18 contiguous rooms of a single room block, 34 isolated rooms and five cists at Alibates Ruin 28. Exterior testing at the latter site included 544 "sections" within eight "areas" of two separate excavation "units." Along Corral Creek seven rooms and 50 "sections" were excavated at the Chimney Rock Ruins (No. 51, Studer designation). The unpublished quarterly and final reports contain a wealth of information. Each room is 
individually described and illustrated, and a quantified sumary of selected artifacts from each room and section is presented (Baker and Baker, 1939a-c, 1940a, b, 1941a-d; Baker 1940a, b). Unfortunately, for most sites, the reports do not generally show the relationships between rooms and features. Recent maps of Antelope Creek 22 and Alibates 28 prepared by the Potter County Historical Society Committee are of considerable help, but they contain some errors and show discrepancies with other maps (cf. Baker and Baker 1941a:64; Duffield 1970).

The extensive WPA excavations provided a significant contribution by discerning the internal structures of entire rooms and room blocks. Much of the architectural terminology still in use (e.g.., central channels, channel curbing, platforms/altars, passageways, entry steps, etc.) was developed by the Bakers and disseminated at various regional meetings (Hobbs 1941). The WPA workers encountered several variations in room size and layout and recovered extensive samples of the material assemblage. The Bakers were among the first to notice similarities between sites in the Canadian River valley of Texas and those in the Republican River valley of Nebraska (Baker and Baker 1939b). Unfortunately, the outbreak of world war II terminated the WPA projects and prevented extensive documentations of the sites. Studer (1942) prepared a comprehensive report on Alibates 28, 28A, and 30 and hired a ghost-writer (Anonymous n.d.) to complete the report on the Antelope Creek sites, but neither report was printed or released.

Not all information went unpublished. At the end of the first WPA project, Stuart Johnson, who developed the first WPA proposal to conduct archasological work, prepared a summary of Antelope Creek Ruin 22, utilizing Baker's room designations (Johnson 1939). Much of the architectural discussion is rendered virtually meaningless without the publication of a site 
map keyed to the text. There was also no attempt to correlate and integrate information from the eleven rooms that Lowrey and Sayles excavated. The results of the WPA excavations were presented at the Southwestern Division of the American Association for the Advancement of Science (Hobbs and Tichy 1941; sumnarized by Hobbs 1941). Both published summaries stressed the contiguous room block structure found at Antelope Creek 22 and Alibates 28 Unit I and ignored the isolated room structures at most of the other sites. A scale model of the Antelope Creek 22 site built by WPA personnel and currently on display at the Panhandle-Plains Historical Museum also contributed to the notion of large villages consisting predominantly of contiguous room structures.

Thus, numerous large scale excavations were conducted at the larger sites in the Texas and Oklahoma panhandles during the 15 years prior to World War II. In contrast to earlier work, most projects were sponsored by local institutions and were supervised by local archaeologists. With the exception of Holden's work, most were not geared toward systematically testing regional problems but rather were aimed at specific sites for the purpose of accumulating artifacts. Considerable difficulty existed in defining the nature of the architectural features. The extensive WPA field work was the first to expose entire rooms and room blocks, and to indicate the consistent patterns in architecture and the range in architectural variation. The local research orientation is reflected in the inability of local archaeologisis to formally define and establish a uniform cultural nomenclature, even though several good syntheses were published during this period. Although sites with a variety of architectural types were investigated, the results were presented either in short summaries or (as in the case of the FERA and WPA projects) existed as manuscripts which generally lacked site 
maps. The contiguous room structures at Antelope Creek 22 and Alibates 28 , Unit I, received the most attention in print and overshadowed the field work conducted at sites with isolated room structures. Nevertheless, the results conclusively demonstrated that aside from the architecture, the cultural remains most closely resembled other late prehistoric plains cultures.

1945 TO 1961: PERIOD OF CULTURAL SYNTHESIS.

Between 1945 and 1961, the pace of research in the Texas panhandle slowed considerably. Federal support ceased during the war. This was a period for reflections and syntheses of the earlier fieldwork.

Without a doubt, Krieger's (1946) comprehensive synthesis is the single most important contributius to understanding the late prehistoric period in the Texas panhandle. He rejected Sayles' "Panhandle Phase" as covering too wide an area and being too restrictive and opted for the hierarchical "advantages" offered by the Midwestern Taxonomic System (MTS) (McKern 1939 ). The system uses material traits to recognize a hierarchical series of culture units ranging from the detailed "focus" to the iess specific "aspect," "phase," "pattern," and "base" without implicit regard for temporal or spatial considerations. Relying primarily on the WPA materials and earlier publications, Krieger explicitly defined the Antelope Creek focus for the Texas panhandle and proposed (but never defined) the Panhandle aspect for the slab house cultural manifestations throughout Texas, Oklahoma, and adjacent regions. As initially defined, the Antelope Cresk focus was characterized by large contiguous Pueblo-like structures such as those found at the two type sites, Antelope Creek 22 and Alibates 28, Unit I. The economic orientation most closely resembled the bison hunting and horticultural system in the Central Plains. Krieger (1946:54) was aware of the excavations 
at the Stamper site and suggested that the isolated room sites might eventually form a separate focus. Other variants of the Panhandle aspect were thought to be present in northeastern New Mexico (Krieger 1946:74). While some of the basis for these other undefined foci relied on the variations in form, geographical and regional differences were obviously considered. In addition to explicitly defining the content of the taxonomic units, Krieger's synthesis was the first to make detailed regional comparisons. Since adjacent late prehistoric Southern Plains complexes were not described, Krieger accepted and stressed Wedel's (1934) and the Bakers' (1939) suggestions of possible Upper Republican aspect relationships with the Panhandle aspect. Ultimately, the Antelope Creek focus was thought to represent selective borrowing and acculturation by Plains and Puebloan groups. A patrilocal residence pattern was advanced as the mechanism behind the cultural blending (Krieger 1946:74). Krieger's work was well received by Plains and Southwestern archaeologists alike (Wedel 1947; Reed 1947). However, Reed suggested that a matrilocal residence pattern was more consistent with the ceramic evidence (also see Duffield 1970:12; and Marmaduke and Whitsett 1975: 81 for independent restatements of this position).

A few years later, a detailed description and analysis of the Stamper site materials was completed (Watson 1950). This study was handicapped by misplaced site maps. Consequently, the location of the fieldwork within the site and the spatial arrangement of the structures were difficult to ascertain from the notes. Although 12 of the more than 18 structures at the site were excavated, the details of four structures unearthed by Fred Carder were too vague to be used (Watson 1950:13). Most structures at the Stamper Site were isolated room units; however, the rediscovered site map indicates that some contiguous room blocks were present (Schneider 1969:172; 
map partially reproduced in Lintz 1978a:39). Following krieger's suggestion, Watson defined the Optima focus as a variant of the Panhandle aspect primarily on the basis of architectural differences (Watson 1950:53, 59). Other differences were rarely represented in the material assembleges and, in some instances, reflect either nonindigenous trade items or perishable materials. Using a trait list comparison between the Antelope Creek and Optima foci with the Upper Republican aspect, Watson concluded that the Optima focus was culturally and geographically intermediate. From this she postulated that the three cultures represented different acculturation stages of Upper Republican people as they migrated towards the Southern plains and became "Puebloanized." Thus, the Optima focus was thought to be geographically separate and perhaps somewhat earlier than the Antelope Creek focus. Subsequent syntheses during this period generally reaffirmed the validity of the geographical distinctiveness of the Antelope Creek and Optima subdivisions within the Panhandle aspect (Troike 1955; Suhm, Krieger and Jelks 1954; Suhm and Jelks 1962; Bell and Baerreis 1951; Wedel 1961: 142).

Occasional excavations were conducted during this period. In 1951 Studer retired as director of the archaeology department at the PanhandlePlains Historical Museum and was replaced by Jack Hughes. Much of Hughes' early effort concentrated on documenting the Archaic and woodland stages in the Texas panhandle (Speer 1980). Nevertheless, he either sponsored or sanctioned excavations at Roper, Pickett, Cottonwood Creek Ruins, and the Canadian River 1 Sites by members of the Norpan Archaeological Society (Glasscock and Glasscock 1955; Crabb 1968:84; Carter and Carter 1958; Duffield 1970) and directed the Panhandle-Plains Historical Museum excavations at Sanford Ruins (Dufiield 1970). Even though these sites are at the 
center of the Antelope Creek focus region, several of them contain isolated room structures. However, most of these sites have yet to be published, and tine range of structural variation is generally unknuwn to archaeologists outside of the panhandle region.

Thus, for the 15 years following World War II, the intensity of field work in Antelope Creek focus sites diminished. However, great strides were made in organizing and synthesizing the information obtained from the pre-war excavations. The cultural foundation defined by krieger on the erroneous basis of large contiguous room structures is still in use but has been substantially modified.

1961 TO PRESENT: PERIOD OF RENEWED INTEREST IN FIELD WORK.

During the 1960s, the pace of field work intensified in several areas. Most investigations were aimed at gathering chronological and paleoenvironmental information to develop regional models of past environmental conditions (Crabb 1968; Baerreis and Bryson 1965, 1966; Bryson, Baerreis and Wendland 1970; Duffield 1970) and with refining the Antelope Creek focus concept (Duffield 1964; Green 1967; Schneider 1969; Campbell 1969 ). In a series of articles, Baerreis and Bryson (1965a, 1965b, 1966) delineated a series of Holocene climatic episodes and began investigating the cultural responses to the postulated changes. They advocated that Krieger and Watson were essentially correct in attributing the Antelope Creek origins to Upper Republican groups; however, they also provided an eloquent caus.: explanation for the postulated migration. They postulated that beginning ca. A.D. 1200, a dominance of the Pacific air mass pushed dried air across the central plains, which decreased rainfall and led to deteriorating environmental conditions. At the same time, the frontal 
storm track shifted south, resulting in increased rainfall and improved horticultural conditions on the Southern Plains. Thus, the cause of the migration was attributed to catastrophic reduction in the reliability of conditions favorable to horticulture in the Central Plains and a concomitant increased reliability of conditions on the southern plains.

In support of this hypothesis Baerreis and Bryson undertook an extensive chronological study of Panhandle aspect sites (Baerreis and Bryson 1966). A total of 36 radiocarbon dates from 13 sites did not support previous contentions that the Optima focus was earlier than the Antelope Creek focus. Both foci, however, were thought to date between A.D. 1200 and 1450 and were slightly later than the age of Upper Republican sites (Baerreis and Bryson 1965b:71; 1966:114). Despite differences between the two cultures, no transitional sites had been located in Kansas (Wedel 1968:61). Nevertheless, Baerreis and Bryson argued that since the Upper Republican groups had a dual hunting-horticultural economy, they seasonally covered vast areas and probably noticed the changing environmental conditions in the panhandle region. The migration over long distances may have occurred in a very short time with little evidence in the intervening region. Indeed, we are assured that:

With considerable statistical certainty one can say that the people were not there (in the Panhandle) between A.D. 1180 and 1200 and that they were there by A.D. 1220. Evidently the sudden climatic change was followed by a rapid immigration of sedentary peoples into the Panhandle--probably not as rapid as the "Boomers" of 1889, but also probably not a slow drift Exom site to site that finally dribbled into the Panhandle. (Bryson, Baerreis and Wendland 1970:69).

A subsequent study of faunal remains from 11 Panhandle aspect sites generally supported the climatic aspect of the Baerreis-Bryson hypothesis. Based on the changing frequency of faunal remains reflecting various 
habitats, Duffield (1970:255) concluded that a relatively moist climatic regime was present at the beginning of, or prior to, Line panhandle aspect. However, the area gradually became drier until about A.D. 1300, when drought conditions set in. Despite this general support for the postulated climatic conditions, there has been little support for the postulated migration of Upper Republican groups (Duffield 1970:22, 226; Lintz 1978a; Ludwickson 1978). Although the Upper Republican aspect slightly precedes the Panhandle aspect, there are numerous stylistic differences between the two complexes. The distinctiveness of the Antelope Creek focus from other Central and Southern Plains cultural manifestations has also been underscored in a number of syntheses which contrast two or more cultures (Campbell 1969, 1976; Collins 1971; Keller 1961; Hughes 1974a, 1979; Lintz 1974, 1982; Holden 1964; Wedel 1959; Wendorf 1960).

Also during the 1960s, refinements in the Antelope Creek focus concept arose from the intensified field work which accompanied the development and maintenance of Lake Meredith and the Alibates National Monument. Following recomendations based on a limited survey of the reservoir area (Davis 1962), salvage excavations were conducted at the Spring Canyon, Medford Ranch, and Conner Sites near the proposed dam axis (Duffield 1964) and later at four other house sites (41Mo-5, the Turkey Creek, Arrowhead Peak, and Footprint Sites) and two Woodland sites near the proposed flood pool level (Green 1967). Both mitigation projects encountered separate circular and rectangular room structures similar to those reported for the optima focus at the center of the Antelope Creek geographical region. These isolated structures posed a dilemna: either the Antelope Creek focus as conceived by krieger was too narrowly defined, or the geographical range of Antelope Creek and Optima architecture overlapped. Duffield (1964:75) 
attributed the variation to possible temporal and functional differences and advocated that the focus concept required further refinements. Green noted that the material assemblage from the isolated room sites closely resembled the assemblages defined for the contiguous room sites of the Antelope Creek focus. Consequently, he enlarged the definition of Antelope Creek architecture to include the small isolated room forms (Green 1967:186).

Although this definition could include the structures from the Stamper Site, Green was reluctant to reject the validity of the Optina focus, citing that the basic distinction between the two is reflected by ceramics, not architecture, as originally proposed. Since then, other studies have shown that the "distinctive cambered rims" on the Optima focus ceramics occur on only nine of the $271 \mathrm{rim}$ sherds reported from four excavated sites in the oklahoma panhandle (Lintz 1978a:47). Thus, the ceramic differences are not great.

More recently, joint vocational and avocational excavations at the Marsh Site, the Jack Allen Site, and the Zollars Site have also documented the use of isolated one room rectangular and oval shaped structures. In contrast, excavations at Emeny Ruin and two sites along Big Blue Canyon have partially exposed contiguous room structures within the Canadian River valley. Unfortunately, the materials from most of these sites have not been analyzed, and the excavation results have yet to be published.

In western Oklahoma the Hedding Site (Shaeffer 1965) and the Zinms Site (Saunders 1973; Flynn 1983) contain isolated room structures with depressed floor channels reminiscent of those in the Texas panhandle. Details of these sites are poorly documented at present. Other excavations at the Roy Smith Site (Schneider 1969) and the Two Sisters Site (Lintz 1972, 1976, 1979a) were conducted on contiguous room structures in the Oklahoma 
Funhandie. The spatial relationships of rooms at these sites showed strong similarities with others in Texas. Consequently, the idea of regionally distinctive architectural differences between the Antelope Creek and optima foci must be rejected.

Unaware of Green's unpublished modification of the Antelope Creek focus definition, Schneider $(1969: 176)$ proposed that both foci designations be abandoned and that the whole complex throughout Texas and oklahoma be designated the Panhandle aspect. Others (Hughes, in Duffield 1964:21; Lintz 1978a:39) have advocated similar positions until further analyses could discern meaningful differences. Until then, the Panhandle aspect would have no focus expression.

During this same time, an extensive survey and testing program on the Chaquaqua Plateau in southeastern Colorado provided basic information which indirectly expanded and modified the Panhandle aspect concept. Campbell (1969, 1976) was able to define an indigenous local sequence from the Late Archaic through Protohistoric Periods. The architectural methods in southeastern Colorado employed vertically-set stone slab foundations as early as the foodland Period (A.D. 700-1000) and continued with minor modification through the Village Period (A.D. 1000-1450). The late prehistoric cultural manifestation in southeastern Coloracio was designated the Apishapa focus, since it showed differences in site layout, room shape, and variations in the portable artifacts from those of the Antelope Creek focus (Campbell 1969:504-507). Campbell assigned the Apishapa focus to the Panhandle aspect, along with the Antelope Creek/Optima foci, because of the general similarities in architectural style. To incorporate this new focus, Campbell (1969:21-22) provided the first formal definition of the Panhandle aspect as having: 
- - a horticultural-foraging economy, defensive villages

with house clusters, houses of various forms, but with foundations of vertical slabs and roofs, or superstructures, of perishable materials; grinding implements consisting of slab metates, oval manos, and fixed mortars, cordmarked globular pottery, small triangular, laterally notched projectile points and a few atlatl points; many similar stone and bone implements; and possible storage cists and single flexed burial pits.

Since there is a longer architectural tradition in southeastern Colorado, Campbell (1969:471) suggested that the Antelope Creek/Optima focus represented the remains of progressive groups of people who moved onto the Southern High Plains and came in contact with and were influenced by the adjacent Custer/Washita River groups residing in western Oklahoma. In contrast, the Apishapa focus reflected conservative people who remained in southeast Colorado and northeast New Mexico. A temporal continuum from isolated circular structures to isolated rectangular structures, to contiguous room blocks was postulated to account for the architectural differences between the Apishapa and Antelope Creek areas. Unfortunately, such change has not been supported by the currently available Antelope Creek radiocarbon dates (Lintz 1978c).

The Apishapa focus as a separate cultural expression somewhat resembling the Antelope Creek focus is on a firm foundation based on an extensive sample of tested and dated sites. That sites of this kind should be included within the Panhandle aspect was even anticipated by Krieger (1946: 74). Campbell's taxonomic proposal of retaining separate foci within the Panhandle aspect is more appealing than Schneider's suggestion of dropping all foci distinctions.

Unlike the incessant taxonomic modifications that have been advanced for the Central Plains subarea (cf. Gradwohl 1969:35-56; Kraus 1969; Blakeslee and Caldwell n.d.:10-18), the Southern Plains taxonomies have 
remained relatively stable. Other changes in the Antelope Creek taxonomy have been proposed by archaeologists who are peripherally familiar with the complex. Willey $(1966: 220,324)$ has informally applied the willey and Phillips (1958) taxonomic scheme by recognizing an Antelope Creek phase. Unfortunately, the temporal and spatial limits are merely indicated on summary tables and maps, and the material content is only vaguely mentioned and extremely generalized. The second application of this scheme appeared in an unpublished thesis (Ludwickson 1976). It more rigorously defines a "Panhandle Phase" as cxisting between A.D. 1200 and 1400 and encompassing the approximate region previously assigned to the Antelope Creek and now defunct optima foci. In view of the recent expansion of the "Panhandle concept" to include the Apishapa materials from southeastern Colorado and northeastern New Mexico, the choice of terminology is unfortunate and potentially confusing (cf. Campbell 1976; Thums 1976). To date the term has not been utilized by others working with the culture.

With the passage of the National Environmental Protection Act of 1969, several cultural resource management programs involving the Panhandle aspect were actively developed. Their major efforts with Antelope Creek have been directed towards literature synopses (Bousman 1974a, 1974b) and site inventories (Hughes 1973, 1974b, Hughes, et al. 1977; Guidry et al. 1979; Mitchel1 1975; Marmaduke and Whitsett 1975; Speer 1980; Etchieson 1981). In rare instances, mitigation was undertaken (Keller 1975; Etchieson 1979 ). These studies have contributed important information about site distributions. However, most of the reports are difficult to use in developing settlement pattern models, since the study areas are usually small and it is difficult to determine cultural affiliations, site function and size, and the number and kinds of features present at unexcavated sites. 
Significant new information has come from specialized studies involving a limited segment of the material assemblage. Duffield's (1970) analysis of faunal remains from Antelope Creek sites has already been briefly mentioned. Detailed studies of human dentition, and metric and nonmetric analyses of Antelope Creek skeletal populations have examined various models of population affinities (D.K. Patterson 1974; D.E. Patterson 1974; McWilliams and Jones 1978). In most instances, these important studies suffer from small sample sizes and limited comparative materials from adjacent areas and time periods. Another example is the testing of a lithic reduction model based on a sample of materials from the Turkey Creek Site (Bandy 1976). Replication experiments were used in testing the model which demonstrated that different stages of lithic reduction occurred at different kinds of sites. These various studies have attempted to elucidate some facets of Antelope Creek variability. Most studies have employed information from a limited number of sites, but have not integrated the results into a coherent culture construct. clearly, the present perception of Antelope creek focus is something quite different from that proposed by Krieger in 1946.

\section{Summary and Critique of Cultural Classifications}

The foregoing outline of Antelope Creek research has briefly touched on the recognition of cultural variability and has traced some changes in the perception of the Jate prehistoric manifestations in the Southern High plains. Some problems in applying cultural classifications have been mentioned; however, the implications of employing a specific cultural classification have not been examined in detail. 
Cultural classification systems are mere research tools to conceptually organize, structure and integrate the time, space, and content dimensions of the archaeological record. As a tool, a culture unit provides a rational means of partitioning the diachronic continuity of culture into segments which can be characterized and contrasted with similarly conceived units defined for different time or space. The ultimate goal of archaeology is not mere description, but rather explanation of variation within and between culture trits. Particular taxonomic systems employ basic assumptions about the structural relationships among time, space and content. There is nothing sacred in teing a single taxonomic system. As Brew (1946: 46) indicated nearly 40 years ago, we need more kinds of typologies to address different problems. Yet the structural relationships among the various components are more flexible in some classification systems than in others, and can be modified without violating the basic intent of the tool. In some instances, the tool is inappropriately applied in manners for which it was not designed. In such situations, the modifications nullify the original intent and the cultural variations become obscure. In this section, I will briefly reiterate the major taxonomic systems used at various times in the panhandle and indicate some of the advantages and limitations of each. A correlation of the different conceptual schemes is graphically portrayed in Table 1. This will lead to the development of a modified taxonomic system which will be employed throughout the remainder of this study. Prior to the 1930s, the culture units were poorly conceived. Moorehead and Mason were mainly concerned with the spatial dimensions of the manifestation in relation to the more complex cultural centers to the east and west. They did not formally define its content or temporal parameters. similarly, Studer's use of Southwestern terminology has been shown to be a 
TABLE 1. CULTURAL TAXONOMIES APPLIED TO LATE PREHISTORIC MANIFESTATIONS IN THE TEXAS PANHANDLE

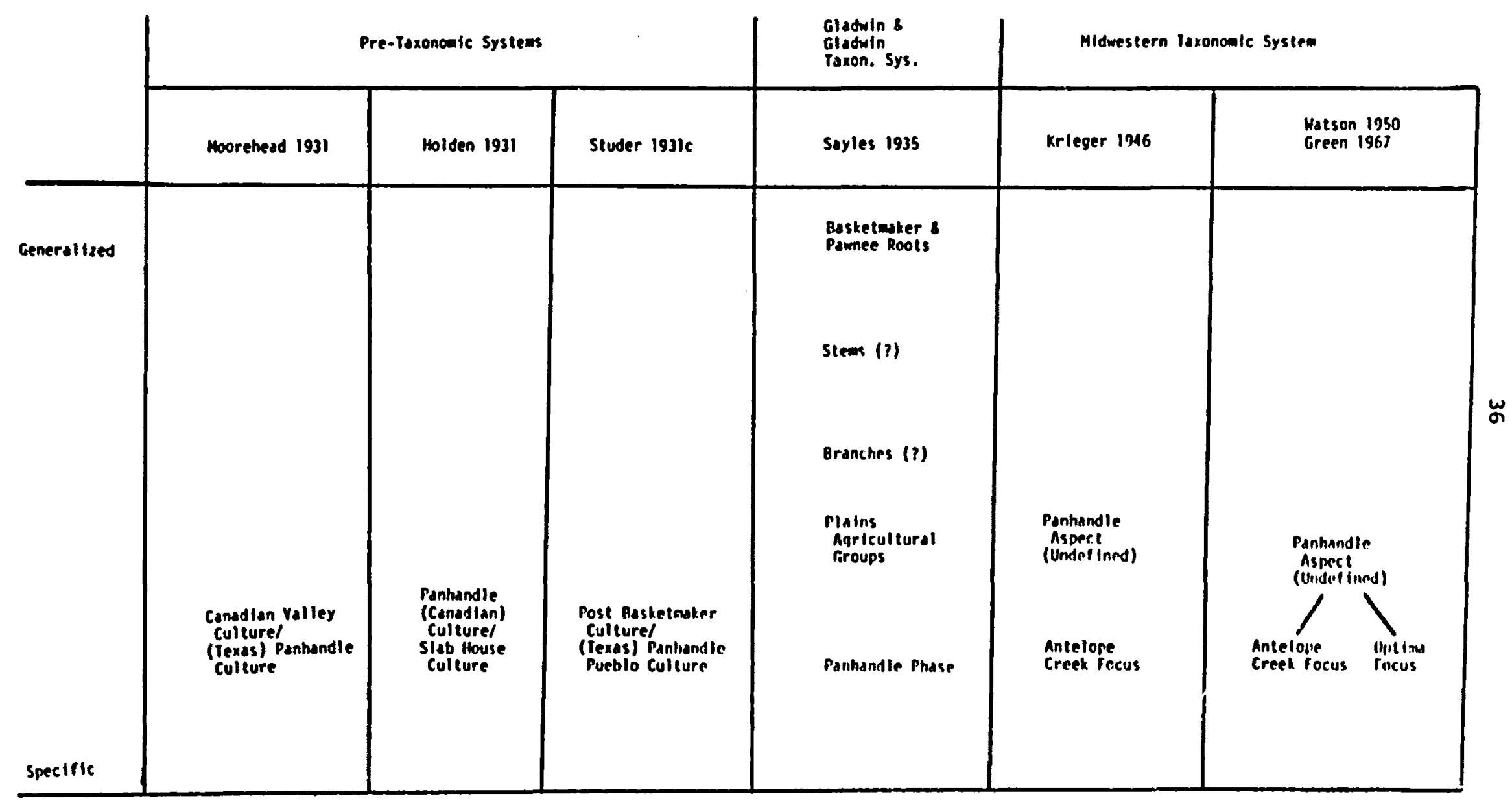


TABLE 1, Continued.

\begin{tabular}{|c|c|c|c|c|c|c|}
\hline & \multicolumn{3}{|c|}{ Hivwestern Ioxonomic System } & \multicolumn{3}{|c|}{ Willey-Phillips Taroncmic Systen } \\
\hline & $\begin{array}{l}\text { Dulfield 1964 } \\
\text { Silhneider } 1969 \\
\text { tint2 } 1976\end{array}$ & $\begin{array}{l}\text { Camplell } 1969 \\
\text { Thness } 1976 \\
1976\end{array}$ & Hedel 1961 & Willey 1966 & Ludwicksun 1966 & $\begin{array}{l}\operatorname{Ln}(\ln 12 \\
\left(\operatorname{mh} i s^{2} \text { stuoy) }\right.\end{array}$ \\
\hline inenerdiced & $\begin{array}{l}\text { Panhindle } \\
\text { Aspuect } \\
\text { (Undefined) } \\
\text { Ho foct }\end{array}$ & 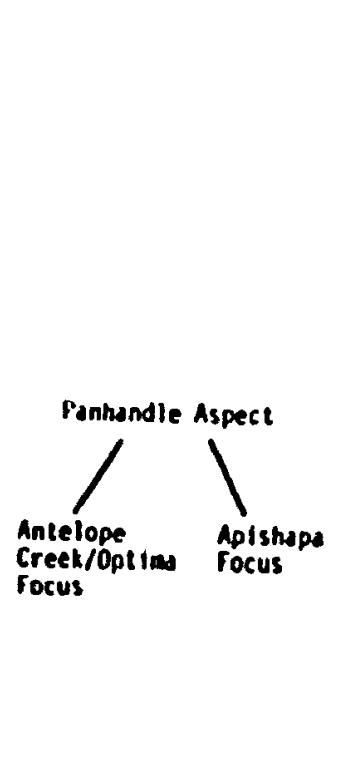 & 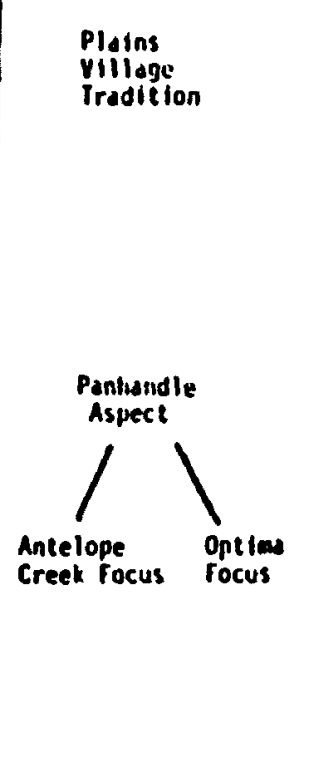 & 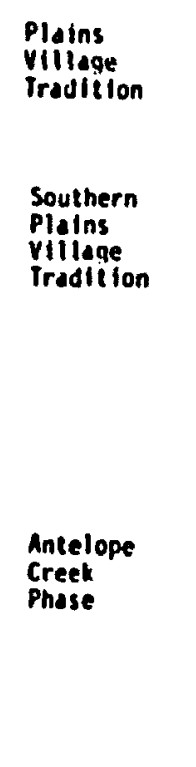 & $\begin{array}{l}\text { Panhandle } \\
\text { Phase }\end{array}$ & $\begin{array}{l}\text { Plains VIllage } \\
\text { Iradition } \\
\text { Southern Plalns } \\
\text { Villiage Tredition } \\
\text { Upper Conark } \\
\text { Regional Variant } \\
\text { Apishape } \\
\text { Phase }\end{array}$ \\
\hline
\end{tabular}


facade employed to characterize a semisedentary lifestyle of an indigenous plains group. The terminology was never formally defined in time, space or material content. Fortunately, it was not adopted by others.

E. B. Sayles (1935) was the first to formally apply a rigorous taxonomic system to manifestations in the region. The cultural designations of the taxonomic system developed by Gladwin and Gladwin (1934:10) were based primarily on spatial considerations (Roots, Stems, Branches), and secondarily on time (Phases) and content. The greatest weakness of this system was an attempt to integrate linguistic stocks into the classification system (Gladwin and Gladwin 1934:10). While linguistics can undoubtedly aid in reconstructing the culture history of groups within a region (cf. Sapir 1916; Hughes 1974), there is no reason to assume that prehistoric groups, using a similar material culture within a region, speak related languages (Trigger 1968). The attempt to equate linquistic roots with taxonomic "roots" (the basic material pattern of the region) created serious difficulties which ultimately led to the modification of the system, and its disuse as a viable taxonomic system in the Texas panhandle.

Since the carly 1940s, the Midwest Taxonomic System (MTS) has been widely employed throughout the Plains region. This system, as originally defined, overtly conceptualized a hierarchy of culture units based on material form and content. Spatial and temporal factors were regarded as independent variables (McKern 1939). Its adoption throughout the Plains reflects difficulties in conceptualizing temporal phases without the kinds of absolute chronologies and methods that are available in the Southwest to help order cultural assemblages. Furthermore, the MTS is particularly well suiced to migratory groups with spatially overlapping subsistence-settlement 
patterns (cf. Syms 1977). A further advantage lies in its hierarchical flexibility.

Krieger (1946) recognized the possibility of regisnal differences within the culture and opted to define only the Antelope Creek focus within the proposed Panhandle aspect. His original definition did not perceive or include local variability or architectural differentiation between localities.

The Mrs has not been without its problems, however (Brew 1946:51-52; Guthe 1952:9-10; :aylor 1948:75-90, 132-134; 141-42; Haag 1961:19-20. The practical application of the system is not consistent with its theory. Considerations of time and space have implicitly crept into its usage. Ever since Holden recovered cross-dated Puebloan trade pottery at Antelope Creek Sites, the age of the manifestation was established around A.D. 1350-1450 (Holden 1934:51; Johnson 1939:190, Krieger 1946:47). Furthermore, the migration models involving either Upper Repulsican (Watson 1950:60) or Apishapa (Campbell 1969; 1976) carry implied notions of temporal priority and spatial segregation. Conflicts in spatial parameters are responsible for the multitude of conceptional schemes reflected by various Midwest Taxonomic Systems employed for the manifestations (Table 1). Such dilemmas are best exemplified by Duffield (1964) and Green (1967) when they encountered architectural styles reminiscent of the Optima focus within 11 kilometers of the Antelope Creek focus type sites. Both were reluctant to assign the sites to the Optima focus primarily because of spatial proximity. Green (1967:181-190) went so far as to redefine the content of the Antelope Creek focus in order to accommodate the variant architectural forms. The inability to characterize regional cultural :aziability is 
perhaps one of the greatest weaknesses of the Midwest Taxonomic System. Any study of cultural variability must regard time and space as dependent variables whereas material content is independent. For these reasons, the Midwest Taxonomic System is poorly suited for the present study. An alternative conceptual scheme utilizing time and space dependent variables has been proposed and extensively modified (Willey and Phillips 1958; Gradwohl 1969; Krause 1969; Lehmer 1971, zeier 1982). The scheme is not unlike the Gladwin's taxonomic system in using a hierarchy of spatial and temporal content divisions, but avoids the linguistically linked pitfalls. Modified versions of the Willey and Phillips Taxonomic System recognize a hierarchical series of spatial units (site, locality, region, subarea and area), and an independent hierarchy of temporal-content units (component, subphase/phase, variant). The chronological linking of components or phases at a site or locality constitutes a local sequence, or on a larger scale, a rcgional sequence of a cultural tradition. However there is no cultural continuity necessarily implied by defining such sequences. The advartage of the Willey and Phillips Taxonomic system lies in the flexibility of temporal-content and spatial parameters. Phases are most easily defined by contrasting the material assemblage content with that from different regions or periods. However, such contrasts often result in apparent homeostatic characterizations of each phase, with an implicit assumption that the phases are separated by rapid transitional periods or short geographical distances. Since components of a cultural system do not change at a uniform rate, there is no reason to believe that phases are static throughout their defined existence (Plog 1974). Once general temporal and spatial limits of a phase have been defined, the minor variants 
in material culture can be examined to determine the kinds and rates of changes within cultural components of the phase. Such studies of introphase variability were anticipated by graphically portraying minor temporal and spatial differences for components comprising a phase (Willey and Phillips 1958: Figure 1) and the establishment of a subphase taxonomic unit. Before undertaking a detailed analysis of variability within the late prehistoric manifestations along the Canadian River valley, it is necessary to define explicitly the spatial, temporal and formal relationship of the culture units used throughout the rest of this study.

\section{Taxonomic Units Redefined}

The late prehistoric manifestations under consideration conform to "The Plains Village Tradition" (Willey 1966:320). This concept was modified from Lehmer's (1954) "Plains Village Pattern" which represents a series of adaptations distinguishable from any others in native North America by the following diagnostic traits:

"1) Subsistence based about equally on hunting and horticulture

2) Semipermanent villages

3) Villages located adjacent to the larger flood plains

4) Semisubterranean earth lodges with entry ways.

5) Undercut and straight walled cache pits in and between the houses

6) Grit-tempered pottery with paddle-marked body and cord or toolimpressed decorations

7) Small, light projectile points

8) Chipped end scrapers

9) Scapula hoes

10) Bone hide dressing tools" (Lehmer 1954:139-140). 
Apparently willey's "Plains Village Tradition" encompasses an area roughly coinciding with a major physiographic division and corresponding to the culture area of the ethnographer (Willey and Phillips 1958:18; Kroeber 1939). Within the Plains area, recombinations of these traits along with other distinctive features have been used to form various subarea divisions, each of which encompassed several distinctive culture units. For the Plains area, most detailed subarea divisions include the Northeastern periphery, the Central Plains, Middle Missouri and Northwestern Plains (Lehmer 1954; Krause 1969). However, Wedel (1961) and, particularly Keller (1961), convincingly argue that the later prehistoric Plains manifestations south of the Smoky Hill-Arkansas River drainage divide are sufficiently homogeneous yet distinctive from other subarea manifestations to be regarded as "Southern Plains Area Co-Tradition." For practical purposes, it can be regarded merely as a Southern plains Subarea of the Plains village Tradition (Krause 1969:96). Through time, the Plains village Tradition on the Southern Plains became more divergent from that of the Central Plains. Each developed its own sphere of cultural relationships and different sources of outside influences. The differences became particularly apparent in the later stages. Manifestations on the Southern Plains lack the ceramic, bone and shell tool embellishments found farther north. Although not all have been redefined in terms of the Willey and Phillips system, the manifestations, particularly in the Southern Plains village Tradition, include Henrietta, Custer, Washita River, Antelope Creek, Apishapa, MidArkassas, Little River, Lower walnut, and perhaps, Ninnescah (Krieger 1946; Hofman 1978; Lintz 1978; Campbell 1976; Kellex 1961). Each manifestation is distinguished by slight differences in settlement/subsistence practices 
and minor variations in the material assemblage. Furthermore, each complex is relatively spatially or temporally distinct. Some complexes reflect continuity in cultural development primarily within a single physiographic region (e.g. the Custer and Washita River phase continuum within the Rolling Red Bed Plains, Hofman 1978). Not only are temporal distinctions apparent, but the material assemblages of the later Washita River phase reflect the embellishments of new traits added to the earlier Custer cultural base. Other relatively contemporaneous complexes, such as Apishapa and Antelope Creek, show strong settlement and material similarities occurring in adjacent (Raton Section and High Plains) physiographic regions. Both examples conform well to Lehmer's (1971:32) concept of a variant, as "a unique and reasonably uniform expression of a cultural tradition which is distinguished from other variants of the same tradition by its geographic distribution, age and/or cultural content." Variants, in essence, group phases together on the basis of similarity and call attention to their distinctness from other phases or variants within the cultural tradition of the subarea.

While some have argued that regional variants are merely "super phases" representing a taxon roughly corresponding to the aspect of the Midwestern Taxonomic System (Blakeslee et al., 1982:87), the heuristic value of regional variants is the flexibility of expressing certain general cultural interrelationships among defined phases and informal manifestations which distinguish them from other phases and manifestations within the broader subarea. Regional variants hecome particularly useful in situations where the local sequence is poorly understood and a site assemblage. shares general attributes with several formally defined phases in adjacent 
areas. The materials should rightfully be regarded as a complex of a regional variant until further research can eludicate the relationship of the local sequence to those established in adjacent areas. The grouping of phases and complexes within a regional variant need not carry implicit notions of cultural continuity or affinity as much as an indication of intense cultural interaction or parallel development.

THE UPPER CANARK VARIANT

On the hasis of distinctive traits and geographical continuity and temporal contemporaneity, the westernmost series of late prehistoric culture complexes within the Southern Plains subarea share sufficient distinctive attributes to be regarded as a regional variant. The Upper Canark Variant is proposed for the Plains Village manifestations occurring along and between the upper portions of the Canadian River and the southern tributaries of the Upper Arkansas River. Geographically, it includes the High Plains Section in the Texas-Oklahoma panhandles and the Raton Section of the Great Plains in southeastern Colorado and northeastern New Mexico. The variant includes phases and manifestations which are generally characterized as having a dual foraging-horticultural economy; a settlement pattern involving a nucleus of farmsteads, hamlets and villages composed of house structures frequently located on high terraces and points; houses of various forms, but with foundations of vertical rows of stone slabs, and roofs or superstructures of perishable materials; the presence of storage cists; predominantiy single, flexed, pit burials; cordmarked globular pottery; chipped stone implements marked by small triangular, side-notched points; end and side scrapers, triangular and ovate knives; 
flanged drills; ground stone characterized by slab metates, one-handed manos and fixed mortars; bone artifacts represented by a wide variety of awls and tubular beads; but considerable variation in the range of other specific artifact assemblage forms.

The architecture and to some extent the spatial patterning of structures are the major differences separating the Upper Canark complexes from other Southern Plains village complexes found farther east. The complete and systematic conversion of all of the various late prehistoric Southern Plains complexes into the willey and Phillips taxonomic system is beyond the scope of the present discussion. Rather, I am concerned only with those culture units that pertain or strongly resemble the late prehistoric manifestations in the Texas panhandle. A clear understanding of the remains in the Texas panhandle can only be gained by contrasting them with other similar manifestations.

At least two geographically, distinct and culturally different phases can be defined for the Upper Canark variant: the Apishapa phase and the Antelope Creek phase. The relationship of other sites with similar architectural and material remains on the Las Vegas plateau of northeast New Mexico to either of these phases remains inclear, and consequently, these sites can oniy be assigned to the Upper Canark variant at this time (cf. Stuart and Gauthier 1981:291-318; Hammack 1965:19-21; Wendorf 1960:62; Kirkpatrick 1976:77-82; Thoms 1976:8-36). Some New Mexico sites formally assigned to the "Panhandle aspect" have a radically divergent lithic assemblage and participated exclusively in a southwestern ceramic tradition (Wiseman 1975). Such sites are not a part of the Upper Canark variant, but rather may relate to Southwestern developments on the eastern range of the 
Rocky Mountains (Kirkpatrick 1976; Glassow 1972).

The Apishapa phase is transformed from the putative Apishapa focus of the Chaquaqua and Raton Section of southwest Colorado. The phase is based on intensive surveys and limited site testing (Campbell 1969; 1976; Simpson 1976; Renaud 1930; 1942). Characterization of the Apishapa phase is hindered by few absolute dates and the lack of extensive excavations at architectural sites. Nevertheless, it appears to be derived from an indigenous tradition of architectural and cultural development. The Antelope Creek phase is redefined from the focus of the same name occurring on the High Plains of the Texas and Oklahoma panhandles. Considerable efforts have been expended obtaining absolute chronological control coupled with extensive excavations at a number of sites. Most regional surveys, however, have been confined to extremely small, usually linear study areas. Consequently, an understanding of the distinctions and relationships of sites is poorly known at this time. The following working definition of the Antelope Creek phase is derived from Krieger's (1946) survey of the WPA field work and later modifications and sumnaries by Duffield (1964), Green (1967) and Lintz (1982). The manifestation may suddenly appear in a fairly developed form in the High Plains area and reflects the recombination of traits into a highly unique cultural manifestation. Subsequent chapters of the present study will examine in detail the range and nature of the cultural variation within the Antelope Creek phase.

APISHAPA PHASE

Subphrase: None recognized. Type site: Snake Blakeslee I (Chase 1951; Chase and Stigler 1949). Other major components: Trinchera Cave (Chase and Stigler 1949; 
Simpson 1976); 50T-79 (Gebhard 1943): Pyeatt Rockshelter, Umbart Cave, Steamboat Island Fort, 5LA-289,5LA-875 (Campbell 1969). Homestead enclosures, 5LA-876, 5LA-847, 5BN-30.

Geographic distribution: The phase is best defined along the Apishapa Plateau. Campbell (1969:559) shows that a majority of sites with stone enclosures are located in the vicinity of Branson, Colorado, and consequently, the sites probably extend into the Raton Mesa portion of the Raton Section of the Great Plains. The sites seem to coincide with mesa and canyon land topography. Similar sites occur in the Black Mesa area of the western Oklahoma panhandle and probably serve as the eastern boundary of the phase (Saunders and Saunders 1982). The northern boundary is roughly placed along the escarpments south of the Arkansas River; the eastern boundary may be placed between the Apishapa and Huerfano drainages in the north, but passes northeast of the Trinidad Reservoir. The southern boundary is foorly defined, but may coincide with the Cimarron-North Canadian River divide. The affiliation with similar sites on the Las vegas Plateau portion of the Raton Section in New Mexico is uncertain.

Temporal span: Campbell's comprehensive survey of the Chaquaqua Plateau recognizes an indigenous, cultural development involving initial and terminal Plains Woodland (A.D. 450-1000) and early and terminal "Panhandle" (A.D. 1000-1550). Absolute dates are rare, and most sites are temporally assigned on the basis of relative ages of projectile points and ceramic styles extrapolated from other areas. Campbell proposes a marked increase in density and size of sites during the early Panhandle Period (A.D. 10001300), followed by a noticeable decrease in material remains following the close of the thirteenth century. The four radiocarbon dates assigned to 
the Apishapa phase range from A.D. $1135 \pm 125$ (GX-0514) to $1360 \pm 110$ (GX-0717) Table 2). Three of the four dates are from different rockshelters, only one of which had a rock wall architectural feature. Although the tradition of using stone structural foundations in southeastern Colorado has been dated to A.D. 450 at the Graneros or Eelwood Site, the rationale for initiating the Apishapa "focus" at A.D. 1000 is on uncertain chronological grounds. The available absolute dates suggest a span from about A.E. iio0-1350 for the age of the Apishapa phase.

Settlement: Surveys of southeast Colorado note three basic kinds of Apishapa sites: rockshelters, surface encampments and stone/slab enclosures ranging from single room sites to "villages" containing nearly 60 rooms (Campbell 1969:20;393). A wide range of settlements were employed. Nearly a third of the Apishapa sites on the Chaquaqua Plateau were rockshelters; many of which were used without modification. Many of the shelters are located along the wide canyon portions of Chacuaco Creek and Smith Canyon. In contrast, the surface encampments tend to be in the upper canyons and mesas but located close to potable water (Campbell 1969: Figure 57). Sites with stone slab enclosures occur in wide canyons, but more often appear in upper canyons and mesas than during the previous Woodland Period. Several of the stone enclosure sites atop steep towers, buttes, vents or along isolated mesa points have stone perimeter walls encompassing up to 37 structures and are thought to be fortified. The overall distribution of sites reflects the exploitation of resources in a wide range of topographic settings.

Architectural features: Architectural features are best known from the stone enclosure sites. Most structures consist of single room units, 
TABLE 2.

RADIOCARBON DATES FROM APISHAPA PHASE SITES

\begin{tabular}{|c|c|c|c|c|c|}
\hline $\begin{array}{l}\text { Site, } \\
\text { Provenience }\end{array}$ & Lab. No. & $\begin{array}{l}\text { Uncorrected } \\
\text { Date A.D. } \\
5568 \text { half-11fe }\end{array}$ & $\begin{array}{l}\text { MasCA } \\
\text { Calibrated } \\
\text { Date (A.D.) } 1\end{array}$ & $\begin{array}{l}\text { Consensus } \\
\text { Calibrated } \\
\text { Date (A.D.) }\end{array}$ & Reference \\
\hline $\begin{array}{l}\frac{\text { Medina }}{\text { Rockshelter }}{ }^{3} \\
\text { Trench A, Level 1B }\end{array}$ & $G X-0515$ & $1140 \pm 85$ & $1085-1275$ & $1035-1330$ & Campbe11 $1969: 345-347$ \\
\hline $\begin{array}{l}\frac{\text { Pyeatt }}{\text { Rockshelter }}{ }^{3} \\
\text { Trench M. Level } 2\end{array}$ & GX-0514 & $1135 \pm 125$ & $1045-1315$ & $1030-1330$ & Campbe11 $1969: 345-347$ \\
\hline $\begin{array}{l}\frac{\text { Umbart }}{\text { Cave }} \\
\text { Upper } 1 / 4 \text { of } \text { fill }\end{array}$ & $G x-0717$ & $1360 \pm 110$ & $1230-1470$ & $1250-1430$ & Campbell $1969: 345-347$ \\
\hline$\frac{\text { Steamboat Island }}{\text { Fort, Structure } 2}$ & GX-0719 & $1175 \pm 85$ & $1115-1305$ & $1045-1345$ & Campbe11 1969:345-347 \\
\hline
\end{tabular}

${ }^{1}$ One standard deviation span. Ralph, Michael, Han 1974.

${ }^{2}$ Klein et al. 1982.

${ }^{3}$ No architecture at site. 
although some rooms may be paired as at 5LA-289, whereas others, particularly those abuttirs vertical bedrock exposures (cf. 5LA-875), may contain eight or more contiguous rooms. Room construction seems to involve considerable opportunistic use of natural boulder and outcrop exposures. Most of the floor plans are circular, but oval, semi-circular and D-shaped rooms also occur to accommodate topography and other existing features. Rectangular room forms are exceedingly rare. Most wall foundations and perimeter walls are made from a combination of horizontal and vertical stone slabs. The size of 68 rooms at 5LA-289, 5LA-977 and 5LA-875 ranges from four to 17 feet $(1.2-5.2 \mathrm{~m})$ in diameter, providing an approximately 12.5-227.0 square foot (1.1-21.1 sq $\mathrm{m}$ ) area (Campbell 1969:256, 265, 269). The smaller "rooms" may have served as storage or granary units, but this suggestion has not been formally tested. Definable entryways are present at only a few rooms, indicating that access may have been gained above the foundation level. Structural floors usually correspond to the original ground surfaces. Few interior features have been found. The structures generally lack a centralized hearth and interior roof support pattern. Most fire pits seem to be located outside the structures (Ibid:392). The numerous rockshelters in the region were used with or without additional modification. Only a third of the shelters with Apishapa materials on the Chaquaqua Plateau have interior "barrier walls." Sucin :ralls usually consist of a single course of stone which was probably used to weight down brush walls or partitions. Tile size circumscribed by the walls inside rockshelters range from 65 to $167 \mathrm{sq} \mathrm{m}$, or nearly three times as large as the stone enclosures. The relationship between the stone enclosures and rockshelters within the Apishapa settlement pattern is still unclear. 
Burials: Apishapa burials are typically flexed, single pit interrments within habitation sites. One grave from 5LA-81 contained the remains of two individuals. The individuals are typically interred without grave accompaniments, suggesting that there is little or no status differentiation.

Subsistence: Subsistence practices reflect a combination of generalized foraging and horticultural activities. Faunal remains reflect emphasis on procuring smaller mamals (rabbits, prairie dogs, gophers and rats). Large mamal remains are dominated by deer and antelope with occasional bison, bobcat, coyote and elk represented in the assemblage (Simpson 1976: 176). Wild plant remains include choke cherry pits, wild plum pits, grape vines, yucca quids, cactus seeds and pinyon nuts (Campbell 1969:84-87; 136). Were it not for the recovery of cultigens in rockshelters, inferences regarding indigenous horticulture would be negligible. Harinosa de ocho, Pima-Papago, Chapolote-Reventador and Fremont-Dent varieties of corn and beans and gourds have been found. Although occasional wooden digging sticks are found, the bison bone-tipped hoe and bone digging stick tips are all but absent from the artifact assemblage (Campbell 1969:391). The artifact assemblage reflects a generalized range of flake and core scrapers, ovate knives, gravers, flange drills and choppers, globular cordmarked pottery, bone shaft wrenches, awls and tubular bone beads.

Specialized tool forms are represented only by snub nose scrapers and small side notched projectile points (Harrell, and Washita types). Missing are such specific tools as the diamond beveled knife, and a variety of pin and t-type "key" drills which commonly occur on other late prehistoric Plains village complexes throughout the central and southern plains. 
The generalized artifact assemblage probably reflects the opportunistic orientation of subsistence coupled with the availability of lithic and biotic resources which are suitable for fashioning tools throughout much of the defined area.

Social organization (polity): Campbell (1969:398) argues that the increase in Apishapa site size and density from the preceding Woodland Period reflects a population increase. Furthermore, the clustering of enclosure sites at particular localities hints of intervillage cooperation that may have given rise to tribal units. Finally, the population increase and "increased complexity of sociopolitical organization" is reflected by the increased use of domesticated plants. There is little evidence to support most of these assertains. The clustering of enclosure sites leading to "intervillage cooperation" assumes site contemporaneity which has not been demonstrated. Features such as springs or seeps in the natural setting may equally account for the apparent clustering of sites.

In contrast, the absence of grave goods, the random arrangement of structures at sites, the absence of plazas and the lack of specialized structures marked by differences in size, shape or interior features, suggest that the Apishapa had little or no apparent status differentiation and little community planning. Further, the scarcity of trade materials from eigher the Southwest or adjacent Plains manifestations suggest that they maintained few alliances outside the region and were relatively isolated. Although they may have had tribal units, it is ciear that they had a loose political organization.

\section{ANTELOPE CREEK PHASE}

Subphases: An "Early" subphase (A.D. 1200-1350), and "Late" subphase 
(A.D. 1350-1500) tentatively defined.

Type site: Alibates 28, Antelope Creek 22 (Baker and Baker 1939, 1941): Conner (Duffield 1964).

Other major components: Saddleback Mesa (Holden 1933), Coetas Creek Ruin 55 (Studer 1934), Footprint; Arrowhead Peak (Green 1967), Spring Canyon, Medford Rock (Duffield 1964), Black Dog Village (Keller 1976), Stamper (Watson 1950), Roy Smith (Schneider 1969), Two Sisters (Lintz 1979a), Chimney Rock (Baker and Baker 1941 d).

Geographical distributicn: The phase is best defined along the Canadian and North Canadian (Beaver) Rivers within the High Plains sections. The sites generally correspond to the High Plains topography. The boundary between Apishapa and Antelope Creek phases is fairly sharply defined as corresponding to the sand dune belt in central and eastern Cimarron Councy, Oklahoma (Saunders and Saunders 1982). The northern boundary can be placed along the North Canadian-Cimarron drainage divide; at least eight stone siai house sites occur aiong the North Canadian in Beaver and Texas Counties, Oklahoma, but no such sites are known for the Cimarron drainage (Brown 1976). The eastern boundary may include a portion of the Rolling Redbed Plains involving the first tier of counties in oklahoma proper. Here, structures at the zims Site and Hedding Site contain similar distinctive Antelope Creek phase floor features but lack the stone slab foundations (Shaeffer 1965:79-149; Saunders 1973). The southern boundary extends as far South as the Prairie Dog Town Fork of the Red River, where stone slab sitc A 739 in Tule Canyon represents the southeast occurrence of such villages (Hughes 1979:43). The western boundary is tentatively placed near the western escarpment of the Llano Estacado. Some sites farther west along the 
Canadian River in New Mexico resemble Antelope Creek sites, but their culcural affiliations remain uncertain until the nature of other Upper Canark sites in New Mexico are delineated.

Temporal span: The Antelope Creek phase is one of the best dated cultural manifestations in the Southern Plains. At least 58 radiocarbon dates and five archaeomagnetic dates provide direct chronological information and 17 types of cross-dated southwestern trade sherds provide corroborative information (Tables 3, 4, 5). Although the radiocarbon dates seem to be scattered over nearly half a millennium, the MASCA tree ring correction procedures (Ralph, Michaels and than 1974) provide a substantially tighter range for the Antelope Creek phase dates between A.D. 1200-1500 (Figure 2).

Settlement: Despite extensive investigations, the structure of the Antelope Creek settlement patterns is still poorly understood. The High Plains area has less relief and topographic diversity than that found in southeast Colorado or eastern New Mexico, and rockshelters suitable for habitation are rare in the region. Most surveys distinguish between lithic scatters, open campsites and "villages." However, the terminology has not been consistently applied. Village sites, for instance, may refer to sites with several score rooms, to those with a single room structure, or merely to non-architectural sites with considerable material density or diversity. There is substantial variation in the size of the sites, the number of architectural units and the size and shapes of the individual structures (Lintz 1979b). These differences may reflect various structural components of the Antelope Creek settlement system involving villages/ hamlets, farmsteads, and perhaps seasonally occupied field huts; but, to date, no formal testing of the various models has been undertaken. 
TABIE 3 .

RADIOCARBON DATES FROM ANTEIOPE CREEK PHASE SITES

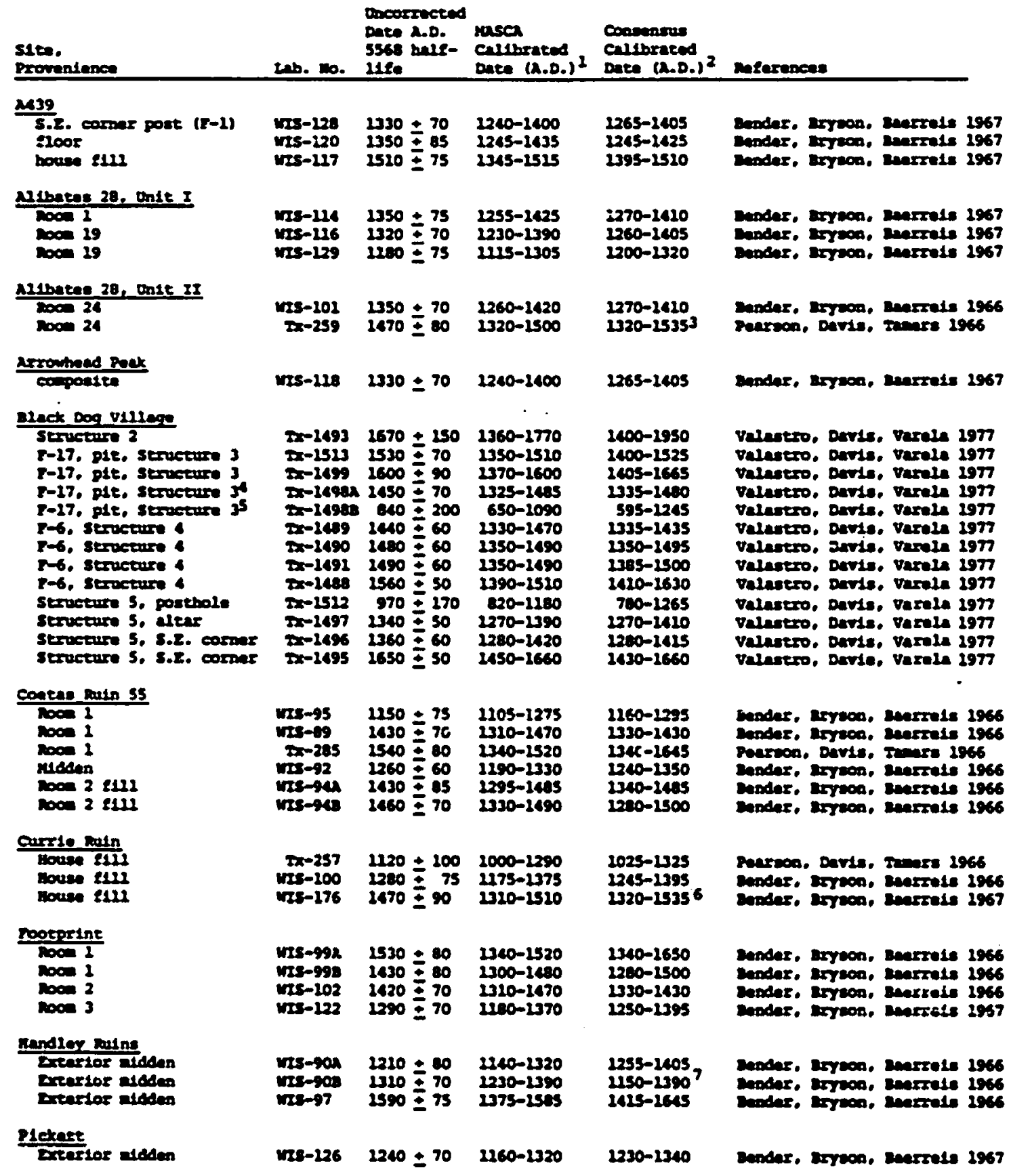


(Table 3, continued)

\begin{tabular}{|c|c|c|c|c|c|}
\hline $\begin{array}{l}\text { Stten. } \\
\text { Proventence. }\end{array}$ & Eab. w. & $\begin{array}{l}\text { Decosrectid } \\
\text { Dete A.D. } \\
5568 \text { hule- } \\
\text { life }\end{array}$ & $\begin{array}{l}\text { msea } \\
\text { callbrated } \\
\text { Dete (A.D.) }\end{array}$ & $\begin{array}{l}\text { Consensus } \\
\text { calihrated } \\
\text { Dete (A.D.) }\end{array}$ & Exterences \\
\hline \multicolumn{6}{|l|}{ Doper } \\
\hline Copoutte & $\frac{\cos -134}{\operatorname{mis}-142}$ & $\begin{array}{l}1300=70 \\
1370 \div 70\end{array}$ & $\begin{array}{l}1220-1380 \\
1275-1435\end{array}$ & $\begin{array}{l}1255-1600 \\
1285-1425\end{array}$ & 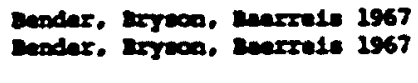 \\
\hline \multicolumn{6}{|l|}{ Dork sith } \\
\hline 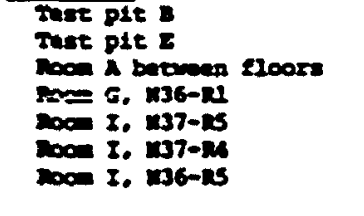 & $\begin{array}{l}\cos -137 \\
\operatorname{mes}-121 \\
\cos -124 \\
\cos -142 \\
\cos -149 \\
\min -147 \\
\min -245\end{array}$ & $\begin{array}{l}2200 \pm 70 \\
1220 \pm 70 \\
1220 \pm 75 \\
1320 \pm 60 \\
1220 \pm 65 \\
1250 \pm 70 \\
2250 \pm 50\end{array}$ & $\begin{array}{l}2140-1300 \\
2150-1310 \\
2145-1315 \\
1290-1430 \\
1255-1305 \\
1170-2330 \\
2190-1310\end{array}$ & $\begin{array}{l}1220-1330 \\
1220-1335 \\
1220-1335 \\
1305-1420 \\
1220-1215 \\
1235-1345 \\
1235-1345\end{array}$ & 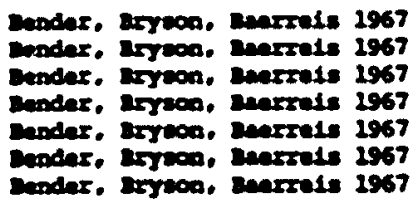 \\
\hline 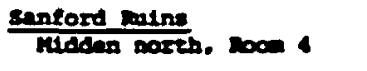 & $2 x-255$ & $2250 \pm 90$ & $1250-1350$ & $2200-1405$ & Pearson, Durls, Twars 1966 \\
\hline 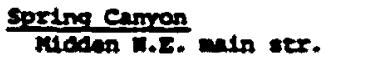 & $7 x-256$ & $1400 \div 90$ & $1280-1480$ & $2265-2490$ & Penrson, Dav1s, Tumera 1966 \\
\hline 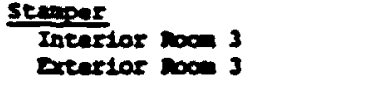 & $\begin{array}{l}\text { Wrs }-84 \\
\text { ins-83 }\end{array}$ & $\begin{array}{l}1300 \pm 75 \\
1300 \pm 70\end{array}$ & $\begin{array}{l}2215-1385 \\
2220-1380\end{array}$ & $\begin{array}{l}2230-1415 \\
2235-2400\end{array}$ & 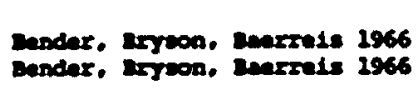 \\
\hline 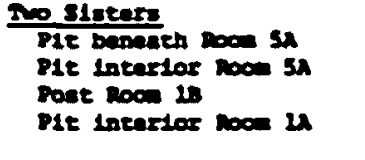 & $\begin{array}{r}x-3260 \\
x-3261 \\
v=-2500 \\
0=2509\end{array}$ & $\begin{array}{l}1060 \pm 50 \\
1440 \pm 50 \\
1605 \pm 55 \\
1350 \pm 50\end{array}$ & $\begin{array}{l}2015-1235 \\
2340-1460 \\
2315-1445 \\
1290-1400\end{array}$ & $\begin{array}{l}1030-1250 \\
1335-1435 \\
1320-1125 \\
1270-1410\end{array}$ & 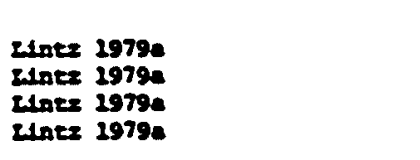 \\
\hline zingese & & & & & \\
\hline 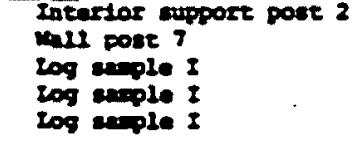 & 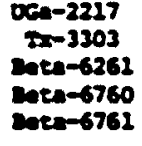 & $\begin{array}{r}895=60 \\
1030=50 \\
1650 \div 50 \\
1370 \pm 50 \\
1600 \pm 50\end{array}$ & $\begin{array}{r}655-995 \\
2005-1125 \\
1460-1670 \\
1290-1420 \\
1320-1440\end{array}$ & $\begin{array}{r}870-1055 \\
1025-1245 \\
1435-1665 \\
1285-1425 \\
1320-1425\end{array}$ & 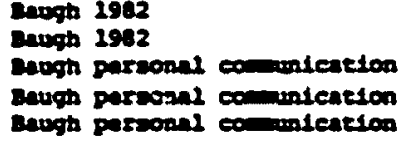 \\
\hline
\end{tabular}

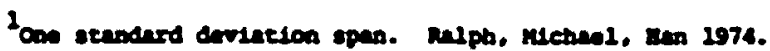

2rate ex 느. 1992.

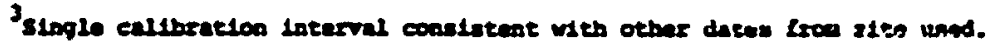

tone epatite dree.

Stowe collegen date.

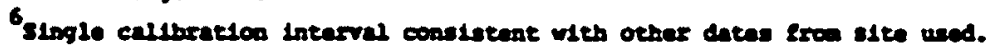

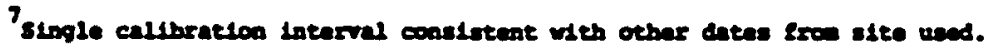


TABLE 4.

ARCHAEOMAGNETIC DATES FROM ANTELOPE CREEK PHASE SITES

Alibates 28 , Unit I

Central hearth,

Room 7

OU-927

Modern

DuBois personal communication

Two sisters

Central hearth.

Room 17

OU-788

1385

3.4

Intz 19798

South wall,

Room IB

OU-887

1420

2.5

Lintz $1979 a$

Central hearth.

Room 18

OU-888

1320

1.0

Lintz 19798

Zimus

South edge of

channel, east

half of house

ou-830

950 or 1450

1.9

Baugh 1982 
TABLE 5.

CROSS-DATED SOUTHWESTERN TRADE SHFRDS FROM ANTELOPE CREEK PHASE SITES

\begin{tabular}{|c|c|c|c|c|}
\hline Ceranic Iype & Estimated Age & Roforences & Antelopo Creek sites & Reforences: \\
\hline \multirow[t]{2}{*}{$\begin{array}{l}\text { Santa Fe } \\
\text { Black-on-white }\end{array}$} & $\begin{array}{l}1200-1350 \\
1225-1350\end{array}$ & $\begin{array}{l}\text { Areternltz } 1966: 95 \\
\text { Stubbs and Stallings } \\
1953: 48\end{array}$ & $\begin{array}{l}\text { CR-1a } \\
\text { Floyd Ranch }\end{array}$ & $\begin{array}{l}\text { Crabb 196n } \\
\text { Crnib } 196 i \text { a }\end{array}$ \\
\hline & $\begin{array}{l}1225 t \\
1225-1350\end{array}$ & $\begin{array}{l}\text { Honea } 1973,77 \\
\text { Crabb } 1960,87\end{array}$ & Hefirath & Lints 1976:58 \\
\hline $\begin{array}{l}\text { Miyo } \\
\text { Biack-on-white }\end{array}$ & $\begin{array}{l}1300-1400 \\
1300+ \\
1300-1400\end{array}$ & $\begin{array}{l}\text { Breternitz } 1966,104 \\
\text { llonen } 1973,77 \\
\text { Crabb 1968:87 }\end{array}$ & $\begin{array}{l}\text { Cr-1n } \\
\text { Floyd Ranch }\end{array}$ & $\begin{array}{l}\text { Crnbb 196A } \\
\text { Crnbb 1968 }\end{array}$ \\
\hline $\begin{array}{l}\text { Ablquiu } \\
\text { Black-on-gray } \\
\text { (Biscult } A)\end{array}$ & $\begin{array}{l}1350 t \\
1370-1430+\end{array}$ & $\begin{array}{l}\text { Honen } 1973,77 \\
\text { Baerrels and Bryson } \\
1966,100\end{array}$ & Sndrllebnck Ruln & Cratib 19rib \\
\hline & $\begin{array}{l}1375-1450 \\
1400-1425\end{array}$ & $\begin{array}{l}\text { Arpternitz 1965:70 } \\
\text { Smiley ot Al. } 1953\end{array}$ & & \\
\hline $\begin{array}{l}\text { Galisteo } \\
\text { Black-on-white }\end{array}$ & $\begin{array}{l}1250-1350 \\
1300-1350 \\
1300-1400 \\
1300+ \\
1300-1325\end{array}$ & $\begin{array}{l}\text { Snow n.d. } \\
\text { Smlley, stubbs and } \\
\text { Bannlater } 1953,58 \\
\text { Areternitz } 1966,76 \\
\text { liones } 1973,77 \\
\text { Crabb 1968,87 }\end{array}$ & $\begin{array}{l}\text { CA-la } \\
\text { Ozler Ranch (z) }\end{array}$ & $\begin{array}{l}\text { Crnbb } 1968 \\
\text { snow n.d. }\end{array}$ \\
\hline $\begin{array}{l}\text { Rowe } \\
\text { Black-on-white }\end{array}$ & $\begin{array}{l}1325-1375 \\
1350 * \\
\text { late } 1300^{\prime} \mathrm{s} \\
\text { ca. } 1350\end{array}$ & $\begin{array}{l}\text { Baerrels and Aryson 1966,Joh } \\
\text { Honea } 1973: 77 \\
\text { Breternitz } 1966: 93 \\
\text { Crabb } 1968: 87\end{array}$ & $\begin{array}{l}\text { Stnmprer } \\
\text { CR-In }\end{array}$ & $\begin{array}{l}\text { Watson 1950 } \\
\text { Crath 196n }\end{array}$ \\
\hline $\begin{array}{l}\text { Kowina } \\
\text { Bluck-on-:thite }\end{array}$ & $1200-1400$ & Crabb 1969:87 & Inolnted flnd near CR-1 & Crahb 1968 \\
\hline $\begin{array}{l}\text { Chupatero } \\
\text { Black-on-white }\end{array}$ & $\begin{array}{l}1150-1400 \\
1200-1600\end{array}$ & $\begin{array}{l}\text { Broternltz } 1966,72 \\
\text { Crabb 1968,B7 }\end{array}$ & Floyd Ranch & Crnabs igrin \\
\hline $\begin{array}{l}\text { Jeddito } \\
\text { Yellow Hare }\end{array}$ & $\begin{array}{l}1300+ \\
1300-11100\end{array}$ & $\begin{array}{l}\text { Snow n.d. } \\
\text { Breternltz } 1966,78\end{array}$ & Oalne Ranch & snow n.l. \\
\hline $\begin{array}{l}\text { Linnoln } \\
\text { Black-ull-red }\end{array}$ & $\begin{array}{l}1347-1366 \\
1300-1400 \\
1300-1400\end{array}$ & $\begin{array}{l}\text { Breternitz } 1965: 82 \\
\text { sallny, stuhbs and } \\
\text { Banniater 1953,5n } \\
\text { Crabb 1968:03 }\end{array}$ & $\begin{array}{l}\text { Alibaton } 28 \\
\text { Antelope Crenk } 22 .\end{array}$ & Crabb 1968 \\
\hline
\end{tabular}


TABLE 5, Continued.

\section{Ceranlc Type Estimated Age}

St. Johns

Polychrom

1200-1300

1200-1275

Heshotauthla

$1300-1400$

1275-1375

Aqua Fria

Glaze-on-red

(Glaze I)

1300-1450

1325-1400

(Glaze A)

1325-1425

1315-1425

$1315+-1425$

Cienequilla

(Glaze I)

$1315-1425$

$1315+-1425$

1300-1450

$1325-1400$

1375-1450

San Clemente

Glaze Polychrome 1315-1425

(Glaze I) 1315-1425

Glaze A) $\quad 1300-1450$

1325-1400

\section{Largo}

Glaze-0n-yellon 1400-1450

$1425-1450$

(Glaze B)

1400-1500

ca. 1425

Largo Glaze

1400-1450

Polychrome

1425-1450

$1400-1500$

ca. 1425

Kuaua Glaze 1425-1490

Polychrome 1450-1490

(Late Glaze I1 1400-1450

Early Glaze III

(Glaze Cl

(Glaze C)
References

Braternitz $1966: 93$

Crabb 1968, a3

Breternitz 1966:77

Crabb 1968:日7

Greternitz 1966,91 Baerrels and Bryson 1966,108

Crabb 1968:87

Harren 1969:37

Honea 1973,81

Snow

Warren 1969, 37

Honea 1973:81

Breternltz 1966:91

Baerrela and Bryson

1966,108

Crabb 1968,87

Snow

Warren $1969: 37$

Honea 1973,81

Bretemltz 1966:91

Baerreile and Bryson

$1966: 208$

\section{Marren 1969839}

Honea 1973,82

Breternitz 1966:91

Crabb 1968,87

Warren $1969: 39$

Honea 1973,82

Bretern1tz 1966,91

Crabb 1968:87

Harren 1969:39

Honea 197J;82
Bretern1tz $1966 ; 91$

Crabb 1968,87
Antelope Creek Sites

Roferancas

Allbates 28

Antelope Creek 22 Crabb 1968

Floyd Ranch

Crabb 1968

Allbatas 28

Antelope Creok 22

Crabb 1968

Blg Blue I

Saddleback Ruln

Saddleback Ruln

Allbates 28

Nitelope Creek 22

Blg Blue I

Floyd Ranch

oster

Oeler

snow n.d.

Ozler

isolated find

Crabb 1968

ceter

Crabb 1968

Saddlebeck Ruln 


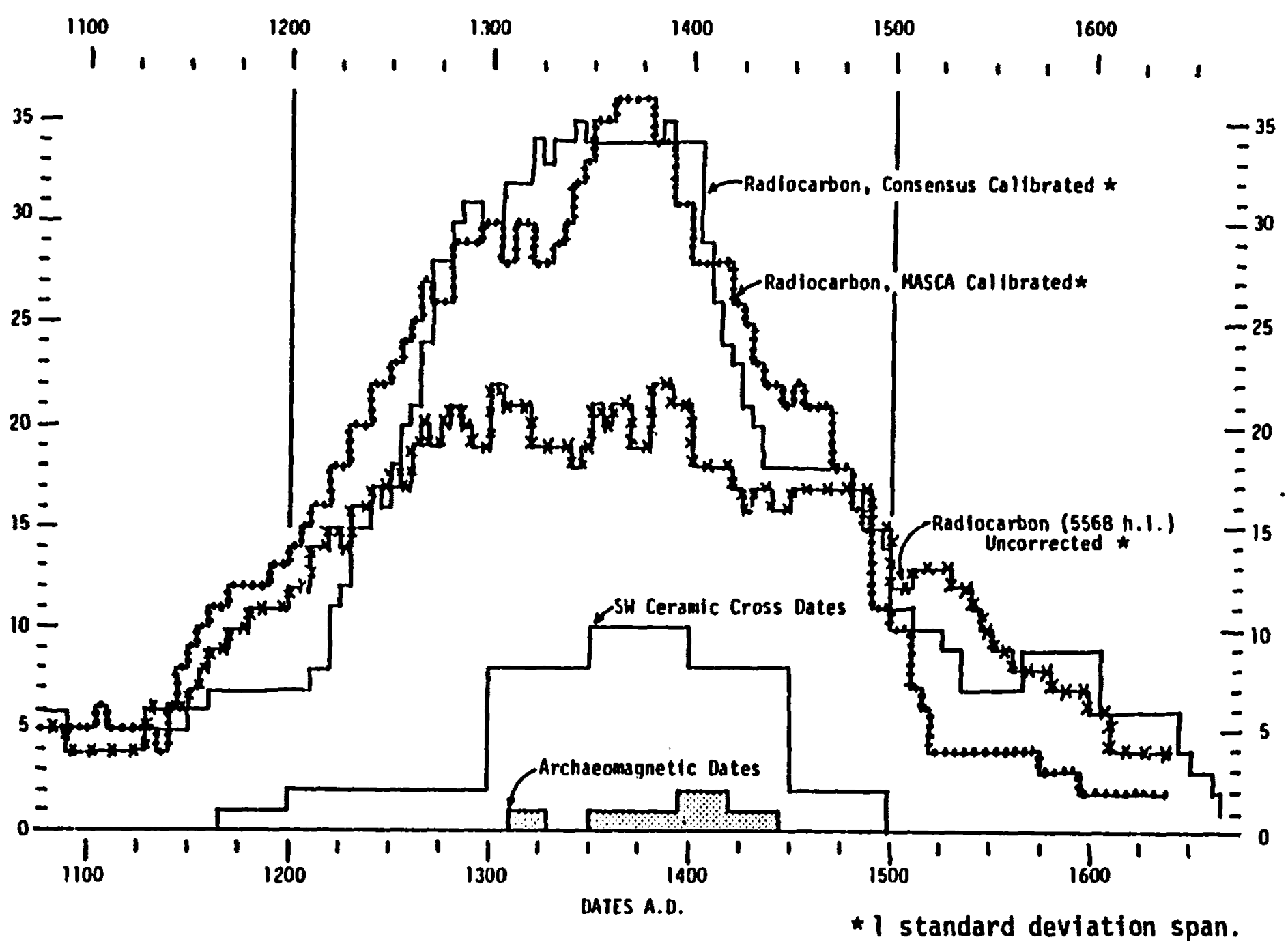

Figure 2. Histogram of Antelope Creek Phase Radiocarbon, Archaeomagnetic and Ceramic Cross-Dates. 
The village sites tend to be located on high terraces within drainage basins, rather than on the Plains uplands. Intensive surveys suggest that primary tributaries of the major rivers have a higher overall site density than the major river valley proper (Etchieson 1981:88; Guidry et al. 1979:V-47; Hughes et al. 1977:221, Table 4). Architectural sites commonly occur atop steep, sloping terraces, on elevated knolls in the floodplain, and in the west, on isolated mesas. Although access to some of the mesa top sites such as Saddleback Ruin and Landergin Mesa is limited, no stone perimeter walls enclosing villages have been reported at any site.

Architectural features: Considerable excavations have been undertaken at architectural sites, and a wide range of forms has been suggested (Lintz 1982). Structures vary between freestanding, one-room buildings and fairly large room blocks in excess of 20 contiguous rooms. The shapes and sizes of rooms commonly range from small circular units with less than a five square meter floor area to relatively large rectangular rooms roughly oriented to the cardinal directions with between nine and 60.5 square meters floor space. While the small circular structures may rely on opportunistic use of the boulders, the larger rectangular structures are often built in shallow pits with elaborate interior features, such as depressed central channels, central hearths, interior roof support posts, eastward extended passages and raised platforms either recessed into or projecting from the center of the west wall. Considerable variation exists in the nature of the building foundation and walls. Foundations often consist of single or double rows of vertically set stone slabs, occasionally supplemented with horizontal slabs, posts, adobe blocks, or any combination of these materials. Similarly, the height of the stone reinforced walls varies from 
mere foundation footing, to stone walls exceeding six feet in height (Bakex and Baker 1941b:33).

Burials: Panhandle phase burials axe frequently single, semiflexed interments. Most occur on hilltop localities, but less often they are located in village structures and rarely in midders. When located in villages, the burials are concentrated in the largest structure at the site (Watson 1950). However, many are located above the floor, indicating that the interments post-date the use of the structure. This suggests that the burials occur in cemetery areas in hilltops or abandoned rooms adjacent to the occupied part of the sites. Most graves consist merely of shallow pits covered with rock slabs. A departure from the single interment practice is present at Room I of the Footprint Site, where each of three graves contained porticns of seven different individuals (Green 1967). Grave goods, consisting mostly of jewelry or domestic utensils, are present in approximately one-fourth of the burials. Few burials have more than two or three artifacts included. The paucity of items suggests little to no status differentiation in burial practices.

Subsistence: The economy is based on a hunting-gathering-horticultural pattern. Hunting focused on bison, but deer and antelope contributed substantially to the diet (Duffield 1970). These basic animals were supplemented by smaller game (rabbit, prairie dog, ground squirrel, gopher, rat, bobcat, raccoon, badger, fox), amphibians and reptiles (terrapins, various aquatic turtles, frogs), fish, mussels, and various indigenous and migratory water fowl. Most bone remains from larger mammals have been systematically reduced to splinters for the extraction of marrow and bone grease (Lintz 1976:87). Wild plant remains include hackberry, mesquite, buckwheat, 
various grasses, cattail stems, plums, persimnons, prickly pear, and Indian mallow (Green 1967:157; Keller 1975:22). Domesticated plants include both popcorn and small flint corn, as well as squash/pumpkins and beans (Green 1967:157; Keller 1975:22). Unlike Apishapa phase sites, horticultural tools consisting of both bison scapula hoes and tibia digging stick tips are frequently recovered in Antelope Creek phase sites.

The Antelope Creek artifact assemblage differs from that of the Apishapa in the quality of knapping and the specialization in tool morphology. Near the Alibates quarries, the tool reduction strategies involve the production of large, flat, tabular flake blades, incidental blades and tool preforms or, more rarely, prepared bifaces for long distance trade (Bandy 1976; Iintz 1978c). The artifact assemblages also show more diversity and specialization (Lintz 1982). In addition to the generalized, modified flake and core scrapers, choppers and ovate knives, flange dxills and gravers, there is a whole series of more specialized chipped stone tools, including alternately beveled, diamond shaped knives, "guitar-pick" scraper/ preforms, pin drills, key or T-type drills, highly formalized end scrapers, delicately manufartured, small side-notched and unnotched points (Washita, Harrell, Fresno, and, more rarely, shetley and the asymetrically notched Temporal Point Type). The chipped stone assemblage occasionally includes corner tanged knives, chipped axes and picks. Pecked and ground stone tools include small, oval, one-handed manos, grinding basins, mortar holes, a wide range of hammerstones, including the oval shaped, faceted edged "bişcuit" hammerstones, awl shapers, shaft smoothers, and elbow pipes. Indigenous ceramics are limited to predominantly large, globular and cordiform, cordmarked jars with wide mouths, sherd disc spindle whorls and clay 
beads. The bone tool assemblage is also varied and specialized. Common tools include bison scapula hoes and squash knives; bison tibia digging sticks; various kinds of awls including rib edge, split rib, splinter and split deer metatarsal forms; pins, pegs, beads, bone wedges, rib "rasps", antler tine billets, pressure flaking tools and more rarely, eyed needles, shaft straightners, and bison femur head hide gruinezs. Freshwater mollusks were used as scrapers and spoons, or rarely cut intc pendants. Trade with southwestern groups is reflected in the presence of marine shell jewelry (olivelli and columella shell beads, conus tinklers, conch shell pendants and gorgets), exotic siliceous materials such as obsidian, mica and turquoise, and painted pottery. Trade with other Plains groups is reflected by red stone catlinite pipes, chipped stone tools of Niobrara Jasper and occasional cord marked sherds with collared rims and perhaps lip tabs.

Social organization: In contrast to the Apishapa phase, the Antelope Creek phase has considerable more diversity in architecture, community and settlement patterning. The mortuary practices similarly show the inclusion of more and varied kinds of grave goods; however, most it.ems represent personal belongings and tools, rather than exotic trade items indicative of status differentiation. Finally, many sites contain trade goods from the Southwest and Plains indicative of the incipient stages of intercultural alliances which culminated in the Protohistoric cultures of the Red Bed and High Plains areas (Baugh 1982; Spielman 1983).

\section{Summary}

This chapter has served a double purpose. First, the history of archaeology in the nortile $c n$ Texas panhandle has been reviewed in order to 
Show how the range of late prehistoric architectural and community variations have been perceived and interpreted. Most sumaries of the Antelope Creek manifestation have been based on characteristics from a few type sites and have not generally included the full range of available information. Furthermore, the cultural variation that has been discerned usually has not been referenced to specific provenience units at a particular site. Consequently, most summaries are based on incomplete information.

Second, the limitations and implications of the cultural taxonomic systems developed for the late prehistoric Texas panhandle manifestations have been reviewed. The use of the Midwestern Taxonomic System (MTS) was found to be cumbersome since the application of the same nomenclature has been applied to different cultural constructs and has left considerable ambiguity. Furthermore, the MrS was not designed to accomodate a critical examination of material variation within the complex. Consequently, the existing late prehistoric cultural manifestations along the upper Canadian and the upper Arkansas River drainages of the Southern Plains Subarea have been redefined using a modified willey and Phillips taxonomic system. Within the Southern Plains Village tradition, the Upper Canark regional variant is proposed. It includes those late prehistoric adaptations involving a semisedentary existence, combined foraging and horticultural subsistence, and is expressed by the predominant use masonry slab architecture, small side notched projectile points, and cordmarked ceramics. Two contemporaneous but spatially distinct expression of the Upper Canark regional variant include the Apishapa phase in southeastern Colorado and perhaps northeast New Mexico, and the Antelope Creek phase in the Texas and Oklahoma panhandles. Similar but poorly reported sites in northeast New Mexico may be related to 
66

either these defined phases, or may constitute a separate phase within the Upper Canark regional variant. The remainder of this study will focus on variations within the Antelope Creek phase. 


\section{CHAPTER 3}

\section{ENVIRONMEITTAL DIVERSITY OF THE STUDY AREA}

\section{Introduction}

From an ecological perspective, cultures are a part of larger environmental systems and interact with natural and cultural components of the system (Helm 1962). Consequently, components of the cultural system (and architectural and community fatterns in particular) are apt to change as the needs of the people respond to changes in the physical and social environmental situation. The congruence or conformity of the cultural response to the environment is regarded as the cultural adaptation. Therefore, one aspect of understanding cultural variation is to examine and document environmental condition within which the culture develops.

This chapter defines a specific area for studying Antelope Creek variation, examines the natural diversity of the study area, and briefly discusses these environmental aspects as they relate to human ecology. The optimal size should roughly be comparable to an archaeological "localịty," defined as the geographical space that might be utilized by a single local group and sufficiently restricted to permit the assumption of homogeneity within the cultural system at any given time (Willey and Phillips 1958:18). This chapter is primarily directed towards discerning variation in the distribution of natural resources within the study area which may underlie differences in the Antelope Creek phase settlement and community patterns. Thus this chapter provides the environmental foundation for later 
discussions of cultural diversity.

\section{General Setting and Definition of the Study Area}

The Antelope Creek phase is located in the south portion of the Great Plains (Fenneman 1931). The character of the Great Plains surface began developing in conjunction with the repeated and widespread uplifting of the Rocky Mountains during the Tertiary Period. The Great Plains represents a series of high overlapping alluvial fans on the east flanks of the Rocky Mountains extending from the Edwards Plateau in Texas, northwards towards Canada.

On the Southern Plains, remnants of these fans have low relief. The Llano Estacado and Panhandle sections of the Southern Plains range from 1350 to $750 \mathrm{~m}$ in elevation and dip an average of $2.3 \mathrm{~m} / \mathrm{km}$ to the southeast (Figure 3). The character of the original fans has been modified by the dissolution of deeply buried salt, gypsum and other soluble deposits coupled with differential settling of the overlying sediments (Gustavson, et al., 1980). Although the Southern High Plains is dropping at a rate of some $15 \mathrm{~cm}$ per 1000 years, localized collapse of overlying beds has produced sinkholes, chimneys and linear depressions. The topography of the fan remnants consist mainly of shallow basins and occasionally pleistocene relic valleys. During wet seasons, an estimated 20,000 playa lakes occur within a $117,500 \mathrm{~km}^{2}$ area (Reeves 1975).

The eastern and western margins of the Southern High Plains are rather sharply demarcated by exosional escarpments. Ts the east, erosion, through the shallower margins of the old fans and along relic and recent stream valleys has left a series of relatively jagged escarpments, 90 to 120 m high, which physiographically separate the High plains from the 


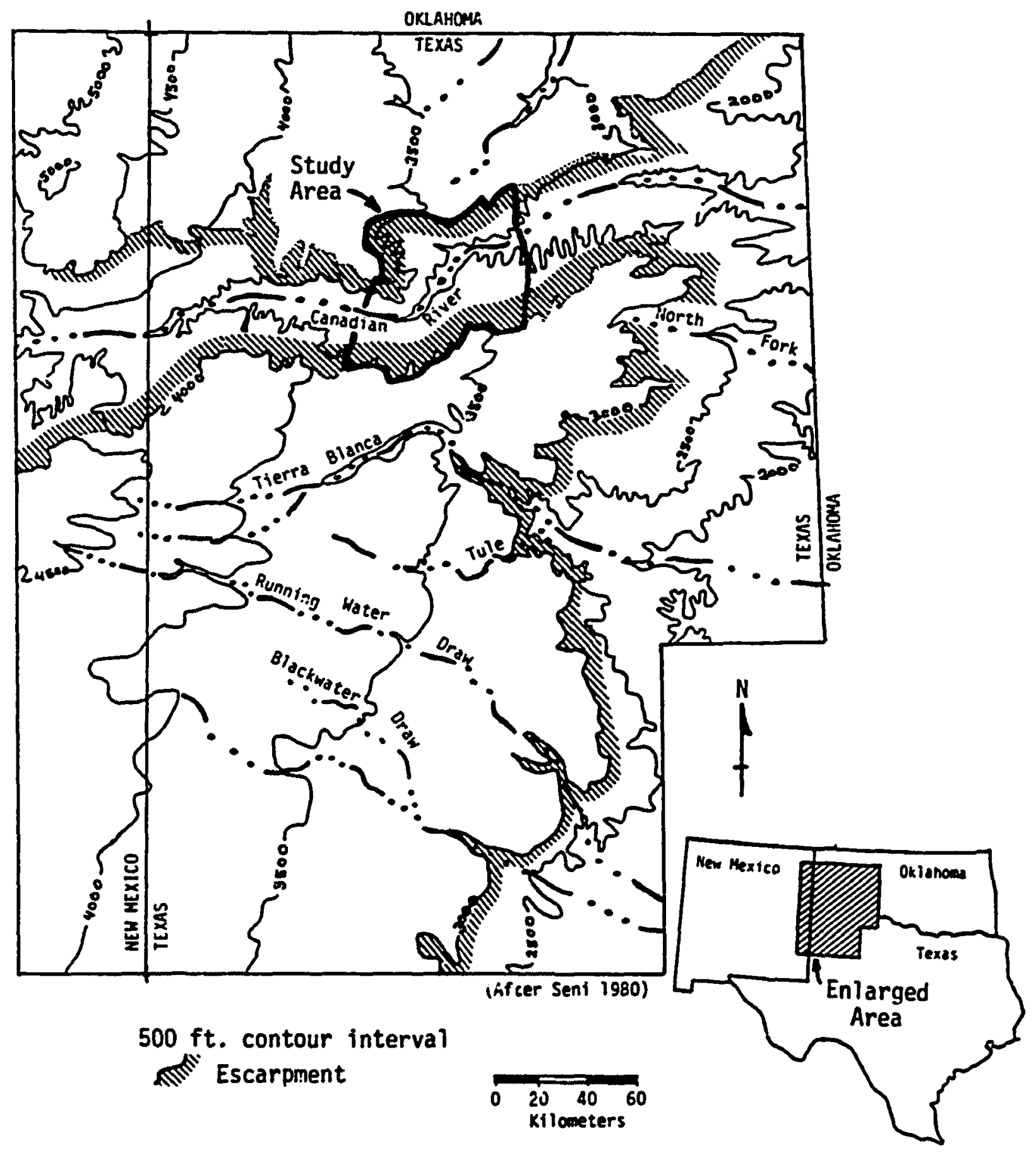

Figure 3. Topography of the Southern High Plains. 
Central Lowlands (Fenneman 1931:4). The western escarpment was formed when the Pecos River cut northward and pirated headwater stream flow across the Llano Estacado (Reeves 1972:110). In contrast to the east, the western escarpment is much straighter.

The two escarpments have left the Llano Estacado and panhandle sections of the Southern High Plains isolated from larger hydrologic systems. The isolation has resulted in a lowering of the regional base and has accentuated entrenchment of the Pleistocene valleys into the High Plains topography (Stafford 1981:550). Although several of these valleys are major drainages originating on the Southern Flains, only the Canadian River crosscuts the High Plains of Texas and transports water from the eastern flanks of the southern Rocky Mountains to the Mississippi Basin. Within the Southern Plains, the Canadian River valley flows northeastward. Lateral tributaries trend north-south, occur at three to five kilometer intervals and range from 20 to 35 kilometers in length. The Canadian River, with its short lateral tributaries, cuts a broad, shallow valley averaging 150-200 meters deep and 50 to 75 kilometers wide. A portion of the Canadian River valley in the Texas panhandle was selected for the focus of study. The choice of this section of the river valley was guided by the following conditions:

1) This section of the valley has been intensively studied by archaeologists since early surveys: the quality and intensity of surveys has varied considerably. Nevertheless, considerable information from extensive excavations at numerous large village and hamlet sites provides a solid base for studying cultural variability. 
2) The valley shows signs of being intensively occupied by relatively sedentary populations. Although numerous temporary camps occur adjacent to playa basins on the uplands, the settled villages and hamlets most commonly occur with the rough, broken lands of the stream valleys. These kinds of settlements are apt to show a wider range of activities than those occurring at smaller, temporarily occupied campsites.

3) Most of the excavated ruins appear to be affiliated with the Antelope Creek phase. Further, the valley has long been regarded as the geographical core of the cultural manifestation (Krieger 1946). The exchange of the famed Alibates "flint" from quarries northeast of Amarillo has been postulated as a means of establishing cultural cohesion between settiements within the valley.

4) The size of the study area is large enough to display some internal, natural diversity, which once identified, can be used as a satural control for comparing cultural variability. The area meeting all of these considerations is an $80 \mathrm{~km}$ section of the Canadian River valley centered around the Alibates National Monument (Figure 4). The north and south boundaries are sharply demarcated by the head cutting of short Canadian River tributaries into the relatively level High Plains. Spring and Moore Creeks form the eastern boundary, whereas Sand Creek and the mouth of the Sierrita de la Cruz Creek form the western boundary. I am designating this section the High Plains-Canadian Valley locality. 
Antelope Creek Phase Architectural Sites within the Study Area indicated on Figure 4.

1 Jack Alten Site

2 Zollars Site

3 Tarbox Site

4 Black Dog Village

5 Cottonwood Creek Ruins

6 Pickett Ruin

7 Sanford Ruin

8 Antelope Creek Ruin 24

9 Antelope Creek Ruin 23

10 Lookout Ruin

11 Antelope Creek Ruins 22 and 22A

12 Conner Site

13 Roper Site

14 Spring Canyon Site
15 Medford Ranch Site

16 Arrowhead Peak Site

17 Big Blue Ruins*and Cemetery

$18 \quad 41 \mathrm{Mo}-7$

19 Turkey Creek Ruins

20 Alibates Ru in 28A

21 Al ibates Ruin 30

22 Alibates Ruin 28

23 Ozier Site*

24 Canadian River Sites 1*and $1 a^{\star}$

25 Footprint Site

26 Coetas Ruin

27 Marsh Site

28 Chimney Rock Ruins 51 and $51 \mathrm{~A}$

* Denotes sites not included in this study. 


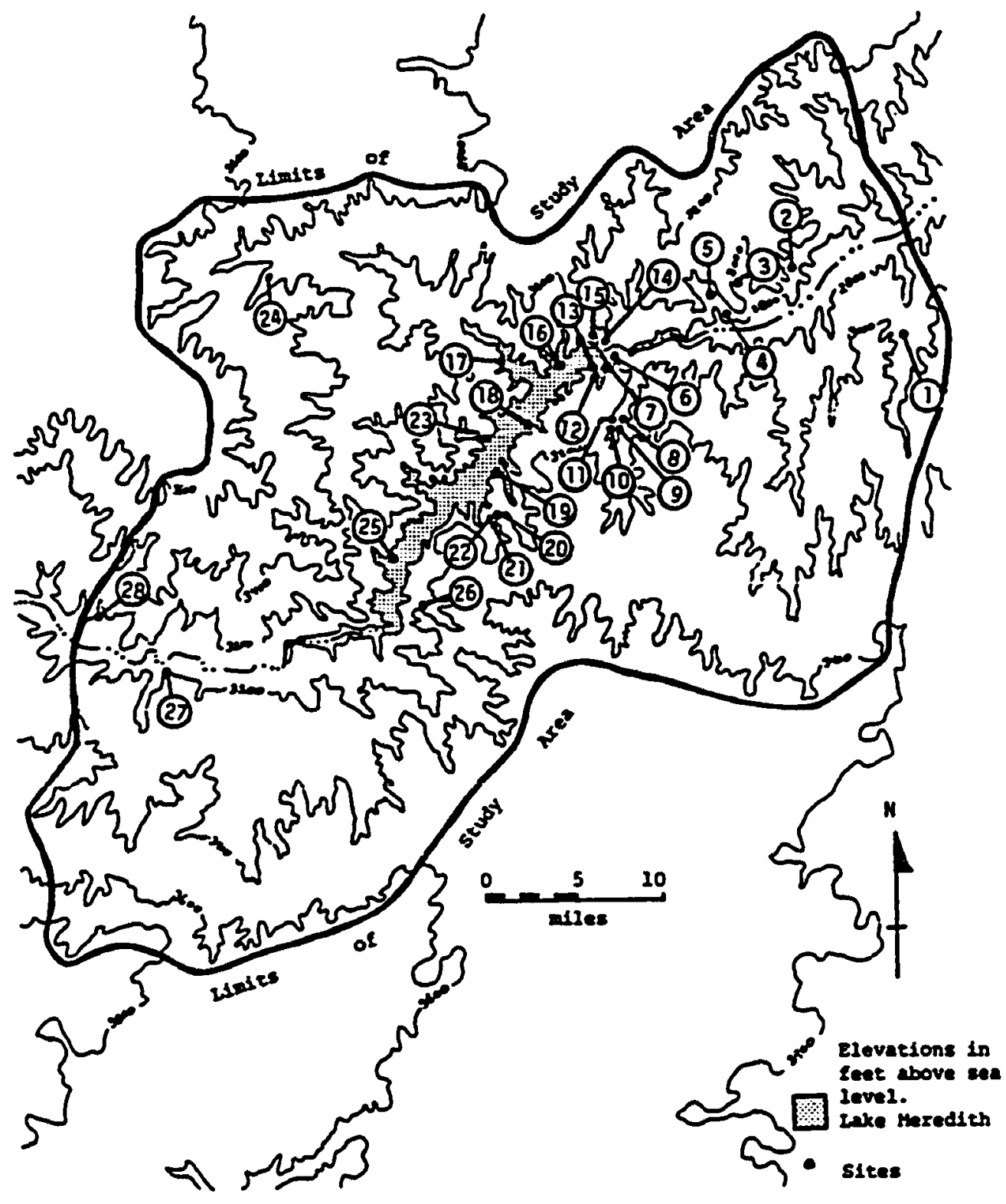

.Figure 4. Topography of Study Area and Distribution of Sites. 
Natural Diversity of the High Plains-Canadian

Valley Locality

From a continental and regional perspective, the physiographic and biotic characteristics of this portion of the Canadian River appear quite uniform (Fenneman 1931; Allred 1956:268; Kuchler 1964:71). But locally there are pronounced differences. The geology, soils, hydrology, climate, flora and fauna within the study area will be presented in order to indicate the present local differences. Available environmental evidence will also be briefly examined to suggest possible changes that occurred during the florescence of the culture at about A.D. 1200-1500.

GEOLOGY

The subsurface geological structures of the Southern High Plains normally have little bearing on prehistoric utilization since they have been mantled by Cenozoic deposits. Only within the Canadian River valley and the margins of the plains have sufficient deposits been removed to expose pre-Cenozoic strata. The formations exposed within the study area include the Permian age Whitehorse, Alibates and Quartermaster formations; and the Tertiary age Ogallala formation (Figure 5). Differential erosion of the Canadian River and its tributaries has formed a dual valley system (Figures $6,7)$. The outer valley is a relatively broad but shallow basin ranging from 50-60 km wide but only $125 \mathrm{~m}$ deep. The terrain is typically rolling topography formed by the exosion of Tertiary age sediments by the Canadian River and its tributaries. In contrast, the inner valley is only lisce to four $\mathrm{km}$ wide but is incised $60-75 \mathrm{~m}$ into the Triassic and Permian age sediments. The terrain of the inner valley is often characterized by bluffs, escarpments, occasional mesas, and "rough broken ground" bordering a two to 


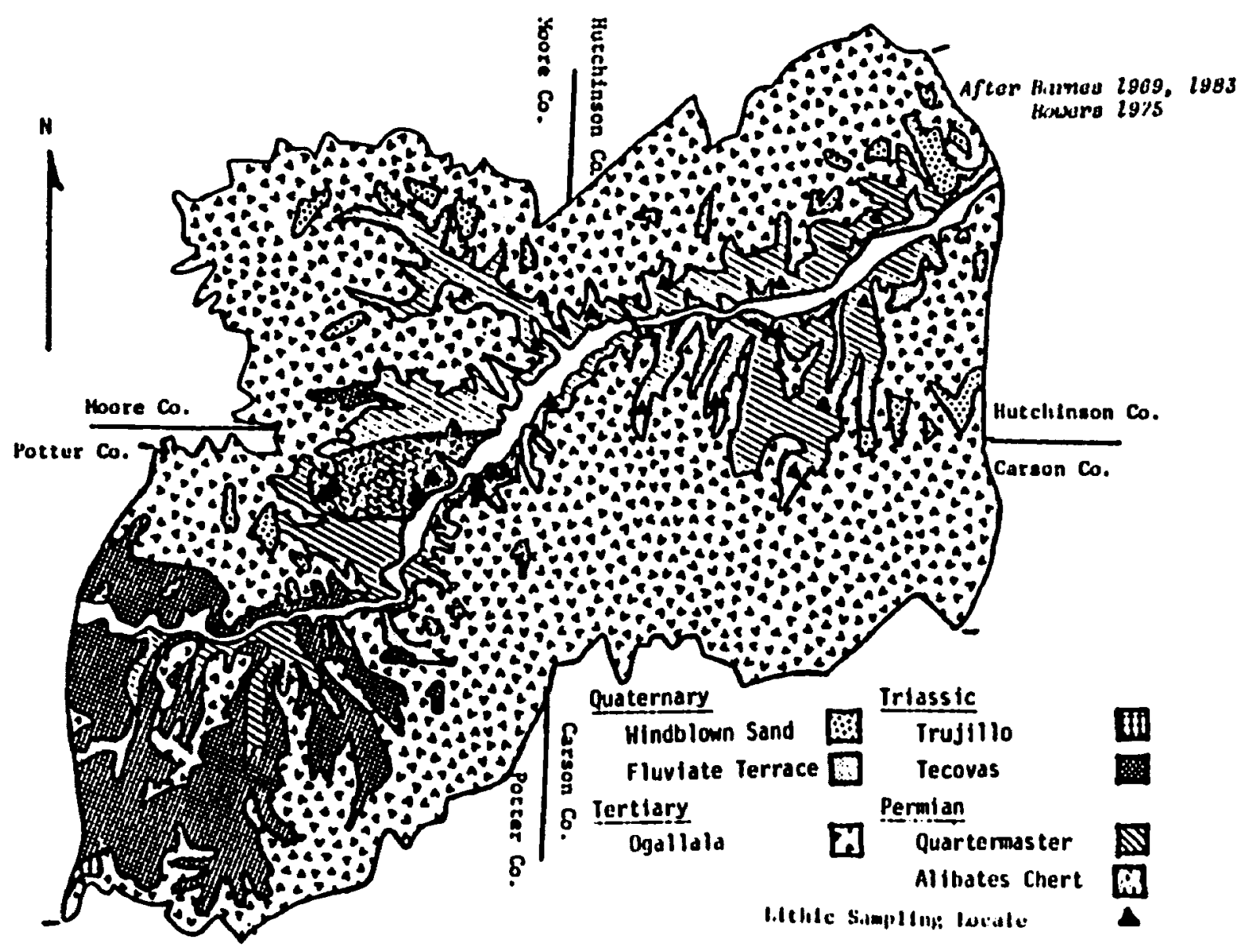

Figure 5. Geology of the Study Area. 


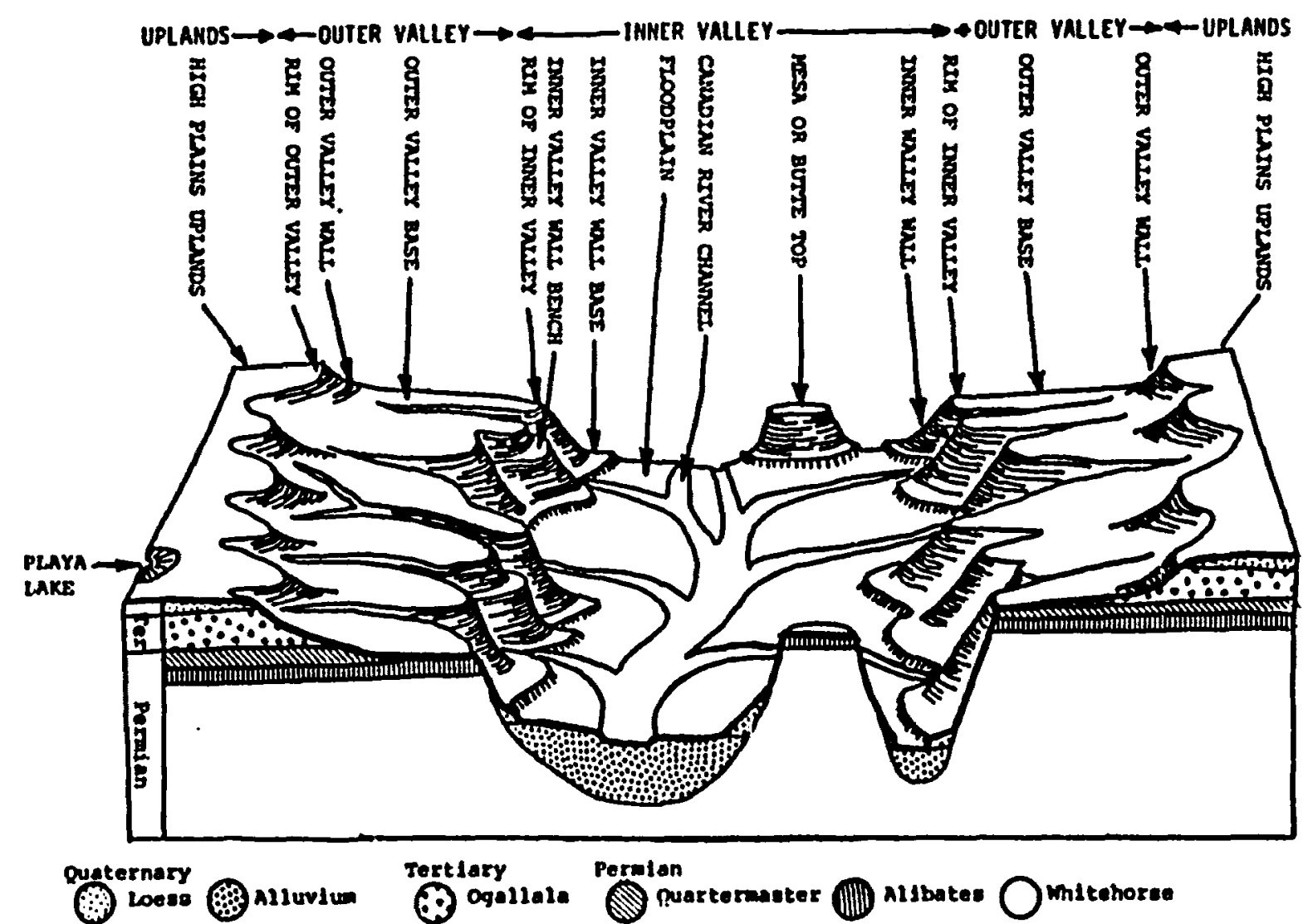

Figure 6. Canadian Valley Topographic Features and Their Relationship to Geological Deposits. 

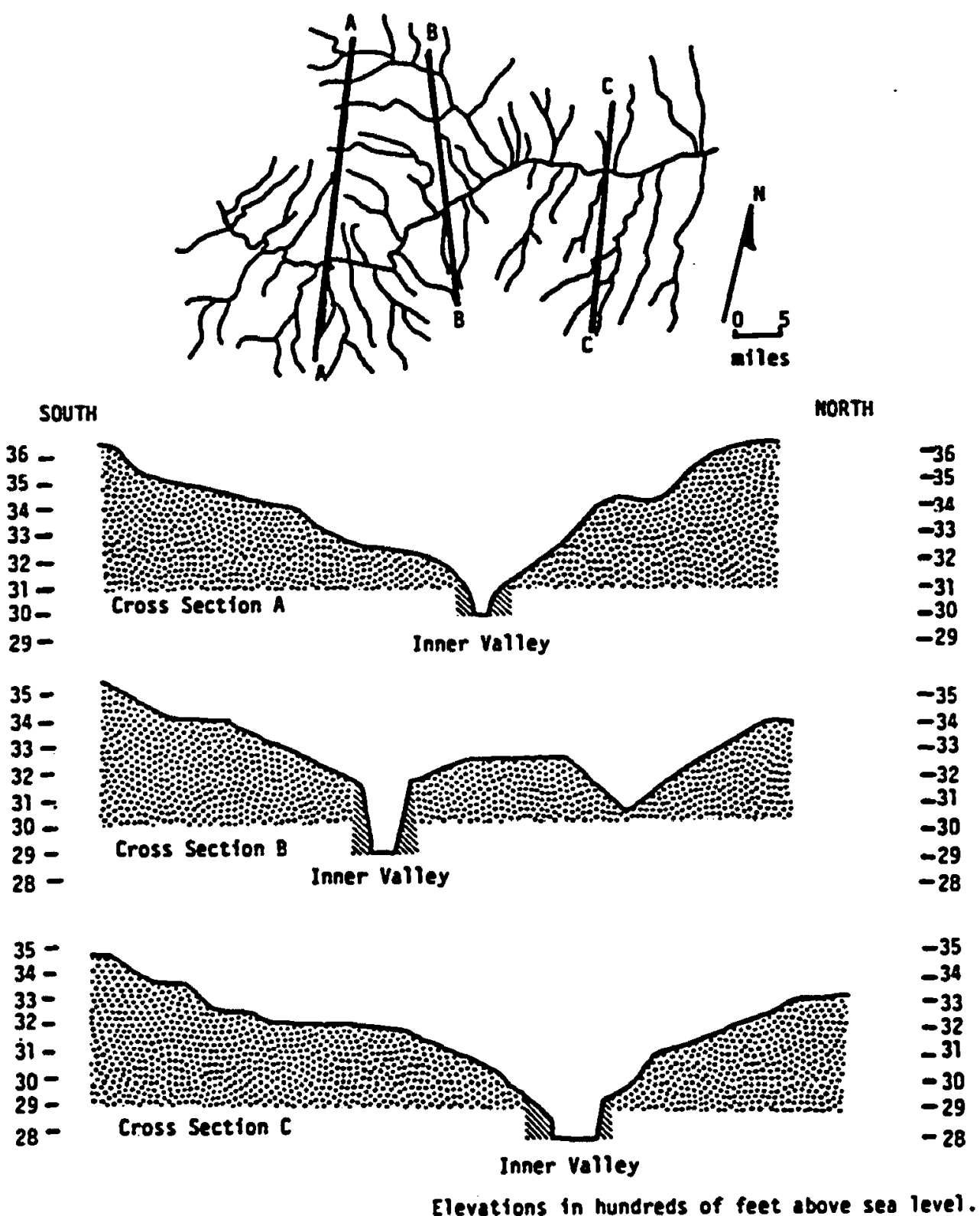

Figure 7. Cross Section of the Canadian River Valley. 
three $\mathrm{km}$ wide floodplain. In comparison to the relatively flat surface of the High Plains, the dual valley system is rugged and referred to as the Canadian River Breaks. However, the distinctions between inner and outer valleys constitute a major dichotomy in the environmental setting. The geology of the study area is of utmost importance since the soils, various aquifers and usable tool stone relate to the different geological exposures. The earliest accessible deposits within the valley are of Permian age, exposed in the inner valley by erosion through the Amarillo Anticline (Totten 1956; Nicholson 1960). Within the Canadian River drainage, the Permian deposits are almost entirely restricted to the eastern two-thirds of the study area. They typically consist of thick red sandstone, siltstone and shales, with more or less persistent beds of dolomite and gypsum (Baries 1969). The Whitehorse formation consists of a thick interval of red bed sandstones forming steep (30-70z) slopes beneath the resistant Alibates (Bowers 1975; 19). At most localities, only a few meters are exposed at the base of escarpments along the margins of the major tributaries. overlying the Whitehorse formation is the distinctive Alibates dolomite, formerly classified as the lower member of the Quartermaster formation, but more recently regarded as a separate formation (Totten 1956:1961; Roscoe and Baars 1972:144; Bowers 1975). The Alibates formation consists of upper and lower dolomite members separated by an interval of calcareous red bed mudstone and shale. The lower dolomite member ranges from one to three meters thick, whereas the upper member ranges to $60 \mathrm{~cm}$ thick (Bowers 1975:22). The two dolomite layers form resistant caprock escarpments along the edges of the inner valley, although the upper member is only sporadically preserved within the study area. These dolomite beds are strongly 
jointed--fractured and faulted as a probable result of both ongoing settling into salt dissolution cavities, and expansion during hydration conversion of anhydrite to gypsum deeply buried in the lower Permian deposits (Redfield 1953:7; Gustavson, Finley and MeGillis 1980). Calcitization and Chertification have sporadically occurred in both upper and lower dolomite members of the Alibates formation. The chert replacement of dolomite is particularly well developed along Bates, Plum and Devil's Canyons where the famed Alibates "flint" outcrops (Shaeffer 1960; Bowers 1975; Etchieson 1981: 9). (Figure 5).

The Quartermaster Formation is the uppermost Permian deposit. It strongly resembles the Whitehorse formation, and where the silibates has been eroded the distinction between the two formations may not be recognizable (Bowers 1975). The Quartermaster consists of red to maroon mudstone, shale, siltstone and sandstone. Overall, the Quartermaster tends to contain more clay and mica than the Whitehorse (Bowers 1975:23). Occasional gypsum beds occur, but they are thin and discontinuous.

The Triassic age sediments include fluvial, deltaic and lacustrian deposits within the Dockum basin which underlies eastern New Mexico, the western Texas and Oklahoma panhandles, and southeastern Colorado. On the. Southern High Plains, Triassic beds are extensively exposed along the southeastern parts of the Llano Estacado and within the Canadiar. River drainage of east central New Mexico (McGowen, et al. 1979:2). Elsewhere, thin exposures are present along the eastern and western escarpments.

- The Amarillo uplift prevented the Triassic sediments from covering Permian deposits. Consequently, the Dockum group occupies a syncline upstream from Tincup Spring and Chicken Creeks. The Triassic beds are confined to the western third of the study area where they comprise the 
lowest accessible deposits. Tecovas and Trujillo are two formations locally represented within the study area.

The Tecovas formation is stratigraphically beneath the Trujillo but represents approximately 858 of the Triassic exposures. It consists of reddish brown, maroon, gray or yellow clay shale and well cemented sandstone and locally contains large petrified logs, micaceous or calcareous deposits (Redfield 1953; Barnes 1969). A mottled orange, yellowish green and blue jasper also locally outcrops in the Tecovas formation. Extensive Tecovas jasper deposits have been known from the eastern caprock escarpment region for years (Green and Kelly 1960); however, more restricted occurrences have been documented recently from the Cimarron drainage in New Mexico (Dale n.d., Banks, 1984:72) and within the study area portion of the Canadian River valley at Rotten Hill, Sierrita de la Cruz Creek and the mouth of Coetas Creek (Couzzourt 1982:64; Cameron 1980).

The Trujillo formation occurs sporadically in areally restricted exposures near the head of the lateral tributaries. The formation consists of gray and brown conglomerates, sandstone and shale. The conglomerates are composed of pebbles of quartz, limestone, siltstone, thin chert and fragments of petrified wood (Barnes 1969). The sandstones are crossbedded, friable, usually coarse grained and are locally calcareous.

The main Cenozoic unit mantling both the Triassic and Permian deposits consists of the Ogallala formation (Frye and Leonard 1957:11). This formation consists of outwash debris from the southern Rocky Mountains which occurred during the Pliocene era of the Tertiary Period. The Llano Estacado and panhandle section of the High Plains are the remnants of three major alluvial fan systems of which the Dalhart-Amarillo lobe covering the study area is the ynungest (Seni 1980:20). Within the Canadian River 
valley, the exposed Ogallala sediments average $115 \mathrm{~m}$ thick (Barnes 1969). Along the eastern edge of the study area, the ogallala extends from the High Plains upland surface to the alluvial filled Canadian River channel. The formation is easily distinguished from other formations by its light brown to buff coloz and by its conglomerate lithology. Although not present everywhere, the gravels are composed of pebbles to cobbles of quartz, quartzite, with minor cherts, igneous and metamorphic rocks. A thick, late Pliocene age, petrocalcic soil horizon in the upper portion of the Ogallala formation forms an erosionally resistant caliche, locally referred to as the Caprock of the High Plains (Reeves 1976).

The guaternary age deposits occur as two types (Barnes 1969). Windblown sand and silt form a series of largely stabilized sheets and dunes, 20-250 hectares in area, within the Canadian River drainage and also a thin mantle over the Ogallala deposits on the uplands High Plains surface adjacent to the study area. The principal dune deposits occur on the outer valley Ogallala exposures north of the Canadian River; some dunes on the south side are present in the study area east of Bear Creek. Stabilized dunes occasionally mantle the inner valley deposits. Fluviate deposits along the Canadian River channel constitute the second form of Quaternary age deposits. They are represented by Pleistocene terrace systems (most highly developed along the eastern portions of the inner valley) and recent alluvium. Core drilling during development of Sanford Dam indicates that alluvial deposits extend to a depth of $45 \mathrm{~m}$ (Redfield 1953:31).

SOIL

Soil development is dependent upon five major factors: parent material, topography, climate, organisms and time (Birkeland 1974:125-126). 
The usual period of soil development is lengthy, and with few exceptions, the soil conditions have not substantially changed during the past few thousand years. The basic soil types in the study area generally correspond to geological formations and topography. In a systemic manner, geology and topography affect the retention of moisture and local soil chemistry which in turn affect the development of generalized vegetation comunities. Furthermore, in the study of horticultural groups, a knowledge of soil characteristics provides some basis for inferring suitable methods and settings for growing certain crops. A brief discussion of the occurrence and characteristics of the soils within the study area is important in understanding the distribution of exploitable biotic resources.

Four detailed soil studies have been conducted within the counties encompassing the study area (Jacquot 1962; Geiger 1975; stringer 1976; Pringle 1980). Unfortunately, each has employed different soil series taxonomies. Nevertheless, these iocal differences are reconcilable when a more systematic and fundamental soil taxonomy is employed iscil s:ars; staff 1975). Five orders of soil are found in the study area: Alfisols, Inceptisols, Mollisols, Entisols and Aridosols (Table 6). The first three soil orders most commonly occur in the outer valley, whereas the Entisols generally occur in the inner valley. Aridosols is a minor soil order occasionally found in the outer valley area. All five orders developed in warm, subhumid to semiarid climatic regions.

The Alfisols are those with a moderate to high base saturation. They tend to form on stable late Pleistocene or older surfaces, and tend to have a developed ca horizon (soj.l Survey staff 1975:95). All Alfisols in the study area are assigned to the Ustalfs suborder which developed on carbonatic parent materials during warm moisture regimes. The Ustalfs are 
TABLE 6 .

ORIGINS AND CHARACTERISTICS OF SOIL SERIES FROM THE STUDY AREA

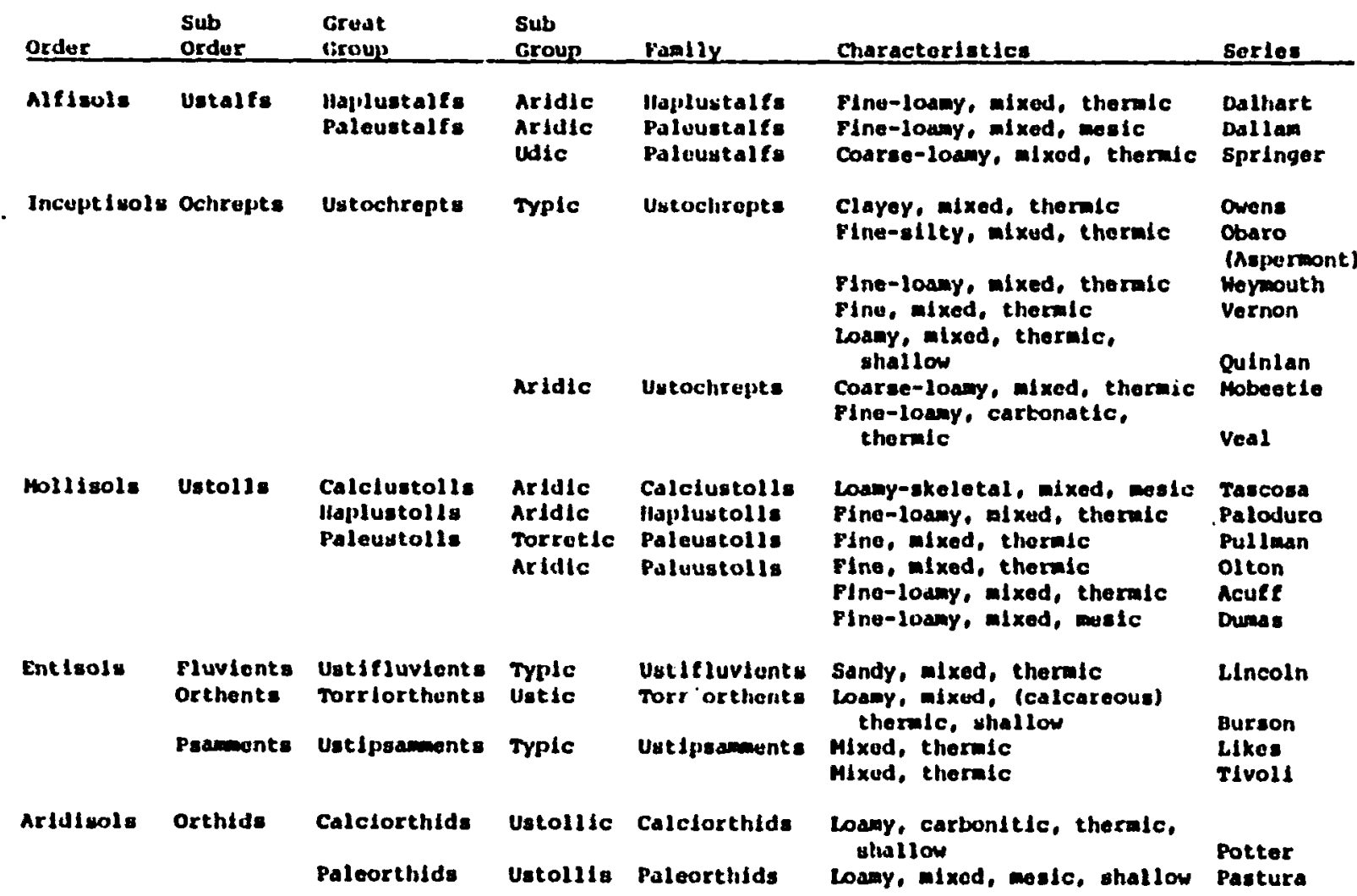


subdivided into two Great Groups--the Haplustalfs and Paleustalfs--depending upon the age of the surface. The Dalhart soil series is the major Haplustalf in the region: it is characterized by a relatively deep, well drained, fine loamy soil which developed on recent (late Pleistocene) upland erosional surface or deposits with slopes ranging from 0-58. It characteristically supports a savannah type vegetation. In contrast, the Dallam and Springer soil series are the major Paleustalfs. Both are deep, well drained soils with a developed ca horizon and strongly weathered minerals. The major distinction is that the Springer soil series has developed on stabilized sandy eolian deposits whereas Dallam occurs on old upland surfaces. Dominant vegetation includes a mixture of grassland and woody plants. Within the study area, Dallam and Dalhart form a major soil association occurxing along the interior margins of the outer valley, possibly correlating with major Quartermaster exposures (Figure 8). The Springer series is a minor association occurring on stabilized sand dunes which are common in the outer valleys.

The Inceptisols are those with leached bases or iron and alluvium, but retain some weatherable minerals. All inceptisols in the study area are included in the Ustochrept Great Group of the Ochrepts suborder. These soils have developed on Holocene surfaces and are characteristically well drained with a calcic horizon. No fewer than seven soil series are included within the Ustochrept Great Group. They are divided into two subgroups (Typic Ustochrepts and Aridic Ustochrepts) depending on their ability to retain moisture.

Mobeetie and Veal series are assigned to the Aridic Ustochrepts. They are deep, well drained, brown soils on loamy alluvial sediments with generally a shallow calcareous deposit. They typically support a native 


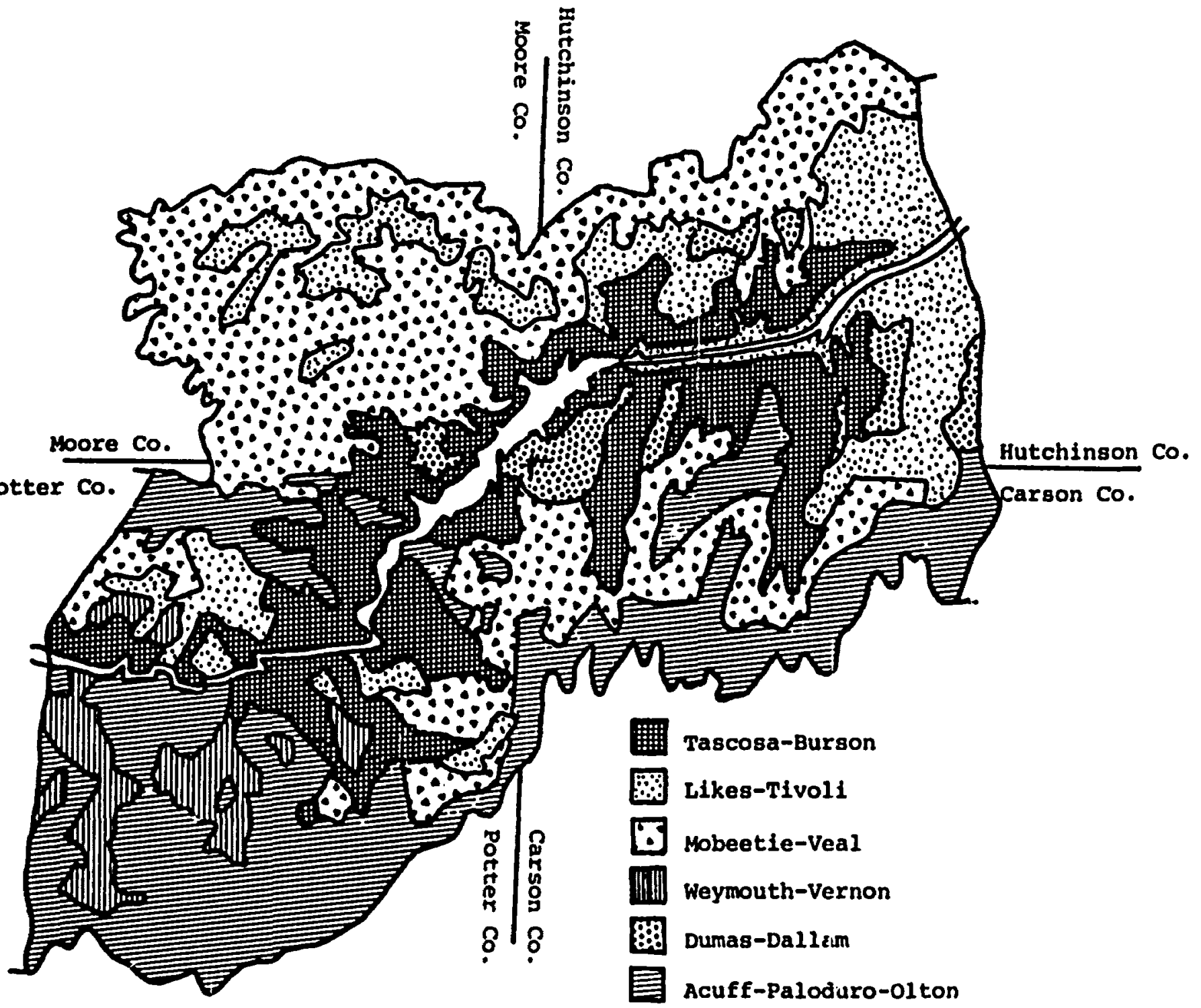

Figure 8. Generalized Soll Associations within the Study Area. 
vegetation consisting of mixed grasses. Within the study area these two series form a major association--(Veal on crests, upper hilis and ridges; Mobeetie on the foot slopes)--which roughly corresponds to the lower portion of the Ogallala formation.

The five soil series comprising the Typic Ustochrepts are the Weymouth, Vernon, Owens, quinlan and Obaro or Aspermont. Weymouth and vernon have developed on moderately deep, clay and shale sediments, whereas the Quinlan and Obara/Aspermont have doveloped on weakly consolidated sandstones and loams. All are well drained and often occur on rolling topography with slopes ranging from 1-128. Weymouth, Vernon and owens roughly correspond to textural differences primarily found within the Tecovas formation (Dockum Group) within the western portion of the study area (Figure 8). Quinlan and Obaro/Aspermont occur primarily on lower terraces as minor soil series associated with Tascasa and Burson in the Quartermaster formation within the central and eastern portions of the study area. The Moilisols are very dark colored, base-rich soils which have developed on Holocene to Mid-Pleistocene or older surfaces (Soil survey staff 1975:271). All soils are assigned to the Ustolls suborder indicating that they are freely drained with a ca or calcic horizon. Three subgroups are distinguished in the study area on the basis of high calcic or petrocalcic horizons (Calciustolls) or minimally altered parent materials (Haplustolls) or the antiquity of the surfaces (Paleustolls). Tascosa is the only series within the calciustolls. It is characterized by a deep, well drained gravelly soil with a shallow calcic or petrocalcic hisizul: which developed on moderate slopes of 30-708. The Haplustolls are represented only by the paloduro series which is a deep, well drained, dark 
brown clay loam with calcareous sediments occurring on 3-8z slopes. The Paleustolls are represented by the Pullman series within the Torretic Paleustolls suborder and the Dumas, Acuff and Olton series within the Aridic Paleustolls suborder. All have developed on old, stable, nearly level land surfaces and comonly have a petrocalcic horizon which recalcified during the Holocene. The Pullman series is a deep, well drained soil developed on clayey eolian sediments. The high clay content has characteristically left wide deep cracks which are open at least half of the year; a calcic horizon may have also developed. The Dumas, Acuff and olton series are all deep, well drained soils which formed on loamy eolian deposits; the differences are mainly textural within the study area. Acuff, Paloduro and olton form an association which roughly corresponds to the upper ogallala formation within the southem part of the study area. Dumas and Pullman are most often associated with the Dallam and Dalhart Alfisols along the interior margins of the outer valley. The Tascosa series has most commonly developed in the steep Permian and Triassic slopes of the inner valley.

The Entisols are characterized by little or no pedogenic development on recent surfaces. Three suborders within the study area reflect differ- . ent origins. Fluvients refer to recent floodplain alluvial deposits; orthents refer to recently eroded/landslide surfaces; and Psaments refer to eolium (sand dune) deposits. The major fluvient in the area is the lincoln series, a part of the Ustifluvients Great Group. This series is charactorized by deep, excessively drained, light brown soils formed in recent calcareous, sandy alluvium on floodplains. It includes the Pleistocene terraces along the Canadian valley margins as well as alluvium on minor 
creeks and tributaries. The Lincoln series commonly supports mixed grasses and xerophytic shruos. The orthents are represented primarily by the Burson series, which is assigned to the Torriorthents Great Group. The Burson series is characterized by silty, very shallow, well drained, reddish soils formed on steep (30-70z slopes), partially cemented, loamy sediments. The excessively high runoff leaves the soils dry; consequently, the soils are sparsely vegetated with xerophytic shrubs and ephmeral grasses. The soil type is associated with the Tascosa series (Mollisols) which are restricted to the steep Permian and Triassic slopes of the inner valley. The Psamments in the study area include Tivoli and Likes series, both of which are assigned to the Ustipsaments Great Group. The eolian sediments are deep. excessively drained, sandy loams occurring as undulating and hummocky dunes. The Tivoli series tends to have steeper slopes (5-308) than the Likes series (1-88). Grass or savannah vegetation occasionally develop on the dunes. Within the study area these soils developed on the Holocene deposits which intermittently mantle sections of the ogallala formarion in the outer valley.

Aridisols, the last soil order, occur as minor associations within the study area. They typically are dry and have little water available from mesophytic plants. Within the study area, the Aridisols belong to either the Calciorthids or Paleorthids Great Groups, each of which is represented by a single, dominant soil series. The Potter series (Calciorthid) is characterized by very shallow, calcareous, gravelly soils found on late Pleistocene eroded surfaces with a 5-30 slope. It typically has a high accumulation of lime, soluble salts, and carbonates. The Potter series is a minor component of the Tascosa--Burson association and occurs primarily 
over the Alibates dolomite along the margins of the inner valiey. The paleorthids are primarily represented by the Pastura series. This is a very shallow, well drained soil formed over old, stabilized beds of cemented caliche and gravel. It typically has a relatively high petrocalcic horizon and more organic matter than is comonly found in Aridisols. Within the study area, the Pastura series is a minor component of the Mobeetie-Veal association occurring on lower slopes of the Ogallala formation.

\section{CLIMATE}

The climate of the Plains has been eloguently characterized as follows:

The Plains are a semiarid land. They are not semiarid in that the climate is halfway between humid and arid. They are not half dry and half wet; rather some years they are dry and even arid; other years they are very wet; and still other years they are wet or dry at the wrong times from the standpoint of agricultural production and yields. This is the undefinable aspect of semiaridity that gives the Plains their distinctiveness. (Kraenzel 1969:12).

Near Amarillo, a dry steppe climate prevails with an average annual precipitation of 20 inches and a mean temperature of $58.7^{\circ} \mathrm{F}$. The area is often windy with a mean speed of 13.7 knots from the southwest and a possibility of sunshine occurring 738 of the year. The growing season is 198 freeze-free days during which time over 758 of the annual precipitation falls (Oxton 1974:906; Pringle 1980:2).

The unpredictable and erratic nature of the semiarid environment makes these annual total or mean figures somewhat misleading. The equinox seasons are marked by climatic instability, whereas winters and sumers are seasons of extremes. January is the coldest month with a mean daily temperature ranging from $23.5^{\circ}$ to $49.8^{\circ} \mathrm{F}$ and a monthly mean temperature of 
of $36.7^{\circ} \mathrm{F}$ (Orton 1974). Winter is the ory season with an average of only 2.04 inches of precipitation, often occurring as light snow. Intermittent storms and blizzards are common most of the winter. Arctic air frequently pushes into the Texas panhandle, lowering the temperature to near zero and dropping an average of 13.3 inches of snow yearly. Temperature drops of $50^{\circ}$ to $60^{\circ} \mathrm{F}$ in a 12-hour period are commonly associated with these fronts, and temperature drops of $30^{\circ}$ to $40^{\circ} \mathrm{F}$ in a few minutes have occurred (Geiger 1975:53). However, cold spells are short and rarely last longer than three days before southwesterly winds bring rapid warming. The record conditions provide some indication of the ferocity of these storms. For Amaril10, the coldest temperature is $-16^{\circ} \mathrm{F}$ (February 2, 1899); raximum snowfall within a 24-hour period is 20.6 inches (March, 1934), and winds ranging from 60-85 miles per hour have been recorded. Under such extreme conditions, 18-26-inch snowfalls have been known to form eight to ten foot drifts; and the wind chill temperature equivalents become unbearable (Geiger $1975: 53)$.

In contrast, the sumers are typically hot $=s .3$ Ary with cool nights. July is the hottest month with average daily temperatures ranging from $67.0^{\circ}$ to $94.2^{\circ} \mathrm{F}$ and a monthly average of $80.6^{\circ} \mathrm{F}$. During the heat of the day, temperatures may top $100^{\circ} \mathrm{F}$; the highest temperature recorded for Amarillo is $108^{\circ} \mathrm{F}$ (June 1953). Relief from such extremes is provided by the summer dominant rainfall pattern. Nearly 50 storms occur each year, but periods of no rainfall for several weeks or more are not unusual. Most of the precipitation falls between May and July in the form of very heavy, Zocalized thunderstorms. Damaging tornadoes, hail, windstorms and intense showers are often associated with thunderstorms. The intensity is 
reflected by the shower of May, 1951, during which time 6.75 inches of rain fell within a 24-hour period (Orton 1974:906). Unfortunately most of the moisture is lost to high runoff, leaving little water incessantly throughout the year. Sumer winds predominantly blow from the south at an average of $12 \mathrm{mph}$; but on occasion, winds caused by strong pressure gradients associated with extra-tropical cyclones can maintain speeds of 50-60 mph for several days and generate severe duststorms. The conditions of irregular rainfall, high runoff, hot weather and strong winds produce an evaporation rate of over three times the annual precipitation rate (64 inches: 20 inches, respectively).

Droughts are a relativeiy common phenomenon. At least nine significant drought periods of varying severity and areal extent have occurred in Texas since 1891 (Lowrey 1959:23). The longest and most severe drought in history lasted between 1950 and 56. Other severe droughts occurred in 1909-12, 1916-18, 1933-34, whereas less severe droughts were recorded in $1891-93 ; 1896-99,1901,1924-25$ and 1937-39.

Despite the general unpredictability of weather, some trends in climatic related conditions can be expected. Although the previous climatic summary is based on records from Amarillo, located on the High Plains, the . conditions within the Canadian Breaks study area are probably somewhat different because of the terrain. Further, topographic variation between the inner and outer valleys undoubtedly are reflected by climatic differences in cold air flow, wind speed and solar heating properties.

- Cold air flow is most often associated with diurnal changes, but also can occur under longer conditions of climatic change (Trewartha 1954:101). The flow of cold air down drainage ways to canyon bottoms can produce 
pronounced differences in nighttime air temperature and humidity between the canyon bottom and the adjacent slopes. Under such conditions, temperatures within the inner valley are considerably cooler than those of the outer valley. Although this diumal change is a welcome relief from the summer heat, it can also bring uncomfortable conditions during the fall and winter.

The topography also affects wind conditions in a predictable manner. Winds within the deeply entrenched inner valley tend to be more subdued than those of the outer valley or the High Plains. The slightly higher wind velocity and greater distance from water for the outer valley is sufficient to keep mosquitos and other pesty flying insects to a minimum.

Investigations of solar heating properties have not been conducted in the Canadian River Breaks. However, the range of land surface configurations of the inner and outer valleys suggests that considerable differences exist. Solar heat is directly dependent upon the relative amount of solar energy absorbed (Trewartha $1954: 18$ ). The absorption of solar energy has been shown to depend upon the angle of the surface inclination, the absorption spectrum (color) of the surface, and the duration of exposure (Trewartha 1954:8; Fleagle and Businger 1963:135-139). Since most of the soils colors in the study area are fairly uniform, the absorption spectrum can be regarded as a constant. The angle of surface inclination is dependent upon a combination of the angle of solar ray intersect and the slope of the ground surface. On a level ground surface, the maximum daily intensity of solar radiation occurs at noon throughout the year with lower solar intensities recorded in the mornings and afternoons. At the $35^{\circ} 45^{\prime}$ latitude of the study area, the maximum yearly intensity occurs at noon on the 
summer solstice when the angle of the sun's rays on a horizontal surface is $77^{\circ} 45^{\prime}$; at the winter solstice, the maximum angle of the sun's rays is only $30^{\circ} 45^{\prime}$. By varying the degree of ground surface inclination, sign::icant differences in the amounts of direct solar radiation can be achieved. During the sunmer solstice, direct maximum solar intensity (1008) occurs on a $59^{\circ} 15^{\prime}$ north slope. As previously indicated, most soil slope in the outer valley ranges from $0-88\left(0-5^{\circ}\right)$, with two associations ranging to 128 $\left(7^{\circ}\right)$, whereas the walls of the inner valley range from $8-708\left(5-35^{\circ}\right)$ slopes (nxingle 1970; Jacquot 1962; Geiger 1975; Stringer 1976). Calculation of the percentage of maximum solar radiation for various north and south exposures during the summer and winter solstices shows considerable differences in the amount of radiation on the outer valley versus inner valley north and south slopes (Table 7).

During the sumer solstice, the entire outer valley and the north slope of the inner valley receive approximately 92-1008 of the possible direct solar radiation, whereas the south slope inner valley receives only some 68-698 direct radiation. The differences are even more marked for the winter solstice. The outer valley receives approximately 35-658; the north slope inner valley receives $65-918$, but the south slope inner valley receives a mere 0-278 of the total available direct radiation. All percentages reflect the insulation conditions at noon, but do not consider the lower slope angles during other parts of the day. In general, the direct solar radiation is lower and roughly corresponds to the angle of the sun; an exception is on north slopes greater than $12^{\circ}$, which actually receive more direct radiation during spring and early sumer during mornings and afternoons. Such steep slopes are usually confined to the north exposures 
TABLE 7

PERCENT OF EFFECTIVE SOLAR RADIATION FOR VARIOUS NORTH AND SOUTH SLOPE SURFACES DURING SUMMER AND WINTER SOLSTICES

\begin{tabular}{|c|c|c|c|c|c|}
\hline \multicolumn{2}{|c|}{$\begin{array}{l}\text { Surface slope } \\
\text { (Gradient) }\end{array}$} & \multirow{2}{*}{ 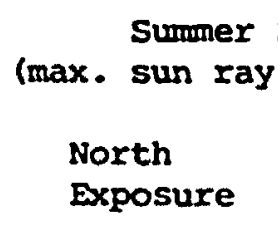 } & \multirow{2}{*}{$\begin{array}{l}\text { Solstice } \\
\left.\text { angle } 77^{\circ} 45^{\prime}\right) \\
\text { South } \\
\text { Exposure }\end{array}$} & \multirow{2}{*}{$\begin{array}{l}\text { Winter } \\
\text { (max. sun ray } \\
\text { North } \\
\text { Exposure }\end{array}$} & \multirow{2}{*}{$\begin{array}{l}\text { Solstice } \\
\text { angle } 30^{\circ} \\
\text { South } \\
\text { Exposure }\end{array}$} \\
\hline Degree & Percent & & & & \\
\hline $35^{\circ}$ & $(70.78)$ & 92.28 & 67.98 & 91.28 & 0 \\
\hline $30^{\circ}$ & $(57.78)$ & 95.28 & 74.08 & 87.38 & 1.38 \\
\hline $25^{\circ}$ & $(46.68)$ & 97.58 & 79.68 & 82.78 & 10.08 \\
\hline $20^{\circ}$ & $(36.48)$ & 99.18 & 84.68 & 77.48 & 18.78 \\
\hline $15^{\circ}$ & $(26.88)$ & 99.98 & 88.98 & 71.68 & 27.18 \\
\hline $10^{\circ}$ & $(17.68)$ & 99.98 & 92.68 & 65.38 & 35.48 \\
\hline $5^{\circ}$ & $(8.7 z)$ & 99.28 & 95.58 & 58.58 & 41.58 \\
\hline $0^{\circ}$ & $(0.08)$ & 97.78 & 97.78 & 51.18 & 51.18 \\
\hline
\end{tabular}

of the inner valley.

Additional variability is introduced by the apparent changes in the sun's dizly path across the sky. Not only does the summer sun reach a higher noon time angle than the winter sun, but the location of the summer sunrise and sunset is more northerly than that of the winter. Overall, the noxthern slopes generally receive more radiation throughout the year. However, since the Canadian River valley is oriented approximately $N 40^{\circ} \mathrm{E}$, relatively more direct solar radiation is accessible to the southeastern exposures during the late spring and summer, whereas relatively higher solar radiation levels are received on the northwestern slopes in the late autumn and winter. 
The duration of solar exposure is the last major variable to be considered in the absorption of solar energy. The duration is dependent upon the length of sunshine of the topography of the inmediate locale. At the approximate latitude of the study area, nearly five additional hours of sunlight are available at the sumer solstice than at the winter solstice (Trewartha 1954:8-9). These seasonal differences do not affect the local variability as much as the local topography. The rolling and broken terrain of the outer valley caused by the numerous tributaries of the Canadian Rivex complicates characterization of the lingth of the solar exposure. Most tributaries are northwest and southeast trending and tend to be in shade during early mornings and late afternoons. Overali, the inner valley has steeper bluffs ranging up to $75 \mathrm{~m}$ tall, which keeps the south margins of the inner valley in shade for longer portions of the day. The combined factors affect ig the solar radiation suggest that there are considerable differences among the north and south slope exposures of the inner valley and the inner and outer valleys. The reduction in solar radiation documented from the south wall exposures and lower talus of the inner valley would result in cooler conditions in sumer and prolonged snow cover in winter. In contrast, the steep north exposures of the inner valley receive the most direct solar radiation throughout the year and have moderate thermal conditions relative to those of the inner valley.

HYDROLOGY

The hydrological aspects are concerned with the drainage configuration, and water sources, occurrence and quality. Nearly all of the present surface water is derived from regulated stream flow through the Canadian River. However, prior to pump irrigation, springs and groundwater seeps 
from the Ogallala and other aquifers contributed substantially to the local hydrological setting. Quantification of both sources is difficult to derive since stream flow records were not monitored until after Concha Reservoir was built in 1937, and groundwater characteristics were not seriously examined until after pump irrigation was established. Effluent water regulation has occurred with the development of Ute Dam in 1962 and Sanford Dam at Lake Meredith in 1964.

The drainage configuration of the Canadian River Valley is influenced by geological patterns. Many of the lateral tributaries coincide with geological faults and joints which occur at some regularity and tend to orient the tributaries perpendicular to the major river (Redfield 1953:27:

Figure 9). In addition, the presence of erosionally resistant dolomite and caliche caprocks has inhibited stream development. The lateral tributaries are fairly short and steep within the drainage basin system. Stream flow down the Canadian River has been quite variable. The river bed is usually between 0.5 and $1.0 \mathrm{~km}$ wide. Before water regulation, the variability prompted one early geologist to remark:

The Canadian River is perhaps more treacherous than any other stream of the plains. The stream is either dry or a raging torrent. The river may have been dry for weeks at a time, then suddenly, without warning, a wall of water several feet high rushes down the channel, sweeping everything before it, and for a number of days the river continues high, then gradually subsides. Following this period of abnormal flow, the sand in the stream becomes 'quicksand', or loose sand which appears firm but gives way suddenly under foot, rendering the stream extremely dangerous to cross. Many a head of cattle has been mired in the Canadian River, and every year loaded wagons and even teams are abandoned (Gould 1906:43-44).

Records indicate that most surface flow occurs between June and August and coincides with the summer dominant rainfall and snow melt patterns in the Rocky Mountains (USGS 1955:386). Even after the stream flow regulation, 


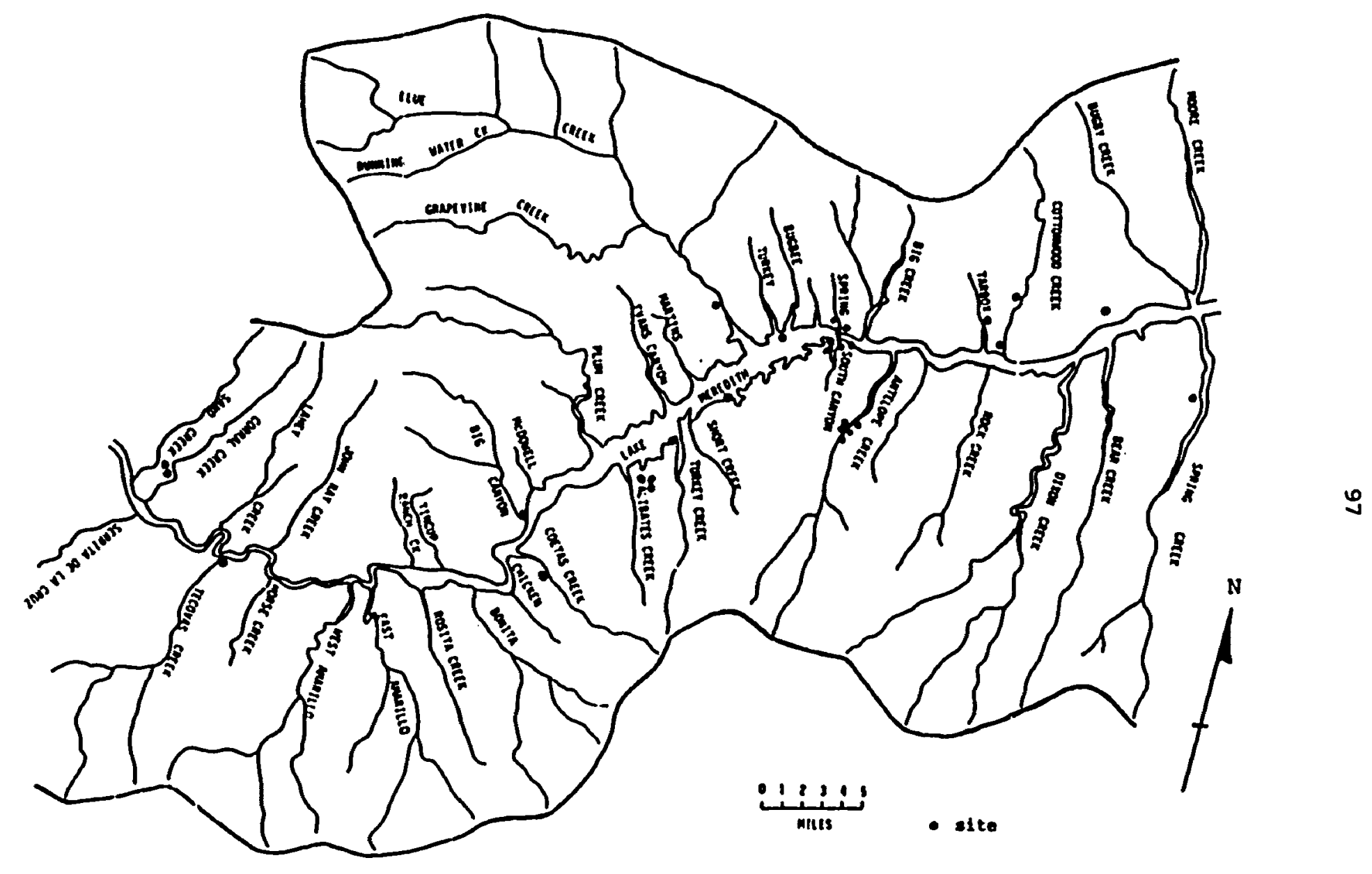

Fig̣ure 9. Lateral Tributaries within the Study Area. 
the mean yearly discharge along the river north of Amarillo ranged from 107 to 2,351 cubic feet per second (cfs); whereas momentary maximum discharge rates of 12,500 to 135,000 cfs were recorded and a minimum daily discharge averaged dxy to only 1.7 cfs for the period 1938-1950. The river usually has a high sediment load and also contains up to $1600 \mathrm{ppm}$ dissolved solids which are predominantly chlorides and carbonates (Etchieson 1981:5; USGS 1960:121). A brinish, artesian aquifer near Logan, New Mexico contributes so much sodium to the Canadian River that the water supply at Lake Meredi h $h$ exceeds the American Water Works Association recomended limits (200 mg/1) for drinking water (Bureau of Reclamation 1979).

Local water resources mainly occur as springs and seeps. Most water is derived from a high aquifer at the base of the ogallala formation; however minor aquifers are also present in the Permian and Triassic formations (Cronin 1969:3). Data from well logs suggest that in 1937 the water table level may have been $25 \mathrm{~m}$ thick with a saturation level some $135 \mathrm{~m}$ above the elevation of the Canadian River bed (Cronin 1969:maps). At that time, springs were located at the heads of many canyons and several short draws. The stream flow and number of springs has decreased sharply after the widespread use of well irrigation during the late 1930s (Green 1973:125). Although the Ogallala saturation level has dropped in excess of $45 \mathrm{~m}$ north of Lubbock, the decrease near the Canadian River Breaks is estimated at only 6-12 m since 1937 (Cronin 1969 :map; Luckey, et al., 1981). Since the recent annual recharge rate from local precipitation is estimated to be between 1.5 to $2.0 \mathrm{~cm}$, it is unlikely that aquifer discharge within the Canadian River valley will ever return to pre-irrigation levels. Water from the Ogallala formation is sufficient to sustain a few flowing streams far enough to reach the Canadian River, but the majority of streams 
disalpear into their sand-filled bcd and are either dissipated by evaporation or reach the river by subsurface flow (Redfield 1953:32). Most of the intermittent tributaries are reputed to have been live streams only a few years ago (Etchieson 1981:5). The water from the Ogallala aquifer is potable but typically hard, and locaily can have high concentrations of fluoride (Cronin 1969:8).

Besides outcropping at the head of canyons, some potable water from the Ogallala aquifer is thought to enter joints in the Alibates dolomite and seep from the Permian deposits along the steep slopes of the inner valley (Redfield 1953:32). However, the water of the seeps and springs has also decreased. Other minor aquifers are present in the Triassic and Permian deposits, but most do not occur as surfac. seeps. Water exposed to Whitehorse deposits for any length of time are apt to become extremely "gippy" or saline and unpotable.

FLORA

The vegetation of the Canadian Breaks tends to be fairly complex, even though it is often regarded as undifferentiated from the surrounding vegetation of the Llano Estacado (Blaix 1950). Those that do differentiate the Breaks generally regard it as a uniform "High Plains Blvestem Community" (Allred 1956), or merely a "Bluestem-Oak" association (Kuchler 1964). However, recent detailed, biotic studies of the inner valley around Lake Meredith (Wright and Meador 1979; Phillips n.d.) as well as the outer valley 15.5 miles west of the study area (Sikes and Smith 1975) rüeal a far more complex situation. At least 487 species of native plants representing some 70 families and an additional 30 species of introduced plants have been recorded with an additional 55 species recorded for the area but not 
confirmed by these three surveys (Wright and Meador 1979; Rowell n.d.).

The detailed botanical studies identify five major plant associations which generally correspond to topographic and soil characteristics. These include: Bottomland, Steep Slope, Mesa Top, Gravelly Slope, and Sand Hill associations (Wright and Meador 1979).

The Bottomland association, as the name implies, is riparian and confined to the recent alluvial terraces along the Canadian River and tributary streams within the inner valley. The soils typically belong to the incoln series. This vegetation association consists of a complex mosaic of stands dominated by trees in some areas, shrubs in others, and by grass or grass-like plants in still others. All are subjected to and tolerant of frequent flooding. Characteristic native species include cottonwood (Populus Spp), chickasaw plum (Prunus angustifolia), hackberry (Celtis reticulata), sedge (Carex spp), salt grass (Distichlis spicata), alkali sacaton (Sporobolus airoides), vine-mesquite (Panicum obtusum), common reed (Phragmites communis), and persicaria (Sorghastrum avenaceum). Significant contributions to the vegetation cover are made by scratchgrass/muhly (Muhlenbergia asperifolia), switchgrass (Panicum virgatum), Canadian wild rye (Elymus canadensis), rush (Juncus spp), lambsquarters (Chenopodium album) and western ragweed (Ambrosia psilostachya). The dominant introduced species are Tamarisco/salt cedar (Tamarix gallica) and Belvedere (Kochia scoparia).

The steep slope biotic association is confined to the flanks of the inner valley, composed of the rocky Tascosas-Burson and Potter soil associations. The present vegetation is sparse and more uniform than the Bottomland association. The steep slopes are dominated by grass stands 
with an admixture of shrubs and forbs. Major native species include: broomweed (Xanthocephalum Spp), polecat bush (Rhus aromatica), feather plume (Dalea formosa), cat's claw mimosa (Mimosa biuncifera), wafer ash (Ptelea trifoliata), sideoats grama (Bouteloua curtipendula), littje bluestem (Schizachyrium scoparium), western fleabane (Erigeron bellidiastrur!), ragweed (Ambrosia Spp), bladder pod (Lesquerella Spp), white aster (Leucelene ericoides), and to a lesser extent by black grama (Boutel oua exiopoda! and western wheatgrass (Agropiron smithii).

The Mesa Top biotic association closely corresponds to the lower portions of the outer valley, directly overlying the Alibates dolomite cap. The soils of this area belong to the Dumas-Dallam and Pullman-Dalhart associations. Major plants occurring on these shallow soils include plains prickly pear (Opuntia Sp), bear grass (Yucca angusticolia), mesquite (Prosopis glandulosa), broomweed (Gutierrezia dxacunculoides), blue grama (Bouteloua gracilis), buffalo grass (Buchloe dactyloides), Indian blanket (Gaillardia spp), bladder pod, plantain (Plantago sp) and Tahoka daisy (Machaeranthera tanacetifolia).

The Gravelly Slope biotic association occurs on ridges, knolls and undulating areas of the outer valley. Stands in the eastern part of the area, roughly corresponding with the Tascosa and Mobeetie, Veal and Berdan soils, are composed of an admixture of grasses and small shrubs, whereas stands in the western part, roughly corresponding to the Acuff-oltonPaloduro soils, tend to have larger shrubs, especially the one-seeded juniper. (Juniperus monosperma).

In addition, other native species are dominated by broomweed, bear grass, cat's claw mimosa, blue grama, hairy grama (Bouteloua hirsuta), 
Texas grama (Bouteloua rigidiseta), sideoats grama, white aster, bladder pod, Indian blanket, six-week fesque (Vulpia octoflora), and an introduced species, Russian thistle (Salsola kali).

Finally, the Sand Hill biotic association often occurs on the likesTivoli-Springer soils of recent sand dunes and humnocks mantling the Ogallala deposits along the slopes of the outer valley. This vegetation association is an admixture of shrubs, grasses and forbs consisting mainly of sand sagebrush (Artemesia filifolia), broomweed, bear grass, chickasaw plus, scratchgrass/muhly, sand dropseed (Sporobolus cryptandrus). lazy daisy (Aphanostephus spp), Indian bianket and mentzelia (Mentzelia strictissima).

The biotic surveys stress that livestock overgrazing since the 1870 's has modified most of the vegetation cover, particularly in the outer valley, and that around Lake Meredith, off-road vehicles have severely disturbed and modified the plant associations within the last 15 years. Under heavy grazing conditions, many of the grasses (Sorghastrum nutans, Andropogon socparius, Panicum virgatum, Andropogon hallii, Bouteloua curtipendula and Elymus canadensis) tend to decrease and are replaced by other grasses (Chloris cucullata, Paspalum Spp, Festuca octoflora), forbs (Gutierrezia Spp, Helianthes Spp, Eriogonum anrum, Oenothera Spp, Zanthocephalum spp) and trees and shrubs (Yucca glauca, Opuntia Spp, Artemisia filifolia, Quercus harvardi, Salsola kali, Prosopis and Rhus Trilobata) (Allred 1956: 275; Wright and Meador 1979:32). The extent of vegetational modification if difficult to imagine from the present vegetation. Kuchler's (1964) reconstruction of the biotic characteristics of the coterminous United States classifies the Canadian Breaks as a midgrass prairie with open to 
dense, broad leaf deciduous shrubs, occasional needle leaf evergreens and low trees. The dominant tree would be shinnery oak (quercus mothriana); however, none of the modern surveys observed this species in the area, even though earlier surveys report it being present (Rowell n.d.).

FAUNA

The fauna are characteristic of the Kansas biotic province, a transitional zone between the western and eastern fauna (Dice 1943; Blair 1950). Recent faunal inventories have been conducted for the Lake Meredith and Alamosa Creek areas (Killebrew 1979; Scudday and Scudday 1975). These studies complement a detailed summary of the Canadian Breaks vertebrae (Duffield 1970).

The Canadian Breaks shows a considerable diversity of faunal resources. At least 59 mamnalian species, 48 reptilian species, 15 amphibian species, at least three kinds of fish and in excess of 100 bird species have been reported to reside or visit the area. Many species tend to reside predominantly in one or more habitat types. Although Killebrew (1979:13) defines seven types of habitats around Lake Mexedith, the difference in animal composition is minor and consists primarily of variation in the relative frequencies. The previously delineated biotic associations do not generally have one-to-one corresponding faunal comunities. Duffield 11970:34; Figure 9) recognizes only three distinct and fairly well defined environmental areas: the "grassland plains of the uplands" (corresponding to the outer valley and High Plains), the "edge-breaks" of the inner valley wall and the "moist-aquatics" of the bottomlands.

The animal comunities of the grassland-plains have changed through the eradication of some native species and the introduction of domestic 
livestock. In the recent pest, the dominant species included buffalo (Bison bison), pronghorn (Antilocapra americana), prairie dog (Cynomys ludovicianus), badgers (Taxidea taxus) and jackrabbits (Lepus californicus). The edge-breaks animal communities reside in a diversity of topographic and biotic settings. The characteristic manmalian fauna include mule deer (Odocoileus hemionus), bobcats (Lynx rufus), skunks (Mephitis spp), porcupines (Erethizon dorsatum), cottontail rabbits (Sylvilagus Spp), moles, three species of shrews, two kinds of gophers, three kinds of ground squirrels and occasionally cougars (Felix concolor), elk (wapaiti), and ringtails (Bassarisus astutus). In addition, badger, jackrabbits, antelope and bison commonly found in the grassland plains frequently occur in the Canadian River Breaks. Most reside in the gently roiling terrain of the outer valley, and the steep slopes of the inner valley. In areas with slight overhangs within and beneath the dolomite ledges, dens for the larger carnivores commonly occur.

The moist aquatic habitat is restricted to the riparian bottomlands along the Canadian River valley and its tributaries. The variation in plant communities supports a wide range of animals. Characteristic animals include opossums (Didelphis virginiana), ferrets, weasels (Mustela spp), muskrats (Ondatra zibethicaus), beaver (Castor canadensis), fox squirrels (Sciurus niger), whitetailed deer (Odocoileus virginiana), as well as two species of aquatic turtle, seven species of frogs/toads, one salamander and a wide range of fish and birds. A number of edge-breaks animals also occurring in the moist aquatic habitat include porcupines, cottontail rabbits, skunks, shrews, gophers and ground squirrels. Early travelers mention the presence of bear within the study area (Thwaites 1905:101). 
Other animals ubiquitous to all three areas include box turtles (Terrapene ormata), raccoons (Procyon lotor), coyotes (Canis latrans), four species of foxes (Vulpes spp) and eight species of mice. The area is along a major flyway, and numerous migratory waterfowl seasonally visit the bottomlands and playa lakes on the uplands.

\section{PALEOENVIRONMENT}

Overshadowing the biotic changes wrought by the recent settlers, the greatest factor molding biotic communities on the Great plains is the variability of climate. Most paleoclimatic studies of the Southern Plains have focused on glacial and early post-glacial fluctuations (oldfield and Schoenwetter 1964; Reeves 1976; Wendorf 1970; Bryant and Shafer 1977). These studies conclude that there have been no radical long term climatic change since the end of the Altithermal--approximately 4000 years ago (Antevs 1954). Nevertheless minor climatic fluctuations historically documented for this semiarid region probably occurred during prehistoric times. In the Central and Northern Plains, tree ring studies have documented a series of droughts lasting longer than a decade and occurring at least once a century during the last 500 years (Wede1 1941:25; 1964:14-15). The climatic conditions on the Great Plains reflect an interplay of three air masses (Baerreis and Bryson 1965b:216). The Pacific air mass consists of warm or cool aerobatically dried air from the west; the Arctic air mass brings frigid, normally dry air from the north; and the maritime tropical air mass brings warm, humid air from the Gulf of Mexico. Changes in the dominance of these air masses cause shifts in storm tract patterns along the frontal edge, resulting in concurrent subregional climatic changes. A dominance in the pacific air mass conceivably could push 
the storm track pattern to the south causing a severe drought in the Central and Northern Plains while normal or above normal precifitation occurs on the Southern Plains.

Based on evidence of synchronous cultural changes corresponding to the age of documented European Climatic episodes, a fairly detailed paleoclimatic model from the eastern half of North America has been postulated (Baerreis and Bryson 1965a, 1965b; Bryson and Wendland 1967; Bryson, Baerreis and Wendland 1970; Wendland and Bryson 1974). The climatic episodes spanning the last 1500 years are summarized in Table 8 . The model was tested and refined based on multidisciplinary paleoclimatic studies of the Mill Creek Culture in Iowa (Henning 1968, 1969). Wright (1967) has criticized the model for expecting abrupt biotic shifts to follow tne rigid episodic divisions. However, of greater concern is that the expected conditions have not been validated on the Southern Plains. Detailed faunal analysis from a series of archaeological sites has suggested that a seemingly moist regime (reflected by prairie vole remains in Woodland horizon deposits) was followed by somewhat drier conditions (Duffield 1970:255; 265; Hughes 1979:43; Hall 1982). A shift from bison to antelope remains in 11 Antelope Creek sites led Duffield $(1970: 241,265)$ to postulate a rapid climatic deterioration towards drought conditions after A.D. 1300. Unfortunately no studies of other climatically sensitive materials have been undertaken on the High Plains to verify the faunal change.

In the Woodland and Prairie Plains regions of Oklahoma, interdisciplinary studies have been conducted with the aim of reconstructing climatic conditions. Geomorphic, molluscan and palynological studies in Hominy, Birch and Caney Creek valleys of north central oklahoma documented the 
Table 8. Late Holocene Climatic Changes

on the Southern Plains.

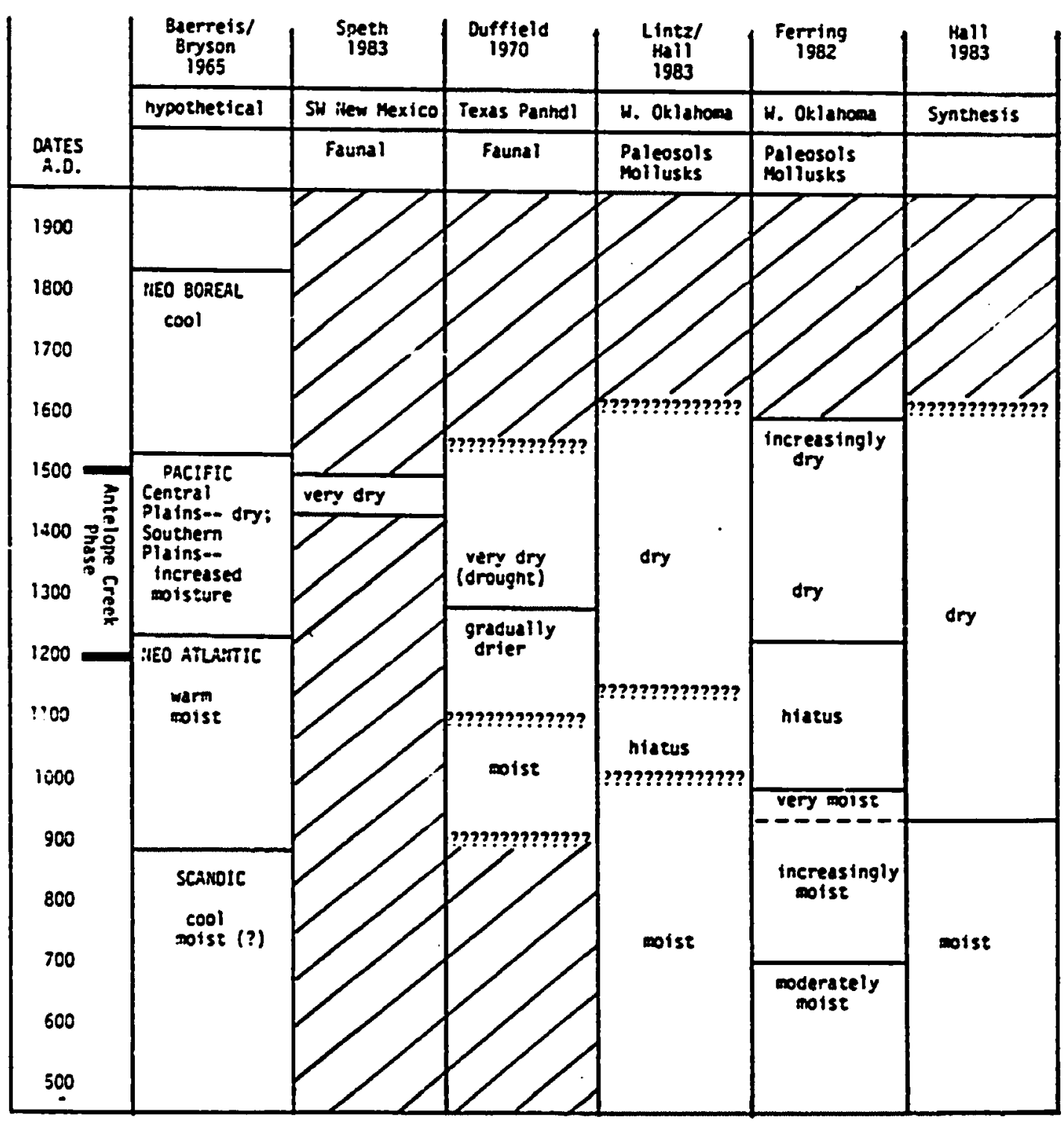


development of the Copan Paleosol during moist conditions between A.D. 600 and 1100 to 1300 which is unconformably overlain by alluvium reflecting drier conditions (Farley and Keyser 1979; Henry, et al., 1979). Other palynological studies of two southeastern Oklahoma bogs reveal an onset of wetter conditions about A.D. 250 followed by dryer conditions occurring between 900 to 1300 A.D. which lasted until the seventeenth century (Albert $1981: 99)$.

In Caddo County of western Oklahoma, interdisciplinary studies in two valleys have recorded a moist period between ca. A.D. 1-1000 which is unconformably followed by a drier period (Ferring 1982; Lintz and hall 1983). In the Southwest, dendrologic (Douglas $1935=42,49,64$ ), geomorphic (Antevs 1955), palynologic (Hill and Hevly 1968:200-205; Schoenwetter and Dittert 1968:46, 54) and biotic (Jelinek 1967: 134-139) studies have also accumulated considerable evidence for an extensive drought around A.D. 1200-1300. Convergent archaeological, geological, palynological dendrochronological and radiometric information from the Colorado Plateaus have been used to suggest widespread and essentially synchronous first-order droughts occurred around A.D. 875 and 1450, and a second-order drought around A.D. 1150 (Euler et al., 1979).

These investigations east and west of the study area indicate that there is no empirical evidence for a significant long-term increase of moisture on the Southern Plains as postulated for the Pacific climatic episode of A.D. 1250-1550. All of the research tends to indicate that moist conditions were present during the first millenium, but after A.D. 11001300, the climate deteriorated towards drought (cf. Hall 1982). The intensity and the impact of the eleventh and twelfth century drought conditions in the Texas panhandle are uncertain. The area probably 
experienced a decrease in precipitation and a concomitant reduction in the effluvient water carried by the Canadian River. However, spring and seep discharge would probably not be seriously reduced since the level of the Ogallala aquifer is based mainly on fossil water reserves. Under the severest conditions, a 100-year long drought with no moisture recharge would result in the lowering of the Ogallala water table by only 1.5 to 2.0 meters at the current estimated recharge rates (Luckey, et al, 1981). This amounts to only one-third to one-sixth of the recent drop in the water table due to modern pump irrigation. Although the seep discharge would undoubtedly be reduced somewhat, it is unlikely that most springs would turn dry. A greater impact would be the decrease in precipitation which furnishes soil moisture for plant growth and causes major changes in biotic community composition due to high evapo-transpiration rates associated with dry winds.

Studies of the severe droughts of the 1930 s in western Kansas and eastern Colorado showed that the best short grass cover was reduced by 10-20z; on less fertile soils, losses were higher (Weaver and Albertson 1956:79; Weaver 1968). Major changes occurred as xeric forms predominated and some forbs disappeared completely. Blue and side-oat grama proved to be far more drought resistant than buffalo grass or little bluestem. Among forbs, such species as ragweed, fleabane, vetch and psoralea were replaced by aster, snakeweed, mallow, plaintain and goldenrod. At the height of the drought, even xeric forbs became smaller. An additional effect of the.1930s drought was the strong winds which brought dust and a myriad of "disturbance plant" seeds. After showers, pigweed, lambsquarters, goosefoot and various cacti were so prevalent that the prairies often appeared 
more like abandoned fields than natural grasslands. Such biotic changes would cause concomitant changes in the faunal resources of the region and tend to favor arid land dwelling species.

\section{Aspects of Human Ecology}

The differences in topography and various geological and biotic resources of the Canadian River valley are far more diversified than those of the upland settings of the Llano Estacado and Panhandle sections of the Southern High Plains. Despite the unpredictable nature of the climate, the valley offors abundant resources suitable for exploitation by huntergatherers, and semisedentary horticulturalists alike. The following sus:marizes the local resources available for human utilization.

Despite the presence of Alibates dolomite and caliche caprocks, the geology of the study area is not conducive to rockshelter formation. Natural shelters are extremely rare, and if of suitable size, were probably occupied. Most habitation sites, by necessity, were in the open. With the possible exception of the inner valley walls, the gently sloped topography provides suitable site settings to accommodate a wide range of activities. The steeper slopes below the inner valley wall escarpments have fairly unstable (Orthlent) soils. Landslides are still an occasional problem (Redfield 1953). Despite the excellent solar radiation potential, at least on the south facing slopes, few permanent habitation sites occur on the walls of the inner valley, except where topographically irregular bedrock benches or shelters exist.

Habitation settlements in the bottomlands are likely to occur on the Quaternary terraces and dunes. The unpredictable and treacherous nature of water flow down the Canadian makes the flood plain unsuitable for all 
but limited bivouac or short term extractive and processing activities. The bottomland localities receive less wind and winter solar radiation, which coupled with diurnal airflow, make them considerably chillier in the winter, but only somewhat cooler in the summer than settings in the outer valley. The bottomland biotic communities are highly diversified and, during the 1820s, few stands of sizable cottonwood and elm along the r-ver were available for construction, tool use and fuel (Thwaites 1905:98-102). The outer valley floor provides a considerably different site setting. The ridge crests provide broad, gently sloping, well drained surfaces. Such exposures receive more direct solar radiation than the bottomlands, even though considerable differences exist depending upon slope angle and orientation. In general, south facing slopes are slightly warmer in winter, but cooler in summer than north facing slopes. The high wind velocity of the outer valley setting helps control mosquitoes and other bothersome flying insects which breed and swarm in the inner valley settings. Construction materials and fuel are provided by scattered juniper and mesquite hardwood trees which tend to be more abundant in the west. Near the rim of the inner valleys favorable building stone for the construction of foundations and walls was provided by naturally spalled slabs of either dolomite. from the Alibates formation in the eastern part of the study area or silicified sandstone from the Tecovas formation in the west.

Tool stone for the manufacture of chipped stone materials is not uniformly distributed throughout the study area. Both Tecovas jasper and Alibates chert occur as bedrock exposures. However, there is so much lateral variability within deposits in the extent of chertification and the knappability of materials, that both formations can be regarded as 
almost point exposure resources. The distribution of quality Tecovas jasper is uncertain, but at least one exposure is reported to be near the mouth of Coetas Creek (Cameron 1980); the most extensively chertified bedrock deposits occur along Bates, Plum and Devil's Canyons (Bowers 1975). Both formations were extensively quarried for lithic materials (Etchieson 1981:87). At the Alibates National Monument, an estimated 550+ prehistorif quarry pits have been located (Studer 1964). Other knappable lithic resources exposed over vast portions of the study area include various metaquartzite, chert, petrified wood and residual cobbles. Most are associated with the extensive Ogallala and Trujillo deposits on the outer valley. Secondary occurrences of Alibates chert and Tecovas jasper can be found as gravels along the Quaternary terraces of the inner valley.

Other geological resources utilized by prehistoric groups may include various clays from the Quartermaster and Trujillo formations for manufacturing ceramics, and possibly, salt from the Whitehorse exposures. Unfortunately, no petrographic studies have been conducted on ceramics to determine clay sources, and better quality deposits of salt are known to occur farther east of the study area (Baugh 1980:2).

The most dependable source of potable water is from springs and seeps located at the heads of the lateral tributaries in the outer valley or from joints in the Alibates dolomite immediately below the rim of the inner valley. The present flows tend to be limited, but once were fairly steady over long periods of time. The tributary flows often become subsurface streams after short distances, but may reappear as pools or surface flow where the tributary crosses bedrock. The Canadian River is seasonally an unsatisfactory water source because of its high sediment loads, 
its somewhat erratic flow and when not in flood stage, its tendency to become "gippy" from considerable quantities of dissolved chlorides and carbonates after lengthy contact with the Whitehorse deposits. On August 4, 1820, James described the Canadian River as a "stream still inconsiderable in magnitude; the water brackish and holding suspended so large a quantity of red earth as to give it the colour of florid blood" (Thwaites 1905:94-95). For gatherers and collectors, the biotic communities provide a wide diversity of usable plant materials. Approximately 100 indigenous species representing 39 plant families are known to contain economically important food, medicinal or commercial properties (Table 9). Unfortunately, the abundance and distribution of these plants throughout the study area have not been reported; consequently it is impossible to assess the importance of different areas within the Canadian River valley or to postulate scheduling patterns to coincide with resource availability. Some consumable plant resources are available year-round, but most occur in the spring through fall. Undoubtedly unpredictable climatic variations would alter the availability and abundance of select resources throughout the year and from one year to the next.

Climatically, the Canadian River valley is marginally suited for raișing domesticated crops without elaborate technological developments. The frost-free growing season is nearly 200 days long, which is only adequate for single cropping of corn per season (Cordell 1979:133; Mackey 1983). During the historic period, the area received only slightly more tinan the criţical eight-inch sumer precipitation necessary for maize production (Wedel 1964:35, 131). Seasonal and annual climatic fluctuations cause considerable uncertainty of horticultural success. 
TABLE 9.

ECONOMICALLY USEFUL PLANTS INDIGENEOUS TO THE STUDY AREA

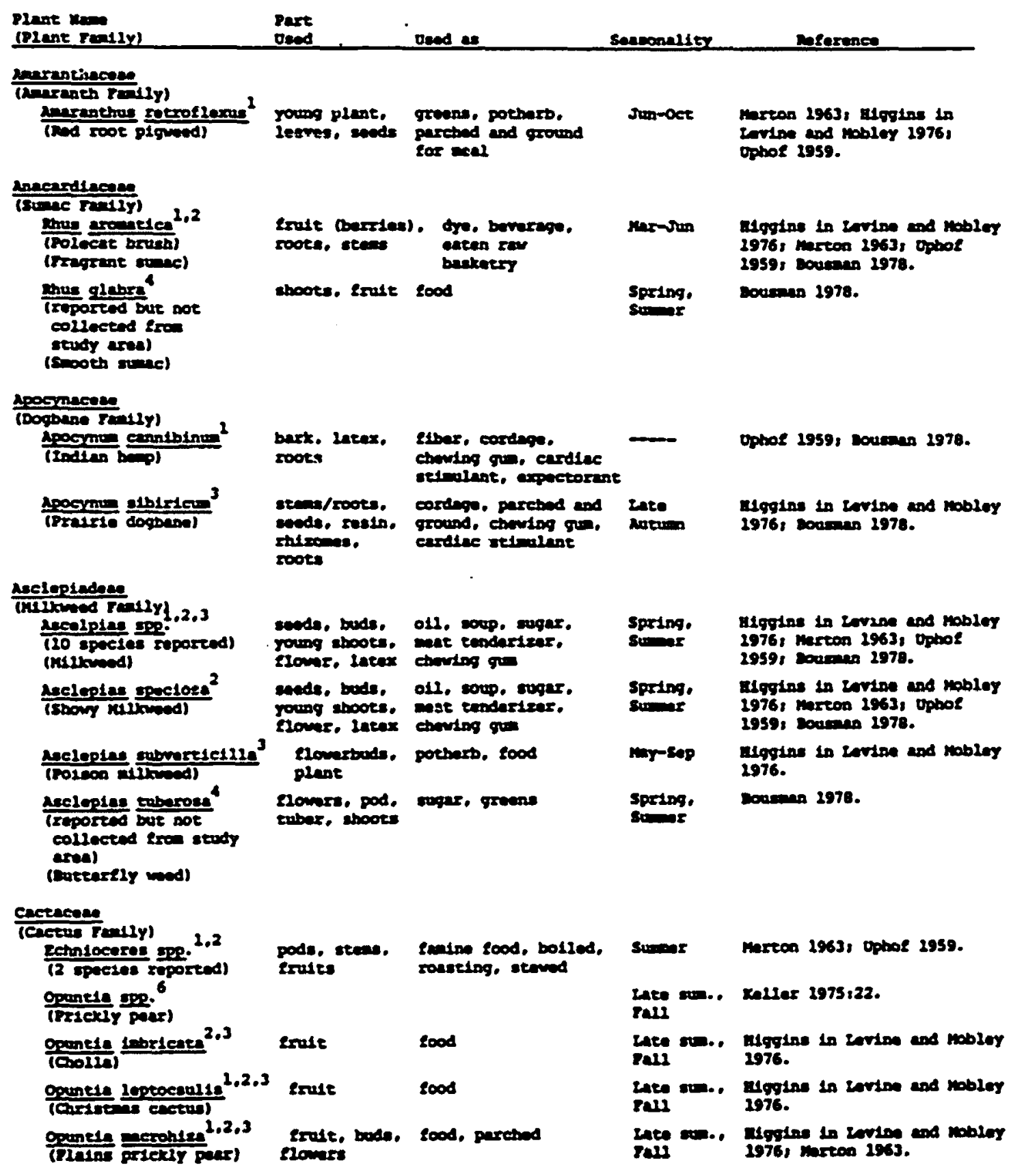




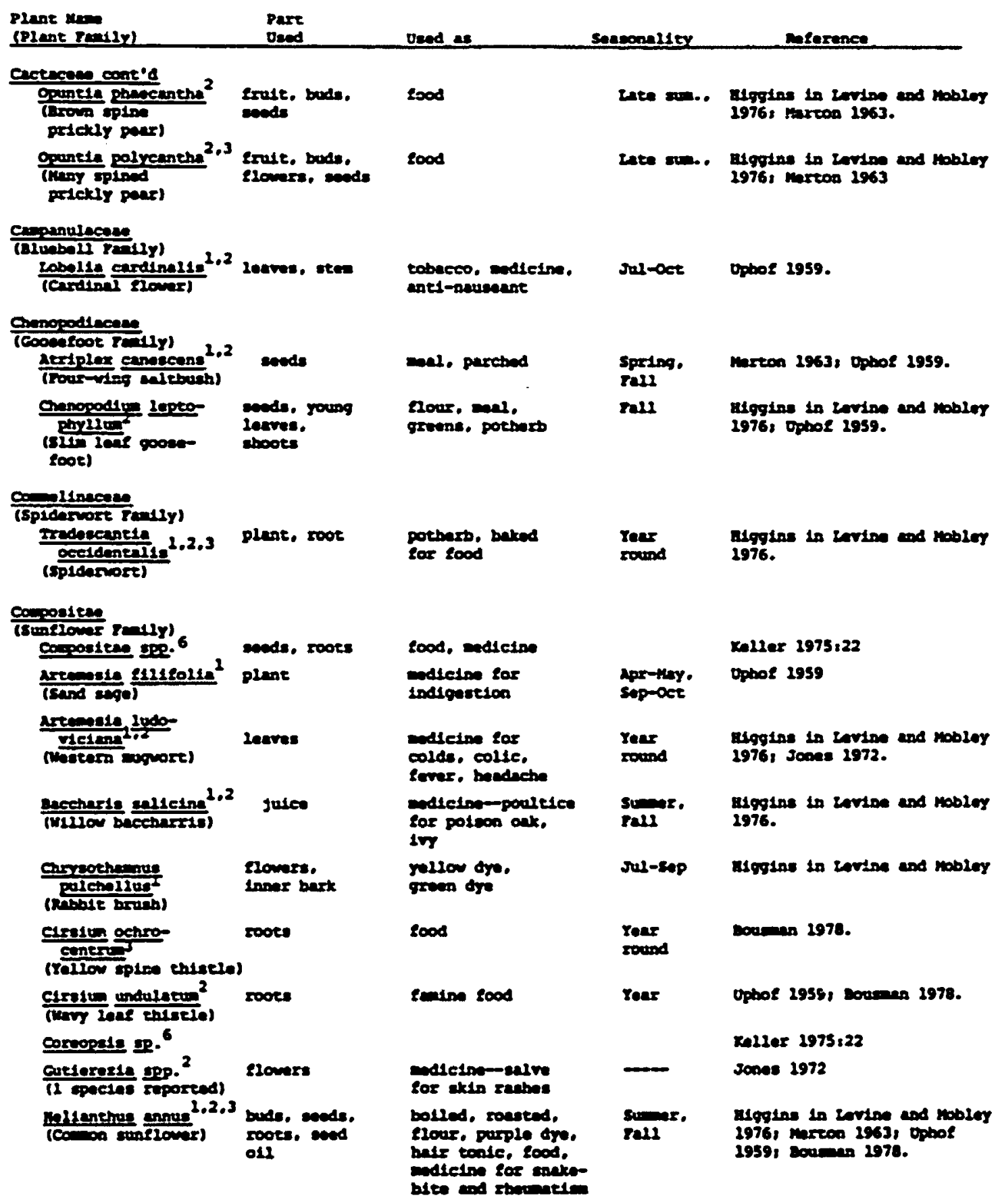




\begin{tabular}{|c|c|c|c|c|c|}
\hline $\begin{array}{l}\text { Plant now } \\
\text { (Plant reaily) }\end{array}$ & $\begin{array}{l}\text { Part } \\
\text { Oand }\end{array}$ & & oned as & Sectenenality & Anferrence \\
\hline 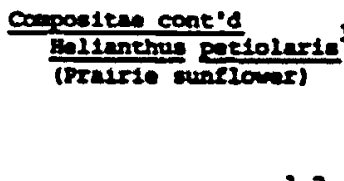 & 3.2 .3 & $\begin{array}{l}\text { buds. } \\
\text { eneds. } \\
\text { soots: } \\
\text { end oll }\end{array}$ & 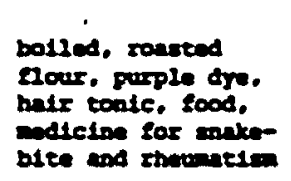 & $\begin{array}{l}\text { sumar, } \\
\text { rall }\end{array}$ & 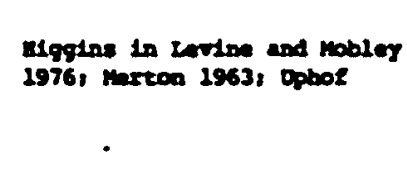 \\
\hline 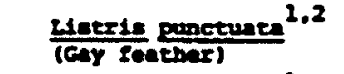 & unspere1 & :ilied & food (2) & somer & Douran 1978. \\
\hline 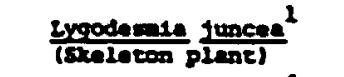 & Juice & & chowiog go & - & vopol 1959. \\
\hline 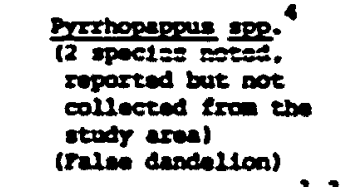 & coots & & $200 d$ & $\begin{array}{l}\text { Lete } \\
\text { Spriog }\end{array}$ & Dourang 1978. \\
\hline $\begin{array}{l}\text { Samecio } \\
\text { (Tareed } \\
\text { sell) }\end{array}$ & plant & & $\begin{array}{l}\text { modseine (use } \\
\text { uncarteln) }\end{array}$ & $n y-n o r$ & $\begin{array}{l}\text { afgoine in Levine and nobley } \\
\text { 2976. }\end{array}$ \\
\hline$\frac{\text { Solidase glgantee }}{\text { (Coldensod) }}$ & $\begin{array}{l}\text { leaves. } \\
\text { seopds }\end{array}$ & & $\begin{array}{l}\text { greens, tea, } \\
\text { food }\end{array}$ & sul-sop & Marton 1963. \\
\hline$\frac{\text { seophanoenria }}{\text { Peuciglores }}$ & Elomes: & & 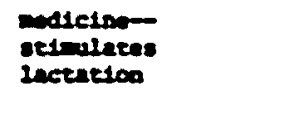 & sul-sug & $\begin{array}{l}\text { Hopins in Levioe and nobley } \\
\text { 1976. }\end{array}$ \\
\hline 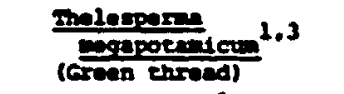 & Leares & & brewed beverage & $\begin{array}{l}\text { sprelog. } \\
\text { rall }\end{array}$ & $\begin{array}{l}\text { Wiggtins in torise and nobleg } \\
1976 \text {. }\end{array}$ \\
\hline 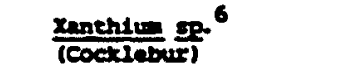 & & & & & Xel10x $1975,22$. \\
\hline 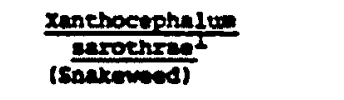 & plant & & $\begin{array}{l}\text { ndietoe- } \\
\text { indre for } \\
\text { insece seing }\end{array}$ & Jul-oce & $\begin{array}{l}\text { Higgine in tervise and pabley } \\
\text { 2976. }\end{array}$ \\
\hline \multicolumn{6}{|l|}{ 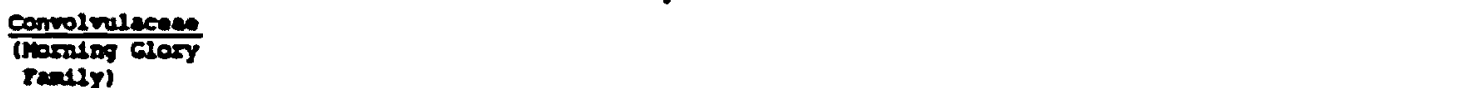 } \\
\hline 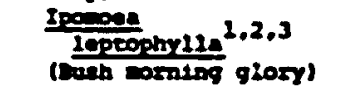 & sooes & & enane $200 d$ & somen & Uphot 19598 sousman 2978. \\
\hline \multicolumn{6}{|l|}{ Cructieree } \\
\hline 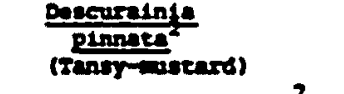 & soods. & Leaves & 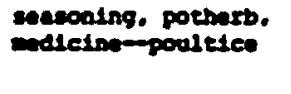 & $\begin{array}{l}\text { Wincer. } \\
\text { Somers }\end{array}$ & 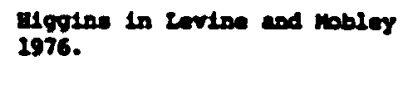 \\
\hline 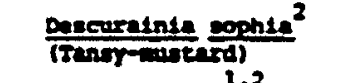 & roung s & shoots. & pothers, enceoning & spriog & Hogias in Lovioe and mobloy \\
\hline 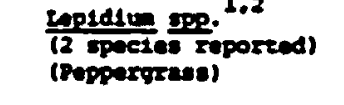 & enedse & & coutonitng & Sumens & Eovman 2978. \\
\hline \multicolumn{6}{|l|}{ 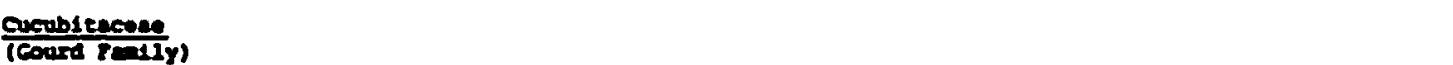 } \\
\hline 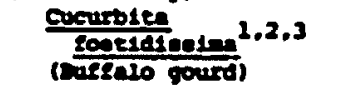 & $\begin{array}{l}\text { plent, } \\
\text { plet, : } \\
\text { dried g }\end{array}$ & $\begin{array}{l}\text { root. } \\
\text { gocods. }\end{array}$ & 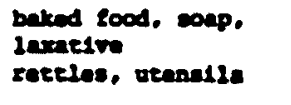 & $\operatorname{sen}_{\text {tost }}$ & $\begin{array}{l}\text { ulggian in coolde and nobley } \\
\text { 1976. }\end{array}$ \\
\hline 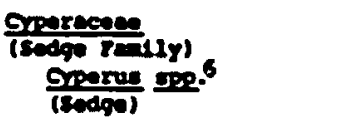 & & & & & Kol1ex 2975122 . \\
\hline
\end{tabular}




\begin{tabular}{|c|c|c|c|c|}
\hline 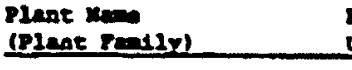 & $\begin{array}{l}\text { Pert } \\
\text { uend }\end{array}$ & Oend as & Seasconellitx & Eefernence \\
\hline 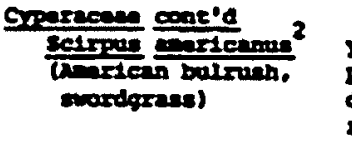 & 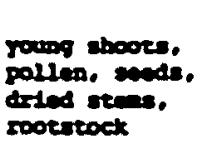 & 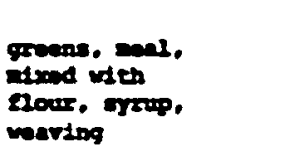 & $\begin{array}{l}\text { Spring. } \\
\text { raul. } \\
\text { rear. } \\
\text { round }\end{array}$ & 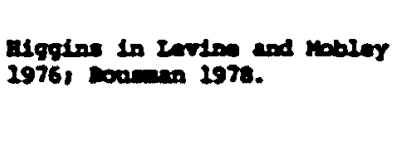 \\
\hline 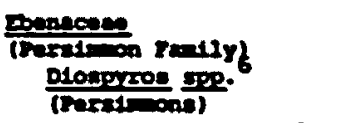 & & & & Croed 1967:157. \\
\hline plosexese virglnde & eraite & $\begin{array}{l}\text { row/dried, } \\
\text { fermented. } \\
\operatorname{low}\end{array}$ & $\begin{array}{c}\text { Late fall } \\
.\end{array}$ & Dousinen 1978. \\
\hline 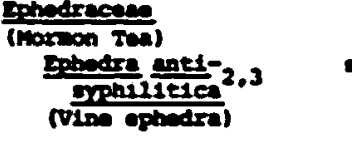 & stem & $\begin{array}{l}\text { beverage, odtelse- } \\
\text { cure for renal dis- } \\
\text { cuse. Hlood purtelar }\end{array}$ & Spriog, & $\begin{array}{l}\text { ulgoing in revine and robley } \\
\text { 1976, opbof } 1959 \text {. }\end{array}$ \\
\hline 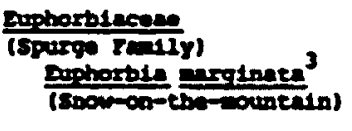 & Letex & choritsg go & $\begin{array}{l}\text { Late Spr. } \\
\text { Tall }\end{array}$ & Opboe 2959, vouman 1978. \\
\hline 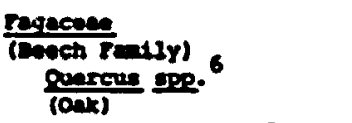 & & & & Groen 1967:157. \\
\hline 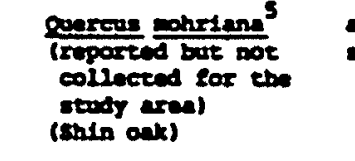 & $\begin{array}{l}\text { ecorminat, } \\
\text { sbell. wood }\end{array}$ & $\begin{array}{l}\text { mal. oll. } \\
\text { ureacile }\end{array}$ & Fall & Ophol 2959. \\
\hline 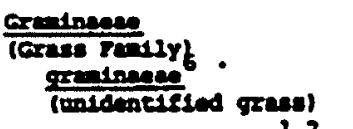 & & & & $\begin{array}{l}\text { Koller } 2975,22, \\
\text { areen } 1967 \% 37 .\end{array}$ \\
\hline 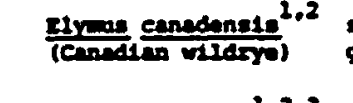 & gands, & 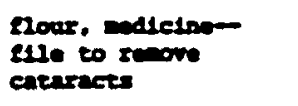 & $\log -\operatorname{sep}$ & Merteo 2963, Josese 2972. \\
\hline 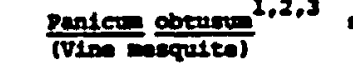 & sends & Elour & rall & oppoue 1959. \\
\hline 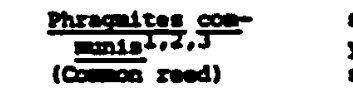 & 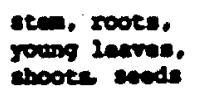 & Sood & $\begin{array}{l}\text { winear. } \\
\text { spring. } \\
\text { rall }\end{array}$ & mreos 2963, Optose 2959. \\
\hline 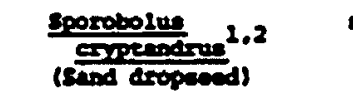 & $\operatorname{send}$ & $\operatorname{sood}$ & $\operatorname{sim}$ & Dptore 2959. \\
\hline 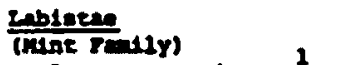 & & & & \\
\hline 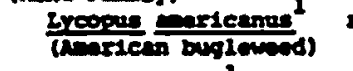 & sooes & $\begin{array}{l}\text { tood } \\
(1001120, \text { deted) }\end{array}$ & $\begin{array}{l}\text { spring. } \\
\text { rals }\end{array}$ & mreos 2963. \\
\hline 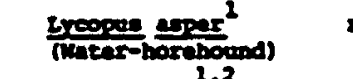 & 2000 & emane $800 d$ & - & Dpeos 1959. \\
\hline 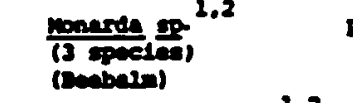 & plant & 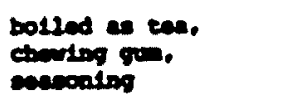 & $\begin{array}{l}\text { spetsos. } \\
\text { rels }\end{array}$ & narteo 1963. \\
\hline 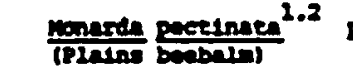 & plene & cancontopg & mysur & Optoos 2939. \\
\hline
\end{tabular}




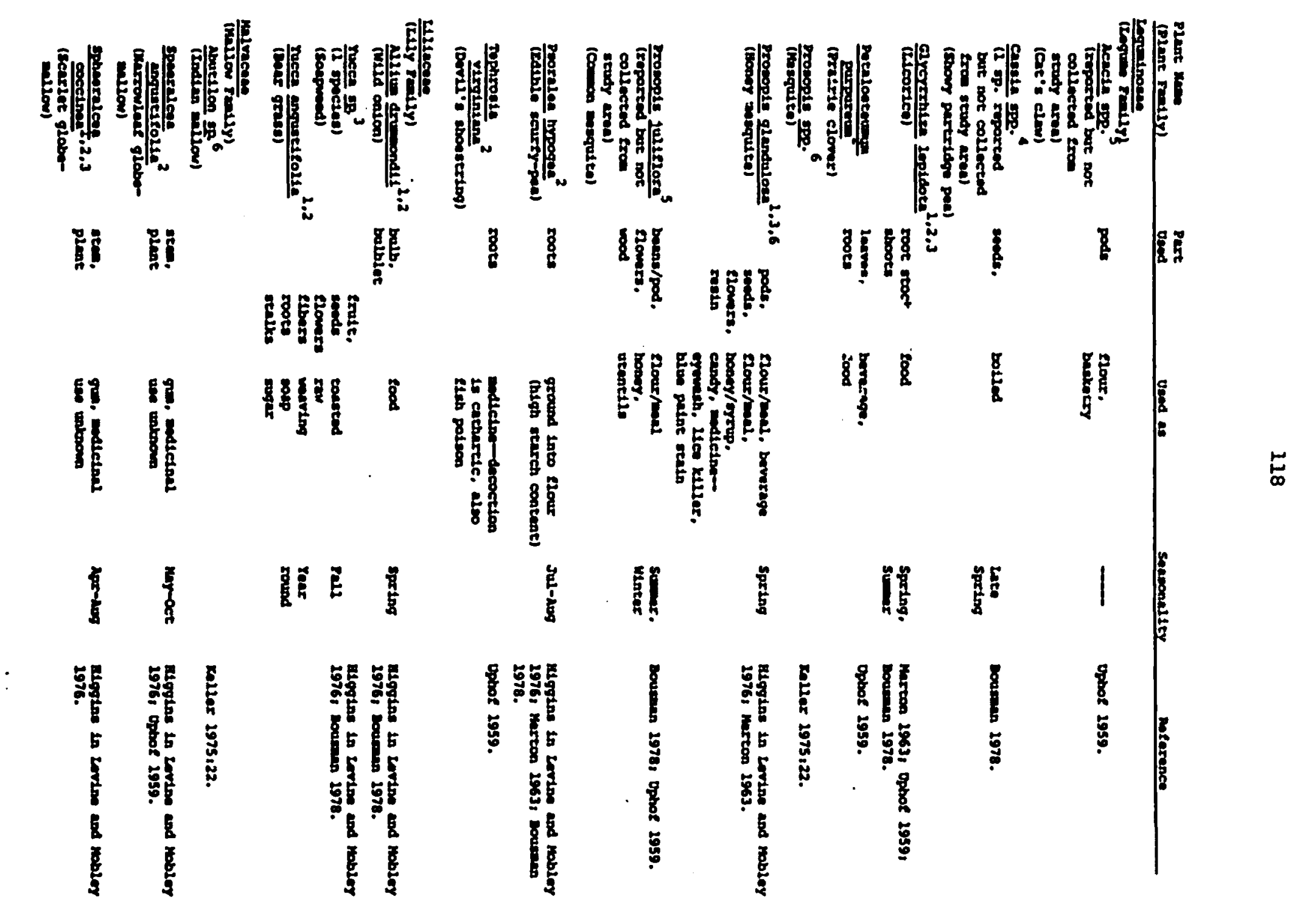




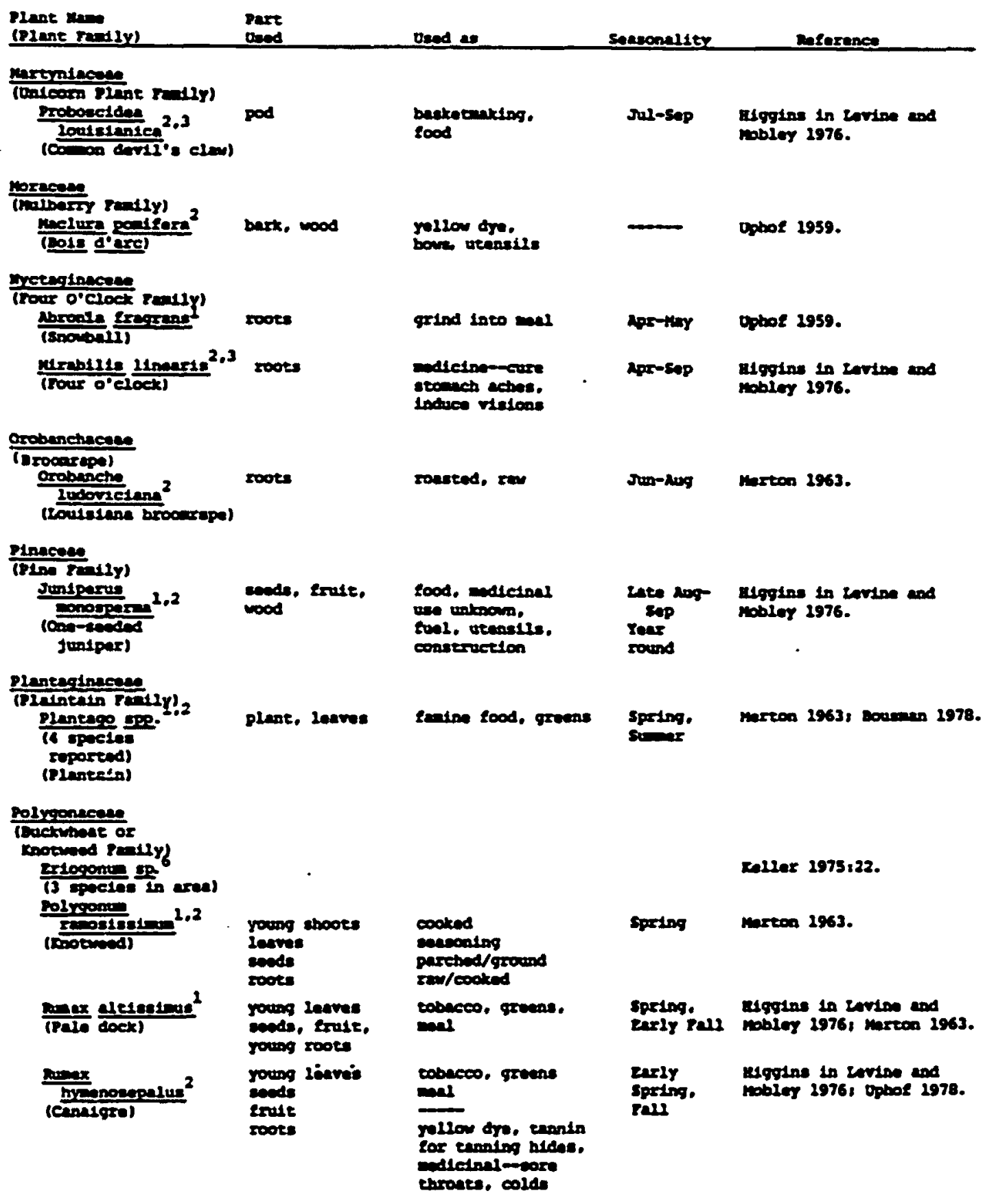

\section{Deseenen}

(noes remsly)

ixine 29

vel1ar 2975.22. 


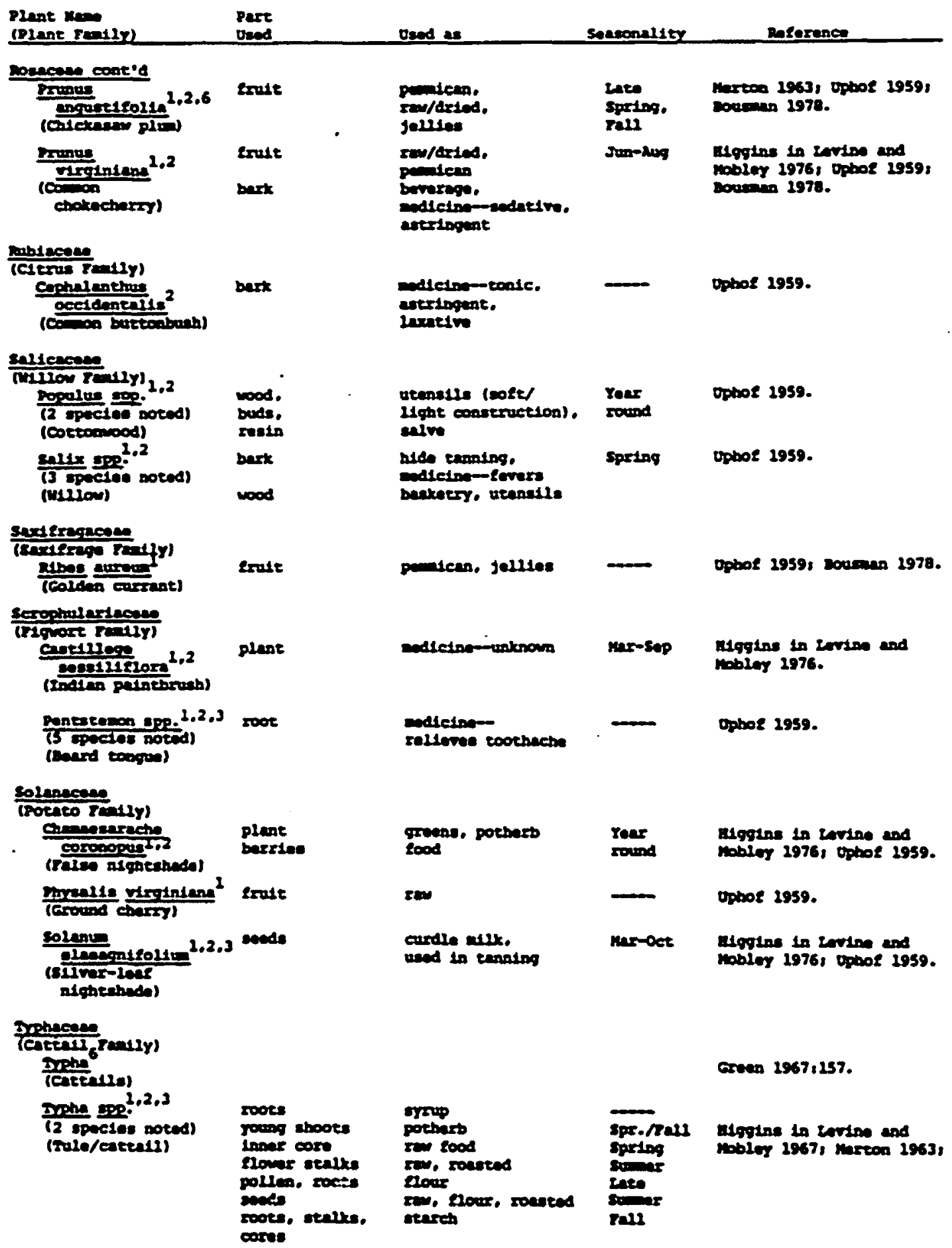




\begin{tabular}{|c|c|c|c|c|}
\hline $\begin{array}{l}\text { Plant } \\
\text { (Plane rending) }\end{array}$ & $\begin{array}{l}\text { Pere } \\
\text { Oened }\end{array}$ & vead as & Seaconel15x & Elarance \\
\hline \\
\hline$\frac{\text { colted }}{\text { (nactbarsy) }}$ & & & & Reller 1975.22 \\
\hline 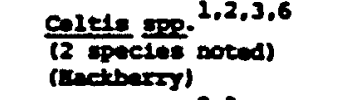 & Erast & pood & rall & 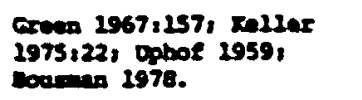 \\
\hline 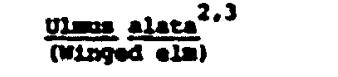 & $\operatorname{cosd}$ & $\begin{array}{l}\text { utensils. } \\
\text { conseruction }\end{array}$ & $\longrightarrow$ & opboe 1959. \\
\hline 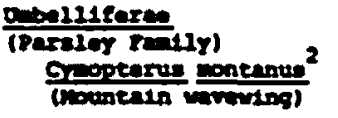 & coote: & 2000 & - & Ophos 2959. \\
\hline 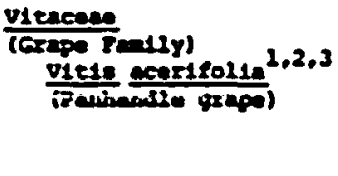 & $\begin{array}{l}\text { ervite } \\
\text { ienves. sen } \\
\text { sap }\end{array}$ & $\begin{array}{l}\text { dried, raw } \\
\text { wrappor for soupend } \\
\text { tood } \\
\text { porable }\end{array}$ & sols & 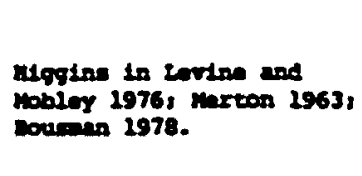 \\
\hline
\end{tabular}

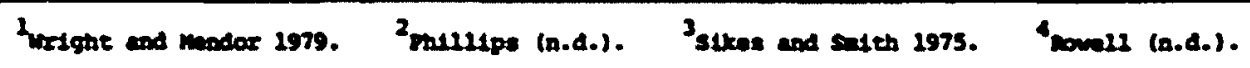

Spuchler 1964. Sincomernd arebenologtenlly. 
Fortunately, from a horticultural perspective, the deeply entrenched river valleys in the High plains have one critical advantage over adjacent regions: the fossil water reserves stored in the Ogallala aquifer. Recent studies indicate that prior to 1937 the watertable was nearly $25 \mathrm{~m}$ thick in the western portion of the study area and only somewhat less farther east (Cronin 1969). Recharge is directly related to the amount, distribution and intensity of precipitation, the vegetation cover and soil permeability. Nevertheless, the vast area covered by the aquifer and the fossil water resources ensure continual discharge of seep and spring water, even during droughts of fairly long duration. Thus the Canadian River valley may have been perceived as a horticulturally marginal area in comparions to adjacent regions during mesic periods, but became more attractive during the droughts after A.D. 1100-1300.

Not all areas are amenable to digging stick and bone-bladed hoe cultivation. Suitable locations must have sufficient water, sparse grass cover, fairly loose soils and the proper soil chemical compositions; yet presumably occur above flood prone regions. Such conditions would eliminate most upland areas of the outer valley, and the steep slopes and active floodplains of the inner valley. Similarly, some technologies are not appropriate for parts of the region. An early attempt by Mexican settlers to irrigate garden crops along Parker Creek (16 km west of the study area) had to be abandoned when the water introduced dissolved minerals into the fields and left a cement-like hardpan layer on the surface (McCarty 1945:7, as cited in Belisle 1971:58). While the slopes of the inner valley are suitable for channelling precipitation runoff onto fields at the bottom, no rock alignments have been reported to date. The most 
ideally suited localities for horticultural gardens would be near springs, on or adjacent to lateral tributaries with silt and humus laden floodplains or perhaps, along the margins of stabilized sand dunes in the uplands.

The hunters encountered the greatest diversity of faunal resources in the bottomlands, along the river, and secondarily, in the uplands of the outer valley. Faunal remains from 11 Antelope Creek sites contained a dominance of bison, antelope deer, six medium and eight small mamal species, four indigenous and nine migratory species of birds, as well as bullfrog and five aquatic and one terrestrial species of turtle (Duffield 1970). In short, a wide range of species was exploited when seasonally available.

Overall, the area contains adequate resource materials. Seasonal and yearly climatic fluctuations, however, would cause marked changes in the plant and animal community composition and distribution, leading to occasional periods of resource scarcity. Such changes would require a diversified subsistence priority with the flexibility to adjust to the changing conditions.

\section{Surmary}

This chapter serves three purposes. It explicitedly defines the area of study, provides a fairly detailed description and distribution of the environmental diversity of the study area, and briefly discusses these environmental aspects as they relate to human ecology. This study of cultural variation focuses on the "High Plains-Canadian Valley" locality, an $80 \mathrm{~km}$ long segment of the Canadian River Valley and its tributaries which transects the the Southern High Plains.

From the local perspective, the study area shows considerable diversity in the kind and distribution of natural resources. Downcutting of the 
Canadian River and its tributaries through erosionally-resistant caprock deposits has created a fundamental dicotomy between inner and outer valley settings. Many of the differences in local topography, elevation, soil associations, geological deposits, temperature, wind speed, solar radiation, water quality and plant and animal communities correspond to the dicotomy of the two settings. Some resources, such as quality tool stone are available at more restricted (near single exposure) localities, whereas others, such $>$ s precipitation are more ubiquitous.

From the perspective of human ecology, the erratic and unpredictable climatic conditions are the most critical. Paleoenvironmental studies suggest that some fluctuations in temperature and precipitation occurred, during the last two millenia and that during the latter part of the Antelope Creek phase, xeric conditions were more common. The climate of the area is considered to be horticulturally marginal, since it receives only slightly more precipitation than the critical eight-inch spring and sumer rainfall. Snow melt from the Rocky Mountains is more predictable but unsuitable because it often comes as floods down the Canadian River. At other times during the growing season the riverbed is dry, or contains stagnant, brackish pools of water. The most dependable source of freshwater is derived from groundwater discharge from the immense ogallala aquifer along the lateral tributaries of the Canadian River. The guantity of fossil water reserves in the Ogallala aquifer are thought to be so extensive that freshwater springs would continue to flow during short-term droughts. The study area also contains a considerable range of animals and economically useful plants. However, the density, and to some extent the distribution, of these resources are also dependent on climatic factors. Thus, given the 
unpredictable nature of the resources, a diversified subsistence pattern based on hunting, gathering and horticulture provided the Antelope Creek people with a flexible strategy for adjusting to seasonal and yearly changes in the resource conditions.

The variations in the distribution of material resources within the study area may underlie some of the apparent differences in the Antelope Creek phase community and settlement patterns. These factors will be considered in subsequent chapters, and cxamined more fully in Chapter 9, once the range of cultural variability has been described. 


\section{CHAPTER 4}

\section{ANALYTICAL METHODS AND SAMPLE LIMITATIONS}

\section{Introduction}

Some cultural variations within the Antelope Creek phase have been recognized since the surveys of the early 1920s. Most discussions of variations have centered around differences in architecture and community patterns because it is precisely these realms of culture which make the Antelope Creek phase distinctive from other Plaiñs or southwestern phases. Yet previous approaches used to examine community patterns were incongruous. Initially, the room layout at one or two large contiguous room sites typified the community patterns for the entire culture. This pattern became an inflexible typology which was applied to all structural features at other sites. Such an approach inevitably led to chaos when new room configurations were added on a piecemeal basis.

The present chapter is concerned with developing a broader approach of examining cultural variation within one locality of the Antelope Creek phase. The methodological approach, sampling strategy, and complexities and limitations of the data base are discussed.

\section{Methodological Approach}

Past goals of archaeology have been to discern and explain patterns of variation and change in the structural components of a culture (Plog 1974). Recent trends have focused on delimiting the subsistence-settlement systems, sought procedures which measure population changes, and attempted 
to delineate a series of causal factors underlying the variation in the structural patterns (Elannery 1976). As laudable as these goals are, the present Antelope Creek information base is not sufficiently crganized or systematically enough coilected to begin to examine many of these intriguing problems. The present study aims at synthesizing and defining the nature of variation in several components of the Antelope creek cultural system. The components of the system were selected for their potential to contribute information which could be used to test previously proposed "explanations" of change.

Within sedentary cultures, the individual household and community represent the focus of the subsistence-settlement pattern to which the products from different procurement and processing localities are returned and utilized (Flannery 1976). Thus, the present goal is to investigate the nature and structure of Antelope Creek houschold and community patterns. Since previous syntheses have suggested that the large contiguous structures represent an accretional development through several construction episodes, an analysis of the total room block configurations would yield a hodge-podge pattern of unit configurations. Instead of imposing an a priori typological pattern of unit layout, the present approach employs an . attribute analysis of architectural traits on individual unit features excavated from numerous sites within the confines of the High Plains-Canadian Valley locality. A series of architectural attributes and metric variables were recorded for each excavated feature unit and these constitute the formal dimensions of architectural analysis. The architectural attributes from a wide range of features did not consistently cluster into discrete types, but rather the attributes displayed some overlap in occurrence. 
Traditional classificatory keys are not suited to such attribute occurrence patterns, since no single attribute is consistently represented, and the subjective selection of "significant" traits is unjustifiable. Consequently, the architectural types in this study represent morphological abstractions, which are determined by a high degree of mutual occurrence of attribute clusters (Brown 1971:1-3). Such a procedure defines the range of moxphological variability within individual architectural units from the study locality. Next, the spatial relationship of dominant and subordinate units and the repetitious patterning of architectural units, particularly within individual room blocks, provide an indication of the number, kinds and relationship of units comprising "household clusters." A household cluster is defined by the presence of a dominant house structure, plus associated features and activity areas believed to be utilized by a single household (winters 1976). In contiguous room block structures, the number of household clusters can be determined by room size, repetition of interior features, partitions separating neighboring households, and the ofcurrence of separate rire places for cooking (Chang 1958:302).

It is assumed that architectural units with similar size, shape, internal morphological characteristics and structural positions relative to other units served a similar range of functions. In some instances, spatial relationships and dimensions of unexcavated architectural units such as those at Tarbox Ruin and Lookout Ruin are used to provide a broader indication of variation within household cluster patterns even though the internal feature pattern is unknown.

While delineation of architectural structure of household clusters can most easily be achieved at the contiguous unit room block, correspond- 
ing architectural units can then be sought at sites with isolated room units. Ideally the correspondence for free-standing architectural units should be based on similarities or such formal attributes as size, shape, and mutual occurrence of internal features, as well as functional similarity as reflected by the associated artifact assemblage. Once this has been achieved, the number, structure and patterns of household clusters and room types can be used to infer the next hierarchical level--the community or site type. The purpose of identifying these levels is not just to provide an adequate description of the settlement system components, but rather to form an appropriate base from which to seek correlations among temporal, functional spatial parameters.

It is precisely by means of these correlations that inferences concerning the structure of the cultural system can be identified and interpreted. Consequently, auxiliary chronological, artifactual, spatial information must be examined to determine whether the settlement variations reflect functionally differentiated or specialized components of the system, temporal variations, or merely environmental differences occurring locally witt.in the study area.

Specialization and differentiation may be inferred from functional. differences in the associated material assemblage, differential burial practices, or differential contact/interaction with adjacent groups. Temporal variability must be examined through stratigraphic and absolute chronologic trends. Finally, environmental differentiation can be examined through a series of spatial correlates. Some of these information sets will be examined later in the next few chapters. 


\section{Sampling Strategy}

Ideally, any study of community patterning should be based on an unbiased sample reflecting the representative kinds, quantities, and distributions of sites from the entire locality (Flannery 1976). Such an unbiased sample of site types could be obtained by conducting systematic surveys using any number of stratified surveying procedures (Mueller 1974). Despite nearly 50 years of archaeological investigations within the Canadian River Breaks, most surveys have been of the informal Type I reconnaissance (Ruppe 1966).

As an extreme example of the unrealistic nature of such surveys, A. W. Davis (1961) and one assistant conducted an inventory of archaeological sites to be potentially affected by the development of the entire Lake Meredith area (involving a $40 \mathrm{~km}$ long segment of the Canadian River's inner valley) within a 10 day period. More recent surveys of Blue West and Bates Canyon (Hughes 1973), the Alibates National Monument property (Bousman 1976) and the Rosita and Blue Creek Off-Road Vehicle Areas (Etchieson 1981) involved more systematic examination of certain land tracts and a number of pipeline surveys around Lake Meredith also potentially offer unbiased transects of the locality. However, differences in field methods and site taxonomies hamper the use of these studies. More important is the realization that surface indications alone provide a poor estimate of the number, kinds and sizes of features and the nature of materials at a site. Since the methods of this study entail on an attribute analysis involving the known occurrence and mutual association of interior features, the most useful information is dexived from excavated sites. Additional excavations could have been undertaken; however, in light of the diminishing 
site resource base due to vandalism and land use patterns (particularly oil and gas field development), a decision was made to conduct a comprehensive analysis of existing information contained in field notes, manuscripts, and reports from previously excavated sites. The strategy of re-analyzing information from excavated sites conserves the contextural integrity of other sites which can be investigated ir. the future to answer other questions.

Within the High Plains-Canadian Valley locality, records exist for no fewer than 34 sites excavated prior to 1981 (Figure 4). From this initial sample, several sites had to be dropped. The Canadian River 1 and Canadian River la sites along Running water Creek were omitted because of conflicting information about the presence of structures and the absence of feature maps or records (cf. Crabb 1968:84; Glasscock and Glasscock 1955). Emeny Ruin on Serrita de la Cruz and the three architectural sites along Big Blue Creek more recently excavated by the Texas Archaeological Society Field School were umitted because of incomplete feature delineation, lack of site maps, or inconsistent record-keeping procedures (Hughes personal communication 1982; Davis 1969). Ozier Ranch Ruin was excluded because of problems in discerning the number and nature of entire rooms at the site (Etchieson 1982). Finally, the South Ridge site was omitted because no architectural features, or burials, and few trade items (two obsidian flakes) were found despite extensive testing (Etchieson 1979). The 28 remaining sites were deemed to have sufficient information for analysis of the various data sets (Appendix A). More than 300 room-like features, 27 exterior pits/ cists and 47 burials have been reported for these 28 sites and detailed records on excavation or testing are available for 290 room-like features, 
22 pits and 45 burials (Table 10 ).

Admittedly this post facto sample of sites and features may not be entirely unbiased. However, the sites show considerable latitude in size, configuration, and locational setting and were selected for excavation because of a multitude of changing reasons and research strategies during the last 50 years. For these reasons, the inclusion of features from a large number of sites is believed to provide a fair indication of the range of architecture and community patterns for this locality.

\section{Capabilities and Limitations of the Data Base}

The compilation procedures used in this study involved amassing, interpreting and cross-checking published and unfublished records for the 28 sites prior to tabulating a series of observations for the attribute analysis. Owing to the limited list of published and unpublished reports, additional information was obtained from museum and archival records.

Information about many of the projects conducted since 1950 was obtained from the Panhandle-Plains Historical Society Archives and Archaeological Laboratory, Killgore Research Center, West Texas State University, or the National Park Service files at Lake Meredith. Most of these projects were fairly limited in scope and copies of original site maps and records were available as fairly complete information sets. In addition, other information was obtained from interviews and personal records of individuals involved witl. the amateur excavations of the late 1950's.

Considerably more difficulty was encountered in obtaining information about projects predating 1950. Archival emphasis was placed on obtaining information about the WPA-funded projects since they account for approximately 85 of the total excavation areas, 55 of the architectural feature units and 70 of the burials from the study sample. 
TABLE 10

EXTENT OF EXCAVATIONS AND KTNDS OF FEATURES ENCOUNTERED

\begin{tabular}{|c|c|c|c|c|c|c|c|}
\hline Site $x$ & $\begin{array}{l}\text { Approxdinte } \\
\text { extent of } \\
\text { excerves }\left(\mathrm{n}^{2}\right)\end{array}$ & $\begin{array}{l}\text { Doons } \\
\text { excav. }\end{array}$ & $\begin{array}{l}\text { Docoses } \\
\text { tented }\end{array}$ & $\begin{array}{l}\text { noose } \\
\text { est. } \\
\text { unexeny. }\end{array}$ & $\begin{array}{c}\text { Exterfor } \\
\text { pites }\end{array}$ & $\begin{array}{l}\text { SIab- } \\
\text { lined } \\
\text { cters }\end{array}$ & somplese \\
\hline N1butes 28-0-5 & 1.516 .0 & $29+$ & 2 & 4 & $x$ & 1 & 12 \\
\hline Altbares 28-0-II & 4.110 .0 & 31 & - & $\mathbf{x}$ & $x$ & s & 3 \\
\hline Nibutes $28 x$ & 381.3 & 1 & - & $9^{2}$ & - & - & - \\
\hline Nlbutas 30 & $223.0^{2}$ & 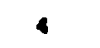 & 5 & $\mathbf{x}$ & - & - & - \\
\hline Antelope Croek 22 & 1.134 .6 & 25 & 2 & 4 & $x$ & 3 & 1 \\
\hline Natelope Creak $22 \lambda$ & $229.0^{1}$ & 6 & - & - & - & 1 & 26 \\
\hline Antelope Croek 23 & $45.5^{\circ}$ & 1 & - & $\mathbf{x}$ & - & - & 1 (2) \\
\hline Antelope Creek 24 & $=0.0^{2}$ & 12 & 3 & 4 & - & - & - \\
\hline Mrrouband Peak & 240.0 & 10 & - & $2^{2}$ & 1 & - & - \\
\hline aluck Dog Village & 280.0 & s & - & $2+$ & 2 & - & - \\
\hline Ondmey rock mustn 51 & 558.0 & 6 & 1 & $23^{2}$ & - & - & - \\
\hline Onimey nock reutn 521 & 42.2 & 2 & - & 2 & - & - & - \\
\hline Cotan min & $225.0^{2}$ & 3 & $23(2)$ & $7-34^{2}$ & - & - & 2 \\
\hline Cotromood Creak puln & 28.0 & 1 & - & $28^{2}$ & - & - & - \\
\hline Cononex & 28.0 & 2 & - & - & - & - & - \\
\hline rootprint & 125.0 & 3 & - & - & $\mathbf{s}$ & 1 & $3^{3}$ \\
\hline Jack Mllen & 55.0 & 1 & - & - & 2 & - & - \\
\hline tookour Buits & 5.6 & - & 1 & 4 & - & - & - \\
\hline Marsh siee & 40.0 & 2 & - & $2(2)$ & - & - & - \\
\hline Medford Ranch & 213.0 & 6 & - & $2+$ & - & - & - \\
\hline $41-10-7$ & 109.3 & 1 & - & - & - & 2 & - \\
\hline Pistect & 26.0 & 1 & - & - & - & - & - \\
\hline Turkey Croek touln & 44.0 & 3 & - & - & - & - & - \\
\hline topax & 75.5 & $\mathbf{s}$ & - & - & - & - & - \\
\hline saneoxd & 80.0 & 6 & - & $3^{2}$ & - & - & 2 \\
\hline Spring Canyon & 82.3 & 1 & 2 & $2^{2}$ & 2 & - & - \\
\hline Tartbox & 36.5 & 2 & 3 & 14 & - & 2 & 2 \\
\hline 2012ars & 34.8 & 2 & - & s & - & - & - \\
\hline Dig alve & 36.0 & - & - & - & - & - & $\mathbf{s}$ \\
\hline roense & 9.901 .6 & 259 & 31 & 233 & 12 & 25 & 47 \\
\hline
\end{tabular}

\footnotetext{
torude astante of excavetion extent.

${ }^{2}$ crude eatinate of muber of unexervated soons.

3 osevary burlals imwolving enveral indivituals.
} 
Copies of a two-volume "WPA Final Report" (Baker and Baker 1941a, 1941b) had been re-issued in 1968 and were readily available. However, these volumes lacked site maps and information on select features at certain sites. Copies were made of fragmented portions of bimonthly and quarterly reports on file in the Floyd Studer Collection at the National Park Service offices, Lake Meredith, and the Panhandle-Plains Historical Museum Archives and Archaeological Laboratory. Most of these reports contain two pages of description and a one-page scaled drawing of each architectural feature unit, and listed the kinds and quantities of artifacts from each of the $10 \times 10 \mathrm{ft}$ exterior excavation sections. Photocopies were made and matched to obtain a complete set of quarterly reports. In many cases, duplicate segments of reports typed by different machines were encountered. In each case, the copies (particularly the feature maps) were checked for accuracy. Transcription discrepancies were encountered and noted, and the structure of the report was evaluated to ascertain which was the earlier version. It was assumed that versions which deleted site information were later copies.

Original WPA site maps showing the spatial relationships of features and excavation units were difficult to locate. A few maps were found showing the excavation layout within a topographically defined area of arbitrary size. In addition, the Potter County Historical Society re-drafted maps of Antelope Creek Ruin 22 and Alibates Ruin 28 in conjunction with the development of the Alibates National Monument; however these were found to contain errors. In a few cases clues regarding the excavation unit size and layout were obtained from finding disxuptions in the sequence of square numbers by structural features which encompassed more than one grid row. 
Site photographs showing the use of large wooden stakes at each $10 \mathrm{ft}$ section corner proved useful in determining distances between features and confirming the size and shape of excavation areas. Ultimately all of the compiled information was presented to Ele and Jewel Baker for confirmation and verification of accuracy.

Additional information about room architecture and contiguous room layout patterns was obtained by re-plotting the individual scale drawings of each feature in the various WPA quarterly and final reports to a consistent size. All details mentioned in the text but not shown on the feature maps were added and mosaics of individual features were compiled to develop new maps of the contiguous room blocks. This method proved helpful in discerning construction episode sequences at Alibates $28 \mathrm{~A}$ and Antelope Creek 22. Finally a generalized cross-sectional map of the contiguous parts of Alibates 28 was obtained by plotting the wall heights and the depth of deposits relative to floor surfaces from each room (cf. Appendix A). Once information from the large scale WPA projects was refined and integrated, the records from the earlier projects at Alibates Ruin 28 and Antelope Creek Ruin 22 were sought to correlate the WPA observations and to add details. The letters, site forms, personal journals, maps, manuscripts and theses of Ronald Olson (American Museum of Natural History), J. Alden Mason (University of Pennsylvania Museum Archives) E. B. Sayles (Axizona State Museum, Texas Archaeological Research Laboratory), E. J. Lowrey (Texas Tech University), and Floyd V. Studer (National Park Service, Lake Meredith; Panhandle-plains Historical Museum) were secured. Attempts to locate Warren Morehead's records proved unsuccessful.

Although each project used a different site, grid and feature designation system, feature correlations were achieved by comparing sketch maps 
and room dimensions. In some cases, rooms which the WPA archaeologists thought had been "vandalized" had been carefully exposed and recorded by previous parties. These records indicated that more structures were present at the type sites than indicated in the WPA documents. The inaccuracies of the WPA documents do not reflect poor record-keeping procedures as much as the disturbed conditions of the sites. By 1938, Alibates Ruin 28 and Antelope Creek Ruin 22 had been excavated by four previous projects, resulting in unfilled eroded excavation pits and mounds of back dixt.

Certain limitations are imposed on this study by the reliance of observations made by many different archaeologists. The riature of observations, in part, reflects a person's ability and an awareness of where to look and what to expect. Since some architectural traits appear to be unique to the Antelope Creek phase, an educational process is evident in the early field records. For this reason, few ways are available to evaluate whether an unrecorded trait reflects its true absence or a failure of the archaeologist to make the proper observations. ${ }^{1}$ Fortunately the intensive work at Alibates Ruin 28 and Antelope Creek Ruin 22 by multiple expeditions over a 20-year period provided a rare opportunity to evaluate the accuracy of different observations of the same locale. In both cases, new attributes and even whole features could be added to the information compiled from the WPA maps and records. In other instances the original observations are assumed to be accurate and correct.

${ }^{1}$ One example of the latter case will suffice: the recessed platform affiliated with large rectangular rooms with central channels was first recorded at the Footprint site, the last locale excavated during the mitigation of sites within Sanford Reservoir (Green 1967). This feature was not observed on 44 similar structures previously excavated, but has appeared on two other structures (Jack Allen and Two Sisters Sites) excavated since then. 
Besides compiling and integrating archival information, trips to Texas Tech Museum and the Panhandle-Plains Historical Museum were made to inspect the condition of artifact collections for possible use in this study. Only an extremely small sample of diagnostic tools from the artifact assemblage was retained from sites investigated by w. C. Holden prior to 1935. Some materials were on loan to other institutions while other items could not be located. At the other extreme, materials from some of the later projects have yet to be washed or processed.

Some artifact provenience information was gleaned from the archival records, but with considerable difficulty. Few of the manuscripts or published reports provide specific artifact provenience information. Most of the artifact catalogue systems examined consist of drawers of the individual specimen cards, rather than quantified tabulations of materials by specific excavation units. In light of the range of field collection procedures, cataloguing practices and subsequent curation policies, functional assignments to the morphological architectural types are tenuous. Only the WPA records and a few of the Norpan and Panhandle Archaeological Society amateur excavation records provide quantification of materials by provenience units. This information is examined in Chapter 6.

\section{Summary}

The present study is based primarily on archival documents of nearly all sites within the study area which were excavated by professional archaeologists before 1981. Even though the sample of features from 28 sites shows considerable diversity of size, layout and setting, there is no assurance that the sample is unbiased. Furthermore, differences in excavation and analytical procedures as well as variations in observations, 
interpretations and reporting qualities impose some limitations to the data base. Nevertheless, the use of archival information has not been previously consulted in a systenatic manner. The present study employs diverse information sources and quantitatively integrates the available information to form the basis of a comprehensive synthesis of a single locality within the Antelope Creek phase. This synthesis serves to indicate both unresolvable problems which need to be tested with information from other sites within the locality, and also as a solid data base for comparing developmental trends in adjacent localities along the periphery of the phase. 


\section{CHAPTER 5}

\section{INTRA-SITE SPATIAL VARIATIONS: ARCHITECTURE}

\section{AND COMHUNITY PATTERNING}

\section{Introduction}

This phase of analysis is concerned with defining the range of morphological variation represented in the architecture and the spatial patterning of structure remains. The examination of architectural remains focuses on the dimensions and associations of architectural attributes of each structural feature in order to establish a limited number of feature type. In many instances the functions of specific features comprising the room types are also discussed. Once the range of individual architectural features has been defined, the spatial aspects of the community pattern are examined. Initially, the contiguous room block sites are analyzed and a series of six patterns of room aggregation are discerned. These patterns of room aggregation reflect the intrastructure and interstructure of the Antelope Creek household clusters. Next, the spatial patterns represented. at sites with free-standing, isolated rooms are examined. Finally, the individual rooin and aggregate types are used to define simple and complex forms of three main types of architectural sites--the subhomesteads, homesteads, and hamlets.

\section{The Nature of Architectural Variations}

The architectural terminology in the existing literature is too loosely defined. Some archaeologists have referred to circular slab-lined 
features with a diameter of nearly $3.5 \mathrm{~m}$ as cists, while others regard them as rooms (cf. Lowrey 1932:38). To avoid such confusion all recorded features, whether they be "pits", "cists", or "rooms", were regarded as "architectural units" and were included in the analysis.

Within the Antelope Creek phase, architectural variations manifests itself at two levels: the individual architectural units, and the contiguous aggregate form. The basic descriptive problem is first to define a number of basic unit types and note their range of variation, and second to examine the spatial relationships of a number of unit types to determine the basic aggregate types. In turn, a number of basic aggregate types are connected to form complex room block configurations at some of the larger sites.

PATTERNS OF ARCHITECTURAL UNITS

A unit type is an ideal composite of mutually occurring morphological attributes present in a number of similar architectural units. Units assigned to a particular type share a strong resemblance to other members, but can still vary in but a few individual traits. In some cases, a type may be defined by a combination of discrete internal attributes shared by a series of architectural units to such an extent that knowledge about one critical attribute would predict the condition or occurrence of other attributes. Most often, the occurrence of several attributes is necessary to assign an architectural unit to its proper taxon. slight differences expressed by units within a type are regarded as unit varieties.

The recognition of unit types and varieties based on attribute analysis is most easily accomplished with units displaying complex morphology, and is most difficult with simple units consisting merely of four walls and 
a plain floor. In complex architectural units, differences in a few attributes do not significantly alter the overall similarity from other units assigned to the taxon. But among simpler, and of ten the smaller, units variation in even one trait can provide a radically different appearance. In order to determine whether the difference is merely a slight variation of a type or justifiably constitutes a separate morphological taxon, a broader attribute context must be considered. Fortunately, the recurring pattern of unit layout, the dominant/subordinate relationships between units at contiguous unit aggregates, as well as the size consistency of isolated and contiguous units between sites, provides clues to the number of different types. Corresponding kinds of units may generally be expected to occur among the isolated structural units.

Initially a series of 61 attribute and variable observations was collected for each of the 223 architectural units at the 28 sites considered in this study (Appendix B). The main criteria used for defining unit types were feature size, length-to-width ratio, and association of attributes comprising the feature. On the basis of these criteria, 11 morphological unit types are defined and three residual architectural units are assigned to a miscellaneous category (Figure 10).

Even though the dimensions within individual units showed sufficient differentiation to indicate thrt measurements were not standardized or precise, in nearly all instances the morphological unit types show a fairly discrete range of floor areas (Figure 11). Six fairly discrete clusters in floor sizes are evident. Very small sized units generally cover less than $1.5 \mathrm{sq} \mathrm{m}$ and are comparable in size to storage pit and cist features inside the large to extremely large architectural units. Small sized units range 


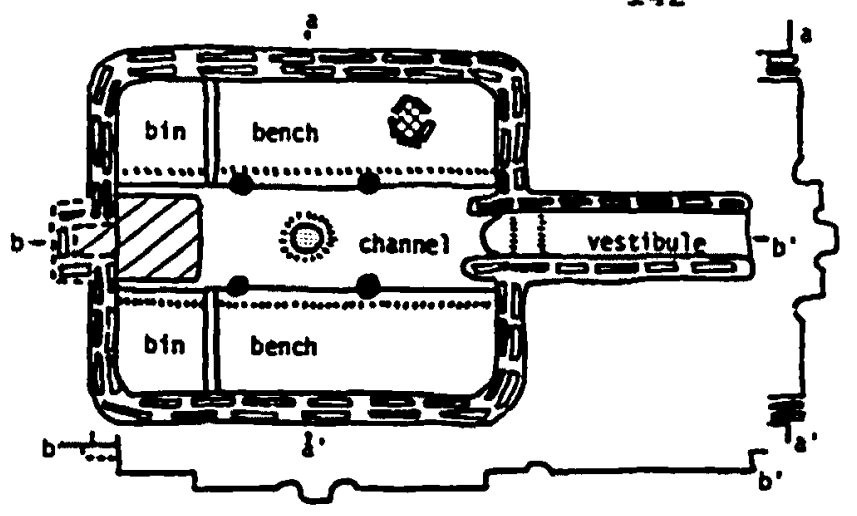

UNIT TYPE I

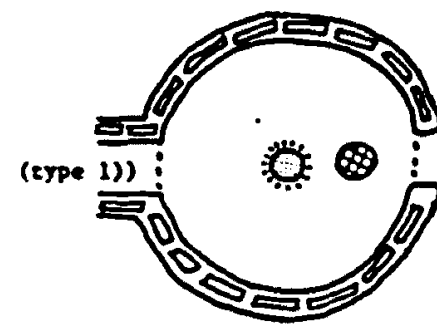

UNIT TYPE 3

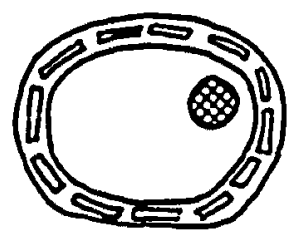

WIIT TYPE 5
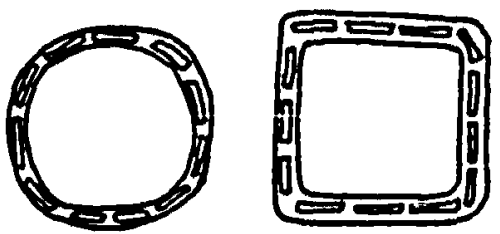

UNIT TYPE 8

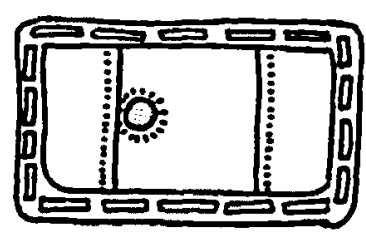

MISCELLUKEOUS ?
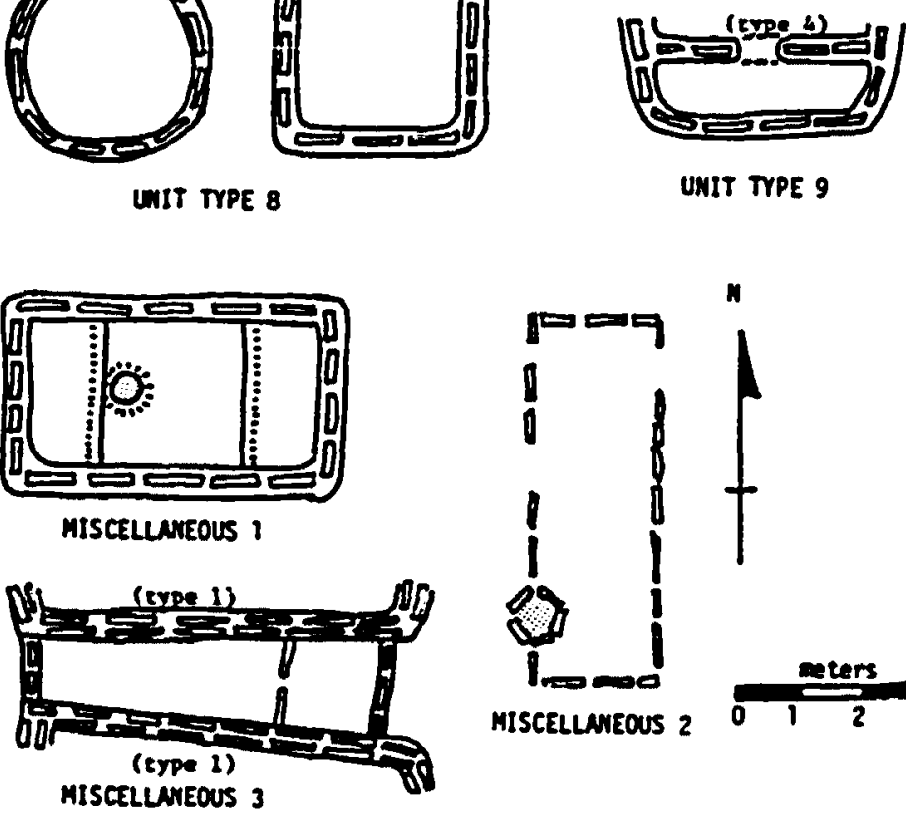

UMIT TYPE 9
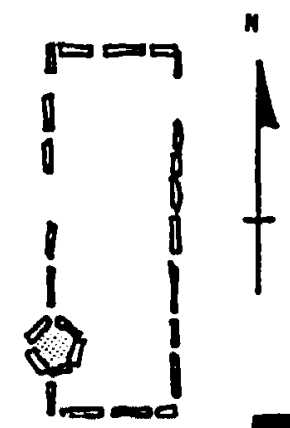

MISCELLANEOUS $201 / 23$

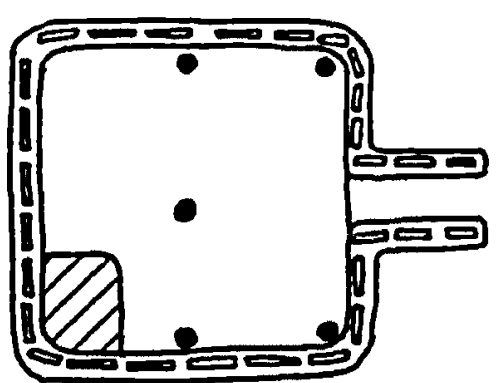

UMIT TYPE 2

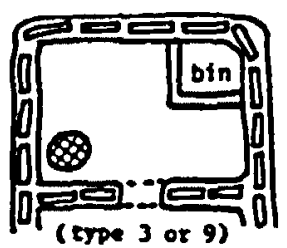

WIIT TYPE 4

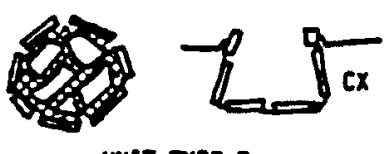

UAIT TYPE ?

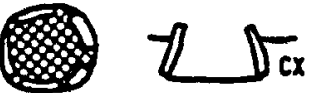

WIT TYPE 10

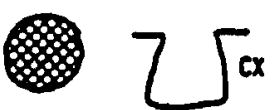

UNIT TYPE 11

Figure 10. Variations in Architectural Unit Types. 


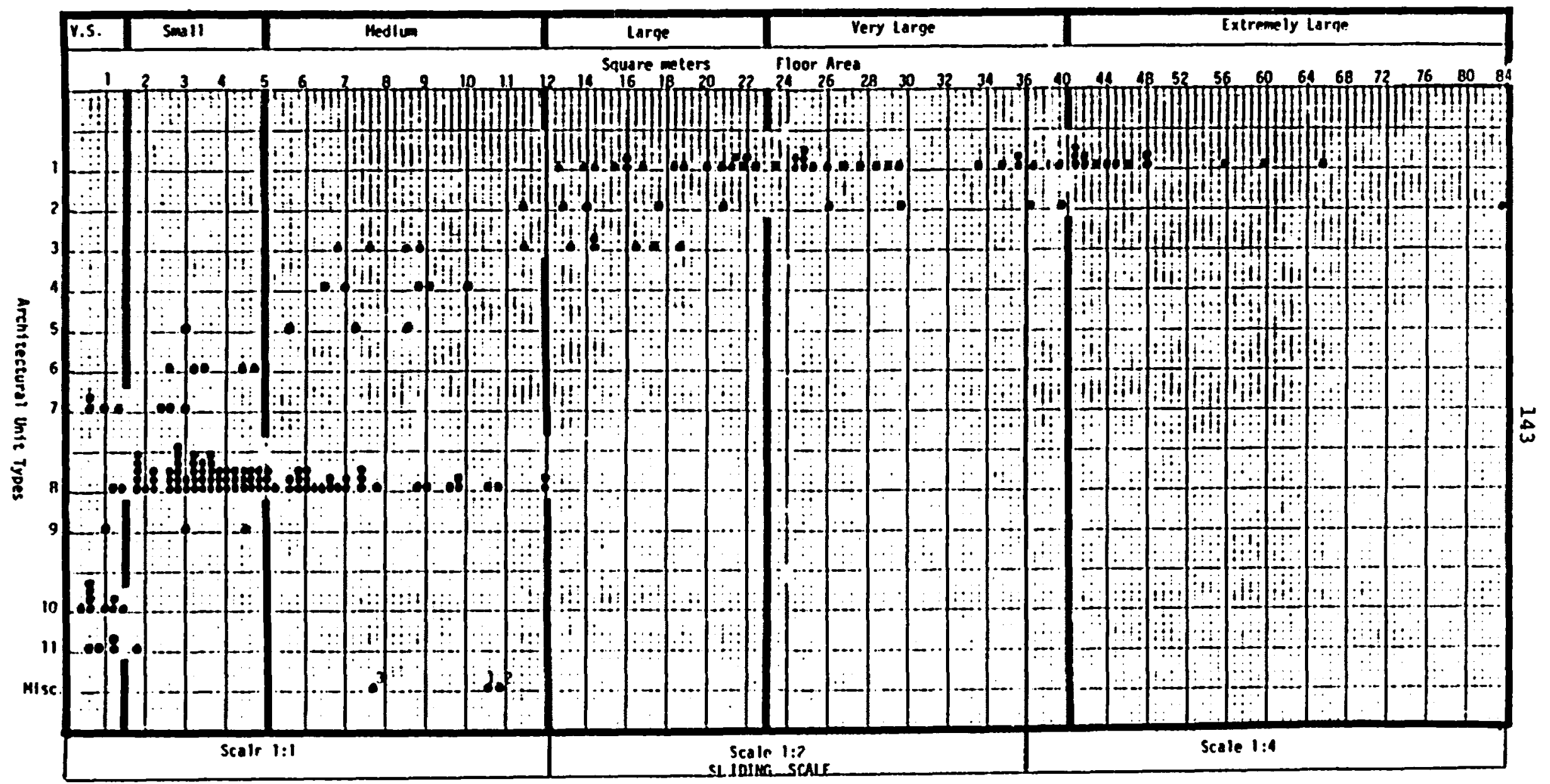

Figure 11. Variation in Size Range of Architectural Unit Types. 
from approximately 1.6 to $5.0 \mathrm{sq} \mathrm{m}$ floor space. Units of this size can occur as free-standing units, paired units, or as a subordinate position against the main walls of large to extremely large units. Medium sized units range from 5.0 to $12.0 \mathrm{sq} \mathrm{m}$ and occur as free-stanciing units or as subordinate rooms either separated from the main units by a series of small rooms, or attached to the main unit in uncommon positions. Although the size range of some units overlaps somewhat, the moxphological distribution between small and medium sized units is apparent from the discrete clusters of units.

Most units within the small to medium size range have a relatively simple morphology which appears to override the size distinction. However, the size of units at most sites tends to discretely cluster into predominantly small or medium intervals. Of the 18 sites with small and/or medium sized units, only two (Chimney Rock Ruin and zollars Site) have equal number of units in both size intervals. Large sized units have at least 12.0 sq $\mathrm{m}$ floor area, and in contiguous form, are distinguished from medium sized features by units located either in the dominant or subordinate "antechamber" position. All units in the dominant position are believed to be the core of the household clusters and typically show a complex morphology with segregated work areas. Because of the extensive range, two other size intervals have been arbitrarily defined to express differences between sizes. Very large units range from 23.0 to $40.0 \mathrm{sq} \mathrm{m}$ whereas extremely large units range from 40.0 to $90.0 \mathrm{sq} \mathrm{m}$ floor area. Overall, the lower four size intervals seem to segregate the various architectural units into realistic morphological differences. The meaning of these differences will be examined in later sections. 
The following description of each unit type provides a synoptic description, then discusses the range of variation in shape, size, lengthto-width ratio, unit preparation, wall type, doorway, roof configuration, interio: features (such as channels, platforms, heat related features, storage related features), and evidence for subsequent modification. Clearly, the following morphological types are based on the study sample. In all instances the mean dimensions will also provide the one standard deviation interval based on the sample under consideration. The differences may not necessarily exactly accomodate all varieties noted in units excavated or reported in the future but at least the present analysis provides a broader basis for architectural comparison. Literature references to specific architectural units are provided in Appendix $c$.

Unit Type 1

$(n=47$ units; possible four additional unexcavated or severely eroded units at Lookout Ruin, Alibates 28, and Tarbox Ruins (Figure 12). This unit

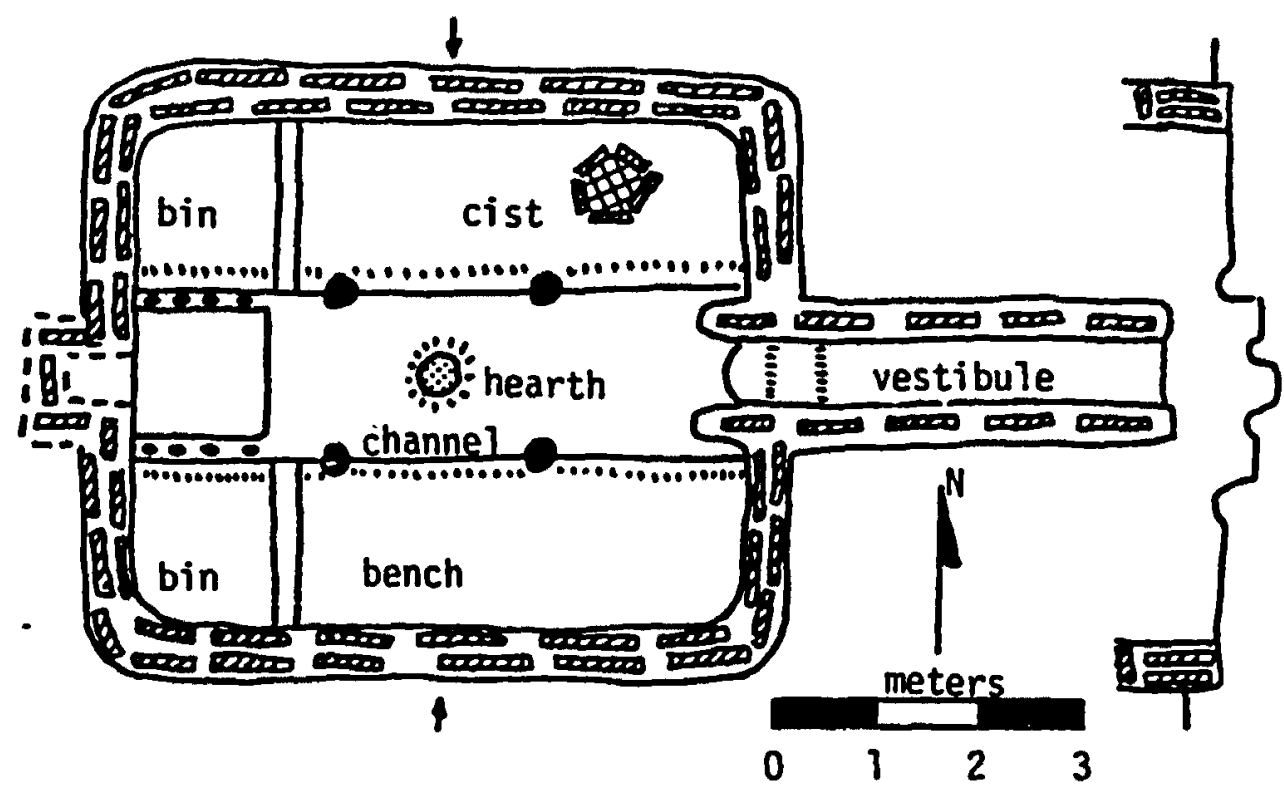

Figure 12. Generalized Example of Unit Type 1. 
type is one of the most common forms. Variations of this type occur at 19 (708) of the architectural sites in this study as both isolated freestanding units $(n=30)$ or as the dominant size unit within an aggregate form $(n=17)$. Minimal criteria for inclusion are a large through extremely large size (12.6 to $60.3 \mathrm{sq} \mathrm{m})$ and the presence of a depressed floor channel extending from the east to west wall through the central portion of the unit. Specific configurations can be quite complex. Other common attributes include a rectangular form, oriented roughly in the cardinal directions, low extended passageway towards the east, an entry step, entry collar, a centrally-located hearth within the channel, two to six roof support posts along the channel margins, bins, cists, or pits located on the raised floor surface flanking the channel, and a platform against the central portion of the west wall, which may either extend into the channel, or be recessed into the wall. The construction details of each trait are elaborated.

Shape: The shape of nearly all of the Unit type 1 features is quadrilateral with rounded corners; however, opposite walls are seldom the same length, While many units tend to be rectanguloid, a few are slightly constricted near one end or the other. This variation does not appear to be patterned, but rather may merely reflect a lack of precision or concern in room layout or execution. At Sanford Ruin a circular unit was encountered. Other than the unit shape, this single exception to the quadrilateral form contained most of the internal attributes and dimensions of the other units assigned to Unit type 1.

Orientation: The walls of Type 1 units are aligned to the cardinal directions. The orientation is predominantly eastward $(n=41)$ as indicated by the side of the structure with an opening or extended passages. In 
addition, most floor features (particularly the central channel) are usually bilaterally symmetrical along the central axis passing through the passage. So formal is this channel-passage axial alignment that the unit's orientation can often be determined by the axis of the channel when the east wall is no longer preserved.

Three of the excavated rooms and one unexcavated room are exceptions to the east-oriented rule. At Sanford Ruin, the channel-passage is oriented towards the northeast whereas at Alibates Ruin 28A the passage is extended from the west wall, towards Ruin 28 across the draw (Appendix A). Most likely, the aberrant orientation in the latter example suggests that the two sites were contemporaneously occupied. The other two examples involve possible multiple doorways. The single isolated structure excavated at Cottonwood Creek had gaps in the north, east and west walls (the southern wall was missing); however, segments of an interior channel were found to be oriented east-west. Finally, the unexcavated aggregate unit at Lookout Ruin appeared to have a gap to the outside in the west wall, and a second gap in the north wall between this ur.it type and a subordinate room. The observations at Lookout Ruin are tenuous since they have not been verified through excavation.

Size: The size refers to both the average metric dimensions along the east-west and north-south axes and the total floor area in square meters (excluding the extended passage). The mean unit size is $30.34 \pm 12.20 \mathrm{sq} m$ floor space, but the area ranges from a maximum of 60.32 to a minimum of $12.64 \mathrm{sq} \mathrm{m}$. Clearly a considerable range is represented. In some contiguous room structures, the size may be limited by available space--either mesa top configuration (e.g. Arrowhead Peak site) or by a series of earlier 
construction episodes (e.g. Antelope Creek 22). In contrast, the size of free-standing structural units is not so inhibited and undoubtedly reflects a host of other factors to be examined later.

Length-width Ratio: The length-width ratio is not a significant criterion in defining type 1 units. Overall, the ratio of the axial length (east-west) to the width (north-south) is not constant. Unit lengths tend to be slightly greater than widths (mean ratio $=0.95$ ); however, the extreme ratios range from 0.69 to 1.32 . These two extremes are found in isolated structures and in no way axe influenced by imposed spatial limitations. In fact, when the last building eposide at Antelope Creek 22 connected two existing room blocks, the length of the added units was shortened in proportion to the imposed width limitations to maintain appropriate room dimensions. Thus, while there appears to be some latitude in length-width ratios, there nevertheless seems to be certain acceptable limits to the room dimensions.

Unit Preparation: The nature of construction work in preparation for unit erection consists of evidence for surface leveling and/or pit excavation in the case of semisubterranean units. Evidence for surface leveling is clearly apparent in only a few instances, yet the nature of the preparatory work suggests that some labor investment was involved. At the cottonwood Creek Site, the Norpan excavations encountered a room built on sloping bedrock which dropped $0.3 \mathrm{~m}$ over a $5 \mathrm{~m}$ distance (Carter 1959:1). In an attempt to level the floor surface, at least $2.68 \mathrm{cu} m$ of sand fill was hauled in and deposited before the floor was plastered.

At least 12 Type 1 units are semisubterranean. All of them are quite shallow. The depth of the floor surfaces flanking the channel ranges from 
0.20 to $0.60 \mathrm{~m}$ (average $0.42 \pm 0.15 \mathrm{~m}$ ) below the original ground surface. At other units the floor surface may have used the original ground surface. Unfortunately, few archaeologists have reported this relationship so it is impossible to determine how widespread the subterranean pattern is.

Wall Types: The nature of wall construction is another area showing variation, in part because of the complexities of using adobe as a building medium. The crisical junction in the construction of an adobe walls is at its contact with the ground surface, since this portion carries most of the weight and is under the most stress. In order to reduce this stress point and prevent the wall from crumbling, the Antelope Creek people employed a range of wall footing styles involving stone slabs, adobe, and occasionally posts. Initial wall construction involved either excavating a wall trench to accommodate the rock and adobe wall footing, or lining the edge of the semisubterranean pit with rocks. In those instances involving posts for wall cores, individual postholes, rather than wall trenches, were excavated. The wall foundations most often consist of one or two tiers of double rows of vertical stone slabs with a rubble-filled cores (358), a single row of vertical slabs (338), or lack of evidence of internal adobe support (158). Other minor wall base forms include a double row of horizontal slabs (0.58), post reinforcement of a double row of stone slabs (28), post reinforcement of a single row of vertical slabs (18) or merely posts used in lieu of stone (28). No wall footing information is available for the remaining 118 of the sample. Despite this diverse range, several distinct patterns underlie the. variation. In general, contiguous aggregate units tend to employ double rows of vertical slabs, whereas free-standing structures often use single vertical slabs, posts, or no core reinforcement at all. 
There is considerable variation in wall thicknesses. At Antelope Creek Ruin 22, the outside walls of the main room block were between 1.22 and $1.37 \mathrm{~m}$ thick near the foundations whereas interior partitions between contiguous Type 1 units erected during a single construction episode were 0.61 to $0.91 \mathrm{~m}$ thick (Lowrey $1932: 12,14$ ). The double rows of vertical slabs offer more stability anci consequently are often employed where stress is greatest. Two examples will suffice: the unit built on a slope at the Cottonwood Creek Ruin which had intentional sand fill beneath the floor employed a double row of slabs only along the downslope side of the unit but used a single row of slabs along the other walls. As another example, the second building episode at Antelope Creek 22 involved the simultaneous construction of four contiguous Unit 1 features. In this instance the exterior walls of the entire room block used a double row of vertical slabs; however, the interior partitions between the four units were made with a single row of vertical slabs. Clearly the stress of retaining interior sand fill or supporting the exterior wall of a large structure requires more substantial wall bases than those used merely for structural siding, in the former case, or as interior walls in the latter. The stone slab features offered another advantage of reducing the detrimental effect of soil exosion along the lower wall base (cf. Hayden 1954:105-112). Post-reinforced walls may have been used for a variety of reasons. In addition to the double row slab foundations at Alibates Ruin 28, 12 posts were used along the north wall of Unit 7 , and five posts were used along the south wall of Unit 19. The infrequent use of this method at the site, coupled with the post placement against the wall rather than at the core between the slabs, suggests that in both instances the posts served to 
strengthen an existing wall which may have begun to sag. In contrast, the posts used at the Footprint Site, Unit 2, and the Jack Allen Site, Unit 1, formed an integral part of the wall structure. The absence of associated rocks at the Jack Allen Site may reflect the scarcity of this basic building material, since this is the only locale situated outside of the Permian and Triassic formations. At both sites, the wall posts were spaced approximately $40 \mathrm{~cm}$ apart in individually excavated postholes.

There is no significant difference in size of the units using single or double row vertical slabs. Although the double row slab foundations may give more support, the size of the average structure using single row slab foundations $(34.98 \pm 12.07 \mathrm{sq} \mathrm{m})$ was somewhat larger than those using double row slabs $(32.78 \pm 13.20 \mathrm{sq} \mathrm{m})$. The apparent discrepancy is due to the occasional use of six or more interior roof support posts within structures using single slab wall foundations; thus more of the roof load is carried in the center of the structure. In addition, most of the structures with single row slab foundations are isolated units and thus the size is not constrained by the locations of adjacent rooms.

The total height of the walls is often difficult to determine from open sites. At Alibates 28, Unit 19, intact walls were found still stand- . ing to a height of $1.91 \mathrm{~m}$ (Baker and Baker 1941b:33). Collapsed wall segments at the Footprint Site, Unit 1, were estimated to be $1.52 \mathrm{~m}$, whereas original wall heights for various units at Antelope Creek 22 were thought to be between 1.83 and $1.98 \mathrm{~m}$ (Green 1967:123; Lowrey 1932:14). If stature estimates of adult burials from Antelope Creek 22A, Alibates 28 and the Footprint Site are representative (males $\bar{x}=1.575-1.690 \mathrm{~m}$; females $\bar{x}=1.575$ $1.592 \mathrm{~m})$, then the outside walls were tall enough to accommodate individuals 
standing near the walls (D. K. Patterson 1974:218).

The construction of the upper wall core is more consistent than the basal foundations of the 20 units with indications of upper wail construction methods. Eighty percent employed layers of adobe spaced with horizontal stone slabs; 15 used posts or post leaners; and 5 report the use of no interior reinforcement. At Antelope Creek 22, Lowrey (1932:Figures 6, $9,18,20)$ records horizontal slab crossties placed between layers of coarse adobe mortar averagirg $13 \mathrm{~cm}$ thick. In most instances a fine textured adobe 3-10 cm thick is plastered over the interior of the walls in order to conceal the stone and coarse adobe core.

Another type of wall core supposedly consists of multiple tiers of vertical slabs set in double rows. Each higher tier is shown to be slightly inset from the one below. This wall form has often been regarded as typical for the culture (Lowrey 1932:12; Krieger 1946:43; Stuart and Gauthier 1981:312). It was originally identified as the south exterior wall exposed in a trench through Unit 8 at Antelope Creek Ruin 22 (Holden 1930); however the observation was not confirmed by the WPA field work (Baker and Baker 1941:29) nor has it been reported at any other site within the study area. While it may be a unique wall form, it is certainly not characteristic or typical of the Antelope Creek phase.

Doorways: Room access was made at ground level or rarely through openings in the upper portions of the wall. Entrance was most often gained by means of a tunnel-like vestibule in the middle of the east wall $(n=33)$; however, eight units merely have a gap or hole in the wall footings. Since localized erosion has undoubtedly foreshortened or obliterated evidence of some extended vestibules, it is difficult to determine if gap openings are 
a valid type. The maximum length of a vestibule is $4.57 \mathrm{~m}$ at unit 5 at Black Dog Village. Not all of the passages open to the outside. In seven instances the vestibules lead to other units in the contiguous room block. Some early investigators thought that these features served as ventilators and that unit access was gained through the roof (Studer 1934b:83; Lowrey 1932:15). However, four factors argue against such an interpretation as their sole function:

1. None of the interior features have been interpreted as ladder support posts indicative of a roof entry;

2. the size of the extended vestibule $(\bar{x}-2.57 \pm 0.90 \mathrm{~m}$ long, $0.69 \pm 0.12 \mathrm{~m}$ wide and $0.67 \pm 0.8 \mathrm{~m}$ high) particularly the width and height is sufficiently large for a crawling adult;

3. the complex morphology involving a series of steps and sills is ideally suited for an entryway:

4. the stone slabs lining the vestibule at Alibates 28 , Unit 7 , were worn slick by contact with crawling bodies (Baker and Baker 1941a:107; Studer 1942:40).

The extended vestibule represented a complex series of attributes (Table 11). As already indicated, all but two of the passageways extend out from the middle east wall. This orientational tradition was so strong that at Chimney Rock Ruin 51, Unit 3, the passage was dug into an uphill slope while at 41Mo-7, Unit 1, the passage opened blindly into the side of a hill (Baker and Baker 1941d:12; Green 1967:56). The passage floor usually has been excavated to a depth coinciding to either the floor of the channel or the floor surface flanking the channel. Six have a raised clay sill at the threshold of the unit which would have functioned like a cold 
Table 11.

Association of Doorway Attributes for Type 1 Units.

\begin{tabular}{|c|c|c|c|c|c|c|c|}
\hline & & \multirow[t]{2}{*}{ No Jata } & \multicolumn{2}{|c|}{ Go-iype Door } & \multicolumn{2}{|c|}{ Vestibule-Type Door } & \multirow[t]{2}{*}{ Total } \\
\hline & & & . & sill & No sith & sili & \\
\hline \multirow{4}{*}{$\begin{array}{c}\text { No } \\
\text { Threshold } \\
\text { Collar }\end{array}$} & ivo Ẽato & $\begin{array}{l}\text { Ant. } C k-22-15 \\
\text { Ant. Ck-22A- } 6 \\
\text { Chimney } 2 k-7\end{array}$ & & & Sanford- 4 & & 4 \\
\hline & :10 Step & $\begin{array}{l}\text { A) ib-28-18 } \\
\text { 2lit- } 30-3\end{array}$ & $\begin{array}{l}\text { Alib-28-23 } \\
\text { Chimey } 2 k-3 \\
\text { Chimey RkA- } \\
\text { Cortomood- }\end{array}$ & & $\begin{array}{l}\text { Alib-28-11 } \\
\text { Alib-28-15 } \\
\text { Alib-28-37 } \\
\text { Alib-28-42- } \\
\text { Alib-28A-1 } \\
\text { Ant.Ck-22-3 } \\
\text { Ant.Ck-22A-1 } \\
\text { Onimey Rk-5 } \\
\text { Marsh- i- } \\
\text { Arrownead- } 2 \\
\text { Arrownead- } 7 \\
\text { Allo-7. i }\end{array}$ & $\begin{array}{c}\text { Alio-28-38 } \\
\text { Black Dog- } 5 \\
\text {. }\end{array}$ & 20 \\
\hline & $\begin{array}{l}\text { Straignt } \\
\text { Steo }\end{array}$ & & $\begin{array}{l}\text { A) } 16-28-2 \\
\text { 2116-28-25 } \\
\text { A116-28-31 } \\
2110-30-2\end{array}$ & & $\begin{array}{l}\text { Alib-28-36 } \\
\text { Alin-?Q-A? }\end{array}$ & $\begin{array}{l}\text { Footprint+2 } \\
\text { ?=-E=-4titi-: }\end{array}$ & a \\
\hline & $\begin{array}{l}\text { Bulbar/ } \\
\text { Fan } \\
\text { Steo }\end{array}$ & & & & $\begin{array}{l}\text { Al } 1 b-28-32 \\
\text { Al 1b-28-38 } \\
\text { Ant. Ck-24-13 }\end{array}$ & Footprint-1 & 4 \\
\hline \multirow[t]{3}{*}{$\begin{array}{l}\text { Threshold } \\
\text { Collar }\end{array}$} & Yo Sted & & & & $\begin{array}{l}\text { Al1b-28-7 } \\
\text { Ant.ck-22-2 } \\
\text { Ant.Ck-22-6 } \\
\text { Ant.Ck-22-8 } \\
\text { Ant.Ck-22-i1 } \\
\text { Contas- 1 } \\
\text { Coetas- 2 }\end{array}$ & & 8 \\
\hline & $\begin{array}{l}\text { Straigne } \\
\text { Steo }\end{array}$ & & & & A14b-28-19 & & 1 \\
\hline & $\begin{array}{l}\text { Bulbarl } \\
\text { Fan } \\
\text { Sted }\end{array}$ & & & & & Jack Allen-1 & 1 \\
\hline \multicolumn{2}{|l|}{ Tozal } & $s$ & 8 & 0 & 27 & 6 & 54 \\
\hline
\end{tabular}


air trap ani also served to keep extraneous dirt from entering the unit. Another attribute is the presenre if i zizaigine $(n=y)$ or fan-shaped entry step $(n=5)$ at the interior of the vestibule which may have served to keep materials inside the channel from being accidentally dragged out of the passage. Another step is sometimes present at the far end.

Usually the vestibules are parallel-sided, but Unit 42 at Alibates 28 and Unit 1 at the Marsh Site have vestibules which are widest in the middle. The walls are usually made of large slabs set vertically and plastered on the outside. Four vestibules still had intact roofs, consisting of small poles placed across the passages, then covered with horizontal rock slabs and dirt (Baker and Baker 1941a:107). Another component of the vestibule observed in 10 units at four sites is the presence of a "threshold collar" or buttress consisting of an extension of the passage protruding an average of $50 \mathrm{~cm}$ into the unit. None of the threshold collars have been found with intact roofs; consequently it is impossible to tell if the roof also extended into the unit. The collar or buttress presumably served as a support for draping a cover over the passage to control the temperature and air circulation within the unit. In some instances loose rock slabs have been found near the threshold (Studer 1955:90). They may have served. as deflectors, or merely helped to hold a passage cover in place.

The above ground opening is more difficult to detect in severely eroded sites. One of three above ground openings on interior walls at Alibates 28 involve a Type 1 unit. In this instance a $50 \mathrm{~cm}$ square opening was found in the north wall of Unit 19, one-half meter above the bench surface. There is no indication that such above ground openings were used as primary entrances to Type 1 units, even though such use is postulated for other architectural types. 
Roof Configurations: Interior roof support posts have been found at approximately 568 of excavated Unit type 1 structures. Although no interior roof support posts were found in 20 units, the frequency of postholes going undetected is uncertain. When supports are present they commonly occur along the channel curbing. One exception is the Cottonwood creek Ruin where posts were found near each corner of the room. The most common positions are four posts quadrilaterally placed around a central hearth $(n=15)$, two posts flanking the hearth $(n=1)$, two posts offset from the hearth (as if half the quadrilateral pattern was missed, $n=6$ ), or six to eight posts $(n=3)$. Among the units with four center posts, the average span between posts on opposite sides of the channel $(1.77 \pm 0.64 \mathrm{~m})$ was considerably less than the average span between posts on the same side of the channel $12.54 \pm$ $0.69 \mathrm{~m})$.

The interior posts worked in conjunction with the walls to support the roof. There is no correlation in the use of posts associated with single or double row vertical slab foundations, but as might be expected there is a general correspondence between the unit size and number of posts in those units where posts were recognized (Table 12). The size of the unit utilizing two support posts flanking the hearth is $13.88 \mathrm{sq} \mathrm{m}$; the mean size of units using either a four post pattern or two posts offset from the hearth is $27.70 \pm 11.38 \mathrm{sq} \mathrm{m}$. The mean size of units with no discernible roof support posts is $32.66 \pm 13.07 \mathrm{sq}$ m. The largest unit measuring 8.91 by 6.77 m has no discernible interior roof support pattern. It is difficult to Delieve that such a large unit had beams spanning the walls without any interior support.

While the absence of intcricz sippori pusihuies in some instances may be attributed to soil preservation conditions, it is impossible to be 
Table 12.

Association of Size, Wall Footing Type, and Roof Support System

For Type I Units.

\begin{tabular}{|c|c|c|c|c|c|c|c|c|}
\hline & No Data & No posts & 2 Posts & $\begin{array}{l}2 \text { Posts in } \\
4 \text { Pattem }\end{array}$ & 4 Posts & 6 or 8 Posts & Total \\
\hline & $\begin{array}{c}\text { No } \\
\text { Data }\end{array}$ & & Ant. CK 22n-6 & & $\begin{array}{l}\text { Coetas -1 } \\
\text { Arrowhead-7 }\end{array}$ & Coetas -2 & & 4 \\
\hline & $\begin{array}{l}\text { Plain } \\
\text { Malls }\end{array}$ & $\begin{array}{l}\text { Alib-2R-18 } \\
4 I 1+0-7-1\end{array}$ & $\begin{array}{l}\text { Alib-28-23 } \\
\text { Alib-28-25 } \\
\text { Alib-2B-38 }\end{array}$ & Alib-28-2 & & $\begin{array}{l}\text { Alib-28-37 } \\
\text { Alib-30-2 }\end{array}$ & & 8 \\
\hline & $\begin{array}{l}\text { Single } \\
\text { Row } \\
\text { Vert. } \\
\text { siabs }\end{array}$ & A]1b-28-36 & $\begin{array}{l}\text { Alib-28-31 } \\
\text { Alib-28-32 } \\
\text { Al ib-30-3 }\end{array}$ & & Ant. CK-24-13 & $\begin{array}{l}\text { Allb-28-34 } \\
\text { Alib-28-42 } \\
\text { Alib-28n-1 } \\
\text { Fooprint-2 } \\
\text { Footprint-3 } \\
\text { Cottormd-1 }\end{array}$ & $\begin{array}{l}\text { Alib-28-47 } \\
\text { Footprint-1 } \\
\text { Black Dog-5 }\end{array}$ & 14 \\
\hline 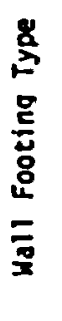 & $\begin{array}{l}\text { Double } \\
\text { Row } \\
\text { Vert. } \\
\text { slabs }\end{array}$ & & $\begin{array}{l}\text { Alib-28-11 } \\
\text { Ant.Ck-22- } 2 \\
\text { Ant.Ck-22- } 3 \\
\text { Ant.Ck-22- } \\
\text { Ant.Ck-22- } \\
\text { Ant.Ck-22- } \\
\text { Ant.Ck-22-11 } \\
\text { Ant.Ck-22-15 } \\
\text { Ant.Ck-22A-1 } \\
\text { Chimney Rk-7 }\end{array}$ & & $\begin{array}{l}\text { Alib-28-15 } \\
\text { Sanford-4 } \\
\text { Arrowhead-2 }\end{array}$ & $\begin{array}{l}\text { Allib-28-7 } \\
\text { Alib-28-19 } \\
\text { Chimey Rk-3 } \\
\text { chimey Rk-5 } \\
\text { Chimey RkA-1 } \\
\text { Marsh-1 }\end{array}$ & & 19 \\
\hline & $\begin{array}{l}\text { Posts } \\
\text { Only }\end{array}$ & & & & & Jack Allen-1 & & 1 \\
\hline $\begin{array}{l}\text { Tots } \\
\text { Mear }\end{array}$ & Size & 32.66 & 10.07 & $\begin{array}{c}1 \\
13.88\end{array}$ & $\frac{6}{20.80 \pm 8.44}{ }_{27.70^{21} \pm}$ & $\frac{15}{29.82 \pm 11.51}$ & $\begin{array}{c}3 \\
4 ? .97 \pm 3.70\end{array}$ & \\
\hline
\end{tabular}


certain that roof support posts were reguired on the smaller units.

The configuration of the roof is unclear. Some early investigators argue that the units had flat roofs (Lowrey 1932:19; Studer 1934b:83). The notion is based on a belief that the architecture is derived from puebloan influences. In contrast, the four, six or eight posts along the channel curbing may have supported a frame of beams scmewhat higher than the walls. Next, long rafters three to ten $\mathrm{cm}$ in diameter might have bees set with one end on the walls (but most of the weight carried by the central frame), and the rafter tips pointing towards, but not covering, the middle. This contral opening served as a smoke hole. These rafters were then covered with laths and thick bundles of grass (Baker and Baker 1941a:36, 97). The four central post support pattern is often regarded as an eastern traic (Hobbs 1941:128; Wallace 1962; Muto, Mayo and Rohrbaugh 1980; Swanton 1946:386-420). The four post pattern is also widespread among southwestern pithouses; however, the pusts are placed against or a short distance inside the walls (Bullard 1962:128-130). The placement of posts close to the center of the rooms, as in the Antelope Creek phase examples, is rare in the Southwest (Ibid:130). Since most Caddoan quadrilateral structures had dome or hipped roofs, the same form has been variously proposed for the Antelope Creek structures (holden 1930:25; Krieger 1946:43; Studer 1942:41; Keller 1975).

Additional consideration must be given the hipped roof form in contiguous aggregate room situations. If the roofs sloped away from the middle of each unit, then the troughs between adjacent units must be equipped to drain the run-off. Perhaps the small quantisies of burned daub with stick and grass impressions reflect plastering along the trough or around 
the smoke hole. Considerably more information regarding daub quantities and distributions within the units is necessary before this issue is resolved.

Interior Channel and Flooring System: The floor surface in Type 1 units consists of a central channel which extends from the east to west wall and two "bench" areas flanking the channel feature. The channel portion is depressed an average of $22 \pm 9 \mathrm{~cm}$ (range 10-51 cm) below the adjacent benches. The floor surfaces in most Type 1 units are plastered with a layer of fine textured adobe.

This channel feature appears to be a unique Antelope Creek phase trait and has not been found in adjacent plains or Southwestern architecture. Its width is quite variable $(\bar{x}=1.83 \pm 0.72 \mathrm{~m})$, but it is often slightly wider than the threshold collar/buttresses on the east ard the raised plazform on the west. The length usually extends from the east to west walls, except in six instances where the platform is wider than the channel. The channel edges are abruptly formed like street curbing and are often roughly parallel, or more rarely divergent or convergent. At Alibates 28 Unit 18 , the channel is considerably wider in the middle than ac either end. Usually the curbed edges are plastered with adobe; but at . Antelope Creek 24 and Chimney Rock Ruin 51, small stune slabs lined the channel edges in four units to help maintain the feature definition. Often a plaster ridge has been built along the upper curb rim, presumably to prevent items from the higher floor surface from falling into the channel area.

- Although considerable attention has been directed towards the unique channel features, the width of the adjacent low bench surfaces is far more standardized. The average width is $1.71 \pm 0.18 \mathrm{~m}$. This suggests that the 
benches were constructed to meet limited specifications, regardless of the total width of the unit. There is a strong relationship between unit width and channel width, since the channel merely encompasses all of the remaining floor area after the benches have been constructed.

The differential distribution of interior features suggests that the activities in the channel area are separate and distinct from those conducted on the bench surfaces. Features within the channel commonly include a raised or recessed flatform against the west wall, a centrai heartii, associated ash and heating pits, and perhaps a deflector. Cooking, an assortment of interior processing activities and access to areas within the structure are postulated for the channel area on the basis of these architectural traits. In contrast, the bench features include a series of interior storage facilities consisting of walled bins, subfloor pits and cists, usually placed near the corners of the unit. In addition, the width of the bench floors is nearly identical to the estimated mean stature of adult males (bench means $=1.71 \pm 0.18 \mathrm{~m}$ versus male stature 1.68 to $1.69 \mathrm{~m} ; \mathrm{D}$. K. Patterson 1974:218). This tenuously suggests that the benches served as sleeping areas in addition to personal and familial storage areas. Differential artifact distributions associated with the floor surface could be used to test tliese hypotheses, but unfortunately precise interior material provenience has not been reported from any of the excavated units.

Fire pits and Associated Features: The system of heat-related features involved a central hearth, auxiliary hearths, ash pits and deflectors. Formally prepared central hearths are present in 32 and absent in only six Type 1 units; no mention of a hearth feature is made for the other nine units. The clay hearths are usually placed along the central axis within 
the quadrant defined by the four roof support posts. They occur in the center of the room but not at the chansel mid-length position in those units containing interior platforms. This placement serves to provide equal heating to all four wall surfaces. The hearths average $57 \pm 23 \mathrm{~cm}$ in diameter but take a variety of forms. The two most common forms are simple adobe lined basin-shaped pits, the rim of which coincides with the channel floor level $(n=15)$, or basin pits with a definite adobe collar raised slightly above the channel floor surface $(n=8)$. One advantage of the latter form may be to prevent items from accidentally falling into the hearth. Other varieties include slab-lined hearths $(n=2)$ at Antelope Creek 26 and Chimney Rock Ruin 51; paired or double hearths $(n=4)$ at Arrowhead Peak, Black Dog Village, Footprint and Antelope Creek 22 Sites; or mamniform or concentric hearths $(n=3)$ found at Arrowhead Peak and 41Mo-7. The slab-lined hearths are not thought to relate to differential thermal properties but rather are necessary to stabilize the sides of features, since similar slabs at these two sites are used to define the edges of the platform and channel features. The presence of double or adjacent hearths may merely reflect subsequent structural modifications, particularly in units with multiple floor surfaces (cf. Black Dog Village Unit 5). At the Footprint Site, a single hearth area associated with the floor contained two fire pits. One of the pits contained ash whereas the other was cleaned out. Possibly two separate and simultaneous functions requiring different quantities of heat or light are represented. One pit may have been used to maintain a fire whereas the other was used to maintain coals.

The manmiform hearth is characterized by a basin fire pit with a smallex cup-sized depression in the base. This form could have been used 
either to keep hot coals above tine insulating ashes, or as a means of supporting the large cooking vessels around the lip of the outer hearth while maintaining heat within the inner depression. Additional studies comparing hearth and vessel morphology may indicate whether tha latter suggestion is plausible. Overall, the variation in hearth morphology relates to a number of practical differences in employing heat. Most are attributed to preferences in hearth arrangements or construction requirements, rather than radical differences in the functions of the unit.

Auxiliary hearths and ash pits refer to the location of other heatrelated features outside of the four roor support post area. These features occur infrequently and seldom show formal preparation or construction. In a burned stricture it is nearly impossible to determine if a particular ash deposit reflects a feature. Nevertheless, hearth areas have been noted on the recessed platform at the Jack Allen Site and on the raised floor areas in the north central and northeastern portions of Alibates 28, Unit 18, and Antelope Creek 22, Init 15, respectively. The hearth in Unit 18 contained eight rocks in the bottom, and may have served to heat stones for boiling activities.

Only two stone deflectors have been reported for Type 1 units in the study area. At Arrowhead Peak, Unit 2, the deflector consists of two large upright stones jutting out from the south edge of the channel. But at the Marsh Site the deflector is a single large displaced slab near the passage. While the deflector function cannot be ruled out, this stone could just as easily have served as the lintel cover at the passage threshold. Thus the study sample indicated that deflector stones were rarely used in Type 1 units, and only one clear example has been reported. 
Flatforms: Platfcims are considered to be the raised clay areas either protruding from or recessed into the west central portion of the unit. They are often ascribed an "altar function" (Krieger 1946). Although they are often mentioned as an integral attribute of Antelope Creek architecture, only nine protruding and two recessed platforms have been reported from the study area. At least $778(n=36)$ of the units do not seem to have this attribute. The scarcity of reported platforms may be misleading, since the recessed form has only been recngnized within the last 17 years (Green 1967). Early excavators simply may have overlooked the recessed form in some excavated units.

The protruding platform is usually slightly narrower than the width of the central channel. It averages $2.24 \pm 0.44 \mathrm{~m}$ wide and projects into the room an average of $1.96 \pm 0.40 \mathrm{~m}$. The height is comparable to or even slightly higher than the adjacent bench surface.

Often the platform is composed entirely of packed clay. At Antelope Creek Ruin 22, Units 7 and 11, stone slabs were used around the platform's basal edge. A series of small postholes may occur nearby. At the Footprint Site and Antelope Creek 22, posts were found near the northeast and southeast corners of the platform, but at Black Dog Village, five small posts were found along the north and south edges. These posts may support a rack over the platform or relate to storage bins on the low bench surfaces adjacent to the channel. Although no artifacts have been found on the platform to indicate its function, aspects of the platform feature may.also extend up the west wall of the unit. At Unit 1 of the Footprint Site, Green (1967:122) observed:

In the rear wall at the center of the platform, there is an unusual wall segment of light reddish-brown adobe in the shape of a 
truncated pyramid. On the interior wall, this adobe feature is 3 feet 3 inches wide at its base and tapers to a width of 2 feet at its top, and there are three equally spaced circular pits approximately 4 inches in diameter and 3 inches deep on the side facing the platform.

Diagrams indicate that the pyramid was truncated by erosion. The upper wall moxphology and the function of the pits in the wall are unknown.

The recessed platform style occurs as an elevated extension of the central channel into the middle of the west wall. This form has been recognized only at the Footprint and Jack Allen Sites within the study area, and is also known from the Two Sisters Site in the Oklahoma panhandle (Green 1967; Harrison n.d.; Lintz 1979a). Both recessed platforms in the study area are associated with small structures having central channels less than $1 \mathrm{~m}$ wide. The dimensions of the recessed platform range from 0.40 to $0.85 \mathrm{~m}$ wide, and extend from 0.40 to $1.40 \mathrm{~m}$ into the west wall. At Unit 3 of the Footprint Site, a dolomite slab incorporated into the center of the platform's back wall had two distinctly pecked and ground human footprints with the toes pointing downwards. Green (1967:141) attributed some ritualistic, religious or mystic significance to this stone's occurrence in the niche. The recessed platform at the Jack Allen site had a burned area which was interpreted as a possible hearth (Bill Harrison, personal communication 1983).

\section{Interior Storage Facilities: Interior storage facilities refer to} bins, slab-lined cists and pits. Nearly all storage facility features are located near the corners, on the higher floor surfaces.

Interior bins consist of floor areas separated by minor wall partitions. A total of six bins has been recognized in four units. They range from 1.38 to $6.04 \mathrm{sq} \mathrm{m}$ of floor space, but average $2.78 \pm 1.66 \mathrm{sq} \mathrm{m}$ in area. 
Five bins are located against the west wall adjacent to the platform features while at Coetas Ruin, Unit 2, the bin is in the northeast corner. The partition wall is usually made of adobe clay and rock slabs, but at Antelope Creek, Unit 8 , the partition is merely indicated by a series of postholes. The paucity of associated daub suggests that a woven screen may have been used. The most unusual pair of bins occurred on each side of the platform at Antelope Creek, Unit 7. Here, the bench area within the bins had been excavated to coincide with the floor level in the channel, and on the east, small walls $0.15 \mathrm{~m}$ higher than the bench surfaces were erected to prevent accidental spillage (Baker and Baker 1941a:27). The only feature enclosed by the bin walls is a pit as observed at the Coetas Creek Ruin (map, Studer's files \#655, National Park Service). A similar situation has been recorded at the Two Sisters Site in the Oklahoma panhandle (Lintz 1979a).

Several rooms have been constructed over earlier exterior pits, but only three interior basin-shaped pits and three slab-lined pits have been reported from four units. None of these storage features occur in the corners of the unit, but rather tend to be located on the bench floors in the eastern half of the unit.

A basin-shaped pit at Antelope Creek 22A, Unit 1 , measured $1.30 \mathrm{~m}$ in. diameter and held portions of three metates. The other two basin-shaped pits are smaller $(0.43$ and $0.53 \mathrm{~m}$ in diameter $)$ and occur at Coetas Creek Ruin, Unit 2, and Antelope Creek Ruin 22, Unit 8. The basin shaped pit at Coetas Creek Ruin was inside a walled bin in the northeast corner of the room. WPA photographs show another possible pit inside Unit 42 at Alibates Ruin 28, however the pit size and stratigraphic position are uncertain. Two of the three slab-lined pits also occurred inside Coetas Creek Ruin, Unit 2, and Antelope Creek Ruin 22, Unit 8. These slab-lined features 
measured $0.76 \mathrm{~m}$ and $0.41 \mathrm{~m}$ in diameter. The last slab-lined cist, at Alibates 28 , Unit 47 , measures $0.46 \mathrm{~m}$ in diameter. It is unusual in having an additional large vertical slab in the center of the feature. A similar exterior feature was found at site 41Mo-7. Additional observations on other features will be necessary to determine if the central slab is intentionally set, or merely represents the collapse of a stone capping a conventional cist.

The association of bins, platforms and hearth types within Unit type 1 structure shows some consistent patterning, even though information for many units is missing. In general, units with protruding platforms are likely to have single or double basin-shaped hearths or are associated with formally defined bench areas adjacent to the platforms (Table 13). In contrast, collared, rimmed and concentric or mammiform hearths tend to occur in units with recessed platforms or no internal platforms. This distinction does not seem to relate to spatial differences since sites from each end of the study belong to the same taxon. The temporal aspect will be examined later.

Modifications: Despite the quantity of labor invested in the construction of these units, only eight units show indications of repair mouifications involving remodelled floor features or stabilized walls. In one instance, (Unit 2 at the Arrowhead Peak Site) a second hearth was added. At 41Mo-7 and Arrowhead Peak, floor channels were filled in and sealed with a plastered adobe surface (Green 1967). This type of modification suggests that the distinction between Type 1 and 2 architectural units is unclear; since there is no indication of a functional change, both types are thought to be functionally equivalent. At two of the 15 burned units, clean sand 
Table 13.

Association of Interior Feature Attributes for Type 1 Units.

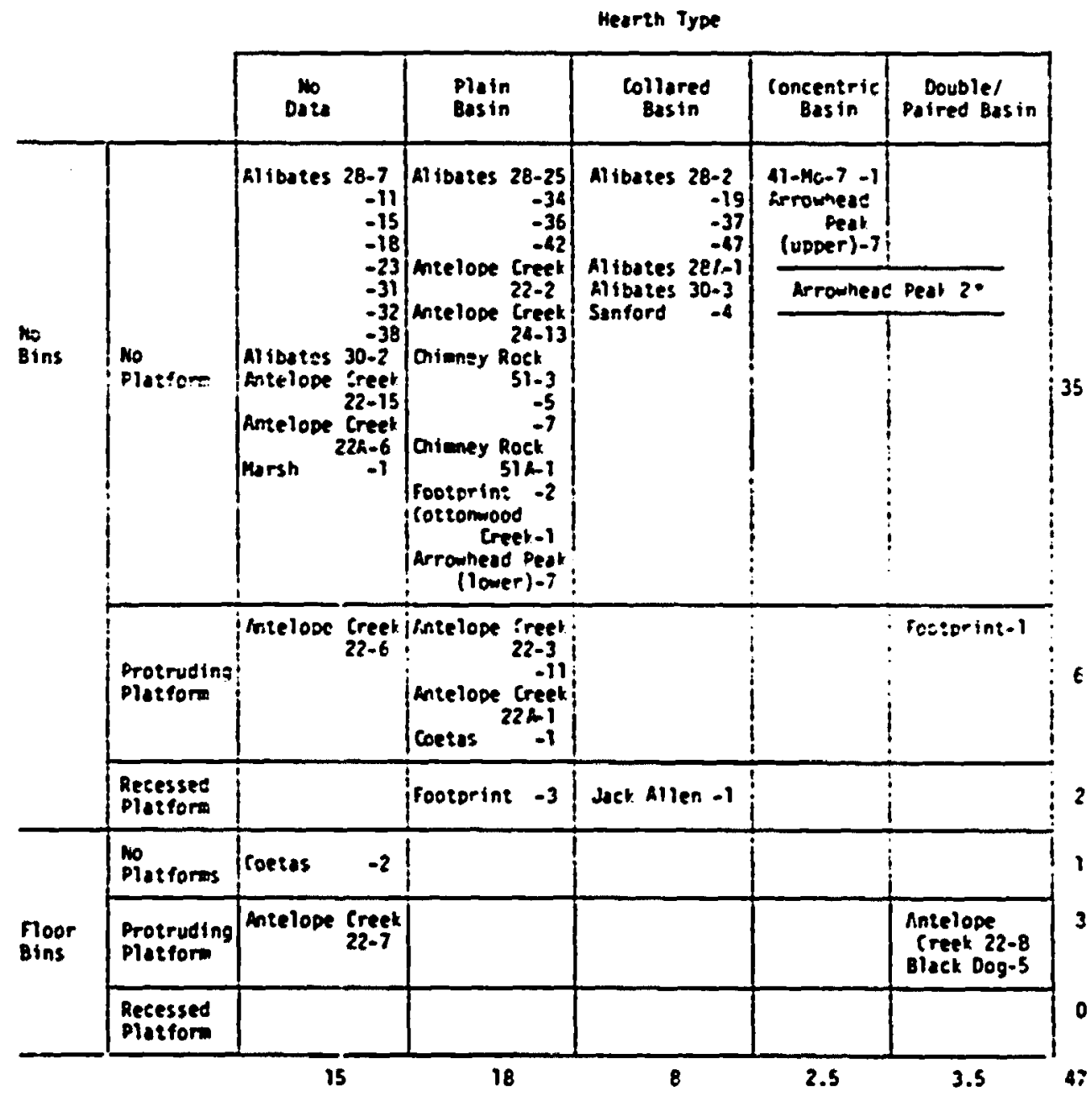

- jeflector present. 
fill was deposited over the charcoal and daub remains and a second floor mirroring the first was constructed utilizing the same walls (Baker and Baker 1941b:154). However, multiple floor surfaces at Black Dog village, Unit 5, attest to remodeling activities, but there is no evidence that this structure had burned (Keller 1975). As already indicated, a series of 12 and five posts were used to stabilize and reinforce the north wall of Unit 7 and the south wall of Unit 19 at Alibates 28 . Quite clearly these kinds of modifications reflect efforts to salvage units in disrepair and recycle rundown units.

Comments: The frequency of occurrence and dominant size suggests that type 1 units represent the nucleus of household clusters. The wide range of features and associated artifacts suggests that the unit was the central focus of indoor activities while the people were sedentary. These structures provided substantial shelter during inclement weather, but much of the daily activities probably occurred outdoors.

The range of internal feature variations undoubtedly reflects the complex range of diverse activities occurring within the unit. Some embellishments, such as the bulbar vestibules and channels, may reflect idiosyncratic behavior. The presence of entry steps, vestibule sills, collared hearths, ridges along the margins of channels and walls along the bins all serve to keep objects from one area out of other activity areas. Some of the subtle differences, particularly the absence of certain traits, may reflect recent vandalism or a failure of the archaeologists to note the critical attribute, rather than the lack of the feature. Nevertheless, some of the patterned variation may be sensitive to spatial, temporal or social differences. These variations will be examined after the range of other unit types are described. 
Unit Type 2 (n=10 units Figure 13).

Type 2 units occur at $7(268)$ of the architectural sites as both isolated $(n=5)$ and parts of aggregate $(n=5)$ features (see Appendix B). This type is a large through extremely large semisubterranean unit with either an extended vestibule or gap wall openings and a centrally located hearth. In many ways Type 2 units resemble Type 1 units in general external morphology. The main distinguishing characteristics separating Type 2 from Type 1 are the absence of formally defined interior areas--specifically, the lack of a central channel, flanking bench surfaces, centrally located platforms, and discrete floor bin features.

Shape: All units are irregularly quadrilateral with rounded corners.

Orientation: The walls roughly align in cardinal directions and extended vestibular or gap openings are commonly in the middle of the east walls.

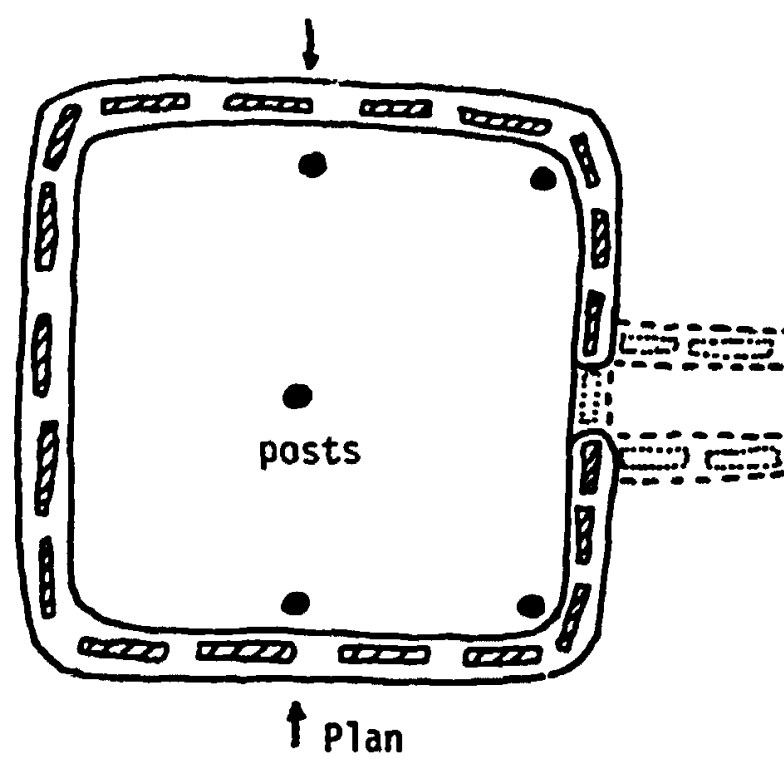

Figure 13. Generalized Example of Unit Type 2.

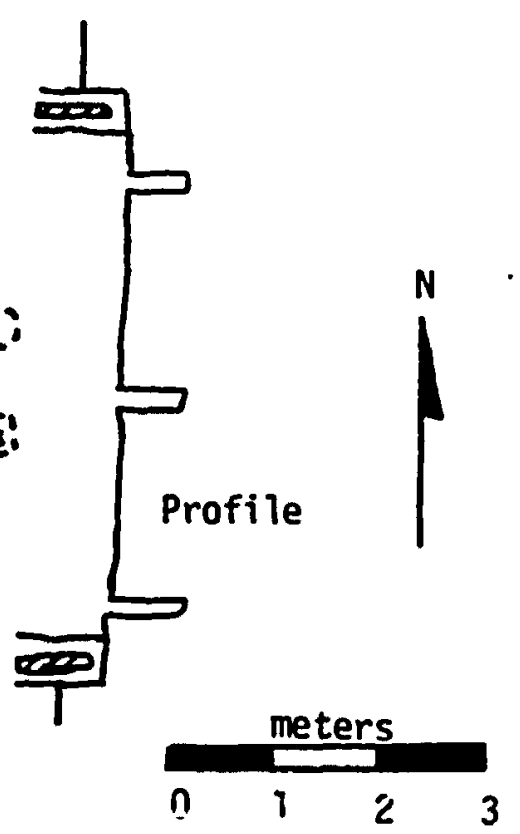


Size: Unit 1 at the Spring Canyon Site is the largest single feature from the study area with an interior floor space of $87.60 \mathrm{sq}$ m (Duffield 1964). The other nine units range from 11.32 to $39.60 \mathrm{sq} \mathrm{m}$ with an average of $23.04 \pm 10.43 \mathrm{sq} \mathrm{m}$. Some spatial limitations may have been imposed by the bluff top configurations at the Arrowhead Peak Site; however, no restrictive features inhibited unit size or development at the other six sites.

Length-width Ratio: The sides of the units are often equidistant although the east-west dimensions tend to be slightly longer. The eastwest to north-south wall dimension ratio ranges from 0.75 to 1.36 . Both extremes occur in isolated unit structures in unconfined situations.

Unit Preparation: The only site showing surface preparatory work in conjunction with unit construction is at the Arrowhead Peak Site, an isolated mesa top locale (Green 1967). Here, the sloping dolomite cap was chipped away in order to provide a level floor surface for Unit 1 (Green 1967:20). An analogous example in terms of labor expenditure from the Oklahoma panhandle involves chipping $37.5 \mathrm{~cm}$ deep holes into solid bedrock for the interior support posts at the Roy Smith Site (Schneider 1969:129). The presence of a solid dolomite base in both instances and at Arrowhead Peak, Unit 3, may have discouraged the construction of interior channel and bench features typical of Unit Type 1. Nevertheless, the other two large mesa top units at Arrowhead Peak appeared to have channel features and certainly the lack of a central channel in Unit 9 on the lower slope cannot be attributed to bedrock conditions. In fact, the sloping hillside had been excavated at Unit 9 to provide a level base (Green 1967:30). Only 
four Type 2 units were reported to be semisubterranean. At Medford Ranch site, the floor of Unit 1 was $30 \mathrm{~cm}$ below the original ground surface while that at Alibates Ruin 28, Unit 35 was $18 \mathrm{~cm}$ deep. The depths of semisubterranean floors at Arrowhead Peak, Unit 9, and Alibates 30, Unit 1, were not reported.

Wall Type: The wall foundations are quite variable in Type 2 structures. Four units have a single row of vertical slabs and two have double rows of slabs with rubblemilled cores. At Arrowhead Peak, Unit 3, the wall base consists of a single row of vertical slabs on three sides but a double row of horizontal slabs along the south side. Unit 9 at Alibates Ruin 30 also had a single row of vertical slabs on three sides but a plastered wall lacking a stone footing on the fourth side. The aberrant wall may have utilized an earlier wall segment from a structure stratigraphically beneath Unit 9. The wall cores consist predominantly of alternating layers of adobe and horizontal slabs. At Spring Canyon, Unit 1, this traditional method also employed a second tier facing of vertically-set stones on the interior of the unit (Duffield 1964:54). Presumably a fine textured adobe was plastered over the wall core. The height of this wall may have been comparable to those of Type 1 units, but no independent information is available from Type 2 units.

Doorways: Doorways were discerned in only six units. They occurred as extended vestibules $(n=3)$ or mere gaps in the stone wall foundations $(n=3)$. The extended vestibules all were located in the middle of the east wall. They range from 1.07 to $1.69 \mathrm{~m}$ long by 0.61 to $1.07 \mathrm{~m}$ wide (mean size $1.35 \pm 0.32 \mathrm{~m}$ by $0.79 \pm 0.24 \mathrm{~m}$ ). None had intact roofs, and only one had an associated entry step. 
Gaps in the wall foundations were recorded in the middle of the east wall in two units, but the doorway of Unit 1 at the Spring Canyon Site was thought to be located in the southeast corner of this extremely large unit. Two piles of horizontal stones encased in adobe-on either side of the corner gap were thought to be basal remnants of plaster columns flanking the opening (Duffield 1964:52). The mean width of all three gap openings is $0.60 \pm$ $0.07 \mathrm{~m}$.

The absence of discernible doorways in the other four units is not thought to reflect above ground wall openings, but rather is attributed to incomplete excavation or superimposed units subsequently built over the eastern portions of the units.

Roof Configurations: Interior posts were observed in the two smallest units (Table 14). The single support post at Arrowhead Peak, Unit 1, was positioned such that it appeared to be the southwest part of a four centralpost frame possibly supporting a hipped roof. The clearest roof support pattern occurred at Medford Ranch, Unit 1. Here posts were placed in the northeast and southeast corners, two others were near the middle of the north and south walls, and a single post was placed in the center of the unit. The pattern suggests that a major support beam was oriented northsouth across the middle and along the east wall of the unit, but no information is available to discern the pitch or slope. Nevertheless, this configuration probably produced a gabled effect rather than the hipped roof found at most Type 1 units. The use of corner posts at the Medford Ranch Site is somewhat reminiscent of the interior posthole pattern at the Cottonwood Creek Site; however, at the latter site, there was no evidence for supports along the north-south axis. It is impossible to ascertain 
Table 14.

- Association of Support Posts, Wall Footings and Doorways for Type 2 Units.

\begin{tabular}{|c|c|c|c|c|c|c|c|}
\hline & \multicolumn{3}{|c|}{ No Support Posts } & \multicolumn{3}{|c|}{ Support Post Present } & \multirow[t]{2}{*}{ Total } \\
\hline & $\begin{array}{c}\text { Single } \\
\text { Vertical } \\
\text { Slab Footing }\end{array}$ & $\begin{array}{c}\text { Double } \\
\text { Vertical } \\
\text { slab Footing }\end{array}$ & $\begin{array}{l}\text { Horizontal } \\
\text { slab Footing }\end{array}$ & $\begin{array}{c}\text { Single } \\
\text { Vertical } \\
\text { slab Footing }\end{array}$ & $\begin{array}{c}\text { Double } \\
\text { Vertical } \\
\text { slab Footing }\end{array}$ & $\begin{array}{l}\text { Horizontal } \\
\text { slab Footing }\end{array}$ & \\
\hline $\begin{array}{l}\text { No } \\
\text { Doorway }\end{array}$ & $\begin{array}{l}\text { Alibates } \\
30-9 \\
\text { Arrowhead } \\
\text { Peak-3 } \\
\text { Tarbox-1 }\end{array}$ & & & $\begin{array}{l}\text { Arrowhead } \\
\text { Peak-1 }\end{array}$ & & & 4 \\
\hline $\begin{array}{l}\text { Gap } \\
\text { Doorway }\end{array}$ & $\begin{array}{l}\text { Al ibates } \\
30-1\end{array}$ & $\begin{array}{l}\text { Antelope } \\
\text { Creek 23-1 } \\
\text { Spring } \\
\text { Canyon-1 }\end{array}$ & & & & & $3 \tilde{\omega}$ \\
\hline $\begin{array}{l}\text { Extended } \\
\text { Vestibule } \\
\text { Doorway }\end{array}$ & $\begin{array}{l}\text { Al ibates } \\
28-35 \star \star \\
\text { Arrowhead } \\
\text { Peak-9 }\end{array}$ & & & & & $\begin{array}{l}\text { Medford } \\
\text { Ranch-1 }\end{array}$ & 3 \\
\hline Total & 6 & 2 & 0 & 1 & 0 & 1 & 10 \\
\hline
\end{tabular}

* Corner doorway

**-Entry step present 
how representative the Medford Ranch roof style is of other structures within the Typ= 2 taxon, since so few had evidence of posts.

Fire Pits and Associated Features: Six of the ten Type 2 structures had evidence of interior heating features including central or auxiliary hearths, ash pits, or possibly a deflector system (Table 15). Formally prepared central hearths were present at three units. In two instances the central hearth was a plain basin-shaped fcatures but at Arrowhead Peak, Unit 9, the central hearth was double or paired. It is uncertain if both hearths functioned simultaneously or if they represent sequential unit modifications. The single auxiliary hearth consisted of a square slab-lined basin measuring $0.91 \mathrm{~m}$ located in the east central portion of Unit 1 at Tarbox Ruin (Holden 1929:27). The bottom of the feature was filled with charcoal and ashes.

Irregular ash pits were found in different places within three units. At Arrowhead Peak, Unit 1, two ash pits were found in the northeast quadrant of the unit near the west wall. The ash pit in Unit 9 was found against the east wall immediately north of the gap doorway. At Medford Ranch, Unit 1, an ash concentration in association with quartzite boiling stones was found in the southwestern quadrant of the unit. There is little consistent patterning in ash pit placement other than that the center of the unit seems to have been avoided. Perhaps this reflects a variety of different processing activity areas.

The only "deflector" found within a Type 2 unit was a large vertical slab located west of the double central hearth in Unit 9 at the Arrowhead Peak Site (Green 1967:30). Its identification as an air deflector is questionable since it occurs between the hearths and the west wall, 
Table 15.

Association of Interior Hearths and Cists for Type 2 Units.

\begin{tabular}{|c|c|c|c|c|c|}
\hline & & \multicolumn{4}{|c|}{ Hearth Type } \\
\hline & & Hearth Absent & Central Basin & Central Paired & $\begin{array}{l}\text { Auxiliary Hearth } \\
\text { or Ash Pit }\end{array}$ \\
\hline \multirow{3}{*}{$\begin{array}{l}\text { Clst } \\
\text { Type }\end{array}$} & $\begin{array}{l}\text { Basin } \\
\text { Pit }\end{array}$ & & & & \\
\hline & $\begin{array}{l}\text { S1ab } \\
\text { Cist }\end{array}$ & & & Arrowhead Peak-9* & Tarbox Ruin 1 \\
\hline & $\begin{array}{l}\text { Cists } \\
\text { Absent }\end{array}$ & $\begin{array}{l}\text { Alibates Ruin } 28-35 \\
\text { Alfbates Ruin } 30-1 \\
\text { Alfbates Ruin } 30-9 \star \star \\
\text { Spring Canyon } 1\end{array}$ & $\begin{array}{l}\text { Antelope Creek 23-1 } \\
\text { Arrowhead Peak-3 }\end{array}$ & & $\begin{array}{l}\text { Arrowhead Peak } 1 \\
\text { Medford Ranch } 1\end{array}$ \\
\hline & Total & 4 & 2 & 1 & 3 \\
\hline
\end{tabular}

Numbers following site name represent Architectural Unit No.

* Deflector located west of the hearth

* Interior Platform in the southeast corner. 
rather than between the hearths and the doorway in the east wall. The rock may have had some function related to the fire pit, but the precise use is unclear.

Platforms: An interior platform was present at Alibates 30, Unit 9, but it differs from those associated with Type 1 units in size and placement. The platform consisted of a packed clay area measuring 1.68 by 1.37 by $0.20 \mathrm{~m}$ located in the southeast corner of the unit (Baker and Baker 1941b: 157, 159). This corner platform is unique among Antelope Creek structures but it bears some resemblance to a northwest corner platform at House 1 from the Goodman I Site, a Custer phase site in Custer County, Oklahoma (Gallagher 1951). The function of these features is unknown.

Interior Storage Facilities: Specialized storage facilities were rare. A single circular slab-lined cist measuring $1.17 \mathrm{~m}$ in diameter was found in the north central portion of Unit 9 at the Arrowhead Peak Site. The cist was not subterranean but rather the walls stood above the floor and were supported by adobe. The rocks were arranged so that the orifice diameter was larger than the basal diameter.

Modifications: The addition of a second hearth inside Arrowhead Peak, Unit 9, is the only modification discernible from the architectural layout.

Comments: Type 2 units resembles Unit 1 Type in basic shape, size and certain interior feature attributes. It has a simple interior design and the absence of the central channels, benches and bins suggests that the interior activities were not as rigidly structured. As indicated, the absence of these traits at some sites may be due to the practicality of 
building on bedrock foundations. Nevertheless, the channel feature is regarded as a fundamental Antelope Creek phase design which may have spatial or temporal significance. The morphological differences between Unit types 1 and 2 may indicate that the structure of activities differ somewhat. But both types are regarded as functionally equivalent, as forming the nucleus of the household dwellings.

Unit Type 3 ( $n=11$ units, Figure 14).

This type includes medium to large circular or quadrilaterally shaped units often with a central hearth and occasionally with a single central roof support post or interior storage pit facilities. The type is recognized at four (158) of the architectural sites as either an isolated structure $(n=4)$ or as part of a larger aggregate room block $(n=7)$. All seven units associated with contiguous room blocks occur at subordinate positions

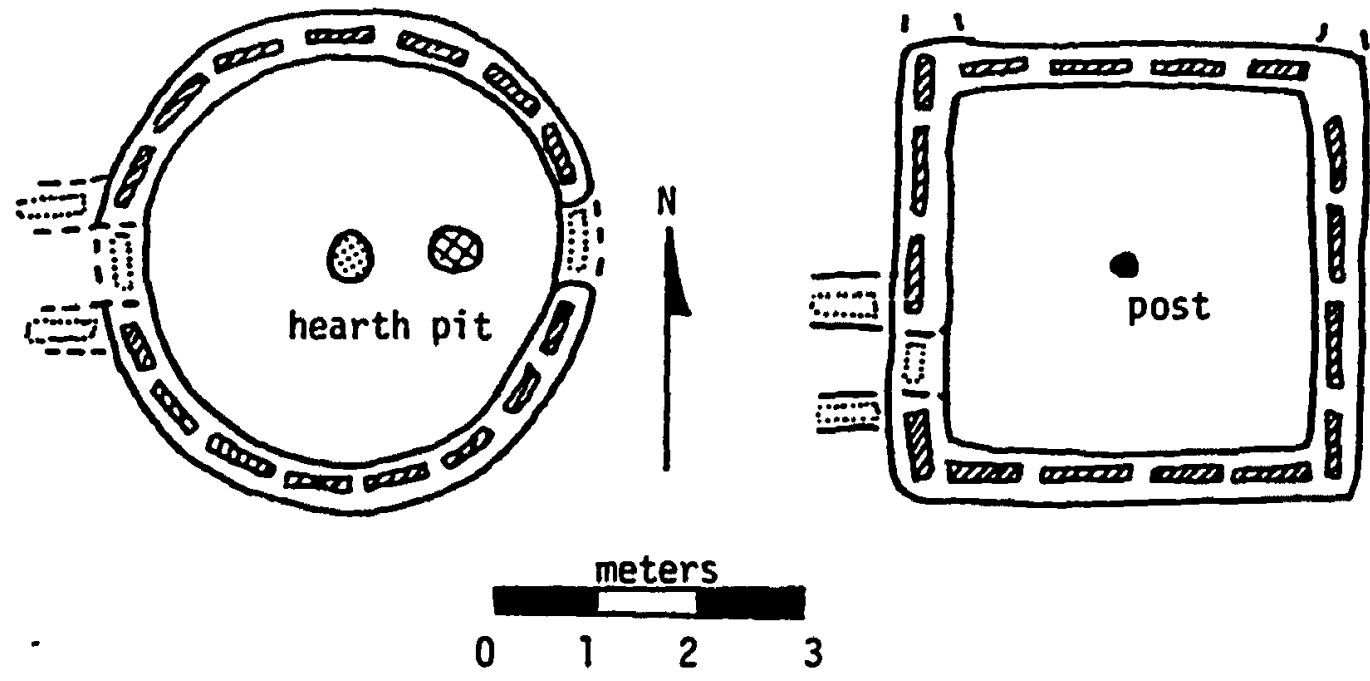

Figure 14. Generalized Examples of Unit Type 3. 
located west of the extended vestibule of Type 1 units, in "anteroom" positions.

Shape: These units are circular $(n=5)$, quadrilateral $(n=5)$ or pentagonal $(n=1)$. The circular shape occurs at the northern or southernmost ends of the room blocks, or in the isolated unit form. In contrast, the anterooms occurring towards the middle of the room blocks and flanked by other units are all quadrilateral or pentagonal. The size and configuration of these latter units are limited by adjoining units within the room block. Two of the isolated units are also quadrilateral.

Orientation: The walls of the quadrilateral units approximate the cardinal directions. In addition to the interior extended vestibules on the west side of all the contiguous Type 3 quadrilateral units, two of the circular forms also had exterior openings in the middle of the east wall.

Size: The floor areas lange from 6.69 to $18.70 \mathrm{sq} \mathrm{m}$. With a mean size of $12.46 \pm 4.17 \mathrm{sq} \mathrm{m}$, the circular units tend to be slightly but not significantly largex than the quadrilateral units.

Length-width Ratio: The quadrilateral units are nearly square, and most of the other units are circular. The length-width ratios of most units range from 0.94 to 1.32 . Unit 27 at Antelope Creek is oval with a larger north-south axis and length-width ratio of 0.75 .

Unit Preparation: Ground preparation for construction of these units primarily involved levelling the original surface. At Alibates Ruin 28, exterior pits (possibly used to mix mortar or as a source of adobe for earlier construction episodes) were filled with earth and debris to form 
a level surface for Units 4 and 8 . However, Units 27, 28, and 29 at Antelope Creek Ruin 22 were built on a slope east of the main room block. In order to obtain a level living surface, the floor was excavated 0.60 to $0.90 \mathrm{~m}$ below the level of other units in the room block (Holden 1930:29; Baker and Baker 1941b:34). Unit 49 at Alibates 28 had a semisubterranean floor surface $0.58 \mathrm{~m}$ below the original ground level.

Wall Types: Considerable variation is evident in the kinds of wall footings in Type 3 structures. Most of the contiguous units had a single $(n=3)$ or double row $(n=5)$ of vertically-set stone slabs at the base (Table 16). But at Sanford Ruin, at least three styles were used in the Type 3 unit within the room block. A double row of vertical slabs occurred along the west wall which was connected to the adjacent units only by the extended vestibule. The north and south wall foundations were of a single row of vertical slabs, and the east wall footing was of seven verticslly-set posts. At Black Dog village, Unit 4, the free-standing unit had no discernible posts or stones around the hard-packed floor. The walls may have been of perishable materials or else the stone foundations may have been re-used during the construction of a later similar type rectangular unit superimposed over this circular structure. In most instances, the upper walls were made of alternating layers of adobe and horizontal slabs. A maximum extant wall height of $1.57 \mathrm{~m}$ was recorded for Unit 4 at Alibates 28 .

Doorways: The vestibules from Type 1 units extending to the middle of the -west wall of Type 3 units are considered to be interior passageways. Other kinds of access to the outside or adjacent rooms include upper wall openings, and gaps in the foundations. Two upper wall openings, each $50 \mathrm{~cm}$ 
Table 16.

Association of Support Posts, Hall Footings and Doorweys for Type 3 Units.

\begin{tabular}{|c|c|c|c|c|c|c|c|}
\hline & \multicolumn{2}{|c|}{ No Support Posts } & \multicolumn{2}{|c|}{ One Central Post } & \multicolumn{2}{|c|}{ Four Corner Posts } & Total \\
\hline & $\begin{array}{c}\text { No } \\
\text { Doorway }\end{array}$ & $\begin{array}{l}\text { Exterior } \\
\text { Gap } \\
\text { Doorway }\end{array}$ & $\begin{array}{c}\text { No } \\
\text { Doorway }\end{array}$ & $\begin{array}{l}\text { Exterior } \\
\text { Gap } \\
\text { Doorway }\end{array}$ & $\begin{array}{c}\text { No } \\
\text { Doorway }\end{array}$ & $\begin{array}{l}\text { Exterior } \\
\text { Gap } \\
\text { Doorway }\end{array}$ & \\
\hline $\begin{array}{l}\text { No } \\
\text { Stone } \\
\text { Wall } \\
\text { Footing }\end{array}$ & & & $\frac{\text { Black }}{\text { Dog-4* }}$ & & & & 1 \\
\hline $\begin{array}{l}\text { Single } \\
\text { Vertical } \\
\text { Slab } \\
\text { Footing }\end{array}$ & $\begin{array}{l}\text { Al ibates } \\
28-8 \\
\text { Al fbates } \\
28-40\end{array}$ & $\frac{\text { Antelope }}{\frac{\text { Creek- }}{22-27^{\star}}}$ & $\frac{\text { Black }}{\text { Dog-2 }}$ & & $\begin{array}{l}\text { Sanford- } \\
6 \star \star\end{array}$ & & 5 \\
\hline $\begin{array}{l}\text { Double } \\
\text { Vertical } \\
\text { Slab } \\
\text { Footing }\end{array}$ & $\begin{array}{l}\frac{\text { Alibates }}{28-1^{\star}} \\
\frac{\text { Antelope }}{\text { Creek- }} \\
\frac{\text { Creek- }}{22-28^{\star}} \\
\text { Antelope } \\
\text { Creek- } \\
22-29\end{array}$ & $\frac{\text { Al ibates }}{28-20^{\star}}$ & & $\begin{array}{l}\text { Al ibates } \\
28-4\end{array}$ & & & 5 \\
\hline Total & 5 & 2 & 2 & 1 & 1 & 0 & 11 \\
\hline
\end{tabular}


181

square, are present in the south and west walls of Unit 4 at Alibates Ruın 28; both provide access to other units. No clear exterior wall openings have been found in the quadrilateral unit form. Offsets in the east wall of Units 4 and 8 at Alibates 28 were once regarded as possible doorways; however, the paucity of artifacts adjacent to the wall offsets makes such an interpretation unlikely (Lintz 1979, Appendix A). Gaps in the middle of the east wall footings have been found in all contiguous intact circular units. Unfortunately, no dimensions are available.

Roof Configurations: Interior support posts were present in one circular and three quadrilateral units. Interior posts tend to be found in the larger units. Possibly the smaller units were roofed without the need for interior supports. A single centrally-placed post was found at one circular and two quadrilaterally shaped units. Such a post pattern may have supported a conical or flat-topped roof. In contrast, interior posts were found near three of the four corners of Unit 6, at Sanford Ruin. Similar corner post patterns have been reported for Type 1 and Type 2 units at Cottonwood Creek Ruin and Medford Ranch Sites. The roof configuration of these dwellings is uncertain. In addition, the presence of hearths in at least six units suggests the presence of some smoke holes in the roofs.

\section{Fire Pits and Associated Features: Basin-shaped hearths were cen-} trally located inside three circular and two quadrilateral units (Table 17). One unit also contained an ash (?) pit, and several units had concentrations of angular quartzite boiling stones near the hearths or along the walls. The most elaborate hcarth occurred at Sanford Ruin where two postholes were found near the north and south edges of a large hearth. The associated posthole probably constitute evidence for a spit or cooking rack. 
Table 17

Association of Unit Shape, and Interior Features for Type 3 Units.

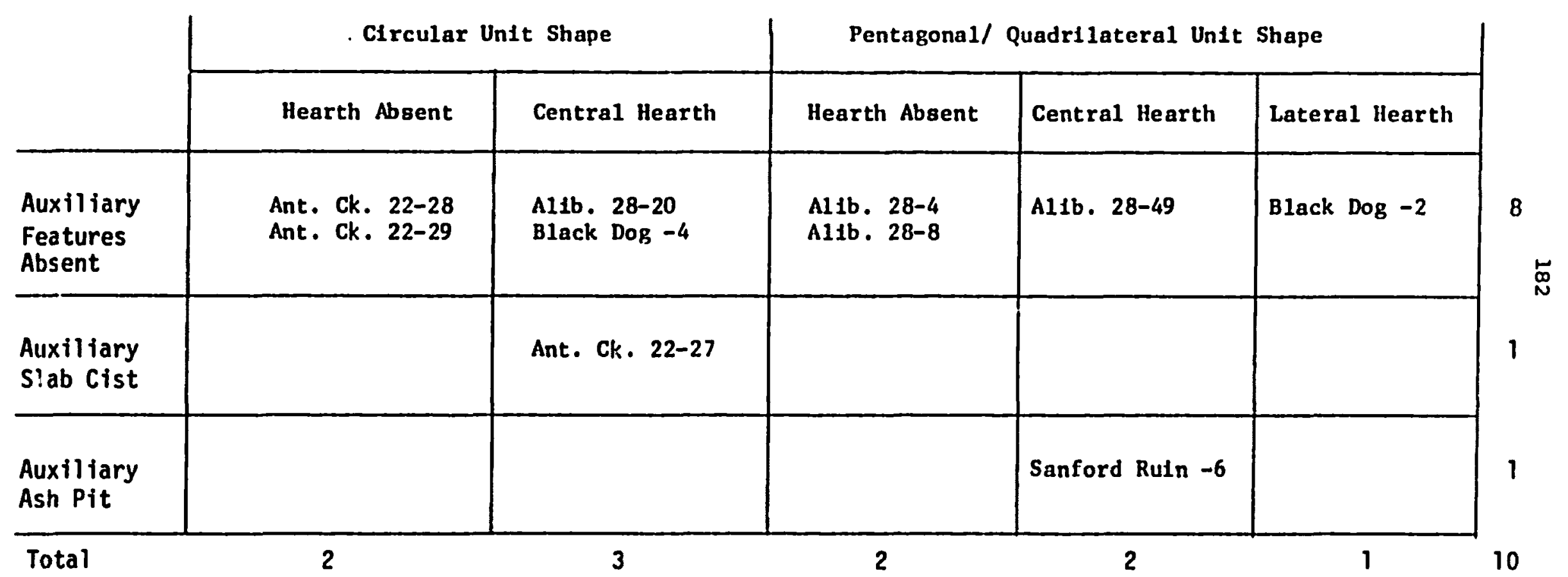

Numbers following site name represent Archltectural Untt No. 
Interior Storage Facilities: Only two units contained pits or cists. A single slab-lined cist was found midway between the central hearth and the east wall of Unit 27 at Antelope Creek Ruin 22 (Sayles 1932), whereas a small pit with two pebbles occurred north of the central hearth in Unit 6 at Sanford Ruin.

Modifications: Several kinds of unit modifications are evident. At Alibates 28, Units 1 and 4, the original floor surfaces had been capped with fill and replastered. A post set in the north central portion of the upper floor of unit 4 may represent an attempt to stabilize the wall or roof. Also, room construction blocked one of the above-floor openings between Units 4 and 10 at Alibates Ruin 28, and the vestibule openings in units 20 and 8 at the same site had been sealed off.

Comments: Early excavatcre helieved that the circular forms of type 3 units were analogous to the Southwest kiva because of the shape, putative unique occurrence and placement relative to other units at Ruins 22 and 28. Unfortunately, many details of these circular kiva forms are still poorly known. Some units were severely damaged prior to intensive field work, but are included primarily on the basis of location relative to other units in the room block. The shape and size of these poorly defined units are based on projections of short wall remnants (Lowrey 1932; Figure 17). Because of their special placement and putative unique occurrence, some units were tested by several field parties, and the records are difficult to reassemble. At Black Dog Village, only a part of the circular unit was excavated, and the reported size differs significantly from measurements indicated on maps (Keller 1975). Integration of the various field records 
from Antelope Creek Ruin 22 and Alibates Ruin 28 indicate that type 3 units are not unique, but rather several such units occur at each site. Unfortunately little artifactual information is available to ascertain the function of type 3 units.

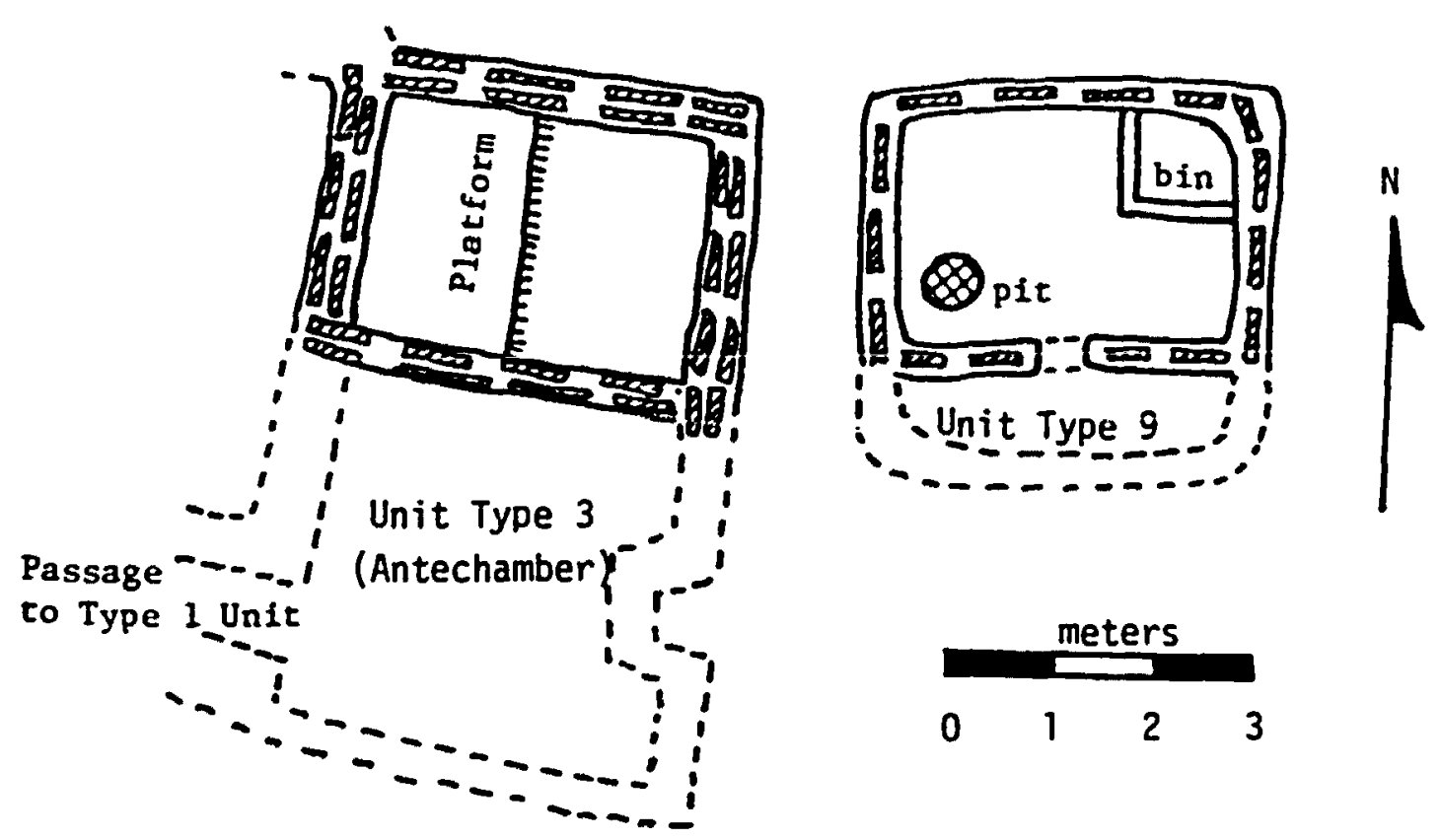

Figure 15. Generalized Example of Unit Type 4.

Unit Type 4 (n=5 units. Figure 15).

Architectural unit Type 4 includes medium sized, quadrilateral units with relatively few distinctive features. They rarely have bins, storage pits, interior platforms, interior roof support posts or ash pits. Units of this type occur at three (118) of the architecturai sites, where they are incorporated into aggregate room blocks $(n=5)$. They are significantly smaller than Type 3 units and maintain two different structural positions. In one aggregate form, this unit is found in a subordinate position often in association with Types 1 and 3 , but flanking the antechamber room. In 
no instance does the extended vestibule from Unit 1 open directly onto the Unit Type 4. In the second aggregate form, the unit holds a dominant position paired directly to a Type 9 unit. The pair may be a separate aggregate or several pairs may be linked together, but in no instance have such pairs been found as part of large aggregates involving either Type 1 or Type 2 units.

Shape: All units are quadrilateral.

Orientation: Walls are approximately aligned to the cardinal directions, but the lack of evidence for exterior doorways prevents determination of the facing direction.

Size: The units range from 6.92 to $10.02 \mathrm{sq} \mathrm{m}$ of floor space, with a mean size of $8.24 \pm 1.49 \mathrm{sq} \mathrm{m}$ area. Spatial limitations imposed by the room block configurations may have affected the size of two units at Alibates 28; however, comparably small units occurred in unrestricted situations at other sites.

Length-width Ratio: Neaxly all units are rectanguloid with one axis markedly longer than the other. East-west to north-south ratios range from 0.59 to $1.44 \mathrm{~m}$, indicating that the long axis can occur in either direction.

Unit Preparation: At Alibates 28, exterior mortar pits were filled to provide a level floor surface. The floor surfaces were seldom plastered and were often difficult to recognize and trace.

Wall Types: The wall footings are predominantly single rows of vertical slabs $(n=3)$ or double rows of vertical slabs with rubble-filled 
cores $(n=1)$. At Black Dog Village, three walls of Unit 1 had single row vertical slab footing, but the south wall shared by a Type 9 unit consisted of a double row of slabs. In all likelihood, this common wall was substantially reinforced to carry the roof weight of both units, or the final wall form reflects separate construction episodes. The upper wall consists of adobe mortar or alternating layers of adobe and horizontal rock slabs. The tallest wall remnant of this unit type stood at least $1.27 \mathrm{~m} \mathrm{high}$ at Alibates 28 , Unit 6 .

Doorways: No clear evidence for exterior access was found at any of the units. Duffield (1964:34) mentions an offset and slight decrease in stone in the east wall of Unit 3 at Medford Ranch. Perhaps entry was gained through above-ground wall openings. An interior doorway to an adjacent Iype 9 unit was encountered in the middle of the south wall footing at Black Dog Village. It measured $0.46 \mathrm{~m}$ wide (Keller 1975:13).

Roof Cunfigurations: The configuration of the roof structure is unknown. The only postholes mentioned occur near the midale of the west wall at Medford Ranch Site, Unit 5. The wall is also shared by Unit 3 . The post may have supported the roof, reinforced a weakened wall, or served as a stand for supporting a variety of hanging items. Quite likely interior posts may not have been necessary in these medium sized units. The entire weight of the roof may have been carried by the walls.

Fire Pits and Associated Features: None of the units had prepared or plastered hearths (Table 18). However, two ash pits and other piles of boiling stones were found adjacent to intweius slorage $z^{i}=s$ near the northeast and southwest corners of Medford Ranch, Unit 3. 
Table 18.

Association of Interior Features for Type 4 Units.

\begin{tabular}{|c|c|c|c|c|c|c|}
\hline & & & Facillties & & Facilities & \\
\hline & & Ash Pit & No Ash PIt & Ash Pit & No Ash Pit & Total \\
\hline \multirow{2}{*}{$\begin{array}{l}\text { No } \\
\text { Door }\end{array}$} & $\begin{array}{l}\text { No } \\
\text { Platform }\end{array}$ & $\begin{array}{l}\text { Medford } \\
\text { Ranch-3 }\end{array}$ & $\begin{array}{l}\text { Medford } \\
\text { Ranch-5 }\end{array}$ & & Al1b. 28-13 & 3 \\
\hline & Platform & & & & Al1b. 28-6 & 1 \\
\hline Door & $\begin{array}{l}\text { No } \\
\text { P1at form }\end{array}$ & & & & Black Dog-1 & 1 \\
\hline Tota & & 1 & 1 & 0 & 3 & 5 \\
\hline
\end{tabular}


Platforms: An interior platform at Alibates 28, Unit 6, consisted of a $1.5 \mathrm{~m}$ wide area along the entire western portion of the unit which was elevated $18 \mathrm{~cm}$ above the eastern floor surface. It is postulated that the platform was added in order to provide easier access to an upper wall opening to an adjacent unit. Although no opening was observed in the wall remnant, the height of the floor surface of Unit 9, to the west, had been artifically raised $51 \mathrm{~cm}$ above the lower floor surface in Unit 6 (Baker and Baker 1941a:103, 111). Similar upper wall openings have been reported from other raised floor units at the same site. The platform clearly served a different purpose than those associated with Type 1 units.

Interior Storage Facilities: Specialized storage facilities associated with Type 4 units have been described only for Units 3 and 5 at Medford Ranch. Linear rock patterns inside the northeast corner of Unit 5 may represent the wall partition remains of a bin encompassing approximately $1.15 \mathrm{sq} \mathrm{m}$. Unfortunately, the subtle soil conditions at the site prevented identification of the floor surface, which might have verified the tentative bin identification. In the adjacent Unit 3 , basin-shaped pits measuring 70 and $79 \mathrm{~cm}$ in diameter were found in the northeast and southwest corners near two ash pits. While both pits may be affiliated with Unit 3 , the failure to discern the floor surface leaves open the possibility that the pits predate unit construction.

Modifications: Little was found to indicate that unit Type 4 was carefully maintained or modified. None of the units had multiple floor surfaces, or evidence of interior feature modifications. The single possible exception is a posthole near the central portion of the wall at 
Medford Ranch which could have been used to brace a wall or ceiling beam.

Comments: The validity of Units 4 Types constituting a distinct morphological taxa is based primarily on the size and association of unit attributes/variables and the unique spatial patterning of the unit in larger aggregate clusters.

The dimensions of this unit type have been calculated using modified values for Unit 13 at Alibates 28. The dimensions provided in the original scale drawing are believed to be in error, since the large size unit would block the extended vestibule of Unit 15 (Baker and Baker 1941a: 125, Appendix A). Other maps and trash disposal patterns show the vestibule to be unobstructed. Consequently, the north-south dimension of Unit 13 has been shortened to accommodate the open passageway.

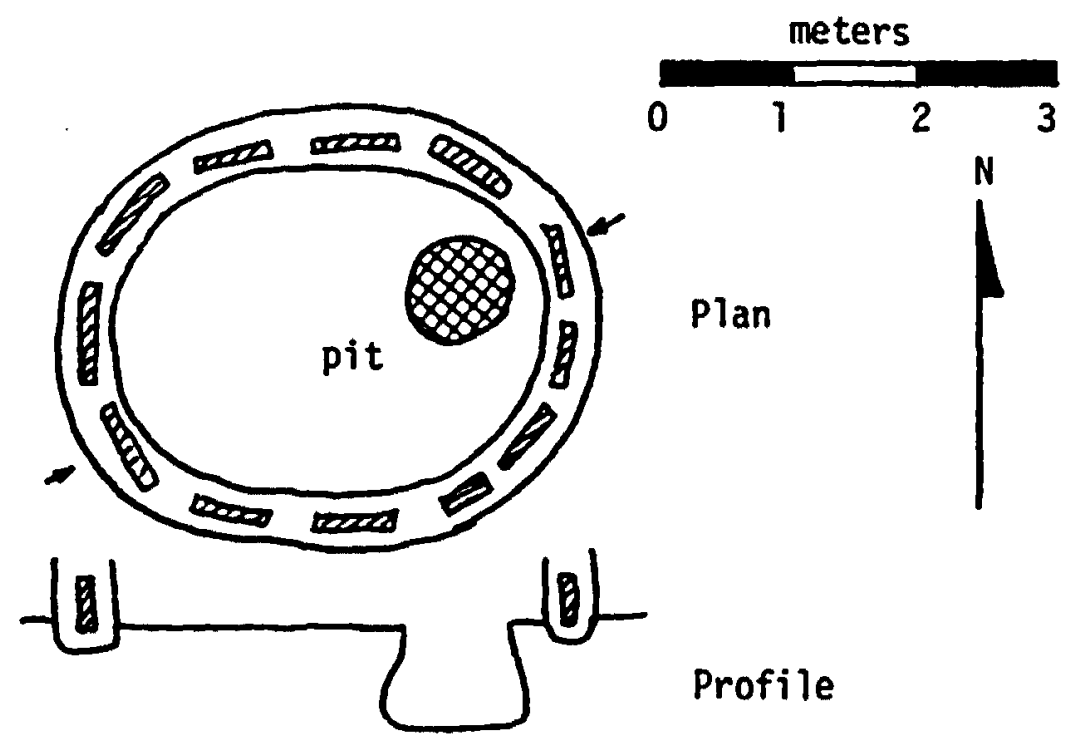

Figure 16. Generalized Example of Unit Type 5. 
Unit Type 5 ( $n=4$ units. Figure 16).

This unit type has been reported only from Alibates Ruin 28 . It is typically a medium sized circular or oval shaped unit with a basin or bell shaped storage pit near one corner. The foundations do not indicate the presence of ground level openings, and none have evidence of interior roof supports. All of the units are probably free-standing isolated structures.

Shape: One unit is quadrilateral whereas the others are oval or circular.

Orientation: There is no consistent orientation to the units.

Size: The single feature from the north end of Alibates 28 is relatively small with a floor area of $2.93 \mathrm{sq} \mathrm{m}$. The other three structures from excavation Unit II range from 5.48 to $8.52 \mathrm{sq}$ in interior floor space. The mean size of all four units is $6.05 \pm 2.42 \mathrm{sq} \mathrm{m}$.

Length-width Ratio: The dimensions of three units are nearly equal. Length to width ratios range from 1.00 to 1.03 . The fourth unit has a slightly longer east-west axis with a ratio of 1.25 .

Unit Preparation: Two of the units are reported to be semisubterrannean with the floor levels ranging from 0.20 to $0.68 \mathrm{~m}$ below the original ground surface. No information is available for the other two units.

Wall Type: The wall footings of all four units consist of a single row of vertical slabs (Table 19). Sayles' observations (field notes Tex:B: $9: 1)$ on Unit 55 excavated by Floyd Studer indicate that the basal slabs lean inwards, but such an orientation may be due to wall erosion after unit 
Table 19.

Association of Wall Footings, Doorways and Interior Pit Location for Type 5 Units.

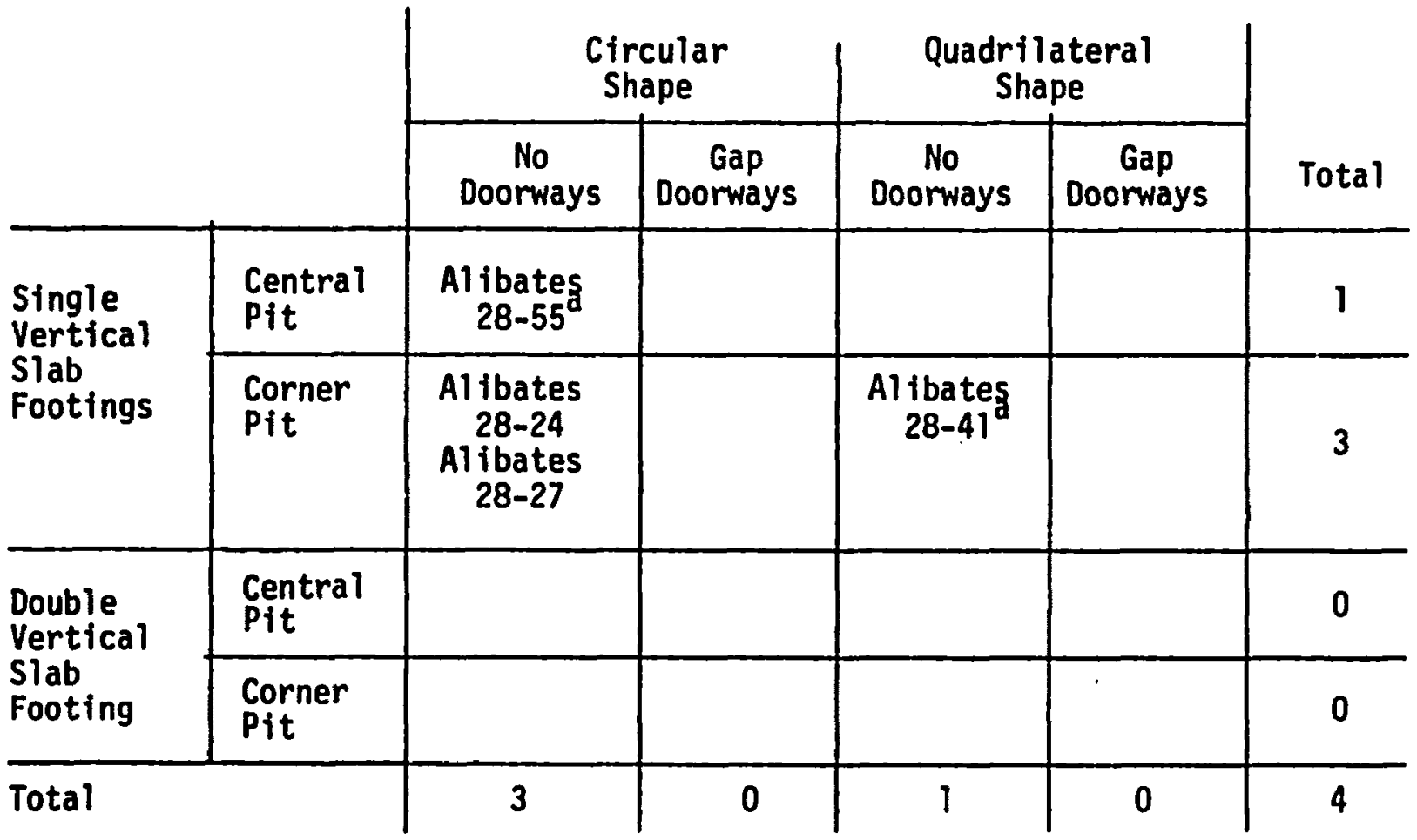

a Flexed burial found inside room. 
abandonment. Quite possibly the stones were set against the edges of the semisubterranean pit and plastered with adobe. The nature and height of the upper walls and the shape of the above ground unit are uncertain. Few rocks were found inside the room fill. Thus, the upper walls may have been made of puddled adobe, adobe and brush, or merely brush walls. No postholes have been recorded along the wall footings.

Doorways: None of the units have gaps in the wall footing stones. Access was probably gained through an upper wall opening. The size and direction of such openings are unknown.

Roof Configurations: No interior or wall postholes have been found. The units are so small that the roof could have been supported entirely by its walls. The roof shape could have been domed, conical or flat-topped.

Interior Storage Facilities: Interior storage pits are present in all units and is the primary criterion for inclusion in this type. The pits excavated by the WPA are typically bell-shaped with orifice dimensions of 0.79 to $1.05 \mathrm{~m}(n=3)$, base diameters of $0.97 \mathrm{~m}(n=2)$, and maximum pit depths or 0.91 to $1.14 \mathrm{~m}(n=3)$. The pits are located in the northeast corner of two units, the western edge of one unit, and in the midale of the fourth unit.

Modifications: None of the units show extensive use or modifications.

Comments: Single individual burials are present in two of these units. At Unit 41 , the buxial was found in the upper fill of the storage pit, whereas at Unit 55, the burial was on the floor adjacent to the centrally located pit. In both cases, the burials seem to be associated with the 
abandonment of the structure. This pattern is quite different from the reuse of abandoned Type 1 units at Alibates 28 and Antelope Creek 22A as cemetery areas.

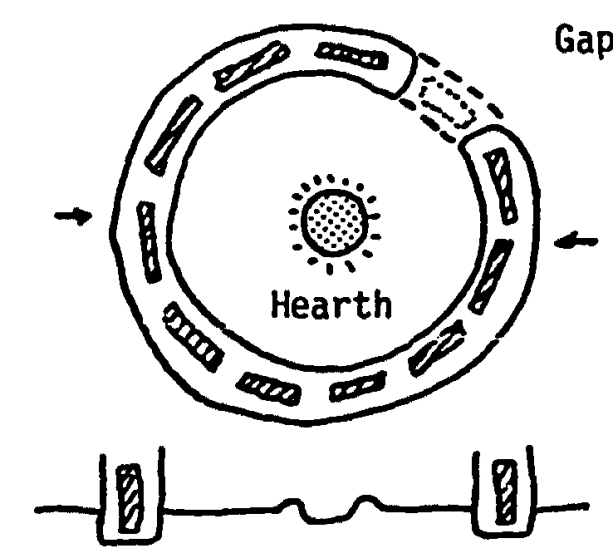

Gap Entrance

Profile

Eigure 17. Generalized Example of Unit Type 6.

Unit Type 6 (n=5 units. Figure 17.

Units assigned to this type all are small circular to oval structures with an interior hearth either located in the middle or along one edge of the feature. Some of the units may have ground level doors. Structures assigned to tinis type are from four (158) of the architectural sites in the sample. The examples occur as free-standing units $(n=4)$ or perhaps contiguous with other units of nearly equal size (Type 8 ).

Shape: The units are oval $(n=2)$ or circular $(n=3)$ in form. 
Orientation: Unit orientations as indicated by door placement are to the north-northeast or east in two units; no orientation could be determined for the other features.

Size: All units are small and range from 2.63 to $4.76 \mathrm{sq} \mathrm{m}$ of floor space. The mean area is $3.67 \pm 0.88 \mathrm{sq} \mathrm{m}$.

Length-width Ratio: Four units have nearly equal wall dimensions, but Unit 1 at the Turkey Creek site has a noticeable east-west long axis with a ratio of 1.58 .

Unit Preparation: Surface preparation was evident only at two structures. At Turkey Creek Site, Unit 1, the floor surface was excavated $46 \mathrm{~cm}$ into the original ground surface. At the Roper Site, Unit 4, limited excavations were conducted to produce a level floor. The other floor surfaces may have been unprepared.

Wall Types: All units employed a single row of vertically-set slabs as wall footings (Table 20). The nature of the upper walls is unknown. Maximum extant height is only $0.30 \mathrm{~m}$. Few loose rocks are associated with the feature; consequently the walls were probably of brush or puddled adobe.

Doorways: Possibly ground level doorways as indicated by gaps in the wall footings were noted for Unit 4 at the Roper Site, and Unit 1 at the Pickett Site. The two doorways are 0.46 and $0.76 \mathrm{~m}$ wide and are both located in the north-northeast wall of the units.

Roof Configurations: None recorded. The roofs may have been domed, conical or flat, built on high or short walls. 
Table 20.

Association of Unit Shape, Wall Footings, Doorways and Hearth Location for Type 6 Units

\begin{tabular}{|c|c|c|c|c|c|c|c|c|}
\hline & & \multicolumn{2}{|c|}{$\begin{array}{l}\text { Circular } \\
\text { Shape }\end{array}$} & \multicolumn{2}{|c|}{$\begin{array}{l}\text { Oval } \\
\text { Shape }\end{array}$} & \multicolumn{2}{|c|}{$\begin{array}{c}\text { Quadrilateral } \\
\text { Shape }\end{array}$} & \multirow[b]{2}{*}{ Total } \\
\hline & & $\begin{array}{c}\text { No } \\
\text { Doorways }\end{array}$ & $\begin{array}{c}\text { Gap } \\
\text { Doorways }\end{array}$ & $\begin{array}{c}\text { No } \\
\text { Doorways }\end{array}$ & $\begin{array}{c}\text { Gap } \\
\text { Doorways }\end{array}$ & $\begin{array}{c}\text { No } \\
\text { Doorways }\end{array}$ & $\begin{array}{c}\text { Gap } \\
\text { Doorways }\end{array}$ & \\
\hline \multirow{2}{*}{$\begin{array}{l}\text { Single } \\
\text { Vertical } \\
\text { Slab } \\
\text { Footings }\end{array}$} & $\begin{array}{l}\text { Central } \\
\text { Hearth }\end{array}$ & $\begin{array}{c}\text { Antelope } \\
\text { Creek } \\
22-30^{\circ}\end{array}$ & Roper- 4 & & Pickett-1 & & & 3 \\
\hline & $\begin{array}{l}\text { Lateral } \\
\text { Hearth }\end{array}$ & $\begin{array}{c}\text { Turkey } \\
\text { Creek- } \\
3\end{array}$ & & $\begin{array}{c}\text { Turkey } \\
\text { Creek- } \\
1\end{array}$ & & & & 2 \\
\hline \multirow{2}{*}{$\begin{array}{l}\text { Double } \\
\text { Vertical } \\
\text { Slab } \\
\text { Footings }\end{array}$} & $\begin{array}{l}\text { Central } \\
\text { Hearth }\end{array}$ & & & & & & & 0 \\
\hline & $\begin{array}{l}\text { Lateral } \\
\text { Hearth }\end{array}$ & & & & & & & 0 \\
\hline Total & & 2 & 1 & 1 & 1 & 0 & 0 & 5 \\
\hline
\end{tabular}


Fire Pits and Associated Features: The interior hearth is the distinctive feature of all units. In only two or possibly three instances, the hearths are carefully prepared basin-shaped features measuring appioximately $0.30 \mathrm{~m}$ in diameter in the center of the unit. In addition, the central hearth at the Pickett Site had a raised clay collar around the rim. In contrast the interior hearths at the Turkey Creek Site, Units 1 and 3 , were unprepared and located against the east wall. These burned surfaces ranged from 0.30 to $0.43 \mathrm{~m}$ in diameter.

Modifications: None apparent.

Comments: These units are found as solitary features or as associated with a few other small to medium sized room types at a site. They seldom seem to occur at sites with large household (Type 1 or 2) units.

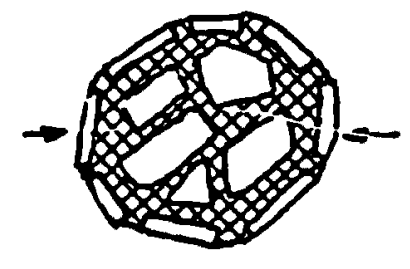

Plan

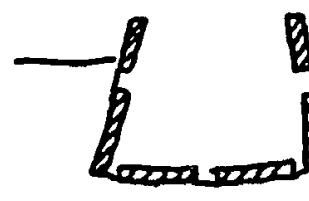

Profile

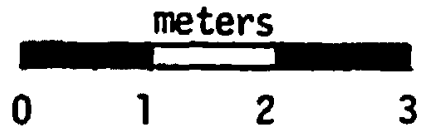
3

Figure 18. Generalized Example of Unit Type 7.

Unit Type 7 ( $n=7$ units. Figure 18).

Units assigned to this type are small to very small features with stone slab walls and stone slab floors. In all instances an adobe mortar was used to fill in between the rock slabs. They occur as isolated exterior features. These features occur at three (118) of the architectural sites in the study area. Although these are architecturally simple 
features, they show considerable variation in shape and depth.

Shape: Two units are quadrilateral and the other five are oval or circular (Table 21).

Orientation: Most of the lung axes are oriented north-south. None of these isolated features are restricted by other features or topographic settings.

Size: The WPA records indicate that these features range from 0.65 to $2.96 \mathrm{sq}$ m floor area, with a mean diameter of $1.64 \pm 0.98 \mathrm{sq} \mathrm{m}$. However, other archaeologists estimate the size of Antelope Creek 22, Unit 16, at $4.70 \mathrm{sq}$ m (Lowrey $1932: 34$, for cist 2).

Length-width Ratio: The dimensional ratio ranges from 0.66 to 1.12 which suggests that the walls tend to be nearly equal in size.

Unit Preparation: These units seem to have little ground preparation prior to construction. At least one occurs as an above-ground feature; others are semisubterranean with raised rims above the ground level. The uneven stone floor surfaces suggest that little effort was expended in preparing the foundations. In contrast, oval Unit 53 (Feature $46 \mathrm{~A}$ ) at Alibates 28 is a deep subterranean feature excavated $1.5 \mathrm{~m}$ below the original ground surface.

Wall Types: In most instances, the walls were made of a single row of vertically set slabs. The height and nature of the upper walls of the surface unit are unknown. The walls of the deep subterranean feature consisted of four tiers of single vertical slabs set in adobe mortar against 


\section{Table 21}

Association of Shape, Wall Footings, and Subterranean Placement of Type 7 Units.

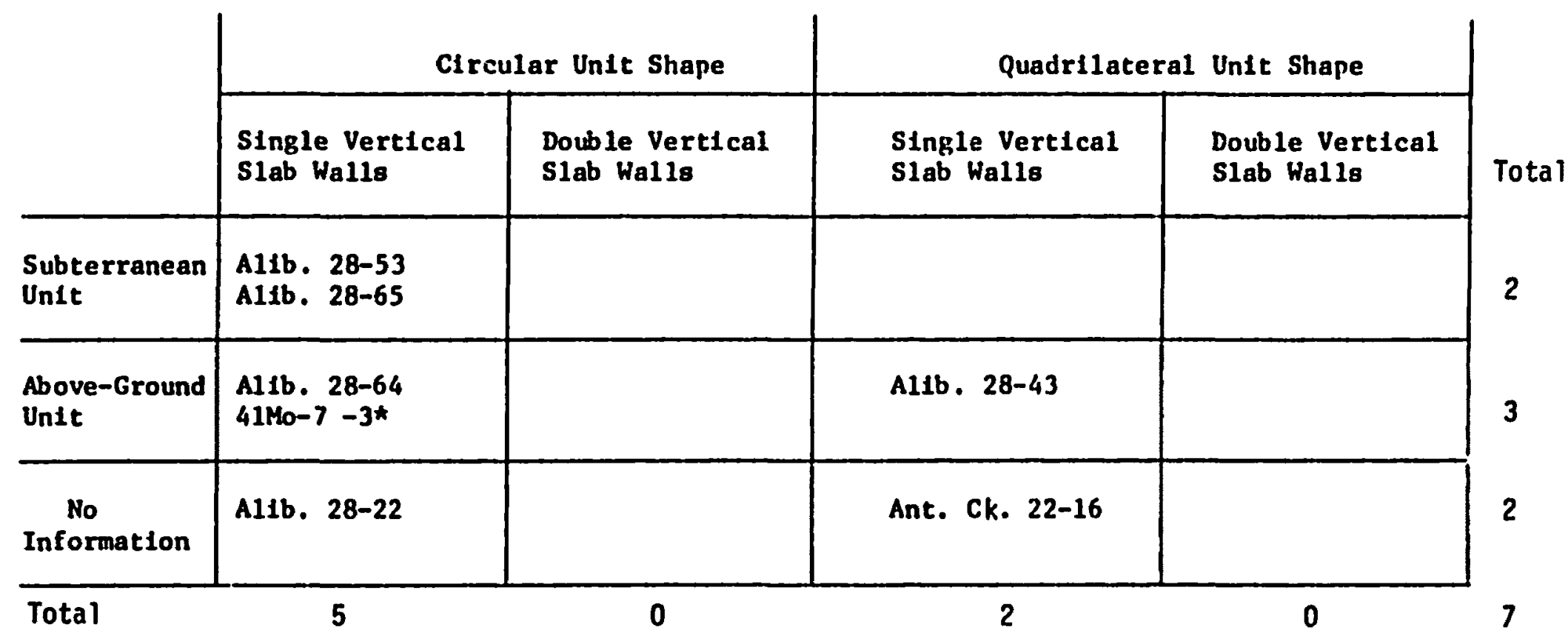

Numbers following site designation represent Architectural Unit No.

* Cover slab (?) oriented vertically in the middle of the feature. 
the slightly sloping walls. In all likelihood, the walls did not extend far above the original ground surface, even though a raised iip was present at Alibates 28, Unit 65 ("cist 5").

Doorways: No openings were discernible. Access may have been gained through the "roof" or top.

Roof Configurations: The upper walls and roof configurations of the surface units are unknown. The subterranean feature may have had a flat covering coincident with the ground surface. Alternatively, the deep feature may have served as a slab-lined pit and was merely filled with grass or earth. An interior vertically--oriented slab at Unit 3 at site 41Mo-7 possibly represents a covering stcre which had fallen into the feature.

Interior Storage Facilities: Except for one vertically-oriented stone in the middle of one feature, no interior features were discernible. An analogous vertical slab feature has been noted in conjunction with an interior slab-lined cist at Alibates 28 , Unit 47 .

Modifications: None discerned.

Cor:ments: The presence of stone floors in three features reflect more intensive labor than merely using the original ground surface or employing an adobe plaster. Baker $(1941 \mathrm{~b}: 38,107)$ suggests that even though the stones are much rougher than clay floors, this construction method may have bcen used to keep down excessive moisture and reduce rodent infestation.

The inclusion of Antelope Creek 22, Unit 16, in this type is tenuous because of conflicting information. The WPA records indicate that this 
vandalized unit is an isolated quadrilateral structure lacking a stone floor and with an approximate area of $2.58 \mathrm{sg} \mathrm{m}$ (Baker and Baker 1941a:5355). Various site maps show the feature to be in the same place as "Cist 2," excavated by E. J. Lowrey. Lowrey (1932:34) indicates that Cist 2 had a stone slab floor, but is circular with an area of approximately $4.70 \mathrm{sq} \mathrm{m}$. I have opted to accept Lowrey's description of the floor surface since he was responsibie for most of the excavations, but have relied on the more detailed WPA descriptions and feature maps to dexive feature dimensions. If indeed both descriptions refer to a single feature, then the differences may reflect the limited extent and inferior quality of the initial fieiu work, coupled with the eroded condition of the unit when the WPA crews started six years later.

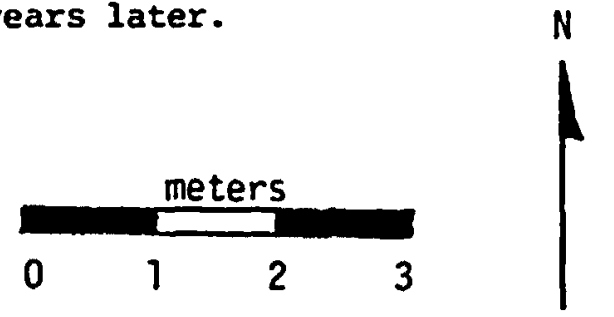

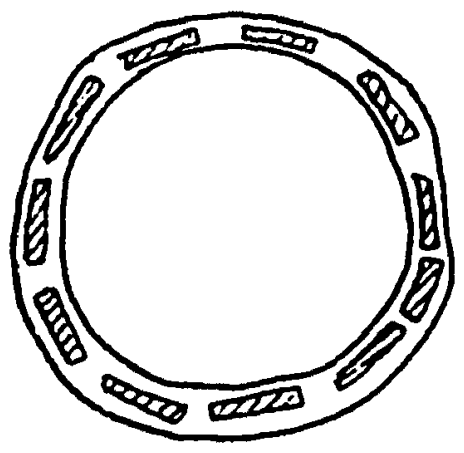

Circular

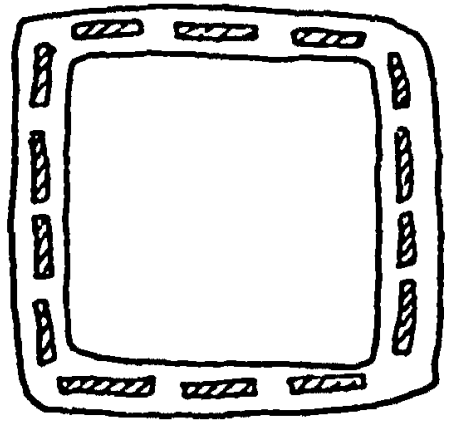

Quadrilateral

Figure 19. Generalized Example of Unit Type 8. 
Unit Type 8 ( $n=91$ units, and possibly three other poorly excavated units at Alibates 28. Figure 19).

These are medium to small sized units characterized by a variety of simple geometric shapes which rarely contain interior features. Several units have gaps in the wall foundations possibly indicative of ground level doorways and a few have raised floor surfaces. These units are present at 17 (638) of the architectural sites in the study area. They occur in three separate modes: (1) free-standing units $(n=18),(2)$ paired with one or two others of nearly the same size to form separate structures $(n=16)$, or (3) attached directly to the outside walls of Units Type 1 or 2 in lärge room block configurations to form subordinate units $(n=57)$. In the last mode, two Type 8 units can share a single wall of the dominant unit, and sometimes additional Type 8 units are positioned at the corners. At Alibates 28, Antelope Creek 22 and Sanford Ruin, these units separate the dominant Type 1 unit from the subordinate Type 3 (antechamber) units at the far end of the vestibule.

Shape: These units range from quadrilateral with rounded corners $(n=37)$, to circular or oval $(n=29), D=$ shaped $(n=16)$, and irregular $(n=5)$. The configuration of the other units is uncertain. As might be expected, the shape of the unit often is influenced by adjoining structures. All of the D-shaped units, 768 of the quadrilateral units and 808 of the irregularly shaped units are subordinate features attached to larger units. In contrast, the pentagonal shaped unit and over half of the oval and circular units are isolated features.

Orientation: The orientation of these small units is impossible to 
determine since none of the isolated units have discernible entrances. The wall alignment of contiguous room units is influenced by the larger adjacent units and is often oriented in cardinal directions. This pattern does not consistently occur in the isolated structures.

Size: The size parameters of this type are defined on the basis of other units. The lower limit is established in isolated units at appro:imately $1.6 \mathrm{sq} \mathrm{m}$ area by the size of interior pit and cist features associated with Type 1 and 2 units. Two contiguous Type 8 units are smaller than this limit but both are incompletely excavated. The upper limit is established at $12.2 \mathrm{sq} \mathrm{m}$. Most of the larger units occur in contiguous room blocks at subordinate positions. Of the 86 measurable units assigned to this type, the sizes range from 1.28 to $12.01 \mathrm{sq} \mathrm{m}$ floor space. The mean size is $4.80 \pm 2.46 \mathrm{sq} \mathrm{m}$.

Length-width Ratio: The east/west-north/south ratios range from 0.53 to 1.58 ; however, the apparent wide range is due to slight differences in the dimensions of these small units. Many units have nearly equal dimensions. Seldom does one dimension exceed twice the other dimension in the unit.

Unit Preparation: There is little evidence for extreme ground preparation in conjunction with the construction of these units, Only Unit 6 at Alibates 30 is reported to be subterranean. In addition, five features at Alibates 28, Unit 2, and one at Chimney Rock Ruin are superimposed over larger rooms or deep cists. Presumably, the earlier structural remains were cleared, or clean fill was introduced to provide a suitable level foundation. Most of the subordinate units within large room blocks have 
plastered floors, and at least seven of these units have multiple floor surifaces. In contrast, most of the paired and isolated free-standing units seldom have plastered floors. Presumably the original ground surface provided a suitable occupation surface. Another variation clearly noted at Alibates 28 , Units 9,10 , and 12 involved raised floor levels. Between 51 and $81 \mathrm{~cm}$ of cultural fill was added to these subordinate units in order to raise the plastered floor surface to a height comparable to the top of the extended vestibules (Baker and Baker 1941a:111, 114, 119). The frequency of this practice is uncertain, since most units have undergone extensive erosion. At severeiy eroded sites, it is difficult to determine if the artifacts near an unprepared sterile surface represent construction fill beneath a floor, artifacts in primary context on a floor, or secondary post abandonment debris above the floor.

Wall Types: As might be expected, the units display a wide range of wall footing within foundation trenches, ranging from predominantly double rows of vertical slabs $(n=34)$, single rows of vertical slabs $(n=32)$, horizontal slabs $(n=1)$, no masonry $(n=1)$ or a combination of single and double rows of slabs $(n=3)$. The nature of wall construction in the other 20 units is not mentioned. The type of wall footings can be roughly correlated with the contiguous nature of the structure (Table 22). Single slab foundation is present at 788 of the isolated and $85 \%$ of the paired units, but only 218 of the subordinate units in large room blocks. It appears that the double slab wall footing used in the dominant units is merely extended to subordinate units in the large room block situations. If several adjoining units are added during a single construction episode, occasionally an interior wall will have a lighter footing support. 
Table 22.

\section{Association of Wall Footings and Contiguous Room Arrangement}

For Type 8 Units.

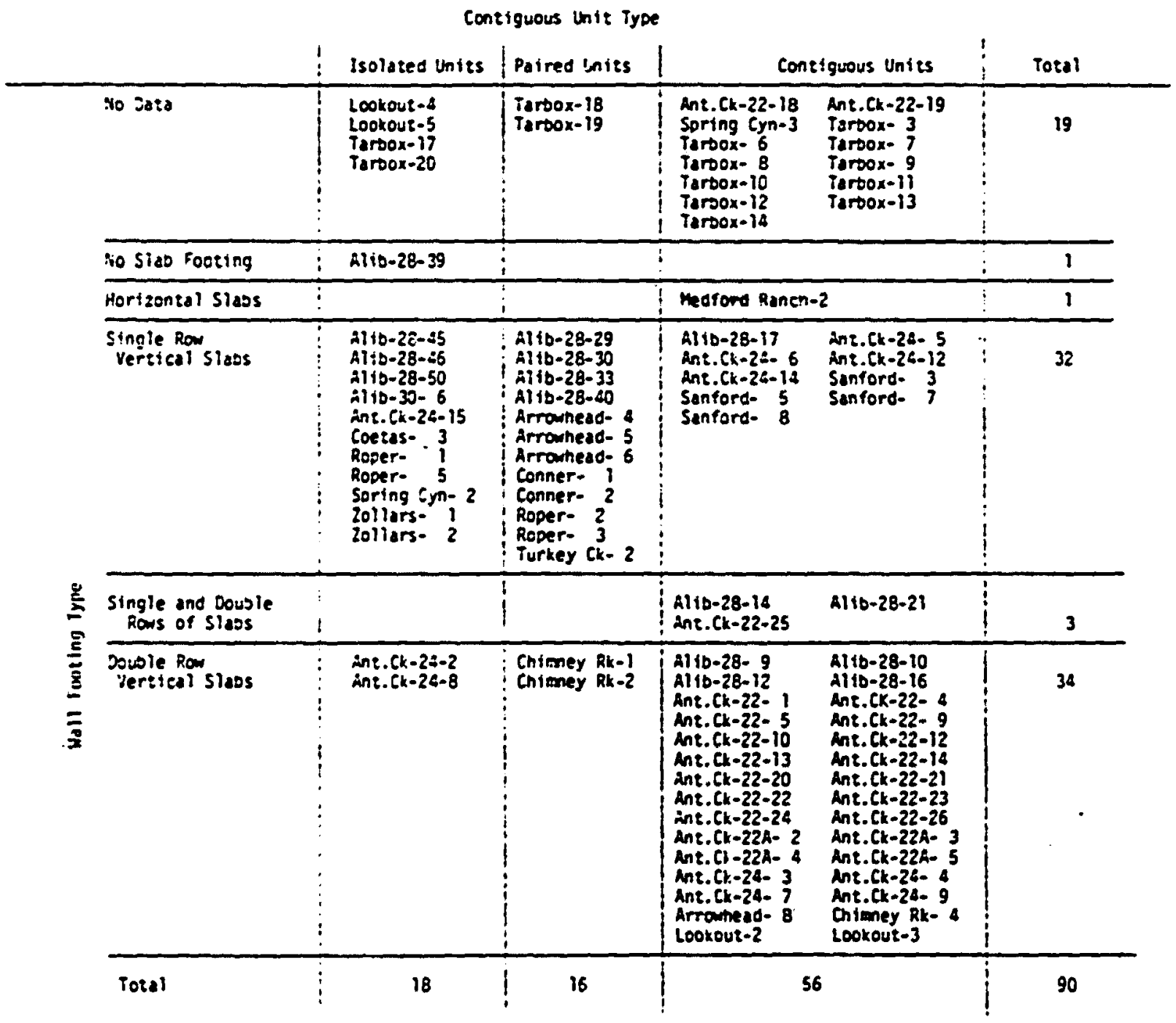


Some variation also reflects the "incidental" formation of a small unit through careful design and placement of other larger units added during later construction episodes (cf. Units 14 and 16 at Alibates 28). The upper wall portions are made of adobe which are sometimes reinforced with horizontal stone slabs. Total wall heights are difficult to ascertain; nevertheless, wall remnants exceeding one meter in height were observed at Alibates Ruin 28, and Antelope Creek Ruin 24 in both paired units, and subordinate units within larger room blocks. Alibates Ruin 28, Unit 12 , had the tallest extant wall, measuring $1.51 \mathrm{~m}$; however, with the floor surface artificially raised $0.81 \mathrm{~m}$ above the wall foundations, the unit only had $0.71 \mathrm{~m}$ headroom.

Doorways: Only nine units had evidence of doorways as indicated by gaps in the wall footings $(n=7)$ or upper wall openings $(n=2)$. Most of the doorways provided direct access to other units or to the vestimula fosiure, rather than the outside. Exterior gap openings were noted in the north, east, or northeast walls of three paired units and one subordinate contiguous unit. The openings in the paired units averaged $0.56 \pm 0.16 \mathrm{~m}$ wide whereas the width of the subordinate exterior opening was $1.46 \mathrm{~m}$. In contrast, the upper wall and interior gap openings were all associated with subordinate contiguous units present at large room blccks. They consistently averaged $0.56 \pm 0.07 \mathrm{~m}$ wide. The upper wall openings are often associated with units having artificially raised or elevated floor surfaces. The scarcity of gaps in wall footings suggests that upper wall openings were the main means of unit access; however, this form was seldom preserved. 
these medium to small sized units. Quite likely the weight of the roof was supported by the walls without any need for additional support. The presence of interior support posts (Feature 8) was postulated from a centrally located area of soft earth inside Unit 3 at the Roper site. The validity of this interpretation is questioned since the ground was not noticeabl $l_{\ddot{y}}$ discolored, and the small unit size (1.69 $\mathrm{m}$ diameter) would not require interior support. The roof configuration is uncertain. It may have been flat, domed, or pitched. At Antelope Creek 22, Unit 10, abundant quantities of burned timber and grass were found above the floor. In one instance, parallel grass stems were found lying on top of a beam (Baker and Baker 1941a:36). This suggests that timber beams supported a cover of grass bundles. Baker indicated that a layer of earth may have capped the grass.

Fire Pits and Associated Features: Hearth features are uncommon in these units. A single interior heazth was recoraled for a sitordinate unit at Antelope Creek Ruin 24. A second hearth attributed to Unit 4 at Chimney Rock Ruin is more likely the central hearth of a Type 1 structure stratigraphically beneath the unit (Baker and Baker 1941d:21).

Platforms: An interior platform was reported along the south wall of Unit 4 at Chimney Rock Ruin (Baker and Baker 1941d:14). As previously indicated, the feature is probably the channel and bench surface from a Type 1 unit stratigraphically beneath the small structure. Apparently Unit 4 had no, prepared rloor surface, so the excavators continued until the floor of the lower unit was encountered. Interior platform features are unknown from Type 8 units. 
Interior Storage Facilities: Interior storage pits were observed in the lowest floor surfaces of Units 13 and 14 at Antelope Creek Ruin 22 (Baker and Baker 1941a:44, 47). The presence of two and three plastered floor surfaces in these units indicates that the pit features were not normally associated with this subordinate room form. The pits possibly represent pre-existing adobe mixing basins which were fillsd p=ior to room construction. Many archaeologists have regarded the smaller units as storage rooms, since their size approaches the dimensions of storage pits and cists inside Type 1 and 2 units, and those with raised floor surfaces apparently had little head room for conducting extensive activities.

Modifications: Extensive unit modification has only been observed in those subordinate units forming part of larger room blocks. At Antelope Creek 24 the wall separating Units 4 and 9 was apparently removed. At Alibates 28, an upper wall opening was blocked by the addition of rooms during a subsequent construction episode. Finally, six units had their floor surfaces replastered once and two units had the floor replastered twice. As much as $15 \mathrm{~cm}$ of fill was introduced to separate the floor surfaces. The replastering undoubtedly served to cleanse the old floor surface of filth and perhaps bacteria buildup within the unit. In contrast to the modifications apparent in the subordinate units, no extensive repairs axe evident in the isolated or paired structural units. This difference may be attributed to the overall labor investment and upkeep of the entire structures. These small units may have been maintained along with the large room forms as an integral part of the entire room block. On the other hand, the isolated or paired units served merely as outbuildings which wexe used less intensively. 
Comments: The large number of units with this type reflects the simplicity of form. Size differences in the clustering and spatial positioning of subordinate units suggests that this morphological type may have accomodated a variety of functions which will be examined in greater detail later in this study. Included in this type were at least 15 vandalized units. Although no hearth features were reported, there is a possibility that some had hearths and should have been assigned to the Type 6 taxon.
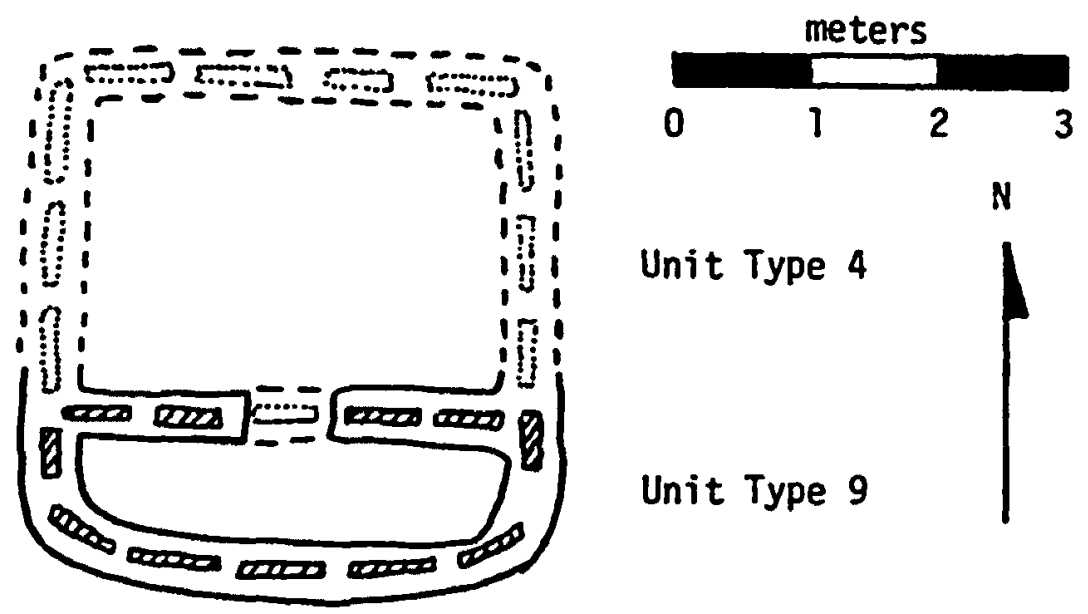

Figure 20. Generalized Example of Unit Type 9.

Unit Type 9 ( $n=3$ units. Figure 20).

This type is defined for medium to small sized units with a long narrow configuration. In all instances, the unit occurs in subordinate positions spanning the entire length of the dominant unit's common wall. The 
extreme length to width ratio makes this type distinct from units assigned to Type 8. In all cases the units are attached to Type 4 units to form an aggregate of units separate from large room blocks involving Type 1 or Type 2 units. Type 9 units are recognized at two (78) of the architectural sites. No spatial limitations were imposed on these units which might modify their shape or orientation.

Shape: These units are all D-shaped or rectangular.

Orientation: All units occur along the south wall of Type 4 units and have an elongated east-west long axis; however, other positions may eventually be recognized.

Size: The floor areas range from 1.05 to $4.47 \mathrm{sq} \mathrm{m}$. The w.ean floor area is $2.84 \pm 1.72 \mathrm{sq} \mathrm{m}$. These floor areas represent between 158 and 458 of the floor surface of the adjacent dominant unit.

Length-width Ratio: The ratios range from 0.29 to 0.75 ; the mean is 0.50, indicating that on the average, lihe width of the structure is about half the length.

Unit Preparation: No information is available concerning the relaEionship of the floor level to the original ground surface, or the preparatory work conducted prior to room construstion. Floor surfaces are difficult to discern and may not have been plastered.

Wall Types: In all instances, the wall footing of the shared wall is different from the other exterior walls. At Medford Ranch, the exterior wall employed a single row of vertical slabs whereas the adjacent unit used 
horizontal slabs. At Black Dog Village, the outside walls were of double rows of slabs whereas the common wall used a single row of slabs. These differences suggest that the Medford Ranch subordinate units may have been added during separate construction episodes, but at Black Dog Village, the weaker footing of the common wall suggests that both units were built during a single construction episode and that the heavier exterior walls carried most of the roof weight. In one instance, the upper wall was made of alternating layers of adobe and horizontal slabs. The total wall heights are unknown.

Doorways: Only one interior doorway was recorded. It consists of a $46 \mathrm{~cm}$ wide wall footing gap in the middle of the comnon wall between the dominant and subordinate units at Black Dog Village. Other means of access may have employed upper wall openings. The single example tenuously suggests that access was controlled through the main (Type 4) unit.

Interiur Storage Facilities: None of the units had interior postholes, hearths or storage features. Most likely, the roof was supported entireiy by the walls. The construction method, shape and pitch of the roof are unknown.

Modifications: None reported. These units may have served as outbuildings to other structures, and consequently little labor was invested to maintain them.

Comments: The small size of the units suggests that they may have served some kind of storage function comparable to the Type 8 units. These three units are typologically separated since they maintain different 
dimensions and unique coupling with Type 4 units as separate paired units. Unfortunately, no reports specify the kinds of associated artifacts; consequently functional interpretations must await reanalysis of artifactual materials.
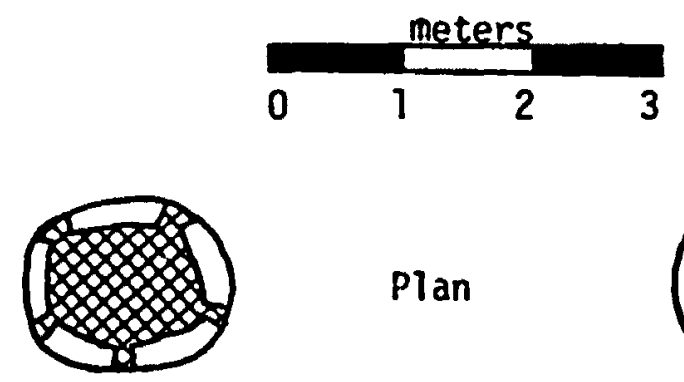

Plan

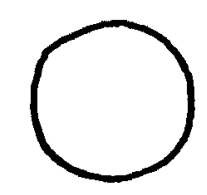

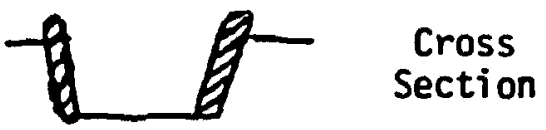

Unit Type 10 Slab Cist

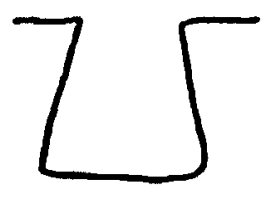

Unit Type 11

Pit

Figure 21. Generalized Examples of Unit. Types 10 and 11.

Unit Type 10 ( $n=12$ units, plus two beneath other features. Figure 21). These isolated units are very small slab-lined features with earthen or adobe plastered floors. No clear size directly separates these features from the smaller Type 8 units; however, a critical value of $1.60 \mathrm{sq} \mathrm{m}$ (1.43 m diameter) has been selected since all storage pits or cists inside larger Type 1 or 2 units are smaller than this figure. Type 10 units can be surface or subterranean units. Most are oval or circular with outward leaning walls. 
Shape: The units are oval $(n=4)$ or circular $(n=10)$.

Orientation: None apparent.

Size: The diameter of these features range from 0.62 to $1.37 \mathrm{~m}$, yielding a corresponding range in floor area of 0.39 to $1.47 \mathrm{sq} \mathrm{m}$. The mean size is $0.91 \pm 44 \mathrm{sq} \mathrm{m}(1.01 \pm 0.26 \mathrm{~m}$ diameter $)$.

Length-width Ratio: Not standardized--most units have equivalent dimensions.

Unit Preparation: No extensive ground preparation is evident but different amounts of labor were involved depending upon whether the feature was a slab-lined pit or above ground cist.

Wall Types: The walls may consist of large siais, or merely adobe with rocks near the rim (Table 23). At 41Mo-7, Unit 2 consists of large slabs lining the upper walls of a pit, the base of which extends $46 \mathrm{~cm}$ below the slabs. In contrast, Units 62 and 63 at Alibates 28 are above ground features made by a single row of large slabs set in a thick adobe mortar. The wall height (or pit depth) ranges from 0.41 to $0.76 \mathrm{~m}$ (mean depth is $0.54 \pm 0.15 \mathrm{~m}$ ). The slab walls inside the pits may flare considerably. The rim diameter of one feature was $1.5 \mathrm{~m}$, while the base was only $0.80 \mathrm{~m}$. In some instances, the rim of one pit feature was built above the original ground surface. The total wall height is uncertain.

Roof Configurations: The nature of cist coverings is uncertain. Perhaps grass and earth were used to seal the contents. Alternatively, large stone slabs such as those associated with Type 7 features may have been 
Table 23.

Association of Wall Footings and Subterranean Placement of Type 10 Units.

\begin{tabular}{|c|c|c|c|c|}
\hline & Above Ground Feature & Subterranean Feature & No Information & Total. \\
\hline Flaring Sides & $\begin{array}{ll}\text { Alibates } & 28-62 \\
\text { Alibates } & 28-63\end{array}$ & $41 \mathrm{Mo}-7-2$ & Al1bates 28-61 & 4 \\
\hline Straight Sides & & Footprint-4 & & 1 \\
\hline No Information & & & $\begin{array}{ll}\text { Antelope Creek } & 22-7 \\
\text { Antelope Creek } & 22-31 \\
\text { Ant } \epsilon \text { lope Creek } & 22-32 \\
\text { Antelope Creek } & 22-33 \\
\text { Tarbox }-4 \\
\text { Tarbox }-17\end{array}$ & 6 \\
\hline Total & 2 & 2 & 7 & 11 \\
\hline
\end{tabular}

Numbers following site designations represent Unit No. 
employed as covers; however, no such arrangements have been reported.

Modifications: None of the features show signs of maintenance or repair.

Comments: The function of these features is uncertain. None contain ashes, charcoal or other evidence that they were used as hearths. Most archaeologists refer to them as slab-lined cists cr storage pits. The features do not involve a great expenditure of labor. They show little evidence of prolonged use.

Similar interior features have been reported from Coetas, Unit 2; Arrowhead Peak, Unit 9; Antelope Creek Ruin 24, Unit 9; and Antelope Creek Ruin 22, Units 8 and 27. In most instances, the interior features are located in typical storage positions on the bench areas flanking the central channel.

Unit Type 11 ( $n=5$, with at least seven others beneath more substantial units. Figure 21).

These units are exterior pit features which show little evidence of architectural development beyond the excavation. They range from carefully shaped basin and bell-shaped features to amorphous depressions. These features are often neglected and poorly described. Full descriptions are available from only three (118) of the architectural sites.

Shape: Carefully constructed pits have circular or oval orifices with walls that expand or contract. The bases may be flat or concave. Many other features are amorphous depressions.

Size: The prepared pits range from 0.83 to $1.52 \mathrm{~m}$ in diameter and 
from 0.71 to $1.22 \mathrm{~m}$ deep. The mean pit diameter is $1.14 \pm 0.27 \mathrm{~m}$. The pit areas range from 0.52 to $1.87 \mathrm{sq} \mathrm{m}$ (mean area is $1.11 \pm 0.47 \mathrm{sq} \mathrm{m}$ ).

Unit Preparation: None; all are fully subterranean.

Wall Type: The walls are of earth; none are lined with adobe plaster.

Roof Configurations: Exterior pits at the Footprint Site were capped with a layer of red clay or large rock slabs at a level below the pit orifice (Green $1967: 127$ ). None are thought to have had a super-structure.

ModiEizations: None evident.

Comments: The carefully prepared features probably served as cache or storage pits. Many seem to have been filled with refuse as if they last functioned as trash receptacles. In contrast to these symetrical features, large amoxphous pits at many sites are thought to be the borrow source for adobe plastex used in construction (cf. Features 10 and 17 at Black Dog Village (Keller 1975]). Similar suggestions have been advanced by Baker and Baker (1941b:131), Duffield (1964:37), and Green 1967:149). However, no formal adobe "mixing pits" have been identified. Unmodified pits are abundant at some sites. At Alibates Ruin 28 , site maps show between 130 and an estimated 160 exterior and 12 superimposed pits within Excavation Unit 1. None of these features has been described, nor has the pit contents been segregated from materials in the surrounding soil matrix.

MISCELLANEOUS STRUCTURAL FORMS

Three units were sufficiently different to warrant segregation from the previous types (Figure 22). Since types should be based on more than 


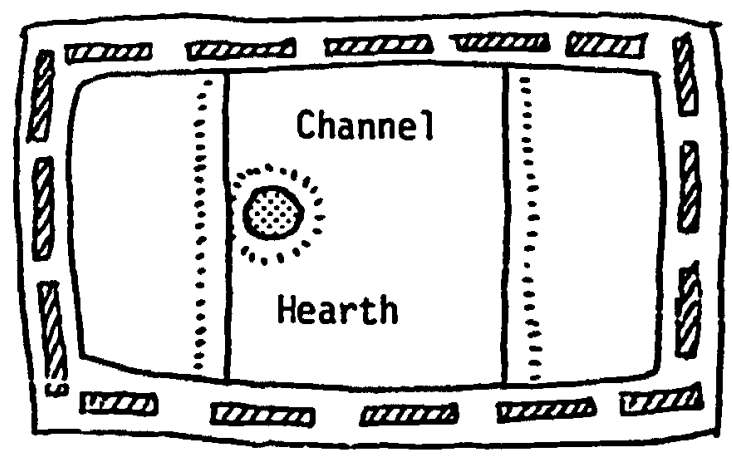

Miscellaneous 1
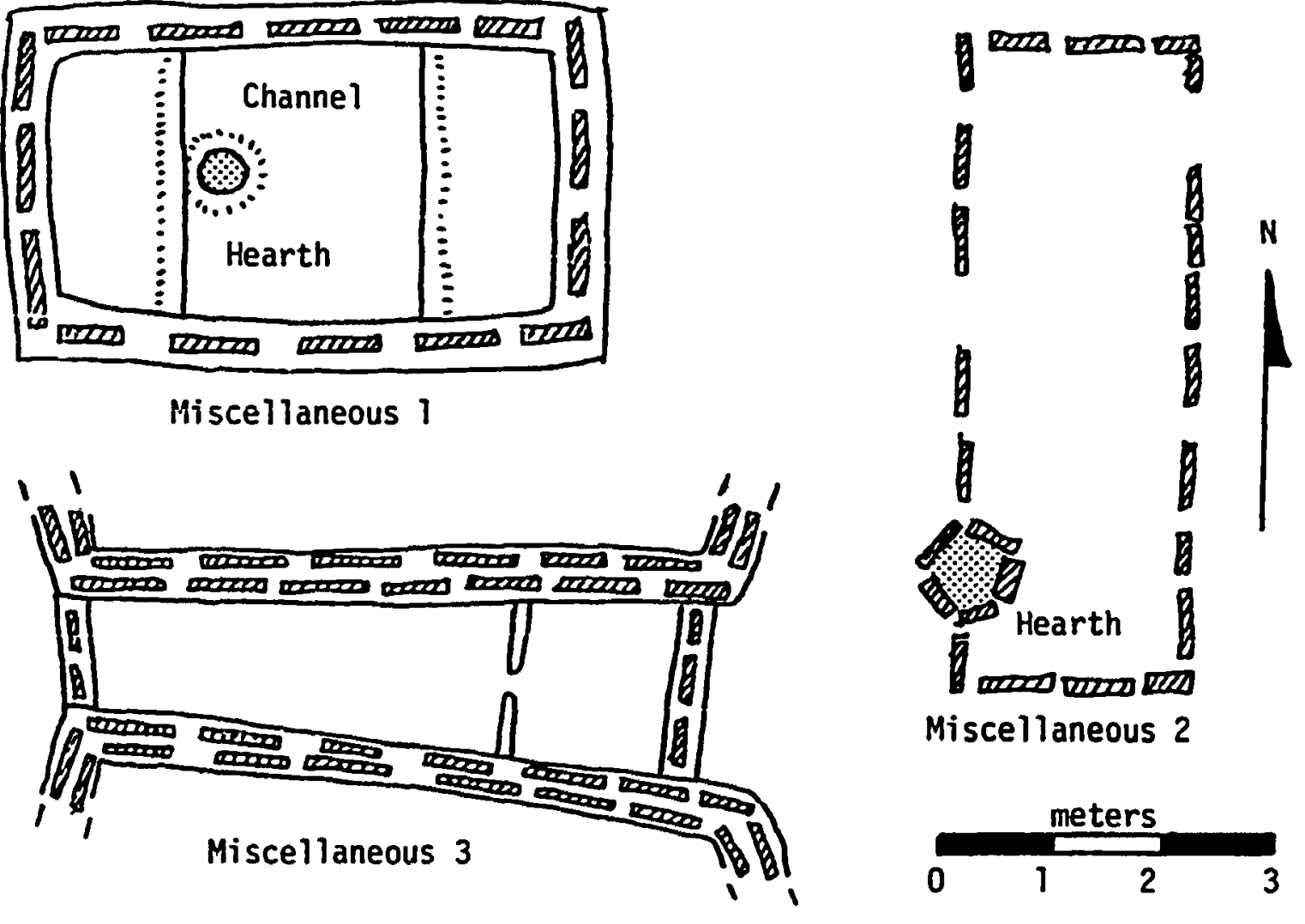

Figure 22. Miscellaneous Unit Forms

a single example, each unit will be individually described and cesignated by a provisional "Miscellaneous Number." Additional field work is required to ascertain if they are valid types or merely idiosyncratically different units. In one instance, the aberrant unit was formed by constructing connecting walls between two closely spaced isolated Type 1 units. Such opportunistic methods of forming units are extremely practical but variations imposed by spatial limitations led to considerable difficulty in defining the boundaries of the taxon.

Miscellaneous Unit 1

Alibates Ruin 28, Unit 48: This unit resembles the Type 1 unit in form and the presence of a central channel feature, but differs in size, 
proportional dimension, wall construction, and the north-south orientation of the channel.

The unit is an isolated quadrilateral structure measuring 4.65 by $2.27 \mathrm{~m}$. This medium sized (10.55 $\mathrm{sq} \mathrm{m}$ floor area) unit is notably smaller than any of the Type 1 units. The proportional ratio of 0.488 indicates that the east-west long axis is at least twice the north-south dimension. The floor surface of this semisubterranean unit is approximately $0.23 \mathrm{~m}$ below the original ground surface, but the lower portions of the walls were not slab-lined. Instead, horizontal slabs set in profuse amounts of mortar were built up from the original ground surface and the perimeter of the semisubterranean pit. Extensive erosion had reduced the walls to low remnants on three sides and had removed the entire east wall. No doorways were apparent. The unit lacked evidence of roof support posts, but given the small east-west dimension, no interior posts were necessary. Interior features were restricted to the north-south oriented channel and a hearth. The channel iloor was $17 \mathrm{~cm}$ below the adjacent low bench surface. Although the channel width $(1.48 \mathrm{~m})$ is within the range of Type 1 units, the bench width $(1.14 \mathrm{~m})$ is considerably narrower than the standardized bench widths (mean $1.71 \pm 0.18 \mathrm{~m}$ ) in Unit 1 features. The central hearth is a basin- . shaped pit measuring about $0.46 \mathrm{~m}$ in diameter. Although its general placement within the channel conforms to the pattern noted for Type 1 units, the hearth was located against the west edge of the channel instead of in the middle of the unit. No storage features or platforms were associated with Unit 48.

Comments: Although the occurrence and patterning of interior features seems analogous to those in Type 1 units, the size and orientational 
differences are felt to be sufficiently distinct to warrant separate treatment. Nevertheless, the morphology suggests that it may have served the same general function. Discrepancies exist between the size of features mentioned in the WPA text and the accompanying map. Consequently, the size of the unit was based on measurements of the scale map, assuming one-half inch to one inch rather than three-eighths to one inch as indicated. Finally, Unit 48 may have some similarities with poorly delineated lnit 44 at the same site. The latter unit is large (exceeding 4.0 by $4.8 \mathrm{~m}$ ) and has a five $\mathrm{cm}$ high ridge extending north-south across the unit approximately $1.20 \mathrm{~m}$ from the west wall (Baker and Baker 194ib:98). If the ridge is analogous to the raised rims along the edges of some benches in Type 1 units, then Unit 44 may have also had a sorth-south oriented channel. Adäitional field work is required to ascertain if the north-south channels are more common.

Miscellaneous Unit 2.

Antelope Creek Ruin 22, Unit 17: This unit resembles Type 9 as an elongated narrow structure, but differs in size, proportional dimension and its noncontiguous arrangement.

The unit is an isolated quadrilateral unit located west of the main room block at Antelope Creek 22. It measures 1.89 by $5.69 \mathrm{~m}$ for a total floor area of $10.75 \mathrm{sg} \mathrm{m}$ and a unit ratio of 3.01 . The wall footing consists of a single row of vertically-set slabs, but the nature and height of the upper wall and the relationship of the floor to the original ground surface aze unknown. Several gaps in the wall footings were recorded in the east and west walls near the north end of the unit. They were thought to reflect the reuse of building stones, rather than as indications of 
doorways. Access to the unit is uncertain. No interior postholes were found, but the narrow width of the unit would not require internal support. The weight of the roof is assumed to have been carried by the walls. The only associated feature was a slab-lined hearth measuring $0.68 \mathrm{~m}$ in diameter located $1 \mathrm{~m}$ north of the southwest corner. Although the hearth occurred on the same level as the floor and interrupted the foundation slabs, the WPA archaeologist could not determine if the hearth was contemporaneous with or postdated the unit (Baker and Baker 1941a:57). No modiEications were apparent.

Comments: Baker and Baker (1941a:57) suggest that the unit represented a temporary shelter used during the construction of the first permanent unit at the site. This interpretation was based on the assumed reuse of building stones and the extensive accumulation of soil over the unit. The paucity of materials in the surrounding test squares suggest that the unit was not buried by trash accumulation. Unfortunately no artifacts were associated with the stiucture; consequently, no function can be ascribed to it.

\section{Miscellaneous Unit 3}

Chimney Rock Ruin, Unit 6: This unit represents the opportunistic development of an elongated room by merely constructing short wall segments between two existing structures. The method transforms two isolated units into a contiguous room block. Many of the formal attributes of size and proportional diameter of the unit reflect pre-existing spatial constraints imposed by the earlier structures. As such, the attributes do not neatly fit the other taxa. 
This feature is a contiguous quadrilateral unit. It measures 5.64 by $1.34 \mathrm{~m}$ for a total floor area of $7.56 \mathrm{sq} \mathrm{m}$ and a length-width ratio cf 0.24. The north and south walls are from the pre-existing units. Both have double row vertical slab wall footings over which adobe and horizontal slabs are used. In contrast, footings of the short east and west end walls consist of a single row of vertical slabs encased in adobe plaster. The extant walls were $0.71 \mathrm{~m}$ high, but presumably they once extended to the roof line of the adjacent units. Direct unit access is uncertain since no doorways were observed. Most likely an upper wall opening was used. No interior support posts were found but, given the narrow width of the unit, none may have been necessary. The nature of the roof is uncertain. If the adjacent units had gables or hipped roofs, then some means of channeling runoff was probably necessary. The only interior feature was a short wall or partition segment built near the east end and subdividing the unit into two areas of approximately 2.9 and $4.7 \mathrm{sq} \mathrm{m}$. The partition was added aftcr the room had accunulated a certain amount of debris, presumably during a separate construction episode (Baker and Baker 1941d:18).

Summary of Unit Types

Descriptions of the eleven type units and their range of variation has indicated some fundamental trends underlying some of the architectural variability within the Antelope Creek phase. Briefly, these trends are:

(1) Units in a fairly discrete size range tend to be associated with similar internal attributes.

(2) In large units, bench widths are far more standardized than the channel width.

(3) The larger unit display formally patterned activity areas as 
indicated by the locations of interior features. In Type 1 units the central channel seems to serve as a familial processing azca while the bench sector serve as sleeping and familial and personal storage areas.

(4) Whereas the large structures reflect multiple discrete activity areas, the range of features suggests that the smaller units have a single or more limited range of activities conducted at any one time.

(5) The subtle variations in the presence of such features as collared hearths, depressed channels, raised rims along edge of benches, walled bins, step entryways, entrance sills, extended vestibules and even upper wall openings all serve to segregate materials from different activity areas or features.

(6) Some variation in wall foundations merely reflects either different construction episodes or structural reinforcement of outer or downslope walls which must endure more strain.

(7) The walls in the aggregate units are as tall as a person and are often made with vertically set unshaped single or double stone slab rows as wall footings, over which are alternating courses of puddled adobe or horizontal slabs.

(8) Plastered floor surfaces are associated most commonly with the large Type 1 or Type 2 units and their subordinate units in the same aggregate. Isolated medium sized to small units rarely have carefully prepared floor surfaces.

(9) In some aggregate room blocks, the subordinate units may have artificially elevated floors. 
(10) The number of interior roof support posts generally correlates to the size of the unit. Two additional central roof support posts are necessary for each $14.32 \pm 0.82 \mathrm{sq}$ in of floor space.

(11) Access to large Type 1 or 2 units involved extended vestibules or ground level wall gap/doorways whereas smaller units employed wall gap doorways or upper wall openings. Extended vestibules commonly oper to the east whereas access to the smaller units is from the east or north.

(12) Extended or recessed platforms against the west wall inside Type 1 or 2 units are only part of a larger feature complex, possibly involving side screen or wooden platforms and elaborate modelled clay or stone petroglyphic motifs against the wall. This elaborate complex may have served as a personal shrine or screened household altar.

(13) Platforms in smaller units seem to have more profane functions. Several are merely elevated floor surfaces which aided in access to adjacent units with raised floors.

(14) The aggregate room blocks and larger isolated units tend to show more extensive maintenance (wall and roof reinforcements, floor replastering, and multiple construction episodes) which suggests longer duration of occupation than isolated small units.

(15) The common occurrence, large size, fairly elaborate constellation of features and extensive maintenance of Type 1 and 2 units suggest that these rooms served as the nucleus rooms of a household cluster. The smaller size, plainer conditions and absence of maintenance or remodeling of Unit Types $3-6,8$ and 9 are 
are indicative of subordinate room-like scitures. In contrast, the minuscule size of Unit Types 7,10 and 11 and the occurrence of comparable units inside Type 1 and 2 rooms suggest that they are rightfully regarded as storage cists and pits.

\section{Spatial Aspects of Community Patterning}

The individual axchitectural units occur as either isolated freestanding structures or as components of larger unit aggregates. Now that the individual units have been defined, the present analysis focuses on the patterns of unit aggregations as exhibited at room blocks, then shifts to the layout of free-standing structures at other sites.

\section{PATTERNS OF AGGREGATION}

Contiguous aggregates are present at 16 of the 27 architectural sites and include approximately half of the architectural units undex consideration (Table 26). Yet the combinations of units are not haphazard. The spatial positions of associated architectural units incorporated within larger aggregates are rigidly patterned. Identification of these patterns eludicates the basic household structure at the larger sites and provides a model for examining the distribution of isolated units at other sites. All of the contiguous architectural units are assignable to only six aggregate type patterns.

An aggregate type is an ideal composite of unit layout patterns based on the spatial positions and mutual association of specific unit types observed at several sites. The aggregate type may involve several features of the same unit type, or combinations of several different unit types.

Two basic aggregate type forms are recognized. An aggregate parity occurs when architectural units of the same type or different unit types 
within the same size class constitute the components of the room block. Such combinations probably indicate comparable structural relationships and are apt to provide information about the number of householus present at the entire community. In contrast, an aggregate disparity involves architectural unit combinations of different types and sizes. It indicates different components of the structural system. The number, size, and spatial placement of the dominant and subordinate units provide information about the organization of individual household units which may constitute only a small part of the entire community. With these distinctions in mind, our attention is focused on describing the six aggregate types evident at the Antelope Creek architectural sites (Figure 23).

\section{Aggregate Type I}

This parity aggregate involved the contiguous placement of Type 1 $(n=8)$ and Type $2(n=2)$ rooms. The pattern is present at Alibates Ruin 28, Excavation Unit 1; Antelope Creek 22; Arxowhead Peak Ruin; Coetas Ruin; Tarbox Ruin, and has been postulated for the eroded portion of Antelope Creek Ruin 24. The rooms typically form a single north-south line so that the aggregate does not interfere with the predominant eastward extended vestibule from each unit. The complex room block arrangements at coetas Creek Ruin may be an exception; however, the kinds of rooms along the westexn edge of the room block are not known. The number of comparable rooms within this aggregate ranges from three to seven.

Evidence from wall abutments indicate most Type 1 or 2 units were added individually during separate construction episodes. Consequently, the final room block configuration reflects an accretional development. However, at Antelope Creek Ruin 22, a core of four rooms was constructed 


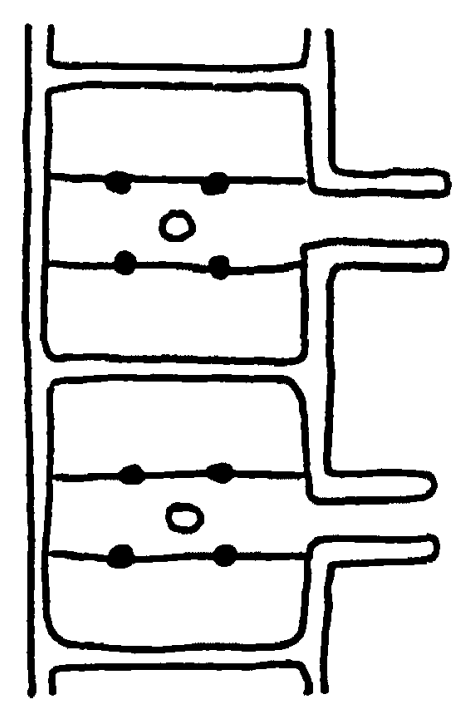

Aggregate Type I

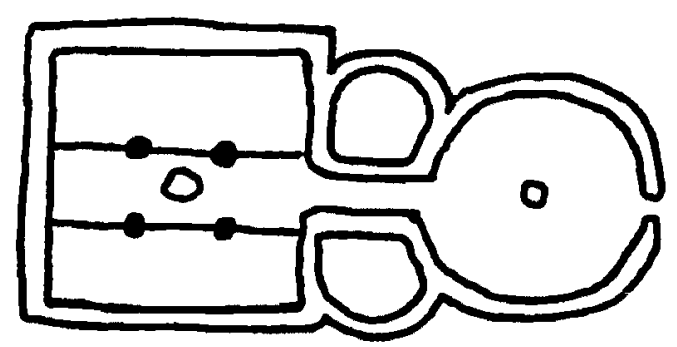

Aggregate Type III

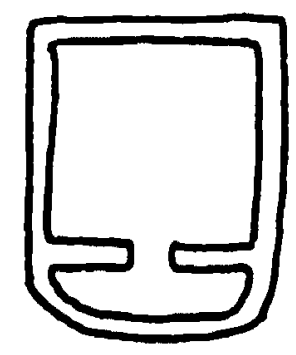

Aggregate Type $y$

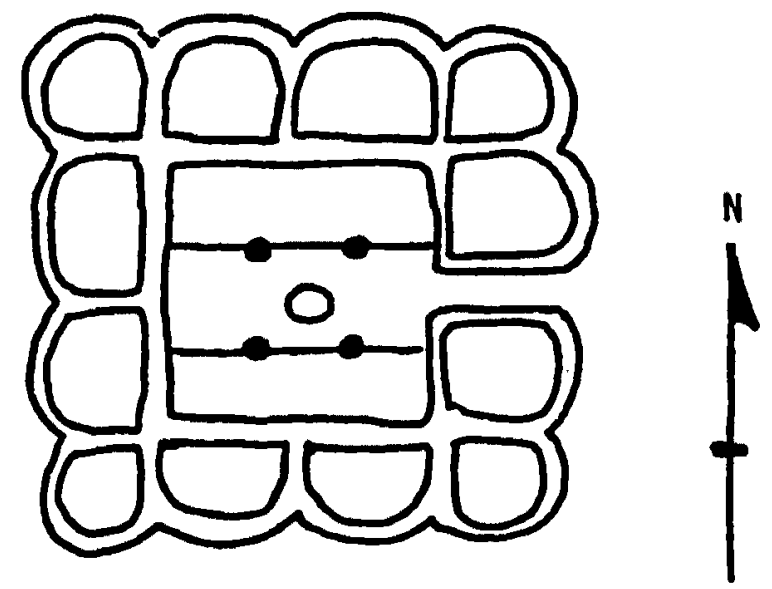

Aggregate Type II

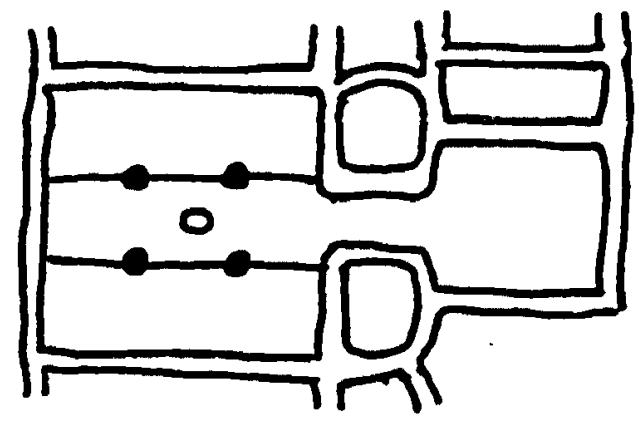

Aggregate Type IV

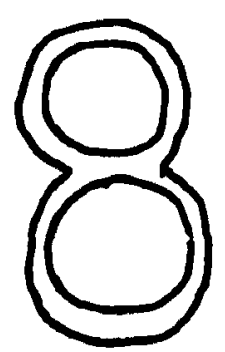

Aggregate Type VI

Figure 23. Unit Arrangements in Aggregate Types I-VI. 
as a separate aggregate room block during the second construction episode; a later aciaition linked this room block to an earlier aggregate built during the first construction episode. Although some units are affected by spatial limitations imposed by mesa top topography (Arrowhead Peak Ruin), or other building episodes (Antelope Creek 22), the room sizes range from large $(12.64 \mathrm{sq} \mathrm{m})$ to extremely large $(49.22 \mathrm{sq} \mathrm{m})$.

In most instances, each room within this aggregate type maintains the dominant position for a series of other disparity Aggregate Types II through IV. Each unit is postulated to be the main domicile nucleus of a separate household cluster.

Aggregate Type II (Figure 23)

This disparity aggregate involves the placement of Miscellaneous Unit $3(n=1)$ and Type $8(n=40)$ rooms in subordinate positions along the outside walls of a dominant Type 1 or Type 2 room. The smaller rooms are contiguous to a single dominant room or to a series of dominant rooms forming Aggregate Type I room blocks. The former situation is present at Antelope Creek 22 (earliest construction episode), Antelope Creek 22A, Arrowhead Peak (early construction episode), Chimney Rock Ruin, Lookout Ruin, Spring Canyon, Medford Ranch, and Sanford Ruin. The latter large aggregate form is found at Alibates Ruin 28, Antelope Creek 22 (second and third construction episodes), Tarbox Ruin, and possibly Antelope Creek Ruin 24. Normally, two of the smaller rooms share a single wall of a dominant room, and other small rooms sometimes occur at the corner positions. Consequently, any single dominant unit could theoretically be surrounded by as many as 12 subordinate units. Such a situation does not occur within the sample. Only 58 subordinate rooms were attached to about 25 dominant 
rooms. Three household clusters have subordinate rooms in a single position, 15 have double positions, three have triple positions, three have quadruple positions, and one has subordinate rooms in sextuple positions. In order to discern underlying patterns in room placement, the subordinate positions must be formally designated, and the frequency of room occurrence must be compiled and presented in an unbiased manner. Accordingly, numerical subscripts were assigned in a clockwise manner to the 12 possible positions relative to the dominant room starting in the northnortheast position (Figure 24 ). Note that the designations are assigned relative to the cardinal directions, and not according to the axis of the dominant room. In most instances, the eastward extended vestibule of the main room occurs between positions 3 and 4 but at Sanford Ruin, the northeastward vestibule is coincident with position 2.

Direct comparison of room frequencies at different subordinate positions cannot be validly accomplished since the total room block configuration, and to a lesser extent, site topography, affects the potential occurrence of rooms at subordinate positions around the main room. The smaller rooms may have an equal chance of occupying any position around an isolated dominant room, but the subordinate positions at the corners $(2,5,8,11)$. and along the north and south walls $(1,6,7,12)$ tend to be preempted when a series of dominant rooms occur in conjunction with an aggregate Type 1 pattern. In addition, the mesa top configuration prevented the placement of subordinate rooms at positions 8 through 11 at the Arrowhead Peak Site. Thus a more meaningful comparison uses the percentage of "actual room occurrence" to the "potential room occurrence" at specific positions as observed from the total room block configurations. The potential occurrence is 

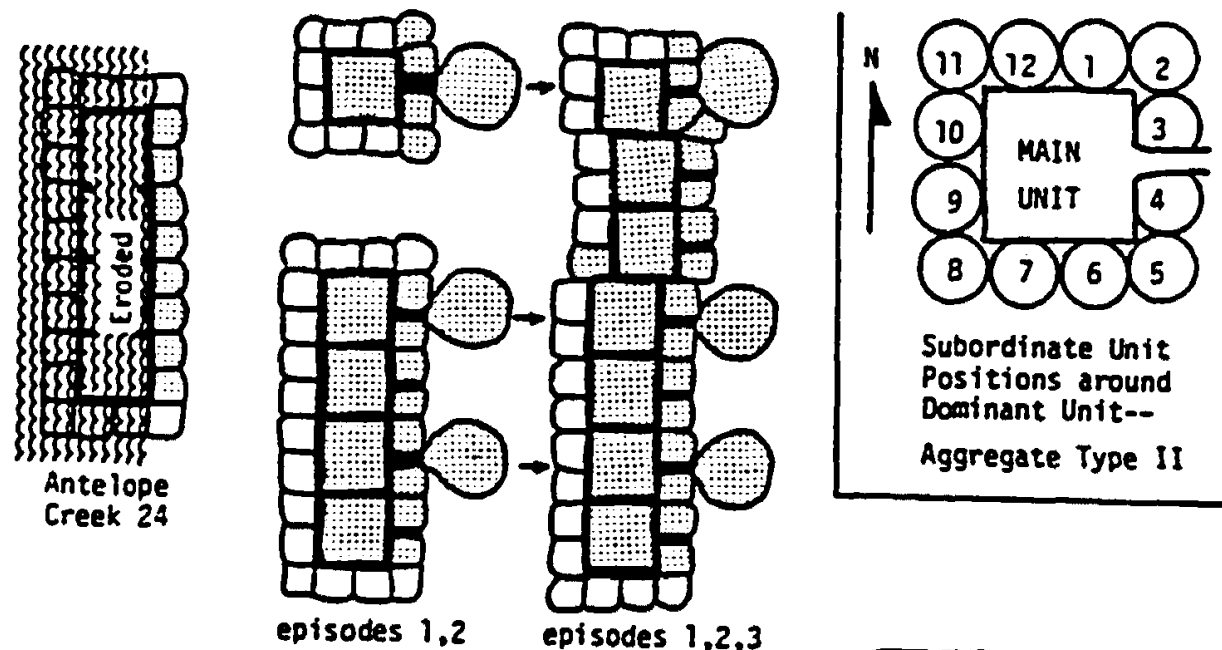

Subordinate Unit Positions around Docainant Unit-Aggregate Type II

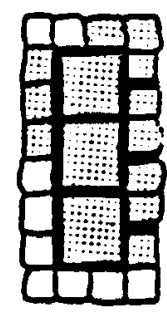

Tarbox

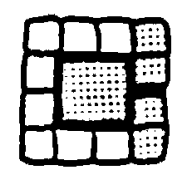

Antelope

Creek 22A

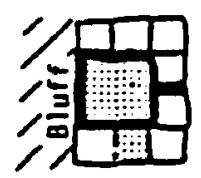

Arrownead Peak

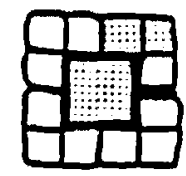

Lookout Ruín

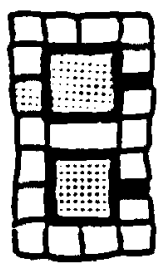

Chimey Rock

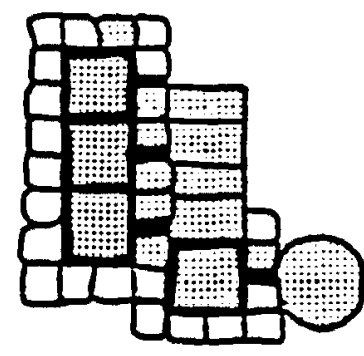

Alibares Ruin 28-1

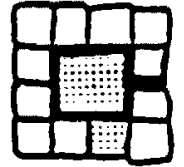

Spring

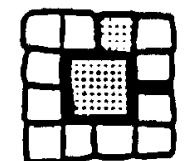

Hedford

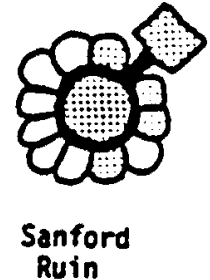

Figure 24. Stylized Layout of Potential and Actual Rooms, Aggregate Type II. 
obtained by plotting the dominant room configurations at the sites exhibition Aggregation Type II patterns, and adding subunits until all positions were filled (Figure 24). The total count of potential subordinate rooms includes a number of units possible for each construction episode at Antelope Creek Ruin 22 and Alibates Ruin 28. Each potential position was assigned a value of one except for Chimney Rock Ruin, Miscellaneous Unit 3. Since this compartmentalized unit simultaneously maintained positions 6 and 7 for the north dominant unit and positions 1 and 12 for the southern dominant unit, each position was assigned a value of 0.5 . The maximum and minimum number of potential subordinate rooms in each position ranged from 11.5 to 26.0 given the configuration of main rooms at the ten sites. However, actual subordinate room counts ranged from 0 to 19 (Table 24). The percentage of actual to potential occurrence ranged from 0 to 73.18. After ranking the placement of smaller rooms the following trends are apparent:

(1) Nearly all (89.88) of the subordinate rooms are along the eastern half (positions 1-6) of the dominant room. Since the extended eastward vestibule is thought to be the entrance, the trend is to locate subordinate rooms towards the front of the structure. Activity areas on this side of the structure are leeward of prevailing southwest winds, are warmed by the morning sun, yet shaded in the late afternoon.

(2) Positions adjacent to the main room walls are more commonly utilized than the corner positions. This trend merely reflects conservation of labor and materials by utilizing existing walls of the main room as part of the subordinate unit. In every instance within the study sample, subordinate rooms at corner positions occur only after other small rooms filled positions against the wall of the main structure. In contrast, corner 
Table 24 .

Frequency of Room Potential and Actual Occurrence in Subordinate Positions within Aggregate Type II.

\begin{tabular}{|c|c|c|c|c|}
\hline $\begin{array}{l}\text { Room } \\
\text { Position }\end{array}$ & $\begin{array}{c}\text { Potential } \\
\text { Occurrence }\end{array}$ & $\begin{array}{c}\text { Actual } \\
\text { Occurrence }\end{array}$ & $\begin{array}{c}\text { Percent } \\
\text { Position } \\
\text { Occurrence }\end{array}$ & $\begin{array}{l}\text { Frequency } \\
\text { Rank }\end{array}$ \\
\hline $\begin{array}{c}\text { (East } \mathrm{Half} \text { ) } \\
1 \\
2 \\
3 \\
4 \\
5 \\
6\end{array}$ & $\begin{array}{l}12.5 \\
12.5 \\
26.0 \\
26.0 \\
13.5 \\
13.5\end{array}$ & $\begin{array}{r}5.5 \\
4.0 \\
19.0 \\
19.0 \\
2.0 \\
3.5\end{array}$ & $\begin{array}{l}44.0 \\
32.0 \\
73.1 \\
73.1 \\
14.8 \\
25.9\end{array}$ & $\begin{array}{c}3 \\
4 \\
1-2 \\
1-2 \\
6 \\
5\end{array}$ \\
\hline Sum & 104.0 & 53.0 & \multicolumn{2}{|c|}{ ( $89.8 \%$ of total) } \\
\hline $\begin{array}{c}\text { (West Half) } \\
7 \\
8 \\
9 \\
10 \\
11 \\
12\end{array}$ & $\begin{array}{l}13.5 \\
12.5 \\
24.0 \\
24.0 \\
11.5 \\
12.5\end{array}$ & $\begin{array}{l}0.5 \\
0.0 \\
3.0 \\
2.0 \\
0.0 \\
0.5\end{array}$ & $\begin{array}{r}3.7 \\
0.0 \\
12.5 \\
8.3 \\
0.0 \\
4.0\end{array}$ & $\begin{array}{c}10 \\
11-12 \\
7 \\
8 \\
11-12 \\
9\end{array}$ \\
\hline Sum & 98.0 & 6.0 & \multicolumn{2}{|c|}{ (10.2\% of total) } \\
\hline Total & 202.0 & 59.0 & \multicolumn{2}{|l|}{$100.0 \%$} \\
\hline
\end{tabular}

1 Considers separate building episodes at Antelope Creek 22 and assigns half values to Miscellaneous Unit 3, since it is shared by two dominant units. 
positions were filled prior to wall adjoining positions at the Roy Smith Site in Beaver County, Oklahoma (Schneider 1969). In general, the corner positions are utilized as extensions of small rooms placed along the front half of the structure.

(3) The most common subordinate room locations are positions 3 and 4 flanking the extended vestibule. Subordinate rooms were present at both positions in 768 of total potential occurrences. Preference for these locations may reflect proximity to both interior and exterior activity areas. At Antelope Creek Ruin 22, Units 1 and 25, and Ruin 24, Unit 9, access to these positions was gained directly from the vestibule. Not only are significant differences evident in the number of subordinate rooms at the front and back locations, but also there may be significant differences in the size of rooms at these positions. A chi-square test was used to investigate this possibility. The contingency table examined the number of regular versus over-sized subordinate rooms occurring at the front (positions 1-6) and back (positions 7-12) of the dominant room. oversized rooms were considered to be any unit where floor surface was greater than the one standard deviation interval of Type 8 units (area 7.26 sq $m$ ). The test determined that the null hypotheses should be rejected, . and that a significant number of oversized rooms are located along the back portion of the household cluster main unit (Table 25). The difference may be even more pronounced, since three of the four oversized units from positions towards the front are unexcavated rooms at Lookout and Tarbox-Ruins. Their oversized dimensions are based solely on surface indications which have not been verified through excavations. 
Table 25 .

Chi Square Test of the Placement of Oversized Subordinate Roans within Aggregate Type II.

Null Hypothesis ( $\left.\mathrm{H}_{0}\right)$ :

There is no significant difference in the size and position of Type 8 Subordinate Units within Aggregate Type II.

Decision Rule:

Accept Ho if $x^{2} \leq$ critical value; reject Ho if $x^{2}>$ critical value.

\begin{tabular}{|c|c|c|c|c|c|}
\hline & $\begin{array}{r}\text { Front } \\
\text { (Positi } \\
\text { Observed }\end{array}$ & $\begin{array}{l}\text { Rooms } \\
\text { ons } 1-6) \\
\text { Expected }\end{array}$ & $\begin{array}{r}\text { Back } \\
\text { (Positi } \\
\text { Observed }\end{array}$ & $\begin{array}{l}\text { Rooms } \\
\text { ons } 7-12) \\
\text { Expected }\end{array}$ & Total \\
\hline $\begin{array}{l}\text { Regular Sized } \\
\text { Type } 8 \text { Rooms } \\
(\leq 7.26 \text { sq m) }\end{array}$ & 45 & 43.56 & 3 & 4.44 & 48 \\
\hline $\begin{array}{l}\text { Oversized } \\
\text { Type } 8 \text { Rooms } \\
(>7.26 \text { sq m) }\end{array}$ & 4 & 5.44 & 2 & 0.56 & 6 \\
\hline Total & 49 & & 5 & & 54 \\
\hline
\end{tabular}

Critical Value at .05 confidence level with 1 degree of freedom $=3.841$ $\chi^{2}$ value $=4.599$ Outcome: Reject Ho. 
Aggregate Type III (Figure 23)

This disparity aggregate developed from and possibly represents a variation of the Aggregate Type II. The pattern involves a single dominant Type I room with two to four subordinate Type 8 rooms flanking the vestibule and an additional circular or rectangular Type 3 room located east of the vestibule. Seven exampies of the pattern are known from Alibates Ruin 28, antelope Creek Ruin 22, and Sanford Ruin. At the former two sites, this aggregate type occurs interspersed with Type II aggregates at complex large room blocks, but the Sanford Ruin pattern occurs in isolation. Some of the difference in the shape of Type 3 rooms reflects limitations imposed by topography or more often, adjacent room configurations. The repetitious occurrence at two sites suggests that the Type 3 rooms relate to some structural differences within the individual household cluster, rather than representing a communal or ceremonial room as once believed. Many of the early excavators focused on testing and retesting this prominent antechamber room, without properly documenting the excavation. Consequently, little is known about the condition of interior features or the nature of artifactual remains. The significance of this pattern and particularly the Type 3 room may require reanalysis of material content or additional excavations at different sites.

\section{Aggregate Type IV (Figure 23)}

Type IV aggregate represents another disparity variation developed from Aggregate Types II and III. This form consists of a Type III Aggregate with the addition of a rectangular Type 4 room north of the quadrilaterally shaped antechamber. Only two examples of this type have been found. Both are associated with dominant Type 1 rooms located near the 
midale of a single complex room block at Alibates Ruin 28. The restricted occurrence of this aggregate type to but a single room block suggests that the configuration does not reflect a common pattern and may not signal any new structural or functional compenent of the basic Antelope Creek household pattern. Instead, the new room placement reflects the most efficient and convenient location for expanding subordinate rooms around a household cluster given the confines of other existing dominant rooms. In both cases, other household clusters preempted the normal placement of Type 8 subordinate rooms along the north and south walls of the deminant unit. Rather than add subordinate units behind the room block, new unit locations were developed. On the basis of size similarities, the infrequent occurrence of the Aggregate IV pattern, and the spatial constraints associated with its occurrence, I suspect that Unit Types 4 and 8 served similar functions.

Aggregate Type $V$ (Figure 23)

The fundamental basis of this aggregate form involves a pairing of a medium sized Type 4 room with a markedly smaller Type 9 room. Three examples occur at Medford Ranch and Black Dog Village Sites. In all three instances the subordinate Unit 9 is contiguous to the south wall of the dominant Unit 4; however contiguous positions against other walls would not be unexpected. The aggregate type at Black Dog Village occurs as a separate structure, whereas at Medford Ranch, two aggregates together for a separate four-unit room block. Although this aggregate may occur at the same sites with the main room of a household cluster, so far they have not been found directly associated in the same contiguous room block. The structurally distinct position of this aggregation suggests that it is different from the other household clusters involving either Type 1 or 
Type 2 units in the dominant position. However, the fundamental pairing of units bears some resemblance to the structural relationship of rooms assigned to Aggregate Type IV. In the Type IV aggregate, the contiguous rooms are of comparable size, and tend to occur in linear patterns, rather than four cell clusters as observed at Medford Ranch Site.

Aggregate Type VI (Figure 23)

This is a parity aggregation of medium to small Type $6 \quad(n=1)$ and Type $8(n=16)$ rooms. The aggregation often consists of two $(n=7)$ or three $(n=1)$ contiguous rooms of nearly equal size which form separate structures. In all instances, the pair of contiguous units have the same general shape. Nine rooms at Alibates Ruin 28, Chimney Rock Ruin, and Arrowhead Peak Ruin are quadrilateral, whereas the eight rooms at Conner, Roper, Tarbox and Turkey Creek Ruins are circular to ovai. Most quadrilateral rooms share a comon wall, but at the Chimney Rock Ruin, the rooms are connected at the corners.

The differences in shape conform to general trends when the entire site context is considered. The oval and circular forms occur at sites with other isolated medium to small sized rooms, but rarely at sites with the main (Type 1 or 2) household rooms (cf. Conner, Roper, Turkey Creek). In contrast, if scattered or isolated Type 1 or 2 rooms are present, the Aggregate VI units are apt to be quadrilateral (cf. Alibates 28, Excavation Unit II; Chimney Rock Ruin). The shape of Aggregate VI units at sites having large Aggregate I-IV room blocks is less clear. At Arrowhead Peak, three contiguous quadrilateral units were superimposed over a Type 2 room, immediately adjacent to other large rooms; the topographic constraints at this mesa top site may have prevented the units from flanking the vestibule 
as is commonly the case in Aggregate Type II sites. The single exception to this trend occurs at Tarbox Ruin where two circular Aggregate VI rooms were found east of a large Aggregate Type II room block.

The size and frequent pairing of Aggregate VI rooms are strongly reminiscent of the size and double positions of subordinate Type 8 rooms often associated with Aggregate Type II. Since Aggregate Types VI and II seldom occur at the same site, I suspect that the rooms maintain comparable structural relationships within the Antelope Creek household clusters. A general similarity in spatial arrangements of units is also evident between Aggregate Types $\mathrm{V}$ and $\mathrm{VI}$.

SUMMARY OF AGGREGATE TYPES

The diverse aggregate patterns and associations of architectural units reflect either individual household clusters (Aggregate Types II, III, IV), separate subordinate components of a household clusters (Aggregate Types $\mathrm{v}$, VI), or the patterning of multiple, household clusters along a north-south axis (Aggregate Type $\mathrm{I}$ ). The analysis of room aggregations has been particularly useful in delimiting the number and kinds of architectural units affiliated with a single household cluster. Similar numbers and kinds of architectural units should be expected in communities consisting primarily of separate one room structures.

PATTERNS OF ISOLATED ROOMS

The spatial patterns represented in the free-standing isolated structures are more difficult to detect than the patterns manifest in contiguous structures, since the sequence of construction events and contemporaneity of architectural units are generally not known. Nevertheless it is assumed 
that the rooms evident in the contiguous household clusters have analogous counterparts in the pattern of isolated rooms. Thus, our present concern is with delineating the association of isolated structures at the various sites and with tentatively discerning the distance and direction of the various architectural components of the household clusters as exhibited among the free-standing structures.

One-room structures are present at 26 of the 27 sites with architectural remains (Table 26). At 11 sites, they consist of both dominant (Type 1 and 2) and subordinate (Types 3, 5-8) rooms, whereas at two sites (Tarbox and Antelope Creek 22), they consist of subordinate units as separate outlying buildings affiliated with dominant units within aggregate structures. In addition, at Alibates Ruin 28A, Arrowhead Peak Ruin, Chimney Rock Ruin 51A, Coetas Creek Ruin, and Cottonwond Creek Ruin, free-standing dominant structures occur with other poorly described isolated rooms, some of which may be subordinate room types. Thus, 18 of the 27 sites have one-room structures conforming to the predicted household cluster pattern involving both dominant and subordinate units. The subordinate free-standing rooms include the same unit types ( 3 and 8 ) that occur associated with household clusters at contiguous room structures. However, some of the small iso- . lated structuxes also have interior pits (Unit Type 5) and hearths (Unit Type 6). At Antelope Creek Ruin $22 \mathrm{~A}$ and 23 , the Footprint Site, Jack Allen Site, and the Marsh site, the free-standing large household rooms occur only with exterior pits and cists (Units 7, 10, and 11), rather than separate subordinate outbuildings.

In contrast to this common pattern, the architectural remains at five sites (Conner, Pickett, Roper, Turkey Creek and Zollars) consist only of 
Distribution of Architectural Units and Aggregates by Site.

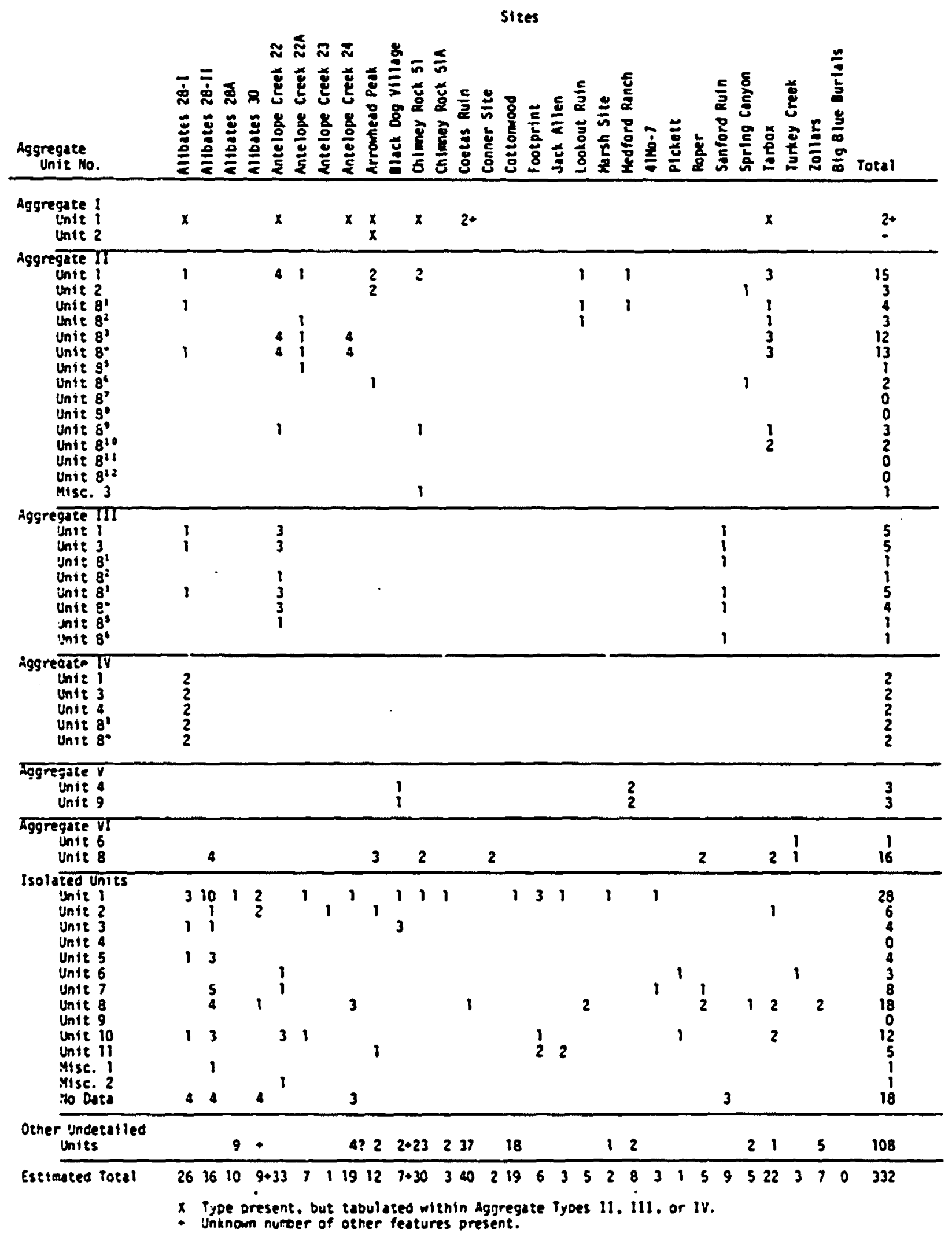


separate subordinate Types (6 and 8$)$ without any indication of larger structures. The absence of a dominant Type 1 or 2 room suggests that these sites may have been specialized and/or less permanent than the others. Duffield (1970:254) has suggested that they may have been seasonally occupied as "field houses" by people residing in larger villages. The specialized nature of these sites will be examined in more detail later.

The underlying distribution patterns of single room structures are not easily discernible at the large commuities. The limited excavation areas, coupled with small samples of exposed structures and poor temporal control at most sites, are the major factors hindering analysis of community patterns. The most extensive and thorough excavations at a community with free-standing rooms was conducted at Alibates Ruin 28, Excavation Unit II (Appendix A). The 16 main household rooms are scattered haphazardly across the $4078 \mathrm{sq} \mathrm{m}$ excavation area. All are oriented in the same direction and do not appear to face or delineate one or more "plazas" in this portion of the site. The artifact distribution indicates that outside activities occurred in front (east) of individual dominant rooms but the rooms are not arranged around or focused on any definable outside public use area. Furthermore the density of artifacts indicates that several construction episodes and multiple occupations are represented. If a plaza is present at Alibates, it may be located in the unexcavated $75 \mathrm{~m}$ interval between Excavation Units I and II. However, the distribution of recognizable structures at Tarbox, Cottonwood Creek, Coetas Ruin, Antelope Creek Ruin 22 and.other large communities does not focus on or define a plaza area.

Archaeological evidence for public architecture (comnunal or monumental structures, mounds, defensive earthworks, etc.) is not clear. No 
palisade ditchworks or stone barrier walls have been reported from Antelope Creek sites, even though the placement of hamlets atop Arrowhead Peak, Saddleback Mesa, and Landergin Mesa has often been regarded as a defensive measure (Krieger 1946).

To date, the clearest example which possibly represents comunal construction activity is the mount encompassing the contiguous room block at Alibates Ruin 28. Here, the contiguous room block containing 16 architectural units was buried with $2.00 \mathrm{~m}$ of fill over the sterile base (Baker and Baker 1941b:33). The natural accumulation of such quantities of fill is unlikely given the mound's location near the bedrock rim at the edge of the inner valley wall. Furthermore, the fill must have been loaded during a fairly short interval, since wall remnants were found standing $1.90 \mathrm{~m}$ tall. Although the fill characteristics are not described by the WPA archaeologists, earlier stratigraphic descriptions mention multiple levels ranging from 0.60 to $2.00 \mathrm{~m}$ below surface inside Room 19 (Olson 1929:7; Mason 1929, Book $A: 15)$. Moreover, the WPA archaeologists encountered a wall segment superimposed $1.22 \mathrm{~m}$ above the floor level of Room 19 (Baker and Baker 1941b: 32). The presence of nine above-floor burials along the northwest slope of the mound (overlying Room 11) suggests that considerable filling had accumulated prior to the abandonment of adjacent ruins. Despite these diverse lines of evidence, the presence of a culturally constructed mound over Alibates Ruin 28, Unit $I$, is still regarded as tenuous. Alternatively, the mounding could reflect the collapse of second story rooms. Elsewhere, multiple tiers of rooms were noted at Saddleback; however, the upper tiers were placed offset on bedrock up the steep slope of the mesa (Holden 1933; Haynes 1932). A prominent "mound" 0.91-1.07 $\mathrm{m}$ tall has also been recorded 
over the main structure at the Spring Canyon Site (Duffield 1964:48-50). Even though the deposits were thought to be windblown, the underlying structure is the largest reported from the study area, and typical interior features such as hearths, roof support posts and channels were not encountered. The presence of either mounds or multiple-storied dwellings at other sites is not well documented. Considerable attention should be paid to the nature of overlying fill during future excavations at such sites.

Since the spatial relationships of free-standing rooms is difficult to discern at sites with multiple households, the pattern at seven less complex sites was used. Site maps were employed to measure distances and general direction of the suborainate units from the dominant household unit. Pit features (Unit Type 11) were excluded from consideration since they presumably served a variety of functions ranging from acobe mortar procurement areas to cache and storage facilities associated with a wide variety of processing activities. The sample consists of outlying subordinate units from Antelope Creek Ruin 22A $(n=1)$, Black Dog Village $(n=4)$, Lookout $(n=2)$, Medford Ranch $(n=5)$, Sanford $(n=3)$, Spring Canyon $(n=3)$, and 41 Mo-7 $(n=2)$. A third of the sample consisted of features unassignable to specific unit types. However, the identifiable unit types seem to be spaced at fairly regular and discrete intervals away from the dominant architectural unit (Table 27). Stone-lined cists (Type 10) occur within $3.6 \mathrm{~m}$ of the dominant structure. Aggregate Type $v$ buildings (Units 4 and 9 ) range from 3.7 to $7.2 \mathrm{~m}$. Isolated Unit Type 8 rooms occur from 7.3 to $14.6 \mathrm{~m}$ whereas Unit Type 3 rooms range from 16.2 to $18.3 \mathrm{~m}$ and the single Type 7 unit was located approximately $25 \mathrm{~m}$ away. In addition over 758 of subordinate units were located north, northeast or east of the dominant household room. This 
Table 27.

Spatial Relationship of Free-standing Dominant and Subordinant Features at Simple Household Sites.

Direction from Dominant Unlt

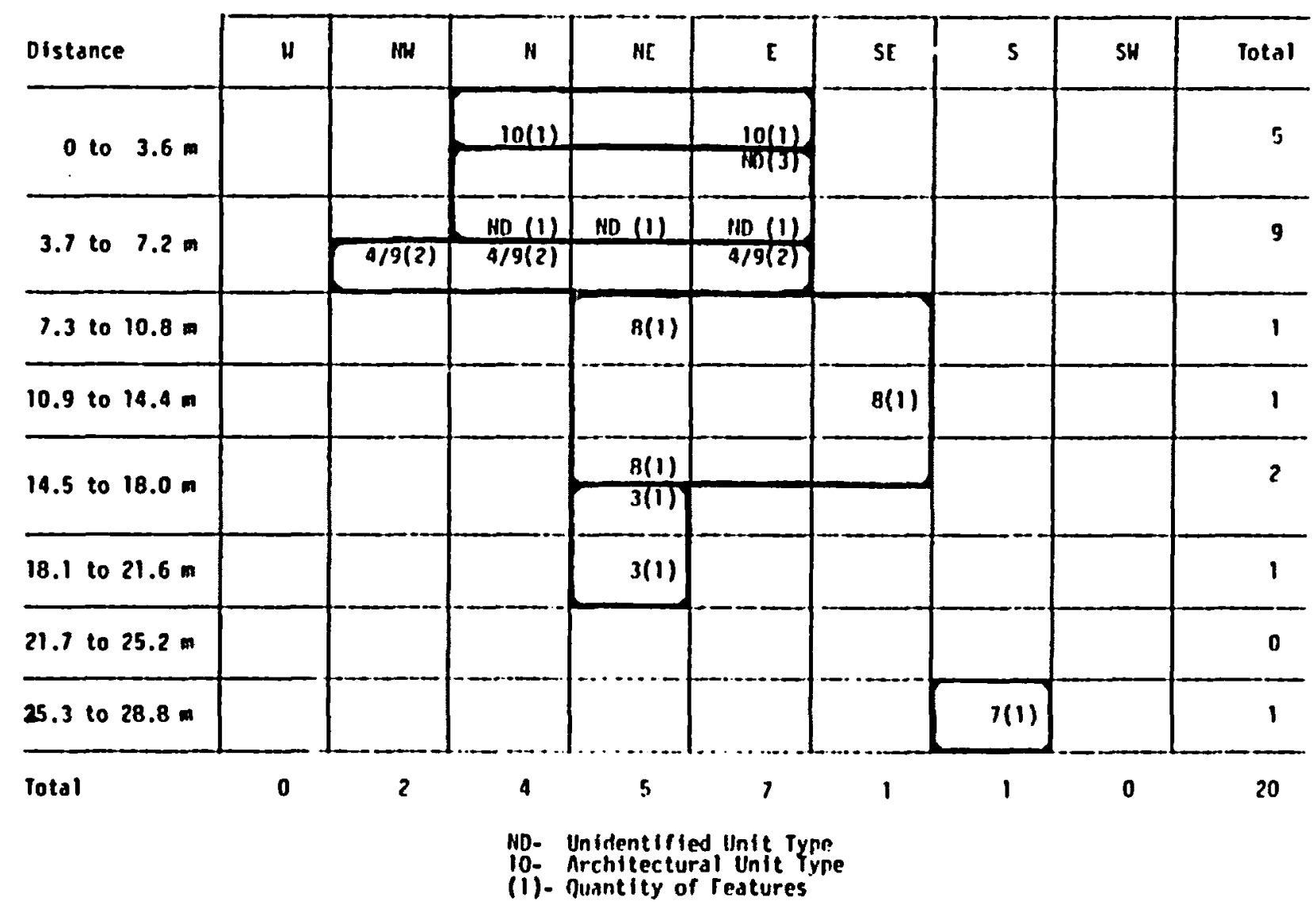


analysis indicates that some of the outlying structures can occur at considerable distances from the main structure, and at larger comnunities mere proximity of separate small structures to a major room may not be a sufficient justification to assume household affiliation.

SUMPARY OF THE SPATIAL ASPECTS OF COMMUNITY PATTERNING

The following trends were discerned from examining the spatial patterns of architectural units at 27 sites:

(1) More sites contain isolated free-standing structures than contigunus room block structures.

(2) The number of architectural units occurring as one-room structures is nearly equal to the number of units involved in large contiguous room block structures.

(3) Six unit aggregate types reflect either individual household clusters (Aggregate Types II-IV), separate subordinate components of a household cluster (Aggregate Types V, VI), or the arrangement of multiple household clusters along a north-south axis. (Aggregate Type I).

(4) The contiguous arrangement of several main household cluster rooms takes precedence over the placement of subordinate rooms within each household cluster.

(5) The typical contiguous household cluster consists of a single main room and from one to six $(\bar{x}=2.4)$ subordinate rooms (Unit Types 3, 4, or 8) placed along the outside wall or east of the vestibule.

(6) Subordinate rooms within larger room blocks tend to occur near the front (east) of the main household unit but the few such 
units placed near the back of the structure are significantly larger than the same kinds of rooms placed near the front.

(7) The aggregate pattern IV (which has subordinate Type 4 rooms adjacent to the antechamber) occurs only when spatial limitations preclude the addition of subordinate units along the north or south walls of the main room. Consequently, Type 8 rooms along the outside walls of the main room are believed to be functionally equivalent to the Type 4 rooms, next to the antechamber.

(8) The pairing of small to medium sized rooms as separate structures in Aggregates $v$ and $V I$ morphologically resembles and perhaps is functionally equivalent to the pairing of subordinate Unit Type 8 rooms cormonly found in Aggregate Types II-IV.

(9) The distribution of isolated and contiguous rooms at large sites does not indicate the presence of definable public use areas or plazas.

(10) The same range of architectural unit types present in large room blocks also occurs as isolated one-room structures.

(11) The isolated subordinate room forms seem to be spaced at fairly regular and discrete intervals away from the main household room. Subsequent chapters will examine the functional temporal, and intersite spatial parameters behind some of these trends.

\section{Architectural Site Types}

One final aspect of analyzing intrasite spatial variation is concerned with defining a number of different architectural site types as a foundation for the subsequent examination of intersite functional relationships and intersite spatial patterning. The major differences among the sites under 
consideration reflect different associations of architectural units and the number of architectural features at the community level (Table 26). More specifically, the main criterion should be based on the presence and number of dominant household rooms (Unit Types 1 or 2 ), subordinate rooms (Unit Types $3-6,8,9)$, and pits or cists (Unit Types $7,10,11$ ). The presence and number of dominant household cluster rooms is used to define three major types of sites--subhomesteads, homesteads, and hamlets. Each type is subdivided into simple versus complex site forms based on the presence of other subordinate room forms. Thus six basic architectural site types are tentatively recognized as part of the Antelope Creek phase settlement system (Table 28).

Simple Subhomesteads consist of sites with less than three "subordirate" rooms, with or without associated pits/cists, but lacking evidence of the large dominant household rooms. The two simple subhomestead sites included in the study sample are Pickett and Conner.

Complex Subhomesteads differ from the simple subhomesteads only in the number of rooms present at the site. They typically have three or more rooms, but in all instances still lack evidence of the dominant household room form. The three complex subhomesteads included in the study are the Turkey Creek Site, Roper Site and the zollars site.

Simple Homesteads consist of sites with only a single dominant room, possibly with or without associated pits/cists but no evidence for subordinate rooms. These sites include Marsh, Jack Allen, 41Mo-7, and possibly Antelope Creek Ruin 23.

Complex Homesteads are sites with but a single dominant room in association with one or more subordinate rooms. All features are thought to 
Table 28.

Distribution of Dominant, Subordinate Rooms

and Pit/Cists by Site Type.

Unit Types

\begin{tabular}{|c|c|c|c|c|c|c|c|}
\hline & $\begin{array}{r}\text { Domin } \\
\text { (Units } \\
\text { Pabulated }\end{array}$ & $\begin{array}{l}\text { ant } \\
1,2) \\
\text { Reported }\end{array}$ & $\begin{array}{l}\text { Subordin } \\
\text { (Units 3- } \\
\text { Tabulated }\end{array}$ & $\begin{array}{l}\text { ate } \\
6,8,9) \\
\text { |Reported }\end{array}$ & $\begin{array}{c}\text { Pits/Cis } \\
\text { CUnits 7, } \\
\text { Tabulated }\end{array}$ & $\begin{array}{l}\text { sts } \\
10,111 \\
\text { |Reported }\end{array}$ & $\begin{array}{l}\text { Unidentified } \\
\text { Reported }\end{array}$ \\
\hline $\begin{array}{l}\text { Simple Subhomestead } \\
\text { Pickett } \\
\text { Conner }\end{array}$ & & & $\frac{1}{2}$ & & & & \\
\hline $\begin{array}{l}\text { Complex Subhomestead } \\
\text { Turkey Creek } \\
\text { Roper } \\
\text { 2ollars } \\
\end{array}$ & & & $\begin{array}{l}3 \\
5 \\
2 \\
\end{array}$ & 5 & & & \\
\hline $\begin{array}{l}\text { Simple Homesteads } \\
\text { Marsh } \\
\text { Jack Allen } \\
41 \text { llo-7 } \\
\text { Antelope Creek } 23\end{array}$ & $\begin{array}{l}1 \\
1 \\
1 \\
1\end{array}$ & & & & $\begin{array}{l}2 \\
2\end{array}$ & & \\
\hline $\begin{array}{l}\text { Complex Homesteads } \\
\text { Black Dog Village } \\
\text { Antelope Creek 22A } \\
\text { Lookout Ruin } \\
\text { Spring Canyon } \\
\text { Medford Ranch } \\
\text { Sanford Ruin } \\
\end{array}$ & $\begin{array}{l}1 \\
2 \\
3 \\
1 \\
1 \\
1\end{array}$ & & $\begin{array}{l}4 \\
4 \\
4 \\
2 \\
5 \\
5\end{array}$ & $\begin{array}{l}x ? \\
2 \\
x \\
3\end{array}$ & 1 & & $\begin{array}{l}2 \\
2\end{array}$ \\
\hline $\begin{array}{l}\text { Simple Hamlets } \\
\text { Footprint } \\
\text { Albates Ruin 28A } \\
\text { Chianey Rock Ruin 51A }\end{array}$ & 3 & $\begin{array}{l}x \\
2\end{array}$ & & $x$ & 3 & 3 & 9 \\
\hline $\begin{array}{l}\text { Complex Hamlets } \\
\text { Arrowhead Peak } \\
\text { Antelope Creek 22 } \\
\text { Antelope Creek 24 } \\
\text { Albates Ruin 28-1 } \\
\text { Alibates Ruin 28-11 } \\
\text { Alibates Ruin 30 } \\
\text { Chimey Rock Ruin 51 } \\
\text { Coetas Ruin } \\
\text { Cottomwood Creek Ruin } \\
\text { Tarbox Ruin }\end{array}$ & $\begin{array}{r}5 \\
7 \\
1 \\
7 \\
11 \\
4 \\
3 \\
2 \\
1 \\
4\end{array}$ & $\begin{array}{l}x \\
x \\
x\end{array}$ & $\begin{array}{r}4 \\
24 \\
11 \\
14 \\
13 \\
1 \\
4 \\
1 \\
15\end{array}$ & $\begin{array}{l}x \\
x \\
x\end{array}$ & $\begin{array}{l}1 \\
4 \\
1 \\
8\end{array}$ & & $\begin{array}{c}2 \\
3 \\
4 \\
4 \\
4 \\
23 \\
37 \\
18 \\
1\end{array}$ \\
\hline
\end{tabular}


relate to a single household. These sites include Antelope Creek Ruin 22f, Lookout Ruin, Medford Ranch, Sanford Ruin, Spring Canyon and possibly Black Dog Village.

Simple Hamlets are sites consisting of multiple dominant rooms possibly associated with pits or cists, but lacking associated subordinate room types. The various structures are presumed to be contemporaneously occupied by more than a single household group. The simple Hamlet sites include Footprint, Alibates Ruin $28 \mathrm{~A}$ and Chimney Rock Ruin 51A.

Complex Hamlets are those sites with multiple doninant rooms associated with subordinate rooms and possibly pit features. They include Arrowhead Peak, Antelope Creek Ruins 22 and 24, Alibates Ruins 28 and 30, Chimney Rock Ruin 51, Coetas Creek Ruin, Cottonwood Creek Ruin and Tarbox Ruin.

\section{Summary}

This chapter has focused on systematically and explicitly defining architectural units, the spatial arrangement of those units within communities, and developing a site typology for the segment of the Antelope Creek phase settlement pattern which has architectural features. In addition, the architectural range of variation, select trends evident in the patterns of variation, and some correlations between architectural units have been postulated. Some variants, such as the number of roof support posts or the nature of wall foundations, merely reflect necessary structural reinforcements. However functional, temporal and intrasite spatial differences may underlie other morphological variations. The importance of explicitly defining the architectural, community and site units is to ensure that subsequent comparisons employ comparable units for analysis. 
CHAPTER 6

FUNCTIONAL CORRELATES OF ARCHITECTURAL UNITS

AND SITE TYPES

\section{Introduction}

The analysis of intrasite architectural patterns have thus far been based primarily on morphology and spatial arrangements of architectural units at excavated sites within the study area. In a number of instances, certain correspondences between different architectural unit types have been postulated because of similarity in the size or the arrangement of features and/or the unit positions relative to others. This chapter is concerned with examining the distribution of artifactual materials in an attempt to discern the activity sets associated with the various unit types. Variation in assemblage composition between architectural unit types presumably reflects functional differences. From this the structural relationship between unit types can be inferred. At a higher level, the distribution and density of materials from the entire excavation area can be employed to establish the general range of activities at a site and relationships between a scries of communities or sites within the locality.

The success of these analyses ultimately depends on the ability to integrate diverse artifact typologies and to assign appropriate functional meanings. In some instances, such procedures were impossible owing to adequate material descriptions and the inability to translate tool morphology to any proper functional activity. Few detalled wear or replicative 
studies have been conducted on some distinctive Antelope Creek artifacts. Nevertheless, the functions of most-artifacts are inferable, and existing ethnographic documents provide functional information for a number of items (Hughes 1968:338-336; Weltfish 1977).

\section{Functional Aspects of Architectural Unit Types}

Some activities associated with certain architectural unit types can be inferred from the occurrence and patterning of internal features. This patterning has been discussed in conjunction with specific unit types throughout Chapter 5. However, our concern is with the artifact and nonartifact remains associated with the different unit types. Unfortunately most archaeologists involved with Antelope Creek excavations have not been overly concerned with reporting the quantities or provenience of materials. Partial artifactual information is only available from 11 sites excavated by the WPA and the amateur Norpan Archaeological Society. These include Antelope Creek Ruins 22, 22A, 23, 24, Alibates Ruins 28, 28A, 30, Chimney Rock Ruins 51, 51A, Roper and Pickett Ruins. Although these sites contain at least 130 architectural units, artifactual remains are reportedly found only with 83 units, representing only eight of the 11 architectural unit types.

The specific identification of a unit's function is occasionally difficult to determine. Previously archaeologists have assumed that the dominant (Type 1 or 2) units functioned as habitation units, whereas the smaller, featureless, subordinate (Type 8) rooms served as storage facilities (Duffield 1970:5; Patterson 1974:14), sleeping quarters or workrooms (Krieger 1946:2). The interpretation of room features has not been without pitfalls. In the southwest, inferred "storage rooms" seldom contain 
inherent morphological attributes indicative of their function, and rarely do they have piles of stored foodstuff or distinctive artifactual assemblages which readily distinguish them from dwelling units (Hill 1970:51). To overcome such problems, the features and artifactual assemblages should be used in conjunction with ancillary studies of bone and lithic debitage, macrobotanical and palynological information.

Obvious data limitations are imposed on the Antelope Creek materials. Most field work has emphasized the collection of readily identifiable tools but has largely neglected other remains. Thus, even though the Antelope Creek phase material assemblage consists of a wide range of highly specialized stone, bone and shell tool forms which were regularly collected, few projects have bothered with the bone and lithic debitage, or systematically collected flotation and pollen samples. Local ceramics were similarly overlooked by the WPA archaeologists, except where restorable vessels were encountered. Consequently, a limited and somewhat biased tool assemblage is all that is presently available to infer room activitics.

A final concern is the imprecise context of the material remains. The WPA artifact lists occasionally allude to stratigraphic differences within the rooms. Artifacts from 22 rooms were directly associated with the floor surface; materials from 25 rooms came from the general room fill (assumed to be floor context and overlying matrix); material from 27 rooms are not assigned to any stratigraphic provenience; materials from five rooms came from subfloor contexts, whereas items for four superimposed rooms were not segregated. In an effort to maintain a large sample size, materials from most contexts were assumed to represent de facto abandoned items associated with the room (Schiffer 1972:160). Exceptions include those items occurring below the floor surface, and materials from two superimposed 
structures involving different architectural types. Realistically, materials from general room fill may represent post abandoment trash, which has nothing to do with the activities conducted in the room. Trash deposition would tend to introduce a wider range of artifactual materials and, in effect, mask discrete differences of the various room types. In lieu of more precise excavation contexts it is momentarily assumed for purposes of this trial examination of room functions that materials within rooms are not trash. Usable artifactual information is available for only 76 architectural units. Most materials are associated with architectural unit Types $1(n=28)$ and $8(n=34)$. Materials from architectural types 2 through 7 are not well represented and are from fewer than five units each. Since the artifact samples may be susceptible to considerable biases, little reliance is placed on the frequercy or even the absence of reported artifacts from these latter unit types.

Table 29 presents the distribution of artifacts by specific architectural sype. The artifacts have been grouped into six broad activity assemblages, and those specific types present in at least one-third of the architectural units are underlined to emphasize their common occurrence. Differences associated with each architectural type are discussed in turn. The large, or dominant, architectural units (Types 1 or 2) are associated with a heterogeneous assemblage reflecting a wide range of procurement, processing, ancillary manufacturing and noneconomic activities. The implements most commonly associated with these structures are precisely the kinds of items with a fairly short use span--projectile points, knives, scrapers, bone awls and drills. Although occurring less frequently, the other kinds of artifacts--hoes, digging stick tips, manos, 
Table 29.

Artifacts Associated with Architectural Unit Types 1-8.

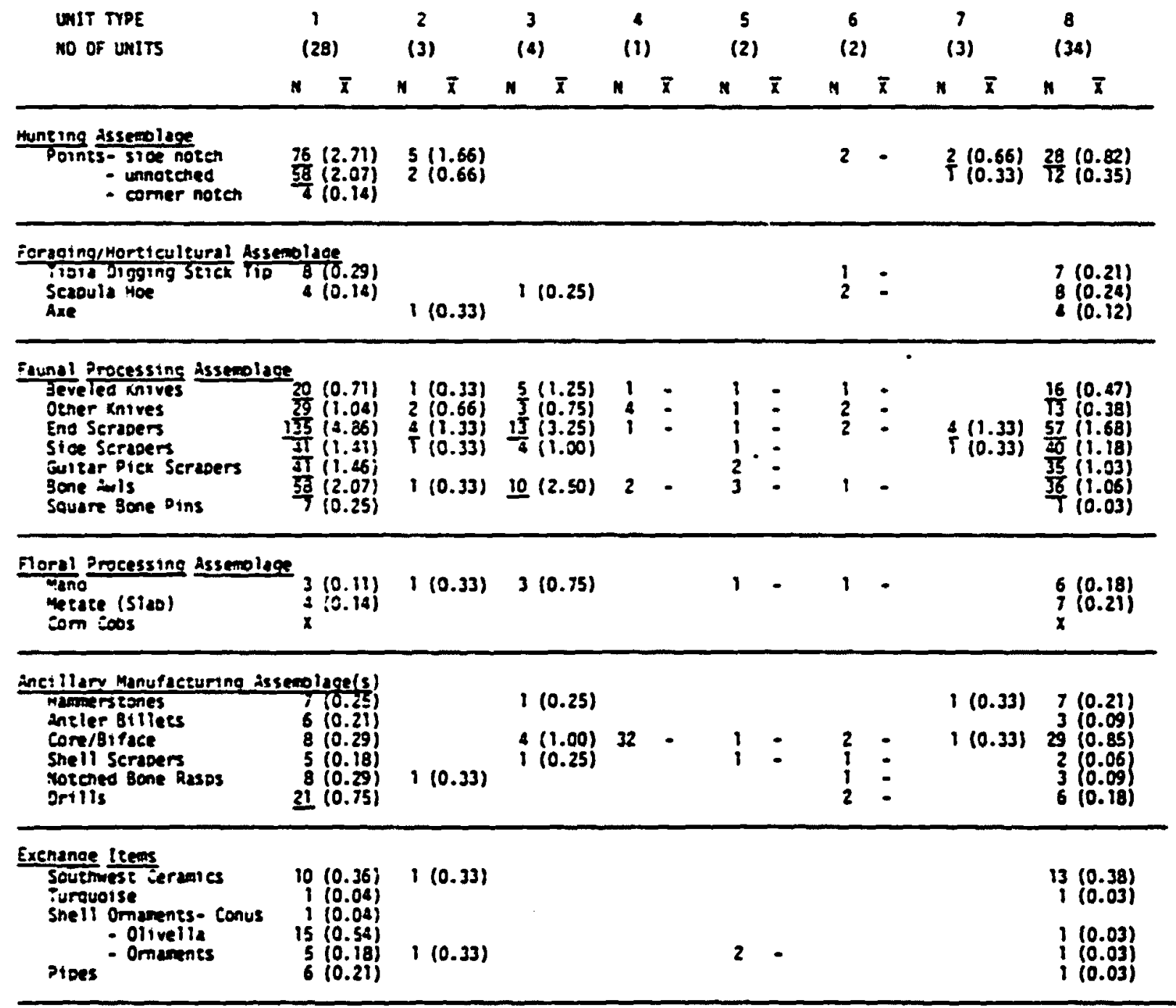

$x$ Itew present. but not quantified.

6 (uncerlines numer): lewes octur in at least one-thire of units. 
metates, flint-knapping tools such as hammerstones and antler billets, and noneconomic items like pipes and shell ornaments--generally have a greater longevity. The assemblage represents a range of both male and female activity sets (Hughes 1968; Weltfish 1977). To some extent, this broad range is not unexpected given the large size of the rooms and their regular internal division by the presence of central channels, bins, platforms and storage pits. The size and complexity of the structures and the range of activities are congruent with the inferred habitation function.

Subordinate room Type 3 is located in an antechamber position and sometimes contains a central hearth. The seemingly rare occurrence of these units at Antelope Creek 22 and Alibates 28 led some early investigators to postulate a specialized, communal and perhaps ceremonial function to the rooms (Baker and Baker 1941b:34). Presumaily activities conducted in specialized communal structures should contain a constellation of artifacts different from those found at other units. The dominant artifacts associated with the room consist primarily of faunal and floral processing implements (knives, scrapers, awls, manos): to a lesser extent knapping materials (hammerstones, core bifaces) and raxely scapula hoes and shell scrapers. Most of these objects predominantly represent female domestic . activities (Weltfish 1977:385, 429 passim). Notably absent are hunting implements, pipes, and trade items. In light of these kinds of remains, there is no clear support for a specialized or "ceremonial" set of actiities conducted within this room.

- Only one subordinate Type 4 room occurs with associated artifacts. It is a featureless room located adjacent to an antechamber at the large room block at Alibates Ruin 28. I have previously suggested that these units may be comparable to the Type 8 rooms, but spatial constraints imposed 
by the other houschold clusters within the room block led to the development of new aggregate patterns. If such correspondences are correct, then the remains in room Types 4 and 8 should be similar. Examination of the evidence is not conclusive. The materials from this single foom primarily reflect faunal processing activities, and the storage of a sizable core biface cache. The same activities occur in Type 8 units as well as evidence for a wide range of other activities. The most compelling similarity in material assemblages between the two room types is the presence of core biface caches. Twenty-three of the 29 core bifaces are associated with the four Type 8 units within aggregate rooms at Alibates Ruin 28, and another cache of 14 core bifaces was found below the floor level of another Type 8 unit. The similar occurrence of core biface caches in subordinate room Types 4 and 8 at the same site strongly suggests that they served the same storage functions.

The separate pit features inside relatively small free-standing oval structures suggest that storage was at least one major function associated with Type 5 units. The artifacts directly associated with this unit type include various kinds of knives, scrapers, awls, manos, shell scrapers and shell ornaments. Nearly all reflect a wide range of female-oriented procurement assemblages, flint-knapping tool kits, pipes, and tradeware materials. It is uncertain if raw materials were stored in the pits waiting to be processed, or if finished products were kept in the pits.

The architectural attribute separating Unit Type 6 from others is the presence of a hearth inside the small oval structures. To date, this room type has been found only at the subhomestead sites. The hearth undoubtedly provided light and heat which could have been used in many 
cooking/processing activities. The materials associated with this room type include projectile points, horicultural tools, knives, scrapers, awls, manos, drills, iune "rasps", shell scrapers and core bifaces. Notably absent were pipes, trade goods, and flint-knapping tools. Nevertheless, the implements represent an extensive range of both male and female activity sets.

Type 7 units are believed to have been small slab-lined cists with stone floors. Their dimensions are too small to have been utilized as rooms. Associated artifactual materials include only projectile points, scrapers, hammerstones, and core bifaces. Since these items predominantly reflect flint-knapping and faunal procurement activities, these storage cists may have been used by males.

Type 8 units are small featureless subordinate rooms occurring as part of larger room block aggregations or as separate isolated or paired room structures. Overall the artifacts associated with these rooms are extensively varied and include projectile points, horticultural tools, axes, knives, scrapers, awls, manos and metates, quantities of corn cobs, flintknapping equipmezt, shell scrapers, notched bone rasps, drills, Southwest ceramics, and more rarely, pipes, turquoise and shell jewelry. The abundance and variety of materials is matched only by the range of items in the large habitation rooms. However, a comparison of the density of specific artifact types found in Unit Types 1 and 8 is insightful. These small rooms contain only higher densities of chipped stone axes, bone hoes, seed grinding implements, core bifaces, and tradeware ceramics. Most of these artifacts reflect female oriented activities. As previously indicated, the core bifaces often occur as large caches inside these room 
types at Alibates Ruin 28. In view of the range and quantity of tools, these rooms seem to have served both as storage and perhaps work/processing areas. Of course, ar:illary studies of bone, lithic debitage, and micro and macro-faunal remains could help verify these activity sets.

Conceivably, the heterogeneaus artifucts issociated with Room Type 3 could reflect the mixing of discrete activity remains which occur in different room aggregate settings. In order to test this possibility, artifacts were tabulated separately for isolated, free-standing rooms $(n=7)$, paired rooms $(n=5)$ and those incorporated in larger room block aggregates $(n=18)$. It was assumed that the range of activities roughly corresponded to the range of artifact types recovered from the three aggregate settings. Iittle variation was found in artifact categories other than the "exchange items" (Table 30). The aggregate and paired room settings shared 18 of 20 artifact types, whereas the isolated room setting had 16 of the 20 types. The three settings contained some items from all assemblage groupings. Often the absence of a particular artifact type (e.g. bone hoe or manos) would be offset by the presence of another artifact type representing a similar function (i.e., bone digging stick tip) or part of the same material set (i.e., metate). Other than the "exchange items", there is no meaningful difference in the range of artifact types or inferred activities at the three different room settings. In each case a wide range of materials was procissed aucijor stored in these units. The most apparent cifference involves the abundance of trade goods found in the paired (Aggregate IV) rooms.

Similar attempts to examine activity differences among the aggregate units were thwarted by inadequate sample sizes. Only one of the 18 rooms 
Table 30.

Distribution of Select Artifacts Associated with

Isolated, Paired and Contiguous Type 8 Rooms

AGGREGATION TYPE

NO. OF UNITS
Isolated Aggregate Aggregate

II

( Sukordinate) (Paired)

$\begin{array}{lll}7 & 18 & 5\end{array}$

Hunting Assemblage

$\begin{array}{crrr}\text { Points- Sidenotched } & 2 & 10 & 15 \\ - \text { Unnotched } & 2 & 3 & 7\end{array}$

Foraging/Horticulture Assembzage

Tibia Digging stick

2

Scapula Hoe

5

Axe

34

31

Faunal Processing Assemblage

Beveled Knives

other Knives

End scrapers

side scrapers

Guitar Pick Scrapers

Bone Awls

Square Bone Pins

$\begin{array}{rrr}3 & 6 & 6 \\ 3 & 5 & 5 \\ 0 & 23 & 21 \\ 8 & 2 & 30 \\ 11 & 10 & 14 \\ 10 & 16 & 8 \\ 1 & & \end{array}$

Floral Processing Assemblage

Manos

Metates

Ancillary Manufacturing Assemblages

\begin{abstract}
Hammerstones
Antler Billets

Core/Biface

She 11 Scrapers

Notched Bone Rasps

Drills
\end{abstract}

Exchange Items

Southwest ceramics

Turquoise

Shell Ornaments Olivella

Ornaments
1

2

1

1

2

$\begin{array}{rrr}2 & 3 & 2 \\ 1 & 1 & 1 \\ 6 & 20 & 3 \\ 1 & & 2 \\ 1 & 1 & 1 \\ & 2 & 3\end{array}$

1

$2 \quad 11$

1

1

1

Pipes 
with materials was from the significantly larger subordinate rooms along the west side (positions 7-12) of the habitation structures. The reported contents were restricted to indigenous and trade ceramics. While it is tempting to attribute an exclusive storage function to these larger subordinate units, the sample of materials from the rooms west of the main unit is inadequate for valid comparisons.

Ir. surmary, a number of different activities has been postulated for the various unit types solely on the basis of artifact associations. Ideally information from other kinds of floral, faunal and lithic residues should also be used to corroborate inferred activities. In lieu of supporting evidence, the following functions should be regarded as tentative activities. Architectural Unit Types 1 and 2 are regarded as habitation structures wisere a wide range of male and female manufacturing, processing and storage activities was conducted, presumably in discrete parts of these large rooms. Although the reports have yet to provide specific intra-room artifact provenience, the patterning of the internal features provides some indications of activity areas. Storage facilities as cists and bins commonly occurred near the corners; manufacturing, processing and interior cooking probably took place within the central channel, and lounging and sleeping probably occurred along the middle of the raised benches flanking the channel. In contrast, the antechamber (Type 3) and separate circular rooms with storage pits (Type 5) seem to contain artifacts reflecting floral and faunal processing activities and material storage, which ethnographically were predominantly female tasks. Small featureless rooms (Types 4 and 8 ) were used primarily for storage, and perhaps a wide range of male and female processing activities within generalized work areas. 
The small Type 6 units containing central hearths occur exclusively at subhomestead sites. Artifactual remains indicate a wide range of male and female activities. This unit may have served as short term living quarters away from the homestead and hamlet sites. Finally, the small Type 7 units with stone slab walls and floors seen to have served as cists for the storage of predominantly male-oriented implements. This interpretation has been based on the assumption that materials found within the room are items abandoned along with the room, rather than from later dumping episodes. Existing records do not provide sufficient information about the archaeological context to warrant such an assumption. However, until detailed studies of assemblages from exclusively burned features can be conducted, the foregoing intrepretations should be regarded as working hypotheses. None of the structures seems to have served predominantly as a sacred or public building. The repetitious occurrence of extended or recessed platforms against the west wall of the dominant rooms within the same room block suggests the presence of individual household altars or shrines, if indeed a sacred function can be assumed. Moreover, the possible symbolic expressions of social differentiation as reflected by trade materials (particularly shell and turquoise jewelry) occur in small quantities at any single structure, or unit type. The paucity of these materials suggests that socially differentiated structures were not maintained.

\section{Functional Aspects of Subhomesteads,}

Homesteads and Hamlets

The three types of architectural sites have been defined in Chapter 5 based on the presence of select architectural features. The present concern is with elucidating intersite functional differences by examining the total 
range and kinds of artifacts. Previous investigators have suspected that some architectural sites served different but complementary functions. Duffield (1970:181, 188) observed a disproportionate occurrence of left bison limbs at the Conner and Pickett Sites and attributed the differences to food sharing and that the inhabitants were dependent on larger nearby groups. Furthermore, the shallow midden deposits, the high number of bone horticultural tools, and faunal evidence for a spring or summer occupation led Duffield to conclude that the Pickett site served as a summer farm or field house used by the inhabitants "to protect their crops from depredation" (Ibid.:192).

If indeed some sites were fairly short term, subservient localities to other more generalized sites, they should have a fairly distinctive artifact assemblage. Such an assemblage may be relatively specialized with a limited quantity and variety of implements which leaves a relatively high density of select tool and debitage categories. Specialized procurement or processing sites should be expected to contain no ritual paraphernalia, status symbols or trade goods.

In order to test for differences between sites, the quantities of select artifacts and debitage categories were tabulated from the 19 sites with previously analyzed collections (Table 31). The archaeologists from six different institutions analyzing the materials used different taxonomies and may have employed somewhat different criteria when recognizing specific artifact types. Consequently, slight quantitative inconsistencies may exist. Undoubtedly an intensive restudy of materials would yield important information supplemental to that reported here. Nevertheless, in order to mitigate against gross inconsistencies, the diverse typologies 
Table 31. Density of Select Artifacts by Site Type.

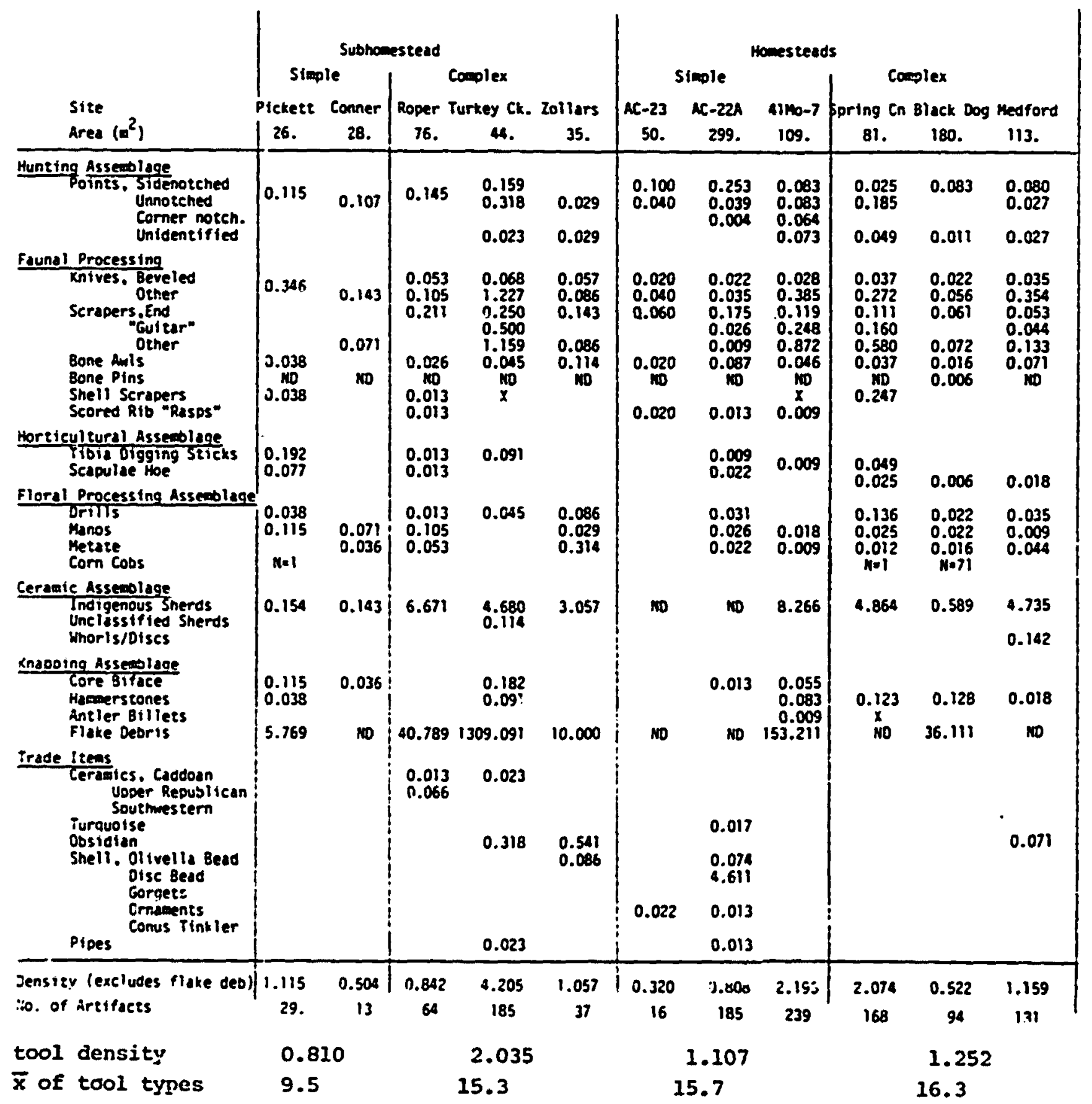


Table 31. Continued.

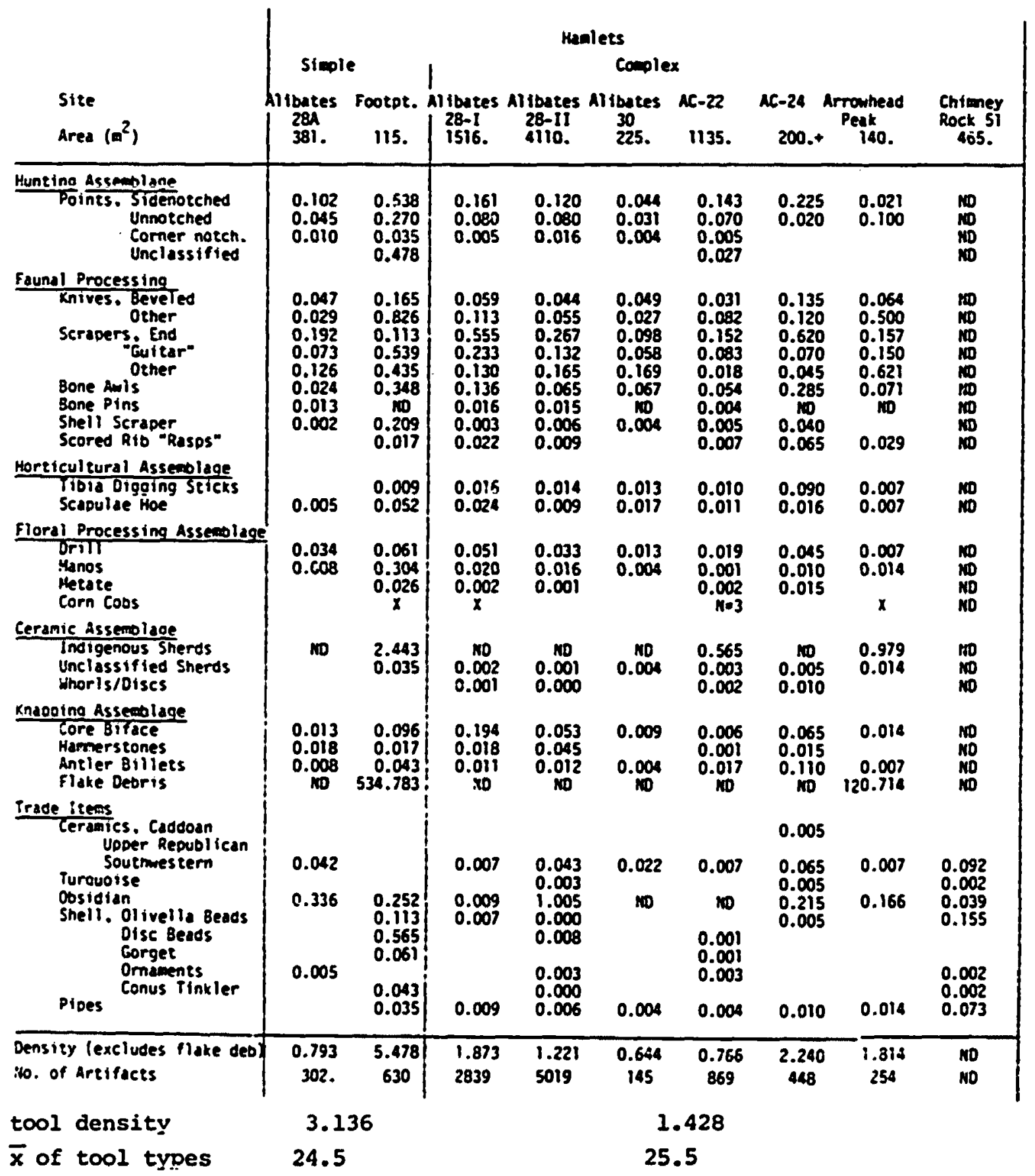


were reclassified into general types based on material form and apparent function. In order to facilitate direct comparison, the density of materials per square meter of excavation area was calculated. The material differences among sites assigned to each site type are discussed prior to generalized comparisons.

The five subhomestead sites share some similarities but are generally characterized by considerable material diversity. All share the presence of projectile points, knives, awls, and ceramics, but the quantities of materials and other varieties of artifacts differ considerably. The subhorrestead sites have an average of 13.2 artifact types represented in their assemblages, and a mean tool density of 1.545 tools per square meter.

The two simple subhomestead sites (Pickett and Conner) generally meet the criteria of subservient sites since they have very low quantities of remains and a limited variety of artifact types. The absence of trade goods and the scarcity of knapping remains suggests that both sites were fairly specialized, subsistence oriented outlying stations. The paucity of ceramics further suggests that little storage or rendering was conducted at these sites. The horticultural assemblage of scapula hoes and tibia digging sticks constitutes nearly a quarter of the assemblage at the pickett site. Coupled with the presence of corr cobs and grinding implements, the primary activities relate to the production and processing of crops and are consistent with Duffield's (1970) fieldhouse interpretation. The knives, points and drills indicate that some hunting originated from the site and limited quantities of faunal remains were processed afterwards. The Conner site assemblage is more limited, and lacks both horticultural digging implenents and knapping equipment. The dominant items include 
scrapers, projectile points and grinding implements. Again, limited hunting and the processing of animals and plants are suggested. Overall, both simple subhomestead sites reflect fairly short term occupations by both males and females, during which time a limited range of activities were done using fairly specialized tool assemblages.

The three architecturally complex subhomestead sites show considerably more diversity and complexity as reflected by a greater range and quantity of tool types. Such patterns reflect either more intensive activities, or more sustained period of occupation than those at the simple subhomestead sites. The presence of nonindigenous ceramics, obsidian flakes, marine shell jewelry, and perhaps pipes, suggests that the nature of activities is more encompassing. These kinds of items are not apt to occur at specialized, economically oriented stations which are subservient homesteads or hamlets. More likely the inhabitants were engaged in some form of direct or indirect exchange while resiaing at these sites. Other differences in the utilitarian assemblage also suggest that the complex subhomesteads are indeed quite different from the simple subhomesteads. More emphasis seems to have been placed on butchering, hide preparation and perhaps the rendering of bone grease and fat, as suggested by the higher densities of knives, scrapers and ceramics. The presence of horticultural digging implements at Roper and Turkey Creek sites and grinding implements at Roper and zollars sites reflects the multiplicity of activities. The exceptionally high density of flake debitage, core bifaces and hammerstones at the Turkey Creek site is in part because of its proximity to the Alibates Quarries. However, the large quantities of knapping residue supports the contention that flake blanks and core bifaces were being produced for trade (Green 1967:92; Bandy 1976:81). 
Overall, artifacts from the subhomestead sites seem to reflect a wide range of fairly diverse activities. In some instances, the sites may have served as subordinate outstations to other localities, but the complex subhomesteads seem to reflect quite a separate site types which could have been occupied for fairly extensive periods of time. In many regards, the extensive tool assemblage for the Roper site resembled assemblages for homesteads more than it does other subhomestead sites.

The material from the homestead sites is marked by a slightly wider range of artifact varieties per site $(\bar{x}=16.0)$, but a somewhat lower mean tool density $(x=1.179$ tools per square meter;. Considerable quantities of materials were recovered from all homestead sites except Antelope Creek Ruin 23, which contained the lowest density of material remains $(0.32$ artifacts per square meter). The paucity of recovered remains from this site may be due to the excavation procedures (which sampled few of the deposits near the structure) and perhaps a brief occupation interval. Common among the artifact assemblages from the other homestead sites are points, knives, scrapers, awls, horticultural digging implements, manos, metates, drills, pottery, and hammerstones. Not surprisingly, the assemblages reflect a wide range of economically oriented activities. The homesteads are the base for hunting and horticultural procurement, and as a locus for a wide range of floral and faunal processing activities. Several material discrepancles are readily apparent between the assemblages from the simple and complex homestead sites. These include the paucity or complete absence of bone rasping sticks, core bifaces, antler billets, and trade goods for the complex homestead sites. The occurrence of trade jewelry and pipes at Antelope Creek Ruin 22A reflects associated and scattered burial goods 
from the later cemetery area superimposed over the site. Furthermore, the paucity of flint-knapping materials possibly reflects the greater distance that all three complex homestead sites are from good quality Alibates flint exposures. Site 41Mo-7, the homestead closest to the Alibates Monument, has the greatest quantities of knapping tools and debitage.

A few anomalies are also apparent in the individual homestead assemblages. An abundance of ceramic whorls and discs at the Medford Ranch site suggests that spinning and perhaps weaving were major activities. The paucity of whorls in other site assemblages may indicate that the Medford Ranch inhabitants were supplying adjacent or distant communities with textiles.

The hamlet site assemblages are characterized by a considerably wider range of artifact varieties $(\bar{x}=25.25)$ than either the homestead or subhomestead sites, and a relatively high density of tools $(\bar{x}=1.854$ tools per square meter). The diversity of the assemblage undoubtedly reflects the increased complexity of the community structures involving multiple households. The vast quantities of remains but lack of precise material provenience hinders any attempt to discern inter-community variability. Most of the hamlet site assemblages appear to have similar quantities and densities of economically oriented materials representing all stages of floral and fauna procurement and processing. However, those sites nearest good flint exposures (Footprint and the Alibates Ruins) have higher densities of knapping tools, biface cores and flake debris.

The greatest difference between the hamlets and the other sites is in the abundance of trade goods--ceramics, obsidian, shell and turquoise jewelry and pipes. At the Footprint Site, most nonlocal materials may 
represent burial inclusions. However, the trade pieces from most of the other hamlets are from midden deposits, and in fact the 11 superimposed burials at Alibates Ruin 28-I rarely contained tradewares. Overall trade materials are concentrated at the hamlet sites. The temporal and spatial trends will be considered in greater detail in the next chapters.

A contrast of the sources of trade goods at the three site types shows a preponderance of Central plains (collared-rimmed) and Caddoan (incised and burnished) ceramics at the complex subhomestead sites, but an overwhelming association of Southwestern (Painted) materials with the hamlet sites. The occurrence of collared rimmed cordmarked ceramics with a generalized Plains aśsemblage at the Roper site might be indicative of shortterm occupation by nonlocal plains groups, since such distinctive Antelope Creek items as "guitar-pick scrapers" and the short stubby bone pins are not reported. Even though the presence of outside Plains groups cannot be ruled out, the presence of stone slab structures at the subhomestead sites suggests that they are affiliated with the Upper Canark regional variant. Alternatively, the trade ceramic differences may merely reflect analytical biases of the various investigators. Materials for half the homesteads and hamlets were analyzed under the supervision of WPA archaeologists who . were poorly versed in Plains and Southeastern ceramics types. The subtle distinctions between the various plains cordmarked wares may have been overlooked, or designated as "unclassified ceramics" by these early investigators. Clearly, the factors underlying these differences cannot be elucidated until the assemblages are reanalyzed in detail.

In surmary, the comparison of total site assemblages suggests that a wide range of different activities was conducted at subhomesteads, home- 
steads and hamlet sites. Based on limited assemblage composition, thin scatters of midden, seasonality indications based on faunal remains, and possible evidence of fooc sharing, the two simple subhomestead sites are thought to be short-term fieldhouse sites subservient to other homesteads or hamlet.s. The assemblages for most of the other complex subhomesteads, homesteads and hamlets reflect a wide range of fairly diverse activities. With the possible exception of abundant ceramic discs and whorls at Medford Ranch, and the high density of flint-knapping tools and debjtage at Turkey Creek, 41Mo-7, Footprint and Alibates Ruin 28, there is little evidense for technological specialization. Most of the sites seem to be fairly selfsufficient in terms of hunting, gathering and horticultural endeavors and in processing the various products. As might be expected, the greatest density of trade goods and religious paraphernalia (pipes) occurred at the hamlet sites, or are associated with cemetery areas. Rigorous reanalysis of the original assemblages would considerably clarify these findings.

\section{Summary}

This chapter has attempted to discern the functions of specific architectural unit and site types by examining the range of associated artifacts. The success of this approach based on the existing Antelope Creek phase information has been mixed. Considerable difficulty was encountered in discerning the functions of individual unit types because the sample of rooms with reported artifacts was small, and the context of materials associated with rooms was uncertain. In some cases, the presence of large artifacts (manos- metate sets, restorable pots etc.) or the occurrence of multiple core biface caches with a unit type were thought to reflect de facto or abandonment materials, but there is little assurance that smaller 
artifacts inside structures do not reflect trash deposition. The frequency of artifact associations within a particular unit type may strengthen the argument for a unit's function; however, considering the limitation of the sample, the kinds of activities attributed to the unit types must be regarded as tentative at this time.

The comparison of tool densities and tool varieties for entire site assemblages was more successful in delineating site functions. The provenience and context of specific artifacts were less critical when an entire site assemblage was employed. The analysis showed that there was considerable variation in tool density and variety between site types, which generally correspond to the size and complexity of the sites. But also, some differences were evident among sites assigned to the same type. Marked differences in weaving tools, horticultural tools, flint knapping equipment and trade goods may reflect different emphasis of activities conducted at different communities. Clearly, artifacts and debitage must be utilized when the functional assessments of architectural room types and settlement patterns are being delineated. The present analysis merely serves as a trial formulation. Rigorous reexamination of tool and debitage assemblages would immensely add to the understanding of Antelope Creek phase site and room functions. 


\title{
CHAPTER 7
}

\section{SOCIO-POLITICAL DIFFERENTIATION AS REFLECTED \\ BY ANTELOPE CREEK MORTUARY PRACTICES}

\begin{abstract}
Introduction
The previous examination of Antelope Creek architecture patterns and community layouts found considerable repetition in structural configuration and associated artifact inventory. The sites are generally not marked by extensive structural differentiation indicative of complex sociopolitical groups. No formally defined plazas, barrier walls, fortification embankments or elaborate public structures were recognized and the hamlets reflect considerable opportunistic aggregational development rather than planned layout and defined plaza areas. Such patterns may reflect a multilineage kinship form of organization (Chang 1958:306). In contrast, the prospects of culturally constructed mounds at Alibates Ruin 28-I and possibly Spring Canyon may imply considerably differsist and more complex forms of organization. In this chapter, the Antelope Creek mortuary practices are examined in an attempt to infer, insofar as possible, the nature of the social organization, since burial infurmation is regarded as a more sensitive indicator of social differentiation than mere architectural remains. Specifically, the Antelope Creek patterns of body disposal and the symbolic expressions of respect are described and interpreted. The social complexity as reflected by the burial data provides an appropriate context for evaluating the occurrence of culturally constructed mounds and
\end{abstract}


differential structure sizes within the Antelope Creek phase.

\section{Nature of Mortuary Variation}

Variations within the form and structure of mortuary practices are conditioned by the form and complexity of the organization characteristic of the larger society (Binford 1973:23). Burial practices consist of a technical aspect of disposing of the body, and a ritual or symbolic aspect consisting of expressing appropriate respect to the deceased. In many societies, different mortuary treatment is accorded the social persona most often along lines of age, sex, relative rank or social status, or social affiliations within the broader social units, although peculiar circumstances surrounding the death may alter the obligations of the survivors. In this section, the Antelope Creek phase patterns of body disposal is discussed prior to examining the significance of the symbolic expressions in terms of social organization.

\section{Patterns of Body Disposal}

Clear delineation of variations within Antelope Creek mortuary practices is hampered by limited and inconsistently collected qualitative observations and small sample sizes. The poor documentation is surprising con- . sidering the fascination many archaeologists have with burials. However, most burials have been accidentally encountered during excavation of architectural features. The early claims of locating vast cemetery areas adjacent to villages on Cottonwood, Tarbox, and Alibates Creeks may be accurate (Moorehead 1931:87, 111, 113). Unfortunately, specific information about these remains has been lost. Undoubtedly distinct cemetery areas away from hamlets were utilzed, but detailed burial information from a portion 
of only one isolated cemetery on Big Blue Creek is available.

The present sample consists of 47 burials involving perhaps 66 individuals from nine sites within the study area (Appendix D). Fifteen burials were found at Alibates Ruin 28, 16 at Antelope Creek Ruin 22A, five at Big Blue Cemetery, two each at Sanford Ruin, Tarbox Ruin and Coetas Ruin, and one each at Antelope Creek Ruins 22 and 23. The three multiple interments at the Footprint site differ markedly and are examined in greater detail separately. With the exception of Antelope Creek Ruin 22A and the Footprint Site interments, the number of burials is far too low to account for the extensive architectural remains. The samples are too small to determine mortality patterns at any specific site. The small burial samples are probably due to the cultural practice of utilizing separate cemetery areas coupled with excavation biases focusing on architectural remains. Although numerous other isolated burials have been found in the Canadian River Breaks, they are generally not included in the sample since most do not have culturally diagnostic grave accompaniments and cannot be confidently assigned to the Antelope Creek phase.

The common Antelope Creek phase burial practice consists of single, flexed and semiflexed primary interments in shallow graves. Exceptions to this pattern are a child, accompanied by a disarticulated juvenile skull at Tarbox Ruin (Holden 1929:29) and an extended supine child near a possible double burial at Antelope Creek Ruin 22A (Baker and Baker 1941a:88). None of the single interments are burned, and no cremations have been reported. This pattern reflects individual interments shortly after death, rather than the curation of remains in charnel areas. The rare multiple burials probably reflect interment of individuals who died at or near the same time. 
The graves for single interments are often shallow ( $\bar{x}=0.75 \mathrm{~m}$ deep) and are covered with rocks. The rock covering, which jointly serves to mark grave locations and to deter scavenging predators, is present over 28 and possibly 38 (64-878) of the burials.

Within the admittedly biased study sample, the burials occur "inside" architectural units $(n=24)$, in exterior midden areas $(n=12)$ or at cemetery plots located 50 to $100 \mathrm{~m}$ away from architectural features $(n=8)$. Most of the burials seem to occur nonrandomly. For example, nine separate burials were found inside the largest architectural unit at the contiguous room block of Alibates Ruin 28 (five other burials were recovered from separate isolated units and midden areas). Similar associations of burials within the largest room have been documented at Tarbox, Antelope Creek Ruin 22A, Alibates Ruin 28 (Excavation Unit II), and the Footprint Site, within the High Plains-Canadian River locality, and at the Stamper site in the Oklahoma panhandle (Lintz 1978a). Although this pattern seems strong, burials are not exclusively associated with the large rooms (Table 32). While 18 burials have been found in four Type 1 architectural units, four burials have been found at three isolated and contiguous Type 8 units, and two burials were found at two Type 5 units. Further, of the 24 burials "inside" . rooms, five occur on or near the floor surface, two occur slightly beneath the floor, and 15 occur in matrix above the floor. The stratigraphic positions of the two other burials are uncertain. Even burials at isolated structures and smaller architectural units are found stratigraphically above the floor surfaces. This pattern clearly reflects the encroachment of cemetery areas over abandoned structures and sites. In addition to rock piles over graves, the wall remnants of abandoned buildings may have served 
Table 32.

Antelope Creek Phase Burial Provenience

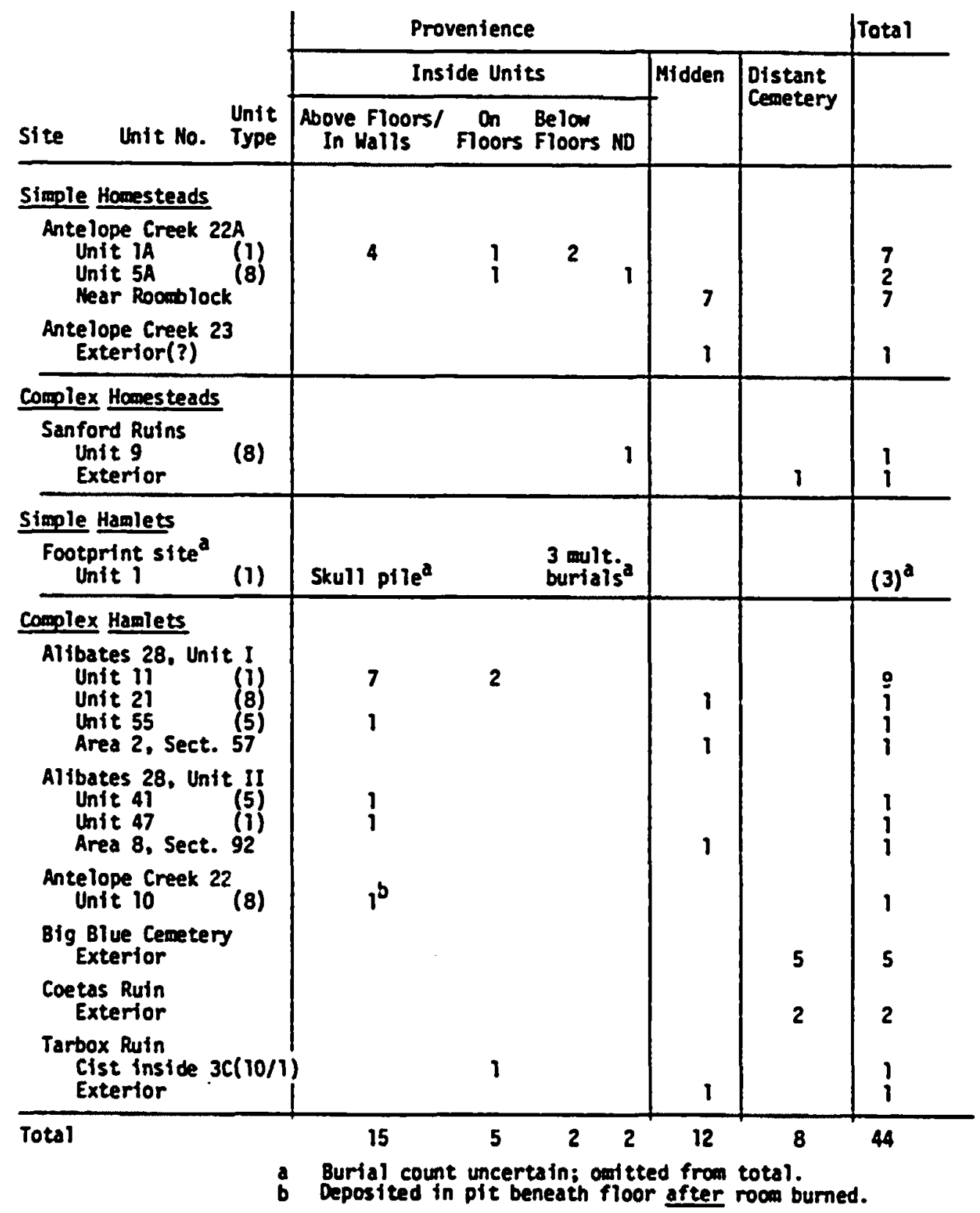


to mnemonically mark grave locations. Thus burial clusters do not usually represent the indigenous inhabitants, but more likely they are deceased individuals from adjacent sites. The occurrence of such cemetery concentrations at Alibates 28, Excavation Unit I, and Antelope Creek Ruin 22A indicate that bcin sites were abanoioned somewhat earlier than the adjacent sites in the same vicinity. Quite likely the disproportionate number of burials versus rooms at Antelope Creek $22 \mathrm{~A}$ reflect former inhabitants for the larger, adjacent inner valley wall ruin--Antelope Creek 22. Finally, the pattern demonstrates that discrete cemetery areas may occur on low floodplain terraces as well as higher ridge settings.

In all instances, the single interments occur at or adjacent to homesteads (Antelope Creek Ruins 22A, 23 and Sanford Ruin), and hamlets (Alibates Ruin 28, Antelope Creek Ruin 22, Tarbox, Coetas Creek Ruin, and possibly the hamlets along Big Blue (reek). The absence of reported interments from the subhomestead sites possible reflects their less permanent and subserient relationship to the larger homestead and hamlet sites.

The cemetery populations are generally too small to discern patterns of age and sex composition (Appendix D). The isolated burials contain a total of 11 adult males: nine adult females, 20 children, one adult of unspecified sex, and three burials of unspecified age and sex (Baker and Baker 1941; Patterson 1974; Holden 1929). Only the cemeteries at Alibates 28 and Antelope Creek Ruin 22A approach a large enough sample to examine internal patterns of interment, but no significant burial patterns involving body orientations, age/sex segregation, or placement relative to structure/midden was discerned. If the samples are representative, then these criteria were unimportant in placing the deceased within the 
cemeteries.

Finally, none of the reports indicate clear evidence of violent deaths among any of the 44 isolated interments. Two projectile points were associated with Burial 4 at the Big Blue Creek cemetery, but their context is uncertain. This does not imply that Antelope Creek phase burials placed in isolated graves died of natural causes. Eyerly (1912:2) excavated a burial with arrowpoints embedded in bone at Handley Ruins, northeast of the study locality.

In stark contrast to common Antelope Creek phase burial patterns are the skeletal remains from the Footprint site, a simple hamlet locality (Green 1967; D. K. Patterson 1974). Within the largest of three free-standing rooms, portions of an estimated 32 individuals were found in three subfloor pits and scattered throughout the room fill (Figure 25). The context and stratigraphy reflects a complex series of pre- and post-abandonment activities. Unfortunately, some critical field observations were missed, and the subsequent comingling of skeletal elements has hindered detailed analysis and interpretation of materials from this unique site (D. K. Patterson 1974:154).

The excavations uncovered three bell-shaped pits (average $1.33 \mathrm{~m}$ orifice diameter, $1.88 \mathrm{~m}$ base diameter and $0.80 \mathrm{~m}$ depth) located along the bench areas of a burned, Unit Type 1 structure. Each pit contained at least seven individuals for a total of 11 adults, six juveniles and four infants. The pit burials were mostly semiflexed in various positions and were directly associated with diagnostic Antelope Creek phase grave goods. In all three cases, some skeletons in the pits were truncated by subsequent interments or pit enlargements. The pit fill contained scattered 

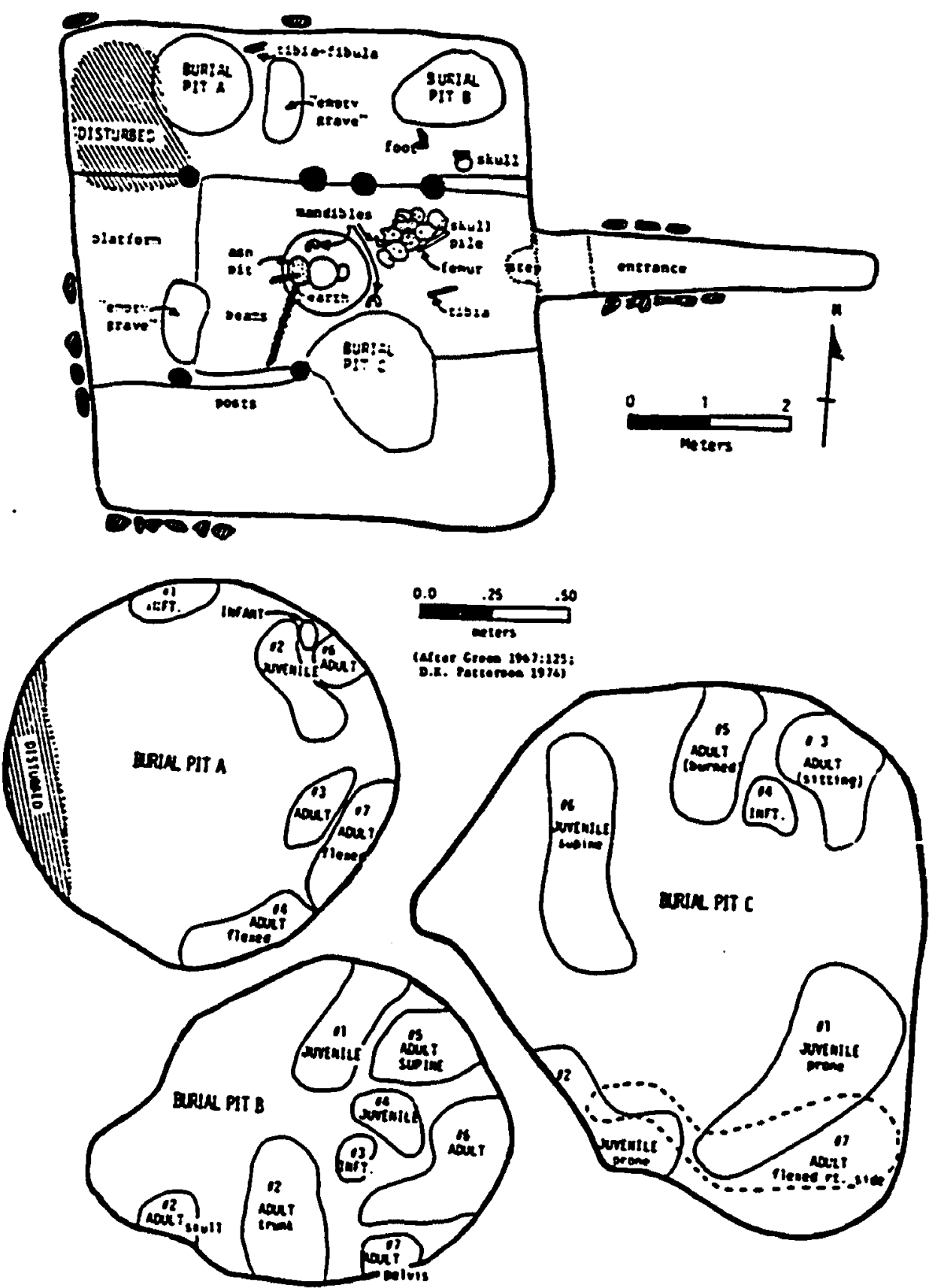

Figure 25. Multiple Interments inside Structure 1 at the Footprint Site. 
and partially articulated human remains. Clearly the pits underwent long term re-use as Antelope Creek phase ossuaries inside of a structure. The presence of charred femurs and skull fragments near a mass of unidentified charred organic material indicated that a small, but intense fire occurred inside Burial Pit $c$. The ambiguous context could reflect either a cremation within a portion of the pit, or a pit left partially open during the burning of the structure. A layer of relatively clean sand and gravel fill was found between the floor surface and the burned roof fall. This layer also contained other scattered isolated and partially articulated human skeletal remains. The most notable elements include three mandibles, two articulated tibae and fibulae (one of which was charred), an articulated foot, a femur, and various other long bone fragments (Patterson 1974:47; Green $1967: 137$ ). The sand layer was capped by burned roof fall debris and evidence of several intrusive pits was found. One pit near the northeast corner of the room contained a cluster of ten adult skulls. None of the elements displayed butchering marks, but one skull somewhat apart from the others had an articulating cervical vertebra and was found directly overlying an Alibates flint knife (Green 1967:138; Patterson 1974:56). The articulation of elements in the sandy fill and the intrusive pits suggest dismemberment and deposition prior to disintegration of connective tissues and ligaments. However, the quantity of skeletal materials within the sand lens is far less than the bulk of skeletal elements expected for the individuals represented by the skull cluster. The paucity of post-cranial remains in the room fill suggests that dismemberment occurred outside the room. Earlier violence is suggested by a possible healed arrow wound on the left frontal bone of an elderly male (Patterson 1974:175). Green (1967: 
128) has proposed the following sequence of events which he feels occurred within a relatively short span of a few years:

1. Original room constructed after partial excavation and leveling ground, and with trough extending entire length of room.

2. Room improved by some replastering and construction of rear platform.

3. Burial pits $A, B$, and $C$ dug and room abandoned.

4. Layer of fairly clean sand and gravel spread over floor, and room re-occupied for brief interval.

5. Occupation ended by possible violence and slaughter with human bones scattered about room. Burial pits $A$ and $B$ may have been re-opened at this time.

6. Roof burned and collapsed.

7. Partial filling over rcof debris, after which oblong pits ("empty graves") were dug, Burial pits A and B probably re-opened, and a shallow pit dug for burial of the ten skulls...

Two studies employing non metric cranial observations to derive a measure of population divergence have utilized the Footprint site burials as part of the Antelope Creek phase sample for both intra- and intercultural comparisons. One study concluded that the Alibates and Antelope Creek skeletal samples are not significantly different from each other, while both diverge significantly from the Footprint skeletal sample (D. K. Pat- . terson 1974:235-238, 289). Furthermore, intercultural comparisons between the Antelope Creek phase cemeteries with Pecos Pueblo skeletons and a hodgepodge of burials from eight Plains Village sites in Nebraska concluded that the Antelope Creek skeletal populations as a whole showed a closer biological relationship with the skeletal populations of the Central plains than with the Pecos Pueblo skeletal populations; but the Footprint Site skeletons were closer to the pecos population and further from the Central 
Plains skeletal population than the burials for Antelope Creek or Alibates Ruin (D. K. Patterson 1974:290).

The second study involving Antelope Creek phase skeletal materials from Footprint, Alibates, Antelope Creek and Matthews Ranch Sites concluded that the most marked divergence was between Matthews Ranch and Alibates (0.455) followed by the separation of Footprint from Matthews Ranch $(0.357)$, Antelope Creek $(0.291)$ and Alibates $(0.273)$. The closest similarity was between Antelope Creek and Matthews Ranch (0.096) followed by Antelope Creek and Alibates (0.150) (McWilliams and Johnson 1979:251). The intercultural comparisons contrasted population divergence among the four Antelope Creek phase cemeteries with the Moore (34Lf-31) and Sheffield Shelter(34Sq22) cemeteries in eastern Oklahoma as representing the Fulton Aspect (Fort Coffee phase) Caddo, the McLemore Cemetery (34wa-5) of west-central oklahoma as representing the Washita River phase, and the Majors Cemetery (25Nh-2) of southeast Nebraska as representing Upper Republican samples. The study concludes that none of the Antelope Creek phase cemeteries show sufficient similarities to indicate genetic deviation with the meager upper Republican sample. The Antelope Creek and Matthews Ranch samples are somewhat similar to the Fulton samples, but the Antelope Creek, Matthews Ranch and particularly the Footprint samples show some similarity with the adjacent Washita River sample. Indeed, the Footprint sample shows less divergence from the Washita River sample $(0.217)$ than it does with the other three Antelope Creek phase samples. Although the studies are not directly comparable, both conclude that the Footprint crania are fairly distinct from other Antelope Creek phase burials.

Both studies have assumed that the skeletal remains from each site constitute a representative sample of a homogeneous population. However, 
the diverse stratigraphic context and the results of the nonmetrical cranial analyses indicate that such an assumption may be unwarranted for the Footprint Site sample. Instead, the aberrant results may be due to mixing Antelope Creek phase individuals for the three subfloor pits with nonAntelope Creek phase crania from the intrusive skull pile. Unfortunately the commingling of skeletal elements prevents reanalysis of the Footprint materials by each contextual unit. Both studies utilized 17 isolated adult crania from the Footprint Site, but only 10 of which were from the skull pile.

In contrast to Green's proposed sequence, an alternative reconstruction which incorporates new information from the physical anthropological studies is as follows:

(1) The original semisubterranean room was constructed with a solid adobe platform against the west wall.

(2) The room was occupied and subfloor pits served as an ossuary for interring the Antelope Creek phase dead, accompanied by occasional mortuary offerings.

(3) The occupation ended in violence and the local Antelope Creek people were slaughtered and partially dismembered during a raid . by an external group.

(4) A sand and gravelly matrix was added over the floor surface and portions of the dismembered Antelope Creek phase individuals were interred in the fill shortly before the structure burned. The difference in interment practices may reflect the peculiar circumstances surrounding the deaths or the rank or status of the individuals killed during the massacre. 
(5) Trophy skulls obtained from people killed or captured during retaliatory raids were buried in the ruins of the structure.

Although this scenario is somewhat speculative, ethnology and historical documents on Southern plains villages support the practices of retaliatory raids, and the taking of captives and trophy skulls (Newcomb and Field 1967:326; Newcomb 1961:268; Hughes 1968:355).

In order to make sense of the Footprint site skeletal patterns, the different contexts must be maintained. The intrusive pits possibly containing nonindigenous individuals killed under unusual circumstances must be segregated from the pattern of subfloor interments.

Thus, the Antelope Creek phase has two basic patterns of body disposal involving either separate cemetery areas or subfloor pits at designated (ossuary?) structures, possibly at specialized sites. In both instances, the common burial pattern involves the primary interment of individuals of both sexes and all ages shortly after death. The individuals were placed in semiflexed positions but oriented in a wide range of directions, and occasionally were accompanied by grave goods. The main differences are that the ossuary structure pattern involves repetitive use of designated pits, the lack of rock in the upper grave fill, and possibly the use of cremations. Clearly the rock covering to mark graves and deter predators is not necessary inside the specializid structures. Furthermore, the evidence for cremation inside subfloor Pit $C$ is not clear, since the structure also burned, and the remains have become commingled. David Patterson (1974:55) indicates that 14 of the 66 "analytical body units" show some evidence of burning, and that an estimated 20 to 308 of the entire skeletal collection from the site has been burned to some extent. The 
cremation issue must await additional evidence from other site contexts.

\section{Patterns of Symbol ic Expressions of Respect}

The pattern of grave accoutrements indicates that not everyone was accorded the same mortuary treatment (Table 33). Overall, grave goods are not common. Only 15 (348) of the individual burials contain grave goods, but small quantities were associated with some individuais in all three subfloor ossuary pits. Items from the subfloor ossuary generally mirror the kinds of grave goods from isolated interments. Nevertheless, among isslated burials the association of grave goods crosscuts all age and sex categories.

The grave accoutrements are not very extensive or elaborate. The quantity of distinct items in isolated graves ranges from one to six,except for individual components of the shell bead necklaces (Table 34). Those burials with four or more items show a redundancy in locally manufactured utilitarian artifact classes (multiple projectile points, knives or bone antler tools) rather than extensive diversity of materials. Indigenous manufactured items are exclusively found in 538 of the burials with grave goods and are found in all age and sex groups. These items include projectile points, knives, side scrapers, awls, antler tools, tibia digging sticks, shell scrapers, cordmarked jars and basketry. Thirteen percent of burials with grave goods contain a mixture of indigenously and nonlocally manufactured goods, whereas 333 have exclusively foreign manufactured items. Nonindigenously manufactured items include turquoise beads and pendants, conch shell gorgets, whole conch shell pendants with turquoise inlays, disc shell and olivella shell beads, rounded and smoothed pieces of "coal", and possibly an elbow pipe. All except perhaps the pipe 
Table 33.

Distribution of Single Interment Sex/Age Groupings and the Association of Grave Goods

\begin{tabular}{|c|c|c|c|c|c|c|}
\hline Sex & Age Group & $\begin{array}{l}\text { Grave } \\
\text { Goods }\end{array}$ & $\begin{array}{l}\text { No Grave } \\
\text { Goods }\end{array}$ & No Data & Total & $\begin{array}{l}\text { Sex } \\
\text { Total }\end{array}$ \\
\hline \multirow[t]{2}{*}{ Children } & $0-12$ & 6 & 8 & 2 & 16 & \\
\hline & $12-20$ & 0 & 3 & & 3 & 19 \\
\hline \multirow[t]{3}{*}{ Males } & $20-30$ & 1 & 1 & & 2 & \\
\hline & $30-50$ & 3 & 6 & & 9 & \\
\hline & $50+$ & 0 & 1 & & 1 & 12 \\
\hline \multirow[t]{4}{*}{ Females } & $20-30$ & 0 & 2 & & 2 & \\
\hline & $30-50$ & 3 & 2 & & 5 & \\
\hline & 5û + & 0 & 0 & & 0 & \\
\hline & Unspecified & 1 & 0 & & 1 & 8 \\
\hline \multirow[t]{2}{*}{ Uniden. } & Adult & 1 & 0 & & 1 & \\
\hline & Uniden. & 0 & 0 & 4 & 4 & 5 \\
\hline Total & & 15 & 23 & 6 & 44 & \\
\hline
\end{tabular}


Table 34.

Distribution and Quantity of Grave Goods by Age and Gender.

\begin{tabular}{|c|c|c|c|c|c|}
\hline \multirow{3}{*}{$\begin{array}{l}\text { Gender } \\
\text { Burial no. }\end{array}$} & Unspectif. & \multicolumn{2}{|l|}{ noules } & \multirow{2}{*}{$\frac{\text { Children }}{\text { Unspectried }}$} & \multirow[b]{3}{*}{ Total } \\
\hline & & meles & Fearles & & \\
\hline & 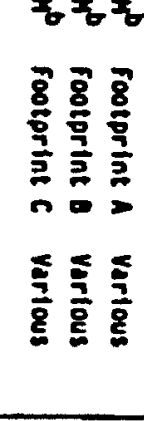 & 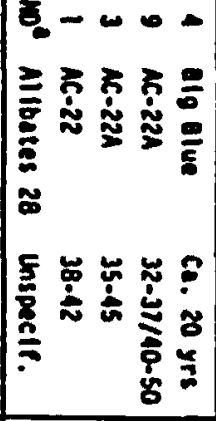 & 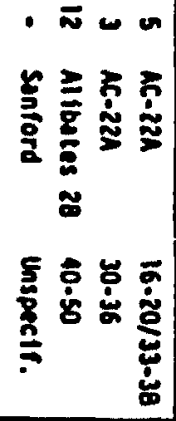 & 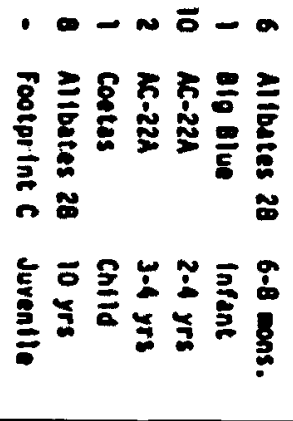 & \\
\hline $\begin{array}{l}\text { Indigenous Grave Goods } \\
\text { Projectile Points } \\
\text { Knives } \\
\text { Scropers } \\
\text { Bone Auls } \\
\text { Antler Tools } \\
\text { Tible Diggers } \\
\text { Basketry } \\
\text { Pottery }\end{array}$ & $\begin{array}{lll}3 & 3 & \\
3 & & 2 \\
1 ? & \\
& \\
& \\
& \\
& \end{array}$ & $\begin{array}{rr}2 & 2 \\
& \\
& \\
& 1\end{array}$ & $11^{4}$ & 1 & $\begin{array}{l}8 \\
7 \\
3 \\
2 \\
4 \\
3 \\
1 \\
3\end{array}$ \\
\hline 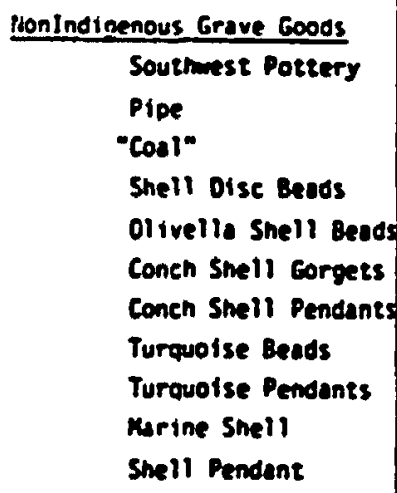 & $\begin{array}{l}* \\
1 * \\
2\end{array}$ & $1^{e}$ & $\begin{array}{rr}1 & \\
4 & \\
& 940 \\
& 4 \\
& 1\end{array}$ & $\begin{array}{rr}1056 & 116 \\
& 13 \\
& 1 \\
& \\
& \\
& \\
& \end{array}$ & $\begin{array}{c}4 \\
2 \\
4 \\
1056 \\
84 \\
3 \\
1 \\
1 \\
3 \\
1 \\
5\end{array}$ \\
\hline $\begin{array}{l}\text { Total Ieens } \\
\text { no. of Artifact classes }\end{array}$ & $\begin{array}{l}10,5 \\
433\end{array}$ & {$\left[\begin{array}{lllll}2 & 4 & 2 & 1 & 4 \\
2 & 1 & 1 & 1 & 3\end{array}\right.$} & 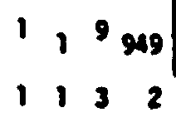 & $\begin{array}{r}10571 / 31+1 \\
111111\end{array}$ & 1191 \\
\hline
\end{tabular}


are probably from the Southwest. It is noteworthy that the elaborately painted and/or glazed Southwestern ceramics are found in midden deposits, instead of burial contexts, even though locally made containers (cordmarked jars and baskets) are a recurring burial association. A single Southwestern sherd was found beneath an adult male burial at Antelope Creek Ruin 22, but tine item was regarded as an accidental intrusion (Baker and Baker 1941a:82). Most burial items are found near the skeletal remains, but the indigenously made digging stick tips and some shell scrapers are often recovered among the rocks in the upper grave fill. Both items may have served to dig the grave and were left with the interment so that these implements of death would not be used in subsequent gardening activities ( $J$. Hughes personal communications, 1981).

The presence, quantities and classes of grave goods are often regarded as an indication of the symbolic expression of respect for the deceased and serve as a fair index for judging a person's rank or status. While accoutrements placed with a burial may express societal bereavement, at the same time the act removes items from circulation and further usage. Small quantities of utilitarian items which can be easily replaced may reflect personal possessions, but large caches of items or exotic materials involved in down-the-line exchange networks, which constitute a loss of labor expenditure and reflect a real drain of wealth, probably reflect contributed offerings. The probability of items representing contributed offerings is increased when the objects are associated with young children who had neither the skill nor means to manufacture or acquire the items by themselves. Thus, the association of grave goods with individuals of various age and sex categories provides considerable information about the complexity of Antelope Creek society. 
Grave goods accompanying adults are somewhat more common $(n=8,408)$ than goods with children ( $n=7,298)$, but overall the differences are not significant. Similarly there is no appreciable difference in the ratios of adult males $(3: 1)$ and adult females $(2: 1)$ with grave associations. However, specific associations of grave goods by age and gender are noteworthy (Table 34). Whereas indigenously made utilitarian implements are equally common among children, men and women, the vast majority of trade goods (consisting mostly of jewelry) are found only with children and women. Indeed, half the isolated child buriais with grave goods have only indigenously made utilitarian associations, while the others have only trade jewelry. The jewelry buried with children can be quite lavish. One two-tofour year old child at Antelope Creek Ruin 22A had a necklace consisting of 116 disc beads, 13 olivella shell beads, 1 turquoise bead, and a complete small conch shell pendant with a turquoise inlay. None of the children have goods of mixed cultural origins. Among adults, women have items either of local manufacture or mixed local and nonlocal maninfacture. The local utilitarian items associated with women include scrapers, antler tools, and tibia digging stick tips. In addition, women tend to have jewelry, pipes and polished pieces of "coal." In contrast, men often are interred with locally made points and knives, ceramic vessels; or perhaps digging stick tips, but rarely with nonlocal items.

\section{Interpretations}

Most utilitarian grave goods seem to represent portions of tool kits segregated by and reflecting sexual divisions of labor. The tools associated with women reflect hide working (end scrapers, antler tools) and perhaps horticultural activities (digging stick tips), whereas those 
associated with men represent hunting or butchering assemblages (points, knives, perhaps ceramic vessels). In addition, the elbow pipe and rounded pieces of smoothed "coal" found with a middle-aged woman at Antelope Creek Ruin 22A may be regarded as ritual paraphernalia--perhaps representing part of a bundle.

The Antelope Creek phase patterns of mortuary offerings show considerable parallels with the patterns recorded ethnographically for the Wichita Indians of western Oklahoma. Among the Wichita, the body was washed and dresjed in the deceased's best clothes and occasionally interred with his own personal possessions (Schmidt 1952:202).

Artifacts accompanying burials should vary widely, with few or none being found in many interments. Graves of poorer individuals would not be expected to have very many artifacts. But also, due to extensive "give-aways" and the rights of nephews and friends, graves of well-to-do people could be relatively barren of materials. Grave goods to be expected occasionally would be: stone and metal arrowheads, knives, whetstones, flint strike-a-light, and guns with male burials; very uccasionally pottery or metal containers, and various bone or metal gardening and skin-working tools with female burials; bone or glass beads and metal trade ornaments remaining from costumes with burials of both sexes, and deer or eagle-bone whistles, bone or horn sucking tubes, and a wide range of miscellaneous objects from medicine bundles accompanying both male and female "doctors." Generally speaking, grave goods would be expected to be scarce. (Schmidt 1952:206).

Aside from the historically introduced items, the similarities are clear and obvious. Mortuary goods are rarely recovered, but when present, they primarily reflect small quantities of utilitarian objects which mirror prescribed sexual division of labor. Although small quantities of grave goods are equally associated with individuals of all sex and age groupings, the preponderance of trade goods and jewelry with women and particularly children reflect ascribed or inherited positions. The occurrence of trade goods exclusively with women and their offspring tenuously 
indicates a matricentered rule of descent. Furthermore, the pipe and polished coal with a middle-aged woman indicates that she may have controlled certain kinds of ritual paraphernalia. That such vital items were removed from the larger social context indicates that they had personal significance, such as a shaman's personal bundle rather than the communal significance of a village bundle.

Although some mortuary differences are evident, the information upon which social organization could be inferred is enigmatic and based on negative rather than positive data. None of the burials are marked by large caches of tools, or excessively lavish quantities of exotic materials; nor are the differences in the quantities of grave goods clearcut along age or sex divisions, as might be expected from high status positions. While the different methods of body disposal could reflect special lineage treatment of the dead, the absence of exotic grave associations indicates that little to no rank or status differentiation is reflected in the mortuary complex.

\section{Summary}

This chapter has focused on Antelope Creek phase mortuary practices in order to discern the nature and complexity of social relationships. Although social complexity undoubtedly is reflected in the architectural remains, the burial practices are regarded as a more sensitive measure of social differentiation. If the burial patterns exhibit marked differences in the means of body disposal and the symbolic expressions of respect, then a higher social complexity reasonably can be inferred. Differences between ascribed and achieved status also should be reflected in the kinds, quantities and sources of grave goods associated with burials of different 
age and sex groupings. If major variations in Antelope Creek burial practices are encountered, then the implications of differential room size and the occurrence of artificial mounds at such sites as Alibates Ruin 28 and Spring Canyon might have to be reevaluated in terms of social complexity. Two basic patterns of body disposal were discerned from the limited sample of reported burials. The most prevalent method involves single semiflexed primary interments in shallow rock-covered graves which are placed either in midden areas, or in discrete cemeteries commonly located 50 to $150 \mathrm{~m}$ from the habitation sites. No significant differences were observed in the orientation of bodies, and the placement of graves relative to structures or middens for the various sex and age groups. All of the burials occur at homestead and hamlets, but none have been reported from the subhomesteads.

The second pattern of interment involves the use of ossuary pits inside a structure. Each of three pits inside a singie room at the Footprint site contained multiple interments which were buried at different times, as indicated by the truncation of some skeletons by subsequent interments or pit enlargement activities. Most of the burials were semiflexed primary interments. Once again, no significant differences were noted in body orientation, grave accoutrements, and age or sex differences. Thus the basic differences between the two patterns merely reflects burial placement (single vs multiple pit useage), and perhaps the amount of grave site maintenance. But little difference is evident in the individual body orientation, or the association of grave goods. Possibly the two patterns reflect specialized treatment of the dead along linage lines. The patterns of symbolic expression, as indicated by grave goods, 
do not reflect much cultural variability. Grave goods are rare, but when present, they occur in small quantities and tend to crosscut all sex and age categories. Most items reflect locally manufactured utilitarian artifacts and are thought to reflect mainly personal tool kits. Since nearly all of the nonlocal items consist of jewelry associated with women and small children, a matri-centered society with ascribed or inherited positions is tenuously inferred. These ascribed positions are ephemoral and the available mortuary evidence suggests that little to no major rank or status differentiation existed. The presence of a possible medicine bundle with one burial suggests that some positions within the community or sodality could be acquired or attained.

Since the mortuary data suggest that the Antelope Creek society was egalitarian, social complexity is thought to have little impact on architectural patterns. The contiguous arrangements of residential units within Aggregation Type I room blocks possibly reflect separate families within the same lineage. But other factors, such as differential family size or functionally discrete activity areas, may be responsible for variations in individual room sizes. Furthermore, the occurrence of an artificial mound at Alibates Ruin 28-I may reflect accumlative patterns of trash, rather than an intentionally planned and deliberately constructed mound. 


\section{CHAPTER 8}

\section{CHRONOLOGY AND TEMPORAL DIVERSITY IN ARCHITECTURE}

\section{AND COMMUNITY PATTERNS}

\section{Introduction}

This chapter is concerned with examining the temporal trends in Antelope Creek phase--architecture and community patterns. Most previous attempts to elucidate the developmental sequence of Antelope Creek architecture relied on models extrapolated from adjacent cultures and supported either by carefully selected dates (Campbell 1969:483; 1976:95-97; Crabb 1968:88; Hughes 1968:188-190) or by a few instances of superimposed structures (Veloz, Jr. n.d.). A more comprehensive examination of the available chronological information has questioned the validity of these limited approaches, but has only considered one facet of the developmental trend (Lintz 1978b). The present chapter summarizes the available relative and absolute Antelope Creek dating methods, temporally orders the sites under consideration, and delineates temporal trends evider, in the architecture and community patterns outlined in Chapter 5 .

A number of different kinds of temporal information is available to help establish the chronological. sequence of the sites. The absolute chronological methods used for Antelope Creek sites include radiocarbon dating, archaeomagnetic dating and trade-ceramic cross-dating (Tables 3-5). Substantial indirect information is also potentially available from changing stylistic frequencies within select material classes and differential densities of some artifactual remains from one site to another. Finally, 
intrasite temporal sequencing is also possible from identifying construction episodes (based on wall abutment, room alignments and differential construction methods), and the stratigraphic superimposition of other architectural features and cemetery areas.

Not all sites are amenable to the dating methods within the study sample. Furthermore, sone methods can only be applied under limited circumstances. The absolute chronological indications are examined first to establish an initial sequencing of sites. Next, the relative dating methods are examined both in terms of internal trends, and in the context of the initial site sequencing in order to expand the number of usable sites within the temporal framework. The temporal ordering of site components will form the basis for discerning changes in the architecture and comunity patterns.

\section{Absolute Dating and Initial site Ordering}

Ceramic cross dating and radiocarbon dating are the only methods using absolute dates successfully applied to sites in the study area (Tables 4-6). All of the valid Antelope Creek phase archaeomagnetic dates are from sites in Oklahoma. Southwestern trade ceramics for Antelope Creek phase sites have long been used to cross date the manifestation (Studer 1931:b; Lowrey 1932; Haynes 1932; Krieger 1946; Watson 1950; Baerreis and Bryson 1966; Crabb 1968; Lintz 1976; Snow n.d.). Identified trade sherds have been reported for only two sites within the study area. The four ceramic types present at Alibates Ruin 28 and Antelope Creek Ruin 22 date from A.D. 1300-1425 (Table 5). The interpretive use of these dates is hampered by the lack of specific provenience of the identified specimens in these complex hamlet sites and the unknown quantity of sherds 
represented by each type (South 1977:207-226). While cross-dated sherds are useful in bracketing the age of the cultural complex, unprovenienced specimens are not much use in discerning temporal changes in architecture and community patterns at these sites, since both communities experienced multiple construction episodes.

Fortunately a considerable number of radiocarbon dates is available to use in temporal ordering. Thirty-four radiocarbon dates from Antelope Creek architectural sites are fxom ten communities included in this study. All but two of the dates were obtained from charcoal (Table 4). Since bone is susceptible to factors that may cause problems in dating, two radiocarbon dates from Feature 17 at Black Dog Village were deleted from further consideration (Michaels 1973; Taylor and Slota 1979).

Fluctuations in the prehistoric amount of atmospheric $\mathrm{c}^{14}$ can cause considerable differences between the radiocarbon age and true sample age. For the interval of the Antelope Creek phase, a major discrepancy has been documented between A.D. 1400-1600 during which the radiocarbon age can vary as much as 100 years from the true age (Ralph et al., 1974). To compensate for these variations, several tree-ring calibration tables have been developed. The three most comnonly used are the Arizona calibration (Damon et al., 1974), the MASCA calibration (Ralph et al., 1974) and the "Consensus Data" calibration (Klein et al., 1982). Comparisons using these various tables indicate that for the time interval under consideration, the MASCA and Consensus Data tables consistently provide tighter clustering of dates for individual features on sites than does the Arizona table. The Consensus Data tables have been touted as a revised standard to replace all other methods. However, this table, which calibrates dates grouped into 
50-year intervals on the basis of rounding off the standard deviation, generally provides excessively narrow dates for those deviations between \pm 50 to \pm 75 years, but too broad dates for those with deviations between \pm 76 to \pm 100 years. To avoid these rounding biases, the MASCA table was selected as the most appropriate.

The provenience of the radiocarbon dates is generally the same as the original excavation unit numbers used in this study (Table 3). Three exceptions are the samples from the Roper, Arrowhead Peak and Coetas Sites. The Roper Site samples are from composite contexts obtained during the 1957 excavations. Even though the context is unknown, the scarcity of debitage and architectural features at this complex subhomestead site, coupled with the consistency of the two dates, suggests that the dates for Roper probably reflect accurately the period of occupation. The Arrowhead Peak sample is also a composite collected in 1965 by Harxison and Corbyn (Bender and others 1967:532). The sample comes from a midden area along the northeast slope between the two excavation areas examined and reported by Green (harrison, personal communication 1982). As such, the date cannot be tied to any one of the multiple construction episodes evident at the site (Appendix A). The Coetas Site dates were also collected some years after Studer's fieldwork. Hughes' unpublished fieldnotes for 5/2/65 indicate that:

We were able to find 3 spots where an adequate amount of charcoal could be collected: The first was $E$ of one of the rooms near the midale of the dug series; the next was just at the $\mathrm{N}$ foot of a huge boulder at the $N$ end of the series where we screened some bits from a midden. . . , and the last was from what appears to be roof fall in a seemingly undug room between the lst two spots.

The dates from Coetas Ruin cannot be directly linked to any of the features used to this study. However the extensive size of Coetas Ruin suggests that multiple construction episodes and perhaps occupations are represented. 
At scieral sites, multiple radiocarbon dates are available from a single archaeological context. In those instances, a weighted averaging proceaure was employed to obtain a mean date of each feature, as well as for the entire site (Long and Rippiteau 1974). The results of radiocarbon averaging are listed in Table 35.

The abundance of radiocarbon dates from different features at Alibates Ruin 28, Black Dog Village, Footprint Site ard Coetas Ruin allows further analysis of the dated contexts in order to ascertain feature contemporaneity. At most of these sites, the mean age of one or more features would appear to differ significantly from other dated features (Figure 26). In order to test contemporaneity, a series of two-tailed t-tests was run to compare the ages of features from the sites (Lapin 1975). Initially, comparisons were made between features with the least differences in mean ages. If the null hypothesis (tho: No significant difference in the ages of features) could not be rejected, then the age of both features were averaged and contrasted with the age of the next closest feature from the same site (Table 36). The results indicate:

1. At Alibates Ruin 28, Features 1 and 19 in Unit $I$ are contemporaneous, but are significantly earlier than Feature 24 in Unit II.

2. At Black Dog Village three possible components are reported. Structure 5 was the earliest, followed by the contemporaneous use of structures 3 and 4 , followed by Structure 2 .

3. At Coetas Ruin, the dates of Feature 1 and the midden are contemporaneous but are significantly earlier than Feature 2.

4. At the Footprint site, all three structures could have been contemporaneous. 
Table 35 .

Mean Feature and Site Age Based on MASCA Calibrated Radiocarbon Dates

\begin{tabular}{|c|c|c|c|c|}
\hline Site/Provenience & Mean Feature Age & $n$ & Mean Site Age & N \\
\hline Alibates Ruin 28-1 & & & $1286 \pm 42^{a b}$ & 3 \\
\hline Room 1 & $1340 \pm 85$ & 1 & , & \\
\hline Roon 19 & $1267 \pm 61^{a b}$ & 2 & & \\
\hline Al ibates Ruin 28-II & & & $1401 \pm 53^{a}$ & 2 \\
\hline Room 24 & $1401 \pm 53^{\mathrm{a}}$ & 2 & & \\
\hline Arrowhead Peak Site & & & $1320 \pm 80$ & 1 \\
\hline Composite Sauple & $1320 \pm 80$ & 1 & & \\
\hline Black Dog Village & & & $1406 \pm 24^{a b c}$ & 11 \\
\hline Room 2 (Feature i3) & $1565 \pm 205^{b}$ & 1 & & \\
\hline Room 3 (Feature 17) & $1448 \pm 66^{a b c}$ & 2 & & \\
\hline Roon 4 (Feature 6) & $1425 \pm 34^{\mathrm{a}}$ & 4 & & \\
\hline Room 5 (Vartous) & $1353 \pm 41^{a b}$ & 4 & & \\
\hline Coetas Puin & & & $1337 \pm 34^{2}$ & 6 \\
\hline Midden & $1250 \pm 70$ & 1 & & \\
\hline Room 1 & $1241 \pm 52^{d}$ & 3 & & \\
\hline Room 2 & $1401 \pm 61^{a}$ & 2 & & \\
\hline Footprint Site & & & $1412 \pm 39^{80}$ & 4 \\
\hline Room 1 & $1410 \pm 64^{2}$ & 2 & & \\
\hline Room 2 & $1390 \pm 80$ & 1 & & \\
\hline 200m 3 & $1275 \pm 95^{\circ}$ & 1 & & \\
\hline Pickete Sire & & & $1240 \pm 80$ & 1 \\
\hline Midden & $1240 \pm 80$ & 1 & & \\
\hline Roper Site & & & $1335 \pm 50^{a}$ & 2 \\
\hline Compostse Sample & $1335 \pm 50^{2}$ & 2 & & \\
\hline Sanford Ruins & & & $1250 \pm 100$ & i \\
\hline Midden & $1250 \pm 100$ & 1 & & \\
\hline Spring Canyon Site & & & $1380 \pm 100$ & l \\
\hline Midden & $1380 \pm 100$ & 1 & & \\
\hline
\end{tabular}

- averaged date following procedures of Long and Rippiteau 1974

b used mean of MASCA span; $1 / 2$ span range added to standard deviation

$c$ bone apatite and bone collegen dates omitted from consideration 
Figure 26.

Averaged Feature and Site Age Based on MASCA Calibrated Radiocarbon Dates.

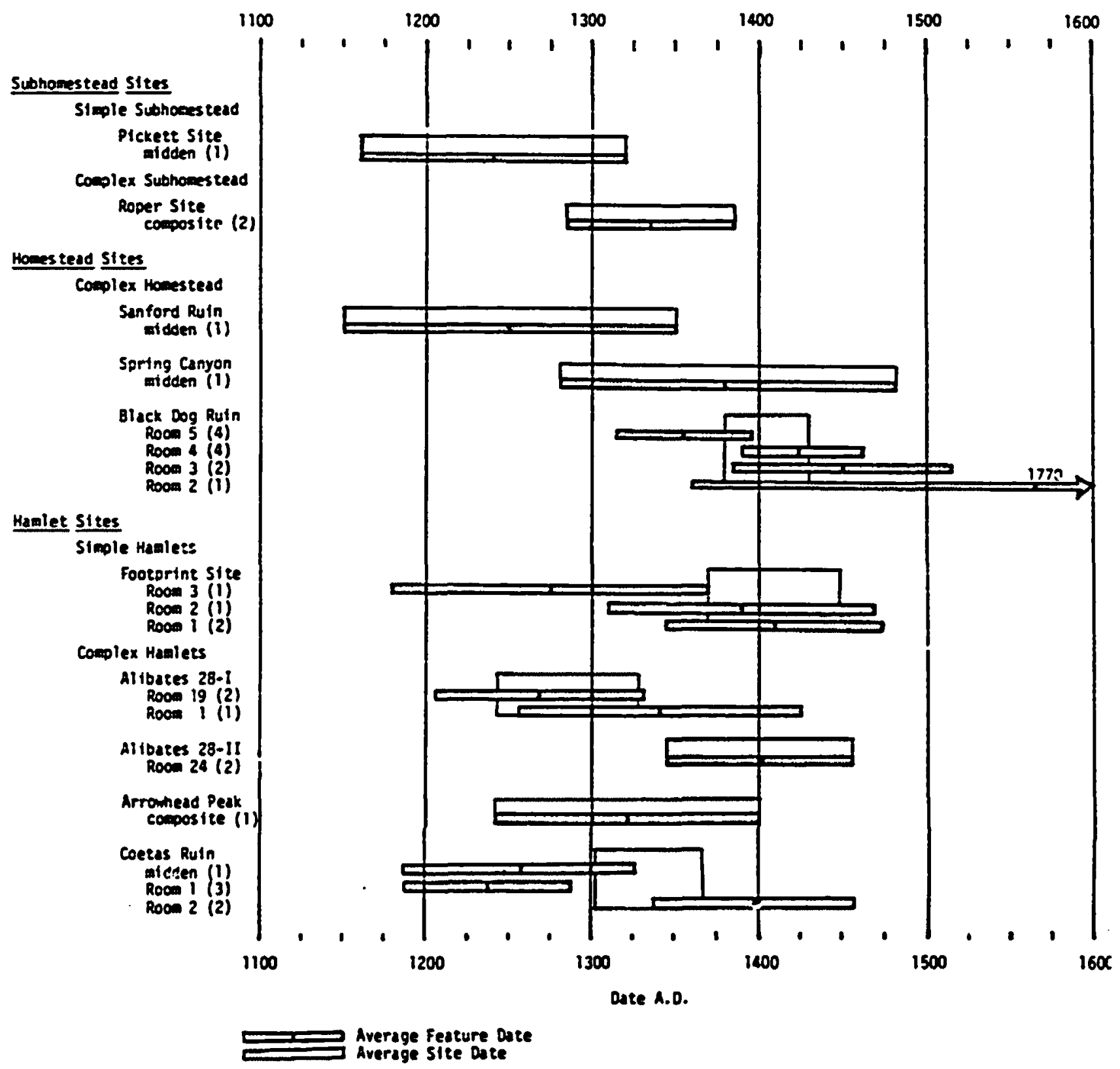


Table 36.

A Two-tailed t-Test for Contemporaniety of Radiocarbon Dated Features.

Ho: There is no significant difference in the mean age of MASCA calibrated and weight averaged Radiocarbon dates between the features under comparison.

Decision Rule: Reject Ho when t-test statistic is greater than the Critical Value

\begin{tabular}{|c|c|c|c|c|c|}
\hline Sites and Features & $\begin{array}{l}\text { No. of } \\
\text { Dates }\end{array}$ & $\begin{array}{c}\text { t-test } \\
\text { Statistic }\end{array}$ & $\begin{array}{l}\text { Degrees of } \\
\text { Freedom }\end{array}$ & $\begin{array}{l}\text { Critical } \\
\text { Valuea }\end{array}$ & Outcome \\
\hline $\begin{array}{l}\text { Al ibates Ruin } 28 \\
\text { Area I: U-1 vs U-19 } \\
\text { Area I, U-1 \& 19 vs } \\
\text { Area II, U-24 }\end{array}$ & $\begin{array}{l}3 \\
5\end{array}$ & $\begin{array}{r}4.934 \\
18.642\end{array}$ & $\begin{array}{l}1 \\
3\end{array}$ & $\begin{array}{r}127.320 \\
7.453\end{array}$ & $\begin{array}{l}\text { Accept Ho } \\
\text { Reject Ho }\end{array}$ \\
\hline $\begin{array}{l}\text { Black Dog Village } \\
U-3 \text { vs } U-4 \\
U-3 \text { \& } 4 \text { vs } U-2 \\
U-3 \text { \& } 4 \text { vs } U-5 \\
U-2 \text { vs } U-5\end{array}$ & $\begin{array}{r}6 \\
7 \\
10 \\
5\end{array}$ & $\begin{array}{l}4.098 \\
15.108 \\
19.757 \\
14.807\end{array}$ & $\begin{array}{l}4 \\
5 \\
8 \\
3\end{array}$ & $\begin{array}{l}5.598 \\
4.773 \\
3.833 \\
7.453\end{array}$ & $\begin{array}{l}\text { Accept } H_{0} \\
\text { Reject Ho } \\
\text { Reject Ho } \\
\text { Reject Ho }\end{array}$ \\
\hline $\begin{array}{l}\text { Coetas Ruinb } \\
\text { U-1 vs Midden } \\
\text { U-I \& Midden vs U-2 }\end{array}$ & $\begin{array}{l}4 \\
6\end{array}$ & $\begin{array}{r}1.764 \\
15.792\end{array}$ & $\begin{array}{l}2 \\
4\end{array}$ & $\begin{array}{r}14.089 \\
5.598\end{array}$ & $\begin{array}{l}\text { Accept Ho } \\
\text { Reject Ho }\end{array}$ \\
\hline $\begin{array}{l}\text { Footprint Site } \\
\begin{array}{l}U-1 \text { vs } U-2 \\
U-1\end{array} 2 \text { vs } U-3\end{array}$ & $\begin{array}{l}3 \\
4\end{array}$ & $\begin{array}{r}1.361 \\
11.139\end{array}$ & $\begin{array}{l}1 \\
2\end{array}$ & $\begin{array}{r}127.320 \\
14.089\end{array}$ & $\begin{array}{l}\text { Accept Ho } \\
\text { Accept Ho }\end{array}$ \\
\hline
\end{tabular}

a Lapin 1975: Table E.

b Unit designations do not correspond to architectural features used in this study. 
This procedure yields an unbiased manner of evaluating the contemporaneity of the features. Thus, based on available absolute dating methods, we can construct an initial temporal sequencing for 10 sites in the study area (Table 37).

An examination of the sequence of sites indicates that homestead and hamiet sites predating A.D. 1350 predominantly occur as major contiguous room block structures, whereas those postdating A.D. 1350 predominantly occur as isolated, free-standing structures. The early occurrence of the large room block structures has been previously documented using different analytical procedures (Lintz 1978b). The reason for raising this point is not to assign haphazardly undated sites to the sequence on the basis of room clusters, since such procedures would be circular. Rather, the issue is raised in order to justify the choice of A.D. 1350 as a reasonable date for subdividing the Antelope Creek phase into early and late "subphases." Evidence for relative dating methods must be used to assign other sites to either of the two subphases.

\section{Relative Dating and Final Site Ordering}

The indirect chronological information must be employed cautiously. Typically, stylistic changes in proportions of ceramic decorative motifs or the morphology of points and other attributes of tools are usually suitable for seriation (Duffield 1964:76). Unfortunately, inconsistency in analytical methods and the lack of adequate descriptions and quantified reporting of tools prevents the use of this method as a means of chronologically ordering the sites.

Generally, quantitative differences among types of tools are more indicative of functional variation between sites. In some cases, 
Table 37.

Initial Temporal Ordering of Sites Based on MASCA Calibrated C-14 Dates.

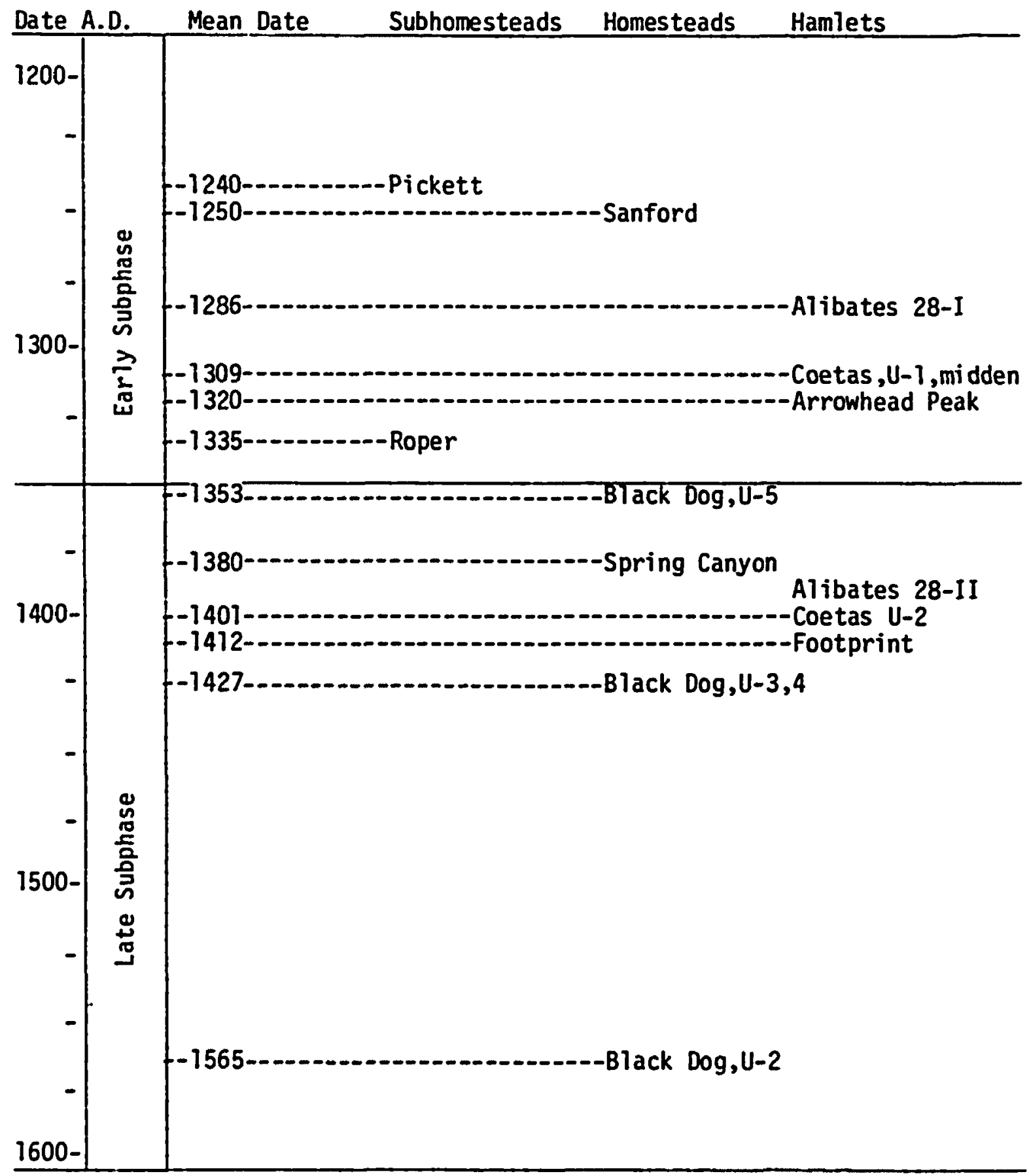


differences among assemblage compositions may reflect specialization or diversification of resource exploitation through time, but without an established chronology, the shifts in economic exploitation are difficult to discern. Less subtle are changes in artifacts not directly tied to primazy procurement or processing activities. One group of such implements indicative of temporal change is trade wares. Although rare, Caddoan and Upper Republican trade sherds have been recovered from some Antelope Creek sites; only the Southwestern materials are reported in sufficient quantities to indicate the potential for discerning change. Several researchers have suggested the intensification of plains-southwestern contacts during or immediately after the Antelope Creek phase; however, few have explicitly examined the relationship in detail prior to the sixteenth century (Hughes 1968:189; Baugh 1982a:195-198; Spielman 1982, 1983; Wedel 1982).

The specific kinds of Southwestern trade artifacts may also be interpreted in discerning temporal change, since the cultural context of the items may vary. Renfrew (1977:77) postulates a faster attenuation of trade goods in "down-the-line" exchange over those items in the "prestige-chain" exchange. Since Southwestern shell and turquoise jewelry commonly occur in burial context whereas Southwestern ceramics and obsidian do not, the trade jewelry items probably belong to a separate realm of cultural contcxi and different sphere of exchange. In general, the ceramics and obsidian are regarded as a better temporal indication, since they are more plentiful, seem to have less "intrinsic value" and consequently were aisposed more readily in trash context.

The nature of contact and exchange is also important when using trade 
items as temporal indicators. Markedly different kinds of artifäct patterns are reflected in a linear down-the-line (neighbor to neighbor) exchange as opposed to directional trade involving the development of hierarchical systems of settlements (Renfrew 1977:85). The directional trade model predicts differential quantities of trade goods commensurate with the size or importance of the site--not just the distance from the source. Valid comparisons must be made between similar kinds of sites. Trade goods are most apt to occur at the more permanent homestead and hamlet sites, rather than the open procurement and outlying subhomestead sites which reflect specialized and seasonally limited occupations. Fuxthermore, the quantity of trade goods is best understood by comparisons with quantities present in adjacent sites.

An examination of the quantitics of Southwestern materials from the radiocarbon dated sites offers mixed support for the notion of increased Southwestern contact through time (Table 31). Southwestern materials are rare at the early subphase homesteads and hamlets--Alibates 28-I, Arrowhead Peak and Sanford Ruin. Furthermore, marked differences are evident in the density of Southwestern ceramics and obsidian between the early (Excavation Unit I) and late (Excavation Unit II) at Alibates Ruin 28. Since these areas are separated by a mere $50 \mathrm{~m}$, the differential material density is believed to be primarily temporal. However, trade ceramics and obsidian seem to be relatively scarce at the late subphase homestead sites-Black Dog Village and Spring Canyon. Since both sites are east of the cheftified Alibates dolomite exposures, the paucity of trade goods may be due to spatial and site hierarchical relationships as expected for a directional exchange system. Despite these limitations, the quantity of 
obsidian and trade ceramics may be indicative of temporal change, if quantitative comparisons are maintained within discrete site clusters or nodes. Although small quantities of trade goods may not be indicative of early sites, an abundance of goods (relative to quartities at adjacent sites; may be indicative of later sites.

A review of the quantity of trade goods at the undated sites shows abundant ceramics and obsidian at Alibates Ruin $28 \mathrm{~A}$ and 30 , Antelope Creek 24, and Chimney Rock Ruin 51. In addition, considerable trade jewelry was recovered as mortuary items from Antelope Creek Ruin $22 \mathrm{~A}$ and the Footprint Site (Table 31). These items suggest that within the Alibates drainage, Ruins $28 \mathrm{~A}$ and 30 postdate the contiguous room structure at Ruin 28, and may be partially contemporaneous with some of the components at Alibates 28-II. Additional support for the late date of Ruin 28A is evident from the westward orientation of the structure, which was situated so that it faced the mound at Ruin 28-I. Overall, the density of materials and the superimposed structures at Ruin 28,Excavation Unit II suggests hamlet growth upslope towards Ruin 30 (Appendix $A$ ). The trade debitage indicates an intensification of occupation at the Alibates locality during the later subphase.

Although a small quantity of trade goods occurs at most sites in the Antelope Creek arainage, direct comparisons with quantities from the Alibates site cluster are difficult to interpret. Some decrease in quantities may be expected from both the greater distance from the southwest source area, and the absence of point locality exposures of tradeable flint resources along Alibates Creek. Nevertheless, an abundance of Southwestern ceramics and obsidian was found at Antelope Creek Ruin 24. The occurrence 
of sizable quantities of Southwestern trade goods at this contiguous room site is enigmatic. Since the pattern at other sites suggests that extensive trade developed after the general abandonment of hamlet sites with large room blocks. Perhaps the large contiguous room block at Antelope Creek Ruin 24 either represents the continuation of a form which lasted longer than anticipated, or the trade ceramics and obsidian are associated with a later component than most of the architectural remains. Considerable variations in the reported depths of overburden are thought to reflect differential amount of colluvium and the proximity to the inner valley wall; there is no stratigraphic evidence of multicomponents at Antelope Creek Ruin 24 (Baker and Baker miscellaneous files, 1941b). In view of the conflicting trends, the architectural remains from Ruin 24 will be excluded from subsequent analyses of temporal trends. The other sites along Antelope Creek are impossible to order temporally solely on the basis of trade goods.

The only other site with high densities of nonmortuary trade items is Chimney Rock Ruin along the western edge of the study area. Even though it is closest to the source area, the abundance of trade materials is indicative of a late subphase occupation (Table 31).

Another line of evidence potentially useful in temporally ordering sites and directly elucidating architectural trends is stratigraphic evidence of feature superimposition. The occurrence of burials above the floor levels at Alibates 28-I and Antelope Creek Ruin 22A indicates that they were abandoned prior to adjacent sites. In fact, the configuration of Ruin 22A is strongly reminiscent of the shape of the earliest construction episode at Ruin 22, immediately upslope. Both may have been occupied at 
the same time or in succession; however, Antelope Creek Ruin 22 accretionally expanded through two later building episodes while Ruin 22A was abandoned and used as a cemetery area.

The few examples of superimposed rooms provide specific examples of temporal change at a single locality. Seven instances of superimposed structures are present from four sites for the study area. At Arrowhead Peak these include Rooms 4, 5, and 6 built over Room 3, and Room 1 built over Room 7. Black Dog village has Room 2 built over Room 4, whereas Room 9 is built over Room 2 at Alibates Ruin 28, Excavation Unit II. In another instance at Alibates Ruin 28, Excavation Unit II, Rooms 29 and 30 were erected over Room 25, while Room 33 and 40 were built over 32 . The most complex instance at Alibates Ruin 28-II involves Room 23 built over Room 27 which in turn was built over Room 25 .

The use of superimposed architectural units to discern temporal changes should ideally entail only situations where comparable architectural unit types are involved, since many of the differences may merely reflect variations in unit function or engineering requirements imposed by the size, shape and roof support configuration of the different types. The four instances where subordinate (Type 8 or 5) units occur above dominant (1 or 2) units involve noncomparable unit types and are ill-suited to discern change in unit form through time. However, superimposed dominant units at Arrowhead Peak (Rooms 1 and 7), Alibates 30 (Rooms 2 and 9) and Alibates 28-II (Rooms 23 and 25) and the subordinate units at Black Dog Village (Rooms 2 and 4). involve comparable unit types and potentially can supply usable information. These four instances provide an opportunity to understand the nature of change; however, the general nature of temporal 
changes must be deduced from morphological differences evident between the structures at early and late subphase sites.

\section{Temporal Variations in Architecture}

\section{and Community Patterns}

Based on absolute and relative dating methods, nearly half the sites in the study can be assigned with confiuence to an early or late subphase (Table 38). The 13 sites contain 107 units or 558 of the detailed architectural features used in this study (Appendix B). In order to discern temporal trends, the association of attributes comprising the various architectural unit types for early and late subphase sites was iäenticied from Tables 11 through 23. These tables were used to determine the number of attributes and variables of units for each subphase (Table 39). Marked diffe:ences in the percentage of occurrence of any observation was regarded as valid trends in samples of at least five units. These trends are regarded as mere tendencies and should not be thought of as temporal index markers, since considerable latitude exists for individual units and a number of architectural units could not be assigned to a subphase.

Some attribute variations previously described for individual unit types are not discussed since they occur in features which could not be temporally assigned. The trends are summarized for each architectural type but are discussed by general feature type.

Temporal trends evident in the dominant household room types are based on 34 Type 1 and seven Type 2 architectural units, or nearly 728 of the total sample. Even though both types are represented in early and late subphase sites, some temporal differences may underlie the occurrence of the central channel, which is the main criterion separating the two 
Table 38

Final Temporal Ordering of Sites by Subphase

\begin{tabular}{|c|c|c|c|}
\hline & & Early Subphase & Late Subphase \\
\hline \multicolumn{2}{|c|}{$\begin{array}{r}\text { Subhomesteads-- Simple } \\
\text { Complex }\end{array}$} & $\begin{array}{l}\text { Pickett Site } \\
\text { Roper Site }\end{array}$ & $-\infty$ \\
\hline homesteads & $\begin{array}{l}\text {--Simple } \\
\text { Complex }\end{array}$ & $\begin{array}{l}\text { Antelope Creek 22A } \\
\text { Sanford Ruin }\end{array}$ & $\begin{array}{l}\text { Black Dog village } \\
\text { Spring Canyon }\end{array}$ \\
\hline Hamlets & $\begin{array}{l}- \text { - Simple } \\
\text { Complex }\end{array}$ & $\begin{array}{l}\text { Alibates Ruin 28-I } \\
\text { Coetas Ruin (?) } \\
\text { Arrowhead Peak }\end{array}$ & $\begin{array}{l}\text { Alibates Ruin 28A } \\
\text { Fntprint Site } \\
\text { Alibates Ruin 28-II } \\
\text { Alibates Ruin } 30 \\
\text { Chimney Rock Ruin } 51\end{array}$ \\
\hline
\end{tabular}

architectural types. The central channel feature is extremely common during both subphases and occurs in all kinds of topographic and geologic settings. But all of the early dominant units lacking the channel feature are from the Arrowhead Peak Site, and were built on bedrock exposires. Given the topographic and geological conditions at this site, it is not surprising to note that Arrowhead Peak has the only recorded instance of a Type 1 unit (with a central channel) occurring superimposed over a Type 2 unit built on bedrock. Considerably more eivdence suggests that the popularity of the central channel was beginning to fade during the late subphase. In all instances, the late Type 2 units occur in geologic settings which would not normally hinder the development of the channel features. In addition, superimposition of structures at Alibates Ruin 30 places Type 2 units above Type 1 units, and at 41Mo-7 and Arrowhead Peak, modifications of Type 1 units involved the filling of the channel feature and replastering the floor. Thus the distinction between the two dominant household unit types may reflect both practical considerations and the beginnings of temporal 


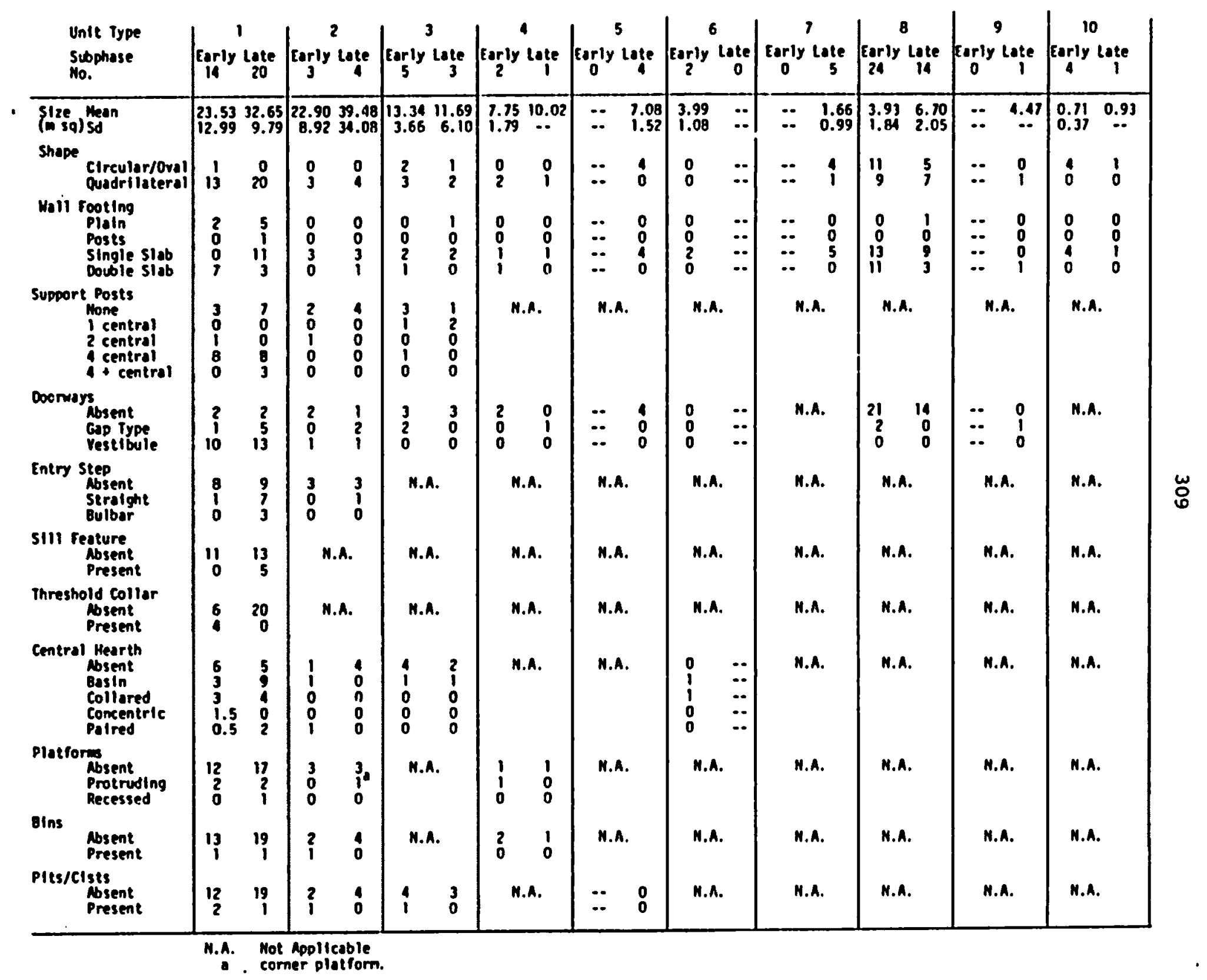

Table 39. Temporal Trends in Antelope Creek Phase Architecture. 
transitions in architecture. The channel feature is certainly an early attribute (cf. Sanford Ruin) which persisted throughout the duration of the phase.

Other basic differences between early and late dominant units involved the slift from iarige conliguous unit homesteads and hamlets to isolatcd room structures. Accompanying the reduction in the total structure size is a marked increase in the size of the dominant household rooms from $23.53 \pm 12.99$ to $32.65 \pm 9.79$ for Type 1 units and from $22.90 \pm 8.92$ to $39.48 \pm 34.08$ for Type 2 units. In addition, the methods of wall footings construction show a tendency to change from double row of upright slabs for the large contiguous structures to an increased use of single row vertical slabs and posts for the smaller structures. However, as the size of the main rooms increased, more interior roof support posts were added.

There is no significant change apparent in the occurrence of extended vestibules, but some temporal differences are evident in the constellation of associated doorway attributes. The threshold collar is exclusively an early attribute, whereas the bulbar or fan-shaped step and the sill ridge are late subphase features.

The interior features also show some changes between early and late subphases. In general, central hearths tend to be more common in the later architectural units. The full range of hearth morphology (basin, collared, concentric or manmiform, and paired) is present during the early subphase but the basin and paired forms become more ccmon later, and the concentric form disappears altogether. There is no significant difference in the occurrence of interior bins, but interior pits or cists tend to be more common during the early subphase. Similarly, the frequency of 
reported interior platforms (altars) does not change significantly throughout the duration of the phase, although the only recessed platform was noted in a late subphase structure.

Some temporal trends are also evident among the smaller subordinate rooms (Unit Types 3, 4, 5, 6, 8 and 9). Fifty-six units representing only 478 of all subordinate rooms were assignable to any subphase. Most unit types are poorly represented. Only Types 3 and 8 have more than four units assigned to any temporal phase. Most of the following temporal trends must be regarded as tenuous, since these smaller rooms are so poorly represented. The most noticeable changes among the Type 3 (antechamber) units is a slight reduction in size $(13.34 \pm 3.66 \mathrm{~m}$ to $11.69 \pm 6.10 \mathrm{~m})$ through time and a shift from contiguous to isolated structures. Other differences in unit shape, nature of wall footings, and such features as support posts, dooxways and hearths do not show any distinctive or significant changes between early and late subphases.

The differences between early and late Type 4 units may be noncomparable. The two early subphase units cccur at Alibates Ruin 28, as part of an Aggregate Type IV configuration. Functional analysis of these units suggests that they may be comparable to Type 8 units. In contrast, the single late subphase unit at Black Dog Village is part of an Aggregate Type $\mathrm{V}$ which is paired with Unit Type 9. The differences in contiguous arrangements diminishes the confidence in the comparison validity, even though these units share many of the morphological attributes. Despite these cautions, and keeping in mind the small sample size, the following trends are tenuously defined. Foremost is the shift to smaller structures coupled with the tendency to increase the individual room size through 
time. There is no major difference in unit shape, wall footing construction, or the occurrence of interior bins between early and late rooms. The presence of a "platform" in one early subphase room has been regarded as an elevated floor area to facilitate access to an upper wall opening. As such, this platform is not comparable to those associated with Types 1 and 2 rooms. Finally, the single clearest difference is the shift from no doorways (early) to gap-type doorways (late). But in view of the small sample size and the changes in contiguous room arrangements, the significance of this change is not clear.

Small sample sizes coupled with the assignment of all unit types to a single subphase prevents the discernment of change for subordinate rooms Type 5, 6, and 9. The restriction of all identifiable room types to a single subphase may in itself represent a temporal trend. A large sample of dated features may be necessary to verify this observation. All temporally assignable small rooms with interior hearths (Type 6 units) are affiliated with the early subphase, whereas the isolated medium-sized rooms with interior pits (Type 5 units) and the Type 9 units are restricted to the late subphase.

The featureless subordinate (Type 8 ) rooms are also characterized by an increase in size and a shift from predominantly circular/oval to quadrilateral form. Although this room type oncurs during the early and late subphases either as isolated one-room buildings, pairs of subordinate units separate from the main household rooms, or as subordinate rooms attached to the household cluster, noticeable changes in frequency occur through time. The isolated room form shows a 2008 increase and the paired structures 1208, a increase but the contiguous subordinate rooms show a 
pronounced decrease to 408 from the early to late subphases. This tendency is another reflection of the breakdown of the large room blocks through time. The methods of constructing Type 8 rooms also show some change. The wall footings of early subphase structures were predominantly single rows of vertical slabs (548) and double rows of vertical slabs (468). During the late subphase, single row slab footings became more common (698) and some rooms werc made without building stones (8\%). Also, the early use of ground level gap doorways for access from the extended vestibule were probably replaced in later times by upper wall openings, as the large contiguous roum blocks were abandoned.

Few temporal changes are evident in the morphology of slab cists with or without stone floors (Unit 'Yypes 7 and 10). In general, early subphase slab cists tend to have earth floors, whereas later subphase slab cists more commonly used stone.

\section{Summary}

The temporal changes evicient auring the Antelope Creek phase include:

1. A shift from a few large contiguous room block structures to many smaller structures consisting of single rooms at homestead and hamlet sites.

2. An overall reduction in the number of subordinate rooms associated with a site. Early subphase sites have an average of 2.13 subordinate rooms for each dominant unit whereas late subphase sites have only 0.83 subordinate units per main room.

3. Although late household clusters tend to have fewer rooms at a site, the size of most rooms is larger. This trend does not seem to reflect the consolidation of activities from separate 
rooms into the main household units, since the frequency of interior cists and bins does not show a corresponding increase through time.

4. The construction methods of building the large main rooms underwent marked changes in conjunction with the abandonment of the large room blocks. Through time, the method of constructing wall footings became less substantial and shifted from predominantly double slab wall bases to single slab or adobe and post wall bases. Similarly, engineering constraints required more interior posts in order to support the larger roofs.

5. Although the extended vestibule remains the dominant entryway for the main household units, the threshold collars (thought to have been used to support an interior flexible partition) are replaced by a more elaborate series of sill and bulbar step features.

6. Interior features within the domirant household structures tend to become simpler as indicated by the loss of the concentric or mammiform hearth.

The implications of some of these changes will be discussed in the concluding chapter. 


\section{CHAPTER 9}

\section{SPATIAL DIVERSITY IN ARCHITECTURE \\ AND COMMUNITY PATTERNING}

\section{Introduction}

The last factor potentially underlying Antelope Creek phase architecture and community variability is a spatial consideration. Mose of the recent theoretical works on spatial analysis in archaeology have been concerned with either people-people rationship (centered place theory, size rule, or gravity models, to mention a few), or people-land relationships (site catchment models). The former approaches are concerned primarily with site spacing and population density (Whallon 1974; Hodder and Orton 1976; Claxke 1977; Stark and Young 1981), whereas the latter approach focuses on the determinants of site location--the availability, abundance, spacing and scheduling of resources in the determination of site location (Roper 1979; Grady 1980).

Many of the sophisticated methods of spatial analysis--particularly . those concerning intersite relationships--cannot be used to examine Antelope Creek spatial patterning, since the number, density, distribution and kinds of sites within the High Plains-Canadian Valley locality are largely unknown. Few intensive systematic surveys have been conducted on sizeable tracts within the study area (Bousman 1974a; Etchieson 1981). At this time, insufficient information is available to examine the population density of the region. Certainly, the information base of the present 
study consists solely of sites, usually in isolation, which have received some form of intensive excavation. Despite this severe restriction, this chapter examines how the natural variation within the study area affected the construction of buildings and the selection of site placement.

The present approach seeks correlations of architectural variability and site types with a series of environmental variables of the study area. Trends in spatial diversity are delineated on a macro- and microspatial level. Since the boundaries of the study area were established specifically to crosscut multiple geologic, topographic, hydrologic and biotic settings, the different kinds of architectural and community site types can readily be contrasted. Comparative methods are used to examine site diversity in relation to geological exposure, soil association, topographic setting and hydrological features on a macrolevel.

The microlevel of spatial analysis employs site catchment methods in order to distinguish between different site type localities. Specifically, site catchment is used to examine biotic diversity in the relationship to site placement. Since the distribution and density, seasonal scheduling and macrochanges in the prehistoric resources are unknown, the catchment study focuses primarily on proximity of general biotic resources to the various site types.

Finally, where feasible, the spatial and environmental patterns are examined diachronically so that general changes through time can be discerned. Overall, there appear to be marked differences in the spatial distribution of the 14 sites assigned to the early and late subphases (Figure 27). The seven early subphase sites include all major architectural site types (subhomesteads, homesteads and hamlets). Five of seven early sites 


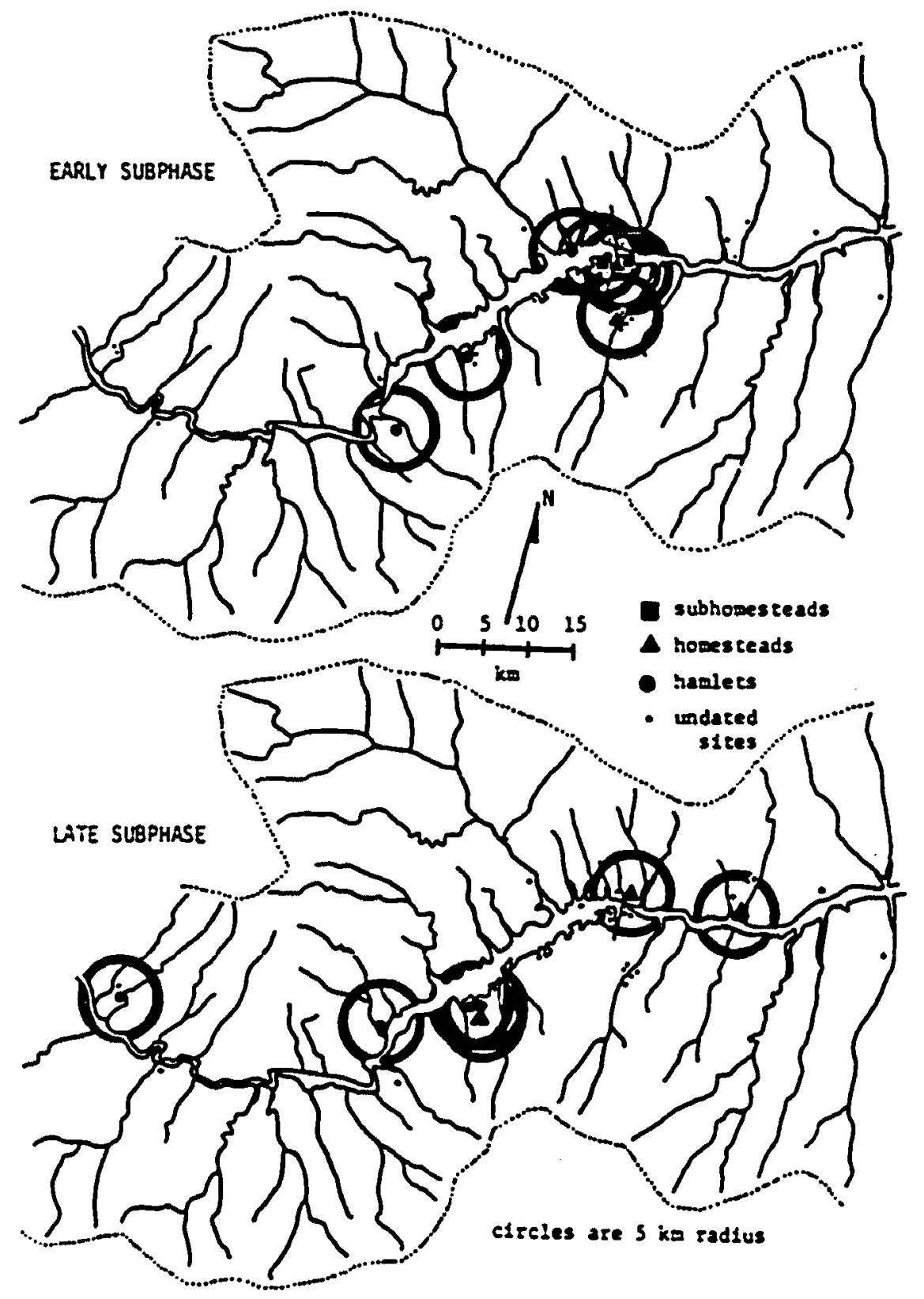

Figure 27. Distribution of Early and Late Sites in the Study Area. 
occur within a five kilometer radius, while the other two are 20 and $32 \mathrm{~km}$ from the farthest early phase site. If the various site types reflect a hierarchy of complimentary activities, then most of the early sites might reflect the remains from but a few Antelope Creek phase social units.. nt the very least, the site clusters reflect intense and continuous interaction of separate social units from a few communities. In contrast to the tight node of early sites, the late subphase sites are widely scattered, and include only homesteads and hamlets, which tend to be spatially segregated. The three late homestead sites are 13 and $22 \mathrm{~km}$ apart and are confined to the eastern portion of the study area. The four late hamlet sites are to the west and overlap the distribution of late homestead sites only at the Alibates quarry. The distance between adjacent late hamlet sites is 10 and 30 kilometers. Altogether, the late sites are spaced over a 70 km section of the valley. With the exception of the three late sites near the Alibates quarry, there was probably far less frequent direct interaction of the occupants of the various late site types. These marked spatial differences between sites assigned to the two subphases should be kept in mind when examining temporal trends underlying the environmental factors of the study area.

\section{Macrospatial Diversity}

The initial approach is directed at discerning spatial patterning among the various site types as they relate to geological deposits, knappable resources, elevation/topographic settings, and distances to the Canadian River and local tributaries within the general study area. In addition, wherever feasible, the relationship of these environmental variables to residential architectural variations will also be examined. Most of 
the basic information is derived from geological maps (Barnes 1969), or 7.5 minute series USGS topographic maps (Table 54 in Appendix A). The distribution of Alibates chertified dolomite is extrapolated from Bowers (1976). Significant correlates of site types with specific environmental variables are regarded as valid spatial trends.

GEOLOGY, SOILS AND TOPOGRAPHY

Within the study locality strong correlations exist between the geological exposures and both the soil association and topographic setting. Such correlations are to be expected, since soils develop over the weathering of parent (geological) material and topography results from differential erosion of the geological deposits. Consequently, all three factors are interrelated facets of the spatial variability of the study locality. The geomorphology and soil conditions are regarded as constant parameters, which have changed very little during the last millenium. Modern conditions ciosely approximate the geologic and topographic conditions during the Anicelope Creek occupations, with the possible exception of increased colluviation at the base of select inner valley wall locations, as indicated by the extensively buried deposits over Antelope Creek Ruin 24. The association of geology, soil texture and types, and topographic setting by general site type are indicated in Table 40.

The geological deposits are not simply stratified beds within the study area. Instead, the pre-Tertiary deposits are clinally segregated (Figure 5). The Permian deposits are primarily located at lower topographic settings in the eastern two-thirds of the study area and the Triassic deposits are restricted to the lower topographic settings of the western third of the area. Both are overlain by Tertiary logallala 
Table 40.

Relationship of Site Types to Geology,

Soil Texture and Topographic Setting.

\begin{tabular}{|c|c|c|c|c|}
\hline & Geology & Soll Texture & Series & Topographic Setting \\
\hline \multicolumn{5}{|l|}{ Simple Subhamesteads } \\
\hline $\begin{array}{l}\text { Conner Site } \\
\text { Pickett Site (E) }\end{array}$ & $\begin{array}{l}\text { Permian } \\
\text { Permian }\end{array}$ & $\begin{array}{l}\text { Loan } \\
\text { Lowe }\end{array}$ & $\begin{array}{l}\text { (Burson) } \\
\text { (osero) }\end{array}$ & $\begin{array}{l}\text { Inner Volley floor Terrace } \\
\text { Inner Voliey floor Terrace }\end{array}$ \\
\hline \multicolumn{5}{|l|}{ complex Subhoresteads } \\
\hline $\begin{array}{l}\text { Roper Site (E) } \\
\text { Turkey Creek } \\
\text { Zollars Site }\end{array}$ & $\begin{array}{l}\text { Permian } \\
\text { Pernian } \\
\text { Permian }\end{array}$ & $\begin{array}{l}\text { Loan } \\
\text { Lose } \\
\text { Loen }\end{array}$ & $\begin{array}{l}\text { (Burson) } \\
\text { (Burson-Quinlian) } \\
\text { (Dosero-Duinian) }\end{array}$ & $\begin{array}{l}\text { Imner volley wall Bench } \\
\text { Inner valley Wall Bench } \\
\text { Inner valley floor Terrace }\end{array}$ \\
\hline \multicolumn{5}{|l|}{ Simple Homesteads } \\
\hline $\begin{array}{l}\text { Antelope Creek 22A (E) } \\
\text { Antelope Creek } 23 \\
\text { Sllo-? } \\
\text { Jack Allen Site } \\
\text { Marsh Site }\end{array}$ & $\begin{array}{l}\text { Permian } \\
\text { Permian } \\
\text { Permian } \\
\text { Tertiary } \\
\text { Triassic }\end{array}$ & $\begin{array}{l}\text { Low } \\
\text { Lom } \\
\text { unidentified } \\
\text { Gravelly Low } \\
\text { Clay Lomalsendy Loan }\end{array}$ & 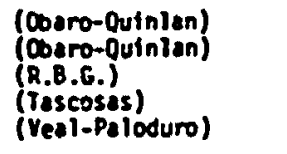 & $\begin{array}{l}\text { Inner Volley floor Terrace } \\
\text { Inner valley floor Terrace } \\
\text { Inner Volley floor Ierrace } \\
\text { Inner valley Floor Terrace } \\
\text { Inner valley Rin }\end{array}$ \\
\hline \multicolumn{5}{|l|}{ Complex Homesteads } \\
\hline $\begin{array}{l}\text { Black Dog (L) } \\
\text { Lookout Ruin } \\
\text { Medford Ranch site } \\
\text { Sanford Ruin (E) } \\
\text { Spring Conyon Size (l) }\end{array}$ & $\begin{array}{l}\text { Permian } \\
\text { Permian } \\
\text { Permian } \\
\text { Tertiary } \\
\text { Tertiary }\end{array}$ & $\begin{array}{l}\text { Loam } \\
\text { Loam } \\
\text { Loaw } \\
\text { Sandy Loan } \\
\text { Sandy Loan }\end{array}$ & $\begin{array}{l}\text { (Doero) } \\
\text { (Doaro-quinian) } \\
\text { (Burson) } \\
\text { (Dallean) } \\
\text { (Dallea) }\end{array}$ & $\begin{array}{l}\text { Inner Valley Floor Terrace } \\
\text { Inner Valley Mesa ToD } \\
\text { Inner Valley Hall Ronst. } \\
\text { !nos toiliey Rin } \\
\text { Inner Valley Rin }\end{array}$ \\
\hline \multicolumn{5}{|l|}{ Simple Hanlets } \\
\hline $\begin{array}{l}\text { Chimey Rock } 51 \text { A } \\
\text { Altoates 28A (II } \\
\text { Footprint Site (L) }\end{array}$ & $\begin{array}{l}\text { Triassic } \\
\text { Tertiary } \\
\text { Permian }\end{array}$ & $\begin{array}{l}\text { Clay } \\
\text { Sandy Loova/Gravelly Loom } \\
\text { Silty Clay Loanloam }\end{array}$ & $\begin{array}{l}\text { (Yernon-Owems) } \\
\text { (Mobeetie-Tascosas) } \\
\text { (Aspermont-Duinlan) }\end{array}$ & $\begin{array}{l}\text { Inner Valley Rim } \\
\text { Inner Valley Ria } \\
\text { Inner Valley Heso ToD }\end{array}$ \\
\hline \multicolumn{5}{|l|}{ Complex Hemlets } \\
\hline 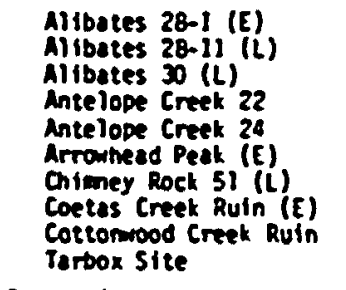 & $\begin{array}{l}\text { Tertiory } \\
\text { Tertiory } \\
\text { Tertiory } \\
\text { Peraion } \\
\text { Permian } \\
\text { Peraian } \\
\text { Triossic } \\
\text { Tertiony } \\
\text { Perwion } \\
\text { Permian }\end{array}$ & 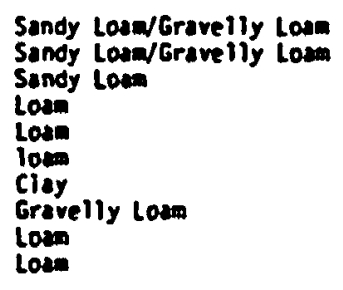 & 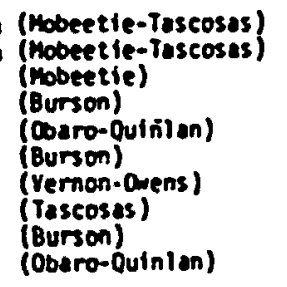 & 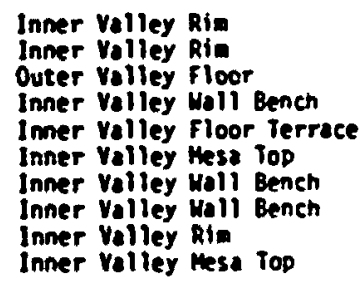 \\
\hline \multicolumn{5}{|l|}{ Ceneteries } \\
\hline Big Blue Cemetery & Permion & unidentifled & (k.B.6.) & Outer Valley floor \\
\hline $\begin{array}{l}\text { (E) - Early suophase } \\
\text { (L) - Late subohase }\end{array}$ & & R.B.G. - Rough Broken Gro & ound & \\
\hline
\end{tabular}


Formation) and Quaternary eolian deposits. In the eastern most edge of the study area these recent deposits comprise all of the exposed formations. Most sites are associated with Permian $(n=17,638)$ or Tertiary $(n=7$, 268) deposits, while few are found with Triassic $(n=3,118)$ deposits (Table 40). Aside from the apparent association of simple and complex subhomesteads with the Permian deposits, there is no significant correlation of site types by geological deposit, nor is tinere any epperent major shift in settlement selection between the early and late subphase sites. The correlation of the subhomestead sites with Permian deposits is regarded as an incidental associatior. of these sites with low topographic settings.

While the geological setting may seem to have little impact on site types, the setting apparently is a major factor affecting architectural construction methods. The Triassic and Permian deposits are the main sources of building stone used in foundations and wall cores. Since the Tertiary deposit cobbles are generally too small for construction purposes, it follows that structures built at sites on Tertiary deposits (especially those far from Triassic or Permian doposits) may be expected to employ different or supplemental methods of wall construction than the methods used at structures built on Triassic or Permian deposits. To test this notion,. the homestead and hanlet sites were grouped by geological setting, then the nature of wall construction methods used in the larger main and anteroom units (Types 1, 2 and 3 ) were tabulated (Table 41). In addition, the distance of sites on Tertiary deposits from the nearest Triassic or Permian exposure was obtained in order to separate sites within $500 \mathrm{~m}$ of a geological boundary from those further away. Even though seven sites are on Tertiary deposits, the five inner valley rim and wall bench sites occur within 
Table 41. Correlation of Wall Construction Methods of Main Residential Untts with Geological Deposits.

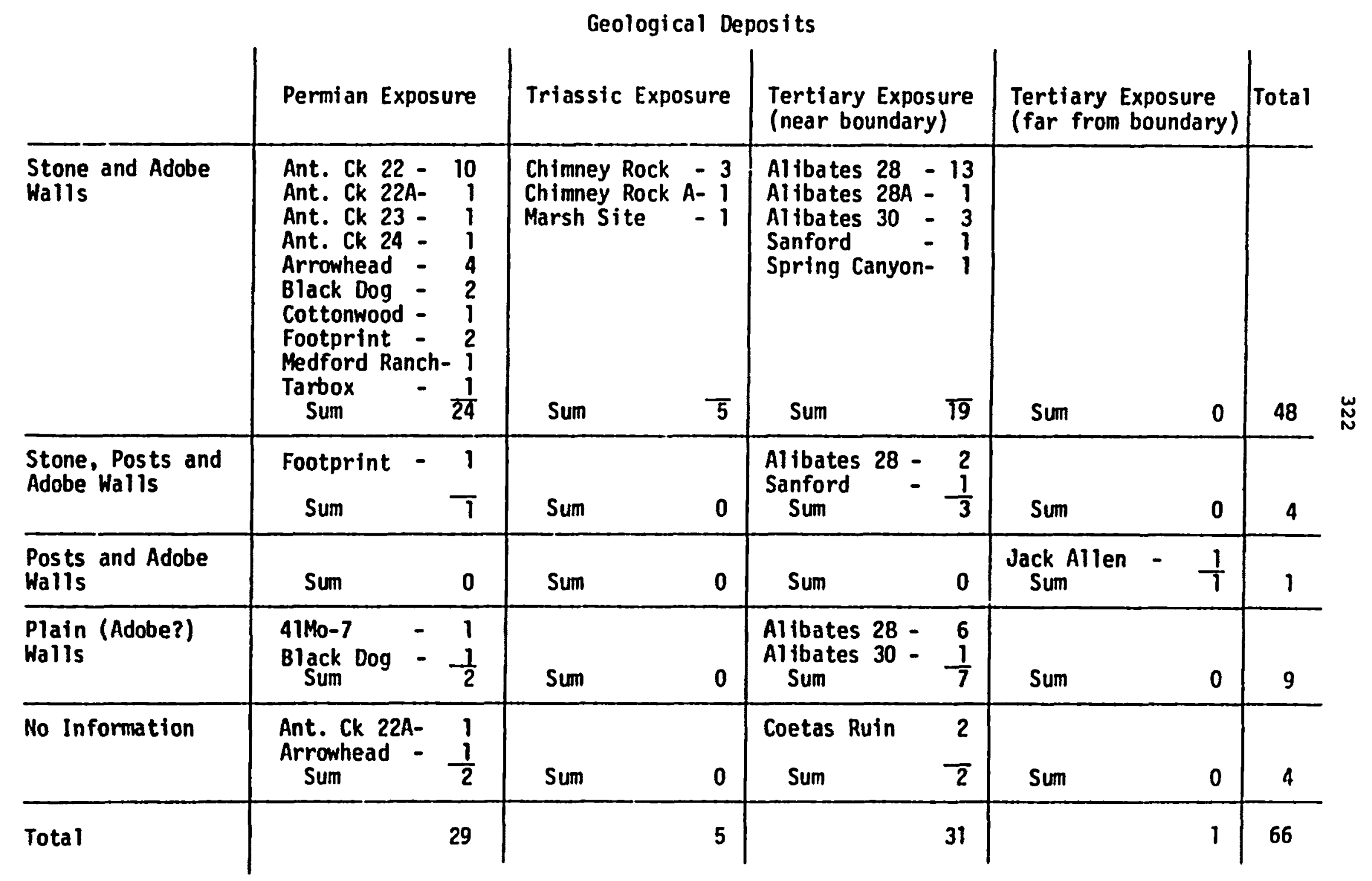


$200 \mathrm{~m}(650 \mathrm{ft})$ of Permian dolomite exposures, and the single outer valley floor site is $500 \mathrm{~m}(1650 \mathrm{ft})$ away. Only the Jack Allen Site at the eastern edge of the study area is considerably further from non-Tertiary resources. The closest Permian exposure is located approximately five km ( 3 miles) away over the adjacent drainage divide (Baries 1969).

An examination of Table 41 shows considerable support for the hypothesis that geological deposits affected the nature of wall construction. In those instances where wall construction methods were noted, stone slabs and mortar were used in 90.68 (29 of 32 units) of the Typs 1, 2 or 3 structures built on Permian or Triassic deposits, but only 63.38 (19 of 30 units) on Tertiary exposures. As expected, stone slabs occur only at sites on Tertiary deposits which are near pre-Tertiary geological deposits. The only stockade post and adobe walled structure was at the Jack Allen Site at a much greater distance from rock exposures. Also, over one-third of the structures built near the edge of Tertiary deposits had either stones with supplemental stockade post reinforcements or walls built without stone. Such deviations have rarely been recorded at sites built directly on Permian or Triassic deposits. These findings indicate that the geological setting is a major influence on the nature of wall construction methods, even. though the general geological setting is not a factor affecting decisions for site selection.

The presence of knappable Alibates agitized dolomite may have also been a contributing consideration in site selection. Extensive sampling and stratigraphic descriptions of 27 Permian exposures within the study area and petrographic analyses of 83 samples from 18 of these geological localities indicated that the most thorough chertification of the dolomite deposits 
has occurred along Alibates Creek and the MCDowell and Big (Devil's) Canyon region within Potter County (Bowers 1975). Elsewhere, the dolomite is less completely chertified or occurs as smaller chert nodules. The impact of Alibates chert cannot adequately be evaluated since the density of sites is uncertain. Bousman (1974a:24) lists 11 Antelope Creek sites and 34 distinct quarry clusters within approximately 3640 acres (1470 ha) of the existing and proposed expanded boundaries of the Alibates National Monument, but control areas away from the monument await survey. Furthermore, the kinds of sites near the quarries are unspecified. Even though the present study has demonstrated that extensive hamlets and cultural mounds occur near the quarries, similar sizes and kinds of sites occur along Spring Canyon, Antelope and Cottonwood Creeks, where the dolomite has not agatized. While the sites near the Alibates exposures may not be unique, the available chronological evidence suggests a shift in settlement intensification between the early and late subphases (Figure 16). During the early subphase, the major cluster of dated homestead and hamlet sites (Arzowhcad Pcak, Sanford Ruin, Antelope Creek 24) are east of the agatized deposits, but by the later subphase, most dated homestead and hamlet sites (Footprint, Alibates Ruin 28, 28A, and 30) shift near the exposures. This shift in intensification of settlement is yet another indication of the importance of Alibates chert in maintaining and strengthening contacts with adjacent groups, which developed during the Antelope Creek phase and culminated in extensive protohistoric macro-economy or mutualistic exchange systems (Baugh 1982; Spielman 1982, 1983).

The soil texture and associations within the study area are strongly influenced by the geological parent material. As a general trend, soils 
developed from Triassic deposits have a finer texture than the Permianderived soils while the later Tertiary-derived soils tend to be coarser. The distribution of site types by soil texture class shows that most sites are associated with loam $(59.68)$ or sandy/gravelly loam (28.98) soil texture classes (Table 42). All of the subhomesteads and most of the hamlet sites are on Permian loam, but a few of the homesteads and hamlets also occur on both fine silty clay/clay soils, or coarser sandy/gravelly loams. Although sites tend to be located on medium to well-drained soils, some homesteads and hamlets in the western part of the study area are located on more poorly drained clayey soils. Furthermore, little change in site setting and soil association is discernible between the early and late subphases. All subhomestead sites assignable to a subphase are early. There is no apparent change in soil texture settings for the homestead sites. They occur in loam and sandy loam settings during both subphases. The hamlet sites, however, commonly are associated with loam, sandy loam and gravelly loam soils during the early subphase. These same soil types, along with clayey settings, seem to be used during the later subphase. The uncertain age of several sites diminishes any significance placed on these trends. Quite likely, the broad range of texture at the hamlet site settings sug- . gests that soil type was only a minor contributing consideration in the overall decision of site selection and placement. Although east-west clinal variation is evident in site association with soil texture, this trend reflects only the geological deposits of the study area. Within the available sample, soil texture seems to have no major impact on architecture or construction method used in building the structures.

The correlation of site types by topographic setting is indicated in Table 43. Clear relationships between settings and site types are evident. 
Table 42. Correlation of Site Types by Soll Association and Texture.

\begin{tabular}{|c|c|c|c|c|c|c|c|c|}
\hline \multirow[b]{2}{*}{ Ceology } & \multirow[b]{2}{*}{ Texture } & \multirow[b]{2}{*}{ Assoclation } & \multicolumn{2}{|c|}{ Subhomesteads } & \multicolumn{2}{|c|}{ Homes teads } & \multicolumn{2}{|c|}{ Hemlets } \\
\hline & & & sleple & comen ! x & Stople & complex & single & complex \\
\hline \multirow{2}{*}{ Irlesste } & Clay & (Vernon-Ouens) & & & & & Chtmey RaA & Chimey RR! \\
\hline & $\begin{array}{l}\text { Clay loowd } \\
\text { Sandy Loon }\end{array}$ & (real-Paloduro) & & & Marsh sile & & & \\
\hline \multirow[b]{2}{*}{ Peralen } & Lasly clay tost & 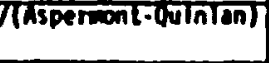 & & & & & Tootprint! & \\
\hline & $\begin{array}{l}\text { low } \\
\text { lown } \\
\text { lom } \\
\text { Lown }\end{array}$ & $\begin{array}{l}\text { (Doaro) } \\
\text { (Doaro. Duinlen) } \\
\text { (Eurson) } \\
\text { (Burson-Qulnlan) }\end{array}$ & $\begin{array}{l}\text { Plckelte } \\
\text { Conner }\end{array}$ & $\begin{array}{l}\text { Zollars } \\
\text { Ropere } \\
\text { Turkey ct }\end{array}$ & $\begin{array}{l}\text { Anl.ck 22ke } \\
\text { Ant.ck } 23\end{array}$ & $\begin{array}{l}\text { Dlack Dos! } \\
\text { Lookout } \\
\text { Hediord }\end{array}$ & & $\begin{array}{l}\text { Ant.ck } 24 \\
\text { Jartox } \\
\text { Ant.ck } 22 \\
\text { Arromhesd } \\
\text { Coltonwood }\end{array}$ \\
\hline \multirow{3}{*}{ Tertiary } & $\begin{array}{l}\text { Sondy Lod } \\
\text { Sindy lom }\end{array}$ & $\begin{array}{l}\text { Tuster) } \\
\text { (mobeetle) }\end{array}$ & & & & $\begin{array}{l}\text { Sontores } \\
\text { spring Canyon }\end{array}$ & & Allbales 30 ! \\
\hline & $\begin{array}{l}\text { Sandy Loand } \\
\text { Gravelly Loum }\end{array}$ & (11boeetle-7ascosas) & & & & & Alibates 28n & Alibates $28^{2}$ \\
\hline & Gravelly lose & (1ascoses) & & & Sack Allen & & & Coetes Ck.e \\
\hline
\end{tabular}

i farly subphase 
Table 43. Correlation of Site Types by Topographic Setting.

\begin{tabular}{|c|c|c|c|c|c|c|}
\hline \multirow{2}{*}{$\cdot$} & & \multicolumn{4}{|c|}{ Inner Valley } & \multirow{2}{*}{$\frac{\text { Outer Valley }}{\text { Floor }}$} \\
\hline & & Floor Terrace & Wall Bench & Mesa Top & Rim & \\
\hline \multirow[t]{3}{*}{ Subhomes teads } & Simple & $\begin{array}{l}\text { Conner } \\
\text { Pickette }\end{array}$ & & & & \\
\hline & Complex & Zollars & $\begin{array}{l}\text { Roper } \underline{\text { e }} \\
\text { Turkey Creek }\end{array}$ & & & \\
\hline & Sum & $3(60 \%)$ & $2(40 \%)$ & & & \\
\hline \multirow[t]{3}{*}{ Homes teads } & Simple & $\begin{array}{l}\text { Ant.Ck } 22 A^{\mathrm{e}} \\
\text { Ant.Ck } 23 \\
41 \mathrm{Mo}-7 \\
\text { Jack Allen }\end{array}$ & & & Marsh & \\
\hline & Complex & Black Dog- & Medford Ranch & Lookout & $\begin{array}{l}\text { Sanforde } \\
\text { Spring Canyon } 1\end{array}$ & \\
\hline & Sum & $5(50 \%)$ & $1(10 \%)$ & $1(10 \%)$ & $3(30 \%)$ & \\
\hline \multirow[t]{3}{*}{ Hamlets } & Simple & & & Footprint 1 & $\begin{array}{l}\text { Chimney RKA } \\
\text { Alibates } 28 A-\end{array}$ & \\
\hline & Complex & Ant.Ck 24 & $\begin{array}{l}\text { Ant. Ck 22 } \\
\text { Chimney Rk } 1 \\
\text { Coetas }\end{array}$ & $\begin{array}{l}\text { Arrowheade } \\
\text { Tarbox }\end{array}$ & $\begin{array}{l}\text { Alibates 28- I } \frac{\mathrm{e}}{\text { Alibates } 28-\mathrm{II}} \\
\text { Cottonwood }\end{array}$ & Alibates 30 \\
\hline & Sum & $1(8 \%)$ & $3(\overline{23 \%})$ & $3(23 \%)$ & $5(38 \%)$ & $1(8 \%)$ \\
\hline \multicolumn{2}{|l|}{ Total } & 9 & 6 & 4 & 8 & 1 \\
\hline
\end{tabular}


Subhomestead sites are all located on inner valley floor terraces or wall benches, but do not occur at higher settings. The simple subhomestead sites occur more often at the lower topographic settings than do the complex forms. In contrast, the homestead sites show a bimodal distribution associated with inner valley floor terraces and rim settings. Once again, the complex homestead forms tend to cluster at the higher topographic setting. All of the homesteads in the sample are within the inner valley basin. Finally, the hamlets are widely dispersed across the inner and outer valley settings, but most are clustered at the higher wall bench, mesa top and particularly the inner valley rim settings. The simple hamlets are restricted to promontories and edges of the inner valley while the complex hamlets occupy a wider range of settings but are concentrated on the $\mathrm{rim}$ and wall bench settings of the inner valley.

An inverse relationship exists between the low subhomestead settings and the high hamlet settings. Since these site types are systematically linked together into complimentary functional components at least during the early subphase, then they are potentially placed at different settings to maximize differential environmental exploitation. In the late subphase no major shifts are apparent in homestead and hamlet site settings, but there is no evidence for late subhomestead sites. Thus one potential change in settlement patterns involves the loss or absence of subhomestead sites on low terrace settings during the late subphase. The significance of this shift is discussed in the next Chapter. A larger sample of dated subhomestead sites will be required to substantiate this observation, however. 
HYDROLOGICAL SETTINGS

The availability of water for human consumption or cultigen production is often regarded as a major environmental variable influencing settlement location among horticultural groups. The presence of extensive Antelope Creek sites on mesa tops or valley rim settings far from the Canadian River has been cited as primary evidence that defensive considerations must have overridden the Antelope Creek people's inclination to settle closer to the river. This view has been most eloquently expressed by Krieger (1946: 42):

Villages: Primarily situated in comparatively good defensive positions; on ridges and promontories overlooking Canadian or its short tributaries, on mesa tops, and small terraces with steep banks. Usually within mile or two of small stream or spring, but convenience to fields and water plainly sacrificed for wide view and defensible features.

In order to examine this proposition certain variables measuring the relationship of site iypes to the hydrological setting were collected (Table 44).

Although the stream rank setting has provided useful information in other study areas, the trellis drainage pattern within the Canadian River Valley has left an overly simplified ranking system. Most architectural sites in this study are located either adjacent to the river or along first-order tributaries. The few second and third order tributaries tend to be short, minor streams, except along Big Blue Creek. 2ollars is the only site located next to a second order tributary. As a practical consideration, the distance of a site from the Canadian River is regarded as a better measure of hydrological setting than mere stream ranking. A tabulation of excavated site distance from the Canadian River shows a trimodal distribution. Twelve sites are close (1ess than $1.2 \mathrm{~km}$ ); 
Table 44. Relationship of Antelope Creek Phase Sites to Canadian River and Nearest Tributary.

\begin{tabular}{|c|c|c|c|c|c|}
\hline & $\begin{array}{l}\text { Olstince to } \\
\text { Canaslan River (m) }\end{array}$ & $\begin{array}{l}\text { Clevation abore } \\
\text { Canadian River }(m)\end{array}$ & $\begin{array}{l}\text { Closest } \\
\text { Incal Iributary }\end{array}$ & $\begin{array}{l}\text { Distance to } \\
\text { Closest Pributary }\end{array}$ & $\begin{array}{l}\text { Elevat ion Above } \\
\text { local iributary }(m)\end{array}$ \\
\hline \multicolumn{6}{|l|}{ Simple Subhomesteads } \\
\hline $\begin{array}{l}\text { Conner Site } \\
\text { Pickett site }\end{array}$ & $\begin{array}{l}900 \\
500\end{array}$ & $\begin{array}{l}\mathbf{6} \\
\mathbf{3}\end{array}$ & $\begin{array}{l}\text { South Canyon } \\
\text { Canadian River }\end{array}$ & $\begin{array}{l}50 \\
50\end{array}$ & $\begin{array}{c}2 \\
\cdots\end{array}$ \\
\hline \multicolumn{6}{|l|}{ Complex Subhonesteads } \\
\hline $\begin{array}{l}\text { Roper } \\
\text { Turkey Creek Site } \\
\text { Zollars }\end{array}$ & $\begin{array}{r}190 \\
910 \\
4500\end{array}$ & $\begin{array}{l}18 \\
15 \\
55\end{array}$ & $\begin{array}{l}\text { South Canyon } \\
\text { Turkey Creek/Conadian } \\
\text { Unnamed }\end{array}$ & $\begin{array}{r}100 \\
150 \\
50\end{array}$ & $\begin{array}{c}10 \\
12 \\
9\end{array}$ \\
\hline \multicolumn{6}{|l|}{ SImple Homestead. } \\
\hline $\begin{array}{l}\text { Antelope Creek Ruin 22A } \\
\text { Antelope Creek Ruin } 23 \\
\text { Alto-1 } \\
\text { Jack Allen S1 te } \\
\text { Marsh Site }\end{array}$ & $\begin{array}{r}7600 \\
7200 \\
1200 \\
8700 \\
300\end{array}$ & $\begin{array}{l}52 \\
42 \\
10 \\
67 \\
30\end{array}$ & $\begin{array}{l}\text { Antelope Crrek } \\
\text { Antelope Creek } \\
\text { Canidian Rivar } \\
\text { Spring Creek } \\
\text { Tecovas Creek }\end{array}$ & $\begin{array}{r}250 \\
125 \\
50 \\
350 \\
150\end{array}$ & $\begin{array}{c}9 \\
6 \\
12 \\
30\end{array}$ \\
\hline \multicolumn{6}{|l|}{ Complex Homesteads } \\
\hline $\begin{array}{l}\text { Black Dog Village } \\
\text { Lookout Ruin } \\
\text { Hedford Ranch Site } \\
\text {-Sanford Ruin } \\
\text { Spring Canyon site }\end{array}$ & $\begin{array}{c}1000 \\
8600 \\
1000 \\
5100 \\
400\end{array}$ & $\begin{array}{l}15 \\
64 \\
36 \\
55 \\
57\end{array}$ & $\begin{array}{l}\text { Coltormosd Creek } \\
\text { Antelope Creek } \\
\text { Spring Canyon Creek } \\
\text { Sotth Canyon/Canadion } \\
\text { Spring Canyon }\end{array}$ & $\begin{array}{l}300 \\
75 \\
200 \\
200 \\
300\end{array}$ & $\begin{array}{l}15 \\
21 \\
33 \\
55 \\
52\end{array}$ \\
\hline \multicolumn{6}{|l|}{ Sinple Maniets } \\
\hline $\begin{array}{l}\text { Chimey Rock Ruin 5iA } \\
\text { Alibates Ruln 28A } \\
\text { - Footprint Site }\end{array}$ & $\begin{array}{r}3000 \\
3900 \\
600\end{array}$ & $\begin{array}{l}67 \\
20 \\
18\end{array}$ & $\begin{array}{l}\text { Corral Creek } \\
\text { Alibates Crerk } \\
\text { Big Canyon/Canadian }\end{array}$ & $\begin{array}{r}450 \\
50 \\
150\end{array}$ & $\begin{array}{l}12 \\
19 \\
18\end{array}$ \\
\hline \multicolumn{6}{|l|}{ Complex Hamlets } \\
\hline $\begin{array}{l}\text {-Alibates Ruin 28-1 } \\
\text {-Albates Ruin } 28-11 \\
\text { Albates Ruin } 30 \\
\text { Antelope Creek Ruin } 22 \\
\text { Antelope Creek Ruin } 24 \\
\text { Arrowhead Peak Ruin } \\
\text { Chimey Rock Ruin S1 } \\
\text { - Coet tas Ruin } \\
\text { Contomood Ruin } \\
\text { - Tarbox Ruin }\end{array}$ & $\begin{array}{l}4000 \\
4200 \\
4400 \\
7600 \\
8000 \\
200 \\
3200 \\
2900 \\
4400 \\
3600\end{array}$ & $\begin{array}{l}73 \\
76 \\
85 \\
67 \\
19 \\
46 \\
52 \\
58 \\
64 \\
55\end{array}$ & $\begin{array}{l}\text { Allbates Creck } \\
\text { Allibales Creck } \\
\text { Alibales Crenk } \\
\text { Anlelope Creek } \\
\text { Anlelope Creek } \\
\text { Canadian River } \\
\text { Corrol Creck } \\
\text { Coctas Creek } \\
\text { Collomwood Crepk } \\
\text { Parbox Creek }\end{array}$ & $\begin{array}{l}100 \\
100 \\
200 \\
300 \\
50 \\
50 \\
300 \\
100 \\
200 \\
100\end{array}$ & $\begin{array}{r}52 \\
55 \\
64 \\
24 \\
6 \\
\dddot{27} \\
24 \\
33 \\
15\end{array}$ \\
\hline \multicolumn{6}{|l|}{ Cemeterles } \\
\hline Biq blue cemetery & 4 Mo & $5 n$ & Bin Alue Creesk & 200 & 33 \\
\hline
\end{tabular}

- Archltectural sltes with Burial Reanins. 
ten sites are midrange $(2.9$ to $4.5 \mathrm{~km})$; and six sites are far $(7.2$ to 8.7 $\mathrm{km}$ ) from the Canadian River. In order to determine whether this pattern is fortuitous or reflects a spatial patterning, a chi-square test compared site types to distance from the Canadian River (Table 45).

Table 45. Chi-square test of Site Type by Distance from Canadian River

$\mathrm{H}_{0}$ : The site types are independent of the distance to the Canadian River; and that the distance from the river was not an influencing consideration for site type placement.

$\mathrm{H}_{1}$ : The site types and distance to the Canadian River are related.

\begin{tabular}{|c|c|c|c|c|}
\hline & $\begin{array}{l}\text { Subhomesteads } \\
\text { bb. Expt. }\end{array}$ & $\begin{array}{l}\text { Homesteads } \\
\text { Ob. Expt. }\end{array}$ & $\begin{array}{l}\text { Hamlets } \\
\text { Ob. Expt. }\end{array}$ & Total \\
\hline $\begin{array}{l}\text { Close to River } \\
\text { (0 to } 1.2 \mathrm{~km})\end{array}$ & 2.14 & 4.29 & 5.57 & 12 \\
\hline $\begin{array}{l}\text { Mid-range } \\
(2.9 \text { to } 4.5 \mathrm{~km})\end{array}$ & 1.79 & 3.57 & 4.64 & 10 \\
\hline $\begin{array}{l}\text { Far from River } \\
(7.2 \text { to } 8.7 \mathrm{~km})\end{array}$ & 1.07 & 2.14 & 2.279 & 6 \\
\hline Total & 5 & 10 & 13 & 28 \\
\hline
\end{tabular}

df $=4 ; \quad x^{2}=24.748 ;$ Significance $=$ less than .001

Reject $\mathrm{H}_{\mathrm{O}}$

The test demonstrates a dependent relationship between site types and distance from the Canadian River. Subhomestead sites occur primarily near the river $(808)$ or at midrange distance (208); homesteads are either near. (608) or far (408) from the river; while hamlets are predominantly at midrange distance (708) as opposed to either close (158) or far (158) from the River. 
This pattern may reflect a maximizing locational strategy. The large villages are placed predominantly at intermediate positions to surrounding homesteads near the Canadian River and up lateral tributaries. In addition, the seasonally utilized and subservient subhomestead sites are located closer to the river. In order to examine this pattern in greater depth, we also need to consider the relative elevation of the various site types.

Site elevations are related to some extent to topographic setting. However, the elevations provide greater insight into placement relative to hydrological setting. In order to compensate for the southeast slope of the entire Southern High Plains topography and the gradient of the lateral tributaries, elevations above the Canadian River and the adjacent tributary were tabulated for each site (Table 44, Figure 28). Note that the elevations of some sites seem to be incongruent with the assigned topographic setting (Figure 28a). The inordinately high elevation of the zollars site is due to its valley floor setting along a secondary ranked txibutary. Similarly, Footprint, Tarbox, Marsh and Lookout Ruins are at relatively low elevations for sites on mesa top and valley rim topographic settings. Undoubtedly these topographic features are remnants of the same formations producing the bench settings along the inner valley wall; however, considering the surrounding topography of these sites, the mesa top and valley rim settings identifications are valid.

Even where the site elevations are adjusted to the local tributary setting, we find a clustering of sites above $42 \mathrm{~m}$ separate and distinct from a cluster of sites below $33 \mathrm{~m}$ (Figure 28b). Two (Sanford and spring (anyon) of the eight sites above $42 \mathrm{~m}$ are homesteads; the other six are hamlets. This clearly supports Krieger's (1946:42) observation that the 


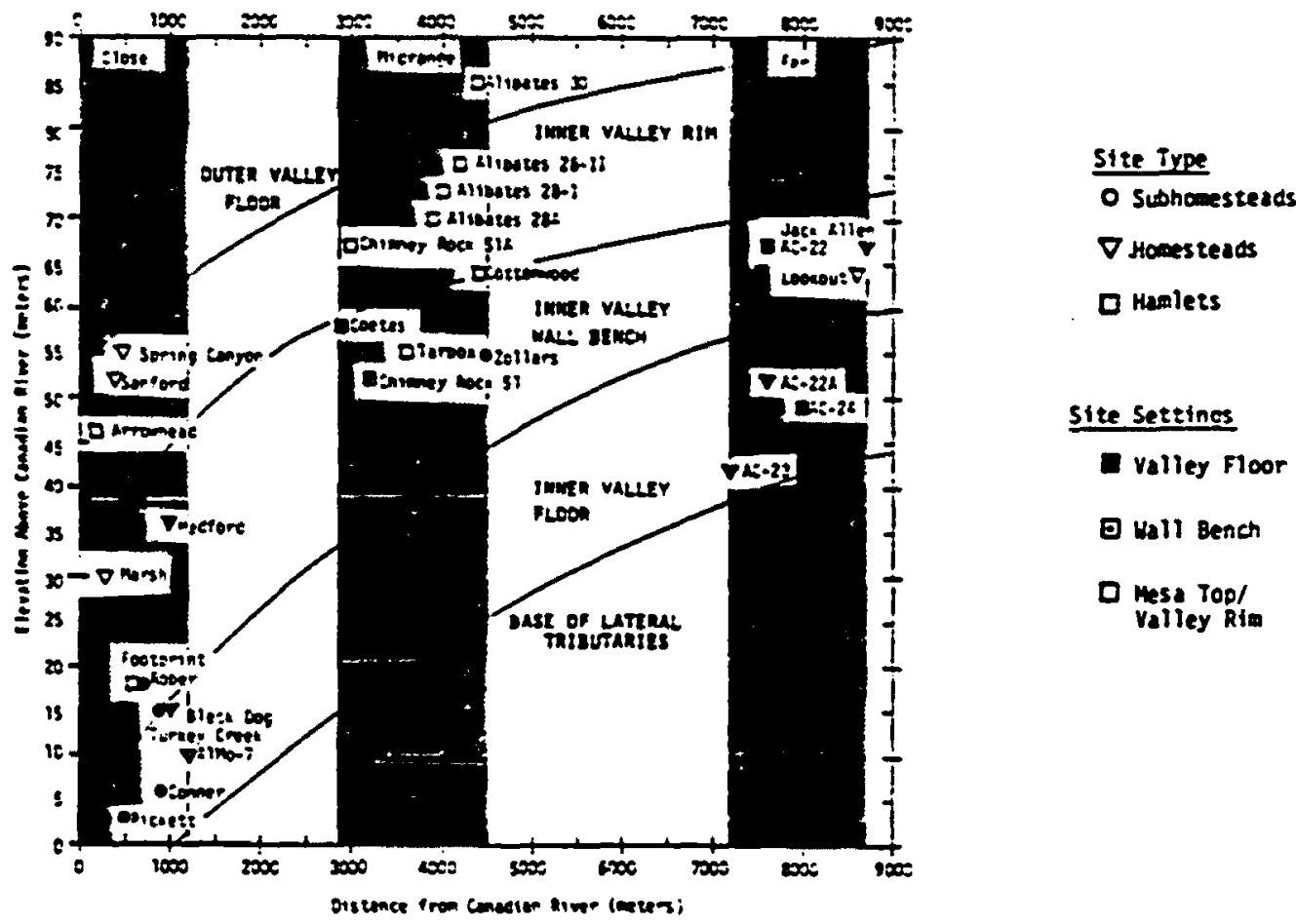

28A. Elevation and Distance of Sites from the Canadian River.

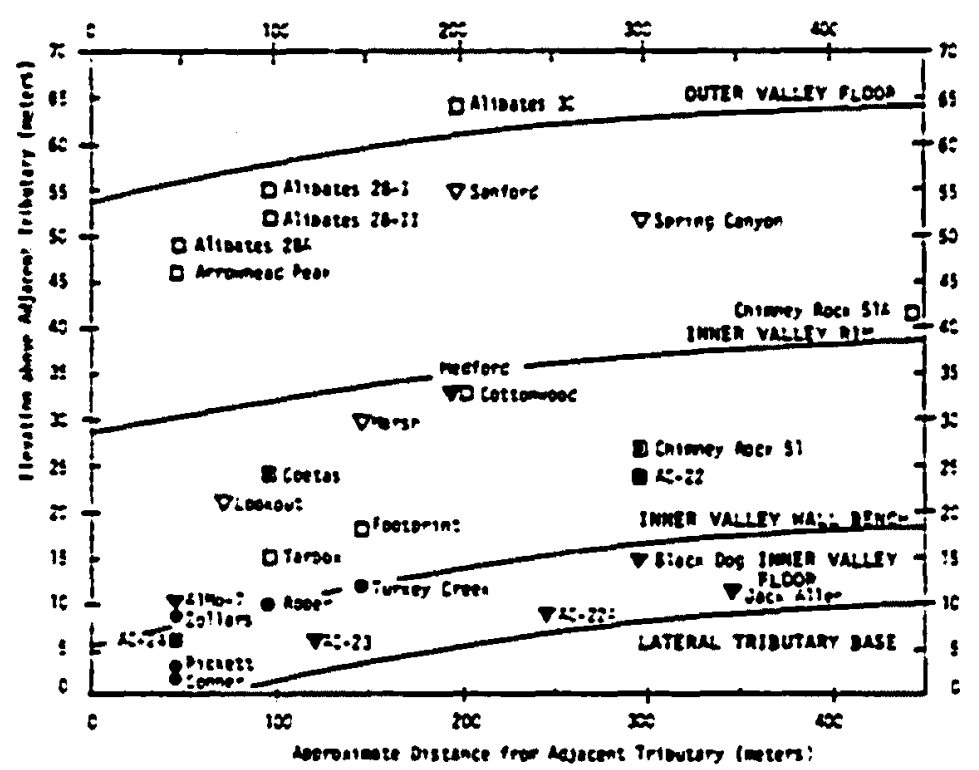

28B. Elevation and Distance of sites from the Nearest Tributary.

Figure 28. Elevation and Distance of Sites from the Canadian River and Adjacent Tributaries. 
extensive sites primarily occur on mesa top and valley rim settings away from the river. But does it confirm his contention that "convenience to water was sacrificed for wide view and defensible features"?

Although the largest river generally contains the most abundant water source in a region, such conditions are not valid in regard to dependable, potable water supply in the High Plains section of the Canadian River Valley. As indicated in Chapter 3, the Canadian River floor is unpredictable. Historically, surface water in the river was available during the growing season, but flooding was a common problem which diminished the utility of river bed and banks as a sole source for horticultural procuction. At slack periods during other seasons, the river is dry or the water is nearly unpotable because of the high concentrations of dissolved salts and sediments. In contrast, the freshest and most reliable source of potable water is from the Ogallala aquifer. Springs and seeps were abundant at the base of the Tertiary deposits just above the rim of the inner valley, and as surface water some distance from the head of the lateral tributaries. The inner valley rim settings are precisely where rost of the hamlet sites are situated, while the smaller subhomestead sites tend to be closer to the main river. Thus the site type settings seem to be segregated according to marked differences in topographic setting, elevation and distance from the Canadian River. But water quality diversity is regarded as one of the critical factors in site placement. Except for a few sites atop isolated mesas (Arrowhead Peak, Lookut Ruin), the high positions for most hamlet sites are in settings closest to the fresh and dependable spring water and seeps. In this instance, high site settings are insufficient evidence to presume the need for defensive measures without direct supportive information indicative 
of sustained hostilities. (I shall pursue this point further in the next chapter.)

\section{Microspatial Diversity}

Unlike the reiatively stable geologic, topographic and hydrologic features of the study area, the biotic conditions have been influenced and modified by land use practices and climatic changes. Limited paleoenvironmental studies in and adjacent to the area under consicleration suggest that mesic conditions existed prior to A.D. 1000 , but then began to shift to xeric conditions. Based on changing frequencies of bison remains through time at architectural sites Duffield (1970:265) noted an intensification of xeric conditions within the duration of the Antelope Creek phase. At this time, the impact of climatic change and the response of the prehistoric biotic communities cannot be directly quantified since the density, distribution and composition of the prehistoric biotic communities is unknown. Insufficient palynologic, microbiotic and faunal studies have been conducted on Antelope Creek phase sites. Similarly, subsistence scheduling activities. cannot be inferred since the distribution of economically useful plants is uncertain.

Nevertheless, crude approximations of the biotic settings may be obtained by comparisons of microspatial diversity within the limited catchment areas surrounding the various site types. The purpose of conducting such comparisons is not to delineate the size or shape of an area surrounding a site from which its inhabitants derived their resources, but rather to compare quantitatively specific site settings to the general study area and to contrast the settings of the various site types. To accomplish this, measures of soil diversity and productivity and landform types are employed as 
a standard against which individual site catchments are subsequently compared.

Direct quantifications of the study area are hampered by inconsistent soil taxonomies used for the four counties encompassing the study area, and in some instances soil fertility information is not available. However, since all architectural sites in this study occur in Hutchinson and Potter Counties, and both counties span the width of the Canadian River valley and its tributaries, the percent soil occurrence within these two counties was regarded as representative of the study universe (Pringle 1980:Table 3; Stringer 1976:Table 1). No attempts were made to resolve the soil taxonomic differences; however, the general soil types were grouped by topographic feature (Table 46).

The mean value of pasture productivity under normal rainfall conditions was used as a measure of soil fertility. Pringle (1980, Table 5) provides pasture productivity in pounds per acre for 27 of the 34 soil types found in the two county area. The productivity for mixed soil associations (i.e., Veal-Paloduro, Mobeetie-Veal, etc.) was derived by adding the productivity of each of the two dominant soil types according to the reiative proportions of soils occurrence in the type association description. (For example, Veal has a normal productivity value of 1500 whereas the normal productivity value of Paloduro is 2000. Since Veal and half of the unidentified residual soils constitute 558 of the association, while paloduro and the remaining residuals typically make up 458, the productivity value of the association is $1500 \times .44+2000 \times .45$, or 1725). Estimates of pasture productivity for Dallas, Obaro, Obaro-Quinlan, Humbarger and Berda soil types were derived by multiplying the dry farming grain sorghum pound production 
Table 46. Rangeland Productivity of Soil Types in Hutchinson and Potter Counties, Texas.

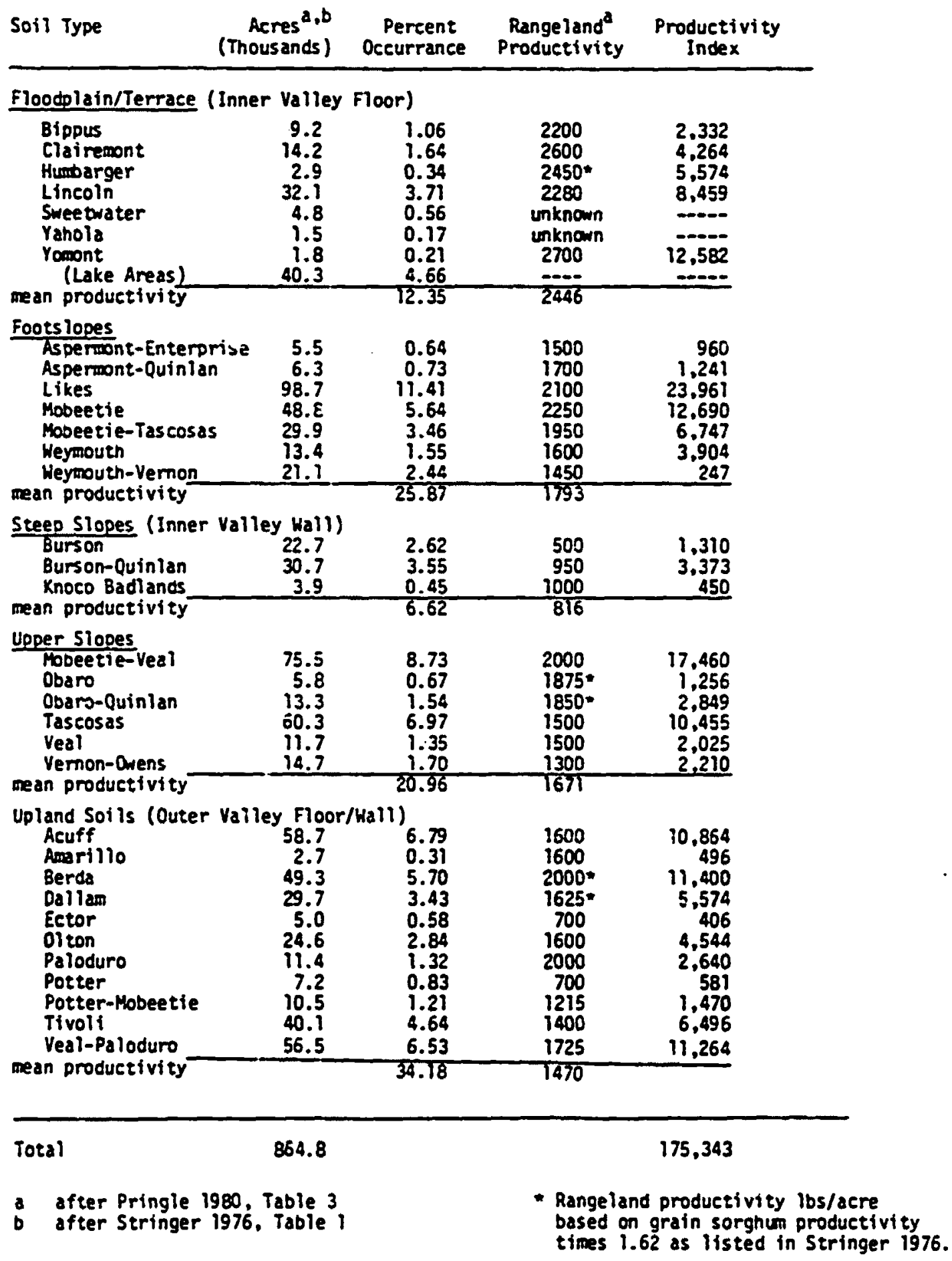


(Stringer 1976, Table 2) by an adjustment factor of 1.62 in order to derive values conparable to those used as indicated for other soil types by Pringle (1980, Table 5). Still, soil productivity values are missing for sweetwater and Yahola soil series, but these two types constitute approximately 0.778 of the two county area. Ignoring these types, a mean rangeland productivity index of 175,343 per unit area for the two counties provides a comparative base for the individual site catchments. This figure may be somewhat low since the soil surveys were condtcted after the construction of Lake Meredith, and information for about five percent of the study area is not taken into consideration. Also indicated in Table 46 is the mean productivity for the five topographic settings. Arranged in order of decreasing productivity, the values are: floodplains and terraces (2446), foot slopes (1793), upper slopes (1671), uplands (1470) and steep slopes (816). These figures supply productivity values for specific site catciments where information is missing due to borrow pit or lake inundation.

In order to quantify the specific site settings, catchment areas surrounding each site were selected and the soil values quantified. Based initially on !Kung observations by Lee (1969:61), many catchment studies have arbitrarily selected a $10 \mathrm{~km}$ procurement radius. Yet differential intensity of resource exploitation has led to the notion of a concentric area of intensified exploitation, or zonation, surrounding the site (Flannery 1976:117). Since Chrisholm (1968) indicates that the majority of any community's economic activities were conducted within one kilometer of the site, this catchment area was selected as a suitable size. The percent of soil types present within each of the local (1 km) catchments was obtained by measuring the county soil aerial photographs 
with a Lasico polar planimeter, model 40 . The results tabulated by topographic setting are presented in Table 47. Soil maps for 11 of 27 architectural site catchments were incomplete due to water impounded by Sanford Dam in bottomland settings and borrow pits in upland locations. The unmapped areas were often small except at Roper, Turkey Creek, 41Mo-7, and Arrowhead Peak sites, where less than 608 of the catchments were mapped. These four sites were excluded from further consideration.

Multiplying the soil productivity by the percent soil type per catchment yields a productivity index per unit area (Table 48). In seven instances where data were incomplete due to inundation or borrow pits, the productivity was estimated by the following procedures. In inundated lowland area, half of the unmapped area was considered to be floodplain/terrace setting and half was considered foot slopes. Thus the percent of the catchment represented by each area was multiplied by the mean productivity of the two topographic settings. Similarly, the percent catchment area affected by borrow pits on the outer valley rim was divided equally between the upper slope and upland areas. Also indicated in Table 48 is the number of different soil types found in each site catchment. This value is considered to be a crude measure of setting diversity.

An examination of Table 48 reveals that only six of the 24 architectural sites are located in catchment areas with higher soil productivity than the mean productivity of the study area as represented by soils from Hutchinson and Potter Counties. Two are homesteads, and four are hamlets located near the extreme edges of the study area. Jack Allen is the only site with high productivity at the easternmost edge of the study area, whereas Chimney Rocix Ruins 51, 51A, Marsh, Coetas Creek Ruin, and Footprint 
Table 47. Percent Soil Type within 1 kilometer Site Catchments.

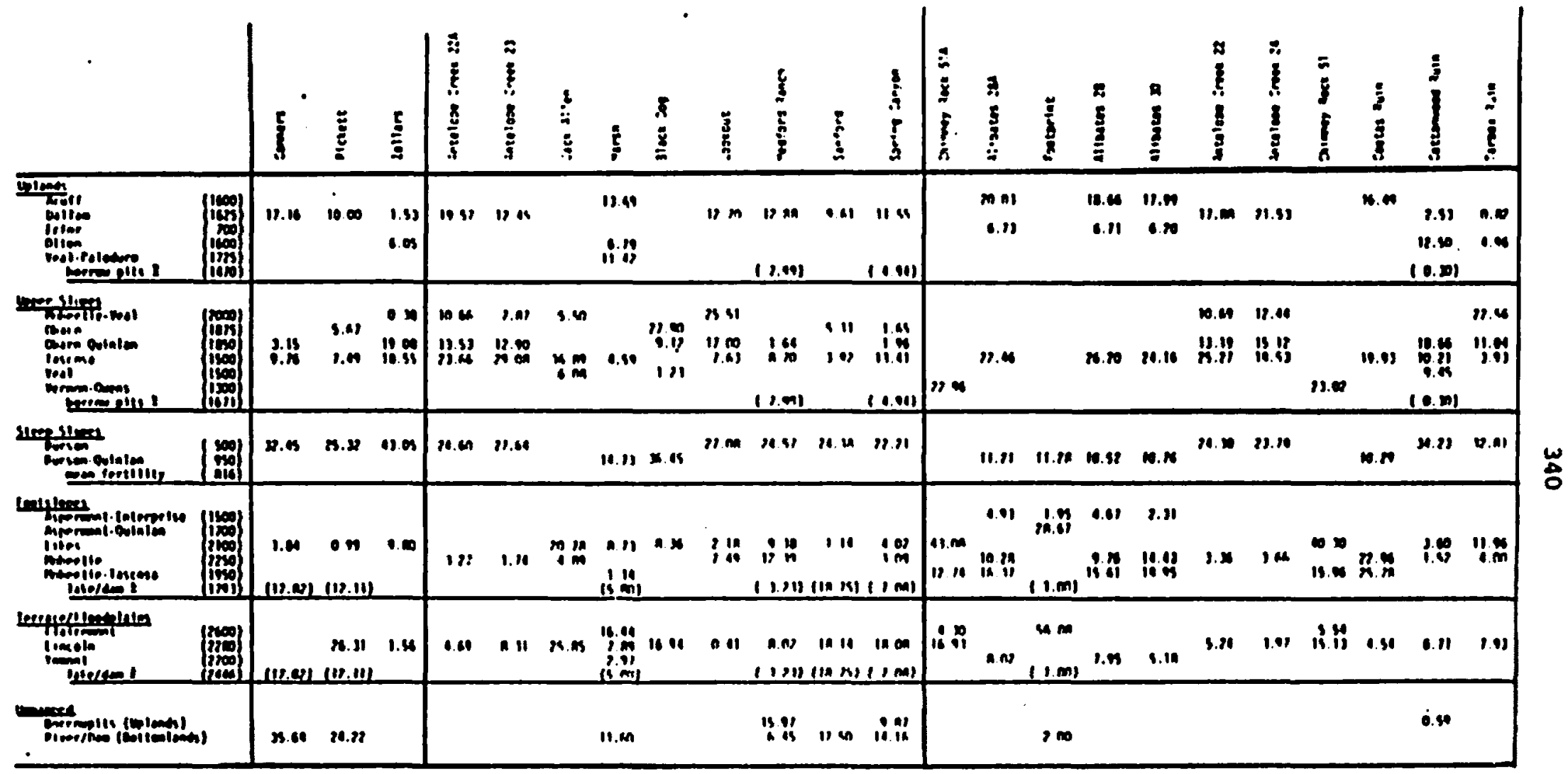


Table 48. Productivity of Site Catchment Areas.

Terrace Foot Steep Upper Uplands Floodplain Slopes Slopes Slopes Product. Index**

Subhomesteads

$\begin{array}{lrllllll}\text { Conners } & 43,588 & 35,815 & 16,225 & 20,468 & 27,885 & 143,981 & 5 \\ \text { Pickett } & 89,608 & 23,792 & 12,660 & 21,866 & 16,250 & 164,176 & 6 \\ \text { Zollars } & 3,557 & 20,580 & 21,525 & 63,883 & 12,168 & 121,713 & 8 \\ \text { mean productivity } & & & & & & 143,290 & 6.3\end{array}$

Homesteads

$\begin{array}{lrrrr}\text { Antelope Ck.22A } & 10,693 & 7,358 & 12,300 & 81,840 \\ \text { Antelope Ck.23 } & 18,947 & 3,915 & 13,820 & 83,225 \\ \text { Jack Allen } & 58,938 & 54,640 & 0 & 75,455 \\ \text { Marsh Site } & 82,939 & 30,955 & 13,994 & 6,885 \\ \text { Black Dog } & 38,623 & 17,556 & 34,628 & 71,030 \\ \text { Lookout } & 935 & 21,430 & 13,540 & 93,915 \\ \text { Medford Ranch } & 26,186 & 53,367 & 12,285 & 29,435 \\ \text { Sanford Ruin } & \mathbf{8 7 , 2 2 2} & 36,013 & 12,190 & 15,836 \\ \text { Spring Canyon } & 58,540 & 28,089 & 11,105 & 35,090\end{array}$

$\begin{array}{rlr}31,840 & 143,992 & 7 \\ 20,231 & 140,138 & 7 \\ 0 & 189,033^{\star} & 6 \\ 52,468 & 187,241 * & 10 \\ 0 & 161,837 & 6 \\ 20,638 & 150,458 & 8 \\ 32,675 & 153,948 & 7 \\ 15,616 & 166,877 & 6 \\ 26,030 & 158,854 & 8 \\ & \text { 161,375 } & 7.2\end{array}$

Hamiets

Chimney Rock 51A

Alibates 28A

Footprint

Alibates 28

Alibates 30

Antelope Ck.22

Antelope Ck.24

Chimney Rock 51

Coetas Ruin

Cottonwood Ruin

Tarbox Ruin

49,780

21,654

115,311

148,254

62,447

53,457

21,465

59,405

$13,986 \quad 72,885$

$11,947 \quad 7,560$

9,052

8,235

48,900

10,351

115,752

15,299

101,931

18,080

10,980

34,116

mean productivity

0
10,650
10,716
9,994
10,222
12,190
11,870
0
9,775
17,115
16,405

29,848
33,690

0

39,300

36,240

83,687

82,147

29,926

29,895

64,512

71,439

\begin{tabular}{|c|c|}
\hline $\begin{array}{r}0 \\
36,759 \\
0 \\
34,553 \\
33,124 \\
29,055 \\
34,986 \\
0 \\
26,384 \\
24,552 \\
9,269\end{array}$ & $\begin{array}{l}194,939 \star \\
165,200 \\
212,427^{\star} \\
164,717 \\
166,457 \\
144,439 \\
146,290 \\
194,578^{\star} \\
178,336^{\star} \\
132,458 \\
149,309\end{array}$ \\
\hline & 168,105 \\
\hline
\end{tabular}

* total productivity value exceedes productivity of study area.

$\star \star$ number of soil associations per catchment. 
are all west of other sites. These high productivity areas are generally characterized by fairly low inner valley walls (constituting less than 158 of the catchments) coupled with broad expanses of floodplain/terrace and foot slopes with limited areas of upper slope and upland settings.

A comparison of the soil productivity for the three site types reveals that tine catchments surrounding hamlets have the highest mean productivity $(168,105)$ whereas the subhomestead catchments have the lowest overall productivity $(143,290)$. This finding is somewhat surprising since, as a general rule, subhomestead sites tend to occur much closer to expanses of fertile soil of the Canadian River than do the other site types. However, in all three instances, the subhomestead sites occur along short lateral tributaries where much of the catchment area consists of steep slopes of the inner valley wall. Even though the overall productivity is low, Conners and Pickett are still adjacent to sizeable tracts of highly productive bottomland soil suitable for horticulture. Furthermore, the mean diversity of soil types is lowest for the subhomestead sites $(6.3)$ and highest for the homestead locations $(7.2)$. This suggests that subsistence activities at the subhomestead locations focused on a limited number of (horticultural?) resource areas. Possibly there was less concern with the overall diversity of resources near the subhomesteads than the range of resource areas near the other site types. In contrast, foraging activities would benefit from the more diversified settings at the homesteads and hamlets. From a productivity perspective, there is no significant change evident between the early and late site settings.

To some extent, the soil productivity values are separate and distinct from the biotic setting since they fail to consider the range of 
diversity within the biotic communities. The biotic conditions of the study area, as outlined in Chapter 3, are extremely diversified, but the bottomland (riparian) association is drastically different from biotic associations along steep slopes, mesa tops, gravelly slopes, and sand hills. The boundaries of the riparian plant associations are rather sharply demarcated, whereas the other associations show overlap in species distribution. From a foraging perspective, the edge of the riparian zone provides ready access to the greatest diversity of plant resources for the least amount of travel. But from an architectural perspective, the soft cottonwoods of the river bottoms are far less durable for the construction of permanent dwellings than the juniper and mesquite in the upland settings. Thus the nonrandom distribution of the three site types across the terrain represent an extremely efficient means of exploiting the diverse biotic communities in the study area.

Similarly, the faunal resources are not uniformly distributed. Duffield (1970) defines three preferred faunal habitats for the study area. These habitats are the Aquatic (roughly corresponding to the floodplain and terrace area), the Edge Breaks (foot slopes and steep slope areas), and the Grasslands (upper slopes and uplands). Through the analysis of archaeologically recovered faunal remains from eight sites included in the present study, Duffield was able to suggest the percent contribution to the faunal assemblages of large (bison, antelope, and deer) and other small mammals from the diverse environmental settings. Direct comparison among the values were. not attempted because of obvious differences in the site topographic settings. However, the percent topographic setting within each site catchment provides standardized values against which the faunal products for the various sites can be compared (Table 49). 
Table 49. Comparison of Percent Preferred Faunal Habitat

and Percent Topographic Features with in Site Catchments.

\begin{tabular}{|c|c|c|c|c|c|c|c|c|c|c|}
\hline & \multicolumn{3}{|c|}{$\begin{array}{c}\text { Aquatic } \\
\text { (Terrace/floodplain Setting) }\end{array}$} & \multicolumn{3}{|c|}{$\begin{array}{l}\text { EAne Breaks } \\
\text { (Footslopes/Steepslopes Settinn) }\end{array}$} & \multicolumn{3}{|c|}{$\begin{array}{c}\text { Grassland } \\
\text { (Upper Slopes/Upland Settings) }\end{array}$} & \multirow{2}{*}{$\begin{array}{l}\begin{array}{l}\text { Duffleld } \\
1970\end{array} \\
\begin{array}{l}\text { reference } \\
\text { page }\end{array}\end{array}$} \\
\hline & $\begin{array}{c}\text { percent } \\
\text { catchment }\end{array}$ & $\begin{array}{l}\text { percent } \\
\text { faund" }\end{array}$ & $\begin{array}{l}\text { catchment } \\
\text { ratio }\end{array}$ & $\begin{array}{c}\text { percent } \\
\text { catchment }\end{array}$ & $\begin{array}{l}\text { percent } \\
\text { fauna" }\end{array}$ & $\begin{array}{l}\text { catchment } \\
\text { ratlo }\end{array}$ & $\begin{array}{c}\text { percent } \\
\text { catchment }\end{array}$ & $\begin{array}{l}\text { percent } \\
\text { fauna* }\end{array}$ & $\begin{array}{l}\text { catchment } \\
\text { ratio }\end{array}$ & \\
\hline \multicolumn{11}{|l|}{ SHALL MAYHALS } \\
\hline \multicolumn{11}{|l|}{ Subhomes tead } \\
\hline $\begin{array}{l}\text { Roper Site } \\
\text { Honesteads }\end{array}$ & 25.0 & $\cdots$ & $\cdots$ & 53.2 & 40.6 & 0.76 & 21.8 & 59.4 & 2.73 & 205 \\
\hline $\begin{array}{l}\text { Spring Canyon } \\
\text { Hedford Ranch } \\
\text { Hamlets }\end{array}$ & $\begin{array}{l}25.2 \\
11.3\end{array}$ & 15.5 & 0.62 & $\begin{array}{l}36.4 \\
49.6\end{array}$ & $\begin{array}{l}72.0 \\
\cdots--\end{array}$ & 1.98 & $\begin{array}{l}38.5 \\
39.7\end{array}$ & $\begin{array}{l}12.7 \\
100.0 ?\end{array}$ & $\begin{array}{l}0.33 \\
2.55\end{array}$ & $\begin{array}{l}175 \\
168\end{array}$ \\
\hline $\begin{array}{l}\text { Alibates } 28 \\
\text { Antelope CK } 22\end{array}$ & $\begin{array}{l}8.0 \\
5.2\end{array}$ & $\begin{aligned} 6.0 \\
\cdots\end{aligned}$ & $\begin{array}{l}0.75 \\
\cdots\end{array}$ & $\begin{array}{l}40.6 \\
27.7\end{array}$ & 57.0 & 1.41 & $\begin{array}{l}51.6 \\
67.1\end{array}$ & $\begin{array}{l}37.0 \\
98.0\end{array}$ & $\begin{array}{l}0.72 \\
1.46\end{array}$ & $\begin{array}{l}119 \\
137\end{array}$ \\
\hline Mean & & & 0.685 & & & 7.383 & & & 1.558 & \\
\hline \multicolumn{11}{|c|}{ LARGE MAMMALS (bison, deer, antelope) } \\
\hline $\begin{array}{c}\text { Roper Site } \\
\text { Honnestead Sites }\end{array}$ & 25.0 & $\cdots$ & $\cdots$ & 53.2 & $\cdots$ & $-\ldots$ & 21.8 & 99.6 & 4.57 & 202 \\
\hline $\begin{array}{l}\text { Sanford Ruin } \\
\text { Spring Canyon } \\
\text { Antelope Ck } 22\end{array}$ & $\begin{array}{r}36.9 \\
25.2 \\
4 \quad 4.7\end{array}$ & $\begin{array}{l}\cdots \\
\cdots \\
\cdots\end{array}$ & -... & $\begin{array}{l}44.3 \\
36.4 \\
27.8\end{array}$ & 18.0 & $\ddot{0.49}$ & $\begin{array}{l}18.8 \\
38.5 \\
67.4\end{array}$ & $\begin{array}{c}100.0 ? \\
82.0 \\
98.0\end{array}$ & $\begin{array}{l}5.31 \\
2.13 \\
1.45\end{array}$ & $\begin{array}{l}215 \\
175 \\
144\end{array}$ \\
\hline Hamlets & & & & & & & & & & \\
\hline $\begin{array}{ll}\text { Alibates } & 28 \\
\text { Antelope } & \\
\text { Antelope } & 22 \\
\text { CK } & 24\end{array}$ & $\begin{array}{l}8.0 \\
5.2 \\
4.0\end{array}$ & $\begin{array}{l}\cdots \\
\cdots \cdots \\
\cdots \cdots\end{array}$ & $\begin{array}{l}\cdots \\
\cdots \cdots \\
\cdots \cdots\end{array}$ & $\begin{array}{l}40.6 \\
27.7 \\
27.4\end{array}$ & \begin{tabular}{r}
31.0 \\
\hdashline$\ldots .5$ \\
3.5
\end{tabular} & \begin{tabular}{l}
0.76 \\
\hdashline .12 \\
0.12
\end{tabular} & $\begin{array}{l}51.6 \\
67.1 \\
68.6\end{array}$ & $\begin{array}{l}\not \ldots .0 \\
96.5\end{array}$ & 1.40 & $\begin{array}{l}119 \\
137 \\
153\end{array}$ \\
\hline Mean & & & 0.0 & & & 0.456 & & & 2.712 & \\
\hline
\end{tabular}

- after Duffield 1970 
The sites were grouped by subhomestead, homestead and hamlet types, and a catchment ratio (percent exploitation area as reflected by faunal remains divided by percent topographic setting for site catchment) was calculated. The catchment ratio indicates the disparity between faunal assemblage and the catchment size; values less than 1.0 indicate that the resource area was under-exploited, whereas values of more than 1.0 indicaie the over-representation of manmals from that setting in the faunal assemblage. An examination of Table 49 shows that for small mammals, the Aquatic resources are under-represerted while the Edge Breaks and Grassland resources are somewhat over-represented for the catchment size. However, for larger mammals, the Aquatic and Edge Breaks are under-represented, whereas the Grasslands are over-represented in the faunal collection relative to catchment size. One could argue that the one kilometer size catchment might account for these differences. In most instances, with an increase in catchment area, the percent aquatic catchment area will become smaller whereas the percent grassland areas will become larger. However, if catchment scale is the only factor operating, we should expect that the three areas show similar mean catchment ratio patterns for the two sizes of animals. The fact that the Edge Breaks area is over-represented for the small. mammals, but markedly under-represented for the larger manmals suggests that differential procurement patterns are operating. Clearly, the high mean catchment ratio for the larger mammals relative to smaller mammals indicates that they were taken from a larger catchment area. The conclusion that-Antelope Creek hunters had to travel further to obtain bison, deer and antelope is not unexpected since these animals are more mobile and have larger territorial ranges. 
An examination of catchment ratio by site types is further limited by the small number of sites reporting faunal remains from the aquatic zone. only preliminary trends are available. In general, people at the subhomesteads traveled farthest, whereas those at hamlets traveled least to obtain larger and smaller grassland animals. But given the pattern of site settings, this merely mirrors the spatial distribution of settlements relative to topographic settings as delineated from the macrospatial analysis. Similarly, on the average, people at the homestead sites procured large and small Edge Break resources from the greatest distance, while those at subhomestead sites traveled least. The low catchment ratios of aquatic animals hinders delineation of specific trends by the various site types. The relative scarcity of aquatic small mammal resources at the subhomestead (Roper) site closest to the Canadian River and the relative abundance of those resources at the hamlet (Alibates Ruin 28) site farthest from the river is somewhat surprising. To some extent, differences in collection methods used by the WPA and Norpan groups may account for these discrepancies.

\section{Summary}

The spatial patterning of sites within the Canadian River Valley is undoubtedly influenced by a combination of social and environmental conditions. Systematically collected information about site size, type, and spacing is insufficient to infer population size or density for the Canadian River Breaks area. Consequently, the societal influences on the total settlement patterns remain unclear.

The present chapter has focused on delineating spatial patterns of the three morphological site types with architectural remains (subhomesteads, 
homesteads, and hamlets) as they relate to a series of environmental variables. Wherever feasible, temporal changes were also considered. Fairly sharp spatial distinctions were found in the placement of the morphological site types within the environmental setting of the Canadian River Breaks. Most large hamlet sites occur 2.9 to $4.5 \mathrm{~km}$ from the Canadian River on the higher elevations (many are over $42 \mathrm{~m}$ above the adjacent tributaries) on high bench settings, mesa tops, and along the rims of the inner valley, as well as on the outer valley floor. These settings are in close proximity to Ogallala aquifer seeps and springs, which provide the freshest and most dependable water supply in the region. The rangeland productivity near these sites is typically high and soils show a medium range of diversity. Although the biotic setting is not especially diversified in comparison to that surrounding other site types, the hamlets are near hardwood (mesquite and junipex) resources useful in construction, and are closest to grassland settings. These habitats were often exploited for bison and antelope, which constituted the vast bulk of meat in the Antelope Creek people's diet. The smaller homesteads are apt to be situated on either the low inner valley floor terraces or on the high rim settings, and tend to be close (less than $1.2 \mathrm{~km}$ ) to the Canadian River or along the middle portions of the lateral tributaries at considerable distance $(7.2$ to $8.7 \mathrm{~km})$ from the Canadian River. Although no perfect correlation exists between topographi= settings and distance from the Canadian River, those homesteads near the river tend to occur at higher settings whereas those far from the Canadian are generally at lower settings. This spatial diversity again suggests that fresh water from either high seeps/springs and flowing spring water near the heads of tributaries was preferred over the waters in the Canadian River 
channel. The rangeland productivity surrounding the homesteads is somewhat lower than at the hamlet settings, but the soils are more diversified. Overall, the homestead sites afe situated with fairly even access to aquatic, edge breaks and grassland biotic communities, but most of the large and small faunal remains reflect predominant exploitation of the grassland habitats.

The subhomesteads are typically on the lower setting (inner valley floor terraces and wall benches) close to the Canadian River. Water would be seasonally available in the Canadian River channel, particularly during spring and summer following the thunderstorms and snow melt in headwater areas. But at other times, it would be sluggishly brackish. The high percentage of steep slope areas within the catchments reduces the overall productivity value of the subhomestead settings, even though the river channel soils are the most productive in the entire study area. Furthermore, the low soil diversity is offset by the unique and bountiful riparian resources. Although wooc is fairly abundant near the river, most species are soft and ill suited for the construction of long term structures.

These three site types reflect only localities with substantial architectural remains. Numerous other kinds of complementary procurement and processing activity areas and base camps are also part of the complex Antelope Creek phase settlement-subsistence pattern (cf. Etchieson 1979). Temporal changes in the settlement-subsistence pattern are difficult to document. The two possible changes involve an intensification of settlements near the Alibates quarries, and the reduction or total deletion of the subhomestead site types during the late subphase. Some implications of these changes will be examined in the next chapter. 
CHAPTER 10

SYSTEMIC CHANGE AND INTERREGIONAL RELATIONSHIPS

\section{Introduction}

Previous chapters have been concerned with explicitly defining the morphological range of architectural and community variability, and with discerning how functional, social, temporal and spatial differences affect these morphological variations within a single locality of the Antelope Creek phase. Nearly all the emphasis has focused on the environmental confines of the High Plains-Canadian Valley locality. Although specific trends have been discerned, there has been little attempt to integrate these patterns, or to elucidate the fundamental relationships among them. It is difficult to discern these fundamental relationships strictly from examining the local conditions, since the Antelope Creek pecple vere historically tied to earlier groups, and responded to changes in the social and natural environment which occurred across the Southern Plains and adjacent areas.

In this chapter I shall examine two facets of the Antelope Creek phase within broader contexts than just the locality. These facets are: 1) the potential origins of the Antelope Creek phase, and 2) the ecological systemics underlying the cultural dynamics of the phase. The origins of the Antelope Creek phase have been addressed a number of times before (cf. Chapter 2). However, instead of merely reiterating the culture-historical continuity, I shall evaluate the evidence for group migration and trait diffusion. In conducting such an evaluation, the general nature of cultural 
transmission is discerned, both the specific kinds of architectural attributes and their potential sources are identified, and finally, two specific mechanisms of cultural transmission are examined. Thus the first facet focuses on how the distinctive Antelope Creek assemblage coalesced, but at this time, information about the environmental conditions, and cultural developments in the Southern Plains and adjacent areas around A.D. 800-1200 is insufficient to indicate why the traits came together.

Next, the cultural dynamics of the Antelope Creek phase shail be systemically examined from an ecological perspective to show that the people were experiencing signs of population stress long before the termination of the phase. It is my contention that some of the seemingly unrelated trends in trade, settlement and community pattern variability reflect "buffering mechanisms" employed by the Antelope Creek people in an effort to cope with population stress. By buffering mechanisms, I mean any cultural mechanism or practice that lowers the risk of starvation by artificially dampening fluctuations in the availability of food resources relative to the human population size within an area (Nelson 1980:15). Several of the trends in trade, settlement and community patterns have been discerned in earlier chapters, and will only be mentioned. However, much of the discussion will focus on one buffering option frequently cited in the Antelope Creek literature, but not previously examined in this study--the evidence for intercultural raiding behavior. The relationships of these buffering options are further discussed in the sumnary chapter of this study. The format and structure used to examine these two issues differ from that employed in other chapters, since both topics encompass considerably greater spatial and temporal parameters. The hypothetico-deductive approach 
is employed to formally examine Antelope Creek origins and cultural dynamics. Basic to this approach is the formal development of hypotheses and the deduction of suitable test implications, which are checked against empirical tests (Hempel 1965, 1966). The soundness of the hypothesis stems from the way the test implications stand up when confronted with relevant observational data. Typically, the test implications are conditional (if/then) statements that predict under what circumstances one would expect the empirical information to occur if the hypothesis is correct. However, the easiest way to test a hypothesis is to develop implications and marshall information that refutes, rather than confirms the implication, since an affirmative of a proposition does not necessarily ensure that the hypothesis is a valid explanation (Hill 1970b:22). Only through the elimination of less tenable explanations can the range of viable alternatives be discerned.

\section{The Origins of Antelope Creek}

The origins of the distinctive Antelope Creek phase have been attributed to either intrusions of immigrants or the adoption by indigenous group of new ideas from a number of different sources. These two positions entail fundamentally opposing perspectives. Each position is examined separately.

\section{IMMIGRATION}

Most of the proposed migrations have been briefly mentioned in Chapter 2, and summarized by Lintz (1976:101-105). Although the immigration hypothesis is popular, there is little consensus as to the source of the immigrants. Their derivation has been variously attributed to unspecified Eastern groups (Holden 1932, 1933; Studer 1934:81; 1955:94; Kenner 1969:5), unspecified Plains groups (Moorehead 1921:21; Wendorf 1960), unspecified Plains and 
Southwestern groups (Krieger 1946:74), and unspecified Southwestern groups (Sayles n.d.; Studer 1931b). In addition, others have derived Antelope Creek from a westward progression of cultural expressions which are ultinately derived from the late Gibson aspect Caddoans to the east (Hobbs 1941:128; Bell 1961; Keller 1975), Upper Republican groups from the northeast (Watson 1950; Baerreis and Bryson 1966b; Baerreis, Bryson and Wendland 1970), the Apishapa to the northwest (Campbell 1969, 1976; Thoms 1976), a combination of Upper Republican and Apishapa groups (Bousman 1974a, 1974b), and a combination of Upper Republican and Southwestern groups (Spencer and Jennings 1965 : 80).

Prehistoric migrations are indicated as "site-unit" intrusions of one cultural unit into an area which may or may not be occupied by a second cultural group (willey et al., 1956:7). However, the nature of the culture contact and its reflection in the archaeological record can vary considerably. Accordingly, four kinds of site-unit intrusions were identified and described (ibid:8). The kinds range from intrusions where the immigrants retain unchanged their cultural identity, to intrusions, which are absorbed into the resident cultural pattern.

Since this early study, a number of other works have attempted to delineate the empirical evidence necessary to infer migrations (Rouse 1958; Meggars 1971; Ludwickson 1975:47). To adequately demonstrate that a migration has occurred, one must: 1) identify specific locations in the study region which are sufficiently distinct from the local tradition as to suggest that the region has been penetrated; 2) identify the source or original homeland; 3) establish the contemporaneity of the culture units; and 4) establish the existence of favorable conditions for migration (Rouse 1958:64). 
The evidence for the penetration of a distinctively different cultural tradition into the Texas panhandle has not been demonstrated, in part, because the proported intrusions coincide with the general widespread shift from Woodland to Village horizons throughout the Plains region. Since the indigenous cultures are undergoing radical change, it is difficult to recognize intrusions of new people. What is apparent, however, is that when the Village pattern finally develops on the Southern High Plains, the sites axe more prominent, possibly more abundant, and show a strong infusion of Southwestern and plains traits. It is precisely this ambiguity in the local development between A.D. 800 and 1150 which permits the continual resurrection as migration as a ready explanation. The multitude of immigrant sources demonstrates that no clear consensus exists regarding who was involved, why they migrated, or how they contributed to the distinctive Antelope Creek phase architecture.

In order to examine the migration theories in greater detail, specific test implications were formulated based on suggestions by Meggars (1971) and Ludwickson (1975). The widespread range of postulated homelands dictates that the implications remain generalized.

Test Implications:

If the distinct architecture and comunity variability of the Antelope Creek phase is due to migration, then:

1) the "donor culture" (Rouse's "homeland") must be temporally earlier than the "recipient culture."

2) a complex of traits, rather than a single trait or few traits should be involved. Furthermore, the migration argument is strengthened if the character of the trait is not determined by 
function.

3) The specific traits should reveal a long period of development in the homeland region and appear fully developed with little indication of experimentation in the Texas panhandle region.

The information used to examine these implications will vary depending upon the available data and the immigrating group involved. For practical reasons, I will only consider those groups whose specific cultural affiliations have been identified. These groups include the Late Gibson aspect Caddoans, Upper Republicans, Apishapa, and "Southwestern" groups. Aspects of some of the postulated migrations have been addressed in other studies. Consequently their results will only be sumarized.

Test 1: The donor culture must be temporally earlier than the recipient culture.

Assuming the available chronometric methods reliably reflect the initial appearance of the Antelope Creek phase (around A.D. 1200), then the age of the donor cultures must be earlier in order to remain a viable source for immigrants. Present summaries indicate that the Upper Republican manifestations florished between A.D. 1050-1350 (Baerreis and Bryson 1965a; Roper 1976; Ludwickson 1975): The Apishapa phase reflects a culmination of cultural development in southeast Colorado which started around A.D. 500 as a Woodland complex, and transcended the Plains Village pattern by A.D. 1000-1350 (Campbell 1969, 1976).

Finally, during late Pueblo II period (A.D. 1000-1200) sedentary Southwest groups were residing east of the Rocky/Sacramento Mountains in the Sierra Blanca, Middle Pecos, and Park Plateau Districts (Kelley 1966; Jelinek 
1967; Kirkpatrick 1976; Ireland 1971). By Pueblo III period (A.D. 1200-1300) a major Puebloan intrusion into the Rio Grande Valley had occurred (Stubbs and Stallings 1953; Cordell 1979:144). Thus any of these groups satisfies the condition and could be the potential source of immigrants. In contrast, radiocarbon dates from the Caddoan and Southern Plains-Prairie areas do not support the progressive westward expansion of village complexes onto the High Plains (Bell 1968:48; 1973). The available evidence suggests that the Custer phase in western Oklahoma are somewhat earlier than the Washita River phase in central Oklahoma; consequently the linear development of culture complexes originating from the Caddoan area must be rejected. On the basis of Test 1, Caddoan groups are thus eliminated as viable candidates for immigrants to the High Plains.

Test 2: The migration should be evident from a complex of traits, rather than a single or few traits. As a corollary, similarities in artistic and stylistic traits are stronger evidence than functional traits in discerning the occurrence of migrations.

The Upper Republican migration hypothesis has been examined in detail elsewhere; consequently only the major points are summarized (Lintz 1978a: 48-49). The complex of traits common to Upper Republican and Antelope Creek include a subsistence based on hunting and herticulture, isolated one room houses, square room form with four interior roof support posts set in a quadrilateral pattern around a central hearth, and eastward extended entrances, globular-shaped cordmarked pots, diamond-shaped beveled knives, side notched points, drills, scapula hoes, bone beads, and stone elbow pipes. These traits are not unique to the two cultures, but occur in culture 
complexes from North Dakota to north central Texas and western Oklahoma. Since this trait assemblage has been regarded as the type characteristics of the Plains village pattern (Lehmer 1954), they can not be used to demonstrate any specific migration.

More importantly, a number of stylistic differences exist in specific patterns of architecture, bone tools and ceramics. Architecturally, Antelope Creek differs from Upper Republican in the use of masonry and mortar walls, contiguous room arrangements, and in the frequent use of depressed central floor channels, raised platforms, and interior wall bins inside the main structures. The bone tool assemblage also shows marked differences. The Antelope Creek assemblage frequently has bison tibia digging stick tips, and notched rib rasps, whereas the Upper Republican assemblage includes bone beamers, bone gorgets, antler bow guard bracelets and bone fish hooks. More significantly are the stylistic differences evident in the ceramic assemblage. Upper Republican jars frequently have a distinctive thickened collared rim and are decorated near the rim with incised "herringbone" and " $x$ " motifs. In contrast, the Antelope Creek phase vessels rarely have thickened rims and the decorative motifs consist primarily of dot punctuations along the lip or rim, diagonal punctuations along the lip, or finger-gouged dots aiong the rim. Although a few collared-rims shexds have been reported in the Texas panhandle, they occur at Antelope Creek phase sites less frequently than Southwestern trade ceramics (Table 31). Although other unexcavated sites in the Texas panhandle reportedly have "significant" quantities of collared-rim sherds (Crabb 1968:84; Hughes 1968:189), the cross-dating of four southwest ceramic types from one such site suggests an A.D. 1300-1350 date (Crabb 1968:84). This age span is considerably later than expected if 
such sites reflect immigrant colonies which precede Antelope Creek phase development. Thus, on the basis of test implications, the proposition involving an Upper Republican migration must be rejected.

An Apishapa migration from southeast Colorado has been postulated to account for the origins of Antelope Creek. Campbell $(1969,1976)$ suggests that Apishapa people moved on to the Southern High Plains, where they came into contact with, or were influenced by such Plains village groups as Custer-Washita River from western Oblahoma, or Upper Republicans from Nebräska. The Antelope Creek traits presumably derived from Apishapa sources include a hunting/horticultural subsistence pattern, semisubterranian structures, contiguous room house arrangements, vertical slab masonry architecture, small circular room forms, above-ground entryways, single, flexed primary interments, nor collar rimmed cordmarked jars, side notched point forms, ovate knives, flange drills, basketry and slab metates. Indeed, nearly all Apishapa traits can be found in the Antelope Creek phase assemblages (Campbell 1969: Table 19).

However, a wide range of Antelope Creek phase traits have not been found to southeastern colorado. The differences in architecture alone is extensive. Traits commonly found at Antelope Creek homestead and hamlet sites but not reported for the Apishapa area include large room sizes, rectangular room shapes, four central roof support posts, central hearths, extended entrances, multiple floor surfaces, interior storage bins and pits, central channels, raised platforms, and double row vertical slab wall foundations along with adobe plaster veneer. Despite the similarity in body orientations, the burials from southeast colorado are not capped with stone piles. Considerable differences are also evident in the tool assemblages. 
The Apishapa chipped stone tool assemblage consists primarily of general biface forms, whereas the Antelope Creek tools are more morphologically diversified and specific. Consequently, the diamond shaped beveled knife, "guitar-pick" scrapers, pin drills, and other specialized chipped stone tools have not been reported from southeast colorado. The bone horticultural tools. and stove elbow pipes, so common in Antelope Creek phase sites are missing in Apishapa assemblages. Finally, decorated ceramics rarely occur at Apishapa sites, yet they constitute between one-fifth and one-tenth of the rims from Antelope Creek sites (Lintz 1978a:Figure 6).

Some traits, such as the raised platforms, central channels, storage bins, stone-covered burials, and ceramic decorative styles do not exist in Custer, Washita River or Upper Republican complexes. Thus their occurrence in Antelope Creek can not be attributed to the adoption of Plains traits by the immigrating Apishapa people. The long list of cultural differences siggests that an Apishapa migration is an unlikely source of the Antelope Creek phase.

The postulation of Southwestern group migrations has not been seriously advanced since 1932. The Antelope Creek trait complex attributed to unspecified Southwestern groups are primarily architectural. The presence at eastern Puebloan sites of snub nose and end scrapers, beveled knives, drills, metapodial fleshers, awls, bison rib shaft wrenches, antler tapping tools and cordmarked pottery occur in such small quantities that they clearly represent introduced items from the Plains (Kidder 1932; Krieger 1946:62; Spielman 1983). The architectural similarity between Antelope Creek and various Southwestern groups is extremely generalized. It consists of semisubterranean structures, interior storage bins, discrete storage rooms, 
perhaps platforms, the contiguous arrangement of certain rooms, and the use of unshaped stone slabs and adobe in wall construction.

Unfortunately, the traits do not occur as an associated complex among any single Southwestern group. The specific Antelope Creek details involving contiguous room aggregate patterns, and the practice of upright stone foundations as a base for horizontal masonry walls also differ significantly from patterns evident among Southwestern groups (Bullard 1962; Kelley 2966; Jelinek 1967; Peckham 1976). The absence of the distinctive Southwestern ceramic and lithic technological traditions at Antelope Creek sites is noteworthy. Finally, metric and nonmetric comparisons of skeletal remains indicate the Antelope Creek phase burials are phenotypically closer to Central Plains (Upper Republican) populations than to Pecos Pueblo populations (D. K. Patterson 1974). Thus, the proposition that the predecessors of Antelope Creek are immigrating Southwestern groups can be rejected. Specific architectural traits will be discussed in greater detail while examining evidence for trait-unit intrusions (Proposition 2).

Test 3: Specific traits should reveal a long period of development in the homeland region, and appear fully developed with little indication of experimentation in the Texas panhandle area.

This test already has been discussed indirectly during the examination of Tests 1 and 2. The Caddoan and Southwestern groups will not be discussed further since their architectural and material assemblages differ significantly from the Antelope Creek assemblages. Furthermore, while some early cultural development is evident in southeast colorado and the Central plains, the differences noted in Apishapa and Upper Republican assemblages have been shown to be extensive. 
In view of the lack of affirmative information for Proposition 2, the various explanations involving cultural migrations must be rejected.

\section{ACCULTURATION}

Mason (1919) was the first to suggest that the distinctive Antelope Creek traits reflect cultural hybridization or blending of cultural traits. Since then, similar stances have been advocated by krieger (1946:73), Hughes (1968:210), Duffield (1970), and Lintz (1976, 1979b:177). Krieger attributes the distinctive Antelope Creek phase to selective borrowing and acculturation between unspecified plains and southwestern people.

Hughes (1968:208-210) sees considerable cultural continuity in the southern High Plains area. Recognizing the presence of numerous, but unpublished, Plains Woodland sites in the Texas panhandle, he suggests that a substantial indigenous population was residing in the region. The strong similarities between Upper Republican and Antelope Creek material assemblages reflects parallel evolution from separate, but related Plains Woodland complexes. The differences are attributed to slightly different adaptive responses to their respective areas and adjacent cultural manifestations. Thus Antelope Creek:

- . may have developed gradually out of woodland under Basketmaker influences to the west and Hopewellian and Gibson influences to the east, and endured long enough to experience Puebloan influences from the west and Mississippian and Fulton influences from the east (Hughes 1968:210).

Such a persuasive argument based on extensive familiarity with the Texas panhandle archaeology has compelled others to take a similar position (Duffield 1970; Lintz 1979). However, details of the argument have not been formally examined. 
Since the 1930s, all of the hypotheses advocating acculturative processes have maintained that the Antelope Creek phase represents a Plain village group, which has adopted a few superficial southwestern traits. The specific architectural traits attributed to southwestern origins include contiguous room arrangements, masonry architecture, semisubterranian structures, discrete storage areas (rooms or bins), and perhaps, platforms.

The archaeological fascination with trait distribution is rooted in the diffusionist approach common during the 1920s-1930s (Harris 1968). Considerable effort was expended by early archaeologists in discerning the distribution of cultural traits. By the 1950s, research emphasis shifted from the objects as entities in themselves to the context of the object within the cultural setting. The recognition of "trait unit intrusions" into a cultural setting obviously indicated some kind of relationships between cultures in a contact situation (willey et al., 1956). Four kinds of contact situations as reflected by trait-unit intrusions were identified and described from archaeological examples (willey et al., 1956). These range from the movement of "trade objects" into an area without fusion of the trait into the receiving culture to the fusion of the introduced trait which apparently accompanies or stimulates innovations in the receiving culture.

Subsequently, Schroeder (1966) refined the typology and recognized two types of trait-unit intrusion (unregulated and regulated diffusion), and site-unit intrusion (patterned diffusion). The latter type is not applicable to the proposition under consideration. Unregulated diffusion involves periodic brief trade contact between cultures wherein varying amounts of a trait assemblage are accepted by and/or are adapted to the culture of the recipient group resulting in trait unit intrusions (Schroeder 1966:683). In 
contrast, regulated diffusion involves the exchange, adoption or adaption of an entire trait complex through direction or instruction of the donor group, with the added implication of lengthy periodic visits of formalized trading expeditions from the donor culture.

Recently, diffusion has been branded a "nonprinciple" with no explanatory valיe (Harris 1968:377). Some archaeologists have regarded the concept with considerable disdain as an vis, stale, overworked concept:

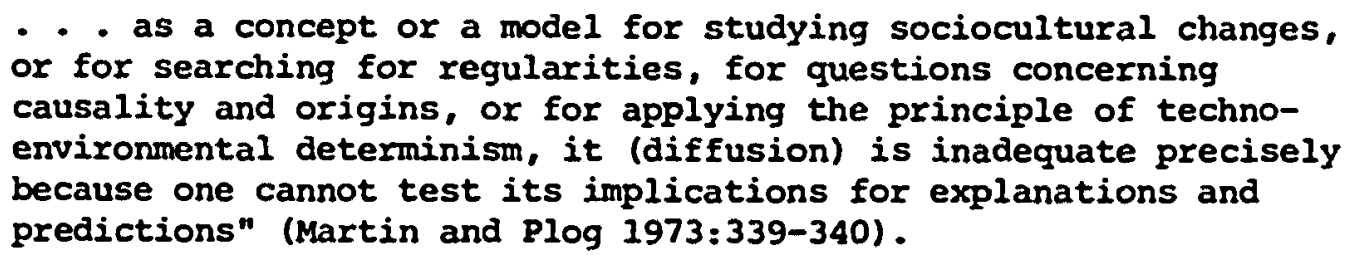

Although diffusion might not be useful to the discovery of cultural

laws, it nevertheless is an historical occurrence and can not be dismissed or ignored. The utility of examining diffusion is to seek potential source areas of contact, and to note the kinds of traits involved at various times. It is a necessary prerequisite for the development of more sophisticated explanations (Troike 1955:116).

The following series of test implications examines the diffusion and acculturation of the Southwestern traits into the early Plains Village setting. Most implications are developed from Schroeder's diffusion dicotomy, as well as from logical extension alternatives of the migration implication.

Test Implications:

If the distinct architectural and community variability of the Antelope Creek phase is due to diffusion of Southwestern traits onto the plains, then:

1) an identifiable indigenous group participating in an appropriate Plains adaptation should be residing in the area prior to the 
development of the Antelope Creek phase;

2) an appropriate trait constellations (possibly involving upright masonry wall foundations, contiguous room block layout, semisubterranean rooms, threshold collars, central channel/platforms, etc.) should be evident among identifiable Southwestern groups slightly prior to and overlapping the development of the Antelope Creek phase. However, the source areas for the diffused traits should be recognizable if regulated diffusion is involved, but may be more difficult to isolate if unregulated diffusion occurred.

3) some degree of experimentation and/or local innovations may be expected as the diffused traits become incorporated into the recipient culture's adaptative strategy. However, the degree of experimentation and innovation is directly dependent upon the kind of diffusion involved.

In order to test these implications, we must examine the cultural situation in the Texas panhandle preceeding the Antelope Creek phase development, survey the Pueblo II (A.D. 900-1200) architectural trends east of the Rio Grande River in New Mexico, and examine the variations evident in the early Antelope Creek subphase.

Test 1: An identifiable indigenous group participating in an appropriate Plains adaptation should be residing in the area prior to the development of the Antelope Creek phase.

- Recent archaeological fieldwork in the Southern High Plains has led to the identification of two culture complexes in the Texas panhandle during the first millenium A.D. These are the Palo Duxo complex, and the Lake Creek complex. 
The Palo Duro complex is based on distinctive artifactual remains from the Deadman's Shelter Site (Hughes and Willey 1978:190). Other Palo Duro components have been reported from Canyon Country Club Cave (Hughes 1969), the upper midden at Chalk Hollow (Wedel 1975), the South Ridge Site (EtchieSon 1979), the County Line and Blue Clay Sites (Hughes and willey 1978), and perhaps the Double Burial Site (Witte 1955). Nearly all these sites are located along the eastern escarpment of the Llano Estacado drained by tributaries of the Red River, and along the Canadian River Breaks. Multiple radiocarbon dates from Chalk Hollow, Canyon Country Club Cave, and Deadman's Shelter indicate that the Palo Duro complex florished between A.D. 120 and 870 .

Many facets of the Palo Duro complex are still unclear. The sites occur in a wide range of settings. Although stone lined and unlined pits have been found, no structural remains have been reported. The burials are typically semiflexed beneath rock piles, and are accompanied by few personal belongings. The individuals from the Double Burial site may not represent members of the complex, as much as victims of their hostilities (witte 1955).

I have no intention of dwelling on all aspects of the Palo Duro material assemblage. However, the distinctive traits include a small, delicately corner-notched point with long barbs (Deadman Type) associated with small and large corner-notch (Scallorn and Ellis Type) points, and occasionally a few sherds of plain brownware pottery. Temper analysis of potsherds from the Blue Clay and Deadman's Shelter Sites reveals that the crushed rock temper is either andesite or aplite from the Sierra Blanca-Sacramento Mountain area of southern New Mexico (Hughes and willey 1978:147-148, 185). The Palo Duro remains are thought to represent nomadic foragers in the upper Red River drainage, 
who served as intermediaries between the Mogollon groups of the Southwest and other groups on the Plains and eastern prairies (Hughes n.d.:61). However, their affiliation with Plains Woodland, Southwestern, or some other early Neo-Indian manifestation in Central Texas remains unclear.

The Lake Creek complex takes its name from the type site (Hughes 1962). Other excavated components include the Maintenance Barn Site (Couzzourt 1982), and perhaps 41MO-5 and 41Pt-29 within the Lake Meredith Area (Green 1967). Undescribed components are thought to be present at the Middle Cheyenne Site, Tascosas Creek Site, and the Border Bridge Site (Couzzourt 1982:70). The distribution of Lake Creek complex sites is concentrated along the Canadian River Valley, and is thought to occur generally north of the Palo Duro complex distribution. None of the Lake Creek components have been dated. However, similarities in ceramics and projectile point styles with items from adjacent manifestations in Oklahoma and southeastern Colorado suggests that it may span much of the first millenium A.D. and is contemporaneous with the Palo Duro complex.

Few of the Lake Creek sites have been extensively tested. Consequently, many attributes of the Lake Creek complex are unclear. A possible structure has been located at the Borger Bridge site, but details of its configuration are unknown. Other features include rock hearths and isolated flexed burials (Hughes n.d.). The most distinctive cultural remains of the Lake Creek complex inciude small corner notched (Scallorn Type) points in association with larger dart forms, and thick, conoidally-shaped, cordmarked ceramics. The predominent ceramic tempering material is crushed bone and scoria. Small quantities of plain brown ware ceranics occur at some Lake Creek sites. These items may be trade wares directly from the Southwest, or through a Palo 
Duro complex intermediary. On the basis of the trait assemblage, the Lake Creek complex represents a local manifestation of the Plains Woodland pattern (Wedel 1961). The participation of the Lake Creek complex in a cordmarking ceramic tradition makes it a likely candidate for the indigenous antecedents to the Antelope Creek phase group. This suggested continuity indicates that the first test implication should not be rejected.

Test 2: An appropriate trait constellation (involving upright masonry wall foundations, contiguous room bluck layout, semisubterranean rooms, threshold collars, central channels, storage bins, platforms etc.) should be evident among identifiable southwestern groups slightly prior to and overlapping the development of the Antelope Creek phase.

A survey of specific architectural trait complexes from Pueblo II (A.D. 900-1200) cultural manifestations located between the Llano Estacado and the Rio Grande/Southern Rocky Mountains is used in this test (Figure 29). Considerable difficulty was encounterec in compiling the architectural traits, since many of the culture complexes are poorly dated, and the ages of some sites are mere guesses.

The occurrence of cormon Antelope Creek phase architectural traits in adjacent oulture complexes with structures is presented in Table 50. Unfortunately, no Pueblo II period free standing structures with masonry have been reported from Ute Reservoir (Hamnack 1965), Conchas Dam area (Lange 1978), Los Esteros Reservoir (Levine and Mobley 1976; Mobley 1978), Brantley Reservoir (Henderson 1976; Gallagher and Bearden 1980), or from the Eastern Jornada Extension (Corley 1965; Leslie 1979). Furthermore, none of the eight 


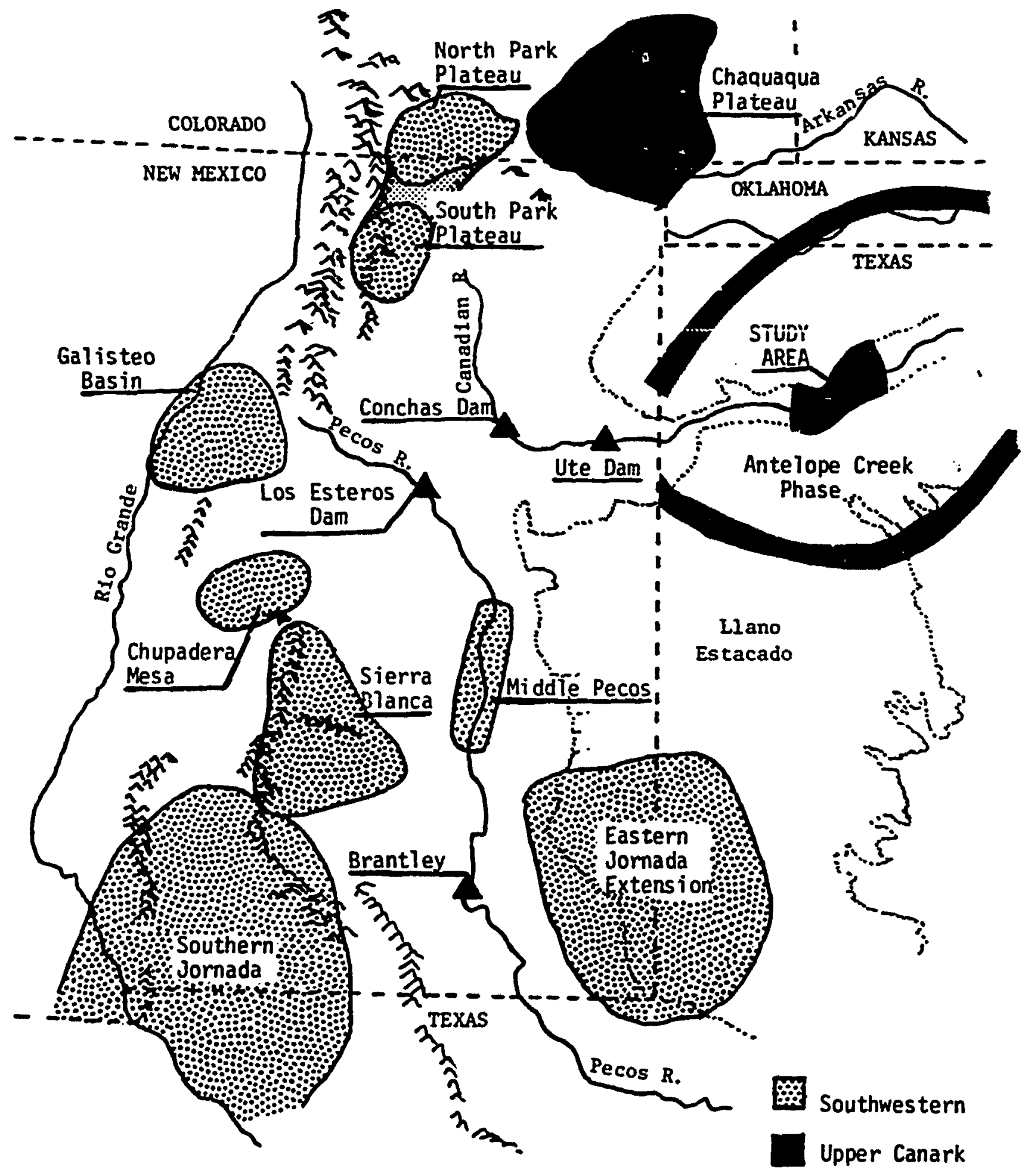

Figure 29. Southwestern Districts Adjacent to the Antelope Creek Phase. 
Table 50. Distribution of Select Architectural Traits

in Pueblo II Period Southwestern Complexes.

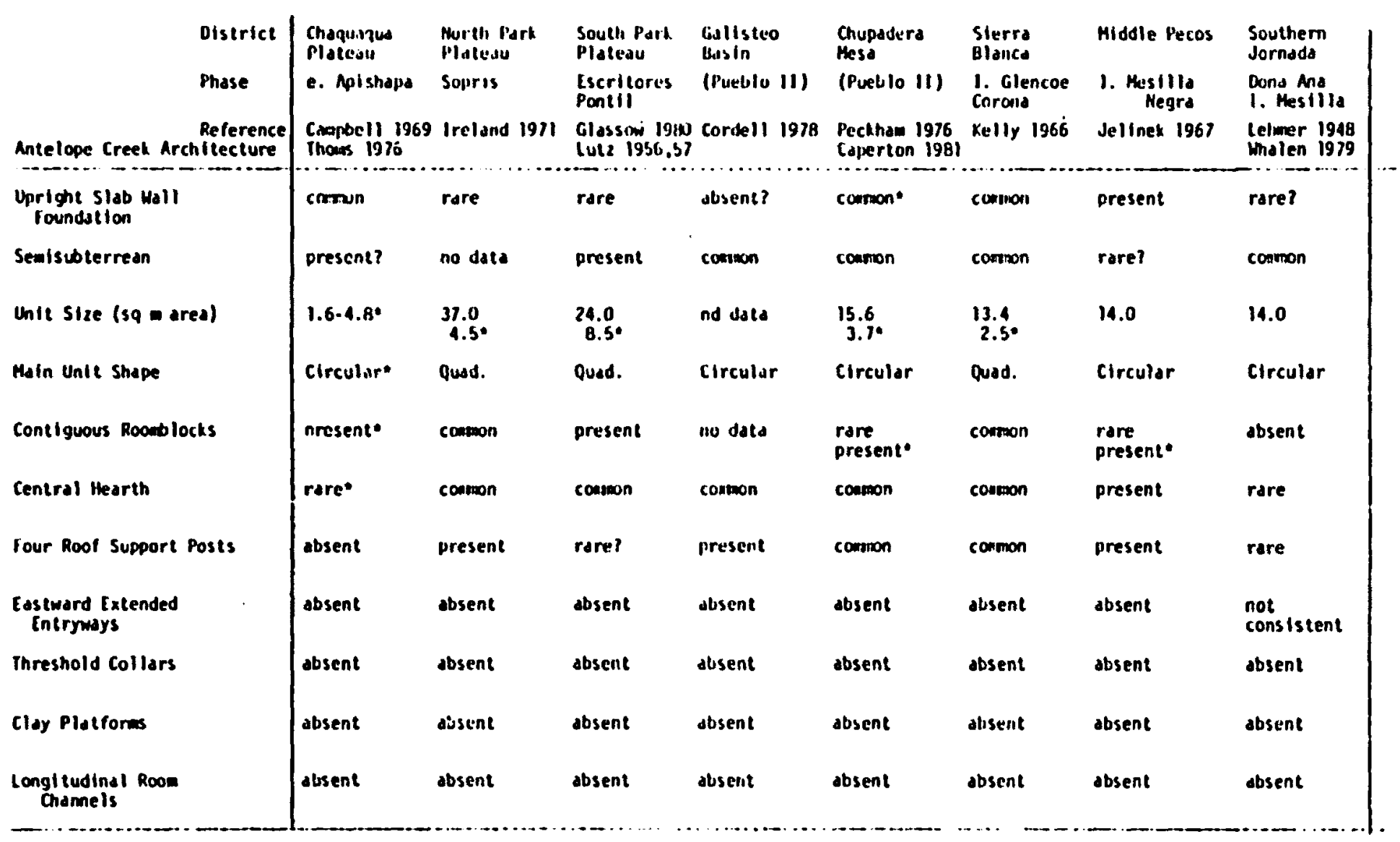


areas with Pueblo II masonry architectural remains has all of the attributes present in the Antelope Creek phase sites.

Specific archaeological similarities between the Antelope Creek phase and the early Apishapa and Sopris-Pontil phases to the northeast of the Antelope Creek phase are weak. During the early Apishapa phase in southeastern Colorado, upright slabs were in use at sites La-977, La-259 and La-875 (University of Colorado sites, Campbell 1969). At the latter site, some of the circular structures were contiguous. However, the floor area of these rooms is typically less than $6 \mathrm{sq} \mathrm{m}$, which makes them comparable in size to the Antelope Creek phase storage units (Unit Type 8). Although a number of rockshelters and caves were occupied at this time, no substantial residential dwellings have been reported and the specific interior features commonly associated with Antelope Creek phase Type 1 units (floor channels, central hearths, four roof support posts, interior bins, eastward extended entryways, threshold collars, etc.) are quite alien to the early Apishapa architectural repertoire.

Two spatially distinct Pueblo II period manifestations have been defined for the Park Plateau physiographic subsection (Baker 1964). These are the Sopris phase in Colorado (Baker 1964; Ireland 1971), and the Pontil Phase in New Mexico (Baker 1964; Lutz 1959; Glassow 1980). The similarity in ceramics (predominantly Taos plain and incised), architectural construction methods and room layout is so strong, that the division along state lines seems artificial and unwarranted. Consequently, the two areas are considered here to be separate localities of a single cultural manifestation. Architectural remains on the Park Plateau typically have a large (24-37 sq m) semisubterranean residential unit with a complex series of smaller storage (?) rooms contiguously built against the main room. In this regard, the pattern 
resembles the Antelope Creek Aggregate Type II; however, the common Antelope Creek room layout of smaller units flanking an east vestibule is not apparent on the Park Plateali. Furthermore, upright stone slabs are only used as a supplemental construction method to the common jacal and adobe walls at such sites as TC:C9:4, TC:C9:9 and NP-1 (Ireland 1971; Lutz 1956, 1957). Interior features associated with residential units on the Park Plateau include a centr:? :verth, and occasionally four support posts and storage pits. But none of the units has the prominent extended entryway, the central channel, raised clay platforms or the threshold collar features found in the Antelope Creek phase units.

Virtually nothing is known about the Pueblo II period architectural remains in the Galisteo Basin, and only slightly more information is available from the area around Albuquerque. A summary of primarily unpublished manuscripts for this period indicates that the structures are predominantly semisubterranean circular pit houses, many with four roof support posts around a central hearth (Cordell 1978). Occasionally separate storage pits are present at the same site. The use of stone slab masonry is not mentioned. Thus, only general architectural similarities exist between the early Antelope Creek structures and the Pueblo II pit houses in the Galisteo District.

Somewhat stronger Antelope Creek phase architectural similarities are evident in the cultural manifestations to the southeast--particularly in the Chupadera Nesa, Sierra Blanca and Middle Pecos districts. Brief surveys and excavations on the Chupadera Mesa have located a number of sites, which employ vertical slab masonxy. Peckham (1976) reports on one such site at Taylor Draw, which has been tree-ring dated to A.D. 950-1000. Here, most of 
residential units are large $(\bar{x}=15.6 \mathrm{sq} \mathrm{m})$, isolated semisubterranean, circular pit houses with central hearths and four roof support posts. Most have definable extesded entryways, but there is little consistency in room orientations. One of the deep pit houses (no. 22) has a banquette completely cncircling the center of the structure. Although few rocks are used in the construction of these pit houses, separate linear arrangements of small $(\bar{x}=3.7 \mathrm{~m} \mathrm{sq})$ rectangular contiguous "granaries" were made with ve-tical slaio masonry as footings for jacal walls. The wall footing for storage rooms 4, 5, 8, 10, 25 and 26 are reminiscent of the Antelope Creek structures in their use of double rows of vertical slabs. Despite the general similarities in wall type and differential ioom sizes, the structures at Taylor Draw differ from the Antelope Creek phase sites in the spatial patterning of the contiguous rooms, and the absence of interior platforms, longitudinal floor channels, and threshold collar features. Elsewhere on Chupadera Mesa, a number of sites (Laboratory of Anthropology numbers La9005, La9013, La9014) have been located with jacal structures, which utilize vertical stone masonry (Caperton 1981). The interior details of rooms at these unexcavated sites are unknown; consequently, it is difficult to make specific comparisons. In the Sierra Blanca district, Kelley $(1966: 66,94)$ recorded the frequent use of vertical slab masonry as wall footings for shallow, semisubterranean, jacal structures during the Corona phase (A.D. 1100-1200). Many of the rooms at the Phillips and Bonnell sites are rectangular and contiguous, but the spatial relationships of dominant to subordinant rooms are unclear from. the limited excavation areas. Apparently, none of the structures in the Sierra Blanca region have the consolidated building arrangement, extended entryways flanked by storage rooms, or antechamber units, as are 
commonly found in the early subphase of the Antelope Creek phase (Kelley 1966: 98). Also alien to the Sierra Blanca region is the notion of depressed floor channels and clay platforms opposite entryways. During the earlier Glencoe phase (A.D. 900-1100), many of the large pit houses have central hearths, interior pits, and four roof support posts similar to the Antelope Creek phase structures, but the room shapes are not standardized (Kelly 1966: 82, 92). These Glencoe traits occur less often in the structures assigned to the Corona phase.

Closer to the study area, Jelinek $(1967: 121,126)$ found evidence of vertical slab architecture at Sites P-24 and P4A-B in the Middle Pecos district. At site P-24 a series of upright sandstone slabs delineátèd several rectangular suriace rooms, which were assigned to the early Mesilla Negra phase (A.D. 1000-1100). Unfortunately, the number, size and spatial arrangement of these structures are not specified; consequently it is difficult to draw firm conclusions. However, the structures at site P4A-B are more clearly deineated, even though they are assigned to the 18 Mile phase (A.D. 800-900). Structure 2 consists of a large (10.5 sq m) oval semisubterranean room with vertical slab wall footings, a central hearth, four roof support posts, and a possible entryway towards the west (Jelinek 1967:121). More importantly, vertical slab partitions formed two bins or interior storage rooms in the northwest and southwest quadrants, immediately flanking the putative entryway of this residential unit. Two columnar pieces of red sandstone and a symmetrically trimmed slab of white sardstone inside the main room area but adjacent to the partition wall has been intcrpreted as a possible "altar" feature. Structure 3 at the same site consisted of at least three small contiguous rectangular storage rooms made with occasional 
upright sandstone slabs (Jelinek 1967:123). These rooms are reminiscent of those found at Taylor Draw (Peckham 1976). Overall, the residential unit (Structure 2) at Site P4A-B is similar to the Antelope Creek phase architectural remains. Although the room faces west and lacks both the central channel feature and a clay platform, the compact clustering of storage bins and bilateral room layout are vaguely familiar. Moreover, the shape of Structure 2 resembles the circular-shaped main unit at Sanford Ruin, which is one of the earliest dated Antelope Creek phase structures in the study area. Nevertheless, the differences in particular details are sufficient to reject the Middle Pecos district as the sole source for the origin of Southwestern-like architectural details observed in Antelope creek phase sites. Finally, the architectural remains of the Mesilla and Doña Ana phases (A.D. 900-1200) of the Southern Jornada District consist predominantly of separate, fairly deep pit houses and contiguous adobe walled surface structures (Lehmex 1948:76, 19; Whalen 1979). The interior features at Los Tules Site display a wide range of variation in the occurrence and placement of roof support posts. Interior hearths tend to be located near the extended entryways, which often face to the east or southeast. The presence of masonry architecture in the Mesilla and Doña Ana phases is exceedingly rare. Overall, the Southern Jornada district prior to A.D. 1200 shows little architectural resemblance to the Antelope Creek phase patterns.

In surmary, no single Southwestern district appears to be the sole source of inspiration for all of the Antelope Creek architectural remains. The wide spread occurrence of vertical slab masonry along the walls of both pits and semisubterranean structures is regarded as an Anasazi trait rooted in the slab lined cists inside Basketmaker III caves (Bullard 1962:149-150; 
Kelly 1966:96). But the use of two parallel upright rows of stone as foundations for masonry walls of the large residential units in the Antelope Creek phase is not evident elsewhere in the southwest. The contiguous placement of small storage rooms against each residential unit shows some analogies with patterns on the Park Plateau where vertical slab masonry was rarely employed. However, similar room configurations are present in the Middle Pecos Valley, and somewhat further to the southeast in the sierra Blanca district, the notions of rectangular rooms, vertical slab wall foundations, central hearths, and four roof support posts are common. These patterns suggest that the unique Antelope Creek architectural developments represent the unregulated diffusion and local adaptation of generalized Southwestern traits from several sources.

Test 3: Some degree of experimentation and/or local innovations may be expected as the diffused traits become incorporated into the recipients culture's adaptive strategy.

The intelope Creek architectural traits not found in adjacent cultural manifestations are considered to reflect architectural experimentation or local innovation. Many of these traits have been identified and briefly discussed as part of Test 2 . These items include parallel rows of upright slab wall footings, the contiguous placement of smaller rooms adjacent to the entrance of the main residential unit, variations in certain room forms, the central floor channel, raised platforms, and threshold collar features.

The local experimentation and adaption of diffused traits include the use of upright slab footings, the structural layout of room blocks, and the change in dominant room shapes from circular (at Sanford Ruin) to rectangular. In all instances, practical considerations underlie most of these 
changes. As indicated in Chapter 5, the double row of vertical slab wall footings is commonly employed to provide additional stability to both major exterior walls, and along downslope sides of large rooms. The placement of subordinate rooms along the east side of the main residential unit reflects a tendency to cluster rooms as the front of the structure and near external activity areas. Finally, the shift from circular to rectangular dominant room form may accompany changes dictated by shifts in the number and kind of interior activities, and changes in the volumetric requirements of the interior facilities (Hunter-Anderson 1977). This change is associated with the increased spatial efficiency of quadrilateral room forms, once multiple residential units became amalgamated into the large contiguous room blocks, as at Alibates Ruin 28, and Antelope Creek Ruin 22.

The presence of central channels, the raised platform, and perhaps the specialized threshold collar feature may be local innovations. The central channel feature has been suggested (in Chapter 5) to be an efficient means of segregating interior personal sleeping and storage facilities from access and familial cooking and processing areas within the main residential unit.

The function of the raised platform against the west wall is uncertain, although it has been regarded as an "altar." Kelley (1966:211), suggests that the Antelope Creek phase altars closely resemble similar features in the contemporaneous La Junta phase of the Trans Pecos region near Presidio, Texas. However, the La Junta phase platforms are much smaller 10.30 by 0.60 by $0.40 \mathrm{~m})$, and are located along the south wall of the deep semisubterranean rectangular structures (Kelley 1949). These features are more reminiscent in size and placement of the entry steps associated with the El Paso Phase houses of the Southe::n Jornada (Brook 1965, 1971, 1980; Davis 1968). In 
contrast, Krieger (1946:72) and Hughes (1968) suspect that the Antelope Creek phase platforms were the forerunner of altars in the Pawnee earthlodges. Whatever the functions of these features, it is difficult to identify analogous examples in complexes contemporaneous or preceeding the Antelope Creek phase.

Finally, the threshold collar (adobe columns flanking the vestibule on the inside of the main room) is also difficult to identify in cultural manifestations preceeding A.D. 1200. The feature is thought to serve as a frame used to drape a flexible (skin or woven) cover over the vestibule in order to regulate air flow inside the room. Comparable kinds of architectural features have not been identified in adjacent areas.

Given the unique occurrence and practical functions attributed to these features, local innovation seems likely. These unique traits coupled with the select occurrence of other Antelope Creek traits from adjacent Southwestern manifestations at an earlier date are clear evidence of unregulated diffusion.

The source areas for the Southwestern traits appear to be diversified. However, the architectural similarities to the southwest--particularly the Sierra Blanca District--are somewhat stronger. This Canadian River ValleySacramento Mountain connection around A.D. 1200 is interesting in light of . the apparent contacts maintained during the first millenium by the Palo Duro groups between the indigenous Plains Woodland (Lake Creek) groups along the Canadian River, and unspecified groups (or at least ceramic temper sources) in the Sierra Blanca District. Quite likely, during the local transition from a Plains Woodland adaptation to a Plains Village adaptation, some architectural influences from southeast New Mexico and elsewhere were incorporated into the adaptative strategy. As Troike (1955:133) has observed: "It is the 
Puebloan ideas, and not the puebloan techniques, that are adopted by the Antelope Creek groups." The sweeping changes which occurred throughout the Southwest during Pueblo III period (A.D. 1200-1350) altered these ties to such an extent that by A.D. 1300-1350 the main source of Southwestern ceramic tradewares evident at Antelope Creek phase sites is from the Middle Rio Grande-Pecos River region (Crabb 1968; Spielman 1983). Although the mechanism for introducing southwestern architectural traits into the incipient Antelope Creek complex are uncertain, one explanation--the practice of cultural exogamy--has been proposed several times (Krieger 1946; Reed 194., Duffield 1970; Marmaduke and Whitsett 1975). Since two opposing positions have emerged, this suggestion will be examined in greater detail. Krieger (1947:74) attributed the exogenous marriage idea to J. Charles Kelly, who postulated that the occurrence of stone masonry architecture in association with Plains tool assemblage to a patrilineal/patrilocal social organization. Noting that Pueblo women are ordinarily in control and authority of the house, he reasoned that as little as a half dozen women residing among the Plains tribes in the panhandle could have introduced the idea of mascnry construction techniques. The patrilocal residence pattern would also account for the absence of Puebloan ceremonial artifacts (which are generally male oriented) among the Antelope Creek people, as well as the occurrence of Plains (male oriented) hunting assemblages at Pecos and other Pueblo sites.

In reviewing Krieger's information, Reed (1947:158) rejects the ascertion of exogamous patrilocal residence patterns for Antelope Creek people. The male hunting assemblages at Pecos merely indicates that parties of men from the Panhandle visited Pecos to trade. He reasoned that the hunting/ 
trading parties did not return with Puebloan wives, but they were impressed by the Pueblo architecture which they started incorporating into their houses. The women kept on making the same kinds of cordmarked "Plains" pottery as before, since the men were not especially interested in the ceramic technology. Reed merely refutes Krieger's hypothesis without advocating any alternatives.

Subsequently, Duffield (1970:12-13) proposes a matrilineal/matrilocal exogamous pattern. The homogeneity of the cordmarked pottery tradition (presumed to be a female craft) is indicative of close female groups and considerable continuity. Yet he argues that the wide range of artifactual forms would arise from a matrilocal exogamous pattern (assuming house-building to be a male task), since the continual introduction of men into the community would constantly bring new and different ideas and construction techniques. Marmaduke and Whitsett $(1975: 81)$ however, find problems with both extreme positions. In regard to Krieger's patrilocal residence pattern hypothesis, they question why the newly arrived Puebloan women could so radically alter the Antelope Creek construction standards, yet not influence the cordmarked ceramic-making tradition. Duffield's matrilocal hypothesis they find similarly untenable:

The bonding effect of a matrilineage operates only within the lineage. What holds the ceramic tradition in such a tight grasp on an extra-lineage basis? Why do not such strictures operate for construction practices? Ostensibly, the male products of a matrilineage are imbued with the same sense of lineal conformity as well as the females [sic]. (Marmaduke and whitsett 1975:81).

Their rationale for rejecting Duffield's position is unclear. If they are suggesting that children (of either sex) of lineage members are enculturated to such an extent that ceramic and architectural technologies are equally integrated according to lineage practices, then Marmaduke and 
Whitsell have misunderstood either the circulatory nature of males in a matrilineage situation, or the level of cultural exogamy implied by Duffield's hypothesis.

Most attempts to delineate and formally test prehistoric residence patterns in the Southwest have relied on comparing stylistic patterns on artifacts from male and female tasks at a single site. Hill (1970b: Table 1) suggests that uxorilocal, and matrilocal residence patterns show nonrandom stylistic patterns for female-related items, but random patterns for the male-related items; the opposite patterns are expected for virilocal, patrilocal or avunculocal residence patterns. Neolocal and bilocal residence patterns show randomized stylistic patterns in male and female-related artifacts, whereas such items are nonrandomized in a duolocal residence pattern. Three factors influence the ability to delineate the residence patterns:

1) the patterns are clearest when exogamy involves groups with radically different cultural heritages, but are more difficult to discern when two groups with similax heritages are involved, or when exogamy is practiced on the village level. Clearly both Krieger and Duffield postulate cultural exogamous relationships involving groups familiar with masonry architecture. But exogamy involving Apishapa or other Upper Canark groups with a Plains tool assemblage would be more difficult to recognize than exogamy practiced with Anasazi or Mogollon groups with Southwestern assemblages.

2) in all instances, the studies assume that activity assemblages for both sexes can be correctly inferred, and that the remains occur with sufficient frequency and stylistic embellishment to permit such analysis. At present, the range of artifact assemblages at most Antelope Creek sites are 
inadequately described and quantified to permit an examination of stylistic patterns. A cursory examination of tool assemblages from several sites suggests that few tool classes are artistically or stylistically modified.

3) the stylistic pattern distribution as outlined by Hill (1970b) is based on a whole series of assumptions regarding the nature of cultural transmission and enculturation. Other studies have shown that technology is not always rigidly transmitted along lineage lines (Stanislawski 1969) or that other factors may yield artifact distribution patterns similar to those expected for kin groups (Dumond 1977). Consequently, artifactual remains may be difficult to use.

Nevertheless, Hill's basic tenet may be valid if applied to the patterns of sksletal morphology of the population. The use of skeletal remains eliminates problems inherent with correctly inferring artifacts to sex related tasks, the mechanism of cultural transmission, and the degree of stylistic embellishment as required to operationalize the traditional approach to this problem.

If the Antelope Creek people practiced cultural exogamy, then the adult skeletons of one sex should show more morphological diversity than those of the other sex, or of the immature skeletal remains.

Note that the expectation does not directly compare male to female skeletal remains, since any difference may merely reflect sexual dimorphism of the population. Instead, significant morphological differences for each sex are sought between the burials at different Antelope Creek cemeteries. This comparison assunes that given cultural exogamy, members of Antelope Creek lineages at separate villages will tend to obtain their mates from 
different non-Antelope Creek sources, and that the newly arrived mates will be more biological heterogenous than the indigenous residents.

Metric and nonmetric traits have been used to examine prehistoric population affiliations (Berry and Berry 1967; Brothwell 1959; Jantz 1974; Rightmire 1970; Jantz and Ubelaker 1981). Both methods have been used to compare biological distance of Antelope Creek skeletal populations with those from adjacent select Pueblo and Plains populations (D. K. Patterson 1974; D. E. Patterson 1974; McWilliams and Johnson 1979), but none of the studies considers the possibility of examining cultural exogamy. Nevertheless, usable information is readily available in two lengthy studies (Patterson 1974; Patterson 1974).

A major part of both studies involves the metric comparison of skeletal remains from Antelope Creek Ruins 22 and 22A, Alibates Ruin 28 and the Footprint site in order to discern the homogenity of the population. Using the skeletal remains from two cemeteries at a time, a series of $t$-tests was used to determine significant differences in cranial and post cranial variables and indicates, stature estimates, and mandibular and maxillary tooth sizes for males and females (D. K. Patterson 1974; Tables 74-87; D. E. Patterson:Tables 2-15). Differential preservation limited the number of observations possible on each sex for any single cemetery. A maximum of 154 different traits/indicates were used for males, but only 81, 121, and 123 observations were available from the three cemeteries. Similarly, poorer preservation of female skeletal remains permitted only 98 different trait/index determinations, and only 16, 43, and 86 specific observations were available from the three cemetery samples. Thus, depending upon the available observations, the t-tests could involve: 1) a "single" comparison of a trait of two cemeteries; 2) a "double" comparison of a trait from 
one cemetery against each of the two other cemeteries; or 3) a "triple" comparison of a trait among the three cemetery samples.

Altogether, 325 t-tests were conducted for the male samples and 145 t-tests were run on the female samples (D. K. Patterson 1974; D. E. Patterson 1974). The results specified by level of significance are summarized in Table 51. Only a single trait was found to be significant at the .01 level in each sex group. Furthermore, only 4.0 percent of the t-tests conducted on the male samples, and 4.8 percent of the t-tests run on the female samples were significant at the .05 level. The similarity of these values suggests that cultural exogamy involving biologically distant groups was not occurring among the Antelope Creek populations. Since the skeletal sample sizes are small, these findings must be regarded as tentative. However, the available biological evidence suggests that cultural exogany must be rejected as an explanation for architectural and comunity variability.

SUMMARY OF TRAIT ORIGINS.

Formal testing procedures were used to determine whether the origins of the distinctive Antelope Creek phase architectural and community variations were due to site unit (immigration), or culture unit (trait diffusion) intrusion on to the Southern High Plains. The evidence presented showed that adjacent cultural manifestations are not of the proper age, or do not display the appropriate architectural and artifactual trait complex to be the potential source of groups imnigrating on to the plains. Instead, the Lake Creek complex, an indigenous Plains Woodland adaptation in the Texas panhandle is regarded as a likely antecedent of the Antelope creek phase. This conclusion is based primarily on the continuity of a cordmarking 
Table 51.

Sumary of Metric Observation t-Tests of Male and Female

Skeletal Remains from Alibates Ruin, Antelope Creek Ruin, and Footprint Sites.

MALE BURIALS

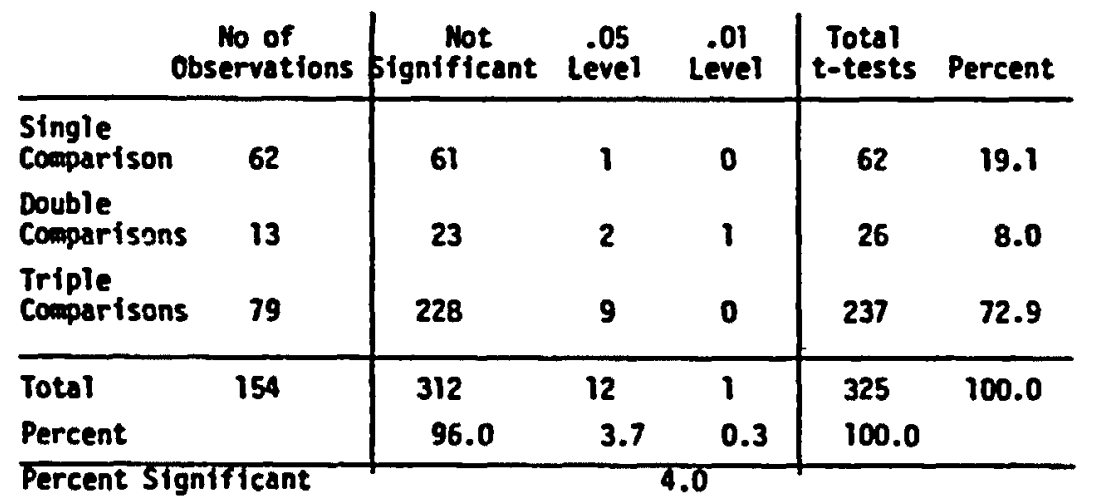

FEMALE BURIALS

\begin{tabular}{|c|c|c|c|c|c|c|}
\hline & $\begin{array}{l}\text { No of } \\
\text { Jbservations }\end{array}$ & $\begin{array}{c}\text { Not } \\
\text { Significant }\end{array}$ & Level & $\begin{array}{l}.01 \\
\text { Level }\end{array}$ & $\begin{array}{c}\text { Total } \\
\text { t-tests }\end{array}$ & Percent \\
\hline $\begin{array}{l}\text { Single } \\
\text { comparison }\end{array}$ & 61 & 57 & 4 & 0 & 61 & 42.1 \\
\hline $\begin{array}{l}\text { Double } \\
\text { Comparisons }\end{array}$ & 27 & 54 & 0 & 0 & 54 & 37.2 \\
\hline $\begin{array}{l}\text { Triple } \\
\text { Comparisons }\end{array}$ & 10 & 27 & 2 & 1 & 30 & 20.7 \\
\hline $\begin{array}{l}\text { Total } \\
\text { Dercent }\end{array}$ & 98 & $\begin{array}{l}138 \\
95.2\end{array}$ & $\begin{array}{l}6 \\
4.1\end{array}$ & $\begin{array}{l}1 \\
0.7\end{array}$ & $\begin{array}{l}145 \\
100.0\end{array}$ & 100.0 \\
\hline
\end{tabular}

Information complied from D.K. Patterson 1974: Tables 74-87:

D.E. Patterson 1974: Tables 2-15. 
ceramic tradition, and presumed parallel developments in plains Village transformations which occurred elsewhere along the eastern margin of the Plains. Antelope creek thus reflects the introduction of new architectural ideas around the same time that the local woodland group was being transformed into a plains village complex.

A survey of Southwestern architectural remains in eastern New Mexico found no strong architectural parallels in any single pueblo II period complex which could have been the source for these new ideas. Some general similarities were found among cultural manifestations in the Chupadera Mesa, Sierra Blanca and Middle Pecos districts of southeastern New Mexico. But many architectural attributes seem to be unique to the Antelope Creek phase. This lack of congruency in architectural form suggests that the Antelope Creek architectural development represents the unregulated diffusion and local adaptation of generalized southwestern traits from perhaps several sources.

Although several archaeologists have suggested that cultural exogamy may have been the mechanism responsible for the introduction of Southwestern traits, an analysis of Antelope Creek skeletal remains found no support for this contention. Reed $(1947: 158)$ and Troike $(1955: 134)$ have presented comm pelling arguments that male hunting and gathering groups came in contact with southwest Puebloan villages and were impressed by the architectural remains, which they attempted to copy using locally innovative building techniques. These arguments may address how the influences became incorporated into a Plains village culture, but they do not indicate why they were adopted. At this time, considerably more details about the systemic relationships of the local environmental setting, the indigenous Woodland 
manifestations in Texas, and the late prehistoric adaptations in eastern New Mexico are required to answer this intriguing problem.

\section{Ecological Systemics and Cultural Dynamics}

The ramifications of natural or social environmental change on Antelope Creek phase adaptations have not been systematically advanced, or rigorously examined. Nevertheless, such causal factors have been implied when archaeologists advocate 1) that burned structures, and the occurrence of sites in defensible mesa top settings may reflect raiding (Krieger 1946:42; Marmaduke and Whitsett 1975:98; Lintz 1979:44, 1984:33); or 2) the demise of the Antelope Creek phase may be due to the arrival of allegediy "hostile" nomadic groups, and/or environmental deterioration due to climatic changes (Studer 1931b:13; Lowrey 1932:43; Holden 1932a:293; Baerreis and Bryson 1966:114; Duffield 1970; Marmaduke and Whitsett 1975:82, 97; Campbell 1976: 107-108; Hughes 1979:45; Lintz 1984:340). A major factor for all of these explanations is population pressure. An examination of this concept and underlying assumptions is in order before we can consider changes in the Antelope Creek phase architecture and comunity patterns.

\section{THE ECOLOGICAL SYSTEMICS OF POPULATION PRESSURE}

Population pressure is simply the ratio of population size to the "carrying capacity," (a hypothetical upper limit of population growth which does not damage the ecological network of a region (Hassan 1981:166)). Implicit to the notion of population pressure is an assumption that human populations have a natural propensity to increase until a point is reached at which further growth creates or poses threats of major shortages to the important resource base. Many archaeologists have argued that the resultant 
environmental stress on human populations promotes technological expansions, economic growth, and increased socio-political complexity (Boserup 1965; Flannery 1969; Spooner 1972; Sanders and Price 1968; Martin and Plog 1973; Cohen 1977).

The level of population stress is extremely difficult to measure, since the variables determining the goodness of fit between population size and carrying capacity are complex, and the human responses to stress can be quite varied. Both of these points need to be examined in more detail. The complexity of variables involved in measuring population stress stems from the systemic nature of carrying capacity. The systemic relationship not only involves the dynamic interaction of human and natural environmental components within certain technologically limited processes, but it must also consider dynamic interaction of yarious human components within the social processes, and the dynamic interaction of other nonhuman environmental components within ecological processes. Consequently, population stress may arise from an actual increase in human population size (due to natural growth or inmigration) during periods of stable resource availability, or from a perceived decrease in the resource base (due to changes in the natural environment caused by such factors as stochastic fluctuations in climate, soil nutrients, insects, parasites, diseases and competition from other animal consumers) during a period of population stability (Street 1969). Note that in the latter case, population stress is attributed to human perceptions, rather than actual availability of resources. This is because political organization, land tenure rules, and social symbolism involving sacred or haunted areas may severely restrict the use of productive lands and alter the size and variety of the potential resource base 
(Hardesty 1977). In addition, diet, culinary preferences and taboos may place priorities and inherent limitations on the utilization of all available economically useful resources (Hassan 1981:166; Brush 1975). Thus, even with a simple level of technology, human societies far exceed the basic subsistence requirement.

Nevertheless, the maximum population size depends not so much on the presence of unexploited economically useful resources or even on the abundance of preferred resources during short periods, but rather on the quantity of essential foodstuff present in minimum amounts over moderate or long term periods. Hassan $(1981: 166)$ has cogently argued that even when caloric requirements are satisfied, amino acids, vitamins and certain trace elements are necessary for the continued welfare of the population. Thus he suggests that it is the quantity of nutritionally critical foodstuff, which is present in minimum amounts, that determines the critical carrying capacity and in turn, the maximum population size. However, he argues that populations do not live at the brink of disaster, but rather tend to stabilize at an optimum carrying capacity level below the critical carrying capacity as a cushion against stochastic fluctuations in resource availability. At the optimum level the groups usually can monitor population and resource fluctuation and initiate proper alternative strategies to diminish the effects of stress.

The population responses to stress can be quite varied (Brookfield 1976; Hardesty 1977; Street 1969; Hassan 1981; Blakeslee 1975). Most actions are essentially buffering mechanisms which are employed until the stressful conditions ameliorate or the group becomes extinct. The range of buffering mechanisms may include: 
1. redistribution of the population within an area to maximize exploitation of marginal zones;

2. lower the standard of living by changing the diet and intensifying procurement practices to emphasize secondary resources;

3. increase procurement and expand stored reserves obtained during periods of resource availability;

4. expand trade networks to tap complimentary resources in adjacent regions.

5. lower population density through group fission and emigration to other areas, which in effect, physically expands the territory size; .

6. modify religious and political beliefs to permit the exploitation of lands and resources which were formerly forbidden;

7. intensifying production through increases in either labor input, or technological development;

8. increase resource accumulations and perhaps reduce population size through raiding;

9. limit the population growth by lowering the birth rate through birth control or increased spacing of ofispring;

10. reduce the population size by raising the mortality rate through the culturally approved genocide of select age or sex groups,

11. face reduction in population from such naturally induced causes as diseases, famines or nutritional deficiencies, once the population exceeds the carrying capacity level.

Minnis (1981) has suggested that when facing stress, populations will

first select the option that has the fewest permanent effects on the biological or cultural systems. More drastic options as measured by more severe consequences to the social and biological systems will be employed after 
the initial buffering mechanisms have been exhausted. However, the consequences of adopting any one or combinations of several buffering mechanisms can vary considerably.

Some low level options may be adequate strategies for a population to endure short term periods of population stress with little lasting impact on the existing cultural system, but more drastic measures will undoubtedly affect major changes of the entire cultural system.

For example, the intensification of production through increased labor input coupled with technological development can ultimately raise the optimun carrying capacity level and accommodate continual population growth, which in turn may necessitate restructuring of the social systems and the settlement patterns (Boserup 1965). However, it is important to realize that intensified production is not the only available option. Most of the buffering mechanisms aimed at controlling population size relative to resource availability do not alter the optimum carrying capacity level, and thus do not automatically initiate the causal chain of events as postulated by the Boserupian model (cf. Cowgill 1975; Hassan 1981).

Although the carrying capacity concept is an excellent heuristic device, it is difficult to operationalize in prehistoric situations. To derive a carrying capacity (threshold) value, the archaeologist must reconstruct and discern changes in the size and configuration of the catchment areas, the variety, density, distribution and scheduling of available and perceived prehistoric resources, the density, distribution and scheduling behavior of the human population, and the technological level used in extracting the resources. Thus believable calculations of specific threshold values are impossible to derive in prehistoric situations. 
On a more general level, the carrying capacity concept provides a framework for interpreting sanifestations of cultural buffering options within the systemic relationship of population size and natural environmental contexts. Thus, such seemingly diverse trends as trade intensification (Chapter 6), occasional evidence for hostilities (Chapter 7) and shifts in the spatial patterning of site locations (Chapter 9) may all reflect different low level buffering options used by Antelope Creek phase groups in order to cope with population pressure within the short 400 year span.

The mere advocacy that the population increased, or that the region was susceptible to climatic fluctuations and/or was marginally suited for certain exploitation endeavors is insufficient to invoke population pressure as a causal explanation. Instead, a comparison of the changes in population size relative to the environmental conditions are required to document the existence of stress. Once stress has been demonstrated, then the effect of specific buffering mechanisms on Antelope Creek phase architecture and settlement patterns can be examined.

\section{EVIDENCE FOR POPULATION STRESS DURING THE ANTELOPE CREEK PHASE}

An assessment of the existing information from Antelope Creek phase sites quickly reveals that considerable information crucial to thoroughly examine the issue of population stress is not available. Sorely needed is additional information regarding the size, distribution, density and the various type of sites within the study area, the subsistence and technological aspects of resource scheduling and procurement, and refinements in paleoenvironmental reconstructions for the period A.D. 1100-1500. Nevertheless, some information can be gleaned from the existing records. And 
although the analyses will not conclusively demonstrate the existence of population stress, it will provide new insights into the complexity of factors affecting Antelope Creek phase architectural and community patterns, as well as indicate the specific kinds of information needed.

Since the size of prehistoric population can not be directly measured, it must be inferred from other kinds of archaeological remains. Estimates of population size can be based on the quantity of faunal remains, select artifact types, architectural remains, or total site area (Hassan 1981:63-94). In this instance, the architectural remains offer the most complete set of available information for the Antelope Creek phase.

An estimate of the Antelope Creek population is based on the number of residential sites in the study area, the number of household units at the residential sites, and the size of the families occupying the household units. Since projections of the number of Antelope Creek phase residential sites can not be ascertained from the existing data base, absolute population increase can not be conclusively demonstrated. Nevertheless, specific site information can be used to detect changes in the number and size of household units from the early and late subphases. Major changes in these variables may be indicative of the Antelope Creek population dynamics; however, a systemic survey of several Canadian River tributaries will be necessary to assure that the trends are valid.

Population estimates based on site specific information from early and late subphases must still be grounded on a number of assumptions regarding the function of sites, length of household occupation, the contemporaneity of household clusters at a single site, and the number and size of indoor activity areas. The present analysis has further assumed that the various 
excavations exposed a representative number and proportion of different feature types at each of the sites. For purposes of this analysis, it was assumed that only homesteads and hamlets reflected residential sites; that all household clusters were utilized for approximately the same duration; and that barring evidence of room superimposition, all rooms at a site were contemporaneously in use. Alibates Ruin 28 was regarded as an exception, since radiocarbon dates, superimposed rooms and differential artifact densities indicated either multiple occupations, or sequential growth of the hamlet (Chaptex 8, Appendix A). In this instance, Excavation Unit I, and the north and south portions of Excavation Unit II were considered to be three separate components. Only the architectural remains from Excavation Unit I were considered to be affiliated with the early subphase.

Differences in the number and size of rooms at early and late subphase sites were regarded as crude indications of the population size during each of the two subphases. Table 52 compares the number of household clusters, the mean size of the main rooms within a household cluster, and the mean size of all rooms with the household cluster at sites assigned to the two subphases. Note that the mean number of household clusters, as indicated by the main architectural 1 and 2 unit types, is larger during the early subphase ( $\bar{x}=3.75$ rooms), than during the late subphase ( $\bar{x}=3.16$ rooms). At face value the decrease in the mean number of main rooms may reflect a decline in the number of family units and hence, the size of the population. However, a drastic increase is evident in both the mean main room size, and the mean total indoor space size from early $\left(\bar{x}=24.00 \mathrm{~m}^{2}, 43.24 \mathrm{~m}^{2}\right)$ to late $\left(\bar{x}=33.18 \mathrm{~m}^{2}, 55.58 \mathrm{~m}^{2}\right)$. Thus the data may be reflecting a pattern of larger, but more dispersed family units during the late subphase, than during the 
Table 52. Number of Household Clusters and Size of Structures

at Early and Late Sutphase Sites.

\begin{tabular}{|c|c|c|c|c|}
\hline Site & $\begin{array}{l}\text { Numb } \\
\text { Main } \\
1,2\end{array}$ & $\begin{array}{l}r \text { of Rooms } \\
\text { Subordinate } \\
3,4,5,6,8,9\end{array}$ & $\begin{array}{l}\text { Mean Floor Area } \\
\text { of Màin Rooms } \\
\text { in House Cluster }\end{array}$ & $\begin{array}{l}\text { Mean Floor Area } \\
\text { of All Rooms } \\
\text { in House Cluster }\end{array}$ \\
\hline \multicolumn{5}{|l|}{ EARLY SUBPHASE } \\
\hline Antelope Creek 22A & 2 & 4 & 44.02 & 51.89 \\
\hline Arrowhead Peak & 5 & 4 & 20.746 & 24.676 \\
\hline Coetas & $\cdots-\cdots+n+1+x$ & --..- & 28.400 & $\cdots--$ \\
\hline Sanford Ruin & 1 & 5 & 21.570 & 64.27 \\
\hline Alibates 28-1 & 7 & 14 & 19.696 & 32.119 \\
\hline Mean & 3.75 & 6.75 & $24.001 \mathrm{~m}^{2}$ & $43.237 \mathrm{~m}^{2}$ \\
\hline \multicolumn{5}{|l|}{ LATE SUBPHASE } \\
\hline Black Dog Village & 1 & 4 & 43.480 & 84.18 \\
\hline Spring Canyon & 1 & $2+$ & 87.600 & 90.87 \\
\hline Footprint & 3 & 0 & 28.256 & 28.256 \\
\hline Alibates 28-IIn & 6 & 5 & 28.435 & 32.890 \\
\hline Alibates 28-1Is & 7 & 9 & 32.210 & 43.565 \\
\hline Alibates 28A & $\cdots--$ & $\cdots$ & 21.100 & $\cdots-\cdots$ \\
\hline Alibates 30 & $\cdots$ & $\cdots-\cdot$ & 29.858 & $\cdots--$ \\
\hline Chimney Rock 51 & 3 & 4 & 38.660 & 53.740 \\
\hline Mean & 3.16 & $\mathbf{5 . 0 0}$ & $33.184 \mathrm{~m}^{2}$ & $55.583 \mathrm{~m}^{2}$ \\
\hline
\end{tabular}


early subphase. To further quantify these differences, two overall inside area indices for early and late subphase sites were obtained by multiplying the mean number of households by the Main Room Size (MRS), and the Total Indoor Space (TIS) for each of the two subphases. The results show that the overall inside area is larger for the late subphase sites (MRS=104.86 $\mathrm{m}^{2}$, $T I S=175.64 \mathrm{~m}^{2}$ ), than for the early subphase sites (MRS $=90.00 \mathrm{~m}^{2}, T I S=162.14$ $\mathrm{m}^{2}$ ). Although these indices suggest that the population may have been increasing through time, this trend by itself does not automatically indicate population stress unless it can be shown that the environmental situation remained stable, or was deteriorating.

The effects of deteriorating environmental conditions during the Antelope Creek phase occupation requires an examination of the interrelationships of a whole series of variables. These include the identification of the primary subsistence resources used by Antelope Creek people, an examination of the environmental factors potentially affecting these resources, the paleoenvironmental situation in the study area during the Antelope Creek occupation, and a discussion of the probable responses of the major subsistence resources to the paleonenvironmental cunditions.

Little information is available for the reconstruction of the Antelope. Creek scheduling and food resource procurement practices. To date, no systematically collected micro- or macrobotanical studies have been completed and faunal analysis has only been reported from 11 sites within the study area (Duffield 1970; Keller 1975). The remains from these archaeological contexts indicate a mixed hunting-gathering-horticultural subsistence base. But the relative importance of these resources are unknown. The abundence of bone horticultural tools (Table 31) and the chance recovery of charred 
corn, squash, and beans indicates that some local horticulture was practiced. However, the domesticated products are believed to be far less important to the Antelope Creek people than to the Puebloans, who derived over 80 of their caloric intake from cultivated crops during the historic period (Ford 1968, as cited in Nelson 1980:9). Only limited sampling for wild food remains has revealed the presence of acorns, hackberxy, mesquite, wild buckwheat, cattail stems, plums, persimmons, prickly pear and Indian mallow (Green 1967; Keller 1975). Considerably more information is available from the faunal studies. Duffield (1970) identified skeletal remains from 19 species of mammals, 13 species of birds, six species of amphibians, plus reptiles, fish and mollusks from Antelope Creek phase sites in the study area. However, bison contributed from 78.98 to 98.48 to the potential usable meat weight, whereas deer and antelope contributed 20.18 and 1.58 meat weight from these same sites (Duffield 1970:163, 189). Thus bison is identified as the most important animal resource, and corn is assumed to be at least one of the important plant resources used by the Antelope Creek people.

The environmental variable most likely to affect the availability of food resources in the study area is the semiarid character of the climate (cf. Chapter 3). Despite a lengthy growing season of almost 200 frost-free . days, the region receives on an average of only 20 inches of precipitation annually. However, the intensity and occurrence of precipitation is erratic. Most precipitation normally comes during the spring thunderstorms but normally, the study area receives only slightly more than the critical eight inch sumer precipitation necessary for maize production. Droughts are common. Significant ones lasting longer than one year occurred on an average of once a decade during the last century. 
The one advantage that the study area has to partially offset the unpredictable occurrence of rainfall is the flow of fossil water reserves from the Ogallala aquifer. Springs and seeps were once common along the rim of the inner valley, but surface water flow was most dependable for short distances near the heads of the Canadian River tijibutaries. Even during mild aroughts, these lateral tributaries continued to provide limited quantities of potable water long after water in the main Canadian River channel and lower tributary portions was absorbed into the sandy floodplains. Even though precipitation (which is the crucial limiting variable for food resource availability) is extremely erratic and unpredictable, the presence of fossil water reserves are a potential environmental buffer, which could be used to offset the extreme precipitation fluctuations during all but perhaps the severest droughts.

Evidence for paleoenvironmental conditions in the study area are limited. Most studies concede that no radical climatic change has occurred during the last 4000 years; however, numerous minor climatic fluctuations of varying magnitudes and durations have occurred since then (Bryant and Shaeffer 1977; Hall 1982). Considerable paleoenvironmental evidence from east of the High Plains has documented mesic conditions throughout much of the first millenium A.D., followed by an onset of xeric conditions (Ferring 1982; Lintz and Hall 1983; Hall 1982). Little information is available for specific conditions during the first half of the second millenium A.D.

Only one attempt has been made to reconstruct the environmental conditions of the study area for the duration of the Antelope Sreek phase. Noting that deer and antelope feed on drought resistant forbs and browse, whereas bison primarily consume lush grass, Duffield (1970:241, 255) suggested 
that the relative frequency of bison remains could be used as a measure of relative aridity. Using the relative frequency of bison to deex and antelope remains from five radiocarbon dated sites, Duffield found a marked decrease in the frequency of bison remains after A.D. 1300. Thus he suggested that the study area was gradually drying out from A.D. 1250 to 1400 , but after A.D. 1300 , dessication became even more severe.

Duffield's findings are based on an assumption that the faunal remains from archaeological collections are representative of the actual frequency of animals in the area. This assumption may be unwarranted for three reasons: 1) differential procurement techniques may have been used to obtain bison vs. deer and antelope, since these species frequent different habitats, have different seasonal movements, and congregate in different kinds of social groupings. Thus, the faunal remains at sites may only reflect the hunting strategies, or seasons, and not necessarily the proportional availability of the animals. 2) The sites used in the aralysis include subhomesteads, homesteads and hamlets. Since some food sharing of bison was evident from one of the dated sites and the general range of activities differ among the site types, the occurrence of faunal remains may be biased. 3) Differential recovery and curation methods were employed to obtain the samples. Overall, the WPA crews did not systematically screen the fill and only saved the larger "identifiable" elements, whereas the later projects used more thorough recovery techniques and thus obtained a more representative sample. Of more concern, however, is the fact that the methods Duffield used to determine bison, deer and antelope frequencies are not specified, and the results used to infer climatic change differ from that reported throughout other portions of his study based on the number of bone elements, minimum number of individuals, 
and estimated meat weight from the separate sites (Duffield 1970: compare Table 35 against Tables $3,20,23,25$ and 28 ).

In sum, a number of nonclimatically related factors were not considered in the reconstruction of environmental conditions on the basis of large mammalian remains. Additional paleoenvironmental studies are required to validate Duffield's findings. Nevertheless, a number of other studies have documented drought conditions on the Southern Plains during the fifteenth and sixteenth centuries (Hall 1982; Speth 1983:131-141; Spielman 1982:287-293). The issue does not concern whether drought conditions ever occurred during the Antelope Creek phase, but rather the timing of the drought. Presently, it is impossible to determine if xeric conditions started during the middle (A.D. 1350) or near the end (A.D. 1450) of the Antelope Creek phase occupations. Additional evidence is required to resolve this critical issue. The impact of drought conditions on maize production and bison resources would depend upon the character, intensity and duration of the drought conditions. Since the scheduling of rainfall is critical for corn production, maize growth could occur even during climatic regimes with low annual precipitation, provided that sufficient amount of water was available during critical portions of the growing season. Under more severe conditions or during situations when precipitation fell at the wrong timcs, we might expect crop failure in marginal garden plots, and a decrease in both the size of successfully cultivated acreage and the productivity of corn. Given the diverse sources of water within the study area, crop failure would probably occur earlier in fields along the Canadian River and its lower tributaries, than in fields near the r ributary heads, which are watered by reserves from the Ogallala aquifer. However, the topography of the tributary 
heads limits the amount of arable lands suitable for cultivation, and hence, the size of the fields. Variation in productivity from these small garden plots may have made reliance on horticulture too precarious and unpredictable to sustain large populations residing within the study area without employing other buffering options.

The bison resources may have been equally susceptible to prolonged or severe drought conditions. Recent research has begun to unravel the complexity of the bison ecosystem (Reher 1978; Speth 1983). Bison are the most social big game animals in North America, but their availability is dependent upon seasonal breeding patterns and long term climatic patterns. Bison aggregation and dispersal are seasonally conditioned. During the nonbreeding season, these gregarious animals form small groups of around 20 or more; but during the summer rut, the ranks may swell to several thousand (McHugh 1972). This tendency to congregate in groups, coupled with their aimless mobility across vast territories, makes bison an unpredictable food resource.

Bison populations are also fairly sensitive to long serm climatic fluctuations. Recently, Speth (1983:119-131) has noted that the quality of forage (as expressed by fiber content and available protein) is more critical for weight maintenance than the abundance of forage, since the quantity of consumable grass is limited by the mastication rate. Furthermore, he has found that the principle grass species of southeastern New Mexico presently contain insufficient protein and phosphorus for the continued maintenance of bison body weight during six and eight consecutive months a year. This accounts for the considerable fluctuations in bison weight duxing the yearly cycle. With the onset of drought conditions, selective changes in the biotic communities tend to favor xeric plant, which are characterized by a high 
fiber and low protein content. Over the long run, these plants may be inadequate for bison survival, since they require considerable time to digest, and provide a low protein return. The bison population may respond by initially moving to better pastures near more permanent water sources, either around the upland playas, or along the headwaters of the Canadian River tributaries, in close proximity to human groups. Thus during short term periods of drought, bison may actually be more susceptible for human predation. But droughts of longer duration or higher magnitude, the bison population may abandon the region in favor of tall grass prairies or perhaps experience a higher mortality rate (Reher 1978:35). In either case, less bison would be available for human consumption.

To sum up, the available, albeit incomplete, information suggests that even within the short duration of the Antelope Creek phase, the human population was increasing (as indicated by larger indonr floor areas) at the same time that climatic conditions were changing towards more xeric conditions. Even though the precise timing of these events is uncertain, both conditions would have detrimentally affected the Antelope Creek people's primary food resources by increasing the resource demand at a time of decreasing resource availability. The resultant population stress may have been felt long before the demise of the Antelope creek phase. In fact, some of the changes evident between the early and late subphases are believed to reflect several buffering mechanisms employed in an attempt to alleviate the stress.

\section{EARLY BUFFERING OPTIONS USED BY THE ANTELOPE CREEK PEOPLE}

None of the excavations at Antelope Creek phase sites has been specifically designed to systematically gather information about potential buffering options implemented to reduce population stress. Consequently, critical 
information necessary to document the range of options implemented is lacking. Nevertheless, three of the trends previously discerned in this study are thought to reflect buffering behavior. These include:

1) the possible breakdown in social cohesion, as reflected by the shift from hamlets consisting of a single large contiguous room structure involving multiple household clusters (Alibates 28, Unit I, Antelope Creek Ruins 22 and 24, Tarbox, and Coetas Creek Ruin), to hamlets consisting of many individual households (Alibates 28, Unit II, Chimney Rock Ruin 51, and possibly parts of the Cottonwood creek Ruin). The spatially discrete placement of households during the later subphase suggests a decrease in cooperation among the separate household units, since multiple isolated room structures require more time, energy and material to build, than a single contiguous room unit.

2) the possible shift in settlement patterns away from the Canadian River and towards the lateral tributaries. Manifestations of tinis change is reflected in the abandonnent of the subhomestead sites, which were in use along the Canadian River terrace during the early subphase. This trend possibly reflects a redistribution of the population, or at least a deemphasis on the utilization of the main Canadian River valley in favor of spring fed locales along the lateral tributaries.

3) an expansion of trade networks to tap complimentary resources in adjacent regions. Although cross dated southwestern ceramics indicate that contacts with the Middle Rio Grande Valley may have started as early as A.D. 1200, all of the same Southwestern ceramic types would have been present at the Antelope Creek phase sites if trace was initiated between A.D. 1300 to 1325 (Table 5). Furthermore, the occurrence of Southwestern materials in the 
panhandle shows a marked increase during the late subphase, after A.D. 1350 (Table 31). More than likely, obsidian, painted pottery, turquoise and shell jewelry were included as gifts to enhance exchange offers primarily involving food (Spielman 1983:258). However, the density of late subphase settlements near the Alibates quarries suggests that the mining of flint for exchange (possibly along with or in lieu of bison products) was intensified towards the latter portion of the Antelope Creek phase (Figure 27). Spielman (1982, 1983) has argued that plains bison was crucial in the mutualistic exchange system developed with Southwestern groups, and she noted that comparatively few tools made of Alibates have been reported from Southwestern sites dating prior to A.D. 1450. However, Alibates was an increasingly important commodity among other plains village sites prior to that time. At Antelope Creek phase sites in the Oklahoma panhandle (located approximately $130 \mathrm{~km}$ from the quarry source), Alibates constitutes approximately 618 of the stone tools and debitage at the thirteenth century component at the Roy Smith site, whereas the toolstone represents almost 808 of lithic materials at the fourteenth century component at the McGrath Site (Lintz 1976:90). This increase in Alibates consumption at distant Plains village sites is yet another sign of the intensification of quarrying activities and long distant transport of mate- . rials during the late subphase.

In addition to these buffering options, intertribal raiding may have served as a mechanism employed to alleviate population stress. Raiding could function as a buffering mechanism if it were conducted for the purpose of 1) driving other groups out of an adjacent productive area, 2) discouraging other groups from expanding into the existing resource area, or 3) obtaining booty in the form of either actual food reserves, or technological supplies 
(equipment, domesticated animals or slaves) which would simplify the procurement or processing of food resources. Thus, the issue of raiding, its impact on Antelope Creek phase community and settlement patterns, and its role as a buffering mechanism are examined in greater detail.

The existence of raiding, warfare or massacres among Antelope Creek people has been variously cited ever since the earliest excavations at Handley's Ruin, when Eyerly (1907:222) found burned structures, scattered human bones, and a broken arrowhead imbedded in human remains. Since ther, raiding or warfare has been cited as a contributing factor affecting Antelope Creek site locations (Studer 1931c:13; Krieger 1946:42; Marmaduke and Whitsett 1975:98; Lintz 1983:40), accounting for the abundance of burned structures at certain sites (Studer 1934a:81), or underlying the termination of the phase (Anonymous n.d.:7; Haynes 1932:43-44; Sayles 1935:121; Holden 1933: 51: Hughes 1979:45, 1968:194). Other workers refuting suggestions of continuous warfare cite the scarcity of whole or restorable jars inside burned stxuctures as indicative of a leisurely abandonment (Studer 1934a:81; 1934: 84; Baker and Baker 1941b:2, 175), and the nondefendable positions of some sites (Green 1967:56, 181; Duffield 1964). The reconciliation of these opposing positions is difficult without first examining the practice of raiding on a tribal level, and without reexamining the evidence on which these positions are based.

A certain amount of external "warfare" is common in cultures with a tribal organization, especially if they are experiencing some forms of population stress. Service (1971:104) maintains that continuous long term campaigns aimed at true conquest are economically impossible to sustain and are self defeating for tribal societies, since the spoils are usually not great 
enough to sustain the conquerors. Instead of decisive battles, most engagements among tribal groups occur as ambush or hit-and-run raids, which are designed primarily to harass the enemy. Destruction of property, fields and food reserves, theft of goods, continual threat, sniping, and terrorization, often accompanied by such atrocities as head hunting, cannibalism, torture of prisoners: rane and massacre are effective forms of harassment, which usually involve less risk and psychologically inflict more damage than continual long term sieges.

If advanced warning of a raid was obtained, some members of the target group may organize resistance, or retreat temporarily to sites in defendable settings in order to minimize the loss of life. With recurring raids, the population may abancion outlying or marginal settlements and aggregate into larger settlements located at easily defended positions. Thus barring other factors, the size of the community and the number of "defendable sites" can be used as a crude measure of the frequency and importance of raids.

In order to discern the occurrence of raiding behavior among Antelope Creek people, a series of test implications was deduced for critical examination.

Test Implications:

If raiding behavior was present during the Antelope Creek phase, then:

1) clear evidence for the systematic/selective destruction of property should be expected.

2) evidence for refuges in defendable settings should be evident.

3) evidence for violence, and particularly atrocities, should be present among Antelope Creek skeletal remains. 
Selected information from the study area and adjacent sites assigned to the Antelope Creek phase are used in examining these tests.

Test 1: Clear evidence for the systematic and selective destruction of property should be found.

Even though the focus of raiding may have been the destruction of fields, food reserves or lodging, the records from excavated sites provide only partial information on the destruction of buildings. Studer (1934a:81; 1934b:83, 84) and Krieger (1946:43) maintain that the numerous burned structures at nearly every excavated site provides a clear indication of raiding. But this observation from early fieldwork is contrary to findings from some of the more recent excavations further east (Duffield 1964:72).

The mere presence of burned structures at a site does not constitute sufficient justification to proclaim that a site was subjected to raiding. Any number of the other natural and cultural incidents may cause the accidental or intentional destruction of a building by fire. Accidental burnings may arise from lightning strikes, prairie fires, sloppy hearth tending or vermin control (see Weltfish $1977: 252,281$ for the use of fires to control fleas inside Pawnee earth lodges). On the other hand, structures may be intentionally burned in order to consecrate the possessions of the deceased, or perhaps to demolish a run down structure. In most cases, accidental burnings should involve few structures at a site, and the destruction is likely to be confined primarily to the main household dwelling. Prairie fires may be an exception, but the destruction would probably be widespread and nonselective to specific room types. Presumably the targets of raids would be restricted to the main dwellings (Unit Types 1 and 2), and/or the store rooms (Unit Type 8). Furthermore, one may expect to find 
an extensive artifact assemblage consisting of intact or restorable tools, and/or stored foods inside the rooms, if the raid occurred while the site was occupied and food was being stored.

In order to formally examine these ideas, a review of the Antelope Creek site literature was undertaken in an attempt to quantify the frequency and kinds of burned structures present in the study area as a possible measure of raiding behavior (Table 53). Considerable difficulty was encountered, since few reports specify the condition of the excavated rooms. Consequently, the number of burned structures may be underrepresented in the analysis. An examination of Table 53 shows that recorded burned structures are primarily confined to the main household rooms (Unit Types 1 and 2). The solitary burned structure at the Jack Allen Site may have been an accidental or intentional event at this simple homestead site. Multiple burned structures are present at Alibates Ruin 28, Units I and II, Alibates Ruin 30, Coetas Creek Ruin, and the Footprint site. Although the information may be incomplete, interesting spatial and temporal patterns may underlie the restricted occurrence of extensively burned sites. First, sites with multiple burned households are all located close to choice Alibates chert deposits (compare Figures 4 and 5). Second, the sites with selectively burned structures are somewhat more common in the late subphase (post-dating A.D. 1350) than in the early subphase. These patterns alone are tantalizing, but are insufficient to demonstrate that raiding occurred, since a multitude of other factors could have been responsible for the burning of the structures. Unfortunately, the available records concerning the quantities and conditions of artifacts associated with these burned rooms are not clear enough to show that these structures were abandoned in haste. Thus the evidence of 
Table 53. Distribution of Curned Structures at Antelope Creek Phase Sites.

\begin{tabular}{|c|c|c|c|c|c|c|c|c|c|c|c|c|c|c|c|c|c|c|c|c|c|c|c|}
\hline $\begin{array}{l}\text { Architectural Unit Type } \\
\text { Condition of the thit }\end{array}$ & $\mathbf{A}$ & I & $\mid \begin{array}{ll}1 & \vdots \\
A & B\end{array}$ & $\begin{array}{ll}B_{1} & \\
& c\end{array}$ & $\mid \begin{array}{ll}\text { A } & \text { B }\end{array}$ & B C & a & $\begin{array}{ll}4 \\
B & c\end{array}$ & $\mid \begin{array}{ll}5 \\
A & B\end{array}$ & c & $\mid \begin{array}{ll} & 6 \\
A & B\end{array}$ & c & & $\begin{array}{ll}7 \\
B\end{array}$ & $\mid \begin{array}{ll} & B \\
A & B\end{array}$ & $\mathbf{c}$ & A & $\begin{array}{ll}9 \\
B\end{array}$ & & $\begin{array}{r}10 \\
18\end{array}$ & c & & $\begin{array}{ll}11 \\
B\end{array}$ \\
\hline Early Subphase & & & & & & & & & & & & & & & & & & & & & & & \\
\hline Alfbstes 28- Unlt I & 2 & 14 & - & -- & 22 & 0 & 1 & 10 & 10 & $\mathbf{0}$ & - . & - & 02 & 20 & 12 & 4 & - & $\cdot-$ & 0 & 03 & 0 & - & $-\cdot$ \\
\hline Coetas Ruin & 2 & 00 & - & $-\cdot$ & - - & $=$ & - & -- & - & $\cdot$ & $1-\cdot$ & - & $-\cdot$ & - - & 100 & 1 & - & $-\cdot$ & - & - - & - & - & $\cdot \cdot$ \\
\hline Arrowhead Peak & $\mathbf{0}$ & 20 & 103 & 30 & $=-$ & - - & - & - & - & - & $-=$ & - & - - & - & 104 & $\mathbf{0}$ & - & $-\cdot$ & & - & - & 0 & 10 \\
\hline Sanford Ruln & 0 & 01 & - - & - & $\begin{array}{ll}0 & 0\end{array}$ & 1 & - & $-\cdot$ & $-\cdot$ & - - & 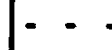 & - & - - & - - & $\begin{array}{ll}0 & 0\end{array}$ & 4 & - & $-\cdot$ & & - - & - & - & $-\cdot$ \\
\hline Antelope Creek 22A & 0 & 20 & - - & $-\cdot$ & - - & - - & - & $-\cdot$ & - - & $\cdot$ & $=$. & - & - - & - - & 01 & 0 & - & - - & & $\begin{array}{ll}0 & 1\end{array}$ & 0 & $\cdot$ & $=$ \\
\hline Roper site & - & - & $1-$ & $-\cdot$ & $-\cdot$ & - - & |- & $-\cdot$ & $1 \cdot$ & - & 100 & 0 & $-\cdot$ & $-\bullet$ & $\begin{array}{ll}1 & 3\end{array}$ & $\mathbf{0}$ & - & $\cdot-$ & & - - & - & & $-\cdot$ \\
\hline Pickett Site & - & - & - - & $-\bullet$ & $-\cdot$ & - - & - & $-\cdot$ & $-\cdot$ & - & $\mid \begin{array}{lll}0 & 1 & 0\end{array}$ & $\mathbf{0}$ & - - & - & $-\cdot$ & $\bullet$ & - & - - & & - - & - & - & - - \\
\hline Potal Early Subphase & 4 & $5 \cdot 5$ & $\begin{array}{ll}0 & 3 \\
\end{array}$ & $\begin{array}{ll}3 & 0\end{array}$ & 22 & 1 & 1 & 10 & $\begin{array}{ll}0 & 1\end{array}$ & 0 & 110 & 0 & 02 & 0 & 213 & 9 & - & - & & 04 & 0 & 0 & 10 \\
\hline ate Subphuse & & & & & & & & & & & & & & & & & & & & & & & \\
\hline Alibates 28- thit II * & & 21 & 10 & & 10 & 0 & - & $-\cdot$ & 12 & 0 & $\cdot-$ & - & $\begin{array}{ll}0 & 3\end{array}$ & 0 & 106 & 2 & $\cdot$ & - & & - & - & & - \\
\hline Allbates 28A & 0 & 10 & - - & - & $-\cdots$ & - & - & $\cdot-$ & $\cdots$ & $\cdot$ & $-\cdot \cdot$ & - & - & - - & - - & - & - & $\cdot$ & & - - & - & & $\cdot$ \\
\hline Allbates 30 & 2 & 00 & 11 & 10 & $-\cdot$ & - & - & $-\cdot$ & $-\cdot$ & - & $=-$ & - & - & - - & $\begin{array}{ll}0 & 1\end{array}$ & 0 & - & $-\cdot$ & & - & - & & - \\
\hline Black Dog Village & 0 & 10 & $-\cdot$ & - - & 11 & 0 & 0 & 10 & -- & $\cdot$ & $-=$ & - & - & - & - & - & 0 & 10 & & - & - & & - - \\
\hline Chimeny Rock Ruln 51 & $\mathbf{0}$ & 30 & $-\cdot$ & - & - & - & - & $-\cdot$ & - & - & $=-$ & $=$ & - & - - & 03 & 0 & $\cdot$ & - & & & - & & $-\cdot$ \\
\hline rootprint & 2 & 0 & - & $\cdot-$ & - - & - & - & $-\cdot$ & - & - & - $\bullet$ & - & $-\cdot$ & - - & $-\cdot$ & - & - & - & & 01 & $\mathbf{0}$ & 0 & 20 \\
\hline Spring Canyon site & - & $-\cdot$ & 10 & 0 & - & $\bullet$ & - & $-\cdot$ & - - & - & $\cdot \cdot \cdot$ & - & $=$ & - & 0 & 0 & $\cdot$ & $\cdot$ & & $-\bullet$ & - & & $-\cdot$ \\
\hline Potal Late Subphase & 13 & 72 & 122 & 0 & 21 & 0 & 0 & 10 & 12 & 0 & $1-$ & -1 & 03 & 0 & 1012 & 2 & 0 & 10 & 10 & 01 & 0 & & 20 \\
\hline
\end{tabular}


Table 53, Continued.

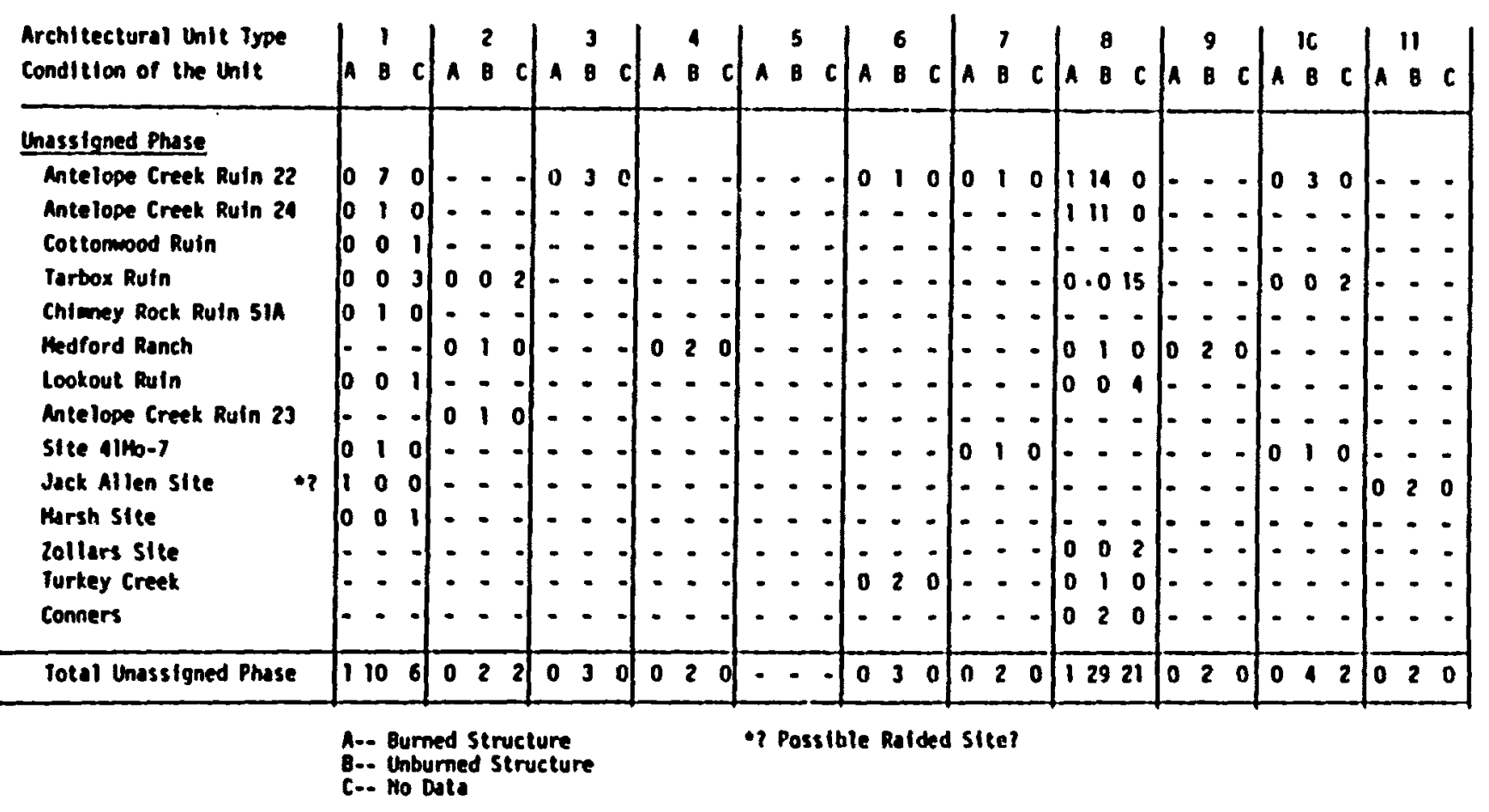


selective property destruction generally supports the notion of raiding, but confirmation from other tests is required to strengthen this observation.

Test 2: Evidence for refuges in defendable settings should be evident. Several early archaeologists working in the Antelope Creek region regarded any homestead or hamlet situated far from the Canadian River and on the rim of a steep escarpment as being a defensive site (Studer 1931c:13; Krieger 1946:42). Thus the locations of such sites as Alibates Ruin 28, 28A and 30. Antelope Creek Ruin 22, Sanford, Medford Ranch, Coetas Ruin, Tarbox, and Cottonwood Ruin on the rims and benches of the inner valley wall were considered to be defensive, since the locations provided a commanding view of both the surrounding valleys and neighboring sites, and the settings provided difficult access from the valley floors. However, the sole criterion of topographic setting is a poor basis for invoking a "defensive site" argument, since these same locales are close to fresh spring water seeping from the ogallala aquifers. In addition, these inner valley bench and rims site settings are vulnerable from an upland approach. None of the sites included in this study contain defensively constructed features, such as the barrier walls found in southeastern Colorado (Campbell 1976), or parapets associated with sixteenth century sites along the eastern edge of the Llano Estacado (Baugh 1982; Parker 1982). Moorehead (1931:106) may have located a parapet east of the Antelope Creek Ruins, but the embankment is not adjacent to the ruins, and its cultural affiliation remains unknown. Many other Antelope Creek phese sites in the study area are at settings poorly suited for defense. These include subhomesteads (Roper, Pickett, Conner, Turkey Creek, zollars), homesteads (Jack Allen, 41Mo-7, Antelope Creek Ruin 22A, Black Dog Village), and a few hamlet sites (Antelope 
Creek Ruin 24, Chimney Rock Ruin 51). The unprotected nature of these sites is evident from their placement at lower settings with limited visibility and easy access to the bottomlands. In at least one instance, at 41Mo-7, the eastward extended vestibule of a single family dwelling opened blinily ontc the side of a hill (Green 1967:56).

While most site settings in the study area reflect little apparent concern for defense, the mesa top sites, Arrownead Peak, Lookout Ruin, and perhaps Chimney Rock Ruin 51A, may be possible exceptions. Since Arrowhead Peak and Lookout Ruin are on mesas protruding out of the valley floor, the occurrence of seeps near the mesa rims is unlikely. Presumably all provisions, including water, had to be hauled up steep slopes to these mesa top sites. Even though these sites can not be dismissed as refuge localities, no special architectural features which enhance their defensive quality have been reported. On the basis of the available evidence, a few defensive refuges are thought to be present within the study area, but their occurrence is believed to be rare. Most settlement locations seem to have been chosen with little concern of the consequences from possible outside raiding.

Test 3: Evidence for violence, and particularly atrocities, should be present among the Antelope Creek skeletal remains.

Few of the burials reported from the study area show evidence of violent death (Chapter 7, Appendix D). Only three Antelope Creek phase interments have been reported with arrow points embedded in bone or near the body area (Eyerly 1907:222, 1912:2; Patterson 1974:231-232; Texas Archaeological Society, n.d.). In each instance, it is impossible to determine if these individuals succumbed to external or internecine hostilities. 
Other evidence strongly suggests the presence of intertribal violence. An extra skull was found interred with a child burial at the Tarbox site (Holden 1929:29). Clearer evidence comes from the Footprint site where partially articulated human limbs were found scattered near the floor of structure 1, and a pile of 11 skulls was placed in a pit after the structure was burned (Green 1967:137-138). On the basis of morphological variability of skeletal remains and contextual differences, I have interpreted the scattered remains near the floor as the butchered remnants of Antelope Creek residents, whereas the skull pile reflects spoils from a retalitory head hunting raid against a non-Antelope Creek group (refer to Chapter 7 for details of this argument). Clearly the scattered remains and trophy skulls reflect atrocities comunitted by separate hostile groups.

The evidence cited in tests 1-3 clearly indicates that some hostilities conducted by and against Antelope creek groups have occurred. Furthermore, the target of those raids seems to have focused on major sites located near the choice Alibates chert deposits. However, the impact, timing and specific external groups involved with these hostilities are unclear. The lack of constructed defensive features at sites on the inner valley bench and rim settings suggests that the threat of hostilities was a less important consideration than access to potable water from the ogallala aquifers. This lack of precautions may indicate that raids were infrequent and had little impact on the Antelope Creek societies, or that security was derived from maintaining a perimeter of defensive sites along the east and west margins of the Canadian River trench. Lookout Ruin and Arrowhead Peak are two mesa top sites within this study locale that might have served as defensive refuges from outside groups approaching from the east, whereas 
Saddleback Ruin (Studer 1931a:134-136; Holden 2933; Haynes 1932; Be1isle 1971), Landergin Mesa (Moorehead 1931:114; Mascn 1929:333; Marmaduke and Whitsett 1975:93-94), Little Landergin or Mesa Alamosa (Marmaduke and Whitsett 1975:94) and perhaps Congdon Butte Sites (Moorehead 1931:116, 139) may have served similar purposes for groups approaching from the west. The disproportionate number of riesa top sites west of the Alibates exposure may indicate the direction of greatest concern from hostile groups.

It is impossible at this time to identify the specific group(s) engaged in raids against the Antelope Creek people. However, several likely candidates can be deduced, and other groups can be eliminated. The Middle Rio Grande Puebloans can probably be eliminated, since their territory seems to be the source area of ceramics, and probably turquoise and shell jewelry and obsidian found in Antelope Creek sites. The nature of these goods (particularly the obsidian) is thought to reflect trade materials, rather than coveted spoils from raiding expeditions. Furthermore, fortifications among Middle Rio Grande sites have not been reported. In contrast, sites with barrier walls are fairly common in the Afishapa phase of southeastern colorado between A.D. 1000 and 1500 (Campbell 1969:336-339; 1976). Unfortunately, insufficient field work has been conducted in this region to determine if burned structures or mass murders occur at these sites. Considerably more evidence is available from the eastern extension of the Mogollon in the Sierra Blanca region of southeastern New Mexico, and the lower Texas panhandle. A number of mountain top fortified sites have been found which are assigned to the Lincoln Phase (A.D. 1200-1300). Excavations revealed that many of the rooms were burned, and at Bloom Mound, at least 15 badly charred skeletons, soine lacking select limbs, were found scattered beneath burned 
roof fall debris (Kelley 1966:590). Skeletal remains from Block Iookcut (Smokey the Bear Site), and the Salt Cedar Site also display evidence of multiple violent deaths during the thirteenth through fifteenth centuries (Stuart and Gauthier 1981:214). Thus, raiding seems to be a fairly widespread pattern on the western border of the Southern Plains. Unfortunately, it is still unclear if the Apishapa, Antelope Creek and eastern Mogollon groups were feuding among each other, or all were beind harrassed by yet some other group. The suggestion that the castcrn Mogollon near the Sierra Blanca region may have been one of the groups involved in fourteenth century feud- . ing with Antelope Creek people does not cnnflict with the idea tha many of the architectural concepts adopted bv the Antelcfe Creek groups during the twelfth century came from this same area. Quite likely, the thirteenth century intrusion from the Chaccan area into the Middle Rio Grande Valley disrupted existing relationships among groups east of the Rocky Mountains by increasing the competition for Plains resources. The conditions of intertribal raiding as described by and against the Antelope Creek people meets the criterion of a buffering mechanism, since it involved the maintenance of strict control over both the valuable Alibates chert resources used in trading, and the lush spring fed areas around the Llano Estacado.

In sum, this examination of the Antelope Creek phase cultural dynamics has revealed a number of buffering mechanisms which were implemented in an attempt to aleviate population stress. Although controversy may surround the timing and sequence of implementation, these mechanisms started long before the termination of the phase. Many of the changes evident within the Antelope Creek phase reflect attempts to cope with the increasing population stress which occurred during much of the late subphase. The bitter afguments 
surrounding the historical identity of the Antelope Creek people only underscore the extent to which these people were forced to radically change their settlement and subsistence patterns and perhaps abandon the Southern High Plains after these early buffering options failed to maintain the existing cultural system (Hughes 1968:193; Campbell 1976:98; Lintz 1979:178).

\section{Summary}

This chapter has examined two facets of the Antelope creek phase which extend beyond the strict confines of the High Plains-Canadian River Locality. These two topics concern 1) the potential origins of the Antelope Creek phase, and 2) the ecological systemics underlying the cultural dynamics of the phase. Formal testing procedures were used to examine both problems. The examination of Antelope Creek phase origins considered both immigration and acculturative processes of cultural transmission. Although the phase has been variously attributed to immigrating groups from a number of different sources, these suggestions are rejected since the timing of events are wrong, and/or the constellation of traits from the proported source areas does not closely match the Antelope Creek traits. The distinctive Antelope Creek architectural and material assemblage has been attributed to the adoption of Southwestern ideas by an indigenous group at the time of its transformation from the Plains woodland to the Plains Village stage. More specifically, the Lake creek complex is thought to be the direct progenitor of the Antelope Creek phase, which employed innovative building techniques to copy Southwestern architectural ideas. Although no single southwestern district was the sole source of inspiration, somewhat stronger influences seem to be derived from Pueblo II Period sites in southeastern New Mexico. 
Although intertribal marriages have been postulated as the mechanism responsible for the introduction of Southwestern ideas, an examination of the diversity in adult male and female skeletal morphology found that one sex was not significantly more phenotypically heterogenous than the other. Thus, cultural exogamy as a mechanism of diffusion is regarded as unlikely. Considerably more research into the environment and social conditions throughout the Southern Plains around the end of the first millenium is required before we can begin to understand why these local innovations occurred. Some clues, however, may be present in the timing of the transition to a village pattern. The available chronological information suggests that the Antelope Creek phase may have developed nearly a century behind other Plains Village complexes in adjacent areas. Perhaps the High Plains were regarded as less suited than the eastern prairie for intensive horticultural production solely on the basis of precipitation; however, the presence of spring water from fossil reserves held by the Ogallala formation made the area more attractive as precipitation became less predictable.

The cultural dynamics of the Antelope Creek phase are closely linked to population pressure caused by an increase in the size of the group curing a time when primary food resources became less predictable due to deteriorating climatic conditions. In response, four buffering mechanism were implemented in an attempt to alleviate the population stress. These buffering mechanisms include 1) a breakdown in social cohesion and coopesation, as reflected by a reduction in the number of families occupying the single dwelling; 2) a shift in settlement patterns away from the Canadian River in order to capitalize on resources surrounding springs at the heads of the lateral tributaries; 3 ) an expansion of trade networks with the Middle Pecos 
region in order to expand the resource base; and 4) the development of intertribal raiding to prevent outside groups from utilizing the spring fed tributaries and the Alibates chert reserves. Ultimately these measures proved to be insufficient in coping with the deteriorating environmental conditions. By the late fifteenth and early sixteenth century, the culture was forced to make other major adaptive readjustments which altered the Antelope Creek cultural system to such an extent that their historical affiliations remain unclear. 


\section{CHAPTER 11}

\section{SUMMARY AND CONCLUSIONS}

\section{Introduction}

This study has examined both the nature and causes underlying some of the cultural variability within the Antelope Creek phase, a late prehistoric cultural manifestation on tile Southern High Plains. The analysis has focused primaxily on architectural and community differences, since these aspects of cultural variability are regarded as fairly sensitive indicators of adaptive measures taken in response to natural and social conditions affecting the prehistoric society. In addition, burial practices and artifactual remains were employed to help delineate fundamental differences within the Antelope Creek phase cultural system.

The purpose of this concluding chapter is two fold. First, the essential points of this study are summarized in order to present briefly the important findings of this research. Second, several avenues of research are enumerated in order to indicate possible directions for future study necessary to correct weaknesses in the existing Antelope Creek phase information base.

\section{Study Synopsis}

As a prelude to delineating the nature of architecture and coumunity variation within the Antelope Creek phase, a review of early fieldwork among late prehistoric Southern High Plains complexes showed that considerable 
architectural and community variability was encountered. However, the integration and interpretation of the diversity was hampered by the limited extent of excavation and/or delays in reporting excavation results in detail on the one hand, and the general kinds of problems examined on the other. Although many of the earliest fieldworkers promptly reported their excavation results, the architectural information was extrapolated primarily from surface indications and limited trench excavations. Subsequent excavations were more extensive, but the findings were obscured by delays or failure to publish the results. Furthermore, most of the problem oxientations were concerned with culture historical or intercultural relationships. The Midwestern Taxonomic System, which defined cultures on the basis of artifact content, was well suited to examining these issues, but the system conceptually hindered the examination of cultural variation within the Antelope Creek manifestation. Consequently, it was necessary to redefine the culture using time and space parameters as dependent variables.

The Upper Canark regional variant was thus defined to include the semisedentary cultural groups residing in the western portion of the Southern Plains during the first half of the second millenium A.D. These groups share a generalized plains Village tool assemblage (cordmarked ceramics, small side notched points, oval knives, and an extensive array of bone tools) but employ masonry and adobe in the construction of dwellings and storage structures. Two contemporaneous but spatially distinct groups affiliated with the upper Canark regional variant are the Apishapa phase of southeastern Colorado, and the Antelope Creek phase of the Southern High Plains of Texas and Oklahoma. The present study focused on natural and cultural diversity within the High Plains-Canadian River locality near the geographical center of the Antelope Creek phase. 
From a local perspective, the study area shows considerable diversity in the kinds and distributions of natural resources. Erosic: of the Canadian River and its short lateral tributaries through the dolomitic caprock deposits has created a fundamental dicotomy between a narrow deeply entrenched inner valley and the broad rolling topography of the outer valley. Most differences in topography, elevation, soil characteristics, geological deposits, temperature, wind speed, solar radiation, water quality and plant and animal cormunities correspond to these two fundamental settings. However, the distribution of high quality chert and other usable tool stone is practically restricted to single exposure localities, whereas critical climatic conditions such as precipitation are more ubiquitous.

The erratic and unpredictable climatic conditions of the semiarid southern High Plains is one of the most critical factors affecting late prehistoric village groups. The climate of the study area is considered to be horticulturally marginal, since it presently receives only slightly more precipitation than the critical eight inch spring and summer rainfall necessary for maize cultivation. Snowmelt from the Rocky Mountains is more predictable in occurrence but unsuited because the water often comes as floods down the Canadian River. At other times during the growing season, the river bed is dry, or contains stagnant brackish pools of water. The most dependable source of fresh water is derived from groundwater discharge of fossil water reserves from the immense Ogallala aquifer. Springs and seeps commonly occur along the rim of the inner valley settings. Surface water is concentrated at the heads of lateral tributaries, but after flowing short distances, much of the water sinks into the sand filled bottoms.

Paleoenvironmental studies have suggested some fluctuations in temperature and precipitation during the last two millenia. Baerreis and Bryson (1965a, 1966) 
have postulated that the Antelope Creek culture in the Texas-Oklahoma panhandles developed at a time when the Central Plains region was experiencing droughts and becoming depopulated. Thus, they argue that around A.D. $1200 \mathrm{dry}$ Pacific air pushed into the Central Plains from the west and forced the storm track pattern to the south over the Southern Plains whers increased precipitation made the area more conducive for settlement. Unfortunately, paleoenvironment. studies adjacent to the Southern High Plains suggest that xeric conditions were common on the Southern Plains at the same time that environmental conditions were deteriorating in the Central Plains (Hall 1982). In contrast to the BaerreisBryson model, I maintain that the fossil water reserves of the Ogallala aquifer, and not precipitation, was instrumental in the development of the Antelope Creek phase. Furthermore, many of the basic changes in Antelope Creek architecture and community patterns reflect cultural responses implemented to buffer against effects of drought conditions which generally intensified throughout the duration of the phase. Much of this study has focused on documenting the range of architectural and community variability and seeking functional, social, temporal and spatial/environmental correlates before returning to the issue of High Plains adaptations.

Traditionally, the Antelope Creek phase architecture and community patterns have been characterized as displaying considerable heterogenity (Green 1967; Duffield 1964; Krieger 1946; Lintz 1978b). However, much of the complexity stems from a piecemeal approach to examining structural differences, and from over emphasizing subtle differences in room form. To circumvent these problems, an attribute analysis based on a sample of 223 excavated discrete architectural units from 28 sites in the study area served as the foundation for defining variability on three levels-- architectural, community and settlement. The following 
synopsis discusses functional (engineering and behavioral), social, temporal and spatial factors underlying variability at each of these levels.

The architectural level of variability refers to differences evident at the single room/pit feature level. The repetitious clustering of 62 attributes and variables was used to define 11 polymorphic architectural types. Subtle differences among architectural units assigned to the same type were regarded as unit varieties. Thus the unit varieties represent examples of actual variation upon which the ideal unit types are based. Major differences in unit type size and complexity of feature attributes permitted the delineation of dominant (Unit Types 1 and 2), and subordinate (Unit Types 3-6, 8 and 9) rooms of a household cluster quite separate and distinct from cist and pit features (Unit Types 7, 10 and 11).

The dominant rooms (Unit Type 1 and 2) are regarded as residential units, since they are fairly common and are the largest rooms. They typically have a complex constellation of interior features and often show extensive maintenance and remodelling. At least one room at the Footprint site, however, may have been an ossuary structure rather than a residential unit.

A number of factors have influenced the configuration of these rooms. Some of the differences in the central channel, bench features, storage pits and cists, platforms and hearths are regularly patterned and reflect discrete interior activity areas. Raised clay or earthen rims around the channel edge, central hearths, wall bins, and the entry steps and entry sills are all thought to have served to segregate the interior activity areas by keeping materials inside definable areas within the structure. The bench areas north and south of the central channel are regarded as familial sleeping and storage areas, whereas the channel area served as an interior cooking, manufacturing/processing 
and thoroughfare area. The platform against the west wall may have been a household altar or shrine. Most of these formally patterned areas reflect social and behavioral aspects of the Antelope Creek society.

In contrast, the strict relationships anong room size, wall foundation type and the number of interior roof support posts (two additional posts required for every $14.32 \pm 0.82 \mathrm{~m}^{2}$ floor area) are thought to reflect solutions to engineering problems axising from the size of these large units. In some cases, extra posts or double slab wall foundations were employed to alleviate stress and to reinforce exterior and/or down slope walls. Furthermore, the complex configuration of the extended vestibules, which consists of eastward oriented extended crawlways with sills and threshold collars, may have served to regulate air temperature and control drafts within the room.

Spatial and environmental constraints had a limited impact on the development of these main household units. At the Arrowhead Peak Site, the construction of the main rooms directly on bedrock deposits may account for the absence of central channels. In addition, the distance of the site to bedrock exposures with suitable building stone clearly accounts for much of the variation in the wall form of these units. Finally, some units built on poorly consolidated sandy soil occasionally used stone slabs along the edge of the floor channel and platforms features to help retain the definition of these room attributes.

Some general changes in these main residential units are also evident between the early (A.D. 1200-1350) and late (A.D. 1350-1500) subphases. These changes include an increase in room size $\left(\bar{x}=24 \pm 13 \mathrm{~m}^{2}\right.$ to $\left.32 \pm 10 \mathrm{~m}^{2}\right)$ with an concominant increase in the number of roof supports, the use of less substantial wall footings (shift from predominantly double slab to mainly single slab foundations), a simplification of interior feature form, and an increased complexity 
of the entryways. The increase in the room size may signal an increase in the number af sccupants using the structure, whereas the simplification of the wall foundations relates to changes in room aggregation, which is discussed in a moment.

The subordinate rooms (Unit Types $3,4,5,6,8$ and 9 ) served a variety of different functions, but all are regarded as either directly or indirectly subservient to the dominant room types. Fewer engineering problems were involved in the construction of these smaller rooms, since the weight of the roof could we carried entirely by the walls. The presence of interior hearths, storage pits, corner platforms and raised floor surfaces inside some units suggests that the subordinate rooms served a wide variety of storage, cooking and/or processing functions. Access to many of the units was gained through upper wall openings or gaps in the east or northeast walls. The interior platforms and raised floor levels in these small rooms are associated with contiguous room block structures and reflect a series of specialized features developed to navigate around obstacles imposed by the aggregate form. Quite clearly, the artificially raised floor levels at Alibates Ruin $28-I$ were used to provide split level access to storage areas. Furthermore, the spatial morphology of the complex room blocks may have radically altered the size, shape and placement of functionally equivalent rooms. Thus, Unit Types 4 and 8 are regarded as functionally equivalent when they are incorporated into the large contiguous room structures. Most of the morphological variability among Unit Types $3,5,6$ and 8 are thought primarily to reflect functional differences: however, attempts to use associated artifacts to verify these functional differences was hindered by poor contextual records. Although Unit Type 3's (antechambers) were once regarded as "kiva-like" ceremonial rooms, available 
information indicates thay they are common and redundant at contiguous room block sites. Furthermore, associated artifacts reflect secular activities. The morphology and content of the various room types fails to discern any communal or strictly ceremonial structures at any of the Antelope Creek sites. Quite likely, the platforms which redundantly occur inside main household residential rooms reflect a familiar sacred orientation.

No clear spatial trends are discernable from the subordinate room forms. Although the sample of dated features is too small to place much confidence in temporal differences, it is interesting to note that Unit Type 6, with central hearths, is affiliated with the early subphase, whereas Unit Type 5 , with interior pits, is assigned to the late subphase.

The pit and cist features (Unit Types 7, 10 and 11) are exceptionally small (less than $1.6 \mathrm{~m}^{2}$ ) and are regarded as exterior storage features. Their small size presented little engineering or construction problems. No clear social, temporal ox spatial differences were discerned among these feature types.

The community level of variability refers to the differences in the spatial relationship of contiguous and isolated room structures at a site. The repetitious occurrence of room forms at contiguous room block structures was used to identify six patterns of room aggregation. The aggregate patterns involve the placement of multiple household clusters together along a northsouth axis (Aggregate Type I), the spatial arrangement of subordinant rooms around an individual residential room (Aggregate Types II, III and IV), or the contiguous pairing of two subordinant units as a structure separate from the residential room (Aggregate Types $V$ and $V I$ ).

The analysis showed that contiguous arrangement of several household 
units (Aggregate Type I) takes priority over the placement of subordinant rooms within each household (Aggregate Types II, III, IV) when both patterns occur at the same room block. Furthermore, the subservient storage rooms (Unit Type 8) tend to be located along the eastern or front half of the structure. The few subordinant rooms located behind the residential room are significantly larger than their counterparts located towards the front.

No clear spatial factors seem to have influenced the moxphology of the aggregate room block. The single exception is perhaps the spatial constraints imposed at mesa top locations such as the Arrowhead Peak Site. Significantly, all of the dated sites with room aggregates involving main residential units are assigned to the early subphase (A.D. 1200-1350). The shift from large contiguous room structures involves both the separation of discrete household clusters (Aggregate Type I) and the marked reduction in the number of subordinate rooms $(\bar{x}=2.13$ to 0.83$)$ associated with any single residential unit. The placement of subordinate rooms relative to main residential units at sites with isolated structures seems to adhere to fairly strict spatial and directional patterns. Most subordinate rooms occur east, northeast or north of the main unit. Pit features (Unit Type 10) occur within $3.6 \mathrm{~m}$ of the residential unit, whereas storage rooms (Unit Types 4,8 and 9) range from 3.6 to $18.0 \mathrm{~m}$ away. Isolated Unit Type 3 rooms occur 15 to $22 \mathrm{~m}$ away, and slab cists (Unit Type 7) occur 25 to $29 \mathrm{~m}$ from the main residential units. Burials may occur inside isolated subordinate rooms (Unit Types 5,6 or 8) or rarely inside ossuary pits within Type i residential rooms, but most are located in discrete cemetery areas 50 to $100 \mathrm{~m}$ from sites with one or more residential units.

None of the sites examined in this study were arranged around a plaza or common use area, and no definable public structures were evident from morphology 
or artifactual contents. A $1.9 \mathrm{~m}$ tall mound developed over the contiguous room block at Alibates Ruin 28-I, and another $1.0 \mathrm{~m}$ tall mound may be present at the Spring Canyon site. Although these features are undoubtedly cultural, there is no indication that these mounds were the resuit of planned construction. This issue could be clarified by additional excavatisas at the Spring Canyon site mound, Evidence derived from mortuary practices suggests no significant rank or status differentiation among the Antelope Creek irdividuals. Consequently, the society is regarded as politically egalitarian.

The settlement level of variability refers to the kinds and distribution of architectural sites across the landscape. The number and association of various unit types were used to define three types of sites: subhomesteads, homesteads and hamlets.

Subhomesteads are sites consisting of subordinate room forms (Unit Types 5,6 or 8 ) with or without pit/cist features (Unit Types 7,10 or 11) but lacking evidence of an associated dominant household rooms (Unit Types 1 or 2 ). Simple subhomesteads have less than three subordinate rooms, whereas complex subhomesteads have four or more. These sites are thought to have been used intermittently or cuntinuously over a fairly short time period as outlying or subsidiary sites to the other more permanent site types. Typically, the subhomesteads occur on low topographic settings within the inner valley and are placed close to rich bottomland soils along the Canadian River. These sites generally have a low tool density and limited tool variety marked by a scarcity of trade wares. Furthermore, the artifacts reflect a specialized tool assemblage oriented towards horticultural production and processing activities. Thus, the simple subhomesteads seem to have served as summer field huts situated close to crops. The dependent relationship of these sites is reflected in the 
faunal remains, as indicated by food sharing, or more likely, food brought from the residential sites. Burials have yet to be reported from the subhomesteads. All of the dated sites are assigned to the early subphase.

Homestead sites have a single dominant room (Unit Types 1 or 2) with pit and cist features (Unit Types 7,10 and 11 ) occasionally in association with subordinate rooms (Unit Types $3,4,5,6,8$ and 9). Simple homesteads lack the subordinate rooms, while complex homesteads have them. These sites are believed to be occupied by a single family. Homesteads tend to be located either close to (less than $1.2 \mathrm{~km}$ ) or far from $(7.2$ to $8.7 \mathrm{~km}$ ) the Canadian River and commonly occur on the low inner valley floor or the higher inner valley rim settings. These sites typically have a greater density and variety of tools than the subhomestead sites and are occasionally marked by the occurrence of Southwestern trade goods. Burials are occasionally found at numesteâu sitcs. The hamlet sites have multiple dominant rooms (Unit Types 1 or 2 ). Simple hamlets lack associated subordinate rooms but may be associated with pits or cists. In contrast, the complex hamlets may have the full range of subordinate rooms along with pits and cists. The hamlets are thought to reflect the simultaneous occupation of a locality by multiple family groups. The maximum size of Antelope Creek phase hamlets is uncertain. Early reports mention sites with nearly a hundred rooms; however, the validity of these reports is uncertain since the rooms reflect a mixture of dominant and subordinate forms, and the contemporaneity of the structures is undemonstrated. Extensive excavations at Alibates Ruin 28-I exposed over 65 architectural units; however, radiocarbon dates and differences in the quantity of trade goods and artifact densities across the site suggest the presence of three separate components each involving perhaps less than eight different families (Appendix A). 
Hamlet sites tend to be located 3 to $4.5 \mathrm{~km}$ from the Canadian River on inner valley wall bench and rim settings. Although far from the Canadian River and its tributaries, these locations are in close proximity to springs at the base of the Ogallala formation. As might be expected, hamlet sites typically have the greatest range and density of artifact types. In addition, large quantities of Southwestern trade wares are present, as are human burials.

Two fundamental trends in settlement seem to transcend the site types. These are the apparent breakdown in social cohesion and cooperation as reflected $b_{;}$the shift from large contiguous room blocks to isolated household units and perhaps a basic shift in settlement patterns. This shift may involve the abandonment of subhomesteads placed near the Canadian River coupled with more intensive settlements along the lateral tributaries in order to take advantage of water flow from spring and seeps (Etchieson 1981:88; Hughes et al. 1977).

Another aspect of the Antelope Creek cultural system briefly examined in this study involves intra and intercultural exchange. Three lines of evidence suggest that a certain amount of intracultural exchange occurred among Antelope Creek phase occupations at different sites. Specifically, these are the evidence for food sharing based on a disproportionate kinds of bone elements at the various site types (Duffield 1970), the presence of abundant quantities of Alibates chert at Antelope Creek phase sites in the Oklahoma panhandle (Lintz 1976), and the possible excessive production of woven goods as inferred from a disproportionately high number of spindle whorls recovered from the Medford Ranch Site (Duffield 1964). The patterns of food sharing probably reflect the subservient position of the subhomesteads in the Antelope Creek phase site hierarchy. But the other two patterns of exchange may reflect reciprocal trading of locally 
manufactured goods. A detailed reanalysis of site assemblages may reveal other evidence of intracultural trade.

Antelope Creek phase intercultural exchange involves contacts with Caddoans to the southeast, Plains Villagers (specifically Upper Republicans) to the northeast, and Puebloans to the west. However, trade materials from the former two groups are not as easily discerned as items from the Puebloans. Consequently, most of our knowledge about intercultural exchange in confined to this latter group.

Nearly all of the Southwestern trade goods seem to originate in or filter through the Middle Rio Grande district of New Mexico. Trade goods recovered at Antelope Creek phase sites include painted and glazed pottery, obsidian, and jewelry made of shell and turquoise, but these items are only thought to represent trinkets added as trade incentives in order to enhance the exchange of food resources (Spielman 1983). In exchange for these items, the Antelope Creek people were providing Alibates chert, bone tools, and bison products (Baugh 1982).

Although some contacts between Plains and Southwestern groups occurred prior to the development of the Antelope Creek phase, present evidence suggests that the exchange intensified considerably during the late subphase (after A.D. 1350). The distribution of Southwestern goods at Antelope Creek phase sites. does not strictly reflect material attenuation as expected in neighbor to neighbor or down the line trade. However, some decrease in Southwestern trade wares at sites east of the Alibates quarry is evident (Table 31). Instead, the trade goods are concentrated at select hamlets and homesteads as might occur with directional exchange. The few trade items present at the subhomestead sites undoubtedly reflects another indication of the subservient and temporary nature of these sites in the Antelope Creek hierarchy. 
Finally, the archaeological context of Southwestern trade items suggests that some kinds of these nonindigenous goods were regarded differently from others. The obsidian and painted pottery are often recovered from the midden deposits, while the shell and turquoise jewelry are frequently used as mortuary offerings. The differential depositional contexts suggests that trade ceramics and obsidian were regarded as utilitarian objects of less importance than the trade jewelry.

A finai facet of this study transcented the temporal and spatial limits of the phase and study locality in order to examine the origins and adaptive dynamics of the Antelope creek cultural system. The Antelope Creek phase appears to have developed primarily from an indigenuous Woodland group (Lake Creek complex) as a result of acculturative processes. Formal hypothesis testing procedures were used to reject the often proposed propositions involving culture unit migrations or that exogamous marriage patterns were responsible for the development of the distinctive Antelope creek phase cultural system. The distinctive architecture represents the adoption of Puebloan ideas and forms, but not the Puebloan construction technology. Further research into the cultural and environmental conditions of the Southern High Plains and the Southwest between A.D. 800 and 1200 is necessary to delineate why Southwestern architectural forms were incorporated into the emerging Plains village pattern on the Llano Estacado.

The single factor underlying cultural dynamics of the Antelope Creek phase is population pressure due to increasing size of human populations at a time when the climate was changing towards xeric conditions. These climatic changes of the fourteenth century, in turn, adversely affected two of the most important economic resources utilized by the Antelope Creek people-- maize and bison. In 
an attempt to alleviate the resulting stress, the Antelope Creek people tried a number of buffering mechanisms in a futile attempt to maintain their sedentary lifestyle. Four of these buffering mechanisms implemented during the Antelope Creek phase include: 1) the breakdown in social cohesion possibly reflecting increased competition for resources; 2) a shift in settlement patterns away from the Canadian River to the spring fed lateral tributaries in order to maximize utilization of dependable water resources for himsin sonsumption and crop production; 3) expansion of the trade network systems in order to tap complementary resources from adjacent areas; and 4) development of raiding behavior in order to maintain control over resource availability. Ultimately, these measures proved to be inadequate to continue the Antelope Creek phase cultural system. By the mid-sixteenth century, the Plains villagers were forced to radically alter their settlement and subsistence patterns to such an extent that their historical affiliations remain unclear.

\section{Future Directions}

This study has relied primarily on architectural, comnunity and mortuary patterns in order to discern possible buffering mechanisms employed to alleviate population pressure. In some cases, ancillary studies critically needed to support or strengthen certain facets of this study were lacking or incompletely developed. At this point, it behooves me to address some of these areas so that other studies may continue to make substantial contributions in clarifying Antelope Creek phase adaptations. Although recomendations in numerous areas could be offered, I shall limit my observations to but a few areas.

The first area involves the reconstruction of environmental conditions and examining the impact of the physical environment on the Antelope Creek phase. 
Although studies by Ferring (1982), Hall (1982), Lintz and Hall (1983), Speth (1983), and Duffield (1970) document shifts towards xeric conditions during the late prehistoric period, considerably more information is required to delineate the timing, intensity, duration and periodicity of paleoenvironmental fluctuations. Most of these studies have been conducted adjacent to the Llano Estacado, and the extent that these findings are applicable to the study area is uncertain. Only Duffield's work has been conducted in the High Plains area, but as indicated in Chapter 10, certain problems plague the usefulness of this study. Consequently, additional work is needed. Several independent lines of evidence from geomorphological, palynological, phylolithological, macrobotanical, molluskan and faunal studies should be employed. Ideally, some of these remains should be from non-culturally derived contexts in order to eliminate biases introduced from human behavior. In addition, the timing of climatic fluctuations is critical to understanding the cultural responses; consequently, considerable care should be spent in selecting samples from datable contexts, and in continuing the chronometric program started in determining the age of Antelope Creek phase sites. Refinements in paleoenvironmental studies should improve our understanding of the conditions confronting the Antelope Creek people.

A second area of needed research involves clarification of the Antelope Creek subsistence-settlement patterns. Intensive surveys of large tracts which cross cut environmental differences and ideally contrast two or more lateral tributary drainage basins should provide considerable information about the density and distribution of sites within the study area. Marmaduke and Whitsett (1975) have made a partial survey of Alamosa Creek, just west of the study area, but their results are difficult to use, since their methodology and the size and locations of the survey areas are not specified. Of particular concern is the abundance 
and distribution of nonarchitectural sites and the nature of activities conducted at these locations. To date, Etchieson (1979) has provided the only excavation information about the range of activities at one of these nonarchitectural sites. This is an excellent start, but the range of different open site types associated with various procurement and processing astivities still needs to be delineated for the study area.

Considerable progress could be made by examining the systemic relationships among the various kinds of sites involved in the procurement, use and distribution of select resources. For example Alibates chert was mined at specific areas within the Canadian River valley. Initial reduction may have been conducted near the quarries, but subsequent stages of tool production and the manufacturing of core bifaces, flake blanks and preforms for long distance transport/trade occurred at complex subhomesteads and hamlets near the quarries (Bandy 1976; Baker and Baker 1941b). The terminal manufacture, use, rejuvination and discard of tools made from the trade pieces presumably occurred at more distant sites. To date, the only lithic technological studies have been conducted on a sample of debitage from the Turkey Creek Site near the quarries (Bandy 1976), and on a cache of trade flake blanks from a site in western Oklahoma (Lintz 1978c). Similar studies of samples from the quarries and an examination of other technological stages from more distant sites would provide a clearer understanding of the role lithic resources played in the Antelope Creek economy. However, finer recovery techniques will be required to obtain the necessary debitage, and inferences regarding specific activities conducted at a site should be based on a combination of replication and tool use-wear studies, rather than on general artifact morphology. Similar research desinns could be developed to examine the procurement, utilization, 
consumption and discard practices of other kinds of plant and animal resources exploited by Antelope Creek phase groups.

Further research into the function of specific rooms and site types is urgently needed. Attempts in Chapter 6 to delineate room functions were hindered by imprecise stratigraphic contexts reported for tools and debitage from the WPA and Norpan projects. Although better control may exist for some of the more recent excavations, materials from many of these projects have yet to be formally analyzed and published. In addition, future excavations should attempt to maintain tighter control over material provenience and devote greater attention to recording the nature of soil matrices associated with the various architectural features.

Considerable information amenable for addressing many of these functional issues can be gleaned from existing collections on file at the various institutions. The analysis of curated collections is a far more efficient way (in terms of time and money) to obtain insights into the Antelope Creek cultural system than conducting additional excavations. A rigorous examination of the tool assemblages may ultimately modify or refine some of the interpretations and conclusions I have reached from synthesizing the available literature. The effort spent in analyzing old collections will undoubtedly yield considerable information about the nature of activities conducted at Antelope Creek phase sites. For example, one recent investigation has sought to examine outside activity areas surrounding structural remains by expanding the excavation beyond the limits of the features (Smith and Smith 1982). However, materials from the extensive WPA projects could have been utilized to address this problem without digging into new sites. Antelope creek phase sites have been and are being lost at an alarming rate. Consequently, it behooves us to make the best use of the 
remaining sites. I am not arguing for a moratorium on future excavations. Clearly, some research problems require special collection techniques at specific localities. However, whenever possible, endangered sites that have to be salvaged should be approached with a cogently developed research design and with proper techniques to recover relevent information. Consequently, we should make more judicial use of the existing collections whenever possible and preserve the sites for future problems.

Another area ripe for future research involves the precise timing and mechanisms of cultural transmission of the plains village pattern on the Southern High Plains. Evidence mustered in Chapter 10 suggests that the Antelope Creek phase developed at least a century behind other plains village complexes in adjacent areas. The advantages of groundwater reserves held by ogallala aquifer over the unpredictability of precipitation during drought periods may have been a contributing factor to the development of the distinctive Antelope Creek phase adaptation from primarily an indigenous Woodland group. No evidence exists for a mass migration or culture unit intrusion from an adjacent region. Nevertheless, if historic patterns of trading partners and the fluidity of residence patterns can be validly applied to prehistoric situations (Weltfish 1977), then there is no reason to doubt that family units from distant allied cultures migrated to the Canadian River valley and resided at or near Antelope Creek hamlets. Such situations should lead to the transmission of some ideas and perhaps manufacturing techniques, rut whether or not the Antelope Creek phase represents a full blown cultural coalescence remains to be shown.

The demonstration of cultural coalescence may be exceedingly difficult from extant archaeological remains. The absence of distinctive Antelope Creek 
phase tool types (guitar pick scrapers, stubby bone pins, etc.) from the Roper Site assemblage may be interpreted as either a functionally specialized site, or as a locality potentially occupied by non-Antelope Creek people. One possible solution for resolving this issue involves undertaking a detailed study of Antelope Creek tool manufacturing techniques in order to see if the methods and stages of stone tool production of the Roper Site assemblage differs from the techniques evident in assemblage from more "traditional" Antelope Creek phase sites. Although it is uncertain if differences in kanpping strategies could be discerned, the subtle "stylistic" variations and intuitive differences in the "quality" of workmanship evident among Southern Plains Village complexes suggests that such an approach may be feasible.

The present approach has based the characterization of Antelope Creek on an analysis of sites from a limited portion of the Canadian River valley near the Alibates quarry. Other differences may be expected for sites further removed from this region because of the inherent diversity in the distribution of natural resources and the proximity to adjacent cultural groups. Although some trends discerned in this study may reflect culture wide responses to regional environmental changes, others undoubtedly reflect local conditions. Ideally, cultural variation should be examined from a number of other localities within the Antelope Creek phase. Site clusters along the North Canadian. River in the Oklahoma panhandle, as well as along the eastern and western escarpments of the Llano Estacado may provide different situations for study. Ultimately, information from these other localities could be contrasted to the patterns identified for the High Plains-Canadian Valley locality in order to elucide adaptative differences across the boundaries of the phase. 
The point of suggesting "areas for further work" is not to exhaust all areas of explanation or to force other archaeologists into compiling information for my research interests. Rather, the point is to generate interest in issues beyond mere culture historical problems. The identification of a site's cultural affiliation should not be the ultimate goal of archaeology but rather represents an initial prerequisite for studying cultural adaptations. This present study has hopefully served to provide a solid foundation for understanding late prehistoric adaptations on the Southern High Plains and to stimulate investigations into other facets of the cultural system. 


\section{REFERENCES CITED}

Altred, B. W.

1956 Mixed prairie in Texas. In Grasslands of the Great Plains:

Their Nature and Use, edited by J. E. Weaver and F. W. Albertson. Johnson Publishing Company, Lincoln, Nebraska

Anonymous

n.d. A preliminary report on Works Progress Administration Archaeological Project - 9249, Manuscript on file at the Panhandle Plains Historical Museum, Canyon, Texas. pp. 1-91.

Antevs, Ernst

1954 Climates of New Mexico during the last glaciopluvial. Journal of Geology 62:182-191.

1955 Geologic-climatic dating in the West. American Antiquity 20(4): 317-335.

Antle, H. R.

1939 A proposed nomenclature for Oklahoma archeology. American Antiquity $4(4): 349-350$.

Baerreis, David A. and Reid A. Bryson

1965a Historical climatology and the Southern Plains: a preliminary statement. Bulletin of the Oklahoma Anthropological Society 13:69-75.

1965b Climatic episodes and the dating of the Mississippian Cultures. Wisconsin Archeologist 46(4):203-220.

1966 Dating the Panhandle Aspect cultures. Bulletin of the Oklahoma Anthropological Society 14:105-116.

Baker, Ele

1939 Bimonthly letter report submitted to Floyd V. Studer. On file at the National Park Service, Sanford, Texas. Studer Files No. 708 .

1940a WPA, West Texas State College Archaeological Project WP-13202. Second quarter, 1940 Quarteriy Report for April 1 to June 30. 
1940b WPA, West Texas State College Archaeological Project WP-13202. Second quarter, 1940 Quarterly Report for Apr 11 I to June 30.

Baker, Ele M. and Jewel A. Baker

1939a (Second) quarterly report (1939) West Texas State College -WPA. Archaeological Project. Manuscript on file at the Panhandle Plains Historical Museum, Canyon, Texas.

1939b (Third) quarterly report (1939) West Texas State College--WPA Archaeological Project. Manuscript on fize at the Panhandle Plains Historical Museum, Canyon, Texas.

1939c WPA -- West Texas State College Archaeological Project. Quarterly Report. October 1, 1939 to December 1, 1939. Manuscript on file at the Panhandle Plains Historical Museum, Canyon, Texas.

1940a WPA -- West Texas State College Archaeological Project. Quarterly Report January 1, 1940 to March 1, 1940. Manuscript on file at the Panhandle Plains Historical Museum, Canyon, Texas.

1940b WPA -- West Texas State College Archaeological Project WP13202. Quarter7y Report October 1, 1940 -- December 31, 1940. Manuscript on file at the Panhandle Plains Historical Museum, Canyon, Texas.

1941 a Final Report WPA -- West Texas State Archaeological Project 9249. Unpublished manuscript on file at the Panhandle Plains Historical Museum, Canyon, Texas.

1941b Final Report archeological survey -- 0.P. 665-66-3-404, State Application 30976. Unpublished Manuscript on file at the PanHandle Plains Historical Musuem, Canyon, Texas.

1941c WPA -- West Texas State College archaeological survey, Quarterly Report February 16, 1941 to March 31, 1941. 0.P. 165-1-66-447, WP-17589. Manuscript on flle at the Panhandle Plains Historical Museum, Canyon, Texas.

1941d WPA -- West Texas State College archaeological survey, Quarterly Report April 1, 1941 to July 5, 1941. 0.P. 165-1-66-447, WPm17589. Manuscript on file at the Panhandle Plains Historical Museum, Canyon, Texas.

Baker, Galen R.

1964 The archaeology of the Park Plateau in southeastern Colorado.

Manuscript on file at Seton Memorial Library and Museum, Philmont Scout Ranch, Cimarron, New Mexico. 
Baker, William

1929 The first of the Plainsmen. Southwest Wilds and Waters. November and December issues.

Bandelier, Adolph F.

1892 Final report of investigations among the Indians of the southwestern United States, carried on mainiy in the years from 1880 to 1885. Papers of the Archaeological Institute of America, Series IV, part II: p. 137 .

Bandy, Phillip

1976 Lithic Iechnology: A Reconstruction of a Northern Texas Panhandle Archaeological Assemblage. Master's thesis. Texas Tech University, Lubbock.

Banks, Larry

1984 Lithic resources and quarries. In Prehistory of Oklahoma edited by Robert E. Be11, pD 65-96. Academic Press, Orlándo.

Barnes, Virgil

1969 Geologic atlas of Texas, Amarillo Sheet. Map Scale 1:250,000. Bureau of Economic Geology, University of Texas, Austin.

1983 Geologic atlas of Texas, Tucumcari Sheet. Map Scale 1:250,000. Bureau of Economic Geology, University of Texas, Austin.

Baugh, Timothy G.

1982a Edwards I (34Bk2): Southern Plains adaptations in the Protohistoric period. Oklahoma Archaeological Survey, Studies in Oklahoma's Past Number 8. University of Oklahoma, Norman.

1982b Quartermaster Creek area to be studied. News letter of the Oklahoma Archaeological Survey 2(2):3

Bell, Robert E.

1961 Relationships between the Caddoan area and the Plains. Bulletin of the Texas Archaeological and Paleontological Society 31:53-60.

1968 Dating the prehistory of Oklahoma. Great Plains Journal 7(2): 42-52.

1973 The Washita River Focus of the southern Plains. In Varfations in Anthropology: Essays in Honor of John C. McGregor, edited by D. W. Lathrop and J. Douglase pp 171+187. I7Tinois Archaeological Survey, Urbana. 
Bell, Robert E, and David A. Baerreis

195i A survey of Oklahoma archeology. Bullet in of the Texas Archaeological and Paleontological Society 22:7-100.

Belisle, Harold Juan

1971 The Recreation Potentfal of Saddle-Back Mesa, Texas. M. S. Thesis, Department of Park Administration, Texas Tech University, Lubbock.

Bender, Margaret,..Reid Bryson, and David Baerreis

1966 University of Wisconsin radiocarbon dacies II. Radiocarbon 8:522533.

1967 University of Wisconsin radiocarbon dates III. Radiocarbon 9: 530-544

Berry, R. J, and A. Caroline Berry

1967 Epigenetic variation in the Human cranium. Journal of Anatomy $101: 361-379$.

Birkeland, Peter W.

1974 Pedology, Weathering, and Geomorphological Research. Oxford University Press, New York.

Blatr, W. Frank

1950 The biotic provinces of Texas. The Texas Journal of Science 2(1):93-116.

BTakes Tee, Donald J.

1975 The Plains Interband T.rade System: An Ethnohistoric and Archaeological Investigation. Ph.D. Dissertation, department of Anthropology, University of Wisconsin, Milwaukee.

Blakes lee, Donald J. and Warren Caldwell

n.d. The Nebraska Phase: An Appraisal. Reprints in Anthropology VoTume 18. J\&L Reprint Company, Lincoin.

Blakeslee, Donald J., John Hotopp, Kerry Lippincott, John Ludwickson, and Thomas Witty.

1982 Some responses to Krause. Plains Anthropologist 27(95):83-90.

Binford, Lewis R.

1971 Mortuary practices: Their study and their potential. In Approaches to the Social Dimensions of Mortuary Practices, edited by J. A. Brown. Memoirs of the Society for American Archaeology Number 25.

Boserup, Ester

1965 The Conditions of Agricultural Growth. Aldine Press, Chicago. 
Bousman, C. Britt

1974a Archaeological Assessment of Al ibates National Monument. Archaeological Research Program, Southern Methodist University, Dallas.

1974b Archaeological Assessment of Lake Meredith Recreation Area. Archaeological Research Program, Southern Methodist University, Dallas.

1978 Biotic resources of the Fort Sill area: An ethnographic view. In An archaeological reconnaissance of Fort Sill, Oklahoma edited edited by $C$. Reid Ferring. Chapter 3. Contributions of the Museum of the Great Plains, Number 6. Lawton.

Bowers, Roger L.

1975 Petrography and Petrogenesis of the Alibates Dolonite and Chert (Permian), Northern Panhandle of Texas. M.A. Thests, University of Texas at Arington.

Breternitz, David

1966 An appraisal of tree-ring dated pottery in the Southwest. Anthropological Papers of the University of Arizona Number 10. University of Arizona Press, Tucson.

Brew, John Otis

1956 Archaeology of Alkali Ridge, southwestern Utah. Papers of the Peabody Museum of American Archaeology and Ethnology, Volume 21.

Brook, Vernon

1965 Culture traits of the El Paso Phase of the Mogolion. Transactions of the First Regional Archaeological Symposium for Southeastern New Mexico and Western Texas. pp. 18-22.

1971 Some hypotheses about prehistoric settlement in the TularosaHueco Bolson between A.D. 1250-1350. Transactions of the Sixth Regional Archeological Symposium for southeastern New Mexico and Western Texas. pp. 63-82.

1980 The Sabina site. Transactions of the Fifteenth Regional Archaeological Symposium for Southeastern New Mexico and Western Texas. pp. 15-86.

Brookfield, Harold C.

1976 On the notion of population threshold. In Population at Microscale, editer bv Kosinski and Webb,.pp 31-35. New Zealand Geographical Society and Population Commission.

Brothwell, Don. R.

1959 The use of non-metrical characters of the skull in differentiating populations. Deutsche Gesellschaft fur Anthropologie 6:103109. 
Brown, James

1971 Spiro Studies, Volume 3: Pottery Vessels. Stovall Museum of Science and History and the University of Oklahoma Research Institute. Norman, Oklahoma.

Brown, Ken

1979 Late prehistoric settlement patterns in southwestern Kansas: a model. Plains Anthropologist 24(85):191-206.

Brush, Stephen

1975 The concept of carrying capacity for systems of shifting cul ture. American Anthropologist 77:799-811.

Bryant, Vaughn M. Jr. and Harry J. Shafer

1977 The late Quaternary paleoenvironment of Texas: A model for the archaeologist. Texas Archaeological Society Bulletin 48:1-25.

Bryson, Reid A., David A. Baerreis, and Wayne Wendland

1970 The character of late-glacial and post-glacial climatic changes. In Pleistocene and Recent Environments of the Central Great Plains edited by Dort and Jones,pp 53-77. University of Kansas, Department of Geology, Special Publication No. 3.

Bryson, Reid A. and Wayne Wendland

1967 Tentative climatic patterns for some late glacial and postglacial episodes in central North America. In Life, Land and Water edited by William J. Mayer-0akes. Occastonal papers of the Department of Anthropology, University of Manitoba, Number 1. University of Manitoba Press, Winnipeg.

Bullard, Wililan R. Jr.

1962 The Cerro Colorado site and pithouse architecture in the southwestern United States prior to A.D. 900. Papers of the Peabody Museum of Archaeology and Ethnology Volume XLIV, No. 2. Harvard University, Cambridge, Massachusettes.

Bureau of Reclamation

1979 Lake Meredith salinity study, Canadian River, Texas-New Mexico. United States Bureau of Reclamation, Southwest Regional Office, Amarillo, Texas.

Cameron, Don

1980 Study of Tecovas Jasper of the Texas Panhandle. Paper prepared for Anthropology 402 under professor Jack T. Hughes, West

Texas State University, Canyon, Texas.

Campbe 11, Robert G.

1969 Prehistoric Panhandle Culture on the Chaquaqua Plateau, Southeastern Colorado. Ph. D. dissertation, University of Colorado. 
1976 The Panhandle Aspect of the Chaquaqua Plateau. Texas Tech University, Graduate Studies \#11. Lubbock, Texas.

Caperton, Thomas $\mathrm{J}$.

1981 An archaeological reconnaissance of the Gran Quivira area. In Contributions to Gran Quivira Archaeology edited by Alden c. Hayes. National Park Service Publications in Archaeology Number 17, pp 3-13. Washington, D. C.

Carter, Richard L.

1959 A prel iminary report on a square room in the cottonwood Creek Ruins of Hutchinson County, Texas. Unpublished manuscript prepared by Norpan Lapidary Society for the landowner, in possession of Dick Carter, Amarillo, Texas.

Carter, Richard L, and Mary Ruth Carter

1958 The Pickett Ruin in Hutchinson County, Texas. Unpublished mansscript on file at the Panhandle Plains Historical Museum, Canyon, Texas.

Chang, Kwang-Chih

1958 Study of the Neolithic social groupings: Examples from the New World. American Anthropologist 60(2):298-334.

Chrisholm, Michael C.

1968 Rural Settlement and Land Uses: An Essay in Location. Aldine Press, Chicago.

Clarke, David

1977 Spatial Archaeology. Academic Press, New York.

Clements, Forest

1945 Historical sketches of Spiro Mound. Contributions from the Museum of the American Indian. Heye Foundation. 14:48-68.

Cohen, Mark N.

1977 The Food Crisis in Prehistory. Yale University Press, New Haven.

Collins, Michael B.

1971 A review of Llano Estacado archeology and ethnohistory. Plains Anthropologist 16(52)85-104.

Cordell, Linda

1978 A Cultural Resource Overview of the Middle Rio Grande Valley, New Mexico. U. S. Government Printing Office, Washington, D. C.

1979 Prehistory: eastern Anasazi. In Handbook of North American Indians, Southwest, Volume 9 edited by WiTl iam C. Stürtevant. DD. 131-152. U. 5. Government Printing Office, Washington, D.C. 
Corley, John A.

1965 Proposed eastern extension of the Jornada Branch of the Mogolion. Transactions of the First Regional Archeological Symposium for Southeastern New Hexico and Western Texas. Lea County Archaeological Society BuTletin No. 1:30-36.

Couzzourt, Jim

1982 Archeological testing at Cal Farley's Boys Ranch, Oldham County, Texas Part One: The Maintenance Barn site (A1543). Transactions of the 17th Regional Archeological Symposium for Southeastern New Mexico and Western Texas. Pp 57-134.

Cowgill, George

1975 On causes and consequences of ancient and modern population changes. American Anthropologist 77(3):505-526.

Crabb, Martha

1968 Some Puebloan trade pottery from Panhandle Aspect sitcs. Texas Archaeological Society Bulletin 38:83-89.

Cronin, James G.

1969 Ground water in Ogallala Formation in the Southern High Plains of Texas and New Mexico. U. S. Geological Survey, Hydrological Atias 330.

Dale, Vincent

n.d. Notes concerning the "Baker Flint Quarry" on the Dry Cimarron River Valley of New Mexico. (Vincent Dale Collections). On file at the Stovall Museum of Arts and Sciences. University of Oklahoma, Norman.

Damon, P. E., C. W. Ferguson, A. Long, and E. I. Wallick

1974 Dendrochronologic calibration of the radiocarbon time scale. American Antiquity 39(2):350-366.

Davis, E. Mott

1969 A diary of the 1969 TAS field school at Lake Meredith in the Panhandle. Texas Archaeology 13(2):7-17.

Davis, Leslie

1968 Recent excavations at Hot Well Site (EPAS-3). Transactions of the Third Regional Archeological Symposium for Southeastern New Mexico and Western Texas. pp 23-32

Davis, William A.

1962 Appraisal of the archaeological resources of Sanford Reservoir, Hutchinson, Moore and Potter Counties, Texas. Report Submitted to the National Park Service, Santa Fe. 
Dice, L. R.

1943 The Biotic Provinces of North America. University of Michigan Press, Ann Arbor.

Douglas, A. E.

1935 Dating Pueblo Bonito and other ruins in the Southwest. National Geographical Society, Pueblo Bonito Series 1.

Duffield, Lathel F.

1964 Three Panhandle Aspect sites at Sanford Reservoir, Hutchinson County, Texas. Bulletin of the Texas Archaeological Society $35: 19-81$.

1970 Some Panhandle Aspect Sites in Texas: Their Vertebrates and Paleoecology. Ph.D. Dissertation, University of Wisconsin.

Dumas, William and Clara Dumas

n.d. Excuvation (sic) of A-62 or Roper Nr. 1. Partial draft manuscript on file at the Panhandle-Plains Historical Museum, Canyon, Texas.

Dumond, Don. E,

1977 Science in archaeology. The Saints go marching in. American Antiquity $42(3): 330-349$.

Ellzey, Tom S.

1966 A Panhandle Aspect site (preliminary report). Special Bul letin Number 1. Midland Archaeoiogical Society, pp 59-65. Midland, Texas.

Etchieson, Gerald Meeks

1979 Archaeological Testing at the South Ridge Site, Lake Meredith Recreation Area, Hutchinson County, Texas. Archaeological Research Larboratory, Kilgore Research Center, West Texas State University, Canyon, Texas.

1981 Archaeological Survey at Lake Meredith Recreation Area, Moore and Potter Counties, Texas. U. S. Department of the Interior, Water and Power Resources Service, Southwest Region, Amarillo, Texas.

1982 Archaeological investigations by the Youth Conservation Corps at Lake Meredith Recreation Area, Texas. Transactions of the 17th Regional Archaeological Symposium for Southeastern New Mexico and Western Texas.

Eyerly, T, L.

1907 a The buried city of the Panhandle. Transactions of the Kansas Academy of Science 21(1):219-228. 
1907b Archaeological work in the Texas Panhandle. Bulletin of the Canadian Academy.

1910 The Indian Renoirs of the Canadian River Valley. The Archaeological Bulletin $1(3): 77-80$. Hier, Texas.

1912 The buried city of the Panhandle. The Archaeological Bulletin 3(1):1-5. Hier, Texas,

Euler, Robert C., George J. Gumerman, Thor N. V. Karlstrom, Jeffrey S. Dean, and Richard Hevly

1979 The Colorado Plateaus: cultural dynamics and paleoenvironment. Science 205(4411):1089-1101.

Fenneman, Nevin $M$.

1931 Physiography of the Western United States. McGraw Hill Book Co.

Ferring, C. Reid (editor)

1982 The Late Holocene prehistory of Delaware Canyon, Oklahoma. Institute of Applied Sciences, Contributions to Archaeology \#1. North Texas State University, Denton.

Flannery, Kent

1969 Origins and Ecological Effects of Early Domestication of Plants and Animals (Ucko and Dimbleby editors). Aldine Press, Chicago. pp 73-100.

1976 Empirical determination of site catchments in Oaxaca and Tehuacan. In The Early Meso American Village edited by Kent Flannery, pD 103-117. Academic Press.

1976 The Early Mesoamerican Village. Academic Press.

Fleagle, Robert G. and Joost A. Businger

1963 An Introduction to Atmospheric Physics. Academic Press, New York.

Flynn, Peggy

1983 Preliminary analysis of materials from the Zimms site (34Rm72). Oklahoma Anthropological Society Newsletter 31(3):6-9.

Ford, Richard I.

1968 An Ecological Analysis Involving the Population of San Juan Pueblo, New Mexico. Ph.D, dissertation, University of Michigan.

Frye, John C. and A. B. Leonard

1957 Studies of Cenozoic geology along the eastern margin of the Texas High Plains: Armstrong to Howard Counties. Bureau of Economic Geology Report of Investigations \#32, University of Texas, Austin. 
Gallagher, Art

1951 The Goodman I site, Custer County, Oklahoma. Texas Archaeological Society Bulletin 22:188-216.

Gallagher, Joseph G. and Susan Bearden (editors)

1980 Evolution of cultural resources at Brantley Reservoir, Eddy County, New Mexico. Southern Methodist University, Archaeological Research Program, Research Report \$120. Dallas.

Geiger, Luther

1975 Soil Survey of Moore County, Texas. U.S.D.A., Soil Conservation Service, in cooperation wit the Texas Agricultural Experimentai Station.

Glasscock, Keith and Alma Glasscock

1955 A preliminary report on CR-1, an Indian campsite in Moore County, Texas. Panhandle-Plains Historical Review 28:96-106. Canyon, Texas.

Giassow, Michael A.

1972 The Evolution of Early Agricultural Facilities Systems in the Northern Southwest. Ph.D. dissertation in Anthropology. University of California at Los Angeles.

1980 Prehistoric agricultural development in the northern Southwest: a study in changing patterns of land use. Anthropological Papers \#16, Balierno Press, Socorro, New Mexico.

Gradwohl, David Mayer

1969 Prehistoric villages in eastern Nebraska. Nebraska State Historical Society Publications in Anthropology Volume 4. Lincoln, Nebraska.

Grady, James

1980 Environmental Factors in Archeological Site Locations. United States Bureau of Land Management, Cotorado State Office, Denver.

Green, Don E.

1973 Land of the Underground Rain: Irrigation on the Texas High Plains, 1910-1970. University of Texas Press, Austin.

Green, F. E.

1967 Archaeological Salvage in the Sanford Reservoir Area. National Park Service Report 14-10-0333-1126.

Green, F. E. and Jane Holden Kelley

1960 Comments on Alibates flint. American Antiquity 25:413-414.

Gould, Charles N.

1906 The geology and water resources of the eastern portion of the Panhandle of Texas. U. S. Geological Survey, Water Supply and Irrigation Paper 154. Washington, D.C. 
Griffin, James B.

1946 Cultural change and continuity in eastern United States

archaeology. In Man in Northeastern North America, edited by

Frederick Johnson. Papers of the Robert $\underline{S}$. Peabody Foundation

for Archaeology 3:37-95.

Guidry, Maron, Derl Brooks, Larry Higgins, Jack Hughes, Flavius Killebrew, Gerald Schuitz, Robert Wright

1979 An Environmental Profile of the Palo Duro Creek Basin. Kilgore Research Institute, West Texas State University. Reoort submitted to the U. S. Army Corps of Engineers, Contract No, DAC-W56-78-C-0203.

Gustavson, Thomas C., Robert J. Finley, Kathy A. McGillis

1980 Regional dissolution of Permian salt in the Anadarko, Dalhart, and Palo Duro Basins of the Texas Panhandle. Bureau of Economic Geology Report of Investigations Number 106. University of Texas, Austin.

Guthe, Carl E.

1952 Twenty-five years of archaeology in the eastern United States. In Archaeology of Eastern United States edited by J. B. Griffin. University of Chicago Press.

Haag, William G.

1961 Twenty-five years of eastern archaeology. American Antiquity $27(1): 16-23$.

Hal 1, Stephen A.

1982 Late Holocene paleoecology of the Southern Plains. Quaternary Research. 17:391-407.

Hammack, Laurens C.

1965 Archaeology of the Ute Dam and Reservoir. Museum of New Mexico Papers in Anthropology Number 14. Santa Fe.

Hardesty, Donald L.

1977 Ecological Anthropology. John Wiley and Sons, New York.

Harris, Marvin

1968 The Rise of Anthropological Theory. Thomas Y. Crowell Company.

Harrison, Bill

n.d. The Allen site, a pit-house in the Texas Panhandle. Manuscript on file at the Panhandle-Plains Historical Museum, Canyon, Texas.

Hassan, Fegri $A$.

1981 Demographic Archaeology. Academic Press, New York. 
Hayden, Julian D.

1954 Excavations, 1940, at University Indian Ruin. Southwest Monuments Association Technical Series, Volume 5. GTobe.

Haynes, Guy $H$.

1932 A Report on the Excavations of Saddleback Ruin. Masters thesis, Texas Tech University, Lubbock.

Hempel, Karl

1965 Aspects of Scientific Explanation. The Free Press, New York.

Hempe1, Carl G.

1966 Philosophy of Natural Science. Prentice-Hall, Englewood Cliffs.

Henderson, Mark

1976 An archaeological inventory of Brantley Reservoir, New Mexico. Southern Methodist University Contributions to Anthropology No. 18, Dallas.

Henning, Dale R. (editor)

1968 Climatic change and the Mill Creek Culture of Iowa, Part I. Journal of the Iowa Archaeological Society Vor. 15.

1969 Climatic change and the Mill Creek Culture of Iowa, Part II. Journal of the Iowa Archaeological Society Vol. 16.

Hill, James

1970a Broken K Pueblo. Prehistoric social organization in the American Southwest. Anthropological Papers of the University of Arizona Number 18. Tucson.

1970b Prehistoric social organization in the American Southwest: theory and method. In Reconstructing Prehistoric Pueblo Societies edited by Longacre, P 22. University of New Mexico Press, ATbuquerque.

Hill, James N. and R. H. Hevly

1968 Pollen at Broken K Pueblo: some new interpretations. American Antiquity 33(2):200-210.

Hobbs, Hulda R.

1941 Texas Panhandle ruins. El Palacio 8(6):121-128. Santa Fe.

Hobbs, Hulda R. and Marjorie F. Tichy

1941 Notes on S.W. Science meet. El Palacio 48(5):110-116.

Hodder, lan and Clive Orton

1976 Spatial Analysis in Archaeoloay. Cambridge University Press. 
Hofman, Jack

1978 An analysis of of surface material from the Little Deer Site, 34Cu-10, of western 0k7ahoma. A further investigation of the Wheeler Complex. Bulletin of the Oklahoma Anthropolonical Society 27:1-110.

Holden, Tom C.

1934 A Study of the Pottery of Saddle-Back Ruin. Masters Thesis, Texas Technical College, Lubbock,

Holden, W. C.

1929 Some explorations and excavations in northwest Texas. Bulletin of the Texas Archaeological and Paleontological Society 1:23-35.

1930 The Canadian Valley expedition of March, 1930. Bulletin of the Texas Archaeological and Paleontological Society 2:21-32.

1931 Texas Tech. Archeological expedition, Summer 1930. Bulletin of the Texas Archaeological and Paleontological Society 3:43-52.

1932a Recent archaeological discoveries in the Texas Panhandle. Southwestern Social Science Quarterly 13(3):289-293.

1932b Excavations at Tecolote during Surmer of 1931. Bulletin of the Texas Archaeological and Paleontological Society 4:25-28.

1933 Excavations at Saddleback Ruin. Bulletin of the Texas Archaeological and Paleontological Society 5:39-52.

Honea, Kenneth

1973 The technology of eastern Puebloan pottery on the Llano Estacado. Plains Anthropologist 18(59):73-88.

Hughes, Jack T.

n.d. Cultural development during the Archaic and Neo-Indian Stages on the Texas High Plains. Unpublished manuscript in possession of the author.

1953 Map and field notes concerning Sanford Ruin. Unpublished notes on file at the Panhandle-Plains Historical Museum in Canyon, Texas.

1962 Lake Creek: A Woodland site in the Texas Panhandle. Bulletin of the Texas Archaeological Society 32:65-84.

1967 Unpublished map of the Marsh Site on file at the PanhandlePlains Historical Museum, Archaeological Library, Canyon, Texas.

1968 Prehistory of Caddoan Speaking Tribes. Ph,D. dissertation, Columbia. University Microfi]ms, Ann Arbor. 
1969 The Canyon Country Club Cave, Randall County, Texas, Unpublished manuscript on file at the Texas Historical Comission, Austin.

1973 Data for archaeology section of environmental impact statement on Blue West and Bates Canyon Area, Lake Meredith Recreation Area, Texas. Report submitted to Ecology Audits, Inc., Dallas.

$1974 a$ Prehistory of Caddoan Speaking Tribes. Garland Press, New York.

1974b An archaeoiogical survey of a proposed pipeline route in Alibates National Monument. Report submitted to the National Park Service and Colorado Interstate Gas Company.

1979 Archaeology of Palo Duro Canyon. In The Story of Palo Duro Canyon edited by Duane Guy, pp 35-58. Canyon.

Hughes, Jack T., H. Charles Hood, Billy Pat Newman, and Pollyanna B. Hughes,

1977 Final report on an archaeological survey of the Red Deer Creek watershed in Gray, Roberts and Hemphill Counties, Texas.

Killgore Research Center, West Texas State University, Canyon, Texas.

Hughes, Jack T. and Pat Willey

1978 Archaeology at MacKenzie Reservoir, Archaeological Survey Report 24. Texas Historical Commission, Office of the State Archeologist, Austin.

Hunter-Anderson, Rosalind

1977 A theoretical approach to the study of house form. In On Theory Building in Archeology edited by L. Binford. Academic Press, New York.

Ireland, Stephen

1971 The Upper Purgatoire Complex--a re-appraisal. Southwestern Lore. $37(2): 37-51$.

Jacquot, Louis

1962 Soil Survey of Carson County, Texas. U.S.D.A. Soil Conservation Service, in cooperation with the Texas Agricultural Experiment Station. 1959, Series \#10.

Jantz, R, L.

1974 The Redbird Focus: cranial evidence in tribal identification. Plains Anthropologist 19(63):5-13. 
Jantz, Richard L. and Douglas H. Ubelaker (editors)

1981 Progress in skeletal biology of Plains populations. Plains Anthropologist 26(94 part 2). Memoir 17.

Jelinek, Arthur

1967 A prehistoric sequence in the Middle Pecos Valley, New Mexico. University of Michigan, Museum of Anthropology Papers No. 31 . Ann Arbor.

Johnson, C. Stuart

1934 Report to the Anthropology Department of the University of Oklahoma concerning the fieldwork carried on in the slab-house site on the Stamper Ranch, south of Optima, Oklahoma in the summer of 1934. Manuscript on file with the Stovall Museum of Science and History, Norman; and with the Panhandle-Plains Historical Museum, Canyon.

1939 A report on the Antelope Creek Ruin. Bulletin of the Texas Archaeological and Paleontological Society 11:190-202.

Jones, David E.

1972 Sanapia: Comanche Medicine Woman. Holt, Rinehart, Winston,

Keller, Gordon Nelson

1961 The Changing Position of the Southern Plains in the Late Prehistory of the Great PTains Area. Ph.D. dissertation, University of Chicago.

Keller, John Esten

1975 The Black Dog Village site: a Panhandle Aspect manifestation in Hutchinson County, Texas. Texas Highwav Department Publications in Archaeology, Report $\# \overline{5}$. Austin.

Kelley, J. Charles

1949 Archaeological notes on two excavated house structures in western Texas. Bulletin of the Texas Archaeological and Paleontological Society 20:89-114.

Kelley, Jane Holden

1964 Comments on the archaeology of the Llano Estacado. Bulletin of the Texas Archaeological and Paleontological Society 35: $\overline{1-18}$.

1966 The Archaeology of the Sierra Blanca Region of Southwest New Mexico. Ph.D. Dissertation, Harvard University, Cambridge.

Kenner, Charles L.

1969 A History of New-Mexican -- Plains Indian Relations. University of Oklahoma Press, Norman. 
Kidder, A, V.

1927 Southwestern archaeological conference. Science 66(1716):489-91.

1932 The artifacts of Pecos. Papers of the Southwestern Expedition, Volume 6. Phillips Academy, Andover, Yale University Press, New Haven,

Killebrew, Flavius C.

1979 A Survey and Population Analysis of Mammals by Habitat at Lake Meredith Recreation Area and Alibates National Monument. Report Submitted to the Nlational Park Service by West Texas State University.

Kirkpatrick, David T.

1976 The prehistory of northeast New Mexico. In Guidebook of Vermejo Park, Northeastern New Mexico -- 27 Field Conference, edited by R. C. Ewing and B, S, Kues, Pp 77-82. New Mexico Geological Society.

Klein, Jeffery, J. C. Lerman, P. E. Damon, and E. K. Ralph

1982 Calibration of radiocarbon dates: tables based on the concensus data of the workshop on calibrating the radiocarbon time scale. Radiocarbon 24(2):103-150.

Kraenzel, Carl Frederick

1969 The Great Plains in Transition. Third Edition. University of OkTahoma Press, Norman.

Krause, Richard

1969 Correlation of phases in Central Plains prehistory. Plains Anthropologist 14 (44 pt. 2):82-96. Memoir 6 .

Krieger, Alex D.

1946 Culture Complexes and Chronology in Northern Texas. University of Texas Publication \#4640. Austin.

Kroeber, A. L.

1939 Cultural and Natural Areas of Native North America. Publications in American Archaeology and Ethnology Volume 28. University of California.

Kuchler, A. W.

1964 Manual to accompany the map "Potential Natural Vegetation of the Coterminous United States." American Geographical Society Special Publication \#36,

Langè, Richard

1978 The Archaeology and Culture History of the Conchos Dam and Reservoir Area, San Miguel County, New Mextco. School of American Research, Santa Fe, 
Lapin, Lawrence

1975 Statistics Meaning and Method. Harcourt, Brace and Jovanovich, Inc., New York.

Lee, Richard $B$.

1969 !Kung Bushman subsistence; an input-output analysis. In

Environmental and Cultural Behavior, edited by Andrew P. Vayda, pp 47-79. Natural History Press, New York.

Lehmer, Donald

1948 The Jornada Branch of the Mogollon. University of Arizona Social Science Bulletin No. 17. Tucson.

1954 Archaeological Investigations in the Oahe Dam Area, South Dakota, 1950-51. Bureau of American Ethnology Bulletin 158, River Basin Survey Paper $\$ 7$.

1971 Introduction to Middle Missouri Archaeology. National Park Service, Anthropological Papers 1.

Lestie, R.

1979 The Eastern Jornada Mogollon, extreme southwestern New Mexico. In Jornada-Mogolion Archaeology, edited by P. Beckett and $R$, N. Wiseman, Historic Preservation Bureau, Santa Fe.

Levine, Frances and Charles Mobley

1976 Archaeological resources at Los Esteros Lake, New Mexico. Southern Methodist University Contributions in Anthropology Number 17. Dal7as.

Lintz, Christopher R.

1972 The $19720 . U$. field school. Oklahoma Anthropological Society Newsletter 20(6):8-9.

1973 A possibie chipped stone axe from the Texas Panhandle. Oklahoma Anthropological Society Newsletter 21(7):2-7.

1974 An analysis of the Custer Focus and its relationship to the Plains Village Horizon in Oklahoma. University of Oklahoma Papers in Anthropology 15(2):1-72.

1976 The McGrath site of the Panhandle Aspect, Bulletin of the Oklahoma Anthropological Society 25:1-110.

1978 Panhandle Aspect and its re?ationship with Upper Republican. In The Central Plains Tradition: Internal Development and External Relationships, edited by Donald Blakeslee. Office of the Iowa State Archaeologist, Report 11. University of Iowa. 
1978b Architecture and radiocarbon dating of the Antelope Creek Focus, a test of Campbell's model. Plains Anthropologist 23(82):31'9329.

1978c Flake blank production strategy of the Heerwald site cache. Bulletin of the Oklahoma Anthropological Society 27:179-206.

1979a Radiocarbon and archaeomagnetic dates from the Two Sisters site, 34Tx-32, Texas County, Okiahoma. Oklahoma Anthropological Society Newsletter 27(6):1-9.

1979b The southwestern periphery of the Plains Caddoan Area. Nebraska History 60(2): 161-182.

1982 An overview of the Antelope Creek Focus. Transactions of the 17th Regional Archaeological Symposium for Southeastern New Mexico and Western Texas. pp 37-56.

1984 The Plains Villagers: Antelope Creek. In The Prehistory of Oklahoma, edited by Robert Be11, pp 325-346. Academic Press, Orlando.

Lintz, Christopher and Stephen A. Hall

1983 The geomorphology and archaeology of Carnegie Canyon. Fort Cobb Laterals Watershed, Caddo County, Oklahoma. Oklahoma Conservation Commission, Archaeological Research Report \#10.

Long, Austin and Bruce Rippeteau

1974 Testing contemporaneity and averaging radiocarbon dates. American Antiquity 39(2):205-215.

Lowrey, Ernest J.

1932 The Archaeology of the Antelope Creek Ruins. Master's Thes is, Texas Tech College, Lubbock.

Lowrey, R, L.

1959 A study of droughts in Texas. Texas Board of Water Engineers, Bulletin 5914. Austin.

Luckey, Richard R, Edwin D. Gutentag and John B. Weeks

1981 Water-level and saturated-thickness changes, predevelopment to 1980 , in the High Plains Aquifer in parts of Colorado, Kansas, Nebraska, New Mexico, Oklahoma, South Dakota, Texas, and

Wyoming. U. S. Geological Survey, Hydrologic Atlas 652.

Ludwickson, John

1975 The Loup River Phase and the Origins of Pawnee Culture.

Master's Thesis, University of Nebraska, Lincoln. 
1978 Central Plains Tradition settlements in the Loup River Basin: the Loup River Phase. In The Central Plains Iradition, Internal Development and External Relationships, edited by Donald Blakeslee. Report 11, Office of the State Archaeologist, University of Iowa.

Lutz, Eugene

1956 Report of the Philmont archaeology pronram, June-September, 1956.

Manuscript on file at Seton Memorial Library and Museum,

Philmont Scout Ranch, Cimarron, New Mexico.

1957 Report of the excavations conducted at Philmont Scout Ranch, Cimarron, New Mexico from June to September, 1957. Manuscript on file at the Seton Memorial Library and Museum, Philmont Scout Ranch, Cimarron, New Mexico.

1959 Philmont archaeology report, 1959. Manuscript on file at the Seton Memorial Library and Museum, Philmont Scout Ranch, Cimarron, New Mexico.

McCarty, John Lawton

1945 The History of Tascosa, Texas. Master's Thesis, West Texas State Teacher's College, Canyon, Texas.

McGowen, J. H., G. E. Granata, and S. J. Deni

1979 Depositional Framework of the Lower Dockum Group (Triassic), Texas Panhandle. Bureau of Economic Geology, Report of Investigations \#97. University of Texas, Austin.

McHugh, Tom

1972 The Time of the Buffalo. Alfred Knopf.

McKern, W. C.

1939 The midwest taxonomic method as an aid to archeological study. American Antiquity $4(4): 301-313$.

Mcllilliams, K. .Richard and Jerry L. Johnson

1979 Physical evidence on the origins of the Panhandle Aspect

people. Plains Anthropologist 24(85):249-253.

Mackey, James

1983 The documentation of environmental control of morphological variability in archaeological maize: a paleoenvironmental reconstruction technique. Plains Anthropologist 28(101):209-218.

Marmaduke, William S. and Hayden Whitsett

1975 Reconnaissance and archaeological studies in the Canadian River Valley. Canadian Breaks, A Natural Area Survey. Part VII of VIII. Division of NaturaT Resources and Environment, University of Texas, Austin. 
Martin, Paul S. and Fred Plog

1973 The Archaeology of Arizona. A Study of the Southwest Region. DoubTeday/Natural History Press. Garden City, New York.

Mason, J. Alden

n.d.a Sketchbook of J. Alden Mason. Texas and SW Expedition, 1929. Sketch plans, Alibates Creek Watrous, other sites. On file at the University of Pennsylvania Museum. Philadelphia.

n.d.i Unpublished field notes regarding Alibates Ruins on file at the University of Pennsylvania Museum. Philadelphia.

1929 The Texas expedition, University of Pennsyivania Museum Journal $22: 318-338$.

1935 The place of Texas in Pre-Columbian relationships between che $U, S$, and Mexico. Bulletin of the Texas Archaeological and Paleontological Society 7:29-46.

Meggars, Betty

1971 Contacts from Asia. In The Quest for America, edited by Ashe, Geoffery, et al. Praeger Publishers. New York.

Michaels, Joseph W.

1973 Dating Methods in Archaeology. Seminar Press. New York.

Minnis, Paut E.

1981 Economic and Organizational Responses to Food Stress by NonStratified Societies: An Example from Prehistoric New Mexico. Ph.D. Dissertation. University of Michigan. University Microfilms. Ann Arbor.

Mitchell, Jimny L.

1975 Notes on some archaeological materials from the Palo Duro Creek area of Hanford County, Texas. Bulletin of the Texas Archaeological Society 46:217-231.

Mobley, Charles (editor)

1978 Archaeological Research and Management at Los Esteros Reservoir, New Mexico. Southern Methodist University. Research Report \#107. Dal7as.

Moorehead, Warren $K$.

1921 Recent explorations in northwestern Texas. American Anthropologist 23(1):1-11.

1931 Archaeology of the Arkansas River Valley. Phillips Academy. Andover, Massachusettes. 
1933 The importance of Texas as an archeological field. Bulletin of the Texas Archeological and Paleontological Society 5:9-13.

Morton, JuTia F.

1963 Principal wild food plants of the United States. Economic Botany $17(4): 319-330$.

Mueller, James $h$.

1974 The use of sampling in archaeological survey. Society for American Archaeology, Memoir $\$ 28$. American Antiquity 39(2): Part 2.

Muto, Guy R., Molly S. Mayo and Charles L. Rohrbaugh

1980 The prehistoric architecture of eastern Oklahoma. In of the Earth: nelahoma's Architectural History, edited by H. L. Meredith and M. E. Meredith. pp 6-18. Oklahoma Series Volume 13. Oklahoma Historical Society, Oklahoma City.

Nelson, Ben

1980 Cultural Responses to Population Change: A Comparison of Two Prehistoric Occupations of the Mimbres Valley, New Mexico. Ph.D. Dissertation, Southern II Tinois University, Carbondale.

Newcomb, $W, W$.

1961 The Indians of Texas from Prehistoric to Modern Times. University of Texas Press. Austin.

Newcomb, W. W. and W. T. Field

1967 An ethnohistoric investigation of the Wichita Indians of the Southern Plains. In A Pilot Study of Wichita Indian Archaeology and Ethnology, assembled by Robert Bell, Edward Jelks, and W. W. Newcomb, Jr. Final Report fro Grant GS-964. National Science Foundation.

Nicholson, J. H.

1960 Geology of the Texas Panhandle. In Aspects of the Geology of Texas, A Symposium. pp 51-64. Bureau of Economic Geology publication 6017. University of Texas. Austin.

0ldfield, Frank and James Schoenwetter 1964 Late Quaternary environments and early man on the southern High Plains. American Antiquity 38:226-229.

Olson, Ronald J.

1929 Letters to Clark Wissler and untitled report covering 1929 field work (partial). Unpublished manuscript. American Museum of Natural History. New York. 
Orton, Robert B.

1974 The climate of Texas. In Climates of the States, Vol. II: Western States. by officials of the Natioanl Oceanic and Atmospheric Administration. Water Information Center, Inc. Port Washington, New York.

Parker, Wayne

1982 The Bridwell Site, Crosby County. Historical Commission, Crosby County, Texas.

Patterson, David K.

1974 An Analysis of Human Skeletal Material from Antelope Creek Focus of Northern Texas. Master's Thesis. Eastern New Mexico University. Portates.

Patterson, Deborah E.

1974 Dental Variation among Panhandle Aspect Populations. Master's Thesis. Eastern New Mexico University. Portales.

Patton, Leroy $T$.

1923 The Geology of Potter County. University of Texas Bulletin 2330. Austin.

Pearson, F. J., E. Mott Davis and Murry Tanners

1966 University of Texas radiocarbon dates IV. Radiocarbon 8:453466.

Peckham, Stewart

1976 Taylor Draw: a Mogollon-Anasazi hybrid?. In Collected Papers in Honor of Marjorie Ferguson Lambert edited by Albert Schroeder. Papers of the Archaeological Society of New Mexico \#3.

Albuquerque Archaeological Society Press.

Phillips, Wes

n.d. Plants around Lake Meredith, Texas. April 1, 1978. Notes on file at Lake Meredith Recreation Area.

Plog, Fred T.

1974 The Study of Prehistoric Change. Academic Press.

Pringle, Fred B.

1980 Soil Survey of Potter County, Texas. U. S. Department of Agricutture, Soil Conservation Service.

Ralph, E. K., H. N. Michaels and M. C. Han

1974 Radiocarbon dates and reality. Archaeology of Eastern North America 2(1):1-20. 
Redfield, Robert L.

1953 Summary of data, Canadian River project, Texas. Sanford Dam Site, geological report. Manuscript on file at the U. S. Department of Interior, Bureau of Reclamation, Austin, Texas.

Reed, Eric K.

1947 Review of "Culture Complexes in Northern Texas" by Alex D. Krieger. Texas Archaeological and Paleontological Society Bulletin 18:157-160.

Reeves, C. C., Jr.

1972 Tertiary-Quaternary stratigraphy and geomorphology of west Texas and southeastern New Mexico. In New Mexico Geological Society Guidebook: 23rd Field Conference. East-Central New Mexico, edited by v. C. Kelley and F. D. Travger, pp 108-117. New Mexico Bureau of Mines and Mineral Resources, Socorro.

1975 Pluvial lake basins of west Texas. In Playas and Dried Lakes: Occurrence and Development edited by James T. Neal. Benchmark papers in Geology 20. Dowden, Hutchinson and Ross, Inc. Stroudsburg, Pennsylvania.

1976 Quaternary stratigraphy and geologic history of southern High Plains, Texas and New Mexico. In Quaternary Stratigraphy of North America, edited by H. C. Mahoney, pp 213-233. Dowden, Hutchinson and Ross. Stroudsburg, Pennsylvania.

Reher, Charles A.

1978 Buffalo population and other deterministic factors in a model of adaptive process in the short-grass plains. In Bison Procurement and Utilization: A Symposium, edited by Davis and Wilson. pp 23-39. Plains Anthropologist 28(82 part 2): Memoir 14.

Renaud, Etienne B.

1930 Prehistoric cultures of the Cimarron Vallev, northeast New Mexico and western Oklahoma. Colorado Scientific Society Proceedings 12(5).

1942 Archaeological Series, Second Paper, Indian Stone Enclosures of Colorado and New Mexico. University of Denver Colorado.

Renfrew, Colin

1977 - Alternating models for exchange and spatial distribution. In Exchange Systems in Prehistory edited by Earle and Ericson. pp 71-80. Academic Press.

Rightmire, G. P.

1970 Bushman, Hottentot and South African negro crania reassessed by Multiple Discriminant Analysis. American Journal of Physical Anthropology 33:169-196. 
Roper, Donna C.

1976 A trend surface analysis of Central Plains radiocarbon dates. American Antiquity 41:181-189.

1979 The method and theory of site catchment analysis: a review.

In Advances in Archaeological Method and Theory, Vol. 2, edited by Michael B. Schiffer. Academic Press.

Roscoe, B. Jr., and D. L. Baars

1972 Permian systems. In Geological Atlas of the Rocky Mountain Region: Rocky Mountain Associate Geologists, pp 143-165. Hirschfield Press, Denver.

Rouse, Irving

1958 The inference of migrations from anthropological evidence. In Migrations in New Horld Culture Historv, edited by Raymond Thompson. University of Arizona, Social Science Bulletin \$27. Tucson, Arizona,

Rowel?, $C$.

n.d. A provisional checklist of the flora of the Texas Panhandle based on col lections made in the summers of 1955 and 1957. (mimeoed)-... Results surmarized in Wright and Mendor, 1979.

Ruppé, Raymond

1966 The archaeological survey: a defence. American Antiquity 31 (3):181-188.

Sanders, William T. and Barbara Price

1968 Meso America: The Evolution of a Civilization. Random house. New York.

Sapir, Edward

1916 Time Perspectives in Aboriginal American Culture: A Study in Method. Canada Department of Mines, Geological Survey Memoir 90, Anthropological Series \#13. Government Printing Eureau. Ottawa.

Saunders, Roger

1973 The Zimm's site, a late prehistoric house site in western Oklahoma. Oklahoma Anthropological Society Newsletter 21(6).

Saunders, Roger and Kenneth Saunders

1982 Distribution and density patterns of lithic materials: clues to prehistoric land use in Cimarron County, Oklahoma. In Pathways to Plains Prehistory: Anthropological Perspectives to Plains Natives and their Pasts, edited by Wyckoff and Hofman. pp 99-110. Oklahoma Anthropological Society Memoir 3. 
Sayles, E. B.

n.d. Conjectural evolution of the slab house of the Panhandle. Manuscript on file at Texas Tech University Museum, Lubbock; and Arizona State Museum, Tucson.

1932 Site form and excavation notes on site Tex:B:6:1. Unpublished notes on file at the Arizona State Museum, Tucson.

1935 An Archaeological Survey of Texas. Medallion Papers, Vol. 17. Gila Pueblo. Globe.

Schiffer, Michael $B$.

1972 Archaeological context and systematic context. American Antiquity $37(2): 156-165$.

Schneider, Frederick

1969 The Roy-Smith site (Bv-14), Beaver County, Oklahoma. Bulletin of the Oklahoma Anthropological Society 18:119-179.

Schoenwetter, James and Alfred Dittert

1968 Ecological interoretation of Anasazi settlement patterns. In Anthropolonical Archaeology of the Americas, edited by Setty Meggers. pp 41-66. Anthropological Society of Washington.

Schroeder, Albert $H$.

1966 Pattern diffusion from Mexico into the Southwest after A.D. 600. American Antiquity 31(5):683-704.

Scudday, James F. and LaFerne Scudday

1975 A preliminary survey of the vertebrate fauna of the upper Canadian breaks area. In Canadian Breaks. A Natural Area Survey, Part VII of VIII. Division of Natural Resources and Environment, University of Texas. Austin.

Seni, Steven J.

1980 Sand-body Geometry and Depositional Systems, Dgallala Formation, Texas. Bureau of Economic Geology, Report of Investigations \#105. The University of Texas at Austin. Austin.

Service, Elman R.

1962 Primitive Social Oraanization. Random House.

Shaeffer, J. B.

1958 The Al ibates flint quarry, Texas. American Antiquity 24(2): 189-191.

1965 Salvage archaeology in Oklahoma. "Papers of the Oklahoma Archaeological Salvage Project No's. 8-15." Bulletin of the Oklahoma Anthropological Society 13:79-149. 
Sikes, Samuel and Jackie Smiti

1975 A vegetation study of the Canadian River breaks, In The Canadian River Breaks. A Natural Areas Survey, Part VII of VIII. prepared by the Division of Natural Resources and Environment, University of Texas at Austin. Austin.

Simpson, Caryl Wood

1976 Trinchera Cave: A Rockshelter in Southeastern Colorado. Master's Thesis, University of Wyoming. Laramie.

Smiley, Terah L., Stanley Stubbs and Bryant Bannister.

1953 A Foundation for the Dating of Some Late Archaeological Sites in the Rio Grande Area, New Mexico: Based on Tree-Ring Methods and Pottery Analysis. University of Arizona Laboratory Butletin of Tree Ring Research.

Smith, Gailya F, and Robert L. Smith

1982 The Zollars site: A Panhandle Aspect hamlet in Hutchinson County, Texas. Unpublished manuscript on file at Killgore Research Center, West Texas State University, Canyon.

Snow, David

n.d. Rio Grande ceramics from the Ozier site. Unpublished manuscript on file at Killgore Research Center, West Texas State University, Canyon.

Soil Survey Staff

1975 Soil Taxonomy. A Basic System for Soil Classification for Making and Interpreting Soil Surveys. U. 5. Department of Agriculture, Soil Conservation Service. Agricultural Handbook No. 436.

South, Staniey

1977 Method and Theory in Historical Archaeology. Acádemic Press. New York.

Speer, Roberta

1980 Overview Assessment of the Archeological Cultural Resources of Eleven Counties of the Northwestern Texas Panhandle. Report submitted to Henningson, Durham and Richardson, Santa Barbara, California.

Spencer, Robert F. and Jesse D. Jennings

1965 The Native Americans. Harper and Row. New York.

Speth, John D.

1983 Bison Kills and Bone Counts. Decision Making by Ancient Hunters. Prehistoric Archaeology and Ecology Series, University of Chicago Press. Chicago. 
Spielman, Katherine A.

1982 Inter-Societal Food Acquisition among Egalitarian Societies: An Ecological Analys is of Plains: Pueblo Interaction in the American Southwest. Ph.D. Dissertation, University of

Michigan. University Microfilms 8304601 .

1983 Late prehistoric exchange between the southwest and the southern Plains. Plains Anthropologist 28(102):257-272.

Spooner, Brian (editor)

1972 Population Growth: Anthropological Implications. M.I.T. Press. Cambridge.

Stafford, Thomas Jr.

1981 Alluvial geology and archaeological potential of the Texas southern High Plains. American Antiquity 48(3):548-565.

Stanislawski, Michael

1969 The ethno-archaeology of Hopi pottery making. Plateau 42(1). Flagstaff, Arizona.

Stark, Barbara and Dennis L. Young

1981 Linear Nearest Neighbor Analysis. American Antiquity 46(2): 284-200.

Street, John $M$.

1969 An evaluation of the concept of carrying capacity. The Professional Geographer 21:104-107.

Stringer, Billy

1976 Soil Survey of Hutchinson County, Texas. U.S. Department of Agriculture, Soil Conservation Service in cooperation with the Texas Agricultural Experiment Station.

Stuart, David T. and Rory P. Gauthier

1981 Prehistoric New Mexico: Backoround for Survey. Historic Preservation Bureau. Santa Fe.

Stubbs, Stanley and W. S. Stallings

1953 The Excavations at Pindi Pueblo, New Mexico. Monographs of the School of American Research, Number 18. Laboratory of Anthropology, Santa Fe.

Studer, Floyd V.

n.d.a Chimney Rock Ruin, No. 51. Preliminary Report. Manuscript on file at the National Park Service office, Lake Meredith. Studer files no. 208.

n.d.b Unpublished notes on file at the National Park Service, Sanford, Texas (files no. 17, 183, 652-655.) 
1931 a Some field notes and observations concerning Texas Panhandle ruins. In Archaeology of the Arkansas River Valley, edited by $W$. K. Moorehead. Andover, Massachusettes.

1931b Archaeological survey of the north Panhandle of Texas. Bulletin of the Texas Archaeological and Paleontological Society 3:70-75.

1931c Discovering the Panhandle. Panhandle-Plains Historical Review 4:7-23.

1934a Texas Panhandle culture ruin no. 55. Bulletin of the Texas Archaeological and Paleontological Society 6:80-96.

1934b Hunting Indians in the Panhandle-Plains Museum. PanhandlePlains Historical Review 7:79-94.

1939 Report on department of archaeology and paleontology to the annual meeting of the Panhandle Plains Historical Society at Canyon, Texas, May 12, 1939. Panhandle-Plains Historical Review 12:91-95.

1942 The Texas Panhandle Alibates ruins. Unpublished manuscript on file at Nationai Park Service, Sanford Recreation Area, Fritch, Texas. (earlier version of same paper on file at PanhandlePlains Historical Society Archives, Canyon.)

1955 Archaeology of the Texas Panhandle. Panhandle-Plains Historical Review 28:87-95.

1963 Pueblo ruins in the Texas Panhandle. In Panhandle Geological Society Fieldtrip Guidebook -- September 1963.

1964 Introduction. In Alibates Flint Quarries a National Monument. A Brief Proposal for the Preservation of a Unique, Outstanding and Scientifically Important Segment of our Great American Heritage, Supplenent Volume 2. Potter County Historical Survey Committee and Panhandle Geological Society.

Suhm, Dee Ann and Edward Jelks

1962 Handbook of Texas Archaeolony: Type Descriptions. Special

Publication \#1 of the Texas Archeological Society and Bulletin \$4 of the Texas Memorial Museum, Ausin.

Suhm, Dee Ann, Alex D. Krieger and E. B. Jelks

1954 An Introductory Handbook of Texas Archaeology. Bulletin of the Texas Archaeological Society 25.

Swanton, John R.

1946 The Indians of the Southeastern United States. Bureau of American Ethnology Bulletin 137. 
Syms, E. Leigh

1977 Cultural ecology and ecological dynamics of the ceramic period in southwestern Manitoba. Plains Anthropologist Memoir 12.

Taylor, R. E. and P.J. Slota, Jr.

1979 Fraction studies on marine shell and bone samples for radiocarbon analyses. In Radiocarbon Dating: Proceedings of the 9th International Conference, edited by R. Berger and $\mathrm{H}$. E. Sues5, pp 422-432. University of California Press. Berkeley.

Taylor. Walter

1948 A Study of Archaeology. Arcturus Books (1968 edition).

Texas Archaeological Society

n.d. Big Blue Creek cemetery, field notes and excavation forms from crew members, notes on file at the Panhandle-Plains Historical Society archaeological library.

Thoburn, Joseph B.

1935 Report of an archaeological exploration of a portion of the Cimarron River Valley in Beaver County, Oklahoma and the ancient village site on Sharp's Creek in the southwestern part of the same county. A narrative report to the F.E.R.A. and W.P.A. Unpublished manuscript on file at the National Archives, Washington, D.C.

Thoms, Alston V.

1976 A review of northeast New Mexico archaeology. Awanyu 4(1):8-36.

Thwaites, Reuben Gold (editor)

1905 Part III of (Edwin) James' Account of S. H. Long's Expedition, 1819 -1820. Volume 16. Early Western Trävels, 1748-1846. Arthur H. Clark Company. Cleveland, Ohio.

Trigger, Bruce G.

1968 Beyond History: The Method of Prehistory. Holt, Reinhart and Winston. New York.

Totten, R. B.

1956 General geological and historical development: Texas and Oklahoma Panhandles. American Association of Petroleum Geologists Bulletin 40:1945-1967.

Trewartha, Glenn T.

1954 An Introduction to Climate. McGraw-Hill Book Company.

Troike, Rudolph C.

1955 Anthropological theory and Plains archaeology. Bulletin of the Texas Archaeological Society 26:113-143. 
United States Geological Survey

1955 Compilation of Records on Surface Waters of the United States through September, 1950; Part 7, Lower Mississippi River Basin. GeoTogical Survey water Sup̣ply Paper 1311. Washington, D, C.

1960 Quality of Surface Waters of the United States, 1959. Parts 7 and 8 , Lower Mississippi River Basin and Western Gulf of Mexico Basins. U.S.G.S. Water Jupply Paper $\frac{\text { Bta }}{1644}$. Washington, D.C.

Uphoff, J. C. Th.

1959 Dictionary of Economic Plants. Hafner Publishing Co., New York.

Valastro, Sam, E. Mott Davis and Alejandra Varela

1977 University of Texas at Austin radiocarbon dates XI. Radiocarbon $19(2): 280-325$.

Veloz, Nicolas F. Jr.

n.d. A chronological sequence of house types in the Antelope Creek focus of the Panhandle Aspect. Manuscript on file at the Sanford Recreation Area office of the National Park Service.

Accession No. 357.

Wallace, Benny J.

1962 Prehistoric house pattems of Oklahoma. Bulletin of the Oklahoma Anthropological Society 10:27-68.

Warren, Helene

1969 Torque: One Pueblo's glaze pottery industry dominated middle Rio Grande commerce. El Palacio 76(2):36-42.

Watson, Virginia

1950 The Optima focus of the Panhandle Aspect: Description and analysis. Bulletin of the Texas Archaeological and Paleontological Society 21:7-68.

Weaver, J. E.

1968 Prairie Plants and Their Environments: A Fifty year Study in the Midwest. University of Nebraska Press. Lincoln.

Weaver, J, E. and F. W. Albertson

1956 Grasslands of the Great Plains: Their Nature and Use. Johnson Publishing Company. Lincoln, Nebraska.

Wedel, Waldo R.

1941a Environment and Native Subsistence Economies in the Central Great Plains. Smithsonian Miscellaneous Collections Vol. 101, Number 3. 
1941b Culture sequence in the central Great Plains. Smithsonian Miscellaneous Collections 100:291-352.

1947 Cultural chronology in the central Great Plains. American Antiquity $12(3): 148-156$,

1959 An Introduction to Kansas Archaeology. Bureau of American Ethnology Bulletin 174 .

1961 Prehistoric Man on the Great Plains. University of Oklahoma Press, Morman. (1970 edition)

1964 Prehistoric Man on the Great Plains. University of Oklahoma Press, Norman. Second Printing.

1968 Some thoughts on central Plains -- southern Plains archaeological relationships. Great Plains Journal 7(2):53-62.

1975 Chalk Hollow: culture sequence and chronology in the Texas Panhandle: Actas del XLI Congreso Internacional de Americanistas, Voi 1, 1975. Mexico City, D.F., Mexico.

1981 Towards a history of Plains archaeology. Great Plains Quarterly $1(1): 16-38$.

1982 Further notes on Puebloan-central Plains contacts in light of archeology. In Pathways to Plains Prehistory: Anthropological Perspectives to Plains Natives and Their Pasts, edited by Wyckoff and Hofman, pp 153-162, OkTahoma Anthropological Society Memoir 3.

Weltfish, Gene

1977 The Lost Universe. University of Nebraska Press, Lincoln.

Wendorf, Fred

1960 The archaeology of northeastern New Mexico. El Palacio 67(2): 55-65.

1970 The Lubbock Subpluvial. In Pleistocene and Recent Environments of the Central Great Plains, edited by Wakefield Dort and J. Knox Jones, Jr. pp 23-37. Department of Geology, University of Kansas Special Publication \#3. Universtiy of Kansas Press.

Whaten, Michael E.

1979 Social organization and interaction during the pithouse period in the Jornada area. In Jornada Mogollon Archaeclogy: Proceedings of the First Jornada Conference, edited by P. Beckett and R. N. Wiseman. Pp 345. Heritage Conservation and Recreation Service, U. S. Department of the Interior, Santa Fe. 
Whallon, Robert

1974 Spatial analysis of occupation floors II: application of Nearest Neighbor Analysis. American Antiouity 39:16-34.

Willey, Gordon

1966 An Introduction to American Archaeology Volume 1: North and Middle America. Prentice Hall. Englewood, New Jersey.

Willey, Gordon R. and Phillip Phillips

1958 Method and Theory in American Archaeology. University of Chicago Press. Chicago.

Willey, Gordon R. and others

1956 An archaeological classification of culture contact situations.

In Seminars in Archaeology: 1955. American Antiquity 22(2 part

2): 1-31, Memoir 11, edited by Rober $t$ Wauchope.

Winter, Marc

1976 The archaeological household cluster in the valley of Oaxaca, In The Early MesoAmerican Village, edited by Kent Flannery. Academic Press.

Wiseman, Reggé $N$.

1975 Sitio Creston (La4939), a stone enclosure site near Las Vegas, New Mexico. Plains Anthropolonist 20(68):81-104.

Witte, Adolph, Henry

1955 A double Indian burial from Donley County, Texas. PanhandlePlains Historical Review 28:82-86.

Wright, Robert A. and Keith Mendor

1979 The vegetation of the Lake Meredith Recreation Area, Texas. Department of Biology, West Texas State University. Report on file at Lake Meredith Recreation Area.

Zeier, Charles

1982 The Willey and Phillips system revisited: a proposed expansion of the paradigm. Plains Anthropologist 27(95):29-36. 


\section{APPENDIX A}

\section{THE SITES}

The previous analysis of Antelope Creek variation has been based on observations of architecture, community patterns, burial patterns and trade good information from 28 sites excavated by various archaeologists using different strategies and techniques. This appendix sumarizes the location and setting of each site and discusses the nature, methods, extent and significance of the excavations. Since similar excavation strategies and techniques were employed by members of an institution during the same general period, the sites can be grouped by major sponsoring institution and field supervisor. In instances where a site has been investigated by more than one party, the sitc is grouped with the institution conducting the most extensive fieldwork. However, the nature of other work is summarized and used as a cross check whenever possible.

Table 54 lists the sites constituting the sample by the eight institutional groups. Since different expeditions often referred to a single site by a number of designations, the corresponding site numbers used by the Panhandle-Plains Historical Museum (PPHM), Canyon, Texas; the National Park Service (NPS), Fritch, Texas; and the Texas Archaeological Research Laboratory (TARL), Austin, Texas; and designations used by other groups are provided with the 7.5 minute U.S.G.S. Topographic map reference as an aid to others wishing to examine the original documents and locations for each site. (Table 54.) 
Table 54. Correlation of Site Designations and hap References.

GROUP ARO SITE RAME PPHAM ${ }^{1}$ MPS $^{2}$ TAR: ${ }^{3}$ OTHER USGS QUAD $7.5^{\circ}$

MCMURRY COLLEG/TEXAS TECH SITES (1929-33) H.C. Holden and E.J. Lowrey. Field sudervisors

$\begin{array}{llllll}\text { Torbox Ruin } & \text { AS87 } & \ldots . . & \text { AlHC2 } & \ldots . . . & \text { Stinnett } \\ \text { lookous Ruin } & \text { a776 } & \ldots . . . & \ldots . . . & \ldots . . . & \text { Sanfort }\end{array}$

PANHANOLE-PLALHS HISTORICAL SOCIETY SITES (i730-35) Floyd $\checkmark$. Studer. field supervisor

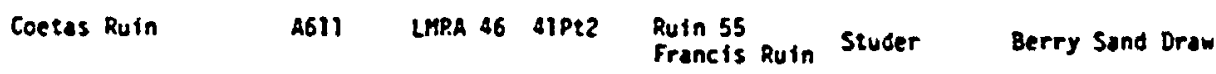

WOPKS PROGRESS ACMIIIISTRATIOn SITES (1938-1981) Ele and Jewel Baker. fleld supervisors

\begin{tabular}{|c|c|c|c|c|c|c|c|}
\hline Alibates & 28 & 245 & LMRA 54 & 41PtII & $\begin{array}{l}\text { Ruin } 28 \\
\text { Tex } 8: 9: 1 \\
\text { Site } \\
\text { a:i-Bivins }\end{array}$ & $\begin{array}{l}\text { Studer } \\
\text { Sayles } \\
\text { oison } \\
\text { Mason }\end{array}$ & Allibates Ranch \\
\hline Alibates & $28 A$ & 265 & LMRA 55 & $\cdots$ & -...- & & Alibates Ranch \\
\hline Alibates & 30 & AA5 & $\ldots$ & 41 PE31 & $\begin{array}{l}\text { Ruin 30 } \\
\text { Tex } 8: 9: 2\end{array}$ & $\begin{array}{l}\text { Studer } \\
\text { Sayles }\end{array}$ & Altibates Ranch \\
\hline Antelope & Creek 22 & A18 & LMP.A 120 & 41 HЕ23 & $\begin{array}{l}\text { Ruin 22/11 } \\
\text { A-C Ruin } \\
\text { Tex } B: 6: 1\end{array}$ & $\begin{array}{l}\text { Studer } \\
\text { Holden } \\
\text { Sayles }\end{array}$ & Sanford \\
\hline Antelope & Creek $22 \mathrm{~A}$ & A18 & $\ldots$ & $\ldots$ & $\ldots$ & & Sanford \\
\hline Antelode & Creek 23 & 2820 & $\ldots$ & 4) Ke25 & Ruin 23/13 & Studer & Sanford \\
\hline $\begin{array}{l}\text { Antelope } \\
\text { Chimeney }\end{array}$ & $\begin{array}{l}\text { Creek } 24 \\
\text { Rock Ruin SI }\end{array}$ & $\begin{array}{l}\text { A19 } \\
\text { A393 }\end{array}$ & $\ldots$ & $\ldots$ & $\begin{array}{l}\text { Ruin } 24 / 12 \\
\text { Ruin } 51\end{array}$ & $\begin{array}{l}\text { Studer } \\
\text { studer }\end{array}$ & Sanford \\
\hline Chimeney & Rock Ruin 51 . & A....... & ..... & $\ldots$ & $\ldots$ & & Bese: \\
\hline
\end{tabular}

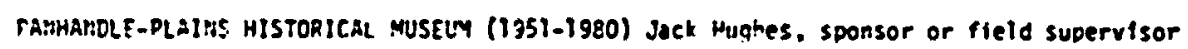

\begin{tabular}{|c|c|c|c|c|c|c|}
\hline Pickete Ruin & Al16 & LMRA is & $\ldots$ & MORPAII 2 & Carter & Sanford \\
\hline Rocer & $A 62$ & LMRA 71 & 41 He6 & MORPAII 1 & Carter & Sanford \\
\hline Sunford Ruin & A61 & LMRA 73 & $41 \mathrm{HC} 3$ & $\ldots$ & & Senford \\
\hline Cottoilnood Creek & A119/120 & --..- & $\ldots$ & $\cdots$ & & Stinnets \\
\hline Marsh site & A656 & $\ldots$ & $\ldots$ & Tecovas Ck & Ruin Huahes & Boden \\
\hline Jack Allen & A654 & $\cdots$ & $\cdots$ & $\cdots$ & & Skellytown \\
\hline Zollars & 22043 & $\ldots .$. & $\ldots$ & ...... & & Plemons \\
\hline
\end{tabular}

UHTERSITY of TEMaS, aUSTIM SITES (1961-62) Laihel Duffield. field supervisor

$\begin{array}{llllll}\text { Spring Canyon } & \text { A41 } & \text { LHRA } 6 & 41 \mathrm{HC20} & \ldots . . & \text { Sanford } \\ \text { Medford Ranch } & \text { Al17 } & \text { LMRA } 7 & 41 \mathrm{HClO} & \ldots \ldots & \text { Sanfer: } \\ \text { Conner Site } & \text { A528 } & \text { LHRA } 96 & 41 \mathrm{HC7} & \ldots . . & \text { Sanford }\end{array}$

TEXAS TECH UMIVERSITY SITES (1965-67) Earl Green, fleld supervisor

\begin{tabular}{|c|c|c|c|c|c|}
\hline $\begin{array}{l}\text { Arrowhead Peak } \\
\text { (Unnamed) }\end{array}$ & $\begin{array}{l}\text { A647 } \\
\ldots \ldots .\end{array}$ & $\begin{array}{l}\text { LMRA } 17 \\
\ldots \ldots\end{array}$ & $\begin{array}{l}\text { 41Hel9 } \\
\text { 41MOT }\end{array}$ & $\cdots$ & $\begin{array}{l}\text { Sanford } \\
\text { Evans Canyon }\end{array}$ \\
\hline $\begin{array}{l}\text { Furkey Creet Ruin } \\
\text { Footorint }\end{array}$ & a.... & LMRA 61 & $\begin{array}{l}\text { 41P28 } \\
41 p 225\end{array}$ & & A) tbates Ranch \\
\hline
\end{tabular}

TEXAS ARCHAEOLCGICAL SOCIETY SITES (1969), CCCll Calhoun. field supervisor

B1g Blue Burial site a679 LMRA 242 ..... ..... Evans Canyon

TEXAS HICHAAY DEPARTMENT SITE (1973) John Keller. fleld supervisor

Black Dog Village ab34/38A ...... \$lHe30 ...... Borger

1. Panhandle-Platins Histortcal Museum tlles

2. Mutional Park Service (LMRA-- Lake Meredith Retreotion iren: SARE-- Sunford Reservoir)

3. Texas Archaeological Research Laboratory 
The following site descriptions are presented in rough chronological order arranged according to the institution sponsoring the fieldwork. The goals and basic field methods used by members of an institution within a given period introduce the nature of the fieldwork. Subsequent discussions of the site settings and the nature and significance of the excavations at each site are provided.

\section{The McMurry College/Texas Technical}

$$
\text { College Sites (1929-1933) }
$$

Between 1929 and 1933, Dr. William C. Holden conducted or sponsored extensive testing at five sites in the Texas panhandle and one in New Mexico. He was attempting to determine systematically the relationship between the Plains and Southwestern cultures. The sites in Texas include Tarbox Ruin, the A-C Ruin (Antelope Creek Ruin 22), Lookout Pueblo, Saddleback Mesa, and Tierra Blanca Ruin. The Tarbox site was examined while Dr. Holden taught at McMurray College in 1929; the others were excavated while he was affiliated with Texas Technical College.

Original fieldnotes are not available; however, Holden and his students published their results in considerable detail ( $w$. C. Holden, 1929, 1930, 1931, 1932a, 1932b, 1933; Lowrey 1932; Haynes 1932; T. Holden, 1934). These reports indicate that the excavations were intended to be limited in scope. With the exception of Saddleback Mesa, most projects examined only a small portion of the site area. Excavations were largely confined to the interiors of stone lined structures and cists. Holden's fieldwork was conducted without the benefit of knowing what architectural details to expect. Consequently, his excavation techniques were largely exploratory and varied from one season to the next. Holden's early work involved complete 
excavation of small cists, the sampling of rooms by quadrants, and trenching along walls to define room shape, size, and orientation. Later strategies at larger contiguous room sites involved an initial trench across the longitudinal axis of a structure to define room boundaries, followed by completely clearing the structure's interior. At Saddleback Ruin, Holden used seven converging trenches, each subdivided into five foot sections, to maintain some horizontal control while defining room locations. Once the rooms were located, the intervening spaces between the trenches were removed. When faced with Jarge, isolated circular structures at the Tierra Blanca site, Holden dug each structure using pie-shaped wedges for hoxizontal control. Vertical control was occasionally maintained using six inch "layers." Most of the fill was loosened with spades and small hand tools and screened. Judging from the small quantities of materials recovered, only near-complete and recognizable tools were saved.

Only three of the five sites examined by Holden and his students are within the study area. Tierra Blanca and Saddleback Ruin are outside the defined area. His work at the A-C Site will be discussed in conjunction with the WPA fieldwork at Antelope Creek Ruin 22. Only the Tarbox Site and Lookout Ruin were exclusively under Holden's jurisdiction. Excavations at both sites were fairly limited. However, available maps and room dimensions based primarily on surface indications contribute to the overall range of Antelope Creek phase community patterning.

The Tarbox Site

The Tarbox Creek area was initially surveyed by Warren Moorehead $(1921: 3)$. He found the stone slab buildings and graves to be so abundant 
that they almost extended to the ruins along Cottonwood Creek, $2.7 \mathrm{~km}$ to the east. Limited excavations were conducted in the area. But it was Moorehead's observations on the abundance of ruins that prompted Holden to visit the area.

Holden's investigations along Tarbox Creek were confined to mapping and testing a series of stone slab features at one site (Holden 1929). Additional limited testing was conducted at the same location by Jack Hughes on July 30, 1964 .

The site is atop a prominent $15 \mathrm{~m}$ high mesa at the confluence of Tarbox Creek and an unnamed tributary located some $3.6 \mathrm{~km}$ north of the Canadian River. Local exposures of dolomite provided an abundant supply of building materials, and potable water was presumably available at the base of the mesa.

Tarbox site was Holden's first excavation experience in the Texas panhandle. He located and mapped five spatially distinct structures within a relatively level mesa top encompassing approximately one-third acre $(0.13 \mathrm{ha})$. Structure A was a large isolated rectangular building, Structures C and E were isolated circular buildings; D was a pair of contiguous circular structures; and B was a fairly large contiguous multiunit building (Figure 30). The latter structure consisted of three household units with a series of smaller circular, rectangular and D-shaped rooms located along the east, north and west sides. Two exterior slab-lined cists were found immediately east of Structure B.

Only limited excavations involving perhaps $56.5 \mathrm{~m}^{2}$ were conducted at Tarbox Ruin. The interior of Structure A was cleared. At Structure B, nearly all of the interior of the Southern dominant room, a portion along 


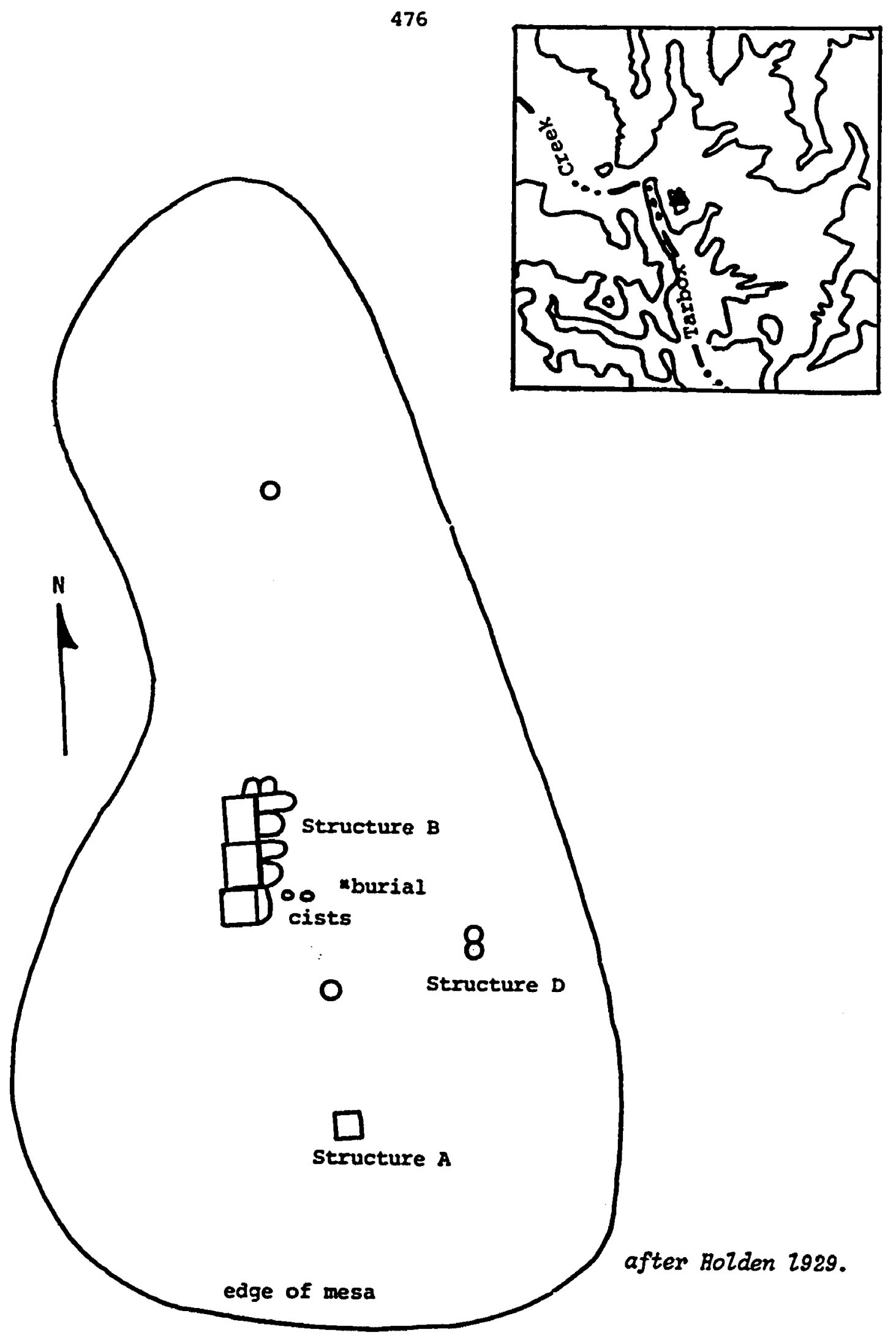

Figure 30. Plan of Tarbox Ruin 
the west wall of the middle dominant unit, the northwest corner of the northern main room, and a trench along the wall separating the middle and northern main units were excavated (Figure 31). A burial was recovered from a slab lined cist along the west wall of the middle room inside Structure B. At Structure $D$, the northern half of the north contiguous circular room was excavated. Finally, limited testing of exterior areas east of Structure B located a second rock covered burial. Hughes' excavations were confined to around the eastern edge of the north room at Structure $D$.

Apparently most of the small room configurations at structure B were based on surficial alignments of rocks. In regard to the reliability of Holden's map, Hughes (fieldnotes $7 / 30 / 64$ ) comments that:

The plan of the rooms seems to have been quite accurate; however, the Big Main series of rooms (Structure B) illustrated by Holden probably have eastward extended tunnels flanked by semi-circular storage rooms. - . . Some digging around his Room 2 makes it pretty clear that it actually consists of two semi-circular storage rooms on the north and south sides of an eastward entry tunnel of Room 1. Hughes also notes the possible presence of an additional structure at the base of the north mesa siope and a couple of extra round ones near the south end of the sumit.

The configuration of rooms and structures at Tarbox Ruins displays a range of architectural types. Unfortunately, the limited excavations in the few rooms failed to record most interior feature details. The recognition of two occupation zones beneath the burial cist along the west wall of the middle main room of Structure B indicates multiple construction episodes (Holden 1929:29). The upper zone consisted of a $5 \mathrm{~cm}$ layer of charcoal dust and soot at a depth of $60 \mathrm{~cm}$ whereas the lower zone was a 15 $\mathrm{cm}$ layer of decomposed ashes and charcoal which extended beyond the west wall of the room. This suggests that the lower occupation zone predates 


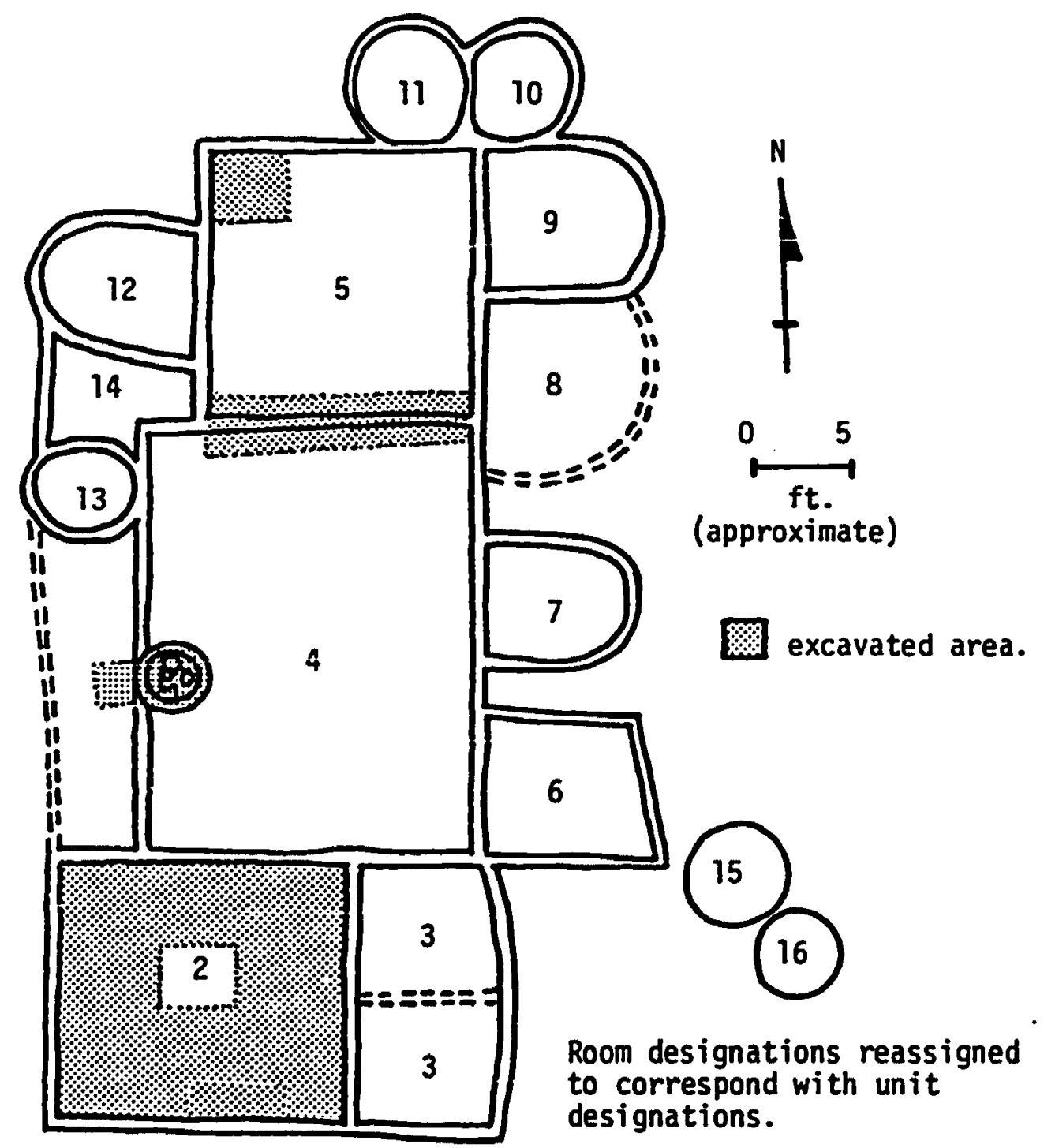

After Holden 2929, Figure 2 and $J$. Bughes fieldnotes.

Figure 31. Structure B at Tarbox Ruin. 
the construction of the room; the upper zone may correspond to the room's floor level, and the burial cist postdates the use of the room. The sequence of room and building construction at the site, as well as the contemporaneity of structure associations, are uncertain. However, the orientation of the rooms within structure B suggests that at some time the three main household units were used contemporaneously. No mention is made of trade items at the site.

Lookout Ruin

Lookout Ruin is located atop a $22 \mathrm{~m}$ tall mesa in the midale of the Antelope Creek floodplain, some $8.6 \mathrm{~km}$ south of its confluence with the Canadian River and $1 \mathrm{~km}$ south of Antelope Creek Ruin 22. The site was briefly tested during May, 1931, by one of Holden's students in conjunction with the work conducted at Ruin 22 (Lowrey 1932:35-38).

Four structural features were located. These include a large threeroom household unit, two isolated circular structures located $7 \mathrm{~m}$ to the wurineast and $11 \mathrm{~m}$ to the southeast, and a small rectangular structure located approximately $37 \mathrm{~m}$ to the south (Figure 32). Although size discrepancies exist between the map and the report, the residential structure consisted of an exceptionally large room (ca. $66 \mathrm{sq} \mathrm{m}$ ), with two smaller D-shaped rooms located to the north and northeast. Gaps in the middle of the double-slab south and west walls suggests the presence of entrances; however, no excavations were conducted to confirm these interpretations. A single 10 by $6 \mathrm{ft}$ (ca. $5.6 \mathrm{sq} \mathrm{m}$ ) test unit was excavated near the western end of the south wall in the main room. No interior features were recognized; however, three floor levels were encountered. While these levels might reflect multiple construction episodes at a single locality, 
480
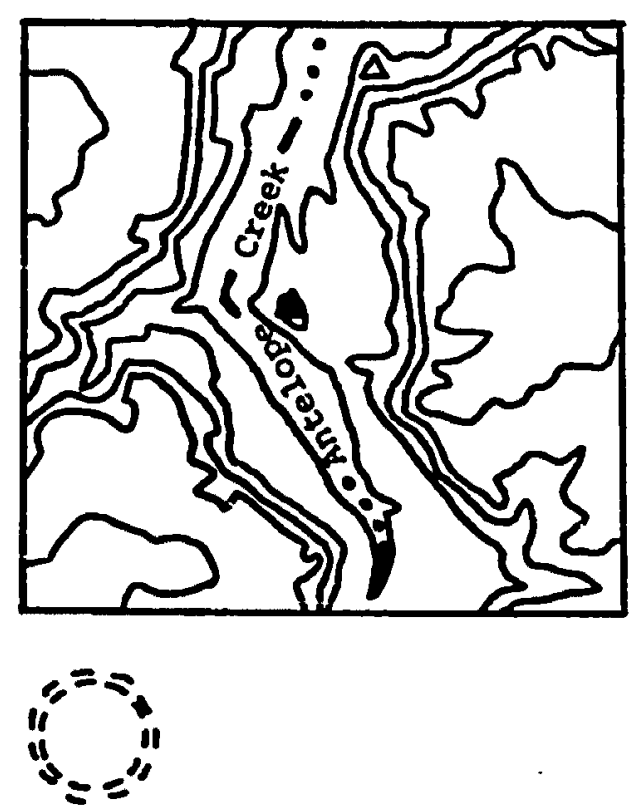

Northeast Cist

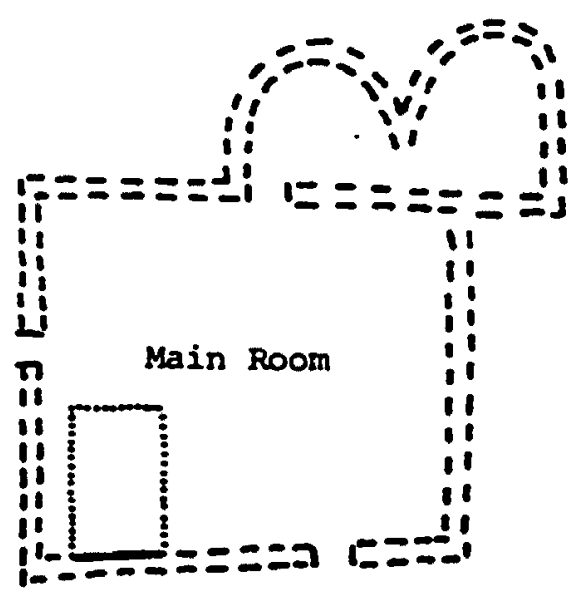

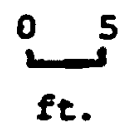

ב-3 Area Tested

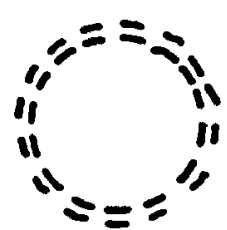

Southeast cist

after Lowrey 2932

Figure 32. Plan of Lookout Ruin. 
the distance between the floor levels $(25$ and $30 \mathrm{~cm}$ ) is comparable to the distance between a platform, the floor level, and the central channel level. Since Lowrey mistook the depressed channel features at Ruin 22 for multiple floor layers, the multiple floor surfaces at Lookout Ruin may merely reflect architectural features of a single component. Additional excavations will be required to clarify these interpretations.

Although little mention was made of the artifact inventory, all items seem to reflect indigenous materials.

\section{The Panhandle-Plains Historical Society}

The early archaeological work sponsored by the Panhandle-Plains Historical society was conducted under the direction of Floyd v. Studer. As an owner and broker of a local insurance agency, studer's devotion to archaeology was largely relegated to weekends. Although he was concerned with locating and recording prehistoric sites throughout the panhandle, he also maintained casual excavations at several large village sites and often directed visiting archaeologists to these choice localities. Three such large sites include Antelope Creek 22, Alibates 28, and Coetas Creek Ruin 55. Studer's weekend crews largely consisted of friends and colleagues who voluntarily shared in the thrills of discovery and reaped most of the findings. From the extent of excavations and the paucity of available records, it is apparent that people were assigned individual excavation tasks and were responsible for keeping their own records. Most of Studer's personal records merely consist of dates, crew rosters, and occasionally assigned work areas; seldom were the sites or features mapped, andy of the units profiled, or a listing of the artifacts obtained from an area 
noted. Excavation units either coincided with architectural features or consisted of trenches randomly oriented on topographic rises. Screens were occasionally used to aid in artifact recovery, but usually only recognizable artifacts were saved. Since Antelope Creek Ruin 22 and Alibates Ruin 28 were extensively tested by WPA crews, only the results of Studer's work at Coetas Creek Ruin will be considered.

Coetas Creek Ruin, No. 55

Ruin 55 is located on a secluded bench along the west inner valley wall of Coetas Creek, some $2.9 \mathrm{~km}$ south of its confluence with the Canadian River. This fairly extensive village site was hidden by the rough broken terrain of the inner valley wall. The site is approximately $24 \mathrm{~m}$ above Coetas Creek floodplain, and some $15 \mathrm{~m}$ below the rim of the inner valley. Except for one eroded gully, the site was in pristine condition when discovered.

Studer, assisted by at least eleven friends, conducted weekend excavations at Coetas Ruin between October 1932 and July 1934 . Unfortunately, litt:le information is available regarding these extensive excavations. Although Studer (1934) mentions that eight rooms were completely excavated, unpublished maps indicate that at least fifteen of the estimated twentythree rooms were dug. The total excavation area is estimated to be nearly $225 \mathrm{~m}^{2}$. The site consists of one main room block involving eleven large rectanguler household units, and at least six other isolated rectangular and seven isolated circular structures (Figure 33). Published descriptions are available from only three rooms (A, B, H) from the site and two burials from across Coetas Creek (Studer 1934). Quite likely, 
Studer personally excavated these features. The reported dimensions of Rooms $A$ and $B$ (redesignated 1 and 2 respectively) vary somewhat from detailed unpublished room maps on file at the NPS offices (Studer's files \#652-655).

The initial excavations involved a three foot wide stratigraphic trench across a trash mound, possibly at the north end of the site. Subsequent work concentrated on the interior portions of rooms. Rooms 1 and 2 are contiguous rectangular structures with central channels and extended passages towards the east with threshold collars (Figure 34). I interpret the attenuated size of the floor channel in Room 1 as an indication of an interior platform against the west wall. The channel in Room 2 is bulbous-that is, it is widest in the center and contracts at the ends. Room 2 also contained a bin and pit in the northeast corner, and a slab lined pit in the southeast corner. A central hearth was only located in Room 1 . Room 3 (H) is an isolated semisubterranian circular structure which apparently lacked interior features. The two burials were children found 1 to $1.5 \mathrm{~m}$ apart interred beneath stone slabs. The younger child had a necklace of 56 olivella shell beads, one bone bead, and two mussel shell pendants; the slder child lacked mortuary offerings.

The available records provide no information on construction episodes or developmental sequences at the villages. The configuration of the main room block as determined from surficial evidence differs considerably from that of other large contiguous room structures by having the main household units on the east edge of the room block. Since the site map was not drawn to scale and descrepancies exist between the field records and the published descriptions, the overall site configuration may be e:aggerated. The significance of the site is dependent solely on the architectural details of 

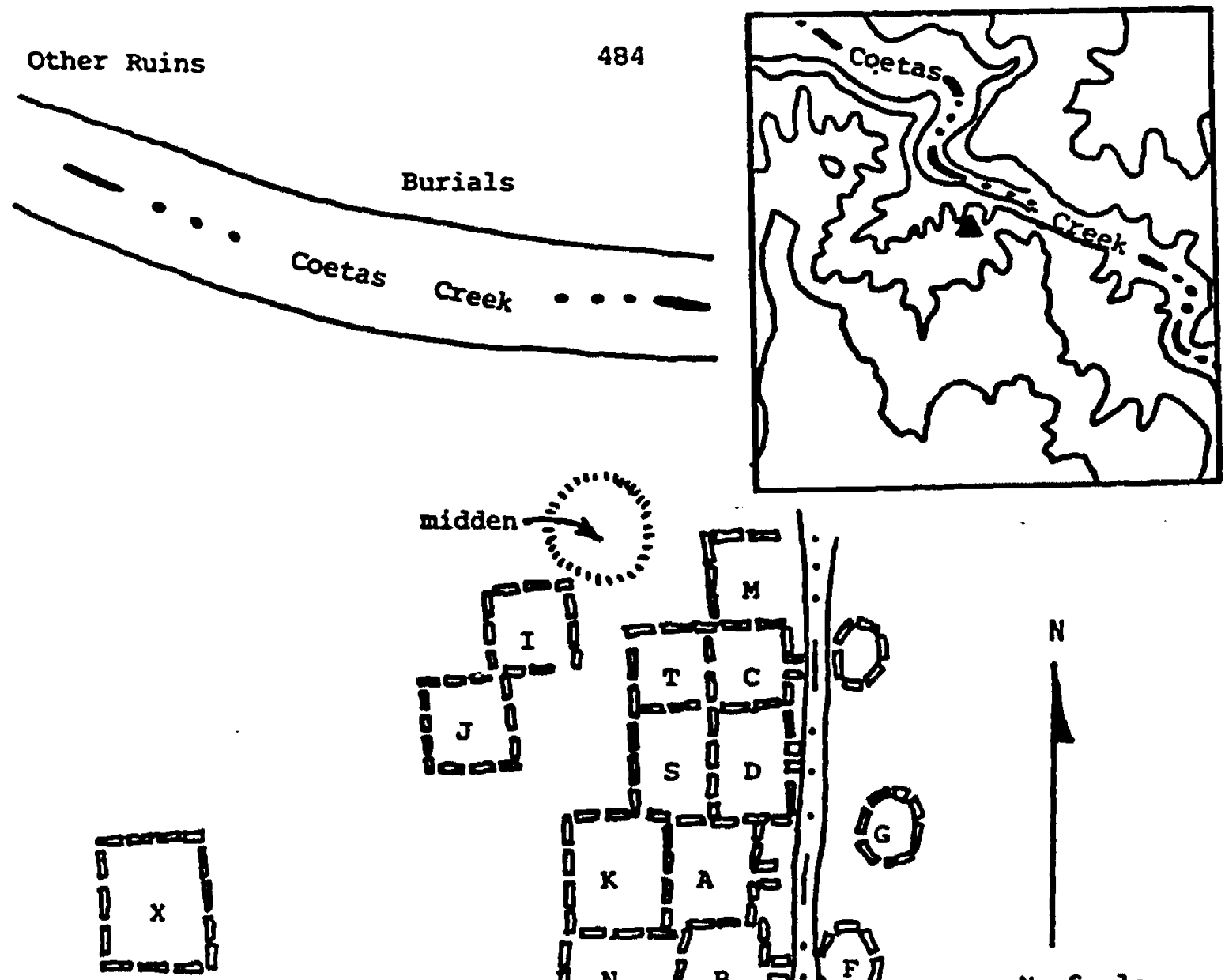

$\sum_{-\infty=1}^{\infty} \omega$
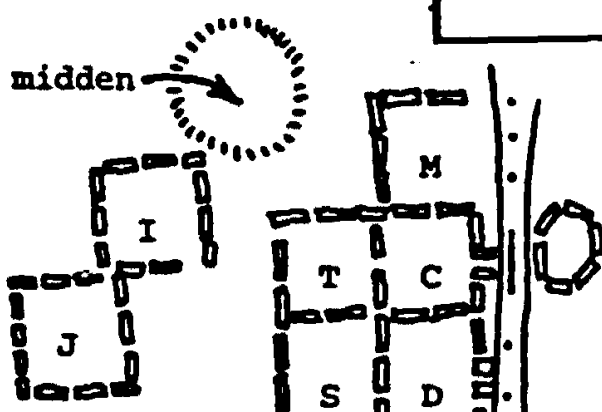


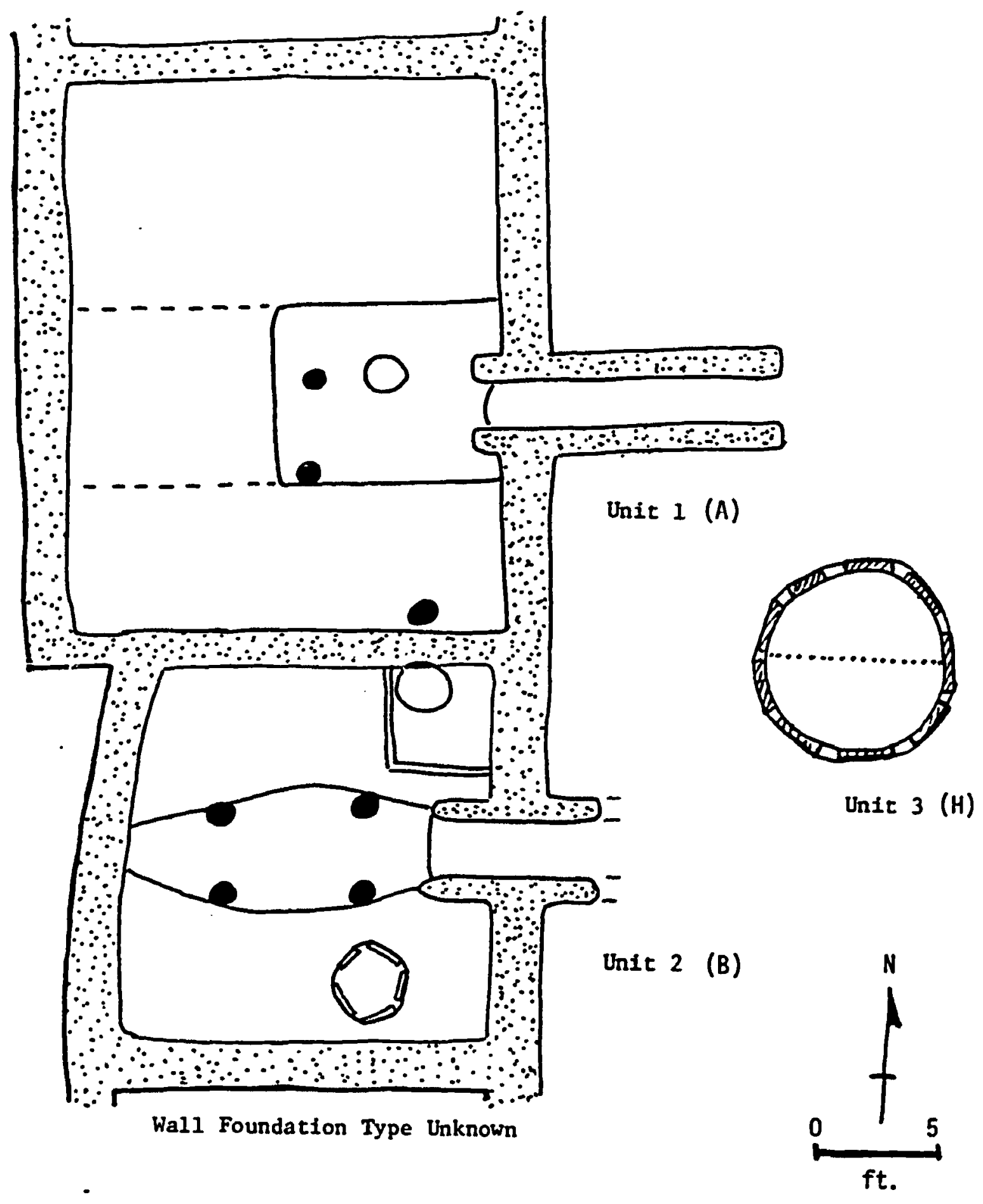

Studer fiezdrotes NPS files 652-655.

Figure 34. Details of Architectural Remains at Coetas Ruin. 
three rooms and the burial information.

Details of the extensive material assemblage indicates that nonindigenous artifacts are represented only by olivella shell beads found as grave goods, turquoise pendants, and perhaps an incised tubular clay pipe (Studer 1934). No trade ware ceramics were reportedly recovered. Six radiocarbon dates were collected from the site by Jack Hughes some thirty years after Studer's field work (Hughes field notes $5 / 2 / 65$ ). None were from the rooms excavated by Studer. Two samples were probably from the fill or a room east of and near the middle of Studer's dug series. They yielded a MASCA calibrated date of A.D. $1410 \pm 80$ (WIS-94A) and A.D. $1390 \pm 95$ (WIS-94B) (Bender, Bryson and Baerreis 1966:529). One sample from the midden beneath a boulder north of the ruins provided a MASCA calibrated date of A.D. $1260 \pm 70$ (ibid.); the remaining three dates, A.D. 1190 \pm 85 (WIS-95), $1390 \pm 80$ (WIS-89) and $1430 \pm 90$ (Tx-258), were from roof fall materials obtained from a previously unexcavated room located near the north end of the room block (ibid., Pearson Davis, Tamer 1966). Quite clearly the 1190 date is incongruous with the other two dates for the same feature. Four of the six dates overlap between A.D. 1340 and 1460 and provide a reasonable estimate for the age of this ruin. However, one of the . early dates from the midden may indicate an earliex component at this large and complex site.

\section{The Works Progress Administration Sites}

\section{(1938-1941)}

Between 1938 and 1941 six archaeological research grants were awarded to West Texas State college to conduct archaeological and paleontological fieldwork, build storage facilities at the Panhandle-Plains Historical 
Museum, and to prepare exhibits. Only three grants supported $\leqslant i=1]$ excs:itions at nine Antelope Creek phase sites. Floyd Studer served as director of the projects; however, nearly all the planning, daily supervision and reporting of the WPA projects was conducted by Ele and Jewel Baker.

The sources of information about the three archaeological field projects are quite varied. Work Project 9249 was conducted between February 16, 1938 and January 10, 1939 at Studer's favorite localities along Antelope Creek (Ruins 22, 22A, 23 and 24), and near the Alibates Quarry (Ruin 28, Rooms 1 through 13). Through some misunderstanding, the required quarterly reports were never prepared. However, the Bakers submitted biweekly letter reports to Studer, and compiled an extensive final report in fulfillment of the grant (Baker and Baker 1941a). The second grant (Work Project 13202) financed further extensive excavations at Alibates Ruin 28 along with supplemental excavations at Alibates Ruins $28 \mathrm{~A}$ and 30 between April 25, 1939 and February 15, 1941. Seven quarterly reports were faithfully submitted, and a final report was also prepared (Baker 1940a, b; Baker and Baker 1939 $a-c, 1940 a, b, 1941 b)$. In addition, studer (1942) compiled an excellent lengthy manuscript concerning all WPA work at the Alibates Ruins and hired a ghost writer to prepare a comparable report on the Antelope Creek sites (Anonymous n.d.a.). The latter report contains some erroneous and possibly some fabricated provenience information. The final grant (Work Project 17589) funded field work at Chimney Rock Ruins 51 and $51 \mathrm{~A}$ along Corral Creek between February 16 and July 5, 1941. The field work was abruptly terminated with the close of the WPA program and only two quarterly reports were prepared (Baker and Baker 1941c, d). Neither contained the artifact quantification or distribution information that was usually presented in the 
other final reports. Studer (n.d.a.) prepared a short sumary of the Chimney Rock Ruin field work, but never published it.

Despite the continuity in field supervisors, the excavation procedures varied depending upon the anticipated extent of involvement at the site, and the length of time left within the field period. At Alibates 28 and Chimney Rock Ruin 51, one of the first jobs was to construct a field laboratory/tool shed modeled after the Antelope Creek Prehistoric structures.

Excavations were initiated by a narrow trench to define stratigraphy and artifact density, but more importantly to keep the excavation area dry by either directing slope runoff or creating drainage ditches. The standard excavation procedure for maintaining horizontal control involved the division of the site into areas, usually of arbitrary size and shape, which were further subdivided into $10 \mathrm{ft}$ by $10 \mathrm{ft}$ sections. The excavation area concept was modified throughout the duration of the WPA program. At Antelope Creek Ruin $22 \mathrm{~A}$ and 24 , an Area referred to general localities relative to the major room blocks; no standardized sections were used to subdivide the areas. At Alibates 28 and $28 \mathrm{~A}$, the areas corresponded to topographic mounds at the site, each of which was excavated by using the $10 \mathrm{ft}$ section sub-units. At Chimney Rock Fuin 51, the areas became a standardized unit measuring $50 \mathrm{ft}$ by $50 \mathrm{ft}$ and encompassing 25 sections. At Antelope Creek 22, the entire site was excavated using $10 \times 10 \mathrm{ft}$ sections designated numerically north to south and alphabetically east to west. Finally, at Antelope Creek 23, Alibates 30, the last four structures at Alibates 28, and Chimney Rock Ruin 51A, the excavations were confined only to room interiors. At all sites excavations were continued to culturally 
sterile soil without the benefit of vertical control, unless a feature was recognized. In such instances, the artifacts from the fill above the floor level were separated from those below the floor level.

Feature numbers were assigned to burials, stone slab cists and rooms. In some instances, packed floors to rooms lacking stone slabs were conferred a feature status. Several pages of systematically collected records and scale drawings were prepared for most features. However, innumerable "pits" lacking stone walls were not treated as features. No notes were taken, nor were the artifacts within these "pits" segregated from the overlying matrix. Maps for Alibates 28, Unit I show 124 of these pit features within a $13,000 \mathrm{ft}^{2}\left(1210 \mathrm{~m}^{2}\right)$ area. Similar pit densities are suspected to occur at other large sites.

The excavations were conducted using small hand tools and shovels. Loose fill was removed by wheelbarrow to the downslope edges of the excavation areas where it was sifted through $1 / 4$ inch mesh screen. All tools and identifiable bones were saved, but other bone scrap, flake debitage and indigenous sherds were often discarded. Few stratigraphic profiles or general site maps showing the spatial relationship between rooms were drafted. Upon completion of the project, the excavated features were left open.

The recovered artifacts were washed, catalogued and restored. Each has a "card" listing the artifact's provenience and dimensions. The two final reports quantify the kinds of select artifacts recovered from each room and section of the sites; however, there are some inconsistencies in reporting practices during the course of the project.

Despite these shortcomings, the WPA excavations were extensive. At eight sites, they cleared 121 rooms, 10 "cists," located 32 burinls and 
excavated to sterile soil nearly 7,250 square meters of extensive midden areas.

Antelope Creek 22

This large continuous room ruin is located on a relatively high, prominent bench on the west side of Antelope Creek, some $7 \mathrm{~km}$ south of its confluence with the Canadian River. At this spot the protruding bench offers excellent visibility of the valley for several kilometers. The site is some $27 \mathrm{~m}$ above the valley floor but some $45 \mathrm{~m}$ below the relatively level outer valley floor.

The major portion of the site consists of a contiguous series of rooms measuring some $50 \mathrm{~m}$ (North to South) by $15.8 \mathrm{~m}$ (East to West). The site has been variously designated by Studer as the A-C Site, Antelope Creek Ruin 10, and Antelope Creek Ruin 22. It was one of Studer's favorite sites, and he encouraged numerous groups to excavate parts of it (Figure 35). Krieger (1946) regarded it as one of the two type localities for his Antelope Creek focus.

Duzing 1920, Moorehead (1931:106) visited and placed a "few pits" into the ruins. However, the location and extent of the work is uncertain. By 1930 the north central part of the ruin was further damaged by a wagon road "blasted" into the bench by pipeline workers (Holden 1930:22). The first extensive excavations were conducted by William Holden (1930). His work focused on a six ft wide trench oriented north-south along the interior west wall of the room block. Two other trenches traversed the south wall of Room 6 and the north wall of Room 3 . Four cists east of the contiguous room block were also excavated. Holden's fieldwork provides details on platforms and interior bin walls adjacent to platforms 


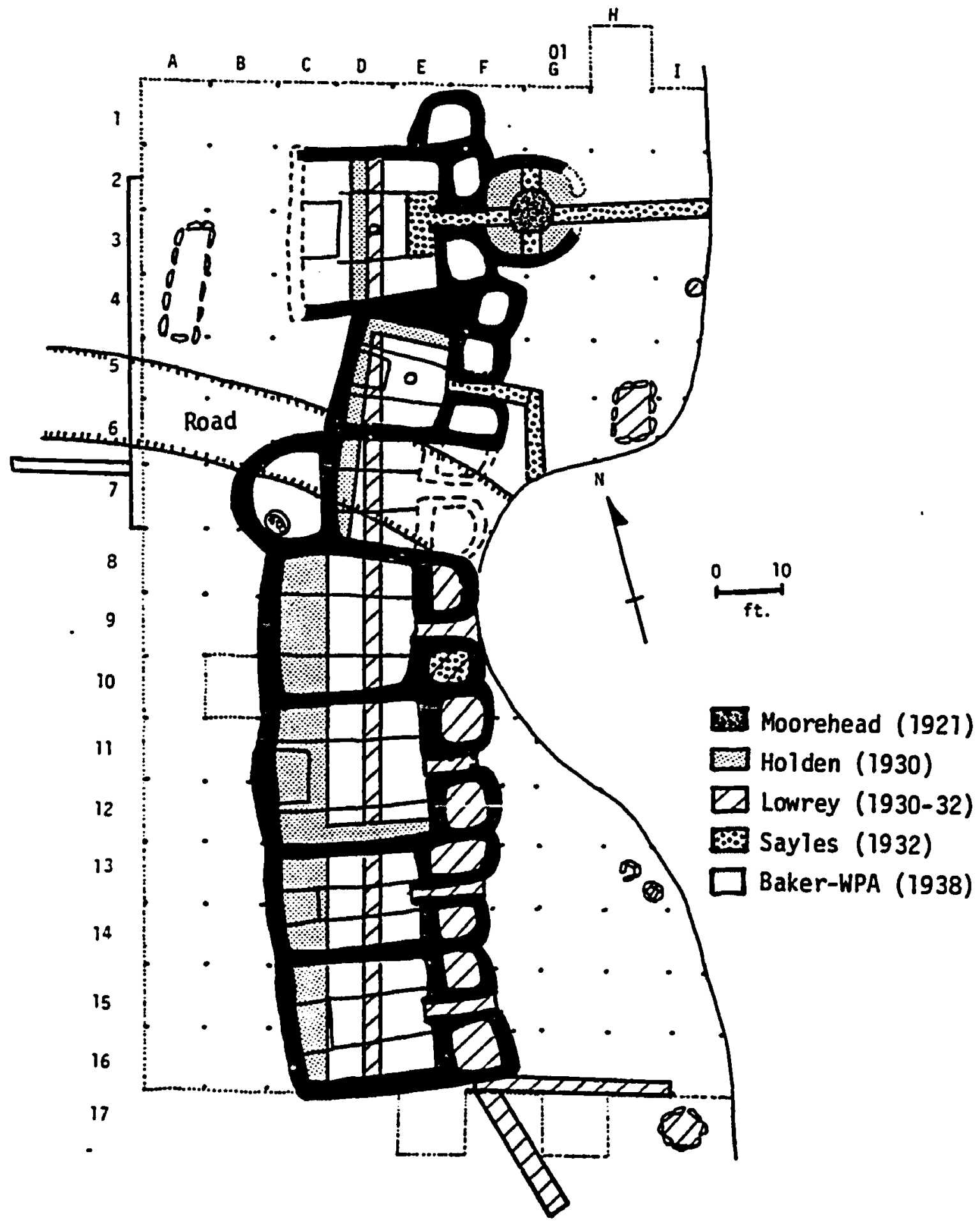

Figure 35. Location of Excavation Areas at Antelope Creek Ruin 22. 
in Rooms 7 and 8 , and indicated the use of paired vertical stone slabs with inset vertical slabs on upper tiers as a means of wall construction. Midden deposits under the house floor indicated that the south rooms were built after the north rooms. A map of the site based primarily on surface evidence shows the presence of a large storage room (No. 28) at the east end of the passage to Room 7 (Figure 36).

Four other Texas Tech expeditions to the site were conducted between November 1930 and July 1932 under the direction of E. J. Lowrey (1932). A sernnd north-south trench through the center of the western rooms was excavated, the entire interiors of east Rooms $1,20,21,22,23,24,25,26$, and the vestibule entrances of Rooms 2, 6, 7, and 8 were cleared. Two trenches to the east and southeast tested the outside midden and searched for other storage features. Lowrey's field work excavated and removed the central hearths for Rooms $2,6,7,8$, and 15. A major contribution was the successfully delineated series of small rooms along the east edge of the room block. Several other hearths and cists were excavated inside the rooms; however, it is impossible to determine whether they are associated with the rooms or are merely earlier features beneath the structure. Both Holden and Lowrey had considerable difficulty in interpreting the depressed channel features, and some of the "multiple floors" clearly represent the differences between the two contemporaneous surfaces. Nevertheless, Lowrey's report also notes the presence of a large circular room (No. 29) at the east end of the passageway to Room 2 and supports Holden's observation of a similarly placed rectangular room (No. 28) east of the passage to Room 7 . He also records the threshold collars inside Rooms 2 and 6.

During August 1932, E. B. Sayles tested Circular Room 27, excavated 


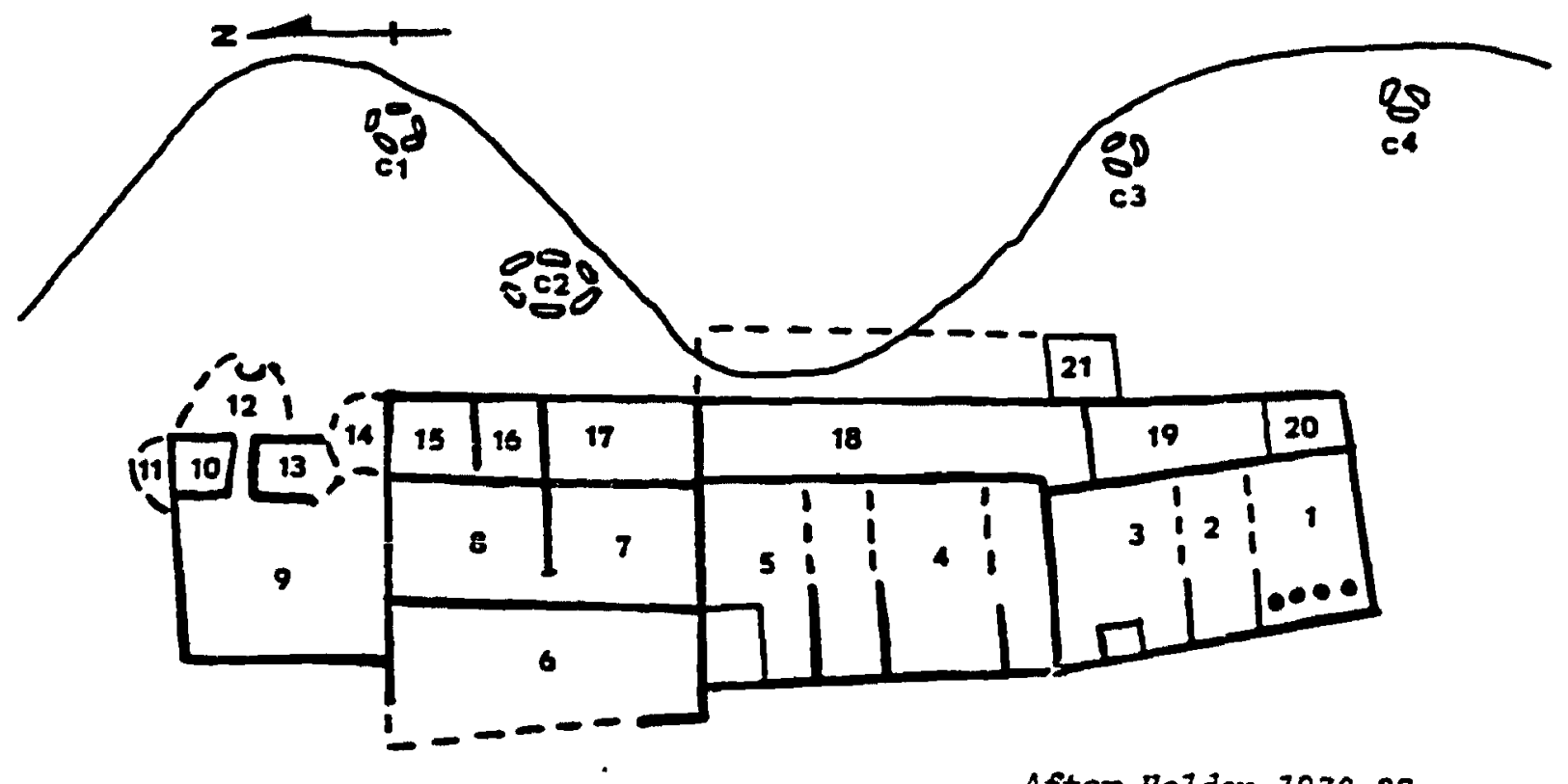

After Bozden 2930:27

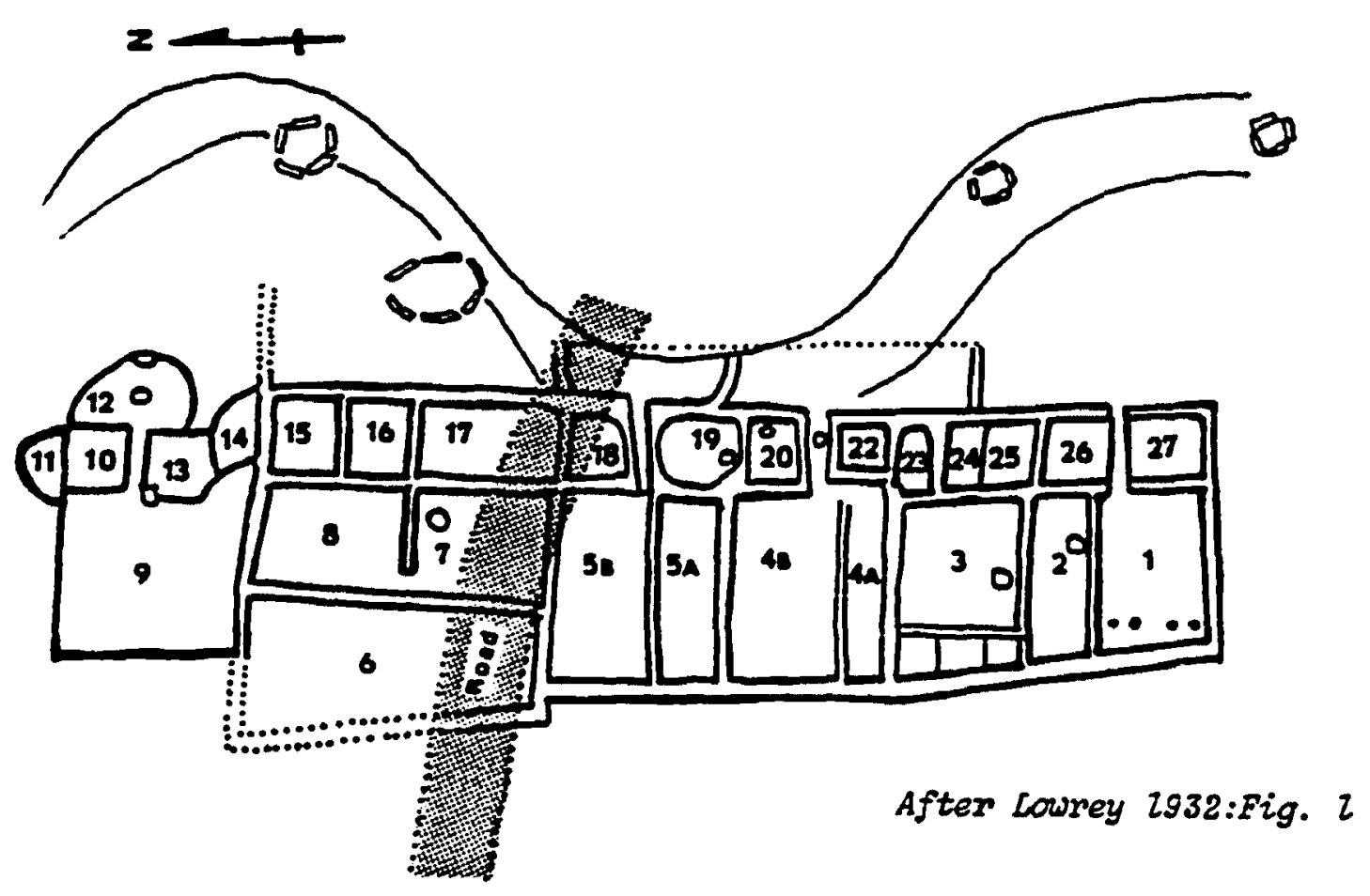

Figure 36. Holden's and Lowrey's Maps of Antelope Creek Ruin 22. 
the passageway of Room 3, and re-excavated Room 21 . Some testing of Room 27 may have been conducted by Moorehead; however, Sayles provides the only records of the interior room features. Excavations east of Room 27 also encountered a small stone cist near the edge of the bench.

The last excavations were conducted by WPA field crews in 1938. Initial excavations focused on two narrow stratigraphic trencies located northwest of the room block. Next, a reference point was established northwest of the ruin, and a series of $10 \times 10 \mathrm{ft}$ squares was imposed over the ruin and midden areas. Squares were designated numerically north-south and alphabetically east-west (Figure 37). Excavations were conducted inside Rooms 1 through 17, and in at least 72 outside squares. The combined wPA and previous projects excavated approximately a 1,130 square meter area. Inside the ruin, platforms were encountered in main Rooms 3,6, and 11 , central hearths were found in Rooms 3 and 11, threshold collars were found near the passage of Rooms 7,8 , and perhaps 11 , and a single burial was found inside Room 10. The clearing of exterior units located an isolated rectangular structure northwest of the room block and clarified the shape of Holden's "cyst 2 ," east of the structure.

Based on evidence of subfloor midden, wall types, and abutments, room size, orientation and the presence of certain interior features, it is apparent that at ieast four construction episodes were involved in the development of the contiguous room block at A-C 22 (Figure 38). The earliest episode involved the construction of a single large household (Room 11) along with appended smaller Rooms 12 and 14, and perhaps 9 and 13. At some later date foux large household Rooms, 2, 6, 7, 8, and their smaller contiguous Rooms 1, 20, 21, 22, 23, 24, 25, and 26 were constructed some $10.5 \mathrm{~m}$ 


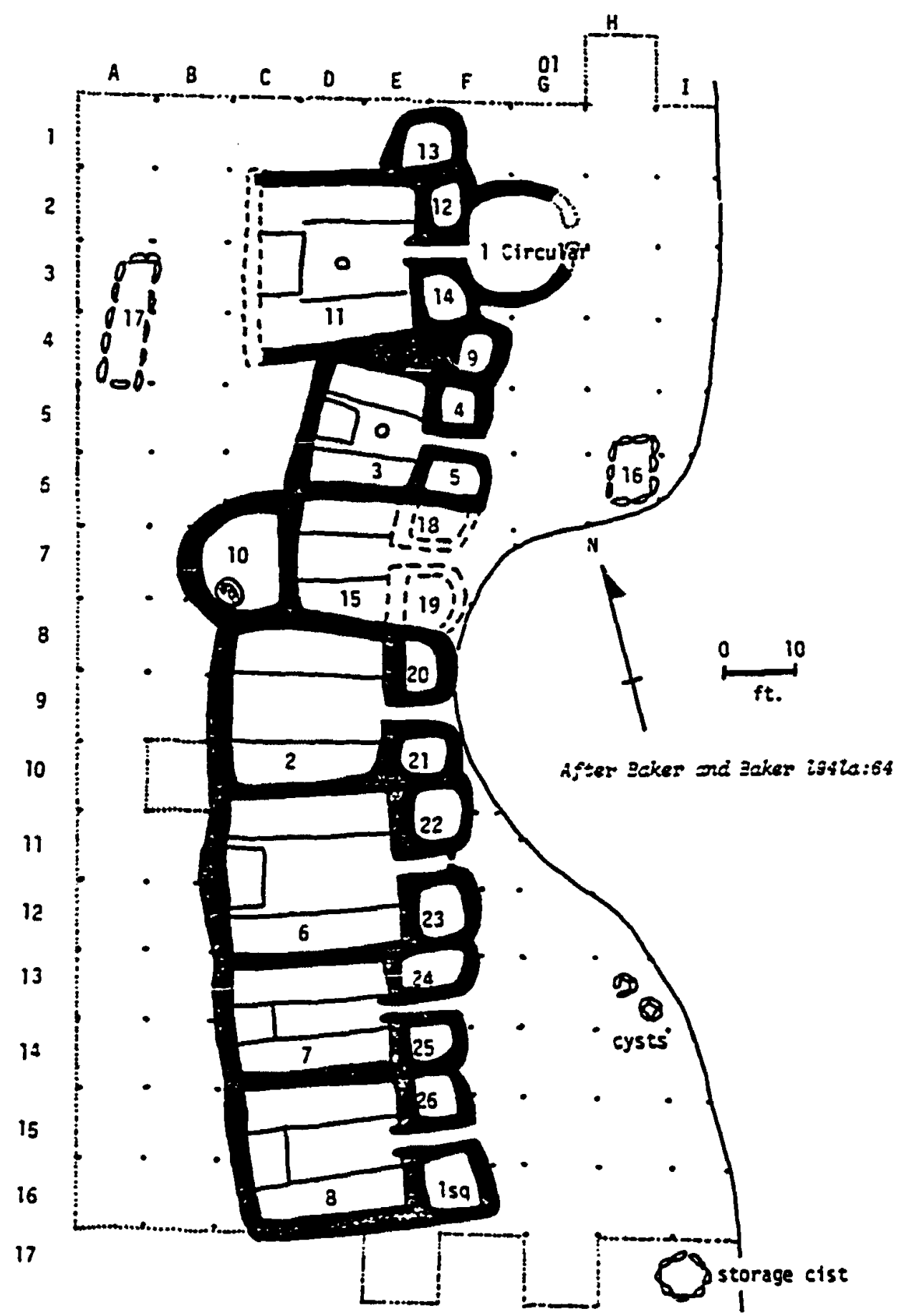

Figure 37. WPA Map of Antelope Creek Ruin 22. 


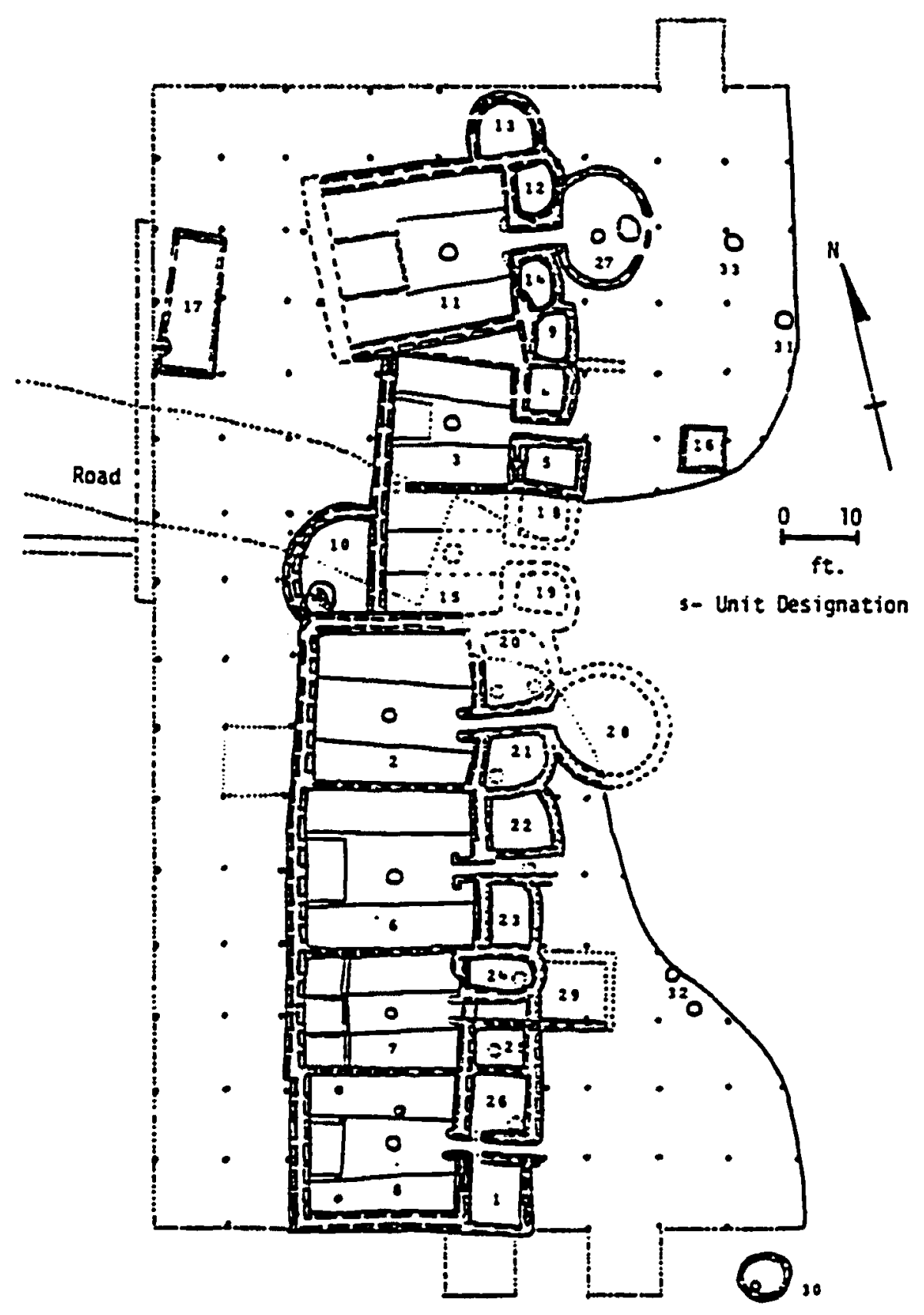

Figure 38. Composite Map of Antelope Creek Ruin 22. 
to the south. Strong evidence for the construction of these rooms during a single episode is provided by the double vertical slab outer wall, yet single slab walls between Rooms $2,6,7$, and 8 ; and the similarity in size, shape, orientation, and the distinctive use of threshold collars in all four passages. At or about the same time, circular Room 27 may have been added east of the original room block, as well as 28 and 29 to the east of Rooms 2 and 7 of the south room block. The third construction episode involves the erection of main Rooms 3 and 15, and contiguous Rooms 4, 5, 18, and 19. The main household rooms are considerably smaller than their counterparts and lack the threshold collars. The smaller size of these rooms undoubtedly reflects spatial limitations imposed by connecting the two existing room blocks. That these rooms were built as a single unit is reflected in the common double slab west wall, yet a single slab wall separating the two main rooms. The final building episode involves the accretional addition of Room 10, which partially incorporates the existing exterior walls of Rooms 15 and 2 . Other modifications are reflected by the construction of isolated Rooms $16,17,30$, several small exterior cists, and the closing of the vestibule to Room 7.

Clearly the development of the room block is accretional. However, . the evidence indicates that several repetitious room aggregate units were added during a single construction episode. Quite likely all seven household units were occupied simultaneously near the end of site utilization, since there is little evidence of later features built over these rooms. - Despite the size of the ruin and extensive area excavated, very few trade items were found. Recovered materials include Pueblo sherds and perhaps two pieces of obsidian. No turquoise or olivella shell/conch 
items were reported. As might be expected, considerable quantities of artifacts and debris were reported east of the structure, in front of the vestibule passageways. The construction patterns probably refleci a combination of exterior activities in front of the structure, and disposal of trash down the steep slope to the east.

Antelope Creek 22A

Ruin $22 \mathrm{~A}$ is a series of small rooms located about $45 \mathrm{~m}$ east of Antelope Creek 22, at the base of the bluff. Rocks on the surface indicated the approximate outline of a contiguous room structure (Baker and Baker 1941a).

Limited excavations were initiated in February, 1939, to supplement information from Ruin 22 on the bluff rim. Excavations focused on clearing the interior area of five contiguous rooms of one structure and opening midden deposits between the structure and the bank of Antelope Creek located some $7.5 \mathrm{~m}$ to the south and east. Three "areas" of varying size and shape were used for crude horizontal control of materials, but no standardized "sections" were employed (Figure 39), nor was vertical control maintained. Presumably the areas were dug to culturally sterile deposits. Area 1 is as wide as the contiguous room structure and extends from the room block eastward to the bank of Antelope Creek. It encompasses approximately $81.5 \mathrm{sq} \mathrm{m}$. Area 2 is approximately $103.5 \mathrm{sq} \mathrm{m}$ located south of Area 1 and the structure. It is bounded on the east and south by the creek bank. Area 3 is an irregular strip approximately $13 \mathrm{~m}$ wide, located north of the structure and extending nearly the entire length of the building. It includes about $44 \mathrm{sq} \mathrm{m}$. No excavations were conducted to the west of the main building. 
B21 - Interlor Burlal 2

B2e - Exterlor Burlal 2
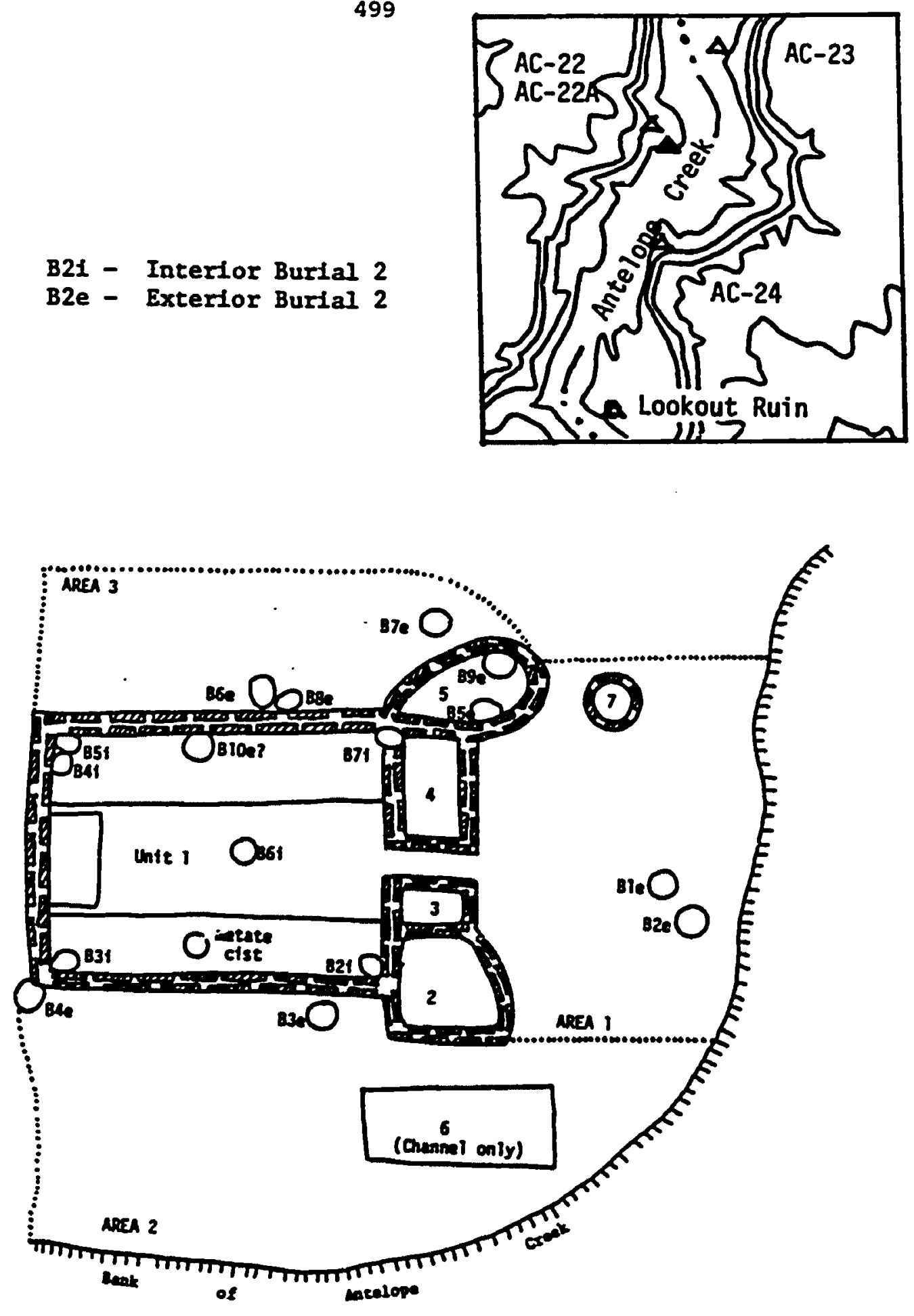

After WPA fieldnotes

Miscellaneous File, PPHM

Figure 39. Antelope Creek Ruin 22A. 
Other architectural features excavated during clearing of the three areas irclude a slab-lined cist (7) and portions of a second structure (Unit 6). Unit 6 was dug considerably deeper than the other rooms. These differences prompted Baker to suggest that the two structures were not contemporaneous. Most of the room was eroded into the creek, and only the portion from the channel curbing to the north wall was discerned. In addition, 16 burials were scattered throughout the excavated area. Many inside the contiguous structure were interred above the floor surface or excavated into the walls, indicating that the interments postdated the site occupation. The burials possibly represent individuals from the adjacent antelope Creek 22 site interred at the base of the bluff after Ruin $22 \mathrm{~A}$ was abandoned. Excluding mortuary goods, fewer than 200 artifacts were recovered from the site. Southwestern materials were recovered only as mortuary items.

\section{Antelope Creek 23}

Ruin 23 is located on the east bank of Antelope Creek, and some $350 \mathrm{~m}$ northeast of Ruin 22. The site is on a lower terrace some $6 \mathrm{~m}$ above the stream at a point some $7.2 \mathrm{~km}$ south of the confluence of Antelope Creek with the Canadian River. Stone slabs on the surface called attention to the presence of structures. Several rooms may have been present; however, most were destroyed by erosion.

Limited excavations were undertaken by WPA crews during the first quarter of 1939. The site was tested to ascertain the nature of structures, since the bottomland setting contrasted with that of Antelope Creek 22. Excavations were restricted to the interior of one room, and to a $45 \mathrm{~m}$ long trench extending northwest of the structure to sample midden deposits and to search for exterior features (Figure 40). Total excavations involved 


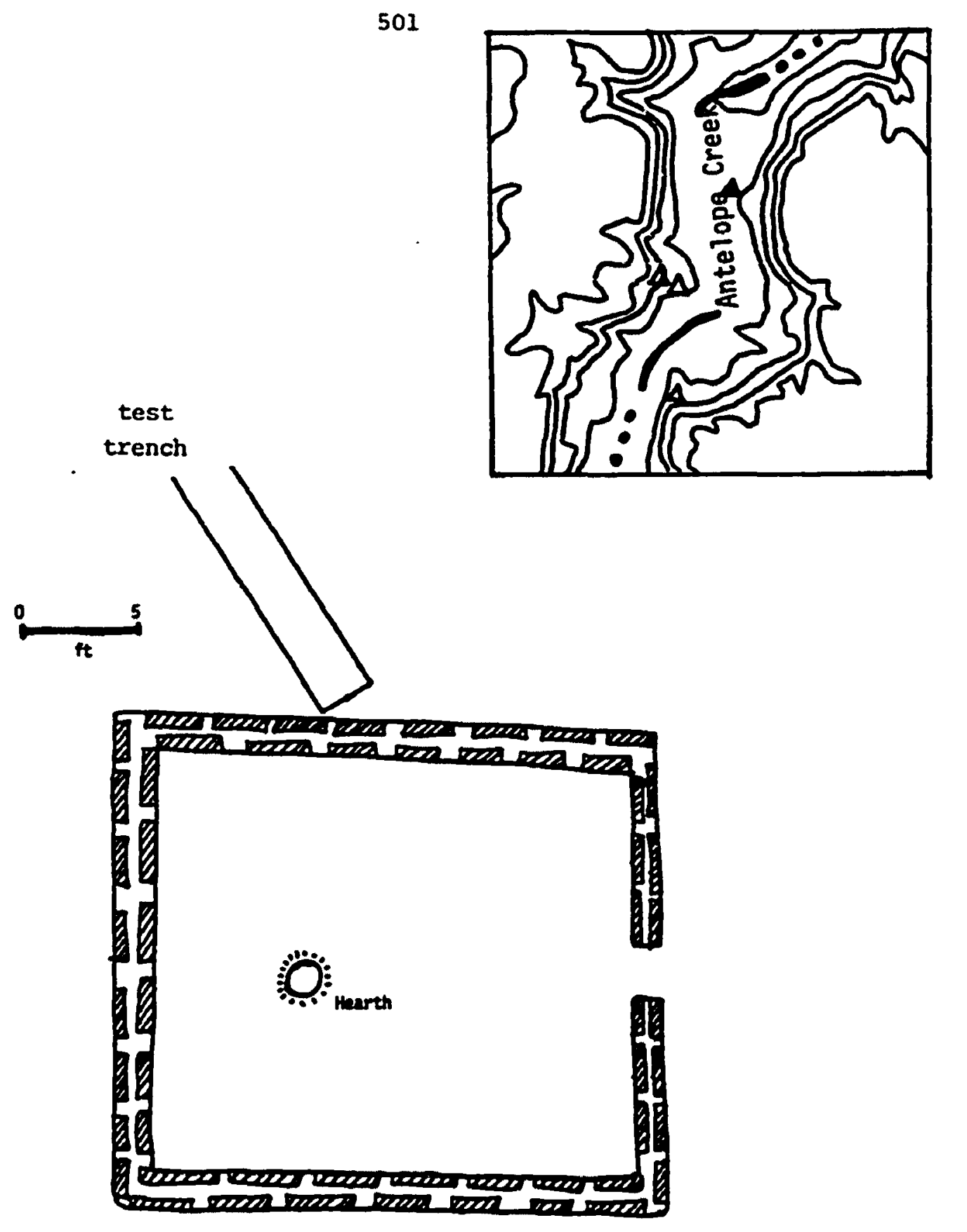

After WPA Niscellaneous Pile Panhondle-Plains Nuserm.

Figure 40. Antelope Creek Ruin 23. 
approximately $45 \mathrm{~m}^{2}$. Apparently a hearth, a burial, and stick-impressed burnt daub were encountered during trenching; the daub suggested the presence of some sort of "brush structure," but excavations were not extended to discern the nature of this second feature.

Little can be discerned about this site from the few remaining notes. No site map exists showing the relationship of the excavated rooms to other features and possible rooms. Nor were records located for the burial and the distribution and kinds of artifacts recovered. Fieldwork was abandoned because of the scarcity of artifactual materials (Baker 1939a). The remaining notes record no trade materials from the site.

\section{Antelope Creek Ruin 24}

Ruin 24 consists of a series of structures at the base of a steep bluff immediately east of Antelope Creek and about $400 \mathrm{~m}$ due south of Ruin 22. The site is some $6 \mathrm{~m}$ above the floodplain at a point $8 \mathrm{~km}$ from the Antelope Creek/Canadian River confluence. No architectural remains were apparent on the surface, but walls and flooring were exposed in the creek bank. Colluviation had buried the ruin by 0.5 to $1.5 \mathrm{~m}$ of $\mathrm{fill}$, and had preserved walls over $1.0 \mathrm{~m}$ high. Excavations revealed the presence of both contiguous and isolated room structures.

Excavations were conducted during March-May, 1939. At least eleven of seventeen "areas" and twelve rooms were cleared; two other rooms were merely tested. Unfortunately no site map was prepared showing the relationship of the structures or the size of the exterior areas. Notes accompanying photographs and on individual rooms provide limited information about the site. Initially a diversion ditch was excavated around the upslope (east) edge of the site to channel runoff away from the excavated 
areas. Excavation proceeded from south to north and extended to the creek bank or gully on the west. In some instances, the room over-burden may have been removed as a single unit without screening. As usual no vertical excavation control was mentioned; however, a stratigraphic block was isolated and left standing in the midale of the site.

Most rooms were located in a north-south line along the western edge of the site. They typically were small rectangular structures without internal features, measuring some 2.25 by $1.50 \mathrm{~m}$. Baker (personal communication 1981) feels that they represent the "storage rooms" flanking vestibule passageways to a series of contiguous larger main rooms which had eroded away (Figure 41). Rooms 5-6 and 12-14 occur as contiguous pairs, whereas Rooms 4-9 contain an offset in the wall and are twice the size of the other rectangular rooms. Although no site map exists, these rooms probably reflect three pairs of smaller rooms flanking passageways to four contiguous main residential units within a single room block. Assuming that rooms were assigned as encountered, and that small rectangular structures of an appropriate size and shape represent these flanking storage rooms, then the arrangement of rooms from north to south may represent Room 3, passage, Rooms 4-9, passage, Rooms 5-6, passage, Rooms 12-14, passage, . and Room 7.

Separate from this contiguous room block was a large rectangular room with a central channel and eastward extended passageway (Room 12), and to the southeast, a large isolated circular room (15). Two other smaller circular or irregularly shaped rooms $(2,8)$ may have also been isolated; however, their location is uncertain. No burials or other exterior features are mentioned in the existing records. The excavations recovered 

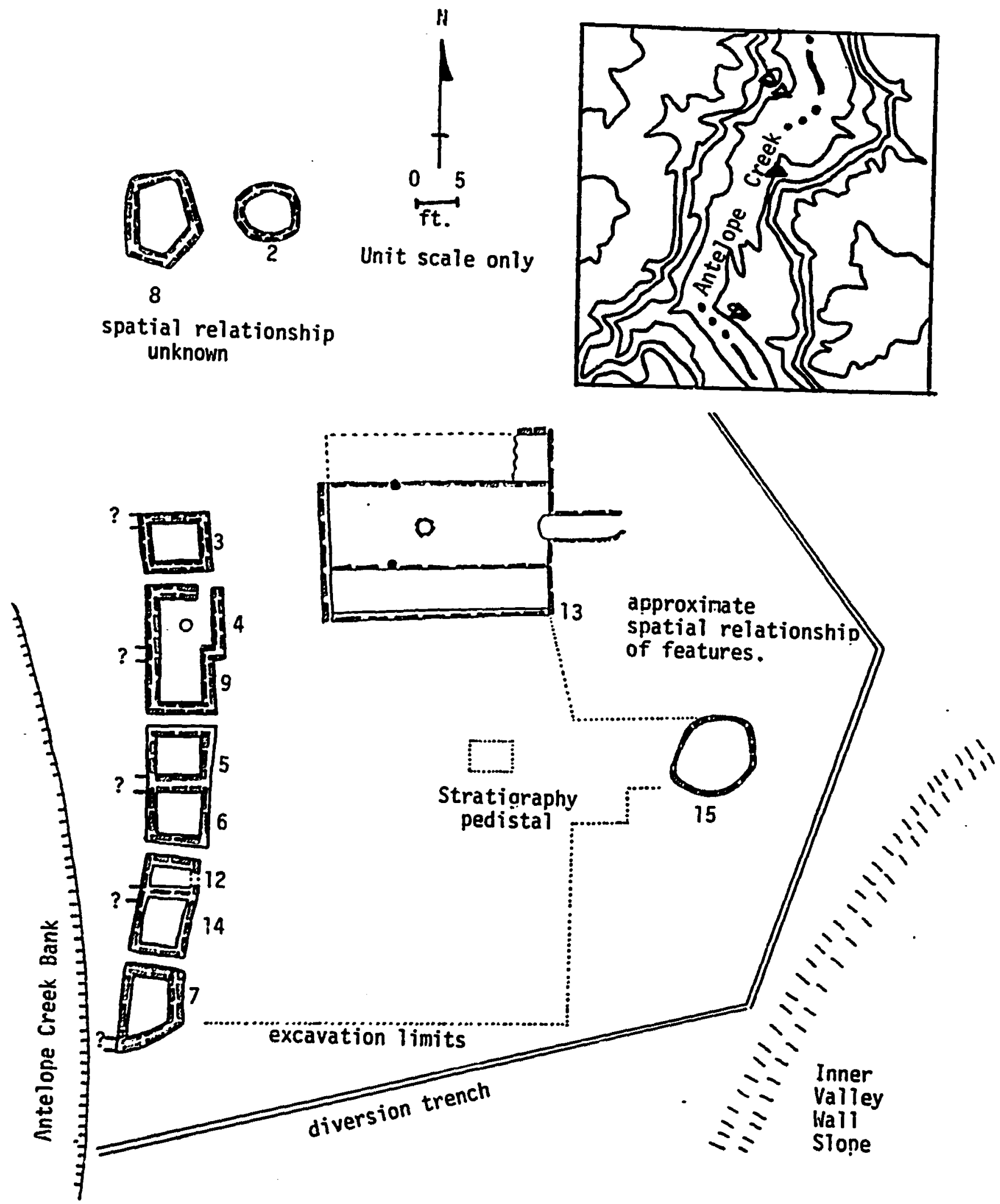

Based on photograph,

Baker and Baker 2939a:29

Figure 41. Skematic Map of Antelope Creek Ruin 24. 
505

nearly 300 artifacts including 12 Pueblo glazed sherds, one "Caddoan" sherd, and one olivella shell bead.

\section{Alibates 28}

The Alibates Creek area has attracted considerable attention because of the occurrence of numerous large sites close to deposits of nearly pure chertified dolomite. Approximately $1.2 \mathrm{~km}$ southwest of the main quarry area is Ruin 28. The site occurs on rolling terrain just above the rim of the inner valley (Figure 42). The site is bounded on the north, norifieast and northwest by an escarpment which drops $21 \mathrm{~m}$ to rough broken land of the Alibates drainage system and $52 \mathrm{~m}$ to the creek bed. An unnamed draw of Alibates Creek is immediately east of the site, whereas the main channel of Alibates Creek is approximately $1 \mathrm{~km}$ to the west. The Canadian River floodplain is $4 \mathrm{~km}$ to the north. No potable water is currently present in Alibates Creek, and a cistern in the unnamed draw near Allen Bate's historic dugout indicates that specialized collective devices were necessary to obtain and store water during recent times. Nevertheless, the presence of seep springs along the base of the escarpment may have produced more water than currently available.

Ruin 28 is one of the largest sites near the chert quarries. It was selected as one of two type sites for.Krieger's (1946) Antelope Creek focus. The site consists of a major contiguous room structure located at the north promontory rim of the escarpment (WPA Excavation Unit I), and a series of isolated rooms scattered through a 275 by $160 \mathrm{~m}$ area to the south (WPA Excavation Unit II, Mason n.d.a.:7). The side has had a complex history of excavation. It was visited and tested by nearly every archaeological expedition to the region prior to the close of the WPA projects. 

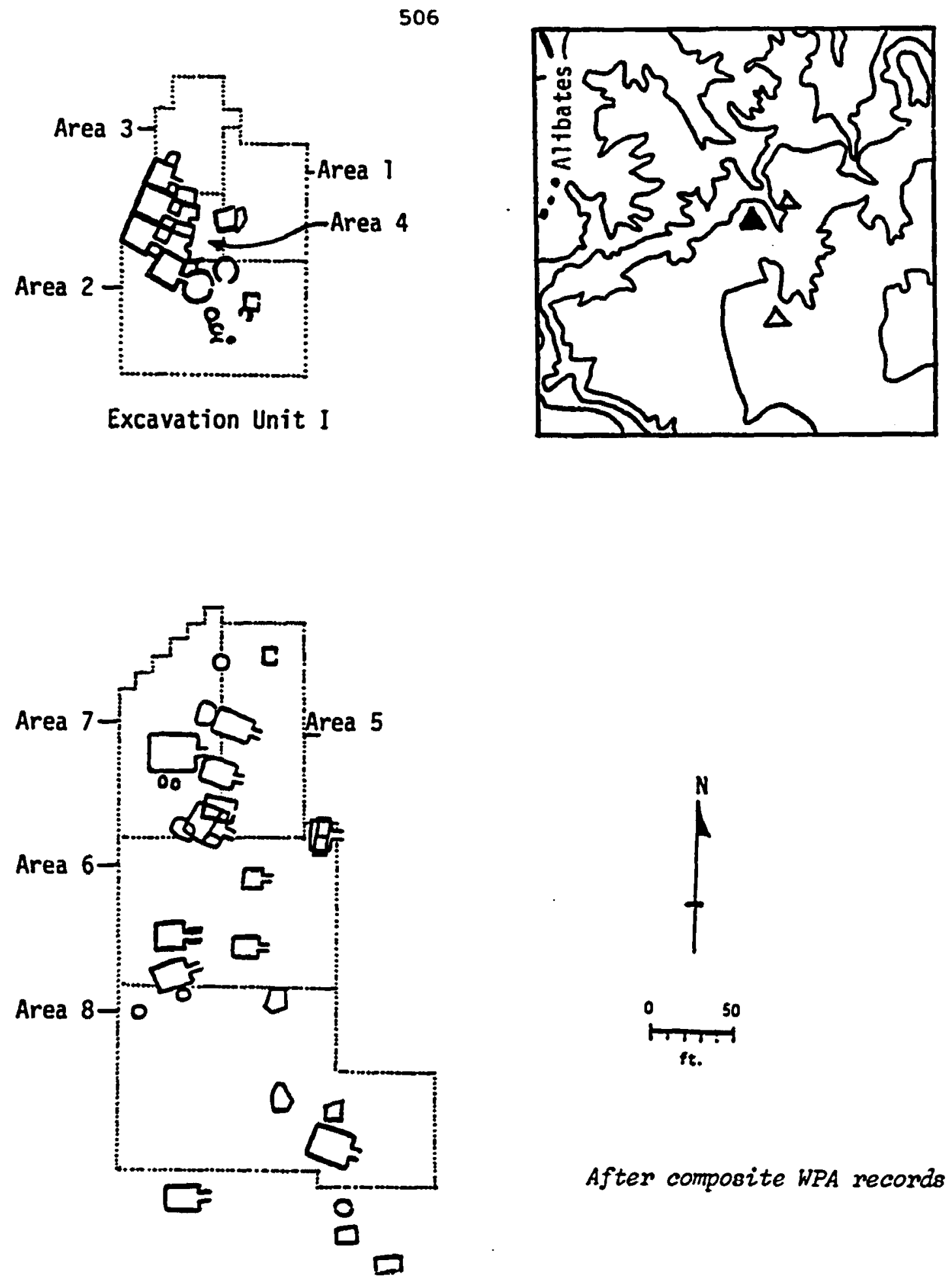

Excavation Unit II

Figure 42. Plan of Alibates Ruin 28. 
Because of the importance ascribed to this locality, the nature and significance of each archaeological investigation will be sumarized. All structural references will be keyed to the WPA designations, wherever possible, since they were the most extensive and systematic exploration of the site.

The earliest expedition to Alibates 28 was by Warren $\mathrm{K}$. Moorehead in 1921. Moorehead merely inspected the site, located "some 50 or more 'graves' and several well defined slab houses." However, he conducted no excavations at the site (Moorehead 1931:113).

Floyd Studer's involvement with the site began in 1926 when he initiated excavations around the main contiguous room block (WPA Fxcavation Unit I). As usual, Studer brought several friends and other volunteers to the site every Saturday and assigned them specific tasks. The excavations were very sporadic and variations in the crew roster indicate little continuity in the excavations. The sparsity of records on certain parts of the site suggests that each excavator was probably responsible for keeping his own records. In an unpublished summary of the work Studer $(1942: 35)$ indicates:

(the work) consisted of roughly surveying the area and picking up surface artifacts, and trenching through the kitchen midden followed by room excavations.

The trench was started from the lower talus, being three feet wide and extending to varying depths to undisturbed soil below. This trench was to serve a double purpose; first to drain water from the rains, second to expose refuse stratigraphy.

A map prepared in 1932 shows six trenches leading away from the contiguous room structure, and the excavations in three rooms correspond to WPA Rooms 6, 7, and 8 or 13 (Figure 43). In all likelihood, WPA Room 20 was also excavated by Studer during this early period. Studer also located 
Inttlal Possible Individual

"Charles"

"Carolýn"

Chas. Renfroe

Carolyn Studer

Floyd V. Studer
Initial Possible Individual

"C.W.S." C.W. Seibel

"J.Robin" J. Robin Allen

19-Areas Excavated

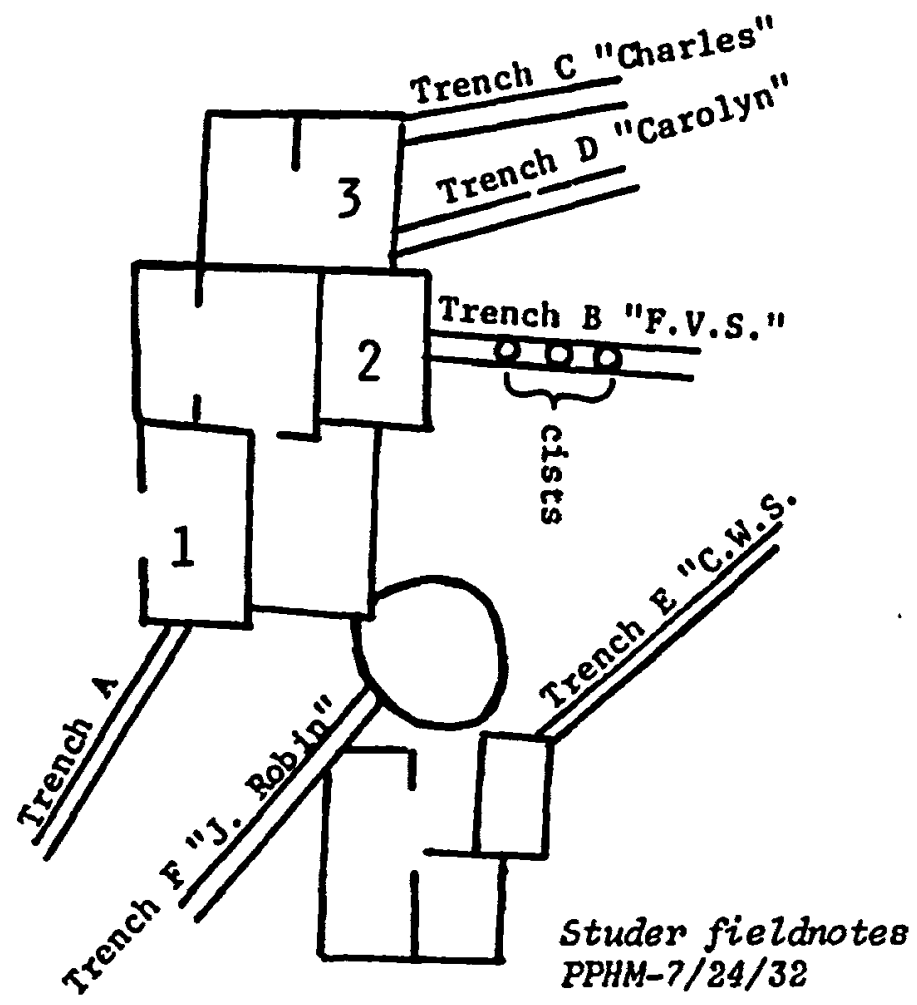

Studer's Map

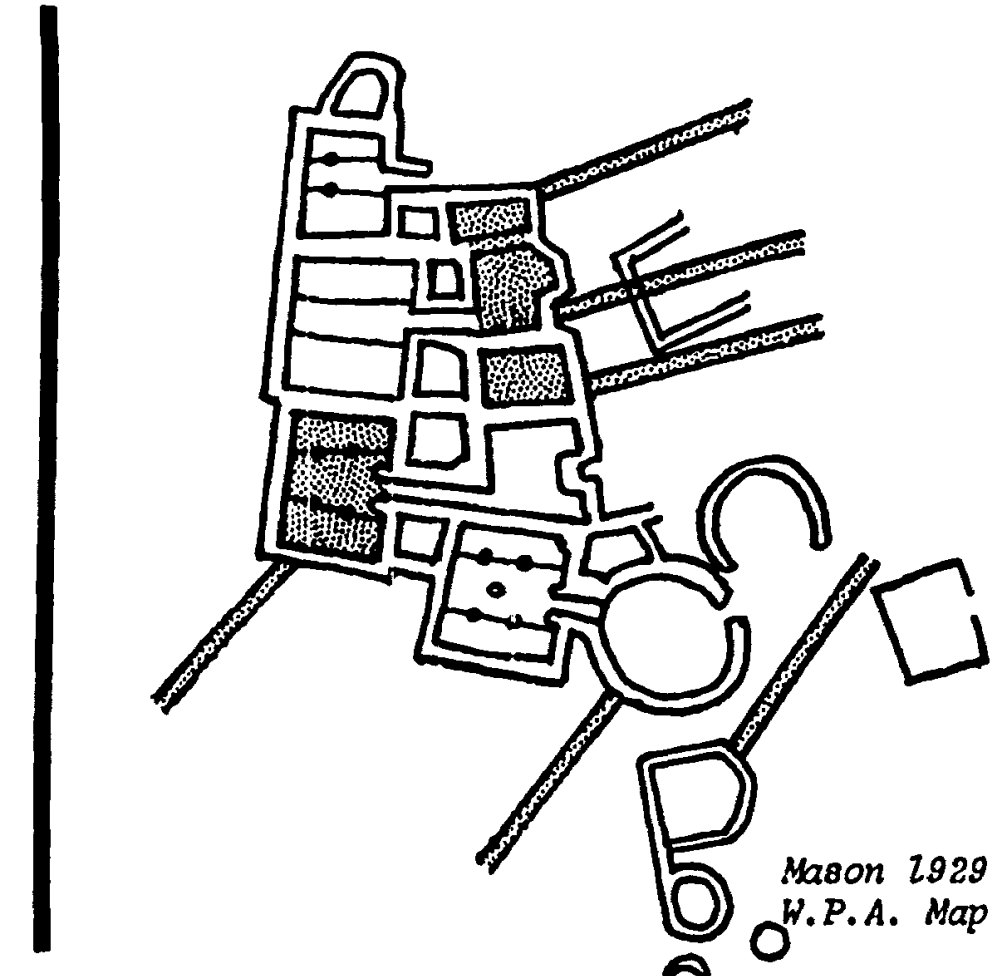

Composite correlation

Figure 43. Map of Studer's Excavations at Alibates 28, Unit I. 
and excavated a series of small circular rooms located within 9 m southeast of the main contiguous room unit which were missed during the WPh excavations (herein designated Rooms 54, 55, and 60; Studer 1934:95; 1942:35; Sayles 1932). With the exception of a burial found in one of the latter circular rooms, Studex's records indicate nothing about the nature of features or artifacts excavated at the site. The cxudeness of his excavation methods prompted Mason (n.d.b.:11) to remark: "Studer's pit is dug inside of (the) mound without reference to (grid) lines or areas of stone." The next professional excavations at Ruin 28 (Bivins Ranch, Site A) were conducted by Ronald olson for the American Museum of Natural History during the last week of July, 1929. Field work consisted of opening two test pits in two rooms near the contiguous rooms structure (WPA Unit I). Olson's excavations concentrated on a $1.90 \mathrm{~m}$ deep test pit along the west wall of "house 1" (WPA Room 19) to ascertain the stratigraphy of the main mound and a $1.5 \mathrm{~m}$ deep test pit in the southeast corner of a 4.5 by $6.4 \mathrm{~m}$ structure east of the main room block (Room 57--not recognized by the WPA excavations). Little was gained from the limited excavations, except that Room 57 was superimposed over a pit. Although Olson's notes are abysmal, members of a subsequent expedition had the foresight to record the locations of Olson's work and make stratigraphic descriptions of his pits (Mason n.d.a.: 7; n.d.b.:3, 4).

J. Alden Mason and two colleagues for the University of Pennsylvania Museum conducted excavations of Ruin 28 (Deal-Bivins site) between August 9-19, 1929 (Mason n.d.a.:6). Mason accurately mapped the configuration of the contiguous room block (Unit 1) and expanded the excavations in WPA Room 19 (Figure 44). Although his work was limited to the west half of the 


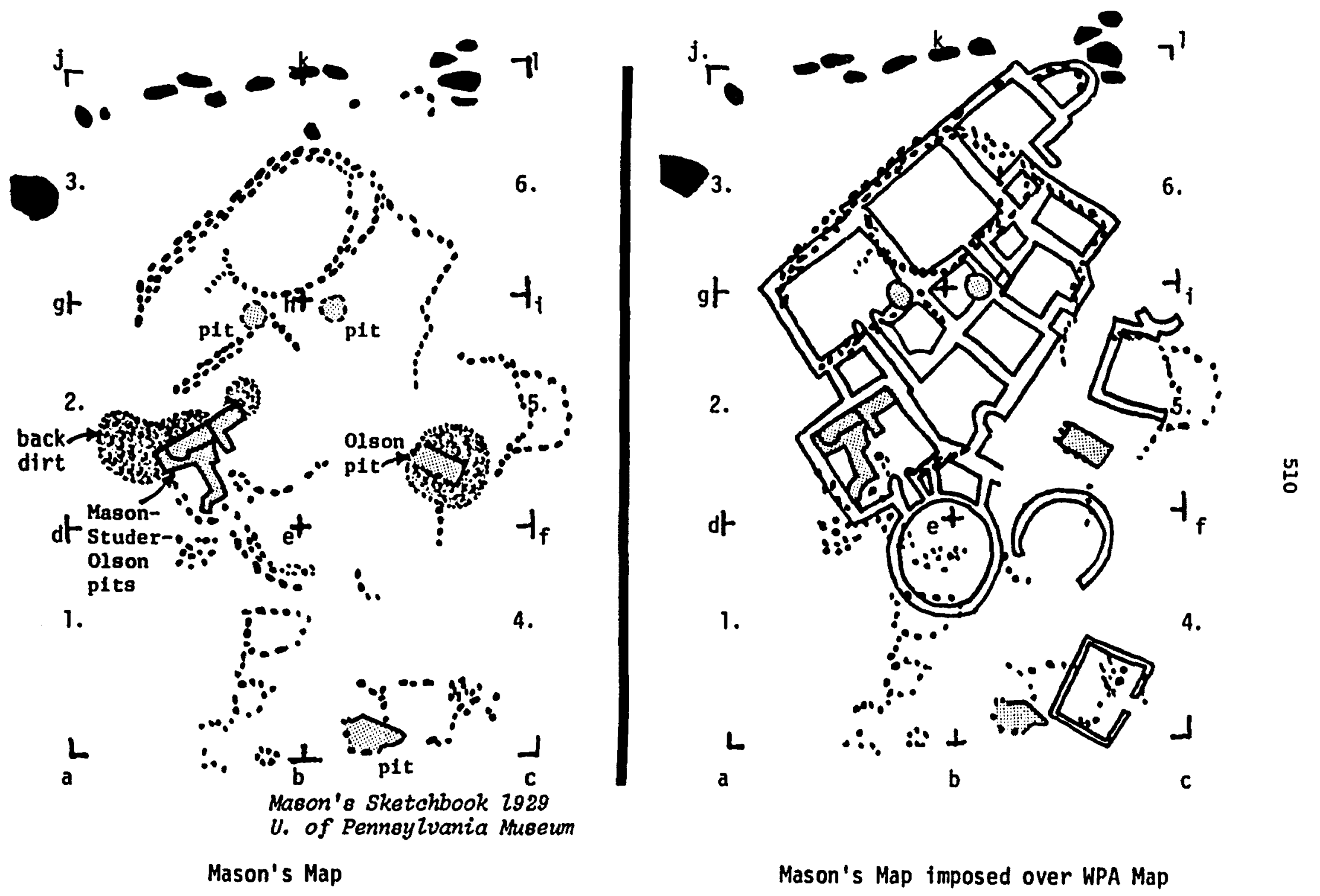

Figure 44. Mason's Map of Mibates 28, Unit I. 
room, he was the first to recognize and accurately report the presence of curbing ("sigmoid plaster") along the edges of floor channels. Additional testing was conducted at two rooms farther south (WPA Unit II). The "Deal 1 " or "Operation 1 " may correspond to the circular WPA Room 22 since it is similar in shape and location. However, later excavations by the WPA in this "disturbed room" located a flagstone floor not mentioned by the Pennsylvania Museum party. Testing was also conducted on "Deal 2, " an isolated rectangular structure corresponding in size and location to WPA Room 36. Despite the extensive work along the tops of walls, in diagonal trenches connecting the room corners, and in the southwest quadrant of the structure, no interior architectural details are reported.

E. B. Sayles, representing Gila Pueblo, visited Ruin 28 (Tex:B:9:1) in July, 1932, during Floyd Studer's excavations of the circular burial room (No. 55) southeast of the main roomblock (Unit I). There is no indication that Sayles was involved with any excavations at the site; however, his notes include a description and photograph of the burial excavated by studer.

The Works Progress Administration field work at Ruin 28 was during two granting periods. The initial work concentrated on the northern room block (Unit I) where 12 rooms and 36 ten foot sections of Area 1 were excavated during the latter five months of 1938 . The second granting period lasted twenty-two months (February 1939-February 1941), during which time seven additional rooms and 109 sections of Areas 2-4 were excavated for Unit $I$ and 31 rooms and 439 sections from Areas 5-8 were excavated for Unit II, $50 \mathrm{~m}$ to the south. Because of the wealth of information obtained by the WPA each Excavation Unit is discussed separately. 
Excavations in Unit I (involving approximately $1515 \mathrm{~m}^{2}$ ) uncovered a series of 19 rooms within a single room blcck and three other isolated structures (Rooms 2, 18, and 20), Despite the extensive exterior excavations, neither the series of small contiguous circular structures mapped by Mason and cleared by Studer, nor the isolated rooms excavated by olson and Mason to the east, were recorded by the WPA archaeologists. The main room block consists of four contiguous main household units characterized by central channels, low eastward extended vestibule passages, and other features, with at least 13 auxiliary contiguous units to the east (Figure 45). This room block was somewhat unusual in that the filled rooms preserved some walls standing to a height of $1.9 \mathrm{~m}$ (Figure 46). The exceptional height of preserved walls, and the prominent mounding of earth at the edge of the escarpment, tenuously suggest that the fill may have been culturally deposited over the rooms. This suggestion is supported by multiple floor levels or filling episodes within the mound, and the subsequent construction of walls approximately $1.2 \mathrm{~m}$ above the original floor surface inside Room 19 (Figure 47).

The presence of subfloor pits, wall abutments and different construction methods indicates that the main room block developed during several accretional construction episodes. The duration between episodes is uncertain, and it is possible that several phases could have been completed at the same time. The earliest rooms, possibly built during a single construction episode, were main household Rooms 7,11 , and 15, followed shortly thereafter by household Unit 19. All involved double stone slab foundations built directly on sterile ground. None of these rooms superimpose earlier pits or cists. The next episode likely involved the 
Based on Mosaics from WPA Features and J. Alden Mason's fiezd mop.

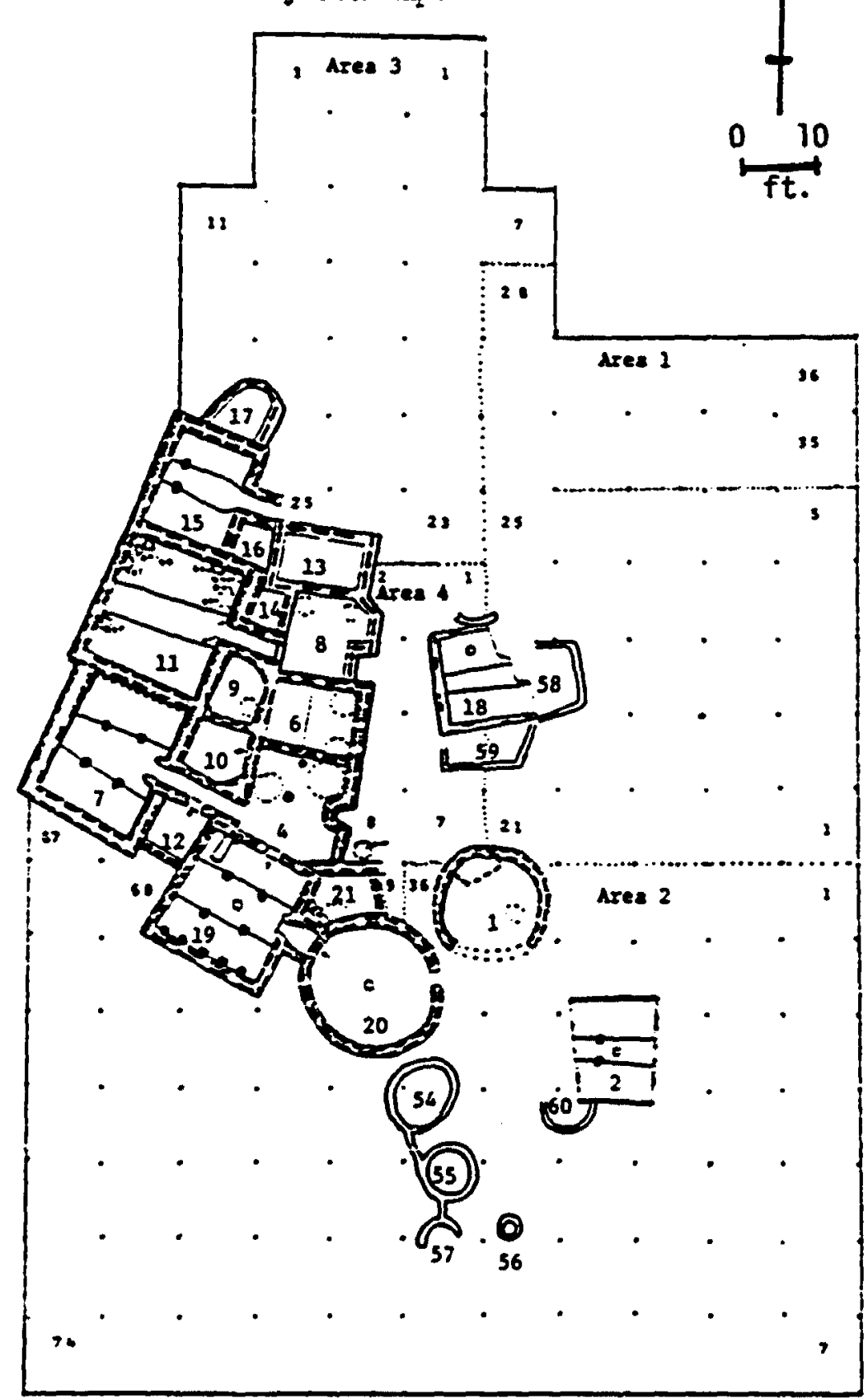

Excavation Unit II, 150 feet south.

Figure 45. Alibates Ruin 28, Unit I, Composite Map. 


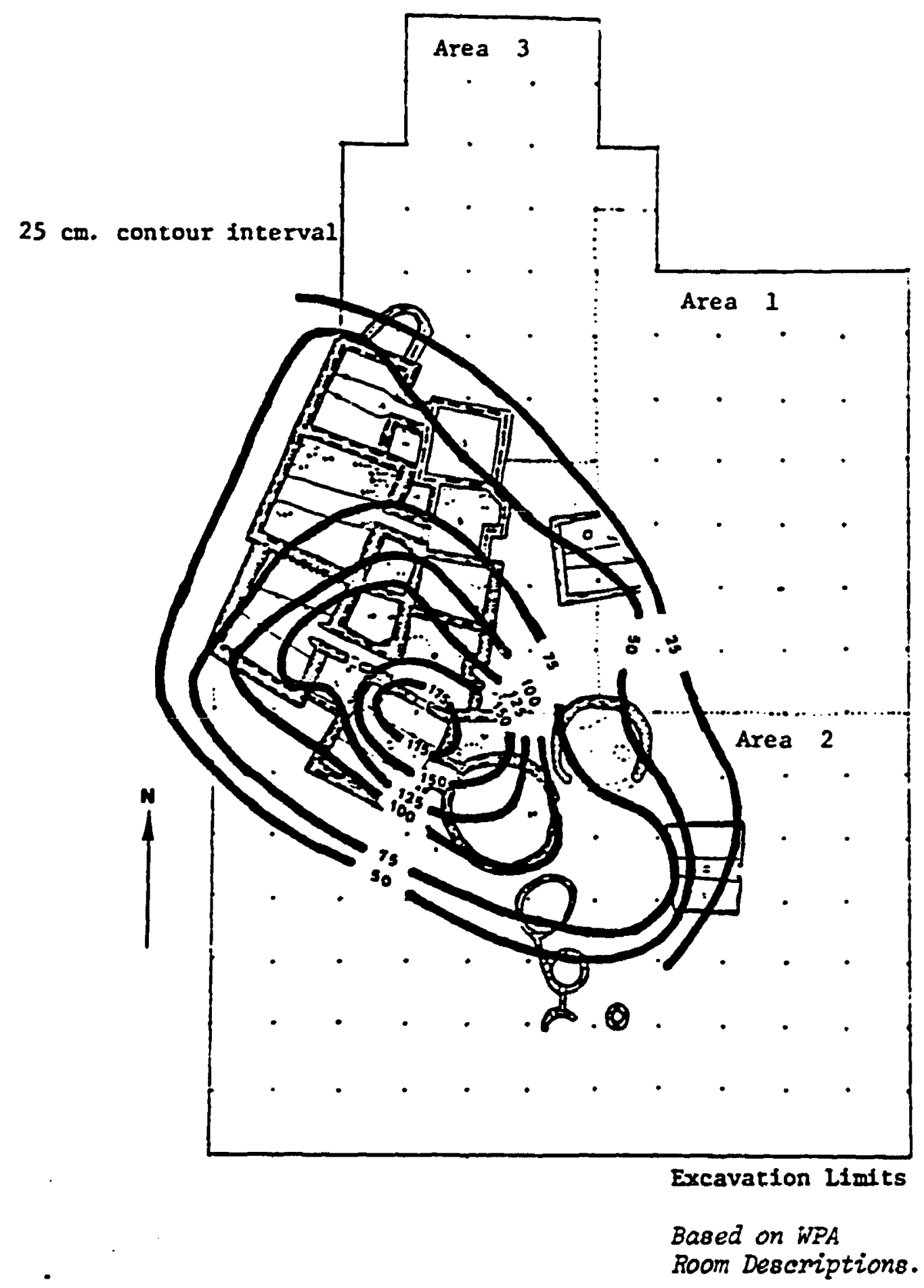

Figure 46.

Mound at Alibates 28 , Unit I as Indicated by Wall Heights. 
515
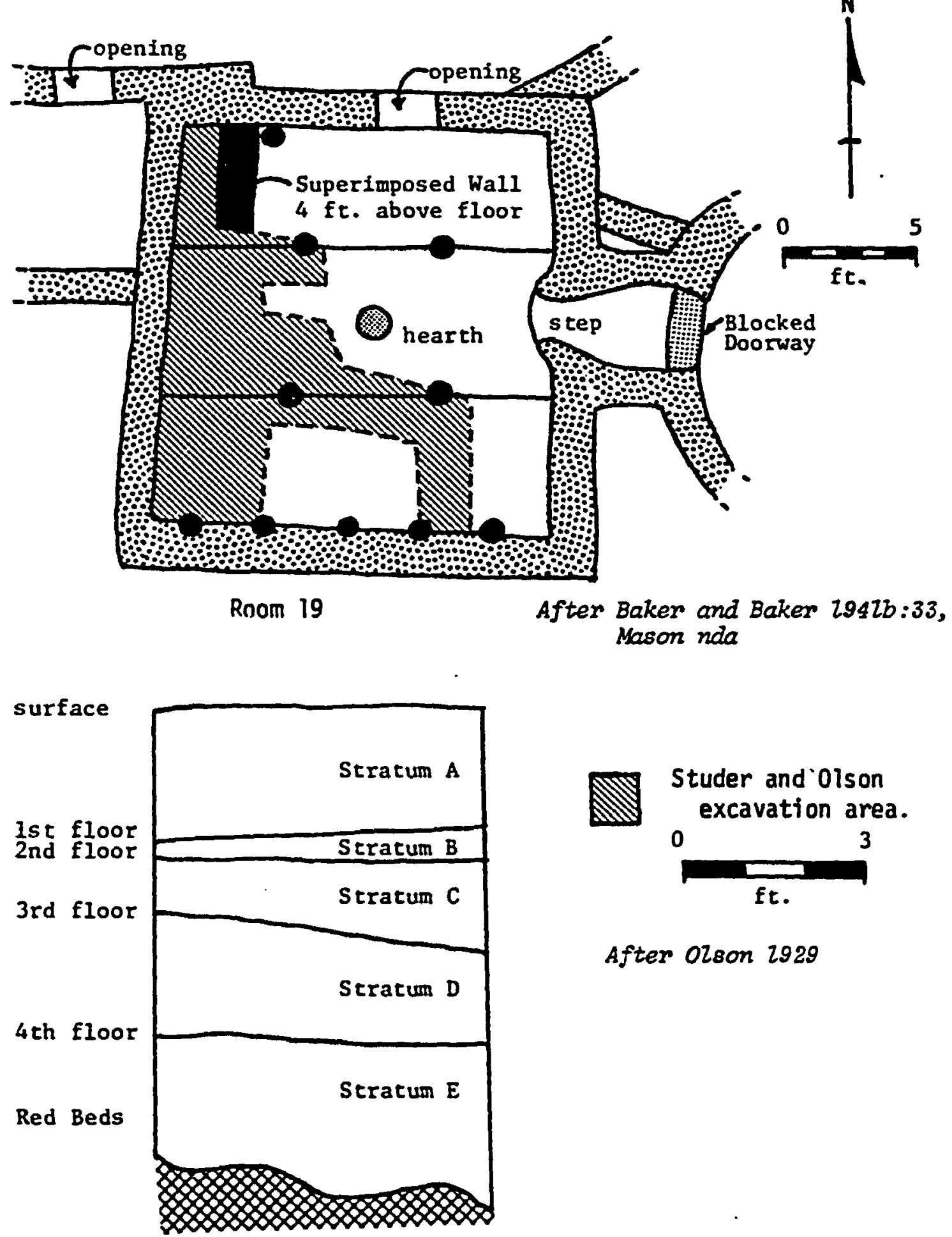

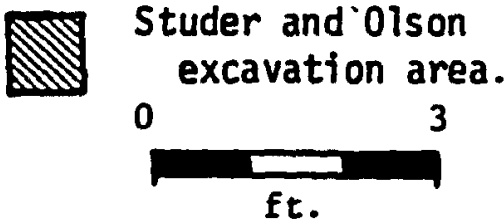

After OZson 2929

Figure 47. Stratigraphy of Mound, Alibates Kuin 28, Room 19. 
addition of circular anterooms, Room 20 east of the passage for Room 19, and possibly the wall segment between Rooms 21 and 4 . The length of the latter wall is unknown; however, given the excavation uncertainty involved with Rooms 3 and 5, as well as olson's excavations, several other unrecorded rooms may have been contiguously located to the east (cf. Baker and Baker 19410:28). The next building episode probably involved the construction of a large anteroom east of Room 7 and southeast of Room 11. This unit was subsequently divided to form Rooms 4 and 6 , with the intervening space between the structures divided into Rooms 9 and 10. All were built over earlier pits possibly used at the source for obtaining construction adobe and mortar (Baker and Baker 1941b:131, Duffield 1970:93). The last construction episode involving several phases is a departure marked by the use of single stone slab foundations. It involved the addition of Room 17 to the north of Room 15; the addition of Rooms 8 and $13^{1}$ to the east of 11 ; and the addition of transverse walls forming Rooms 12 and 21 . At the same time, the passageways to Rooms 11 and 19 may have been sealed off. An interesting aspect of the constructicn episodes involved the intentional deposition of $0.8 \mathrm{~m}$ of trash inside Roors $9,10,12$, and 21 in order to raise the floor level to heights comparable to the top of the extended passages from main Rooms 7, 11, and 19 (Figure 48). The split floor levels created superimposed passageways, and in some instances openings to certain

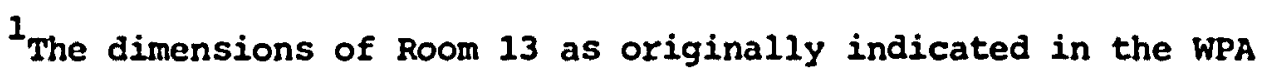
records (Baker and Baker 1941a:123) may be in error since it would block the passageway to Room 15. General site maps and exterior trash disposal patterns clearly indicate that the passageway was open. Either the size of Room 13 was smaller, or else the construction episode was exceptionally late and the general site maps are in error. Observations on Room 13 indicate the former situation and the room dimensions have been adjusted accordingly (Appendix B). 

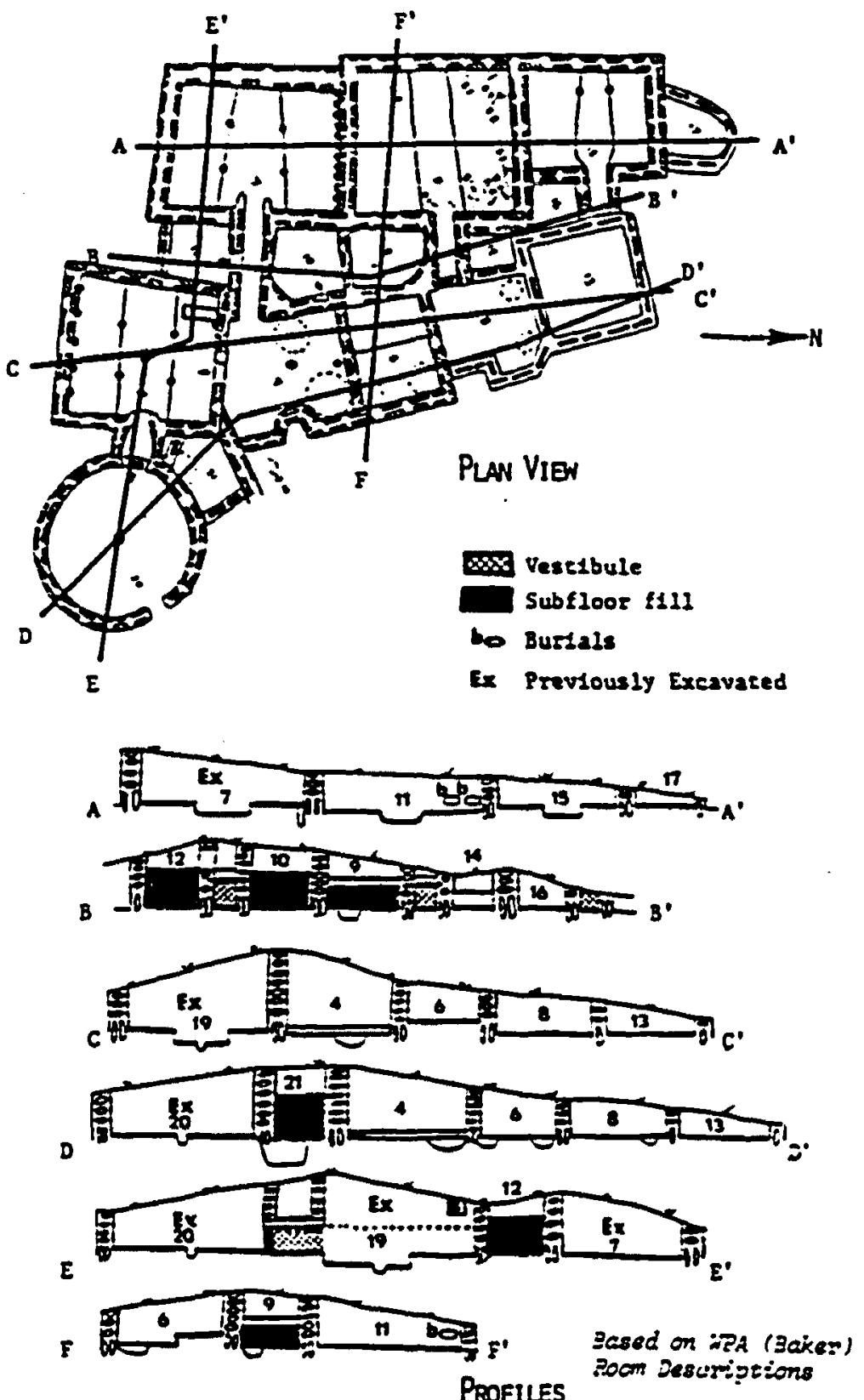

Figure 48.

Cross Sections of Mound at Alibates 28, Excavation Unit I. 
rooms were placed $0.81 \mathrm{~m}$ above the floor. Such openings would not be apparent from the foundation plans of the room if the structure had undergone extensive deterioration.

The room block growth as reflected by the construction episodes support the contention that Rooms 6 and 13 on the north side of the rectangular "antechambers" 4 and 8 are indeed part of a basic room aggregate (Iintz 1979b). However the plan of room growth is not always symmetrical or predictable. The smaller rooms flanking the extended passageways were not built in pairs, or even during the same construction episode. Rooms 10 and 12 flanking the passage to Room 7 , and 9 and 14 flanking the passage to Room 11 were clearly built during different phases. The incidental development of Room 15 (south of the passageway to main Room 15) apparently resulted from construction activities involving Rooms 8 and 13 , east of main Room 11. This strongly implies pooled labor involvement and some planning beyond the individual household unit.

The density of artifacts from the exterior sections reflects a combination of exterior use areas and basic trash disposal practices (figure 49). The distribution patterns clearly show high debris concentrations east and northeast of the extended passage of Room 15, and east and south of the opening in circular Room 20. This pattern reveals that only two openings were utilized. The artifact distribution does not support the notion of entrance to main Units 7 and 11 through Rooms 4 and 8 as previously postulated (Lintz 1979b). The paucity of artifacts between these rooms and Room 18 may be either another indication of additional rooms, or the presence of an exterior plaza area kept clear of debris. The linear extension of tools to the south supports Mason's map showing a series of 


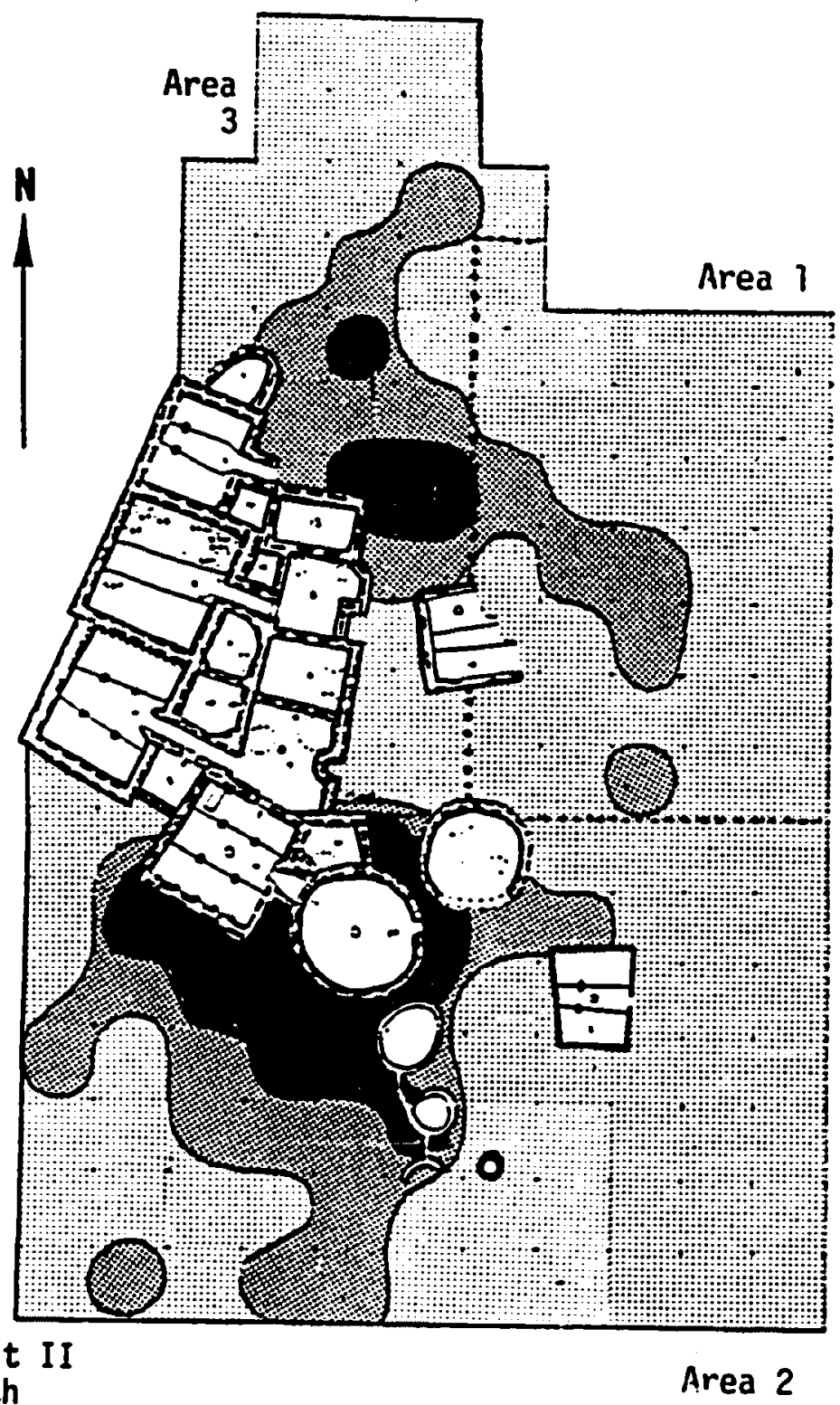

Excavation Unit II 50 meters south

Area 2

$$
\begin{aligned}
& 0-25 \text { tools per } 10 \mathrm{ft}^{2} \\
& 26-50 \text { tools per } 10 \mathrm{ft}^{2} \\
& 57-75 \text { tools per } 10 \mathrm{ft}^{2} \\
& 76-100 \text { tools per } 10 \mathrm{ft}^{2}
\end{aligned}
$$

Based on WPA Analysis and Reports.

Figure 49.

Density of Artifacts in Excavation Unit I, Alibates Ruin 28. 
small contiguous room structures to the south.

A total of 12 single individual interments were recovered from Unit I. Nine were found inside the largest room (No. 11). Only two came from near the floor level and the others were found overlying the floor surface. The burials were spaced near corners or mid-wall areas as if distinct areas were allocated for burial interment. Probably all nine burials represent later interments by individuals from adjacent sites--either Unit II, Alibates $28 \mathrm{~A}$, or Alibates 30 . The other three burials occurred in exterior midden areas or small circular rooms to the east or south of the main rocm block.

Unit II, located some $50 \mathrm{~m}$ to the south, involved an extensive area encompassing approximately $4,110 \mathrm{~m}^{2}$. Thirteen of the 31 structural features encountered in Unit II are large rectangular household units marked by central floor channels, and extended passages towards the east (Figure 50). Nearly all units were isolated; however, two contiguous pairs of rooms (3340 and 29-30) were encountered. While it is impossible to infer building episodes from the scattered room layout, superimposed series of rooms were encountered in two areas. Contiguous Rooms 33 and 40 were built over isolated Room 32 near the northeast corner of Area 6 and three superimposed structures were excavated in the southeast corner of Area 7. The earliest structure was a large household unit (Room 25/28) followed by contiguous room structures (29 and 30 ) and isolated Room 27, which in turn was beneath another relatively small household unit (Room 33).

- Further evidence for multiple occupations is provided by the density and distribution of tools from the exterior areas. High densities of materials were encountered east of the structures in the north end of the unit 


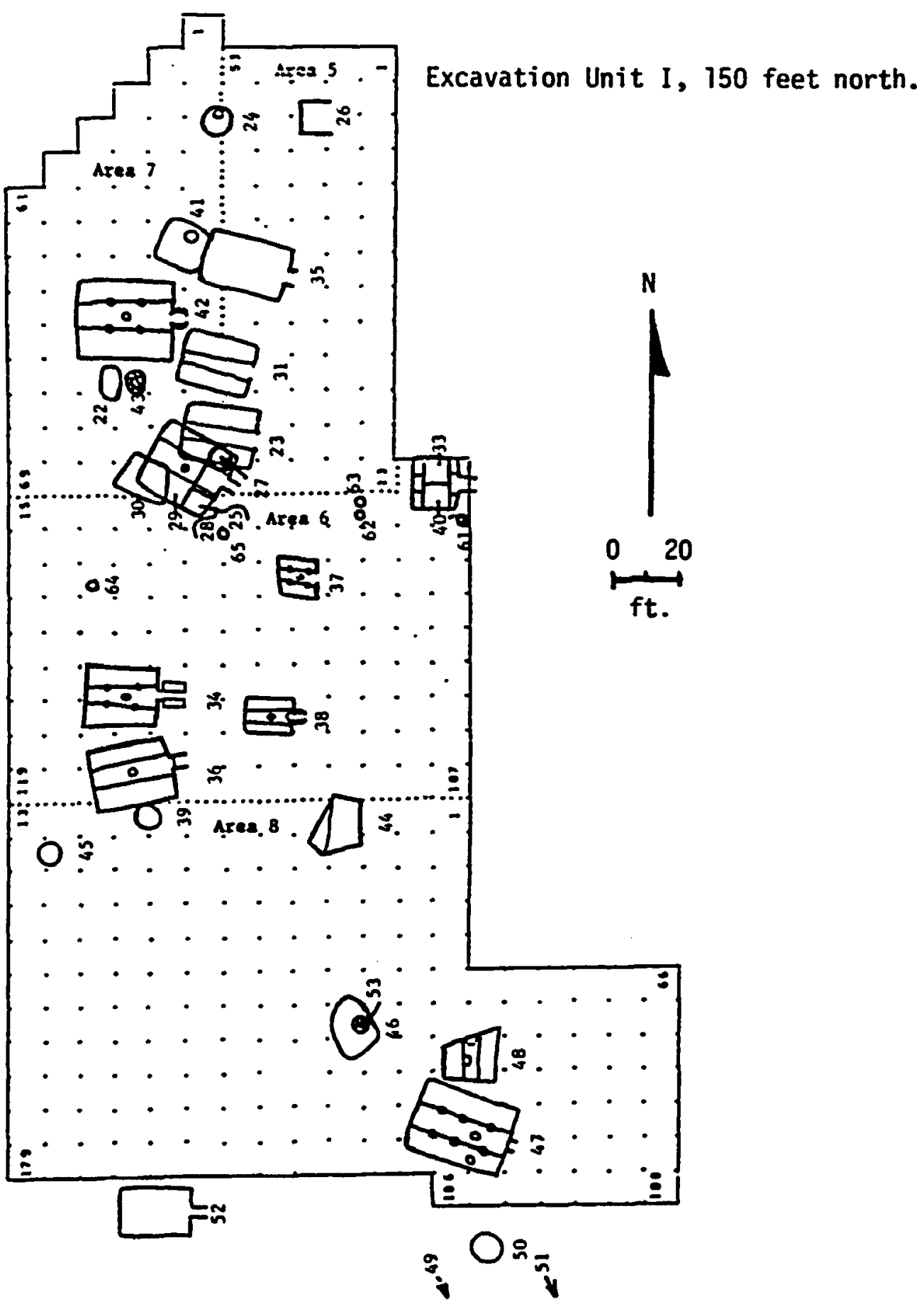

Compiled from sketches in Studer's Files, NPS; Interviews with Ele and Jewel Baker; Photos,

Figure 50. Alibates Ruin 28, Unit II. 
(Areas 5 and 7); however, few items were found near the structures in Area 8 to the south (Figure 51). This suggests that the northern structures may have been occupied for a longer duration and that the village was expanding upridge or to the south. Perhaps only a half dozen household units were initially occupied. Nearly all structures were burned; however, there is little other evidence for raiding. Three burials were encountered during the excavation of Unit II. Single individual interments were found in Rooms 41 and 47, and another burial was encountered east of Room 46. No significant grave goods were found in association.

Besides the obvious difference in community layout between Units $I$ and II, considerable differences are reflected in the quantities of Pueblo trade materials. In Unit I, nonlocal materials were exceptionally scarce: ten olivella shell beads occurred as mortuary items with Burial 8 , but only ten glaze sherds, one unidentified sherd and 13 pieces of obsidian were reported for the $1,515 \mathrm{~m}^{2}$ area. In contrast, nonlocal materials from the $4,110 \mathrm{~m}^{2}$ of Unit II include 178 glaze sherds and 12 turquoise/malachite pendants or ornaments, and at least one olivella shell bead. Obsidian flakes were not systematically tabulated; however, notes indicate that 4,132 flakes were recovered from 322 of the 439 sections in Excavation Unit II (Baker and Baker 1940a:20; Baker 1940a:51; 1940b:44). These differences indicate that Unit II was established during a period of more intense southwestern trade.

A total of five radiocarbon dates is available from Rooms 1 and 19 in Unit I, and Room 24 in Unit II. The MASCA calibrated date for Room 1, an isolated structure, is $1340 \pm 85$ (WIS-114) whereas the dates for Room 19 within the contiguous room block are $1310 \pm 80$ (wIS-116) and 1200-1220 \pm 85 (WIS-129) (Bender, Bryson and Baerreis 1967). All three are considerably 


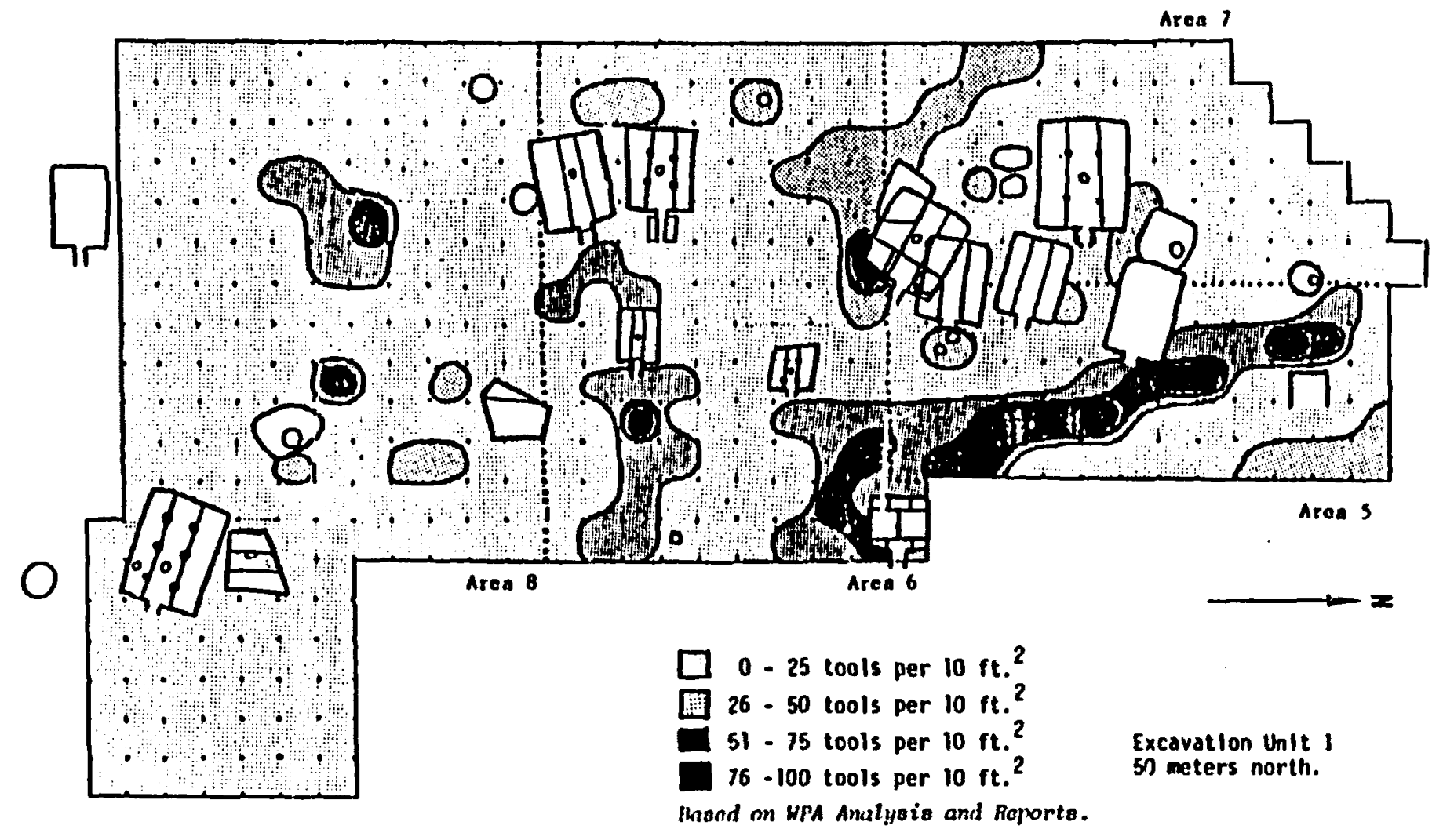

Figure 51. Density of Artifacts in Excavation Unit II, Alibates Ruin 28. 
earlier than the dates of $1340 \pm 80$ (WIS-101) and $1410 \pm 90$ (Tx-259) from Room 24 in Unit II (Ibid., Pearson, Davis and Tamers 1966). These dates are consistent with the postulated trends based on intensified southwestern contacts and support the idea that the site represents multiple occupations.

Alibates $28 \mathrm{~A}$

Alibates $28 \mathrm{~A}$ is a small site located along the west slope of gently rolling terrain above the caprock escarpment. It is $180 \mathrm{~m}$ east of Alibates 28, across an unnamed draw of Alibates Creek. As far as can be determined, the WPA was the only expedition to conduct excavations at the site. The presence of scattered stone slabs suggests perhaps six or seven structures were present, as well as the remains of Allen Bate's historic dugout and cistern (Baker 1940a:37).

During the first quarter of 1940, an 80 by $90 \mathrm{ft}$ area north of the structural remains was staked off into 72 ten foot square sections. However, only 41 sections $\left(318 \mathrm{~m}^{2}\right)$ were cleared. Those sections encompassing a north-south guily through the work area were avoided (Figure 52). The excavation procedures mirrored those used at Alibates 28 . The field work was terminated during the second quarter of 1940 because of a quota reduction in the crew size. Only one structure was exposed.

The structure was a semisubterranean rectangular single room building. The interior features included the typical depressed central floor channel, four interior roof support posts, a central hearth and walls of vertically set stone slab foundations and mortar. One unusual aspect was that the extended entrance was in the west wall, towards Alibates 28 , across the unnamed draw (Baker and Baker 1941b:145). The originally reported size was considerably smaller than other rooms with similar features. 
$0-10$ tools per $\mathrm{ft}^{2}$

il -20 tools per $\mathrm{ft}^{2}$

腾 21 - 30 tools per $\mathrm{ft}^{2}$

$31-40$ tools per $\mathrm{ft}^{2}$

$41-50$ tools per $\mathrm{ft}^{2}$
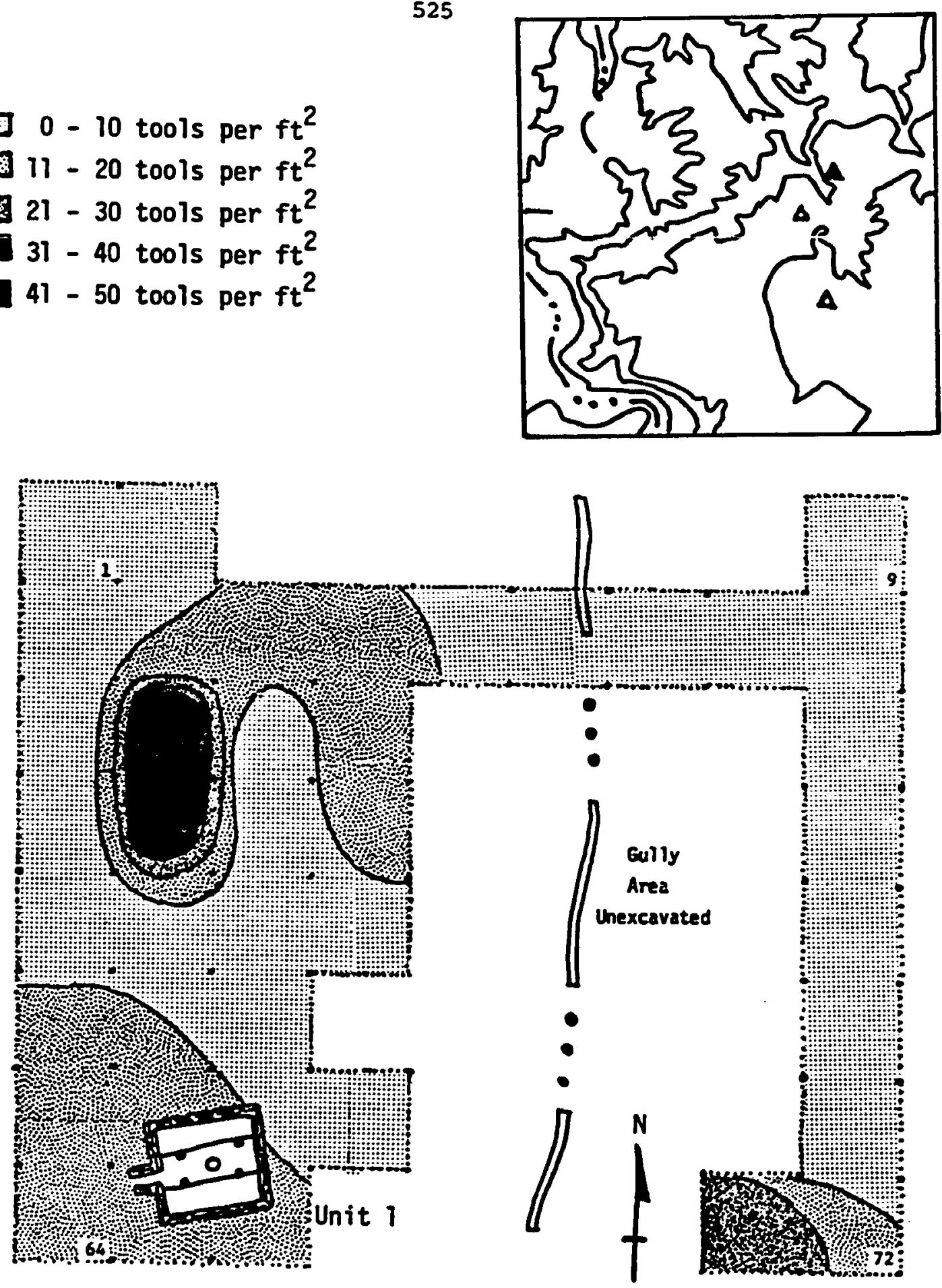

Other Rooms in this area.

- Based on reported refuse areas (Baker 2940a:42-47), and interviews with Ele Baker

Figure 52. Site Map and Tool Density at Alibates Ruin 28A. 
Consequently the room dimensions were checked during a visit to the site in 1983. T e room dimensions are approximately 3.5 times those indicated in the WPA map (i.e., $3 / 8$ inch=1 foot instead of $1 / 4$ inch=1 foot). The density of reported materials shows a slight concentration immediately west of the structure, at the front of the passage, and two higher material concentrations $15.2 \mathrm{~m}$ west and $10.7 \mathrm{~m}$ north of the structure. The available records do not record features or anomalies over these latter artifact concentrations. The doninant materinl remains at both loci include scrapers, projectile points and knives. They may represent outside activity areas. Although the site is undated, at least 16 glaze sherds and 128 obsidian flakes were found (Baker 1940a:51). This is considerably more than that reported for Alibates 28 , Unit $I$, but is comparable to the quantities of trade ware materials from Unit II.

\section{Alibates 30}

Ruin 30 is located on the high flatlands some $800 \mathrm{~m}$ south of Ruin 28 and $4.4 \mathrm{~km}$ south of the Canadian River. The site has numerous isolated structures. Previous field work may have been conducted by Moorehead and perhaps Studer, but there is no map or clear record concerning the location or extent of the early work.

Limited WPA-funded field work was conducted only during the last quarter of 1940 . Crews were shifted to the site when artifactual remains at Ruin 28 became meager. The excavations were limited exclusively to the interior portions of eight structures. Total excavation area is estimated to be approximately $225 \mathrm{~m}^{2}$. Three structures were too severely eroded to discern their size and configuration. The other structures were large rectangular semisubterranean rooms with walls made of a single row of vertical 
Spatial Relationships Unknown.
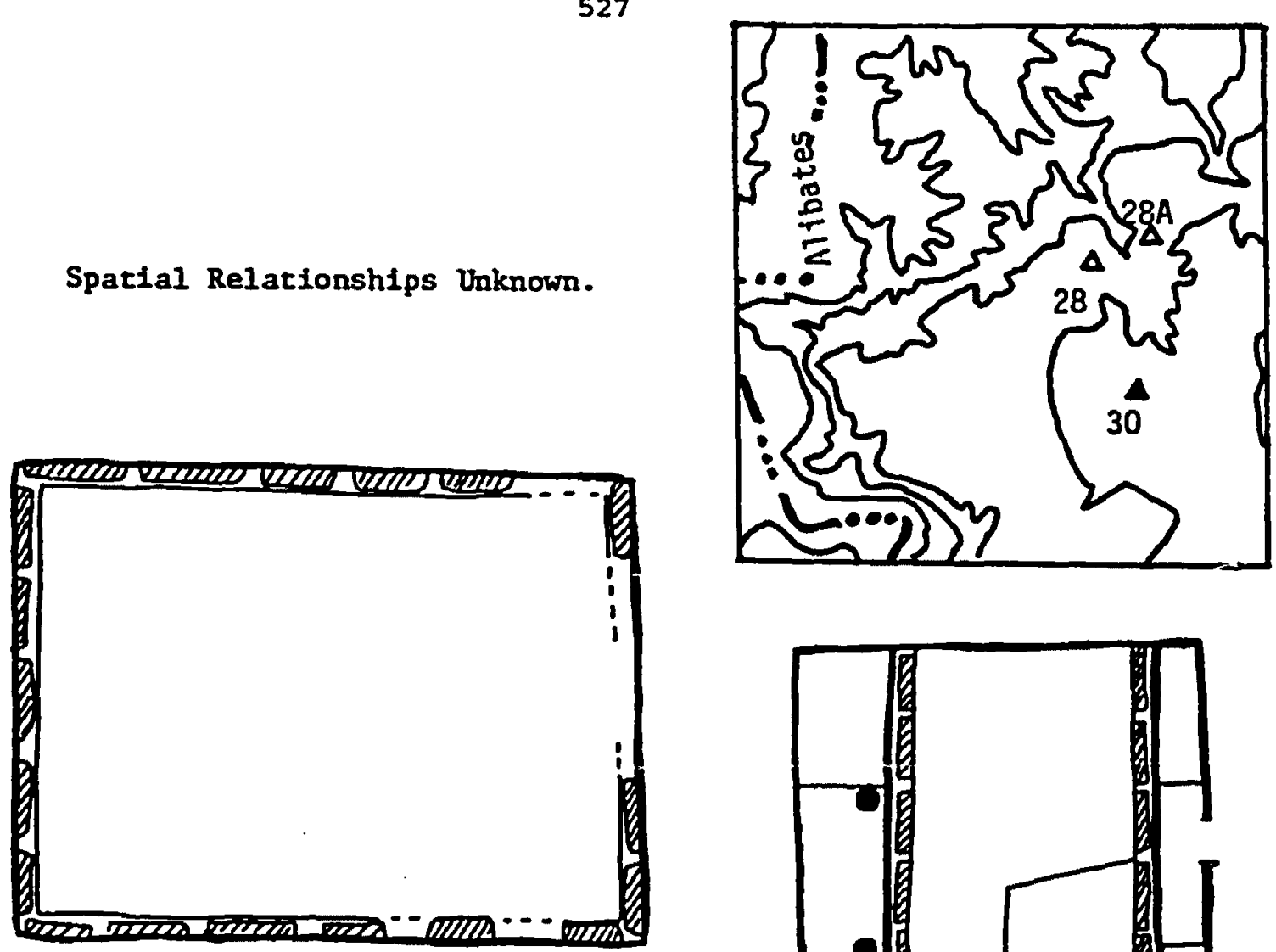

UnIt 1
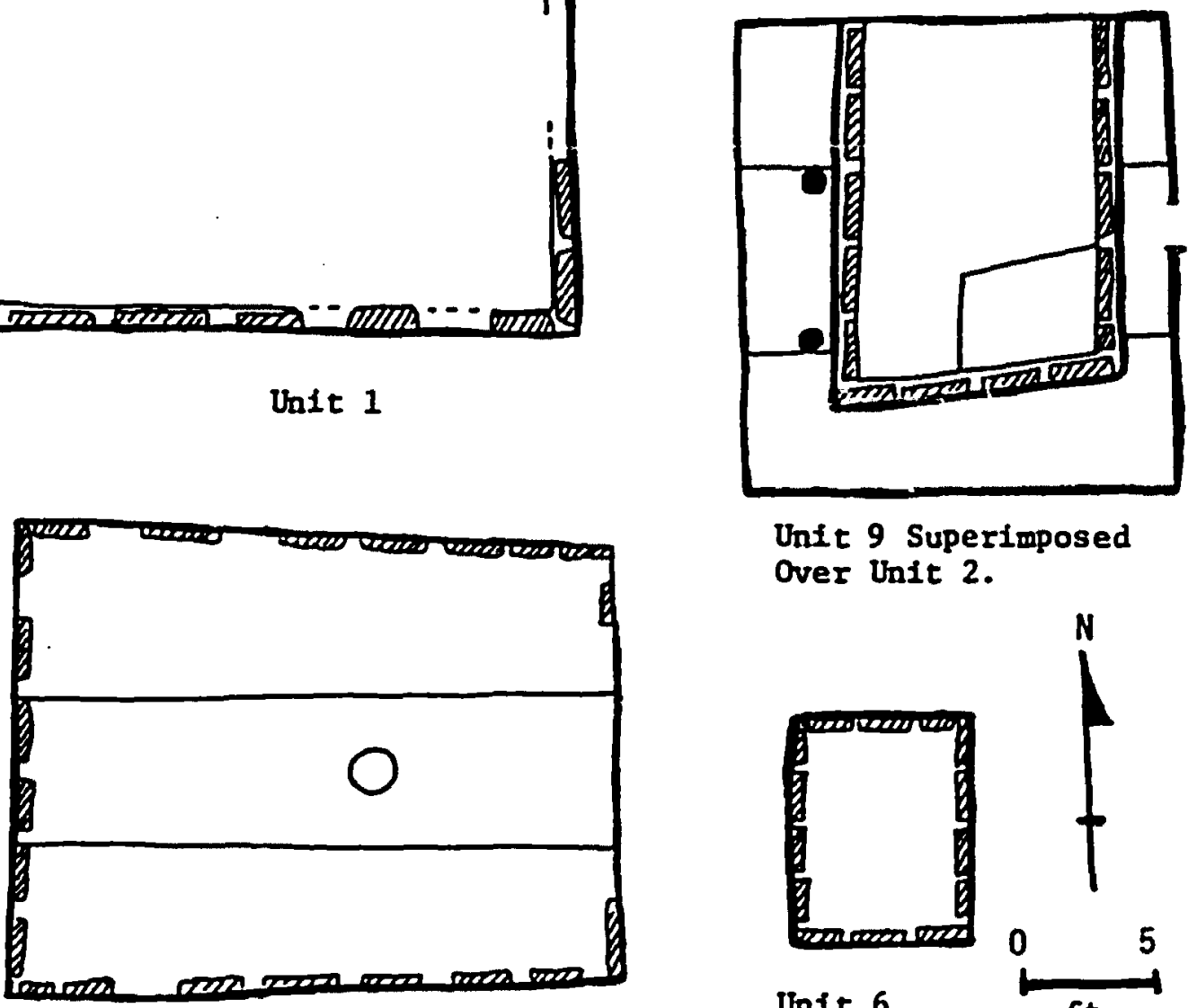

Unit 3

Unit 9 Superimposed Over Unit 2.

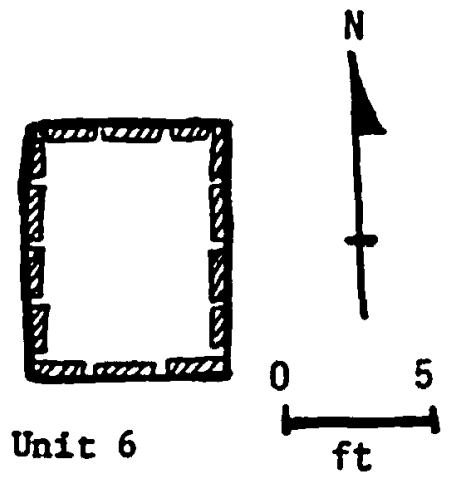

Baker and Baker $2942 \mathrm{~b}$

Figure 53. Architectural Remains at Alibates Ruin 30. 
slabs set in mortar (Figure 53). Many of the structures were incomplete. Frequent gaps in the stone walls were attributed to the reuse of building stones by later tipi-using Indians at the site. Most rooms mirrored the large rectangular household rooms found at Alibates 28; however, Structure 2 lacked stone masonry and was superimposed by an unusual smaller room with a clay platform in the southeast corner. The only other structure reported for the Southern Plains with a corner platform is Bouse 1 at the Goodman I site in Western Oklahoma (Gallaher 1951). This Washita Phase structure is considerably larger than the structure at Alibates 30 , lacks the stone slab walls and has the platform in the northwest corner of the isolated rectangular building. Only five Southwestern trade sherds were recovered as trade items.

Chimney Rock Ruins 51

The Chimney Rock Ruins are located west of Corral Creek and $3.2 \mathrm{~km}$ north of the Canadian River near the west end of the study area. Surface indications suggest that some 27 to 30 structures are present in a saddle between a prominent mesa (chimney) formation and a steeply sloped hill some $28 \mathrm{~m}$ above the Corral Creek floodplain (Studer n.d.a.:4).

The site was excavated by WPA crews during the third grant secured in 1941 (Baker and Baker 1941a, 1941b). A field laboratory/tool shed was constructed at the site, but excavations were suspended after only three months. Unlike the previous WPA field work in the Canadian River valley, the site was systematically gridded. Instead of conforming to topographic features, 12 excavation "areas," each measuring $50 \mathrm{ft}$ by $50 \mathrm{ft}$ were imposed over the site. Each area was subdivided into 25 ten ft by ten ft "sections" which were numbered north to south starting in the northwest corner. No 
vertical provenience was maintained; all units were excavated to culturally sterile soil.

Initial excavations consisted of a north-south trench along the western edge of the ruins and a second trench to the east in order to discern the edge of refuse. A total of 50 sections primarily from areas 1 and 2 was cleared. Six rooms representing portions of at least two contiguous household structures and part of an earlier isolated structure were excavated (Figure 54). Several building episodes are reflected by superimposed structures, rooms over pits, and opportunistic joining of isolated structures by later walls.

Little is known regarding the kinds and distributions of materials at the site. A preliminary draft report mentions that over 2000 artifacts were recovered "in addition to hundreds of Panhandle culture type sherds and thousands of obsidian chips" (Studer n.d.a.). An apparent abundance of Pueblo pottery, obsidian, turquoise, the olivella shell beads at the site has prompted studer (n.d.a.:4-6) to note that a greater percentage of Southwestern trade goods were Found at the Chimney Rock Ruin than at Antelope Creek or Alibates site clusters. Cross dating of unspecified Puebloan sherds indicated that Chimney Rock was occupied from 1300-1450 whereas the . other two site clusters were occupied from 1200-1350 (Studer n.d.a.:4). No finai report was prepared showing the quantity and distribution of materrials from each ccction die to the abrupt termination of WPA funding.

Chimney Rock Ruins 51A

This site consists of three structures located on a small promontory approximately $180 \mathrm{~m}$ west of Chimney Rock Ruin 51 and approximately $42 \mathrm{~m}$ above the Corral Creek floodplain (Baker and Baker 1941b; Studer n.d.a.). 


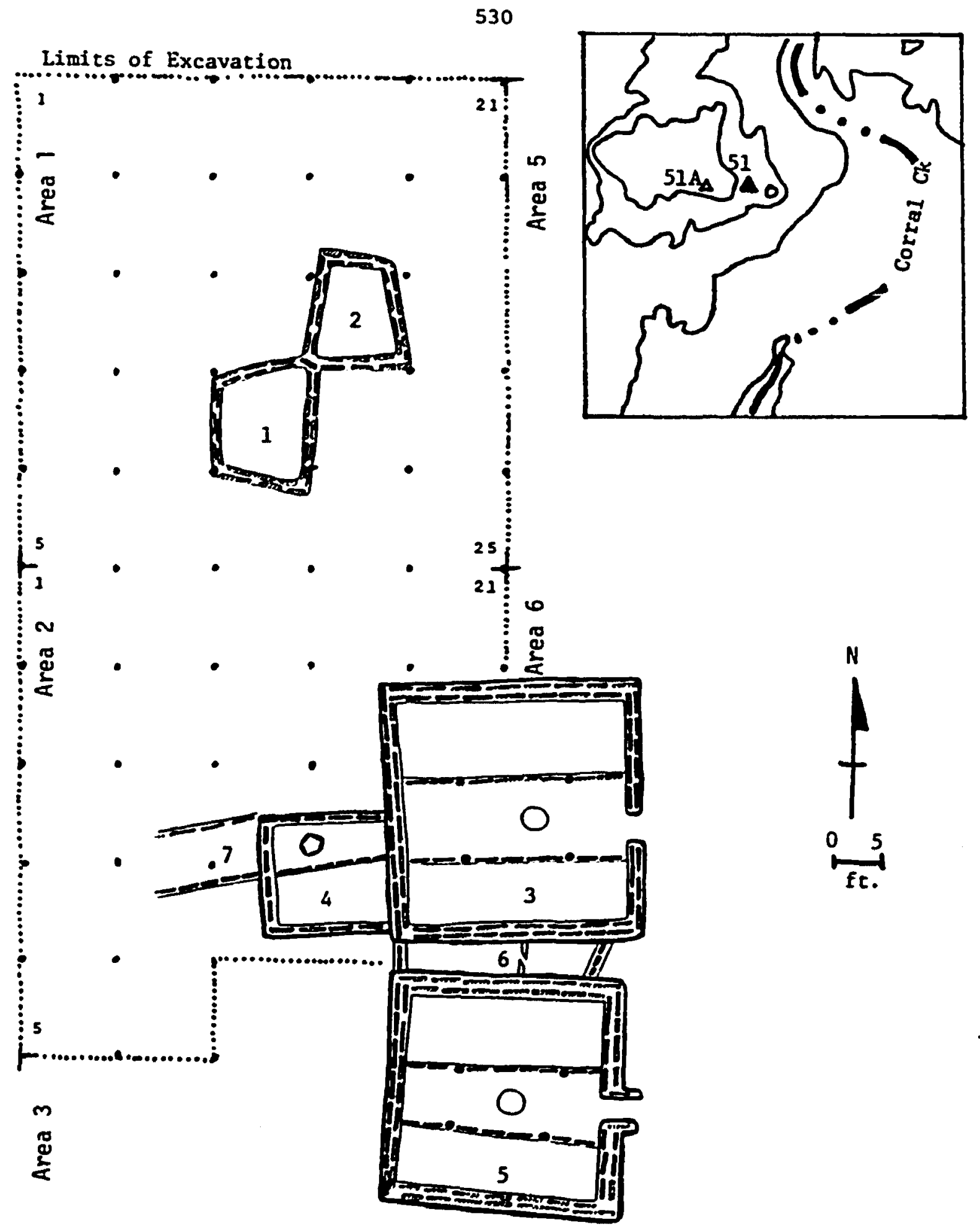

After Baker and Baker Z94Zd:2Z.

Figure 54. Chimney Rock Ruin 51. 
No general site maps were prepared; consequently the spatial relationship of the three rooms is uncertain.

The site was visited and briefly tesced during the second quarter of 1941 in conjunction with the WPA excavations of Chimney Rock Ruin 51. Only the interior portion of a single large rectangular rrom was excavated (Figure 55). The interior features included a floor channel, four interior quadrilateral support posts and a central hearth, reminiscent of the architectural details of other household structures. No artifacts were reported from within the 6.4 by $6.4 \mathrm{~m}$ structures.

Panhandle-Plains Historical Museum (1951-1980)

Seven sites in this study were excavated by, or under the auspices of, the Panhandle-Plains Historical Museun personnel after Floyd Studer's retirement. The labor force consisted of students and volunteers associated with local amateur groups under the direction or assistance of Dr. Jack T. Hughes. These sites include the Sanford Ruin, excavated by the PanhandiePlains Historical Museum; the Roper, Pickett and Cottonwood Creek Ruins excavated by the Norpan Archaeological (Lapidary) Society; the Marsh and Jack Allen sites excavated by the West Texas State University Anthropology Society; and the Zollars Site excavated by the Panhandle Archaeological Society.

The earlier excavations focused on sites near the dam axis of Sanford Reservoir, but as the land came under the control of the National Park Service, later work shifted to private property near the margins of the study area. Most excavations were for short durations with limited objectives, usually to expose one or more rooms. Specific excavation procedures varied according to the size of the crew and nature of the specific objectives. 
532
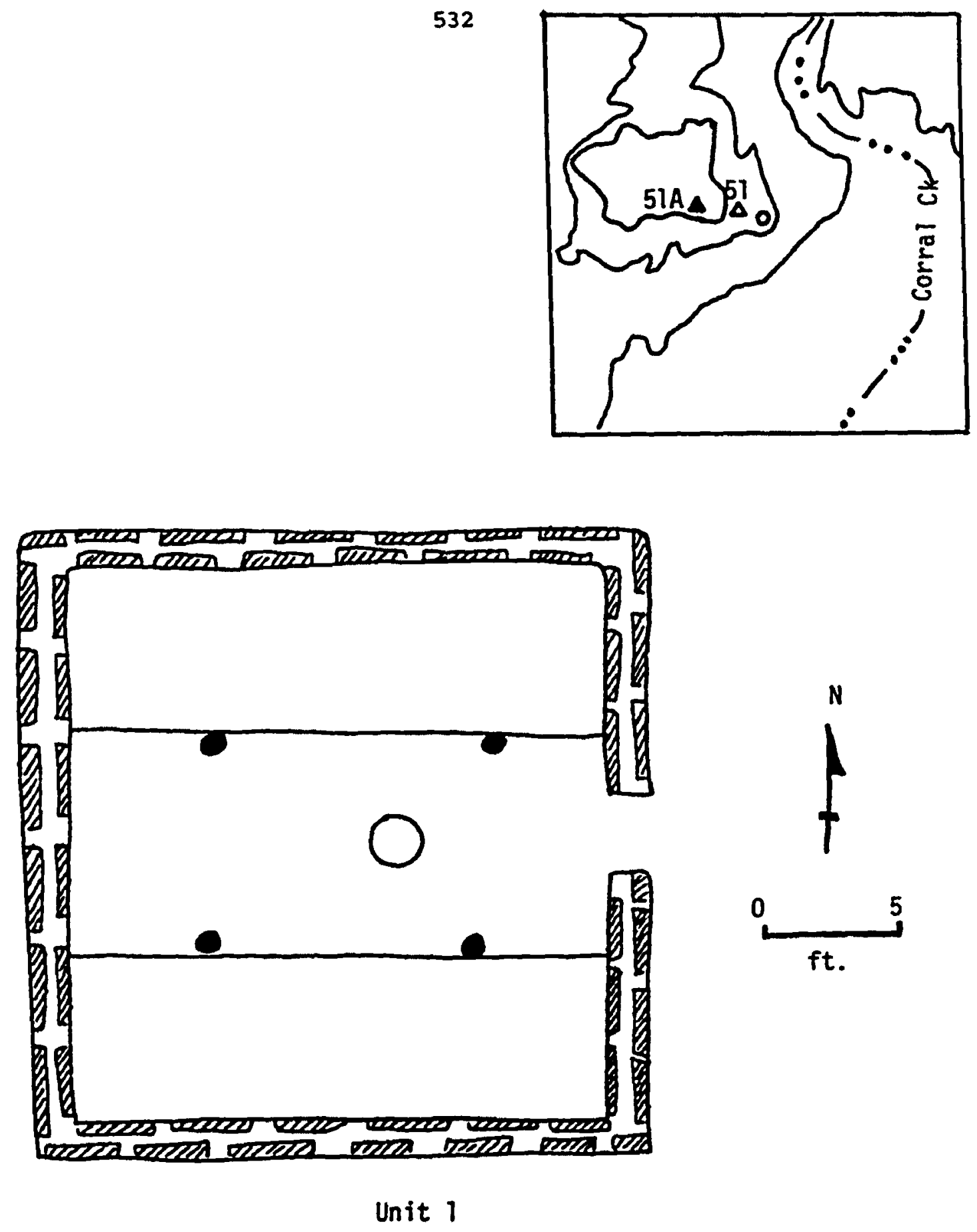

Baker and Baker z942d

Figure 55. Architectural Remains at Chimney Rock Ruin 51A. 
Although unpublished prelimisary reports have been prepared for several sites, artifact identifications and quantities are generally not available.

\section{Sanford Ruin}

The site is on the south rim of the inner valley located some $55 \mathrm{~m}$ above and directly overlooking the Canadian River valley. South Canyon to the east and an unnamed tributary to the west have left a high promontory only a half kilometer from the center of the Canadian Valley floodplain. This promontory, including the Sanford Ruin locality, presently serves as the southern end of Sanford Dam.

Sanford Ruin is part of a cluster of tested sites located near the dam axis. Pickett Ruin is located at the base of the bluff east of Sanford Ruin, whereas the Roper and Conner sites are to the southwest in South Canyon. Across the Canadian River to the north are Spring Canyon and Medford Ranch sites.

Scattered slabs indicated the presence of one fairly large contiguous room structure along the northwest rim of the promontory, and at least three small isolated stone slab features upslope to the east (Figure 56). All of the features had been vandalized to some extent.

Between August 25 and September 12, 1953, excavations were conducted by a small crew of 5-6 people under the direction of Jack Hughes. Most of the work concentrated on the interior portion of the main room block and on sampling an adjacent midden to the north. Initially the loose rock on the surface was removed and stacked into two piles north and south of the room block. Excavations proceeded by "shovel peeling" the soil until stone walls were discerned. No formal grid system was used; however, nine numbers were assigned to work areas generally corresponding to architectural 


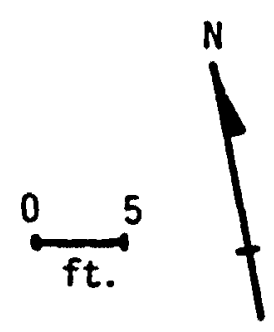

1 foot contour interval

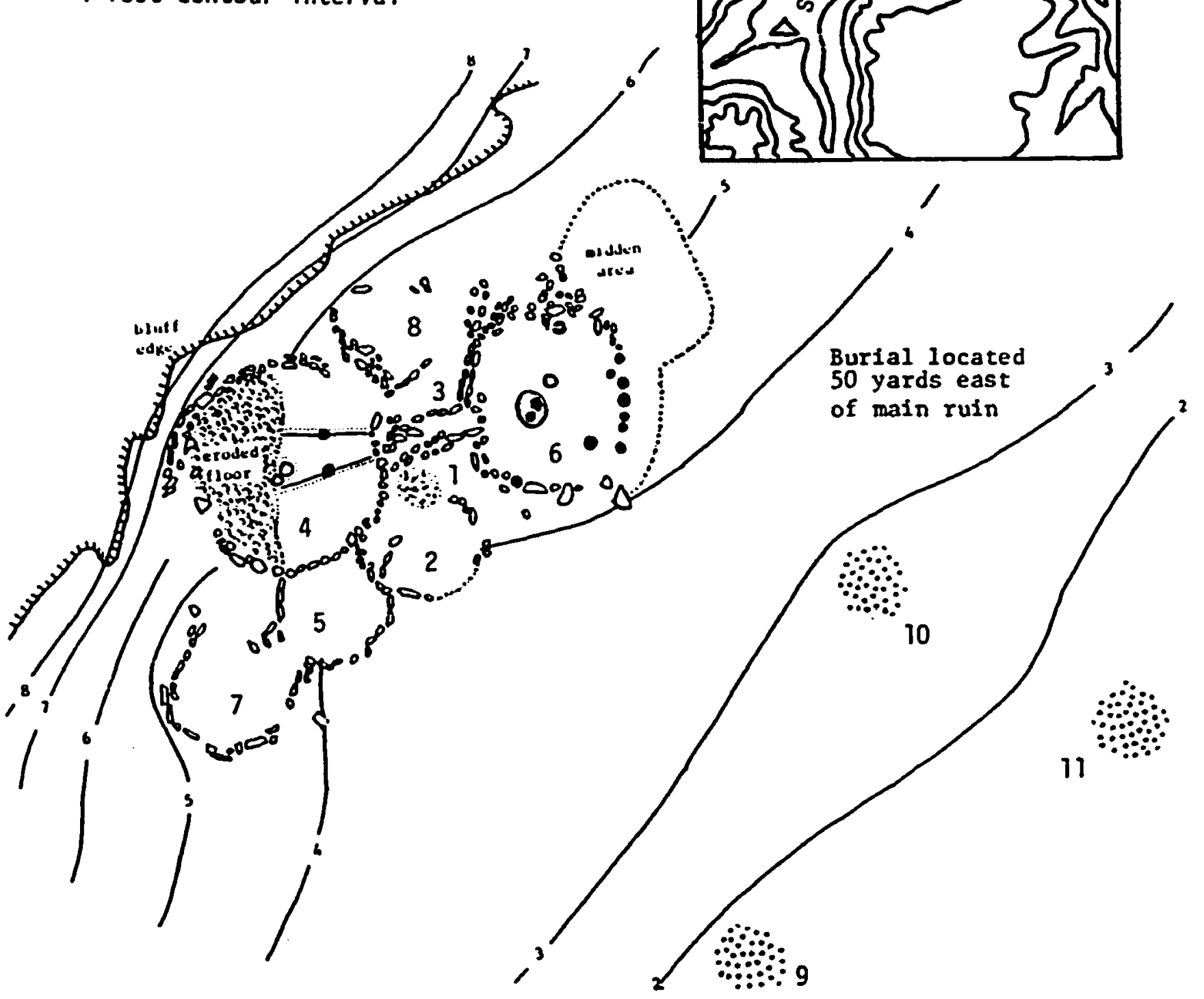

Aften J. Hughes' field maps

Panhandle-Plains Historical Society

Figure 56. Plan of Sanford Ruin. 
units. Each room was excavated by natural strat.igraphy using shovels and small hand tools. Iittle of the room fill was screened; however, the shoveled dirt was reworked on the ground or in wheelbarrows before being hauled to the bluff edge and dumped (Hughes, fieldnotes $8 / 29 / 53,9 / 2 / 53$ ). During the excavation of a midden, $1 / 4$ and $1 / 8$ inch mesh screens were used. Approximately an $80 \mathrm{~m}^{2}$ area was excavated during this period. On October 1011. 1953 additional excavations focused on two of the three outlying structures (designated F-1, F-2 and F-3), and on exposing a burial located along a gentle slope $46 \mathrm{~m}$ east of the ruins. The contiguous room structure consisted of one large circular room with an extended passage towards the northeast (Work Area 4), a rectangular antechamber (Work Areas 6-8), and at least four small circular units flanking the passage and along the south and southeast parts of large circular rooms (Figure 57).

The main circular room measured approximately $5.24 \mathrm{~m}$ in diameter. A plastered floor surface was only discerned in the east half of the unit. Apparently, after the stone walls were built, sterile fill was used to level the floor surface prior to adding the plaster. Erosion along the bluff edge had removed the fill and floor surface in the west portion of the room. The interior features included a depressed central floor channel, a central hearth with an adjacent probable ash pit, and two postholes along the remaining channel ridges in the northeast portion of the room. Although an extended passage was present towards the northeast, no excavations were conducted to discern the nature of this feature.

- A rectangular anteroom was found at the northeast end of the extended passage. Interior features include a central hearth flanked by two posts, an adjacent ash pit, and roof support posts located near the north, east, 


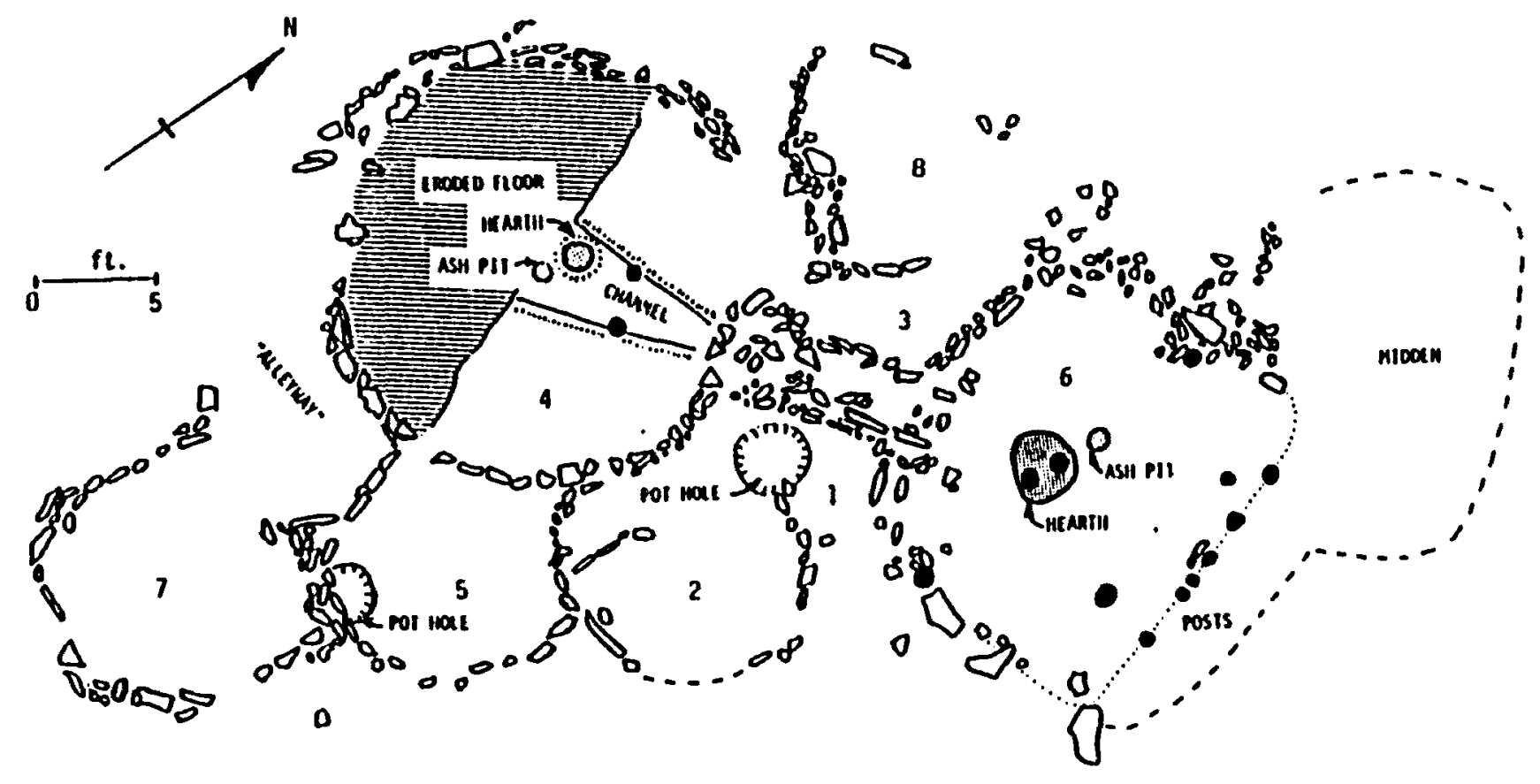

Figure 57. Details of the Main Room Block at Sanford Ruin. 
and south corners. Foundation stones were delineated for the northwest, southwest, and southeast walls, but a series of seven postholes along the northeast edge indicated the presence of a jacal wall.

The four smaller rooms flanking the passage and along the southeast wall of main Room 4 had been vandalized. No interior features were recognized. A gap in the north wall of Unit 7 was lihought to be an entrance. Previous vandalism had disturbed portions of the north wall of Room 2 . Apparently the two units flanking the extending passage ( 2 and 8 ) did not directly abut the antechamber (Unit 6). Instead, the antechamber ins set apart from the other units and was connected only by the extended passage from Unit 4. The two exterior cul-de-sacs on each side of the unit were excavated and assigned work areas 1 and 3 . Although considerable artifacts were recovered, no features were encountered in these areas.

Little information is available concerning the later excavations in the isolated units east of the room block. All three units had been disturbed and human remains were noted in the back dirt piles around Unit 9. Each unit measured approximately $2 \mathrm{~m}$ in diameter. Testing was conducted in Units 10 and 11; however, neither unit was sufficiently delineated to permit adequate descriptions; nor were the functions of features determined.

The buxial located $46 \mathrm{~m}$ east of the ruins was found beneath a pile of dolomite slabs. The interment involved a single female adult in a semiflexed position with her head to the east and facing down. She was placed within a pit nearly $2 \mathrm{~m}$ in diametrr. The only grave accompaniment was a bison tibia digging stick found in the upper fill of the grave.

overall, little information concerning the sequence of room construction was offered. Wall abutments suggest that the smaller flanking rooms 
were built after the main circular unit; however, the number of construction episodes cannot be determined.

The nature and quantities of trade materials for Sanford Ruin are uncertain. Halfway through the excavation phase, the field notes indicate that no Southwest pottery or obsidian had been found, and no mention of trade items appears in the later notes. Presumably southwestern contacts are rare at Sanford Ruins.

A single radiocarbon date for exterior midden deposits yielded a MASCA calibrated date of A.D. $1250 \pm 100(\mathrm{TX}-255)$ (Pearson, Davis, and Tamers 1966). The single date tenuously indicated an occupation during the early portion of the Antelope Creek phase. The paucity of Southwestern trade items provides some support for the early age of the site.

Roper Site

The Roper Site is located on the east central portion of a low bench measuring approximately $90 \mathrm{~m}$ by $18 \mathrm{~m}$ along the west wall of South Canyon near Sanford Dam. The site is some $18 \mathrm{~m}$ above the base of the tributary and approximately $0.7 \mathrm{~km}$ south of the confluence with the Canadian River. Several other sites have been investigated in this valley. The closest is the Conner site located about $0.2 \mathrm{~km}$ to the south. Members of the Norpan Archaeological Society selected the Roper site for excavation, and sought professional advice from Jack Hughes (Dumas n.d.).

Surface indications suggested the presence of at least four small circular structures scattered between two very large boulders spread $9 \mathrm{~m}$ apart. All four structures had been vandalized prior to the Norpan field work. The excavations were conducted between July 27 and October 12, 1957, by twelve Norpan members. Horizontal control was maintained by a five 
foot grid system. The base lines were designated NS (north-south) and EW (east-west). Lines parallel to these base lines were referenced by direction and sequentially numbered ( $E-1$, east one; $N-1$, north one, etc.). Stakes were placed at the intersections of the base lines and squares were designated according to their southwest corner stakes. A total of 125 squares was laid out, but excavations were conducted within only 33 units. The upper edge of one boulder served as a vertical datum point. Six inch levels were maintained in most units. Most fill was sifted through $1 / 4$ inch mesh screens.

Excavations revealed five small circular structures scattered across the terrace (Figure 58). Structure $1(F-1)$, the northernmost unit, is unusual in that it is the only unit in this study which used a natural rock for-

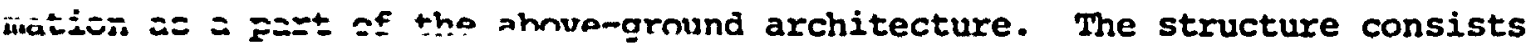
of a D-shaped rock wall approximately $1.5 \mathrm{~m}$ in diameter built west of a large dolomite boulder. The structure had been potted. Interior features include a possible posthole $(F-2)$ near the southwest edge, and a concentration of quartzite "boiling stones" $(F-3)$ near the south wall.

Structure $2(F-5)$ was located approximately $1 \mathrm{~m}$ south of Structure ?. It consisted of a circular unit measuring $1.6 \mathrm{~m}$ in diameter. Vandalism had also destroyed approximately 708 of the central portion of the unit and displaced so many wall stones that no doorway could be discerned. Structure $3(F-8)$ refers to a poorly defined circular concentration of stones located west of Structure 2 in a contiguous position. The site map indicated that it measured approximately $1.7 \mathrm{~m}$ in diameter; a soft area $17 \mathrm{~cm}$ in diameter was interpreted as a possible posthole in the center of the structure. The stones were smaller and more disarranged than those 


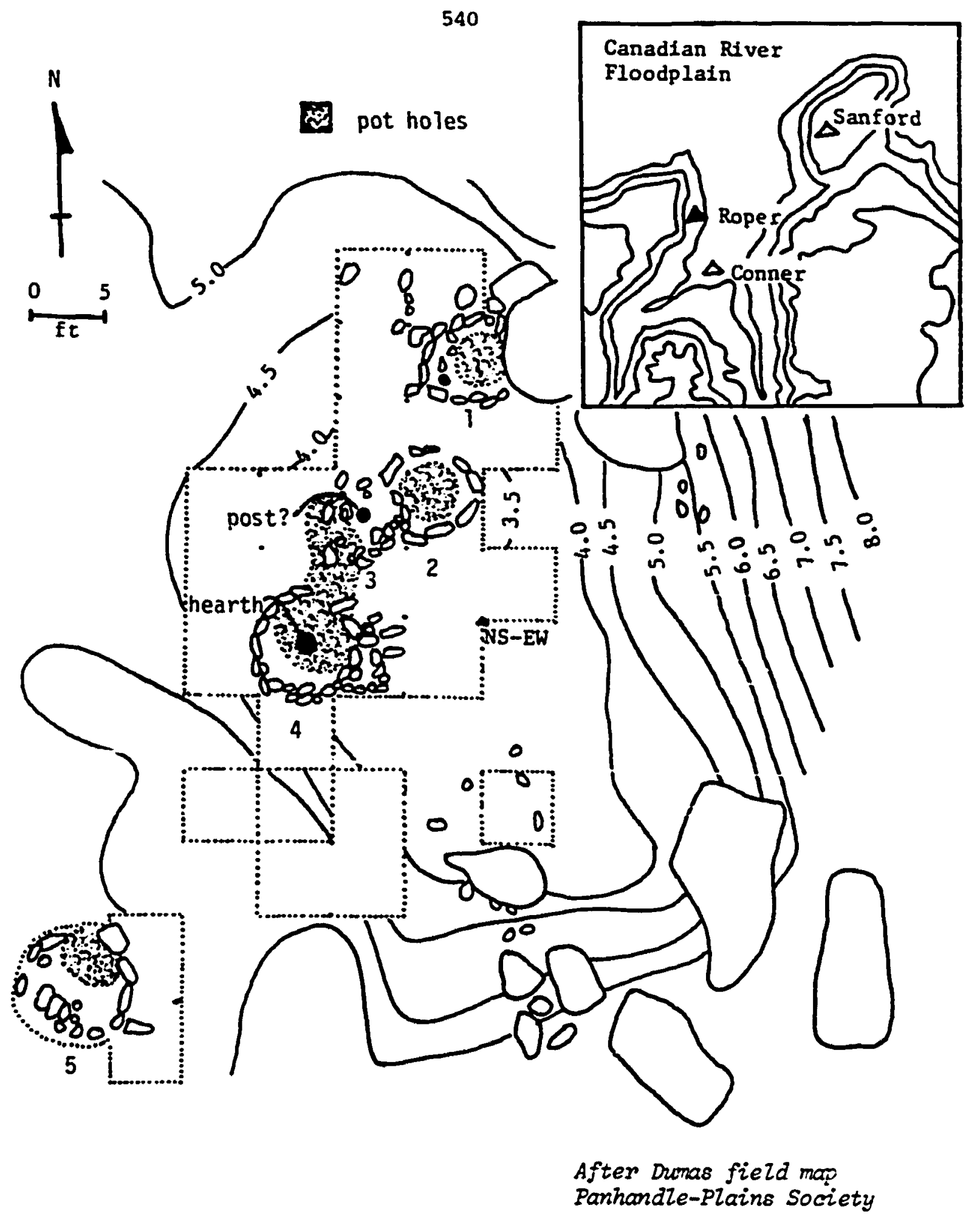

Figure 58. Plan of the Roper Site. 
used in constructing the other architectural units at the site. Wall rubble included three manos and three metate fragments.

Structure $4(F-6)$ measured approximately $2.0 \mathrm{~m}$ in diameter. The floor surface had been leveled by being excavated $5 \mathrm{~cm}$ into the sterile red soil. The wall foundations consisted of stone slabs set slightly into the sterile soil and possibly leaning against the semisubterranean block. A gap in the large foundation stones and differences in the size and orientation of rocks used within the upper portion of the remaining wall was interpreted as a doorway which had been sealed. A small basin-shaped hearth measuring $30 \mathrm{~cm}$ in diameter was found in the center of the unit.

Structure $5(F-9)$ was located approximately $7 \mathrm{~m}$ southwest of the other units. It consisted of a circular unit measuring approximately $2.0 \mathrm{~m}$ in diameter. The southeast portion of the circular wall appeared to have collapsed in on the unit. No entrance was discernible. The unit was also somisubterranean, but the floor surface was concave. Vandalism had obliterated any evidence of a central hearth.

Considerable quantities of additional materials were recovered from the site; most of the midden seems to have been located along the gentle slopes of the bench. The assemblage shows considerable diversity and includes boiling stones, manos, metates, points, beveled knives, scrapers, scapula hoes, a tibia digging stick, corn cobs, shaft straighteners, drills and abundant ceramics. The notes mention the presence of three Upper Republican collared rim sherds from Unit W1-N1, and an "incised" sherd from N5-W4 as possible trade items. No southwest veramics or obsidian flakes were listed in the catalogue sheets or mentioned in the field notes. Composite samples of charcoal from unspecified provenience localities 
were submitted for dating. The two MASCA calibrated samples date to A.D. $1300 \pm 80$ (wIS-134) and $1355 \pm 80$ (wIs-141) (Bender, Bryson, and Baerris 1967). Both are fairly consistent and are regarded as acceptable age determinations.

\section{Pickett Site}

Pickett Ruin is located only $3 \mathrm{~m}$ above the canyon floor of an unnamed tributary $0.5 \mathrm{~km}$ south of its confluence with the Canadian River. The site is part of a cluster of sites including the Roper, Conner, and Sanford Ruins located at the south end of Sanford Dam. Pickett is at the east end of the site cluster on the lower terrace bounded with dolomite talus boulders. Surface indications suggested that only a single small circular structure was present.

The site was found in August, 1953 by Jack Hughes and intermittently excavated by the Norpan Archaeological Society during April-July, 1958 (Carter and Carter 1958). A smals pothole was located in the center of the structure prior to the Norpan excavations. Initially, small test pits were dug southwest and northeast of the structure to avoid covering midden areas with backijut. Next an 18 inch wide trench encircling the exterior of the stone slab structure was excavatizd to search for possibic adjoining rooms. The encircling trench was exsavated by shovel skimming without the benefit of screening the fill. Next, the interior fill of the room was removed and screened using small hand tools. Finally, short trenches were excavated in cardinal directions from the structure in order to locate associated midden areas.

The north trench was later expanded to obtain a larger sample of the midden deposits. The circular structure measured slightly more than 2 in 


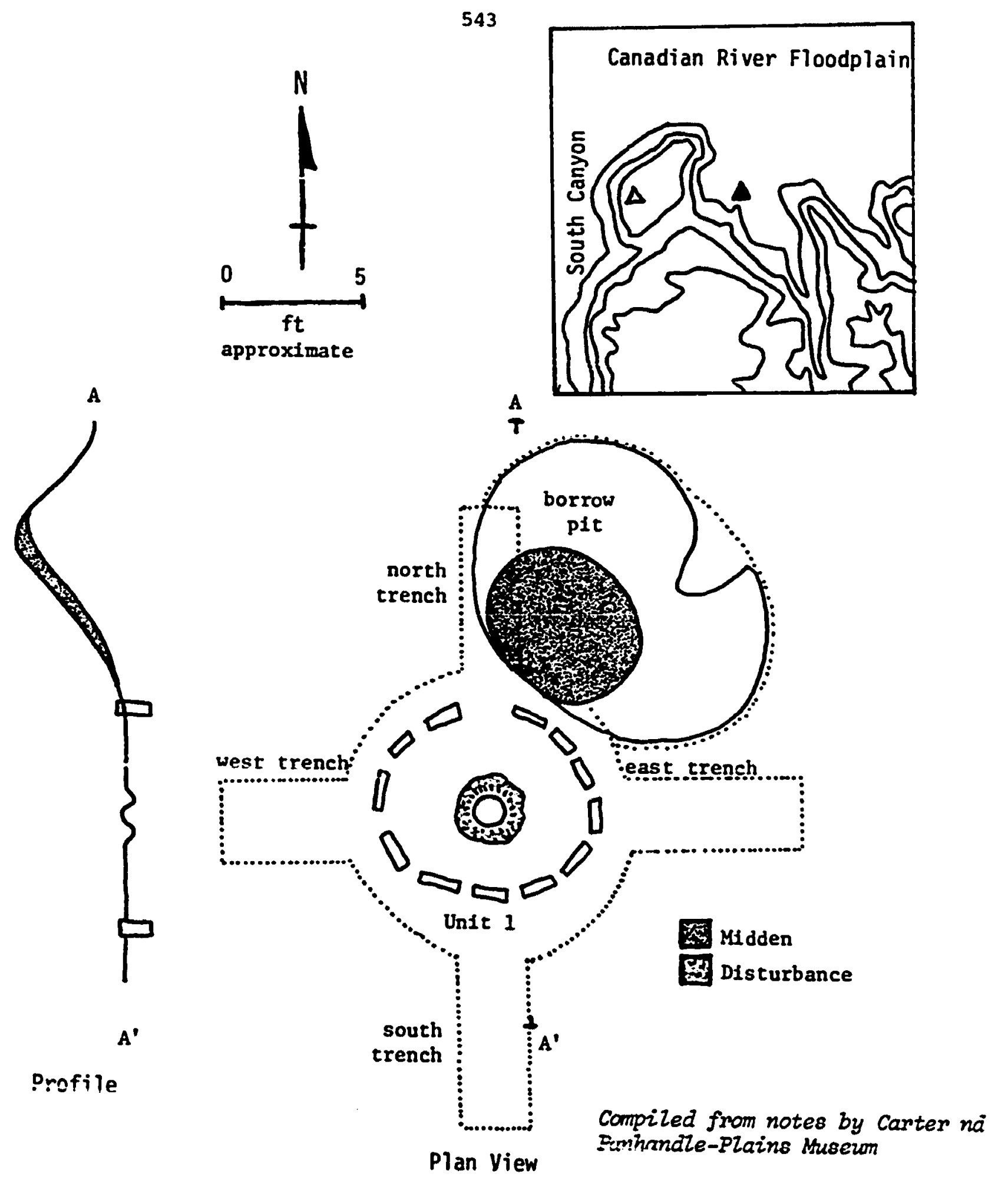

Figure 59. Plan and Profile of the Pickett Site. 
in diameter. It had a central hearth with a raised rim (Figure 59). A gap in the northeast wall possibly represented a door. Testing north of the site located a broad but shallow borrow pit which had been subsequently used as a trash dump. Midden materials were concentrated on the pit slope closest to the room.

Few artifacts were recovered from the estimated $26 \mathrm{~m}^{2}$ area excavated at the site. No exotic trade materials were found; however, a stone pestle (mano?) and portions of two bison tibia digging sticks were recovered. Few potsherds were found. The paucity of materials suggests that the occupation covers a short duration. Faunal analysis indicated that the site was occupied during late spring or summer (Duffield 1970:192). The range of tools and seasonality interpretation, coupled with the presence of an interior hearth, has suggested that the structure represents a field house used as an outlier in conjunction with some other larger site.

A single charcoal sample for the middan area yielded a MASCA corrected date of A.D. $1240 \pm 80$ (wIS-126) (Bender, Bryons and Baerreis 1967). No other samples can corroborate the date; however, the absence of trade items tentatively supports the early temporal position of the site.

\section{Cottonwood Creek Ruin}

This ruin is located atop a fairly steep bluff on the west side of Cottonwood creek at its junction with an unnamed short lateral tributary. The Canadian River is located some $4.4 \mathrm{~km}$ to the south. A spring-fed gully has eroded into the hilltop, and a series of isolated and contiguous structures is scattered near the spring and on both sides of the gully, some $34 \mathrm{~m}$ above the Cottonwood Creek floodplain. 
The site was visited and mapped in 1920. Moorehead (1931:87, 110) observed ten structures or room blocks, and indicated that two of them measured approximately $7.62 \times 5.03 \mathrm{~m}$ and $6.71 \times 5.79 \mathrm{~m}$. He also located 29 "graves" scattered within a 60 by $90 \mathrm{~m}$ area and excavated three or four of them to demonstrate the presence of bones (Figure 60).

By 1927, a Phillips Petroleum refining and pumping station was built southwest of the main site area, destroying at least one cemetery area. The development of road and gas pipeline systems has largely destroyed the site (Holden 1929). By 1929, Holden could only find a few walls which had not been destroyed. In addition to the development of the adjacent site area, continued maintenance of the dirt roads and vandalism by gas plant workers have destroyed most of the site.

In the fall of 1958 and spring of 1959 members of the Norpan Society developed a site map and conducted excavations in one rectangular structure on a low rise in the southern portion of the site (Figure 61). The southern portion of the room had already been vandalized. A five foot grid system was imposed over the single room unit. Several test pits were excavated to establish the stratigraphic sequence. Subsequent work involved "shovel peeling" the room fill to within two or three inches of the floor surface. Small hand tools were used to loosen the remaining fill and expose the floor. Only this lower stratum was systematically screened (Carter n.d.b.:2).

The single room was built on a rocky surface which sloped towards the northeast. The downslope (north) ejge of the structure had a double row of vertical slabs to reinforce the wall but only a single row of slabs on the east and west walls (Figure 61). Sterile soil was used to fill and 


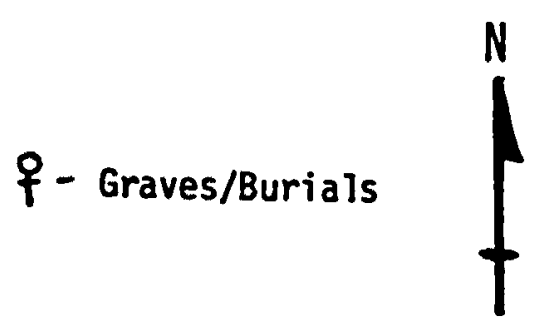

No Scale

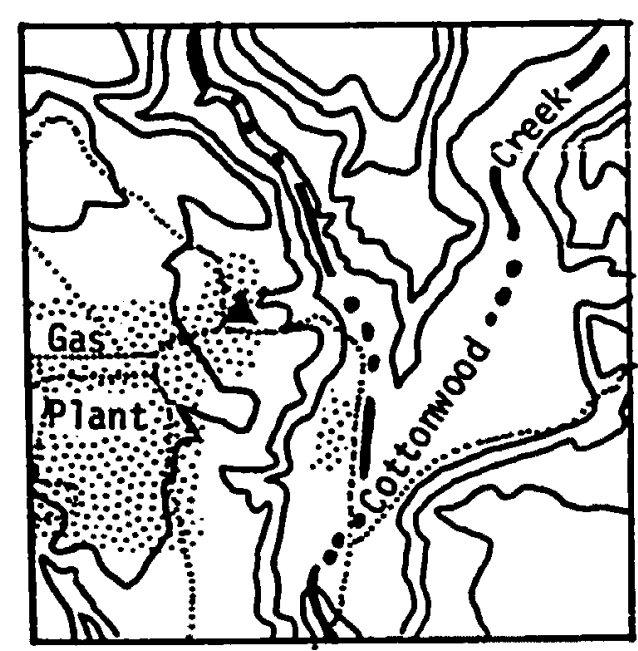

of of

500 feet

to graves
M

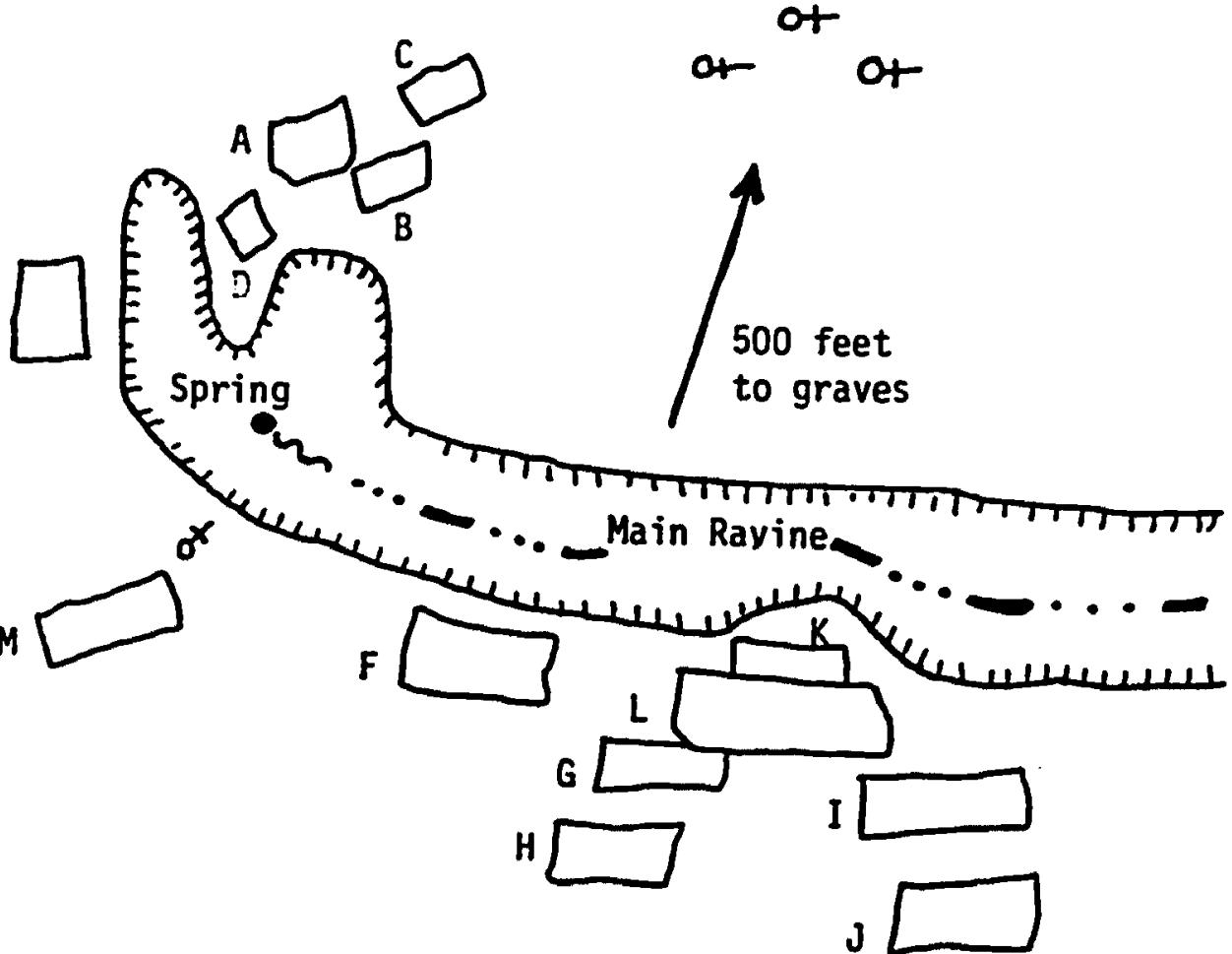

of

After Moorehead 2932:87

Figure 60. Cottonwood Creek Ruins. 

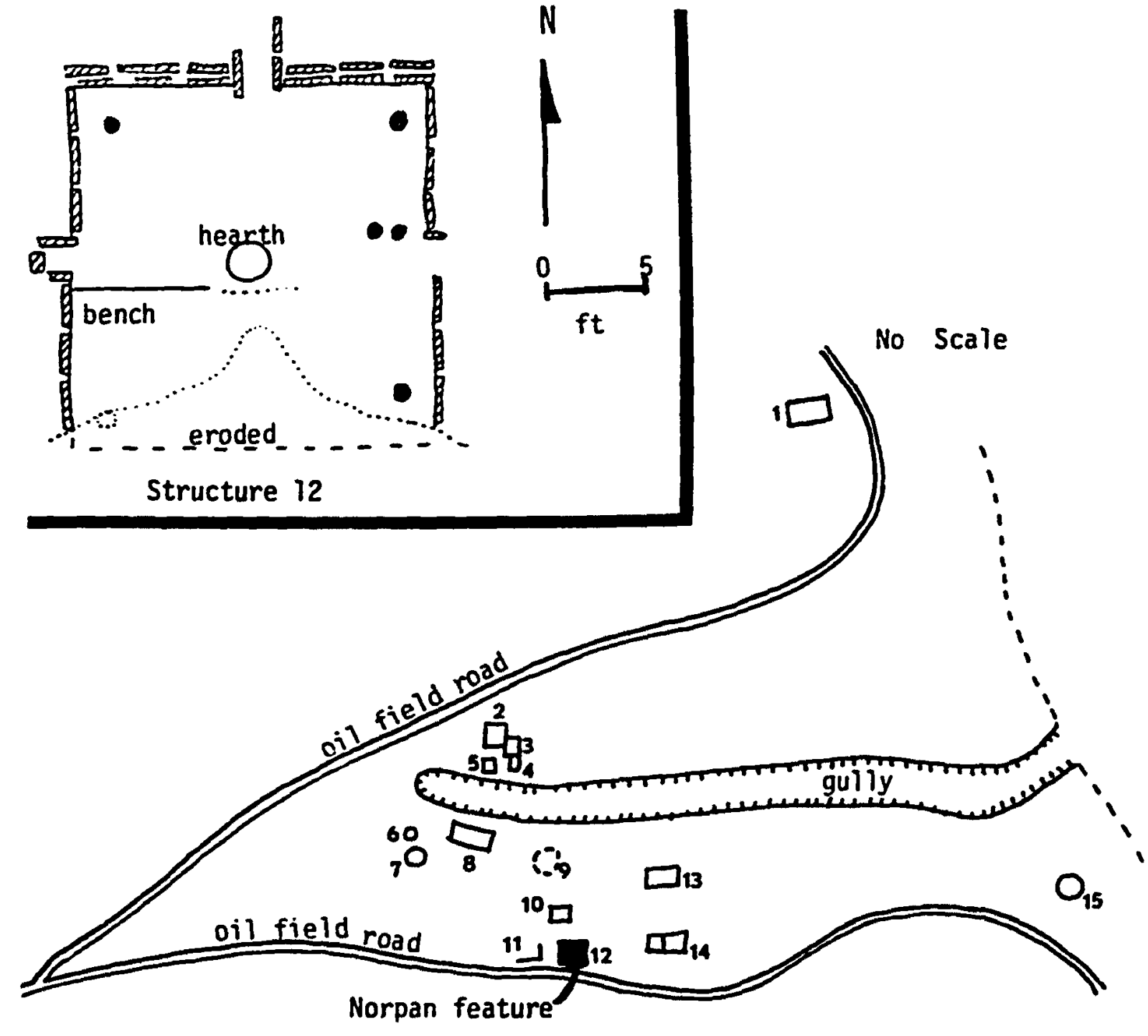

After Norpan field map Dick Carter Collection

Feature dimensions (in feet) listed on Norpan field map.

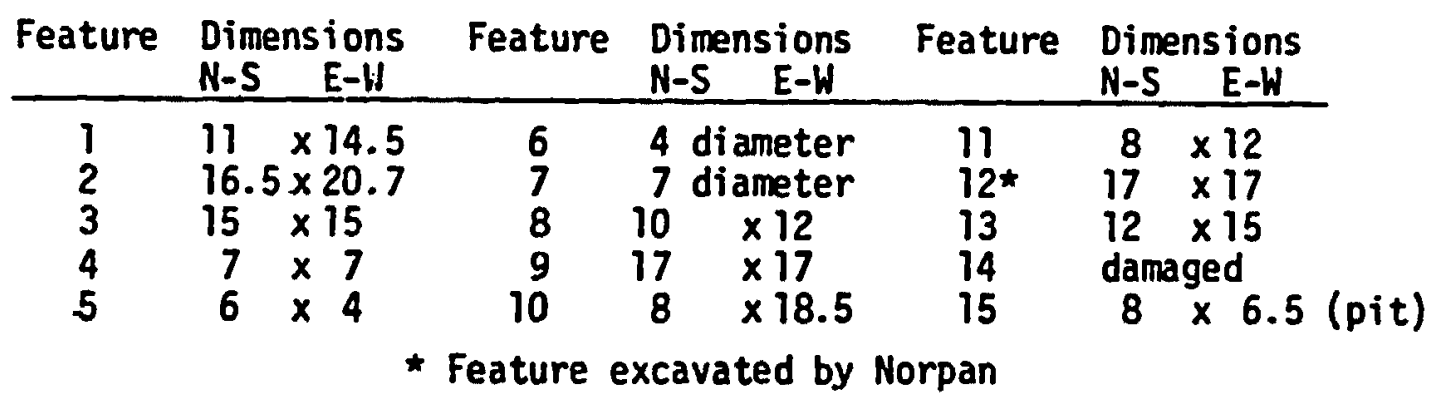

Figure 6l. Norpan Excayations at Cottonwood Creek Ruins. 
level the floor surface. This fill was $0.05 \mathrm{~m}$ on the south side and $0.20 \mathrm{~m}$ on the north. The east, north, and west walls each had a single gap, approximately $0.56 \mathrm{~m}$ wide in the middle of the walls which provided access to the room. Two large slabs had been used to seal the west wall gap entrance. Interior features were difficult to discern. Portions of an $0.05 \mathrm{~m}$ tall channel curbing were found extended from the south side of the west wall opening. It was traced only $2 \mathrm{~m}$ into the room before being lost in the fill. An unplastered "fire area" measuring approximately $1.20 \mathrm{~m}$ in diameter was found near the center of the room. Postholes were found near three of the four corners of the room and at least two other interior posts were in line with the south edge of the east passageway. This unit differs from other units by the presence of multiple passage openings and the location of posts near the corners. Subsequent encroachment of an oil field road has destroyed this structure so that the field observations are impossible to verify. Material remains from the Noxpan excavations were meager. No Southwestern trade items are listed in the report; however, at least four of the seven rim sherds have a collared form reminiscent of Upper Republican wares (Carter n.d.b.:3-4).

The Marsh Site

The Marsh Site is located on a relatively high bluff on the east side of Tecovas Creek. It is approximately $30 \mathrm{~m}$ above the creek floodplain and only some $0.3 \mathrm{~km}$ south of the Canadian River. Dolomite slabs on a narrow point of the inner valley wall rim called attention to the site. The site is believed to represent a single, isolated residential unit; however, at least one other structure is located across a deep gully southwest of House 1 (Hughes, field notes dated 5/6/67). 
Excavations at the Marsh Site were conducted during three weekends in April, 1967 by students of West Texas State University Anthropology Society under the direction of Jack Hughes. Emphasis focused on a single rectangular room structure which had been recently vandalized. The stone walls were traced out, and the room was divided into quadrants. The fill from the postholes was removed separate from that in each quadrant. Shovels and small hand tools were used to loosen the soil before it was passed through $1 / 4$ inch mesh screen.

The room was rectangular with a central extended passage, a central channel and four roof support posts (Figure 62). Vandalism had destroyed the central and western parts of the channel where possible hearths $a n$ ? platforms would likely have been placed. The channel did not extend entirely to the east passageway, and a large slab was found near the eastern edge of the channel near the door which may have been a deflector.

Limited excavations northwest of the structure revealed that it had double vertical slab walls. On May 13, 1967 and Octoker 19, 1968, nine 5 by 5 ft exterior squares were also excavated immediately east of the passageway in order to sample midden deposits. Portions of several irregular pits were encountered which probably reflect the source of adobe mortar.

No description or tabulation of artifacts was available in order to discern the frequencies and quantities of nonlocal materials.

The Jack Allen Site

The Jack Allen Site is the easternmost locality within the study area. The site is located on an old eolian covered terrace along the west edge of Spring Creek, some $8.7 \mathrm{~km}$ south of its confluence with the Canadian River (Harrison n.d.). The site is only some $12 \mathrm{~m}$ above the creek bed. 

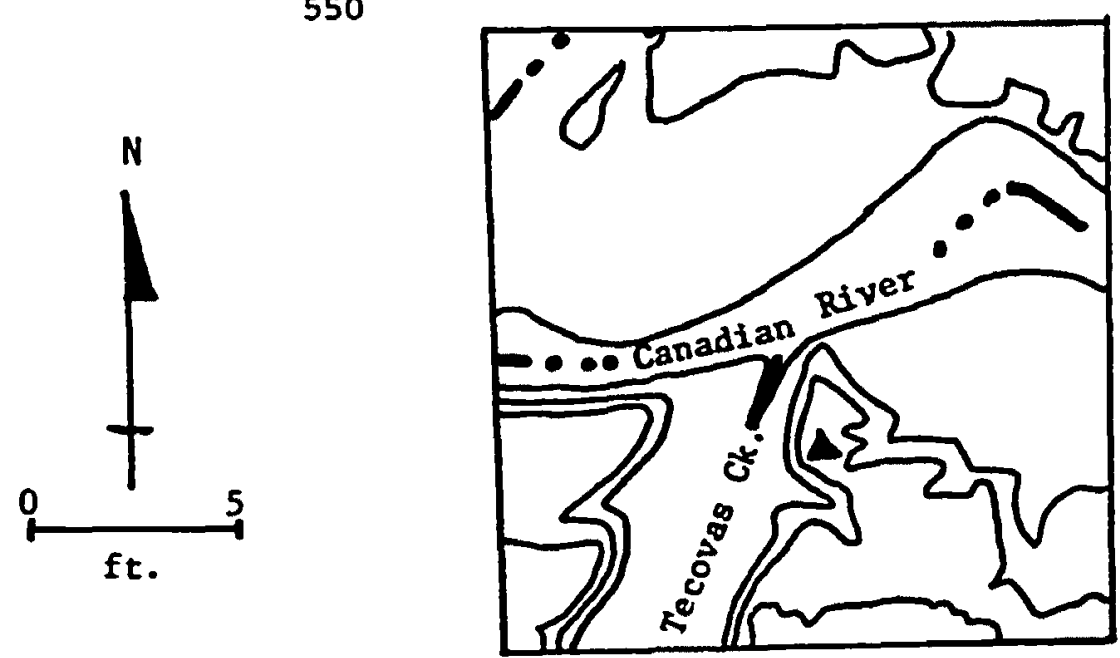

Excavation Limits
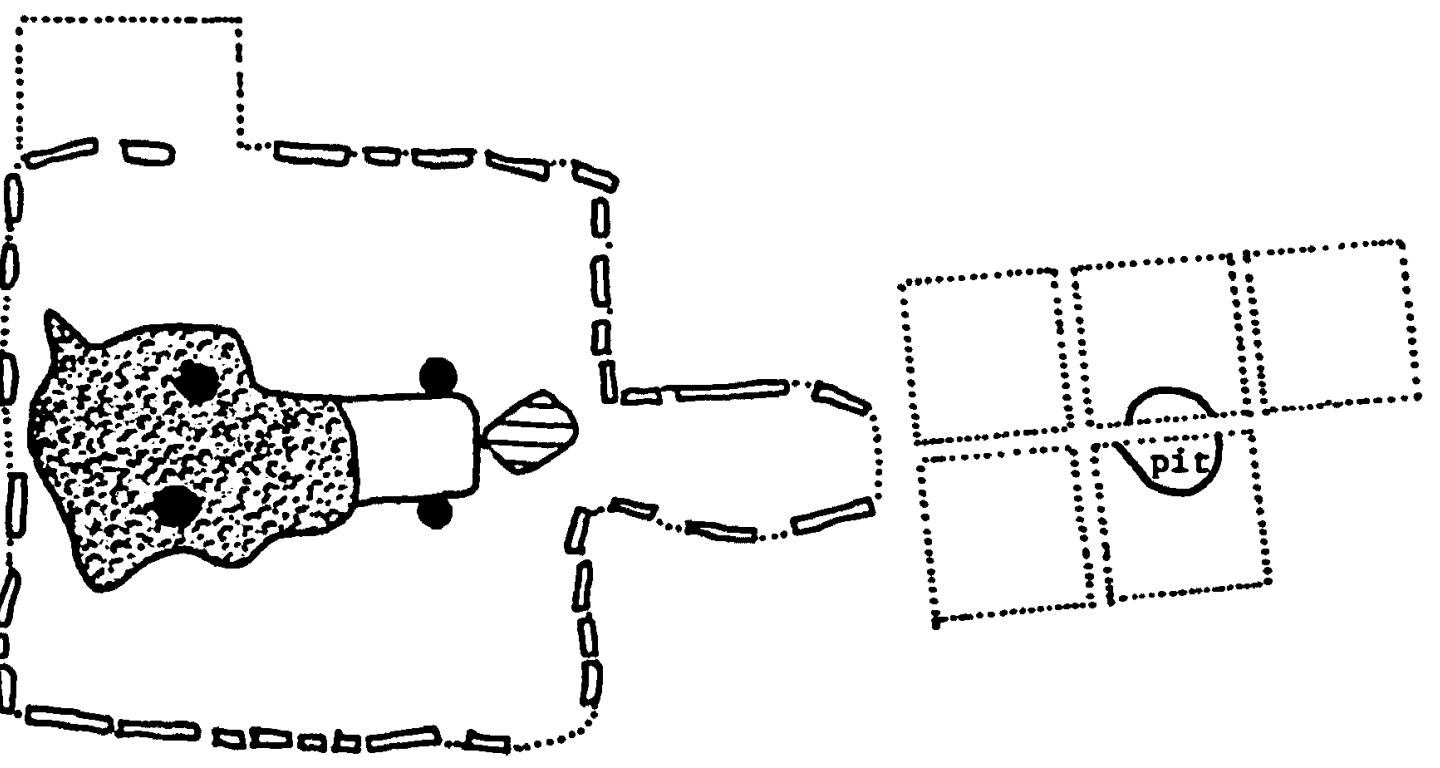

displaced "deflector slab"

Disturbed area

After Jack Hughes field map

Panhandle-Plains Bistorical Museron

Figure 62. Plan of the Marsh Site. 
The area is east of the Permian exposures and no dolomite slabs are present for suitable building material. Harrison notes that although no springs are near the site, several are in the general area, and a large deep arroyo several hundred yards to the south may have had live water during the time of occupation.

Excavations were conducted at the site on six occasions between October, 1969 and April, 1970 by members of the West Texas State University Anthropology society. The presence of daub and a floor surface exposed in an eroded bank indicated the general areas of excavation. In order to expose the structure, six $10 \mathrm{ft}$ squares were established, and were excavated in six inch arbitrary levels. Fill was removed by shovel peeling to just above the floor surface and all fill was screened through $1 / 4$ inch mesh hardware cloth. Only a single room was exposed. A second possible structure is located approximately $50 \mathrm{~m}$ to the northeast (J. Hughes, personal communications, 1984). The excavated room was well baked from an intense fire which preserved numerous architectural details. This house differed in a number of aspects. Most noticeably, the walls consisted of daub covered posts spaced 0.15 to $0.20 \mathrm{~m}$ apart. The room had the typical rectangular shape, eastward extended entrance, central channel, four roof support posts, entry step, threshold columns, and a platform (Figure 63). The edges of the channel were slightly raised, and the platform was recessed into the west wall instead of extending into the room. In addition, the central portion of the vestibule was lower, as if it acted as a cold air trap. Approximately $2.5 \mathrm{~m}$ east of the vestibule were two large pits measuring $1.22 \mathrm{~m}$ in diameter and approximately $1.15 \mathrm{~m}$ in depth. Most of the artifacts from the site were removed from these pits. 

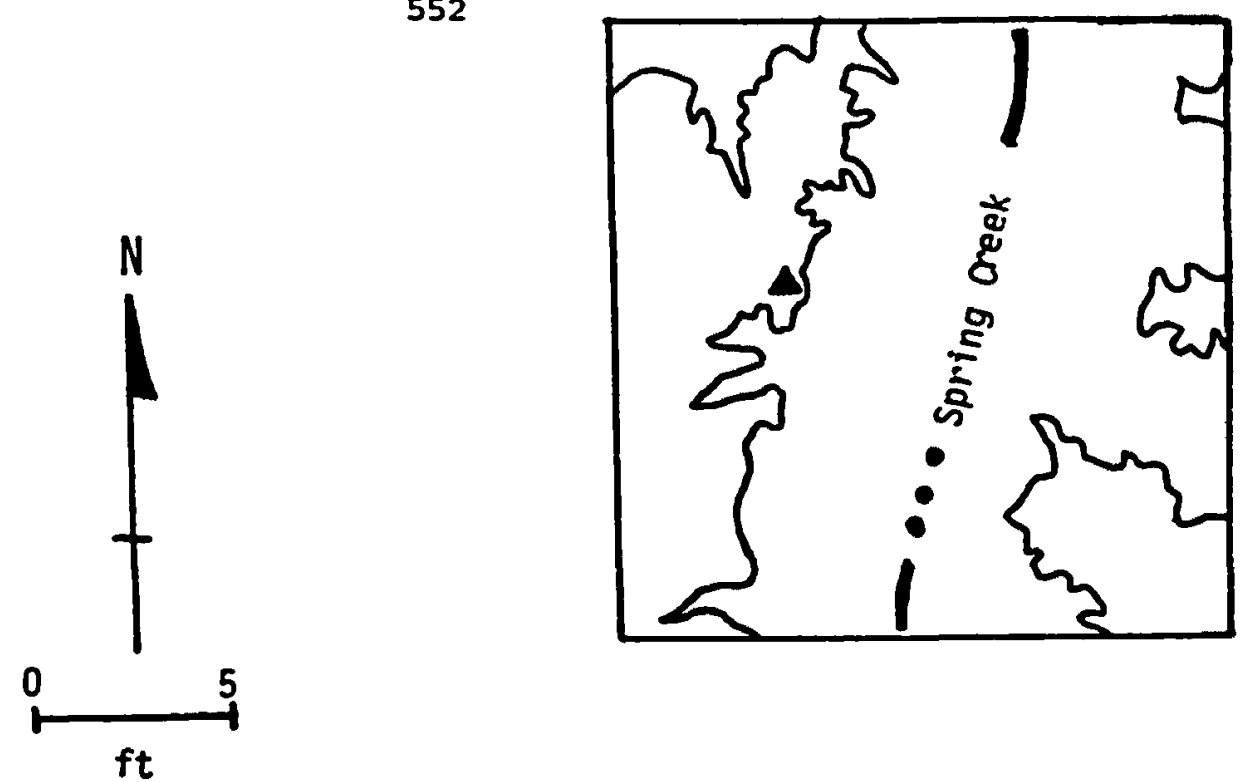

Excavation Limits

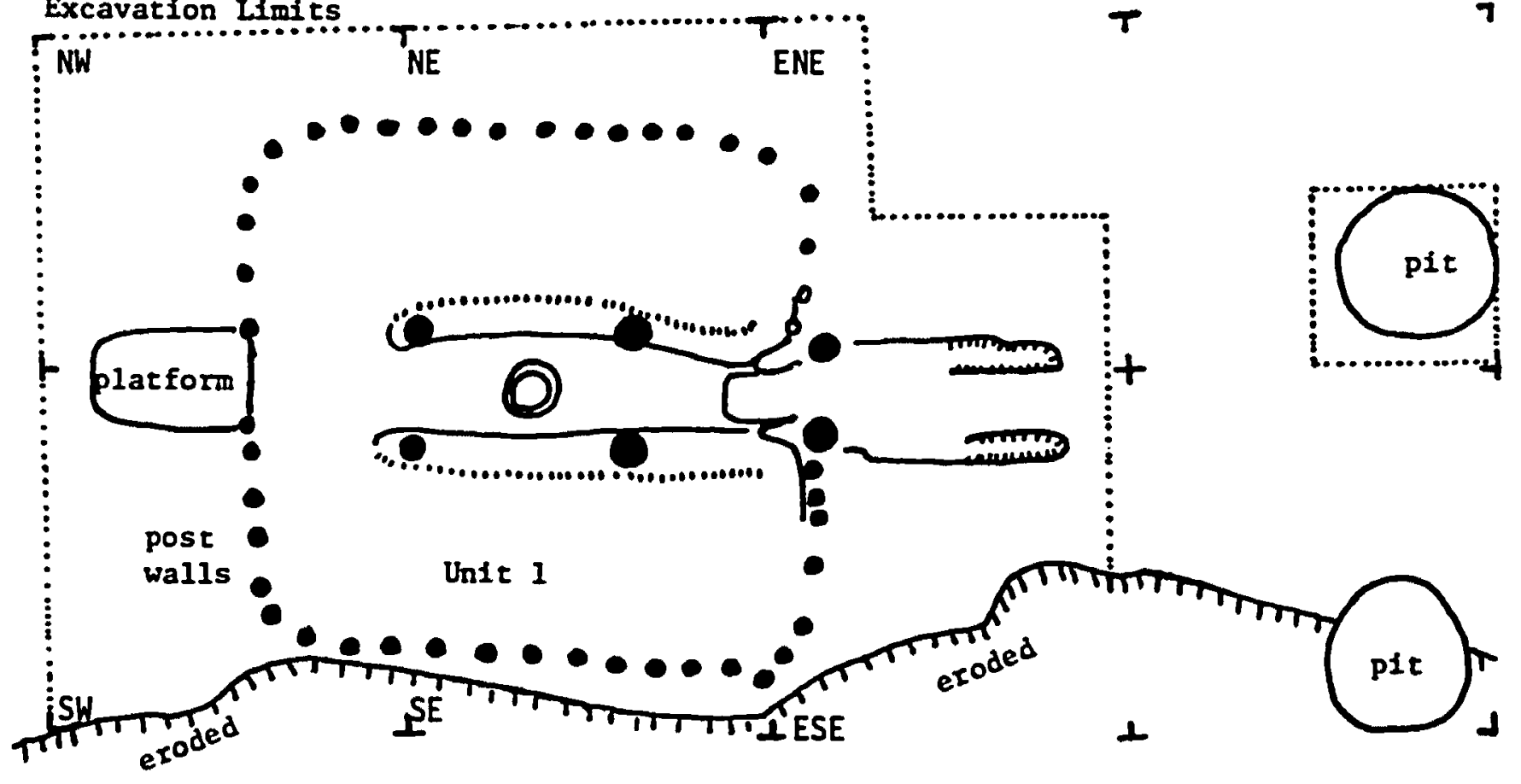

After Jack Hughes field map

Panhandle-Plains Historical Musewn

Figure 63. Plan of the Jack Allen Site 
Details regarding the artifactual remains are presently unavailable. However, a report is currently in preparation and should be available in the near future (Harrison, personal communication 1983).

\section{Zollars Site}

The zollars Site consists of a series of small isolated rooms located on colluvial fans at the base of steep bluffs north of Little Sandy Creek approximately $4.5 \mathrm{~km}$ north of its confluence with the Canadian Riyer. Springs are located at the head of the dry creek, and a draw immediately east of the rooms is thought to have had water.

The presence of dolomite rocks on the surface indicates that seven small isolated oval to rectangular structures were present (Smith and Smith 1982:4). Four structures were linearly arranged north-south adjacent to the draw; the others were scattered to the west (Figure 64). Six structures had been vandalized.

Excavations at two of the eastern structures were conducted by members of the Panhandle Axchaeological Society in 1980. Separate grid systems were established over each structure using four 8 by 8 ft squares. Each square was shovel scraped and trowelled, and the fill screened through 1/4 inch mesh. Emphasis was placed on discovering the nature of each structure as well as testing the surrounding exterior areas.

The structures proved to be separate slab-lined semisubterranean one-room buildings. One was oval whereas the other was square. Excavations outside the oval structure encountered three holes (cavaties) and a "depression" spread equidistant from the four corners. Their interriretation as "posts" seems unlikely since it is unreasonable to expect the cavaties to remain open for several hundred years. No other features were 


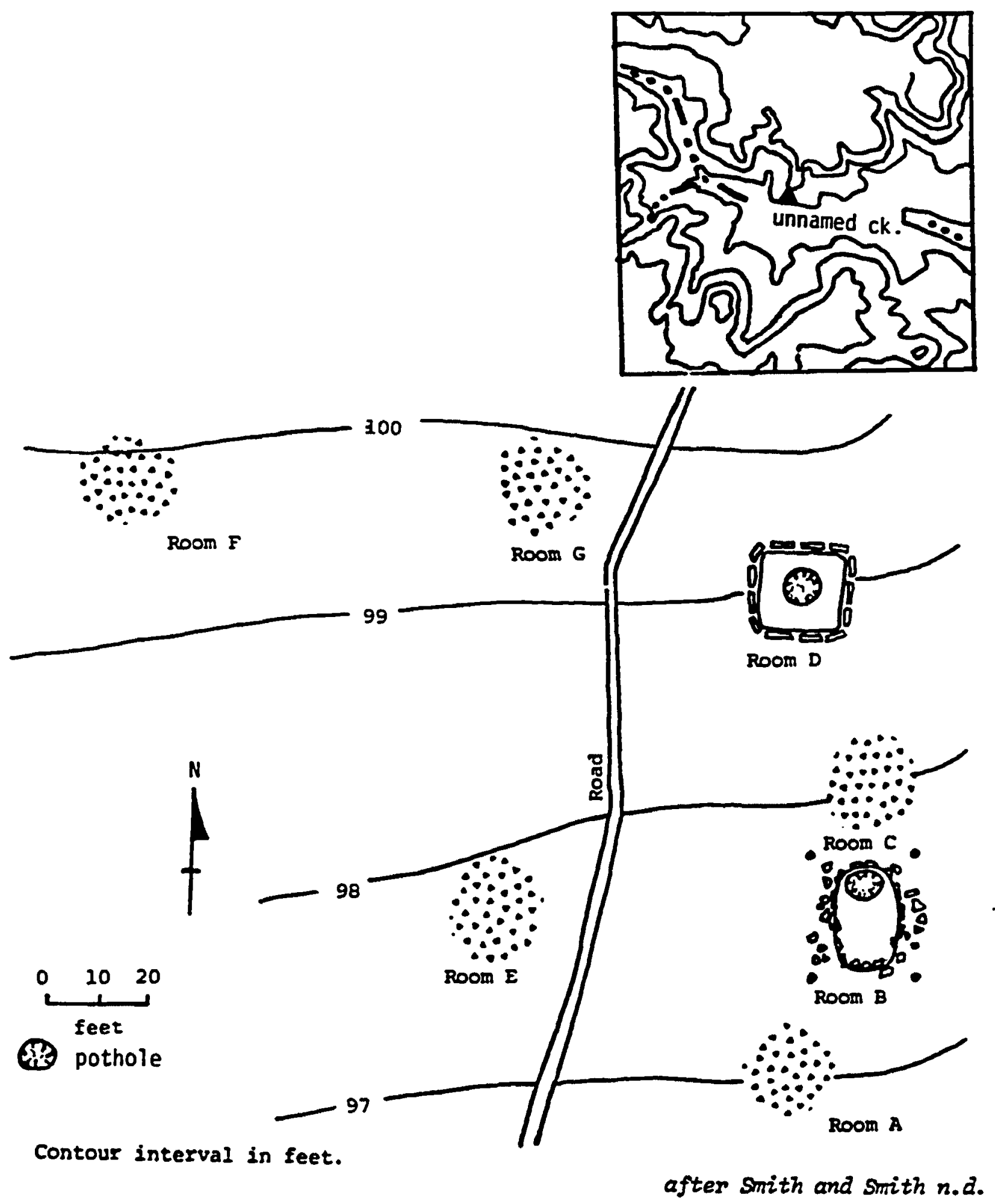

Figure 64. The Zollars Site. 
encountered. The number of components or construction episodes at the site is uncertain. However, the linear arrangement and spacing of the four structures suggests that they may have been built during a single occupation of the site.

A small quantity of tools was recovered from both structures. Most items represent local resources, although the presence of 18 obsidian flakes (58 of the unidentified flakes! indicate some contact with the southwest.

\section{The University of Texas--Texas Archaeological}

Säivage Project (1961-1962)

During the summer of 1961, a field party under the direction of Lathel Duffield from the Texas Archaeological Salvage Project was set to excavate three architectural sites within the proposed borrow area and axis of Sanford Dam. The three sites were selected to represent a variety of topographic settings and architectural/site sizes. The Conner Site consisted of two small isolated circular structures in the lower terraces; the Medford Ranch Site consisted of an "extensive" site of isolated contiguous structures located on an erosional bench along the steep inner valley wall; and Spring Canyon consisted of at least four structures along the rim of the inner valley.

General excavation procedures involved establishing a cardinallyoriented 5 ft grid system over the site to maintain horizontal control. Excavations focused on structure interiors (usually dug in a single horizontal provenience unit), and a sampling of the surrounding soil matrix. Vertical control was occasionally maintained by 6 inch arbitrary levels when time permitted. However, the remains were so scarce that the vertical provenience proved to be of "no interpretative value" (Duffield 1964:22). 
Photographs show that the fill was loosened by shovels and hand tools before being screened. Although the report provides feature and artifact descriptions, the absence of artifact provenience prevents discerning possible differences in room functions.

The Conners Site

The site is located near a promontory $6 \mathrm{~m}$ above the floor of the inner valley in South Canyon, $0.9 \mathrm{~km}$ south of its confluence with the Canadian River. The site is on the west side of the canyon near a major fork in the canyon. The Roper site is across an arxoyo approximately $200 \mathrm{~m}$ to the north. Surficial evidence of one small circular structure was evident from dolomite slabs, and a second adjacent circular structure was excavated while testing the exterior midden areas (Duffield 1964).

The excavations at the Conner Site were limited to a $28 \mathrm{~m}^{2}$ area. Initially the outline of the stone foundations were defined prior to clearing the interior of each structure as a single unit. Additional testing was conducted immediately outside the structures to search for midden deposits or associated features.

The two structures lacked interior features and were similar in size (Figure 65). The proximity of the two structures (about $0.5 \mathrm{~m}$ ) suggests that they may have been contemporaneous. Each had a separate midden of charcoal, shell, bone scraps, and flakes within a $1 \mathrm{~m}$ area located to the northeast. Only 17 artifacts were recovered, including two manos, one metate fragment, three projectile points, four sherds, and seven chipped stone cutting and scraping tools. All materials were indigenous to the Antelope Creek phase. The paucity of artifacts was interpreted to indicate a brief occupation. 

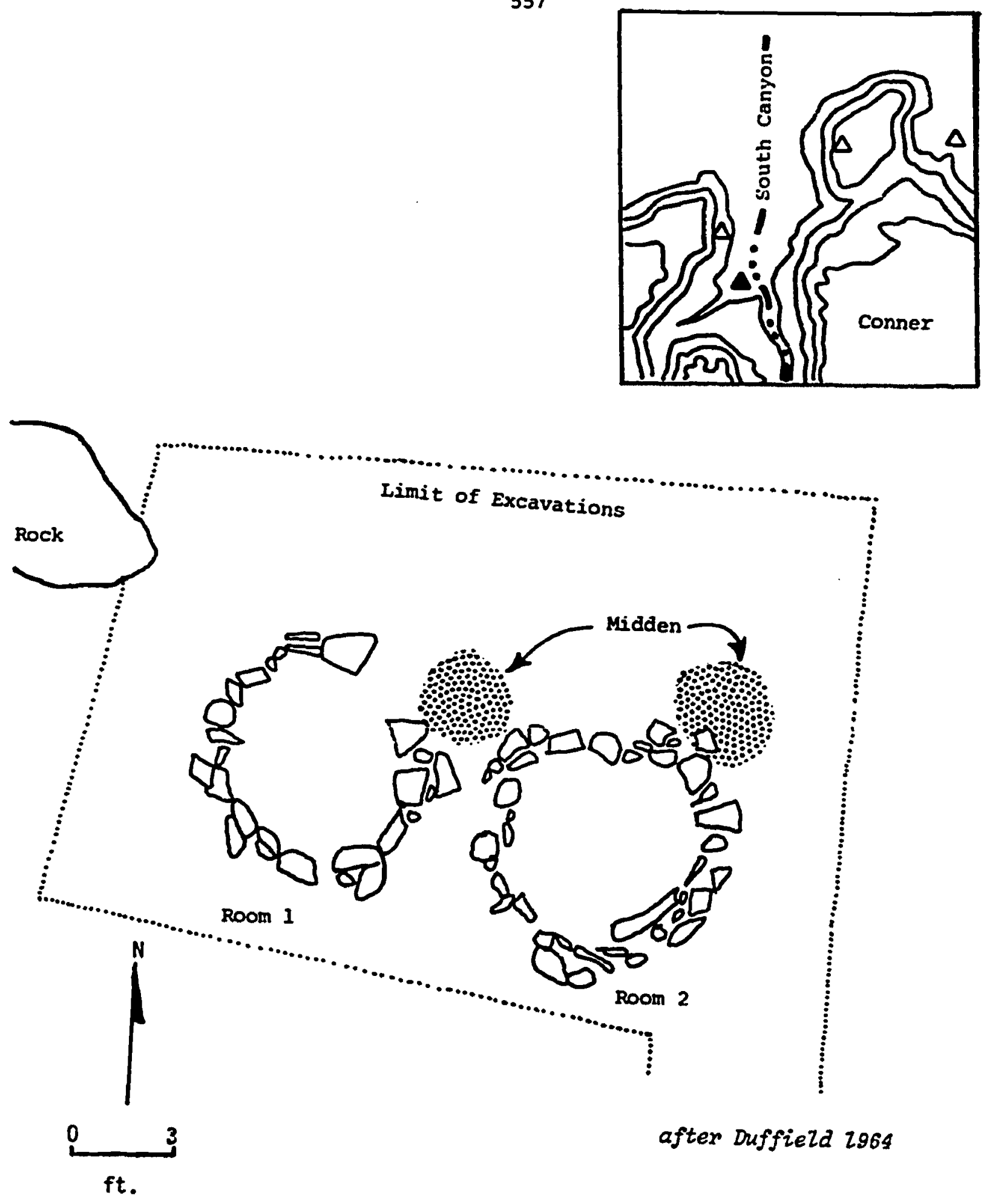

Figure 65. Plan of the Conner Site. 
The Medford Ranch Site

Medford Ranch is located on a high bench of the inner valley wall of the west side of Spring Canyon, some $1 \mathrm{~km}$ north of its confluence with the Canadian River. The bench encompasses some $450 \mathrm{~m}^{2}$ and is flanked by fairly steep walls ascending on the east and descending on the west. Spring creek is at the base of the bluff, approximately $33 \mathrm{~m}$ below the site. It is one of the major dependable spring-fed tributaries to the Canadian.

Stone slabs on the surface indicate that the Medford Ranch site is one of the most extensive of five sites near the Sanford dam. Dolomite slab clusters were noted in four areas of the site; however, three of the structures had been vandalized (Duffield 1964:30).

The slab clusters presented no clearly defined wall alignments. Consequently initial excavations were conducted within the slab concentrations in an attempt to delineate wall bases. The abundance of collapsed wall stone frustrated this approach, so more conventional excavation methods (using trenches and five-foot squares dug in arbitrary levels) were employed around each structure. Once the foundations were defined, the interiors were excavated to floor level. The excavations sampled approximately $113 \mathrm{~m}^{2}$ of the site and exposed two separate room blocks.

Structure A consisted of two contiguous rooms (Figure 66). The main room (No. 1) was rectangular within a semisubterranean pit with an eastward extended passageway. It differed from most "residential units" in a number of ways. It is typically smaller $\left(11.3 \mathrm{~m}^{2}\right)$ and lacks both a central trough and central hearth. In addition, four main roof support posts were located near the walls and a fifth post was placed in the center of the structure. Finally, the stonc slabs were apparently used horizontally. A second narrow 
room (No. 2) flanked the north wall of the main room. Although architectural details were not clearly defined, its smaller size and contiguous arrangement suggest that it is a later addition built on top of trash accumulation. Room 2 is subservient to, but functioned differently than, Room 1; however, both probably comprise portions of a single integrated architectural unit.

Structure B-C consisted of two contiguous intermediate-sized main rooms $(3,5)$ each with a single narrow semicircular room flanking the south side (Rooms 4, 6; Figure 66). Vandalism and the inability to clearly separate in situ from displaced stones hinder interpretations about the nature of this room block. The structures were apparently not built inside shallow pits, nor were plastered floors or regularly spaced postholes located to help discern the layout of the structure. Several features were found inside main Room 3. A single posthole was located along the center of the west wall, and pits were present in the northeast and southwest corners of the structures. Two concentrations of building stones were also noted inside the room (Figure 66 ). A misalignment in the slabs and a reduction in the number of stones along a portion of the east wall led Duffield to suggest the presence of an entryway; however, the evidence based on his map is not clear or convincing.

Main Room 5 was west of Room 3. It had experienced some vandalism and was more difficult to define. Although Duffield mentions no interior features, the linear arrangement of slabs in the northwest corner tenuously suggests the presence of a corner bin. No doorways were apparent in either Room-5 or in either of the narrow semicircular rooms to the south. These rooms are similar in size and layout to Rooms 1 and 3 at black Dog Village (Keller 1975). 


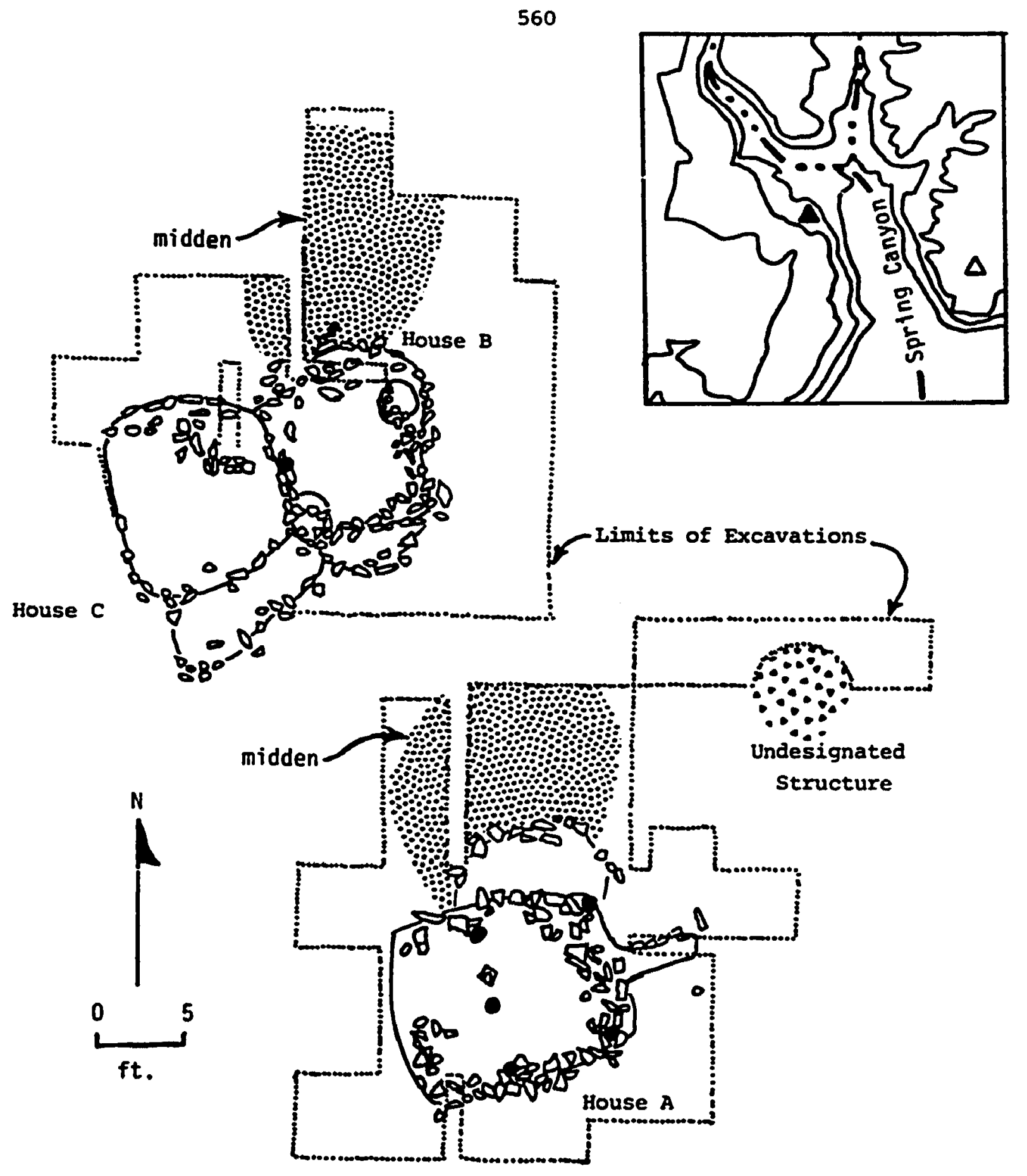

after Duffiezd 2964

Figure 66. Plan of Medford Ranch Site. 
The extensive excavations located a considerable quantity of materials. Much of it came from thick midden areas located northeast of the structures. Although no Puebloan pottery was recovered, seven obsidian flakes and one obsidian point fragment indicated some contacts with the Southwest. The rest of the assemblage is typical of the Antelope Creek phase; however, the recovery of 16 pottery sherd discs is unusual.

The Spring Canyon Site

The Spring Canyon site is located on the east rim of the inner valley, $0.4 \mathrm{~km}$ north of the confluence of Spring Canyon and the Canadian River. The site commands an impressive panoramic view of the Canadian River valley. Potable water was presumably available from either Spring creek or the Canadian River, some $55 \mathrm{~m}$ below the site. Evidence of at least four structures was indicated from one prominent slab mound and three other concentrations of slabs (Duffield 1964:48).

Excavations at Spring Canyon were initiated after a grid system was imposed over the site. Duffield (1964:48-51) indicates that excavations focused on a small isolated circular structure, and on testing portions of the extremely large rectangular structure with a 1 m tall mound. Site maps indicate that limited digging was also conducted at the other two isolated structures (ibid.: Figure 25). The results of testing were apparently not reported since these other structures were not clearly delineated. An estimated $81 \mathrm{~m}^{2}$ of the site was excavated.

Excavations in the major slab stone mound (Room 1) were conducted using controlled methods. The fill from two $5 \mathrm{ft}$ square test units along the northern edge and a center of the mound were dug in six inch levels and 
screened throu-h half-inch mesh. These methods were abandoned after few artifacts were recovered. Subsequent work involved shovel-skimming trenches along both sides of the walls to discern the dimensions of the structure (Figure 67). The extensive size of this room (about $87.5 \mathrm{~m}^{2}$ ) precluded total excavation within the limited allotted time. Consequently fill from the northeast and most of the southwest quadrants of the room was removed without without being screened. Testing was also conducted to discern exterior midden areas to the north and to unsuccessfully search for a possible passage toward the east. Neither a discernible floor level nor such interior features as central hearths or support posts were encountered. Excavations only revealed the dimensions of the room and the nature of wall construction. Two piles of horizontal slabs approximately $60 \mathrm{~cm}$ apart in the southwest corner were thought to mark an entrance, but detailed maps of the room show vertical slabs in place between the piles (Duffield 1964: Figure 21). A possible abutting wall indicative of a contiguous room was encountered during limited testing outside the south wall (herein assigned Unit 3), but excavaticis failed to aefine its extent or function. The limited excavation of this feature and the inability to locate interior architectural features is regrettable since this is the largest excavated room in the study area.

Room 2, an oval structure located northeast of Room 1, was the only structure completely excavated at the site. The location, size, and orientation of Room 2 was delineated by stone slabs on the surface. A gap in the southwest wall was intrepreted as a doorway. The room was generally without interior features. Only a flat-based pit excavatec. $10 \mathrm{~cm}$ into the floor was excavated. Its shallow depth indicated that the pit probably postdates the room's abandonment. 


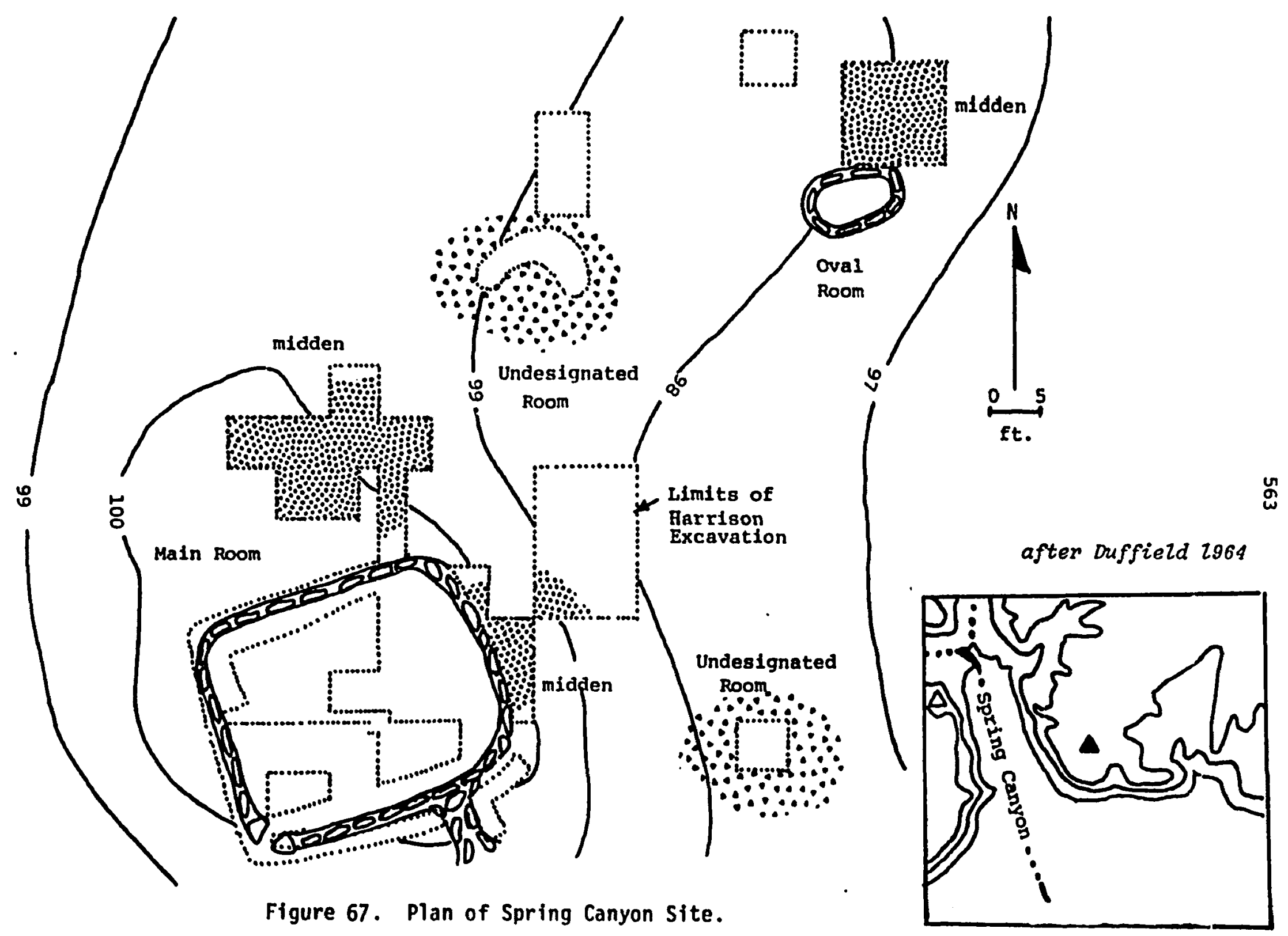


After the termination of the Texas Archaeological Salvage Project field work, additional work was conducted briefly in september and october 1961 by Bill Harrison of the Panhandle-Plains Historical Museum (Harrison, personal communication, 1982). The excavations expanded exterior units east of Room 1 and northeast of Room 2. Although no additional architectural details were clarified, this work succeeded in exposing an exterior pit near Room 2.

Despite the lack of systematic screening, a considerable quantity of materials was recovered. Most came from midden areas north of the four structures. The assemblage is extensive and varied; however, no nonlocal items were reported from the site.

The apparent testing of four structures at the Spring Canyon site gathered little information concerning intrasite development. It is assumed that the smaller outlying structures were in some way contemporaneous with the main large structure. The data are insufficiently clear to determine the possible number of household units occupying the site.

A single charcoal sample from the exterior midden was submitted for dating. A MASCA calibrated date of $1380 \pm 100$ (Tx-256) was obtained (Pearson, Davis, and Tamers 1966). The validity of this single date is difficult to evaluate in lieu of other independent dates.

Texas Tech University Sites (1963-1967)

During the last quarter of 1963 and the second quarter of 1964 , Dx. F. E. Green of the Texas Technological College Museum undertook salvage excavations at six sites within the confines of proposed Lake Meredith. Four sites contained Antelope Creek structures, whereas two were nonarchitectural localities assigned to the Woodland Period (Green 1967). The 
Antelope Creek phase sites include Arrowhead Peak (41Hc-19), Turkey Creek Site (41Pt-8), Footprint site (41Pt-25), and 41Mo-7.

At these sites, excavations focused on visible architectural features and on sampling a portion of the midden. A five-foot grid system was established at each site, and initial testing was conducted in arbitrary sixinch levels. Structures were excavated by natural stratigraphy insofar as possible. The extent of excavations varied with the size and complexity of the site. From one to ten rooms were cleared, and anywhere from six to forty-seven exterior squares were used to test the midden areas. Although the final report provides detailed notes and maps on the architectural features and quantities of artifactual remains, there is no artifact provenience by structure, square or level.

The Arrowhead Peak Site, $41 \mathrm{HC}-19$

This site is located atop a small but prominent isolated butte along the north edge of the Canadian River near the mouth of Bugbee Creek. The butte crest is some $45 \mathrm{~m}$ above the river and is capped with erosionally resistant dolomite. The butte has a relatively level top measuring some 25.5 by $4.5 \mathrm{~m}$ and steep slopes to the north, south and west.

During the fourth quarter of 1963, the Texas Tech Museum crews cleared eight rooms atop the butte and an isolated structure located some $26 \mathrm{~m}$ east and $9 \mathrm{~m}$ below the other rooms (Figure 68 ). Most of the rooms had been extensively vandalized. Only six contiguous five-foot squares adjacent to the butte tops' rooms were used to sample midden areas (Green 1967). In February 1965, one additional 10 by $10 \mathrm{ft}$ square was excavated between the butte top and the isolated structure to test the midden (Harrison, personal communication, 1982). A chipped-stone haftable axe has also been 


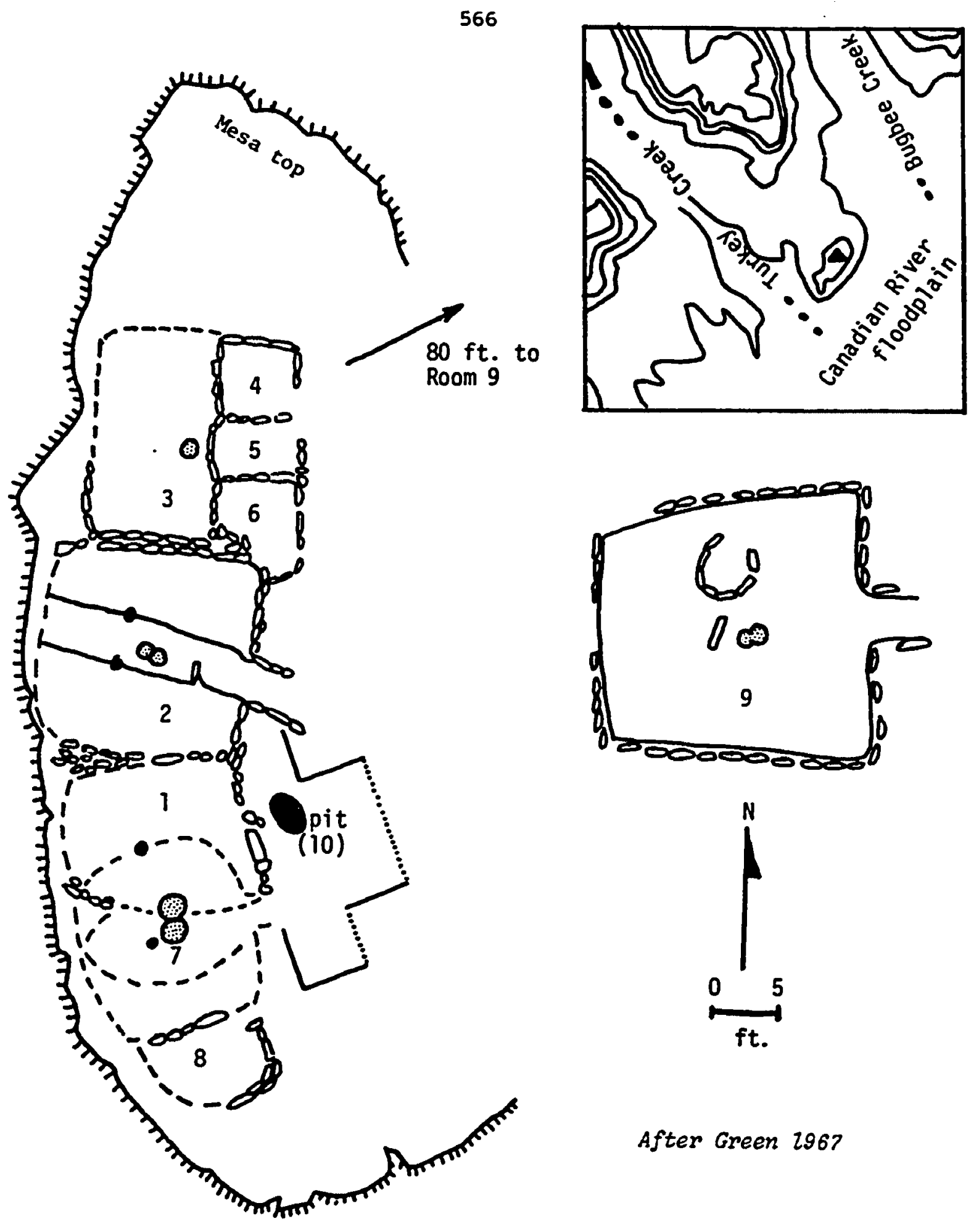

Figure 68. Plan of the Arrowhead Peak Site. 
reported from the site (Lintz 1973). Altogether an estimated $140 \mathrm{~m}^{2}$ of the site has been excavated.

Although most of the rooms are clustered atop the butte, there was clear stratigraphic evidence indicative of several building episodes and possible multiple occupations (Green 1967:17). At the south end of the mesa, Room 1 was built on top of Room 7, which in turn had either undergone extensive modification or was stratigraphically above an earlier undesignated room (Green:Figurz 1). At the north end, small Rooms 4, 5, and 6 were built on top of Rocm 3 .

Interpretation of the precise sequence of architectural development is hampered by vandalism inside some rooms. However, the earliest construction probably involved large household Room 7 as an isolated structure. Part of this room was chipped into the bedrock dolomite. Subsequent modifications may have involved filling the central channel (?), replastering the floor, and at one point adding the smaller Room 8 to the south. The presence of a common wall and comparable orientations of main Rooms 2 and 3 suggest that they were contemporaneously constructed along with, or more likely, slightly later than Room 7. Somewhat later small Rooms 4, 5, and 6 weze built on top of abandoned Room 3. Finally, Structure 1 was built on top of abandoned Room 7. The construction sequence of isolated Room 9 is impossible to determine. Quite clearly, the structures built on the butte top represent an accumulation of dwelling remains. Probably no more than two or three household units were utilized at any one time. Also, it is apparent that the confines of the butte influenced the room configurations. smaller units, which at other sites commonly occur flanking the extended passageways, were either built over abandoned larger rooms (cf. Units 4, 5, 
6) or adjacent to main household units (cf. Unit 8).

A small amount of materials reflects contact with the Southwest and elsewhere. The materials include one "unidentified polychrome" sherd, six pieces of obsidian, and two argillite pipes.

One unprovenienced composite charcoal sample yielded a MASCA Corrected radiocarbon date of A.D. $1320 \pm 80$ (WIS-118) (Bender, Bryson, and Baerris 1967). In light of the apparent multiple construction episodes and lack of provenience of this sample, the significance of this single date is uncertain.

\section{Site $41 \mathrm{MO}-7$}

This site is located on a low prominent terrace some $4.5 \mathrm{~m}$ above the Canadian River valley and abutting the base of the steep inner valley walls. The site is on the south edge of the Canadian River floodplain east of Short Creek at Harbol Bay. Iithic debitage and slabs from two small cists were the only surficial indications of the site. One of the cists had been vandalized.

The site was excavated during the last quarter of 1963. A total of 47 five-foot squares (about $109 \mathrm{~m}^{2}$ ) was excavated, and an isolated singleroom rectangular structure was exposed (Figure 69). The structure is somewhat enigmatic since no evidence of wall types could be discerned. Furthermore, a subsequent modification of the structure is reflected by the filling of the original central channel and replastering of the floor surface. The extended entryway faces eastward towards the steep bluffs. The two slablined cists were located on either side of the structure. Pit A was some $3.5 \mathrm{~m}$ to the north whereas Pit B was approximately $24.5 \mathrm{~m}$ to the south. The latter pit contained a vertically set stone slab in the middle, similar to 


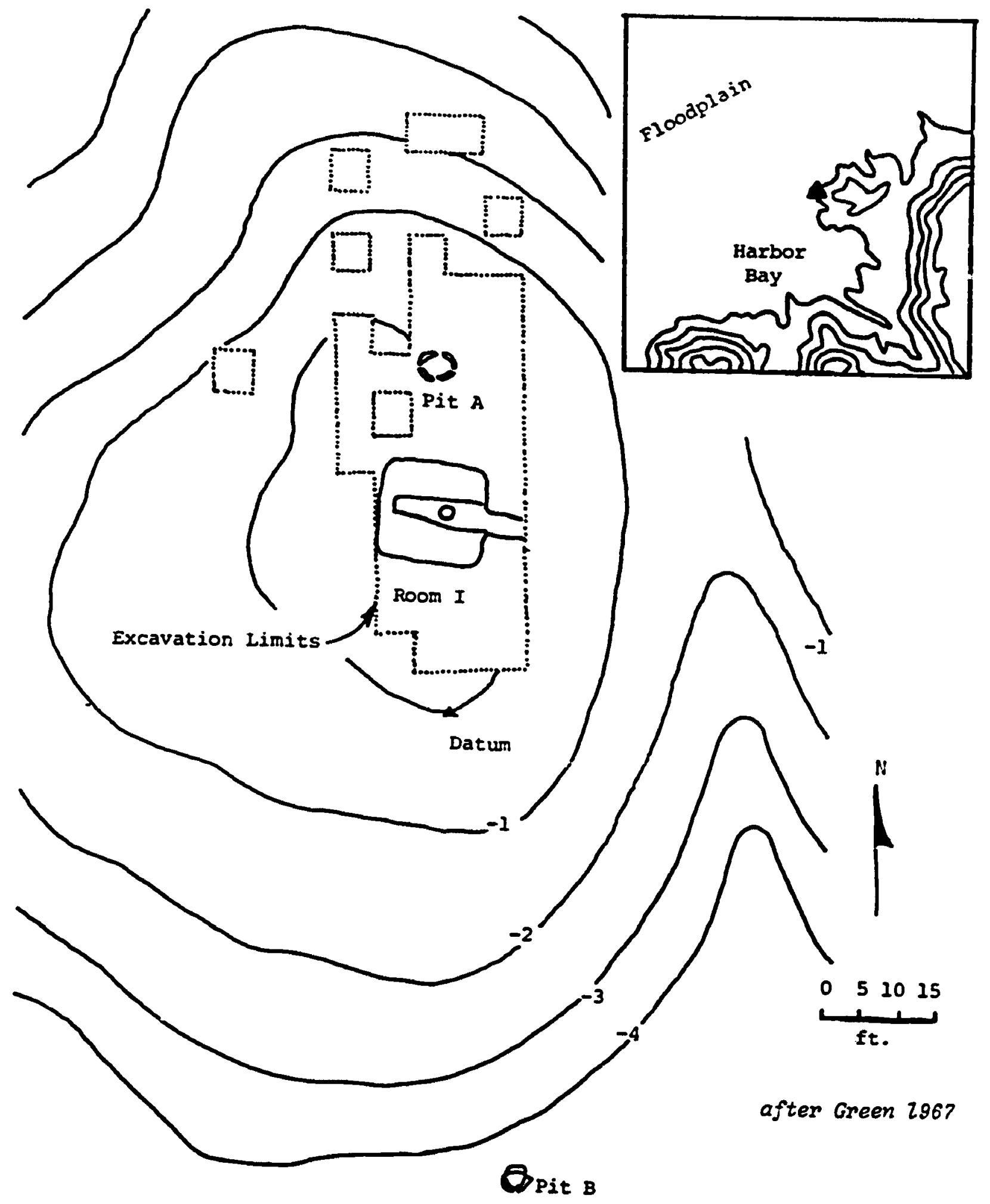

Figure 69. Plan of Site 41Mo-7. 
a feature inside Room 47 at Alibates 28, Unit II. All of the artifacts appeared to be indigenous to the Antelope Creek phase.

The Turkey Creek Site, 41Pt-8

The site is located on a bench of the steep west inner valley wall some $15 \mathrm{~m}$ above the valley floor at the mouth of Turkey Creek. The Canadian River is some $0.9 \mathrm{~km}$ to the northeast. Although the bench $i s$ r.ct $r: z ;: \because i d e$, stone slabs indicated the presence of three small circular and oval structures.

The excavations were conaucted during the inclement winter weather in December 1963 (Green 1967). After a five-foot grid system was established for horizontal control, the three semisubterranean structures were each excavated as single units (Figure 70). Rooms 1 and 2 at the northwest portion of the bench were adjacent oval structures, the long axes of which were oriented perpendicular to each other. Room 3 was an isolated small circular structure located approximately twelve meters to the southeast. Rooms 1 and 3 had hearths near the east walls. No doorways were evident from the remaining stone slab foundations.

In addition to investigating these rooms, 13 exterior test squares were dug around the north ends of Rooms 1 and 2 to sample midden areas. The total ạrea excavated is approximately $44 \mathrm{~m}^{2}$. Approximately 57,000 items were recovered; however, most came from a concentration of Alibates chert debitage within a $2 \mathrm{~m}$ area northwest of Room 1 which was intrepreted as a knapping area. A detailed lithic study of approximately 3000 flakes (58 of the total site sample) from a single test unit has indicated that chert nodules were reduced at the site for subsequent trade (Bandy 1976). Possible trade items from the site are represented by 14 pieces of obsidian, one 


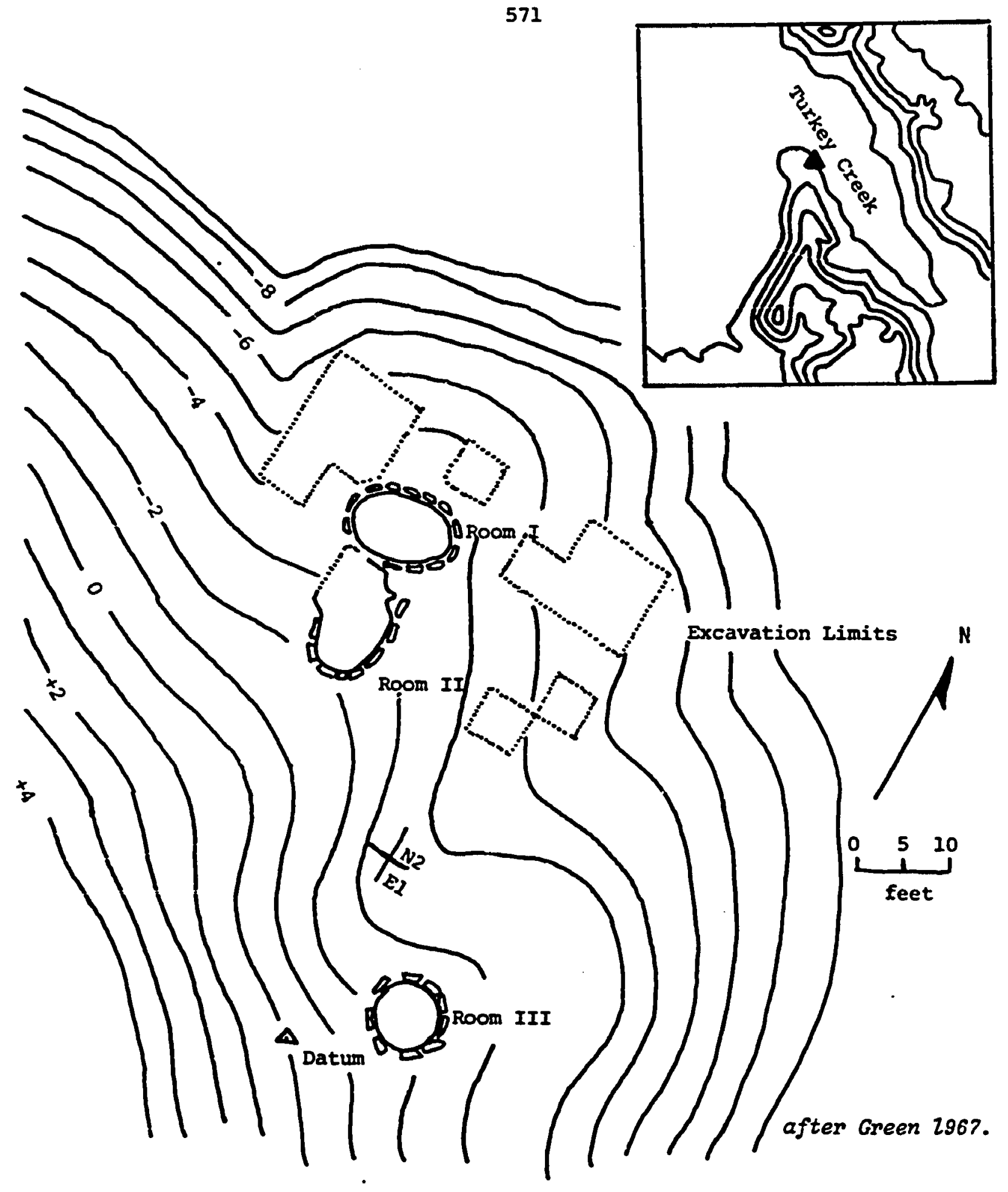

Figure 70. Plan of the Turkey Creek Site. 
sherd tentatively identified as Crockett Curvilinear Incised, and perhaps one stone pipe fragment (Green 1967:101).

Despite the high flake density, the few small structures at the site were thought to reflect a fairly short term occupation. Little information is available concerning intrasite structuring. The perpendicular outline of contiguous oval Structures 1 and 2 may indicate separate construction episodes, either during a single period of site occupation or subsequent seasons of occupation.

The Footprint Site

The Footprint site covers a small knoll top at the eastern mouth of Big Canyon (McDowell Creek). The center of the Canadian River channel lies approximately $0.6 \mathrm{~km}$ to the south. The knoll is topographically isolated from the adjacent ridges, and the flat top stands approximately $11 \mathrm{~m}$ above the valley floor of Big Canyon and $15 \mathrm{~m}$ above the Canadian River channel. Although small eroded dolomite boulders were common on the knoll the flat slabs used architccturally may have been obtained from the adjacent ridges. Some of these slabs in turn may have been removed during historic times to build a homesteader's cabin at the southeast foot of the knoll (Green 1967: 120). Rock slabs on top of the knoll suggested the presence of three isolated one-room structures and a small circular cist. Most of the site had been randomly vandalized, and the interior of the largest room had been extensively potted prior to excavation.

Excavations were conducted during the latter half of June, 1964. The initial procedures involved the establishment of grid coordinates over the site to provide horizontal control. However, most of the excavations were confined to the interior portions of the features. Twelve five-foot 
squares were also excavated southeast of Room 1 and a single square was dug northeast of Room 3 (Figure 71). Approximately $115 \mathrm{~m}^{2}$ of the site were excavated.

The three structures were large isolated rectangular rocms with depressed central channels and eastward extended passages. Structures 2 and 3 had four roof support posts surrounding a central channel, whereas Structure 1 had six central posts. Two of the structures had platforms against the west wall. Structure 1 had a large rectangular interior platform within the channel. The platform in structure 3 was recessed into the west wall and had a petroglyph of two stylized human footprints on the slab at the back of the alcove. Other architectural differences include the use of both stone slabs and posts along the walls of structure 3 and the presence of a raised "cold air" sill in the passages of all three structures.

The largest room, structure 1, contained a considerable quantity of human remains in burial pits $A, B$, and $C$, as well as in the room fill. The three burial nits each contained portions of at least seven flexed individuals. Near the northeast edge of the channel was a pile of ten crania, and other elements were found scattered within the room fill. Green estimates that perhaps 32 individuals are represented. The bodies inside the burial pits were more articulated than those in the house fill; however, some burials truncated others within the pit. This suggests that the pits served as ossuaries used over several years. Detailed analysis of the remains indicates that both sexes and all age groups from infants to old adults are represented in the skeletal sample (D. K. Patterson 1974). Between 20 and 30 percent of the skeletal remains were burned, including some individuals from Burial Pit $C$. This suggests that either some 

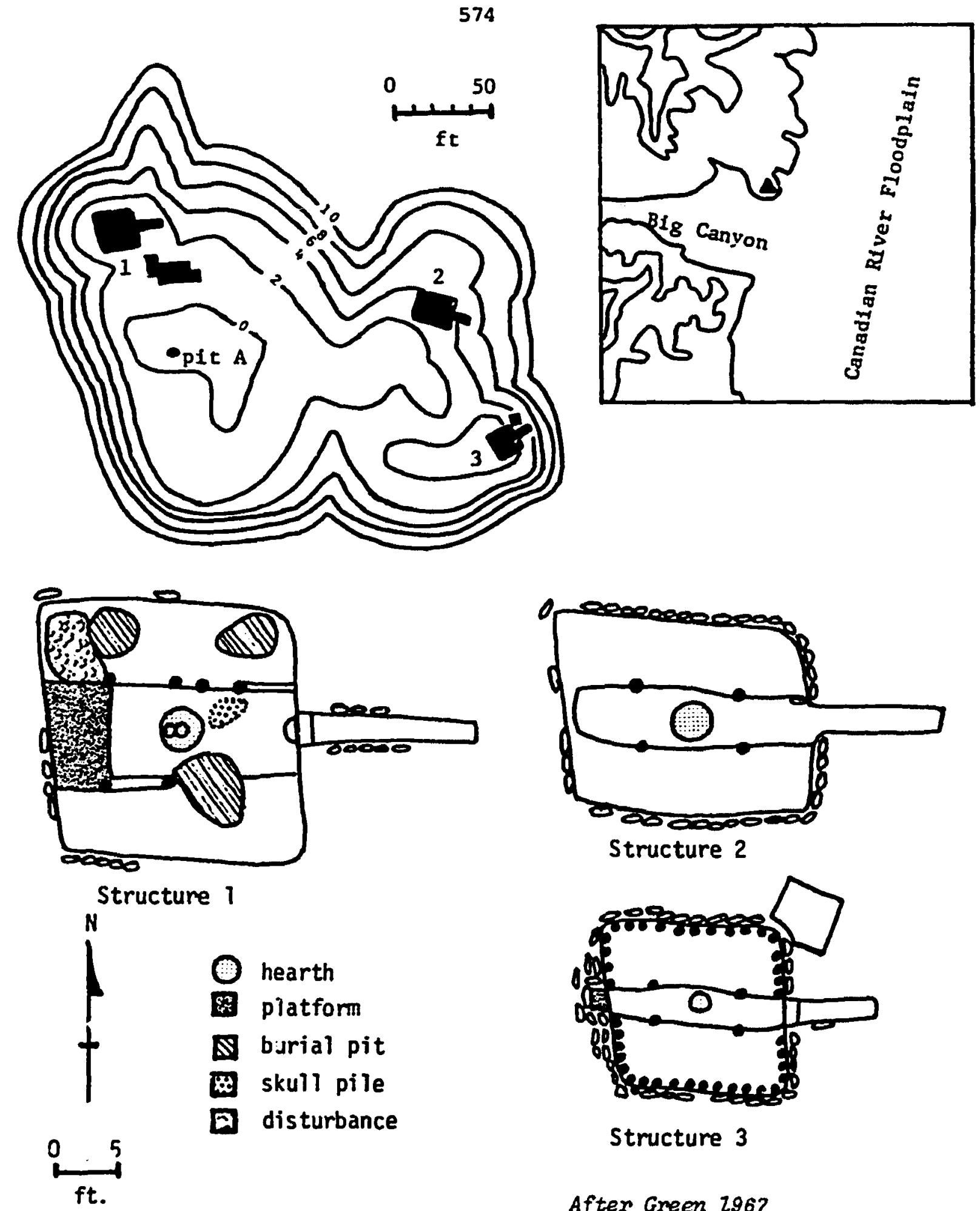

\section{Structure 3}

After Green 2967

Figure 71. Footprint Site Map. 
individuals were cremated, or that some of the bodies were exposed in an open burial pit during the burning of the room. Patterson (1974:56) suggests that the nature and distribution of skeletal remains outside the burial pit is indicative of dismemberment and/or skeletonization. One skull near the crania cluster had an articulated cervical vertebrae and was directly associated with a large flint knife. Analysis shows no cut marks on the bones, but the fragmentary and weathered conditions of these elements may have obscured any evidence.

Extensive excavations southeast of Room 1 located a series of five basin shaped trash pits. Most contained rock and ash, but one was sealed with clay and another had a layer of rocks in the middle of the fill. Green suggests that the pits may have been the source for mortar in constructing the structures.

A considerable quantity of indigenous materials was recovered from the site. In addition, nonlocal items are represented by 29 obsidian flakes and grave offerings, including seven conch shell gorgets and pendants, 13 olivella shell beads, five conus shell tinklers, and 65 disc beads. One tubular pipe and three elbow pipes were also recovered from Room 1. However, the presence of restorable cordmarked vessels in Pit B reflects indigenous burials within the pits.

Four radiocarbon dates are available for the site. Two MASCA corrected dates from Room 1 (1390 \pm 90 (WIS-90B) and $1430 \pm 90$ (WIS-90A)) were obtained (Bender, Bryson and Baerreis 1966). A date of $1390 \pm 89$ (WIS-102) from Room 2 suggests that these two rooms may have been contemporaneously occupied. However, the single date from Room 3 (1260-1290 \pm 80 (WIS-122)) may reflect a somewhat earlier occupation, but is statistically congruent 
with dates from the other structures (Bender, Bryson and Baerreis 1967). In liev of other samples from this structure, it is assumed that all three rooms are contemporaneous.

\section{The Texas Archaeological Society Excavations (1969)}

During mid-June, 1969, the Texas Archaeological Society sponsored excavations on three architectural sites and ore adjacent cemetery along the west inner valley rim of Big Blue Creek (Davis 1969). Despite a sizeable labor force, inclement weather prevented extensive excavations and the relationship and configurations of most structures were not clearly discerned. Jack Hughes served as overall project director, but each site was supervised by a professional archaeologist. The northernmost site, SARE145 (Sanford Reservoir 145) was supervised by E. Mott Davis. Field work focused on two 10 by $10 \mathrm{ft}$ squares within an apparent midden area and succeeded in exposing portions of two to five superimposed structures.

The most extensive excavations were conducted at SARE-146 under the supervision of Dessaime Lorrain. At least five rectangular and D-shaped semisubterranean structures were located deeply buried along the terrace rim of this middle site. Most of the rooms were excavated approximately 46 $\mathrm{cm}$ into the original ground surface. Unfortunately insufficient time prevented the exposure of all structural configurations and clarification of the complex stratigraphic situation. Regrettably, some of the records have been lost to a house fire.

Excavations at the southwest architectural site, SARE-147, were supervised by Bill Harrison. Several contiguous room structures were indicated by slab walls on the surface. However, excavations focused on 
delineating one room block consisting of a larger rectangular room with an extended passage and at least one small circular room attached to the southeast corner (Davis 1969). Interior architectural details apparently include a depressed floor channel and a raised ridge sill in the passage which may have served as a cold air trap. Several other rooms were apparently present at the site. A sketch map made in 1980 shows two potential main room structures with other contiguous rooms, and large isolated oval structures at the site (Etchieson 1981:Figure 26).

At this time, none of the architectural sites has been described or analyzed. A cursory search of the records failed to locate a generalized site map showing the complete detailed architectural configurations. Undoubtedly such information could be derived from plotting informiction from individual level forms; however, the architectural data was generally not in any condition for ready analysis. Because of the ambiguity of the architectural details, the three architectural sites were omitted from the site sample in this study. Nevertheless, information for the cemetery area, SARE-242, was sufficiently complete to warrant inclusion.

\section{Big Blue Creek Burials}

Approximately 52 m northwest of SARE-147, several stone slab concentrations were located. Three of the features had been vandalized and fragments of human bone were associated with one of the disturbed features. This evidence suggested the presence of a cemetery area possibly associated with the adjacent habitation site, or with SARE-146 located $250 \mathrm{~m}$ to the northeast.

Excavations at SARE-242 were directed by Cecil Calhoun. Initially a $10 \mathrm{ft}$ grid system was established over a 200 by $200 \mathrm{ft}$ area encompassing 
the rock features. The entire site was then surveyed twice along the northsouth then east-west grid lines to search for indications of occupation debris, artifacts or additional features. Spot probing was conducted around each dolomite slab and large cobble on the surface to ascertain whether the rock could have been part of a larger stone feature (Calhoun field notes $6 / 21 / 69)$. Subsequently, excavations were conducted within 10 by 10 foot units, 5 by 5 foot units, and 5 by 10 foot units placed over features encountered during the survey and probing activities. Vertical control was maintained by 6 inch levels and the fill was screened through $1 / 4$ inch mesh. Four separate individuals were each buried beneath stone concentrations, and one other stone slab concentration which may have lacked an interment, were uncovered (Figure 72). A sixth feature number was assigned to one of the vandalized stone clusters, but no further excavations were conducted on it. Altogether, $37.2 \mathrm{~m}^{2}$ of the site were investigated. The four relatively intact, primary buriais consisted of single individuals in flexed or semiflexed positions. All occurred within individual grave pits which were capped by rock piles. The bodies were not arranged in any consistent orientation. Two infants and one juvenile were of indeterminate sex. The other burial was a male approximately 20 years old. Large cordmarked potsherds were found among the overlying rock piles of one infant and the adult male. In addition, two side-notched arrowpoints and a bison tibia digging stick were also found in the fill sverlying the adult male. The other two burials lacked funeral offerings. The five apparent burials and the stone slab concentration were roughly arranged in a north-south line and were spaced from 2.5 to $6.7 \mathrm{~m}$ apart. The similarity in interment practices suggests that they represent a single population. 

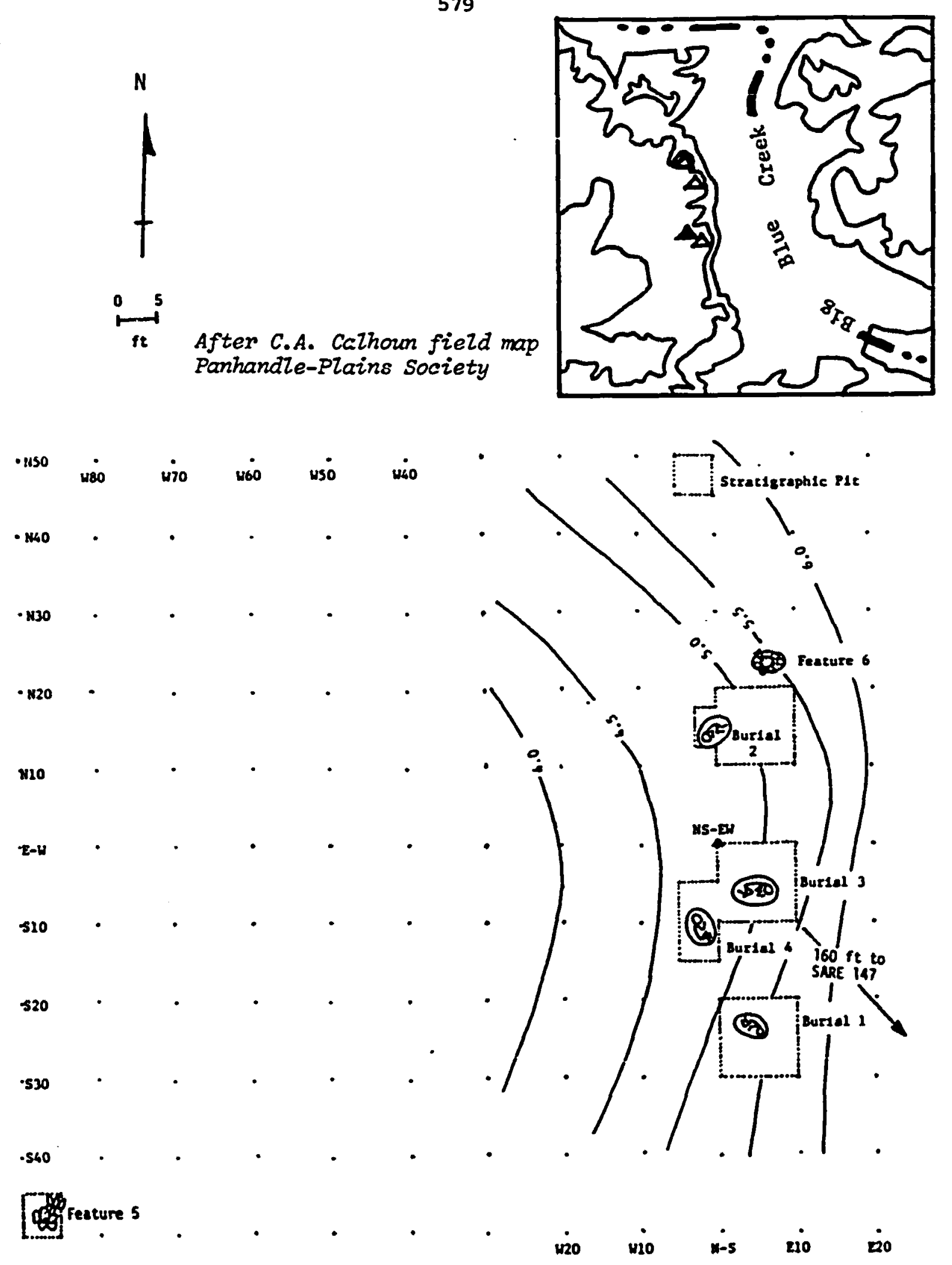

Figure 72. Big Blue Cemetery, SARE-242. 
The presence of ceramics, side-notched points and the tibia digging stick clearly indicates that they are affiliated with the Antelope Creek phase.

The Texas Highway Department (1973)

The Black Dog Village Site

During the early $1970^{\prime}$ 's, the Texas Highway Department in conjunction with the Panhandle-Plains Archaeological Society salvaged structural remains at the Black Dog Village Site within the right of way of Texas Highway 136 (Keller 1975). The site is located on inner valley colluvial deposits on the west side of Cottonwood Creek only $1 \mathrm{~km}$ north of its confluence with the Canadian River. The site is approximately $15 \mathrm{~m}$ above the sand filled channel of Cottonwood creek. Although both drainages are usually dry, potable water may have been available prior to the construction of Sanford dan. Highway maintenance of an embankment exposed three groups of vertical slabs along with considerable quantities of cultural debris which prompted salvage work at the locality. The original extent of the site is uncertain, since earlier highway construction may have removed other structures. It is difficult to determine the excavation methods from the published report. Apparently two intersecting baselines marked at 10 foot intervals were established for reference, yet the exterior excavation areas seem to be of various size, shape, and orientations. The visible structures were cleared of overburden as a unit to provide flexjbility in the excavation procedures. The fill was apparently loosened by small hand tools and screened. Flotation was conducted on the matrix of at least one feature (No. 17). Feature numbers were assigned to structures, soil anomalies and tool associations; however, not all features are identified in the report 
(Keller 1975). The usefulness of the report is also limited by discrepancies in the size and nature of feature constellations, the incomplete listing of radiocarbon dates, contradictions in the number of artifacts recovered and also in the interpretation and significance of components at the site. Because of these problems, the present analysis relied primarily on published maps, rather than text descriptions, since the maps were internally consistent.

The excavations exposed five rooms within three areas (Figure 73). The western area consists of a large rectangular structure with a depressed floor channel, six interior posts, two central hearths, an interior platform and an eastward extended entrance. The presence of several floor levels indicated the structure had experienced some remodeling. A vertically-set stone wall in the southwest corner of the structure was interpreted as evidence of a superimposed structure; however, since the wall coincides with the floor channel curbing and does not extend the structure, it is more likely the remains of a corner bin, such as those found in Antelope Creek 22 Roors 1 and 8 . The southern area located nearly $5.5 \mathrm{~m}$ away consisted of two contiguous rectangular rooms lacking interior features, but similar in shape and dimension to structures $B$ and $C$ found at the Medford Ranch Site (Duffield 1964:35). The northern area, $14 \mathrm{~m}$ away, consisted of a small, rectangular, single room superimposed over a circular depression with a packed floor and a central hearth. A series of shallow depressions on a bench adjacent to the stone walls of the rectangular structure was interpreted as evidence for a slanted or leaning wall; the stone slabs were interpreted to have served as an exterior base abutment for the pole leaners (Keller 1975: 35). Other kinds of features included irregular shaped "trash pits" (adobe 

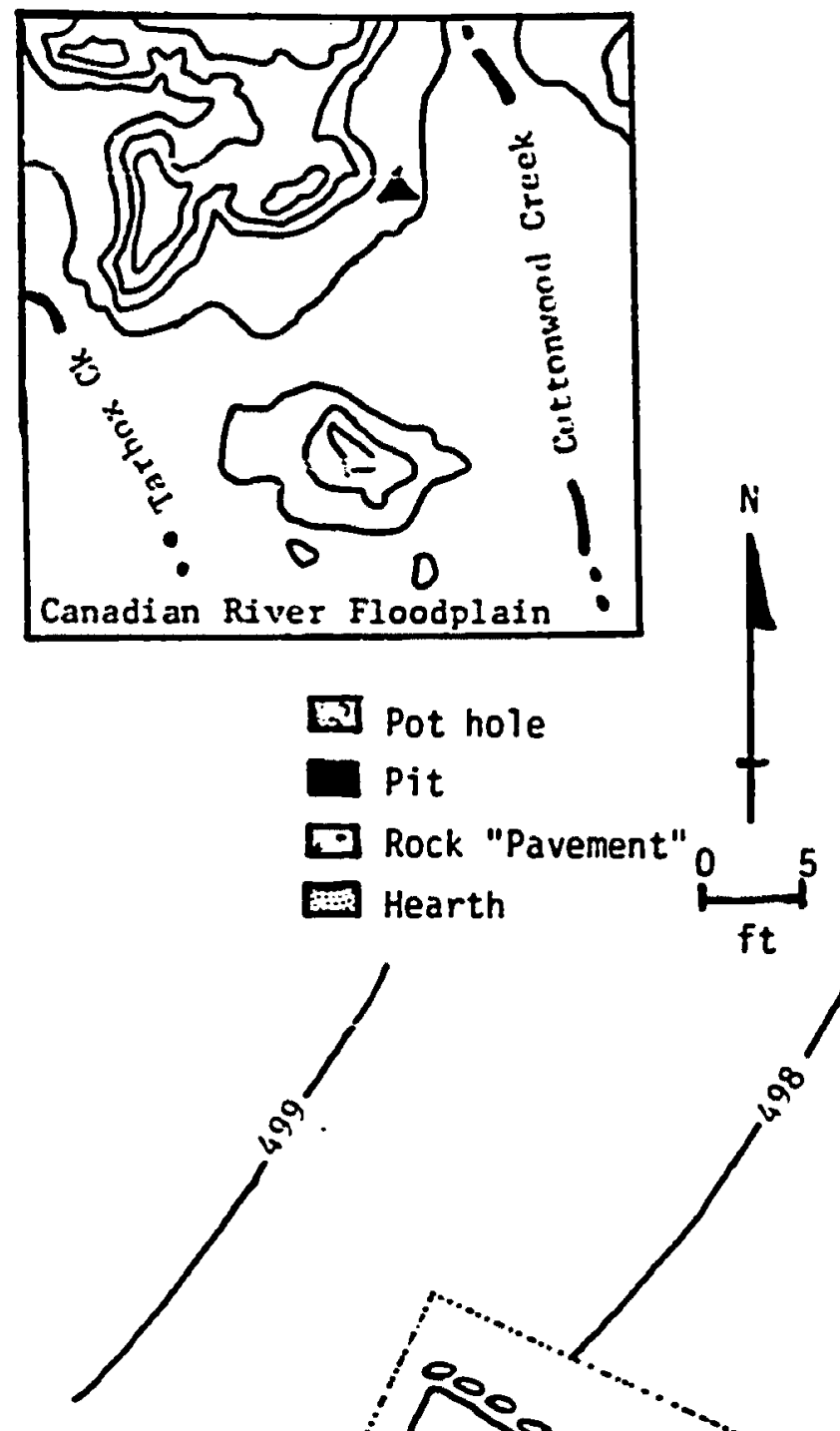

Dot hole

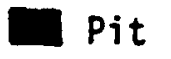

Rock "Pavement"
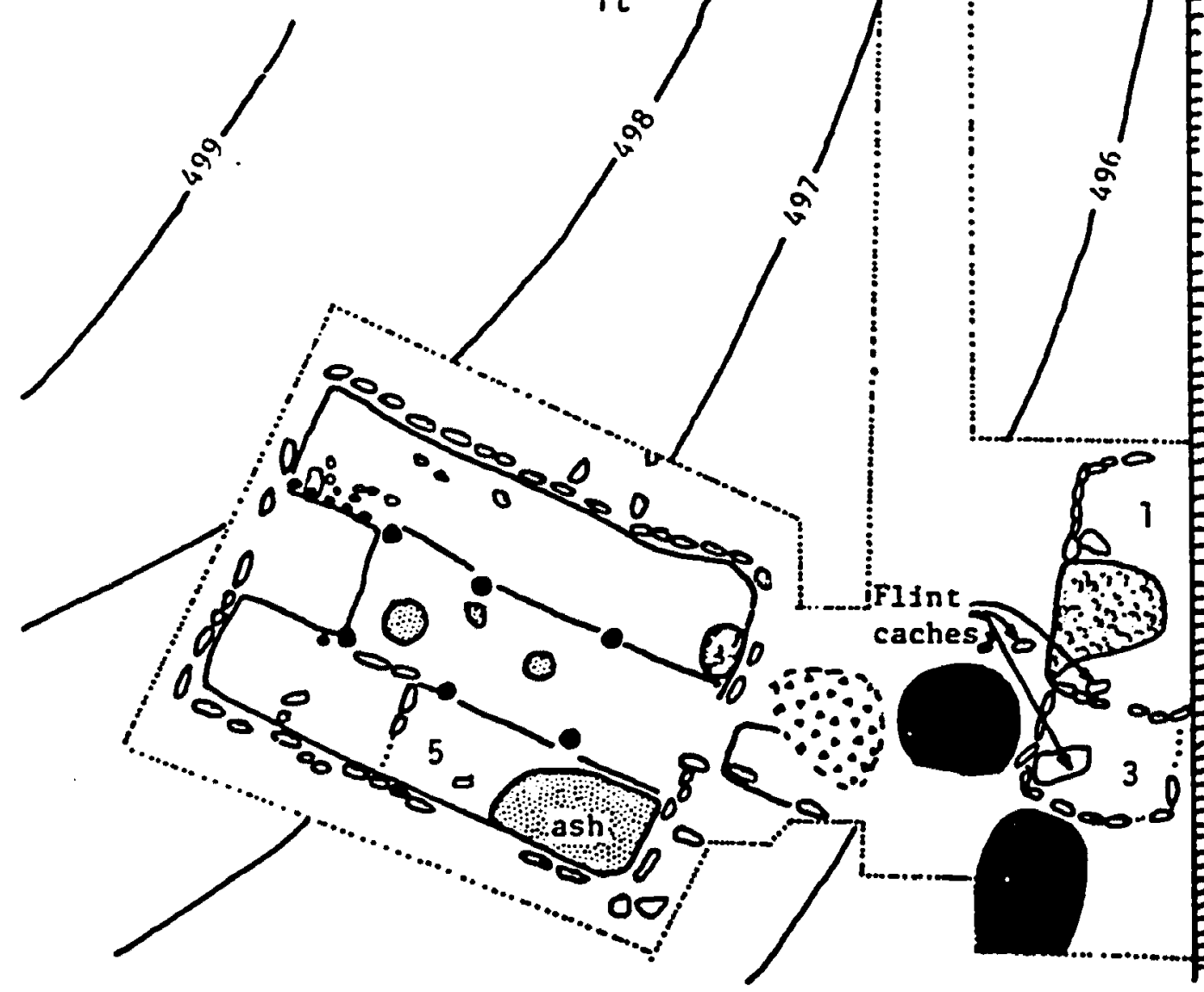

After KelZer 2975, ani field maps Panhandle-Plains Historical Musez.

Figure 73. Black Dog Village Site Map. 
mixing basins?), and at least five flint caches. Despite an extensive amount of excavations (approximately $180 \mathrm{~m}^{2}$;, no trade items were reportedly recovered.

A total of thirteen radiocarbon dates is available for Black Dog Village (Valastro, Davis, Varela 1977). All of the following dates have been tree-ring calibrated using the MASCA formula (Ralph, Michäel and Han 1974). A single carbon sample for the hearth of Structure 2 produced a date of A.D. $1520-1610 \pm 160(T x-1493)$. Despite the higher sigma value, the date is temporally and stratigraphically consistent with a cluster of four dates from Structure 4 located beneath Structure 2. The four dates for structure 4 are A.D. $1400 \pm 70(T x-1489), A . D .1420 \pm 70(T x-1490)$, A.D. $1420 \pm$ $70(T x-1491)$ and A.D. $1450 \pm 60(T x-1488)$. Four radiocarbon dates were obtained from fill matrix of Feature 17, a large pit located immediately south of Room 3. Two of these dates (A.D. $1420 \pm 80, T X-1513$; and A.D. 1470-1500 $\pm 100, T x-1499$ ) are based on charcoal samples; however, a bone apatite date of A.D. $1405 \pm 80(T x-1498 \mathrm{~A})$ and a bone collagen date of A.D. $860-880 \pm 210$ (Tx-149aB) were diso obtained. Quite clearly, the latter date is inconsistent with the other three determinations and should be rejected. The last four radiocarbon dates are all from Structure 5. Unfortunately the dates are not tightly clustered. Charcoal for the north central post yielded an unexpectedly early date of A.D. $1000 \pm 180(T x-1512)$, whereas a date for the southeast floor fill was unexpectedly late--A.D. 1510-1600 \pm 60 (Tx-1495). The two other samples from the floor fill (A.D. $1350 \pm 70, T \times-1496$ ) and near the platform area (A.D. $1330 \pm 60, T x-1497$ ) are more consistent. The wide range of dates and large sigma values make the temporal sequence at Black Dog Village difficult to interpret. Clusters of overlapping 
dates for each architectural unit show that all units could have been contemporaneously occupied around A.D. 1370 through 1390. However, the presence of stratified Rooms 2 and 4 suggests that more than one building episode is represented. The overlapping one sigma intervals grouped by room features suggest that Structure 5 tends to be earlier (A.D. 1280-1390) than structures 3 and 4 which appear to be contemporaneously occupied between A.D. 1350-1490, and which in turn may be earlier than structure 2, occupied between A.D. 1360 and 1770 . 


\section{APPENDIX B}

\section{ARCHITECTURAL ATTRIBUTES AND VARIABLES}

This appendix correlates the feature designation systems used by different projects, and presents all the recorded data for each architectural unit represented as separate rooms or external cist or pits at a site. Each architectural unit has been re-assigned a unit number in order to standardize the various alphabetic and arabic numeral room designations used by different investigators, and to incorporate architectural units overlooked by some excavators. Table correlates the re-assigned unit numbers with the earlier designation systems, and indicates the primary source of abservations on each architectural unit.

At least $\mathbf{6} 2$ observations were collected and tabulated for each unit (Table 55). Each column represents one of the 223 architectural units from the 28 sites. Both the site name and re-assigned unit number are provided. The rows record 42 attributes and 20 variable observations concerning the condition of the unit, extent of excavation, the nature and relationship of the unit to others, and characteristics of its size and form. The attributes include 7 denoting presence/absence of an attribute, 8 indicating the quantity of an attribute, and 27 specifying the state or condition of the attribute. Each of the 20 variables provides the average metric dimension of the attribute. The use of mean dimensions sometimes yields seemingly impossible results. For instance, the average east-west dimension of a non-parallel quadrilateral room may 
Table 55. Correlation of Unit Designations and Original Feature Numbers to Unit Types.

\begin{tabular}{|c|c|c|c|c|c|c|c|c|c|c|c|}
\hline \multicolumn{2}{|c|}{$\begin{array}{l}\text { PRESERT } \\
\text { oEsIanito: }\end{array}$} & \multicolumn{2}{|c|}{$\begin{array}{l}\text { OTHER } \\
\text { DestaUATION }\end{array}$} & \multicolumn{2}{|c|}{$\begin{array}{l}\text { ENTT } \\
\text { JTPE }\end{array}$} & \multicolumn{2}{|c|}{$\begin{array}{l}\text { PRESEET } \\
\text { DESTCUTION }\end{array}$} & \multicolumn{3}{|c|}{ desicuntons } & \multirow[t]{2}{*}{$\begin{array}{l}\text { wist } \\
\text { srpe }\end{array}$} \\
\hline \multicolumn{6}{|c|}{ ALIBATES RUIM 28} & \multicolumn{5}{|c|}{ ALIBATES RUIK 28. continued. } & \\
\hline & Baker & Studer & 02son & sason & & & anker & Studer & 01son & Mason & \\
\hline 1 & Rode 1 & $-\infty$ & - & - & 3 & 45 & 45 & - & - & - & 8 \\
\hline 2 & 2 & - & - & - & 1 & 46 & 46 & $-\bullet$ & - & $\cdots$ & 8 \\
\hline 3 & 3 & - & - & $\cdots$ & ND & 47 & 47 & - & $\cdots$ & -- & 2 \\
\hline 4 & 4 & - & -- & -- & 3 & 48 & 48 & -- & - & - & MIsc-1 \\
\hline s & 5 & $\cdots$ & - & - & 20 & 49 & 49 & - & -- & - & 3 \\
\hline 6 & 6 & 2 & - & - & 4 & so & so & -- & -- & -- & 8 \\
\hline 7 & 7 & 2 & - & - & $I$ & $\$ 1$ & 31 & - & - & - & SDO (13) \\
\hline$\theta$ & 8 & 3 & - & - & 3 & 32 & 52 & - & -- & - & No (23) \\
\hline 9 & 9 & - & - & - & 8 & 53 & $46 \pi$ & - & - & -- & 7 \\
\hline 20 & 20 & - & - & - & 8 & 54 & - & - & - & undes. & 20 \\
\hline 11 & 11 & $\cdots$ & - & $\cdots$ & 1 & 55 & $\cdots$ & Burial & -- & undes. & 3 \\
\hline 12 & 12 & -- & - & - & 8 & 36 & -- & - & -- & undes. & 107 \\
\hline 13 & 13 & 3 & - & - & 4 & 57 & - & - & - & undes. & No \\
\hline 14 & 14 & - & - & -- & 8 & 58 & - & - & -- & undes. & ND \\
\hline 15 & 15 & - & - & $\cdots$ & 1 & 59 & - & $\cdots$ & 2 & - & No $11 / 27$ \\
\hline 16 & 16 & -- & - & - & 8 & 60 & - & - & -- & undes. & ND \\
\hline 27 & 17 & -- & - & -- & 8 & 61 & cise 1 & - & -- & -- & 10 \\
\hline 18 & 18 & -- & $\cdots$ & -- & 1 & 62 & Cise 2 & - & - & - & 10 \\
\hline 19 & 29 & -- & 1 & undes. & 1 & 63 & Cise 3 & - & - & -- & 10 \\
\hline 20 & 20 & undes. & - & -- & 3 & 64 & Cist 4 & - & -- & - & 7 \\
\hline 21 & 21 & $\cdots$ & $\cdots$ & - & 8 & 65 & Cist 5 & - & - & $\cdots$ & 7 \\
\hline 22 & 22 & - & - & $0 .-2$ & 7 & & & & & & \\
\hline 23 & 23 & - & $\cdots$ & - & 1 & ALIBS & AIES RUIM & $28 A$ & & & \\
\hline 24 & 24 & $=-$ & - & - & 5 & & Buker & & & & \\
\hline 25 & 25 & $\cdots$ & $\cdots$ & -- & 2 & 1 & 1 & & & & 1 \\
\hline 26 & 26 & $\cdots$ & $\cdots$ & -- & $\$ 00$ & & & & & & \\
\hline 27 & 27 & - & - & - & $\mathbf{s}$ & ALIBA & ATES RUtn & & & & \\
\hline 29 & 28 & - & - & $\cdots$ & Propmed & & Baker & & & & \\
\hline 29 & 29 & -- & - & -- & 8 & 2 & 1 & & & & 2 \\
\hline 30 & 30 & $\cdots$ & $=$ & - & 8 & 2 & 2 & & & & 1 \\
\hline 31 & 31 & - & -- & -- & 1 & 3 & 3 & & & & 2 \\
\hline 32 & 32 & - & - & - & 1 & 4 & 4 & & & & SD \\
\hline 33 & 33 & - & -- & - & 8 & 3 & 5 & & & & מי \\
\hline 34 & 34 & - & - & $\cdots$ & 1 & 6 & 6 & & & & B \\
\hline 35 & 35 & - & -- & -- & 2 & 7 & 7 & & & & so \\
\hline 36 & 36 & - & - & $20 .-2$ & 1 & 8 & 8 & & & & KDD \\
\hline 37 & 37 & -- & -- & -- & 2 & 9 & 2A & & & & 2 \\
\hline 38 & 38 & $\cdots$ & -- & - & 1 & & & & & & \\
\hline 39 & 39 & - & -- & -- & 8 & ANTEL & OPE CREEK & RUiN 22 & & & \\
\hline 40 & 40 & -- & - & -- & 8 & & Baker & Lowrey & Holden & Seyles & \\
\hline 42 & 41 & - & - & - & 5 & 1 & Room 150. & 27 & 20 & -. & 8 \\
\hline 42 & 42 & - & -- & -- & 2 & 2 & 2 & $5 A, 5 B$ & 5 & -- & 1 \\
\hline 43 & 43 & 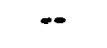 & -- & -- & 7 & 3 & 3 & 8 & 8 & $\cdots$ & 1 \\
\hline 48 & 44 & - & -- & $\cdots$ & $\mathrm{ND}$ & 4 & 4 & 15 & 15 & .. & 8 \\
\hline
\end{tabular}


Table 55, continued.

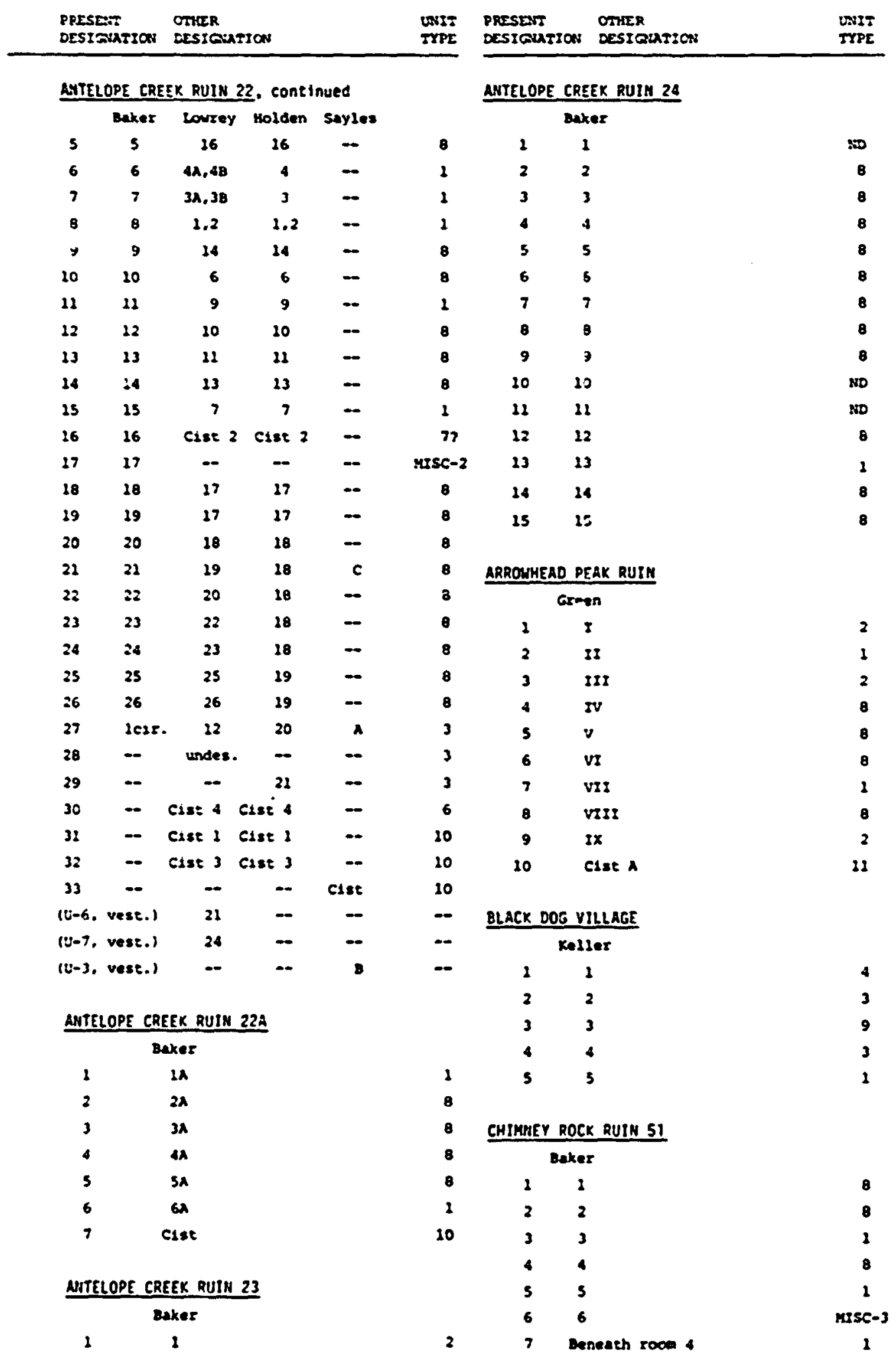


Table 55, continued.

\begin{tabular}{|c|c|c|c|c|c|c|}
\hline $\begin{array}{l}\text { PRESENT } \\
\text { DEsIONATION }\end{array}$ & $\begin{array}{l}\text { OTHER } \\
\text { OESIOUTION }\end{array}$ & $\begin{array}{l}\text { LIITT } \\
\text { TIRPE }\end{array}$ & \multicolumn{2}{|c|}{$\begin{array}{l}\text { DRESERT } \\
\text { Desiaution }\end{array}$} & $\begin{array}{l}\text { OMter } \\
\text { OEsICuTION }\end{array}$ & \multirow[t]{2}{*}{$\begin{array}{l}\text { iNTR } \\
\text { TXPE }\end{array}$} \\
\hline \multicolumn{3}{|c|}{ CHIMNEY ROCK RUIM SIA } & \multirow{2}{*}{\multicolumn{4}{|c|}{$\frac{\text { MEDFORD RAMCH SITE }}{\text { DuEELEIO }}$}} \\
\hline & Bakez & & & & & \\
\hline \multirow[t]{2}{*}{2} & IA & 1 & 1 & ג & & 2 \\
\hline & & & 2 & und & lesig. north of $\lambda$ & 8 \\
\hline \multicolumn{2}{|c|}{ COETAS RUIM 55} & & 3 & $\mathbf{8}$ & a & 4 \\
\hline & Studer & & 4 & \multicolumn{2}{|c|}{ South of 8} & 9 \\
\hline 2 & $\boldsymbol{\lambda}$ & 1 & 5 & \multicolumn{2}{|c|}{ c } & 4 \\
\hline 2 & 8 & 1 & 6 & \multicolumn{2}{|c|}{ South of $c$} & 9 \\
\hline \multirow[t]{2}{*}{3} & н & 8 & & & & \\
\hline & & & \multicolumn{4}{|c|}{ SITE 4IM07 } \\
\hline \multicolumn{3}{|c|}{ CONMER SITE } & \multicolumn{3}{|c|}{ Green } & \\
\hline & Dusfield & & 1 & \multicolumn{2}{|c|}{1} & 1 \\
\hline 1 & 1 & 8 & 2 & \multicolumn{2}{|c|}{$P_{+}:=$} & 10 \\
\hline 2 & 2 & 8 & 3 & \multicolumn{2}{|c|}{ pie } & 7 \\
\hline \multicolumn{3}{|c|}{ COTTOMHOOD CREEK RUINS } & \multicolumn{4}{|c|}{ PICKETT RUIN } \\
\hline & SORPAS & & & \multicolumn{3}{|c|}{ DORPAN } \\
\hline 1 & undesignated & 1 & 1 & 1 & & 6 \\
\hline \multicolumn{3}{|c|}{ FDOTPRIMT SITE } & ROPER & ITE & & \\
\hline & areen & & & norep & Duftiesd & \\
\hline 2 & I & 1 & 1 & 1 & 1 & 8 \\
\hline 2 & $2 I$ & 1 & 2 & 5 & 3 & 8 \\
\hline 3 & 282 & 1 & 3 & 8 & - & $\theta$ \\
\hline 4 & Pit $\lambda$ & 20 & 4 & 6 & 6 & 6 \\
\hline 5 & Jargest basin pit & 21 & 5 & 9 & 9 & 8 \\
\hline 6 & sallest basin pit & 11 & & & & \\
\hline & & & SAMFO & RUIN & & \\
\hline JAC & LEN SIIE & & & Hugh & les Dutfseld & \\
\hline & Marrison & & 1 & 11 & el2epwayl -- & - \\
\hline 8 & 1 & 1 & 2 & 2 & 2 & 8 \\
\hline 2 & Ple & 13 & 3 & 36 & A11erwayl -- & - \\
\hline 3 & pit & 11 & 4 & 4 & 4 & 2 \\
\hline & & & 5 & 5 & 7 & 8 \\
\hline 100 & RUIN & & 6 & $6-8$ & 6 & 3 \\
\hline & Lowrey & & 7 & 7 & s & 8 \\
\hline 1 & main room & 2 & B & - & - & 8 \\
\hline 2 & undesignated & - & 9 & $r-1$ & - & so \\
\hline 3 & undesignated & ब & 10 & $r-2$ & -- & 10 \\
\hline 4 & C1st to NE & 8 & $\boldsymbol{u}$ & $8-3$ & - & $\mathrm{mo}$ \\
\hline s & Cise to SE & 8 & $\cdots$ & 9 & miden & $\cdots$ \\
\hline & $\underline{I T E}$ & & SPRIN & CAMYO & N RUIN & \\
\hline & Hughes: & & & Dues: & $.2 a$ & \\
\hline 1 & 1 & 2 & 1 & Mai & & 2 \\
\hline & & & 2 & ove & & $\mathbf{8}$ \\
\hline & & & 3 & undes & 19. souch of enin & 87 \\
\hline
\end{tabular}


Table 55 , continued.

\begin{tabular}{|c|c|}
\hline 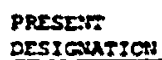 & $\begin{array}{l}\text { ORHER } \\
\text { EES:CLAYION }\end{array}$ \\
\hline
\end{tabular}

TARBOX RUIM

\begin{tabular}{|c|c|c|c|}
\hline & Holden & & \\
\hline 2 & $n-1$ & 2 & \\
\hline 2 & $B-1$ & 1 & \\
\hline $\mathbf{3}$ & $8-2$ & 8 & (double unit) \\
\hline 4 & $8-3$ & 1 & \\
\hline 5 & $8-4$ & 2 & \\
\hline 6 & $B-5$ & B & \\
\hline 7 & B-undestg. & 8 & \\
\hline 8 & B-undesig. & e & \\
\hline 9 & B-undesig. & B & \\
\hline 20 & B-undesig. & 8 & \\
\hline 21 & B-undesig. & 8 & \\
\hline 12 & s-undesig. & $\mathbf{B}$ & \\
\hline 13 & B-undesig. & 8 & \\
\hline 14 & p-undesig. & 8 & \\
\hline 15 & Cist 1 & 10 & \\
\hline 16 & Cast 2 & 10 & \\
\hline 17 & $c-1$ & $\mathbf{B}$ & \\
\hline$: 8$ & $2-2$ & 8 & \\
\hline 19 & $D-2$ & 8 & \\
\hline 20 & $E-1$ & 8 & \\
\hline
\end{tabular}

TURKEY CREER RUIN

Green

12

2

3 III

6

6

ZOLLARS SITE

$\operatorname{sinich}$

18

20

8

8 
be slightly smaller than the average east-west dimension of the central channel feature within the room.

A directory describing each attribute and variable observation precedes Table 56. Related attributes and variables are grouped together. Coservations 1-3 concern factors affecting the reliability and quality of information about the unit. Observations $4-8$ concern the spatial and stratigraf:ic relationship of the unit to other units. Observations 9-12 provide information about the unit's shape and size. Observations 13-28 deal with the walls and features along the walls. Observations 29-59 concern the occurrence and nature of the floor and floor features. Finally, abservations 60-62 address modifications made during subsequent construction activities, and whether or not, the unit burned. Although the directory defines the coding system applicale to specific observations, the following general symbols are also used: ND-- No Data; NA-Not Applicable; ?-- Uncertain Observation; $(-)--$ Not Present; $(x)--$ Present. Variables followed by the code (e) denote estimated measurements.

\section{Quality of Information}

1. CONDITN: The preservation condition of the architectural unit at the outset of investigation. In those instances involving units excavated by more than one field party, the coding reflects the urit condition as reported $b_{y}$ the earliest party leaving adequate records. Code--Undist, no major natural or cultural disturbance; Eroded, disturbed by natural factors; Vandal, vandalized or disturbed by earlier excavations. 
2. EXTEXCAV: The extent of excavation. Code--Unex, not investigated: Test, less than entire unit excavated; Exca, the interior portions of the unit completely cleared.

3. UNITSUITAB: The suitability of this unit for subsequent analysis. Code--Poor, very limited observations available; Fair, observations limited by preservation conditions or extent of excavations: but information is complemented by analogous units of same shape and size in similar spatial relationships to other units; Good, reliability based on extensive testing or excavation of an undisturbed or minimally disturbed/ vandalized unit.

Spatial Relationships

4. AGGTYPE: Refers to spatial proximity to other units. Code: Isolat, isolated, free standing unit; Contig, possibly shares at least one (contiguous) common wall or cornex with another unit; I-IV, contiguous rooms corresponding to Aggregate Types defined in Chapter 5.

5. UNITTYPE: Refers to the type of architectural unit corresponding to the types defined in Chapter 5. In addition, Type 8 units occurring within disparity Aggregation Units II through IV will also specify subordinate 
positions relative to dominant unit (e.g. 8, pos. 3). The position units refer to 12 potential positions surrounding a single dominant unit and are designated in a clockwise manner starting with 1 in the NaNE position: Type 8 Units occurring within parity Aggregate VI will also specify the direction relative to the adjacent unit (e.g. $8 . N$ ) indicates that unit $B$ is north of the adjacent parity unit.

6. SUPRIMPSD: Non-parametric observation concerning the stratigraphic relationship of unit to cultural strata or other feature units. Code: $\underline{X}$, the unit either superimposed by cultural features or midden; $=$, no such relationship noted.

7. SUPOVER: Refers to the kinds of cultural material located beneath the unit under consideration. code: Midden. exterior trash; Unit No, specific architectural unit number: Pits, small features of undetermined characteristics.

8. SUPUNDER: Refers to the kinds of other architectural units overlying the unit under consideration. Since most records do not note post-abandonment trash deposition, the present observation only records features. Code: Unit No, specific architectural unit number; Pit, small features of undetermined characteristics. 
Basic Unit Morphology

9. UTSHAPE: Basic shape of the unit. Code: Quad, quadrilateral; Cir. circular; Oval, oval; Pent, pentagonal; D-shape. D-shape; Irreg, irregular shape.

10. UTSZEiv: A retric variable providing the mear east-west dimension of the unit, or diameter measurement if the unit is circular.

11. UTSZNS: A metric variable providing the mean north-south dimension of the unit.

12. UTAREA: The area of the unit listed in square meters.

\section{Wall Attributes and Features}

13. WALTYPFND: Records the nature of the basal foundation type of the walls. If all walls have similar foundation construction, a single code will be entered; otherwise, the range of foundation types will be entered and the specific locations of each type are denoted in conjunction with Observation 14 (FNDLOC). Code: SV, single row vertical stone slabs; DV, double row vertical stone salbs; $\underline{H}$, horizontal stone slabs; Post, picket-post construction; Plain, no evidence of stone or post walls; BLDR, natural boulder.

14. FNDLOC: The foundation location observation is only employed in circumstances where multiple construction methods were used in the lowest tier of different wall foundations. The respective wall locations will be listed 
immediately below the variable WALTYPFND. Code: $\underline{N}$, north wall; $\underline{E}$, east wall; $\underline{W}$, west wall; $\underline{S}$, south wall.

15. WALTYPUP: Records the construction type used in the upper portion of the walls. Code: SV, single vertical stone slabs; DV, double vertical stone slabs; $\underline{H}$, horizontal stone slabs: SH, single row of horizontal slabs; Post. picket post construction; Plain, no evidence of stone or post walls.

16. WALMXHI: This variable provides the maximum wall height. It is listed to provide a cross-check on the nature of such wall features as passage neight (23) and wall openings. (27) and extent of room disturbance. The variable was provided only for the units excavated by the WPA crews.

17. WALMNHI: This variable provides the mean wall height and is used in conjunction with the maximum wall height to provide a measure of room destruction as well as the presence of openings or passages in the upper portions of the walls.

18. ABUNDROC: Abundance of rock in the upper fill. This nonparametric observation is used as a cross-check on determining the nature of the upper wall configuration (15 WALTYPUP). The observations are most consistently derived from the WPA excavated units. Code: Abund, displaced rock is abundant in the unit; Mod, the presence of moderate amounts of displaced rock 
was noted; Rare, few rocks were encountered in the fill: None, no rocks were encountered in the fill.

19. PASTYP: The type of passage or entrance apparent on or near the floor level. Code: Vest-PN, extended vestibule parallel side: Vest-BR, extended vestibule bulbar form; Vest-DSB, extended vestibule with double slab entrance walls; Gap, opening in the wall; =, no passage or entrance apparent.

20. PASDIR: The passage direction(s) refer to the walls containing the passages. Code: North, north wall; NE, northeast corner, East, east wall; SE, southeast corner; South, south wall; SW, southwest corner; West, west wall; NW, northwest corner.

21. PASLN: This variable provides the length of an extended passage as measured from the interior wall to the furthest portion of the passage.

22. PASWD: This variable lists the interior passage width. In bulbar shaped extended passages, the dimension represents an average width.

23. PASHI: A variable listing the height of the passage.

24. STEPTYP: The type of step occurring at the interior of the unit near the passage marked by a difference in depth between the passage and the floor. Code: $(X)$, plain step present coinciding with wall: Fan, fan-shaped step platform extending into the room: $(-)$, no step indicated. 
25. SILLTYP: The sill is a ridge of clay or earth on the floor of the passage adjacent to the interior of the room. Code: $(X)$, raised sill present; $(-)$, no sill indicated.

26. TRSHCOLLR: The "threshold collar" refers to an extension of the passage walls a slight distance into the main area of the architectural unit. It may have served to direct air vertilation; or else acted as a frame for hanging a skin or woven partition over the passage entrance. Code: $\underline{X}$, collar present; $=$, no collar indicated.

27. OPENSZ: Refers to wall gaps occurring a considerable distance above the floor surface. Some may have served as entrances--particularly in rooms blocks having split floor levels. The variable OPENSZ records the width of the opening.

28. OPENLOC: The location of the opening refers to the wall containing the opening. Code: $\underline{N}$, north wall; $\underline{E}$, east

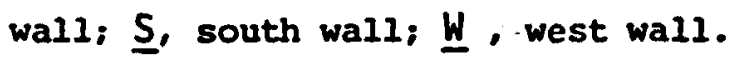

\section{Floor Attributes and Features}

29. CNTHARTYP: This attribute records the type of centrally located prepared hearth within the unit. Code: Plain, prepared clay basin shaped; Collared, basin shape with rim rising above the floor; Slab, basin shaped using stone slabs; Concent, concentric consisting of shallow 
basin within larger basin; Double, two adjacent plain hearths; $\underline{X}$, hearth present but type unknown.

30. CNTHARDIA: A metric variable recording the diameter of the central prepared hearth.

31. DEFLECTOR: The deflector refers to a large vertically-set slab near the central hearth. Code: $\underline{x}$, present; $=$. absent.

32. DEFLTLOC: This records the location of the deflector feature relative to the central hearth position. Code: $\underline{N}$. north of central hearth; E. east of central hearth; S, south of central hearth; $\underline{W}$, west of central hearth.

33. AXHARNO: The number of auxiliary prepared hearths.

34. AXHARLOC: The location of auxiliary hearths. codes refer to the location within the units: NC, north central; $\underline{N E}$, northeast; $\underline{E C}$, east central: $\underline{S E}$, southeast; $\underline{S C}$, south central; SW, southwest; WC, west central; NW, northwest; Plat, platform.

35. ASHPITNO: Ash pits are features which show less formal preparation than hearths or their subservient location relative to plastered hearths. This observation records the number of ash pits within the unit.

36. ASHPITLOC: The location of ash pits within the unit. Code: NC, north central; $N E$, northeast; $E C$, east central; $\underline{S E}$, southeast; SC, south central; SW, southwest; WC, west central; NW, northwest; Cent, center. 
37. CNTPOSTNO: The number of centrally located support posts. Numbers in parentheses are presumed number of posts based on assymmetry of existing posts inside eroded or vandalized unit.

38. AXPOSTNO: The number of auxiliary posts within the unit.

39. AXPOSTLOC: The locations of auxiliary posts within the unit. Code: North, north wall; East, east wall; South, south wall; West, west wall; Ent, entrance: Cor. corners: NoCent, north central; So-East, southeast; No-East, northeast; So-West, southwest; Bin, bin edge; Plat, platform edge.

40. CHANLTYP: The channel is a depressed central section of the unit's floor characterized by fairly abrupt curbing and extending to opposite walls of the unit. The channel may contain hearchs, ash pits, platforms or activity areas. This observation records the type of channel within the structure. Code: Plain, clay curbing without raised rim along edge of top: Ridged, clay curbing with raised rim along upper edge of the adjacent floor; Slab, stone slab curbing without raised rim along edge; Bulbar, a channel form which is wider in the middle of the unit than at either of the ends near the walls.

41. CHANLSZEW: A variable recording the average east-west dimension of the channel.

42: CHANLSZNS: A variable recording the average north-south dimension of the channel. 
43. CHANLDEP: A variable recording the depth of the channel below the adjacent flooring surface.

44. BENCHWD: This metric variable records the average dimension of the floor on one side of the channel. In those instances where the channel is oriented East-West, BENCHWD is derived by $1 / 2 \cdot$ (UTSZNS-CHANLSZNS).

45. PLTFMTYP: This records the type of platforms within the unit. Code: Prot.PN, plain clay or earthern platforms protruding into the unit located along the center of the west wall; ProtSB, slab-lined platforms protruding into the unit located along the center of the west wall; Recessed, large niches recessed into the center of the unit's west wall; Other, raised clay platforms located in different areas of the unit; $(-)$, no platform present.

46. PLTFMSZEW: Metric variable recording the average east-west dimension of the platform.

47. PLTFMSZNS: Metric variable recording the average north-south dimension of the platform.

48. BINTYP: Bins refer to the floor space separated by interior partition walls. The type of bin refers to the kind of wall used to construct the partition. Code: Plain. puddled clay or earthen walls: Slab, walls with stone slab foundations; Post, post-reinforced wall partitions; (-), no bin wall partitions.

49. BINLOC: Location of bins within the larger units. Codes: 
NE, northeast corner; SE, southeast corner; $\underline{\text { SW, }}$ southwest corner; NW, northwest corner.

50. BINSZEW: Metric variable recording the average east-wast dimension of the bin.

51. BINSZNS: Metric variable recording the average north-south dimension of the bin.

52. BINAREA: Variable recording the floor area encompassing the bin.

53. SLBCYSTNO: The number of slab-lined pits or cists present within the unit.

54. PITNO: The number of nonslab-lined pits or cists present within the unit.

55. BURLNO: The number of burial pits within the unit; Mult, multiple interments.

56. STONEFLOOR: This observation records the presence $(X)$ or absence $(-)$ of stone slabs used as the floor surface of the unit; BEDRK, bedrock.

57. FLOORNO: The number of floor levels present within the unit.

58. SUBTERRN: An observation recording whether the unit has been built within a semisubterranean pit. Code: $(X)$, unit built within semi-subterranean pit; $(-)$, not built within a pit.

59. SUBTRNDEP: A metric variable recording the depth of the subterranean pit below the occupation or original ground surface.

60. MODIFCTN: An observation recording whether the unit has 
$(X)$ or has not $(-)$ been modified during its use.

61. MODTYPE: The type of architectural modification occurring within the unit. Code: Fload, floor(s) added: Chanfil, channel filled in; Heartad, hearth added; Partad, partition wall added; WallRem, wall removed; PasBoc, passage blocked; OpenBoc, opening blocked.

62. BURNED: An observation recording whetiver the unit has $(\dddot{x})$ or has not $(-)$ been burned. 
Table 56.

Roon Attributes and Variables

Site: Alibates 28-1

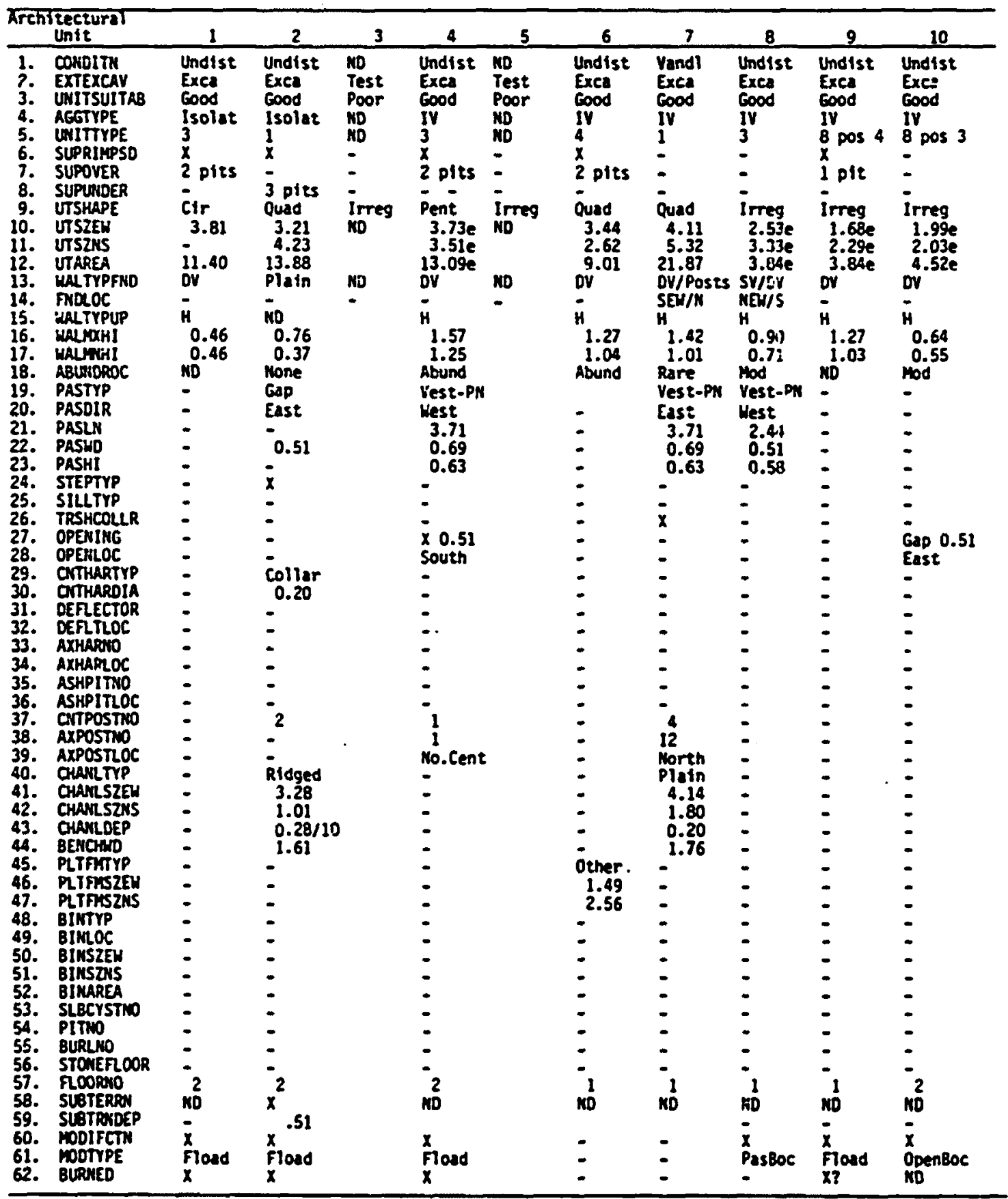


Table 56, Continued.

Site: Alibates 28-1

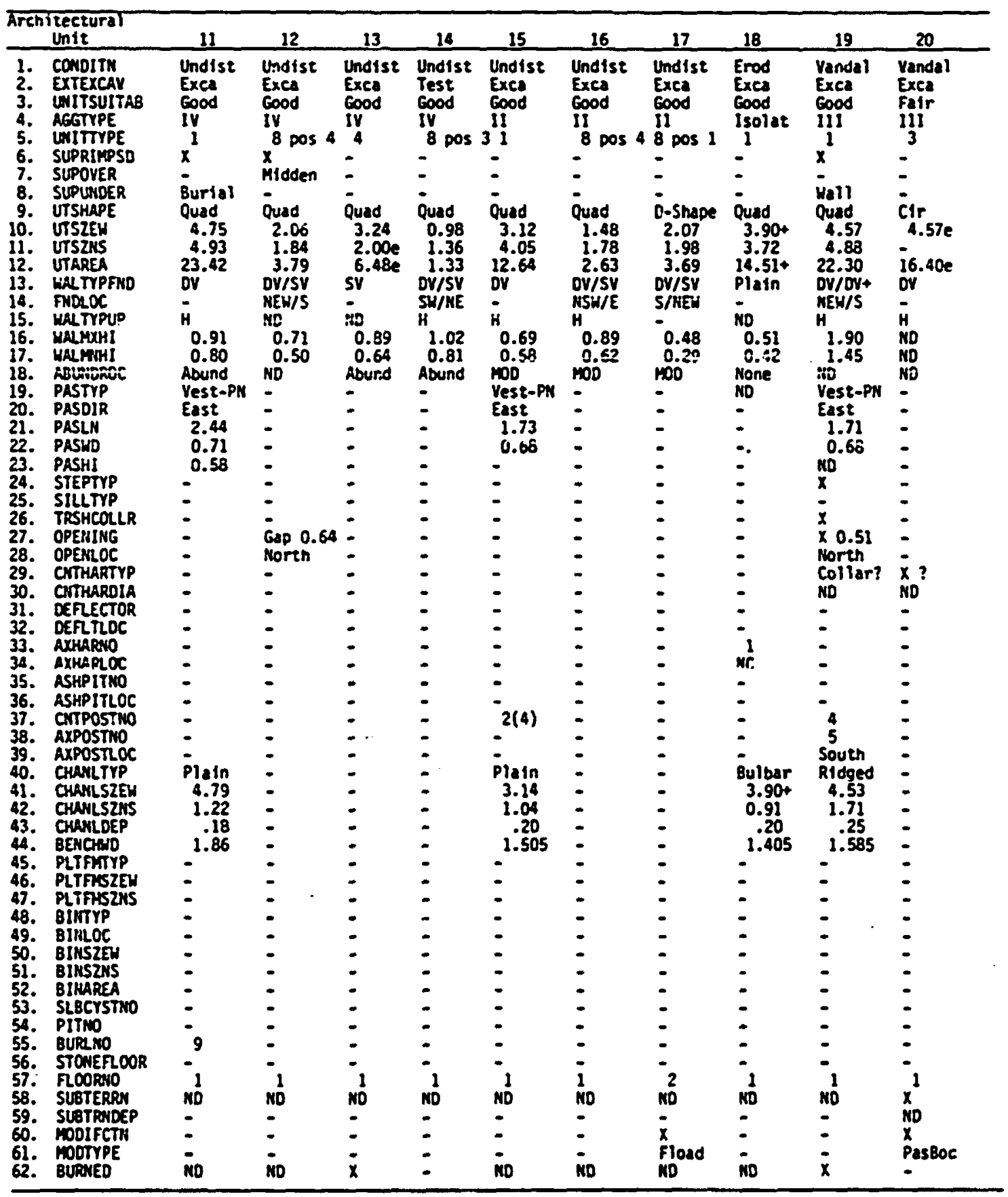


Table 56, Continued.

Site: Alfbates 28-I, II

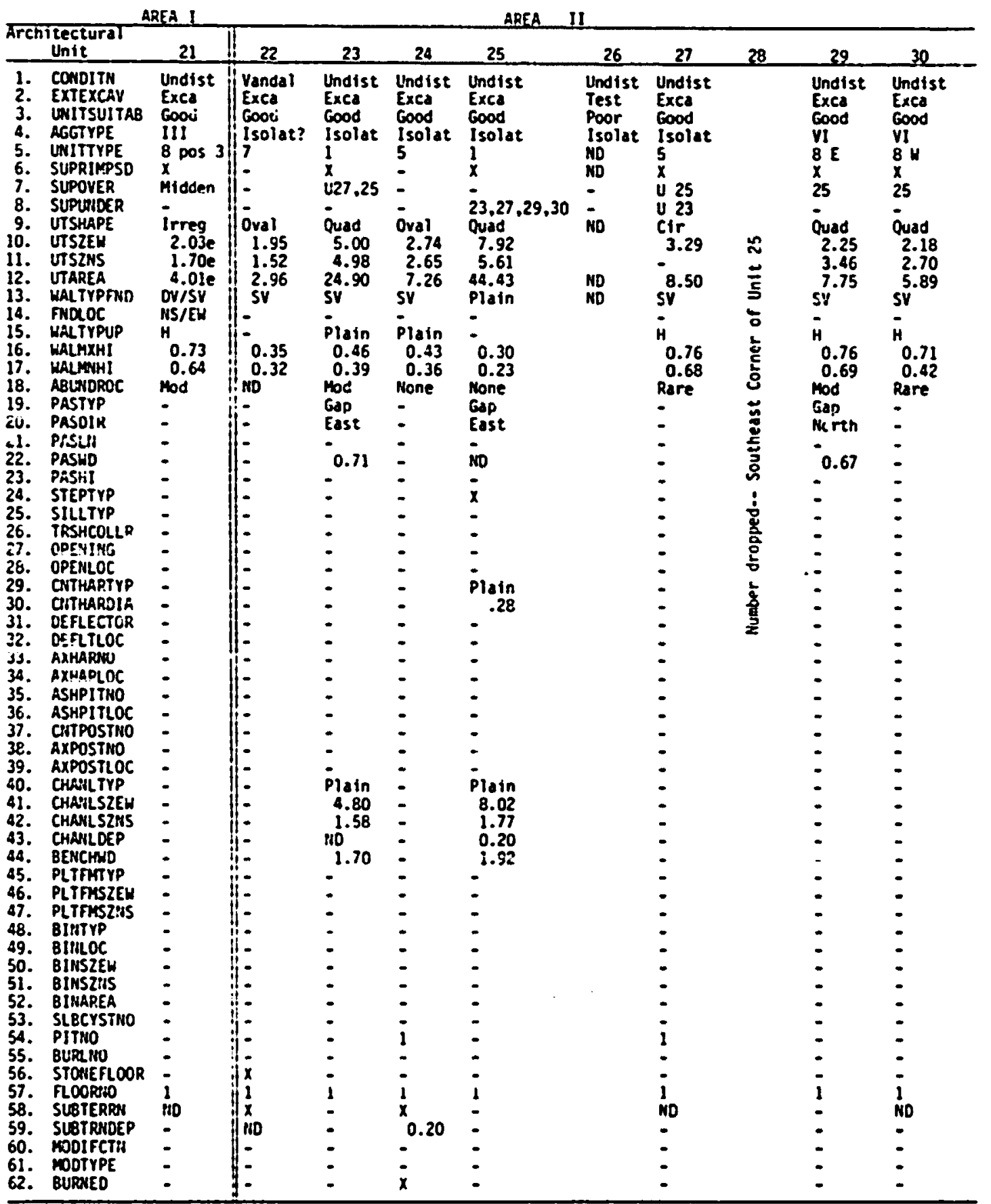


Table 56, Continued.

Site: Alibates 28-11

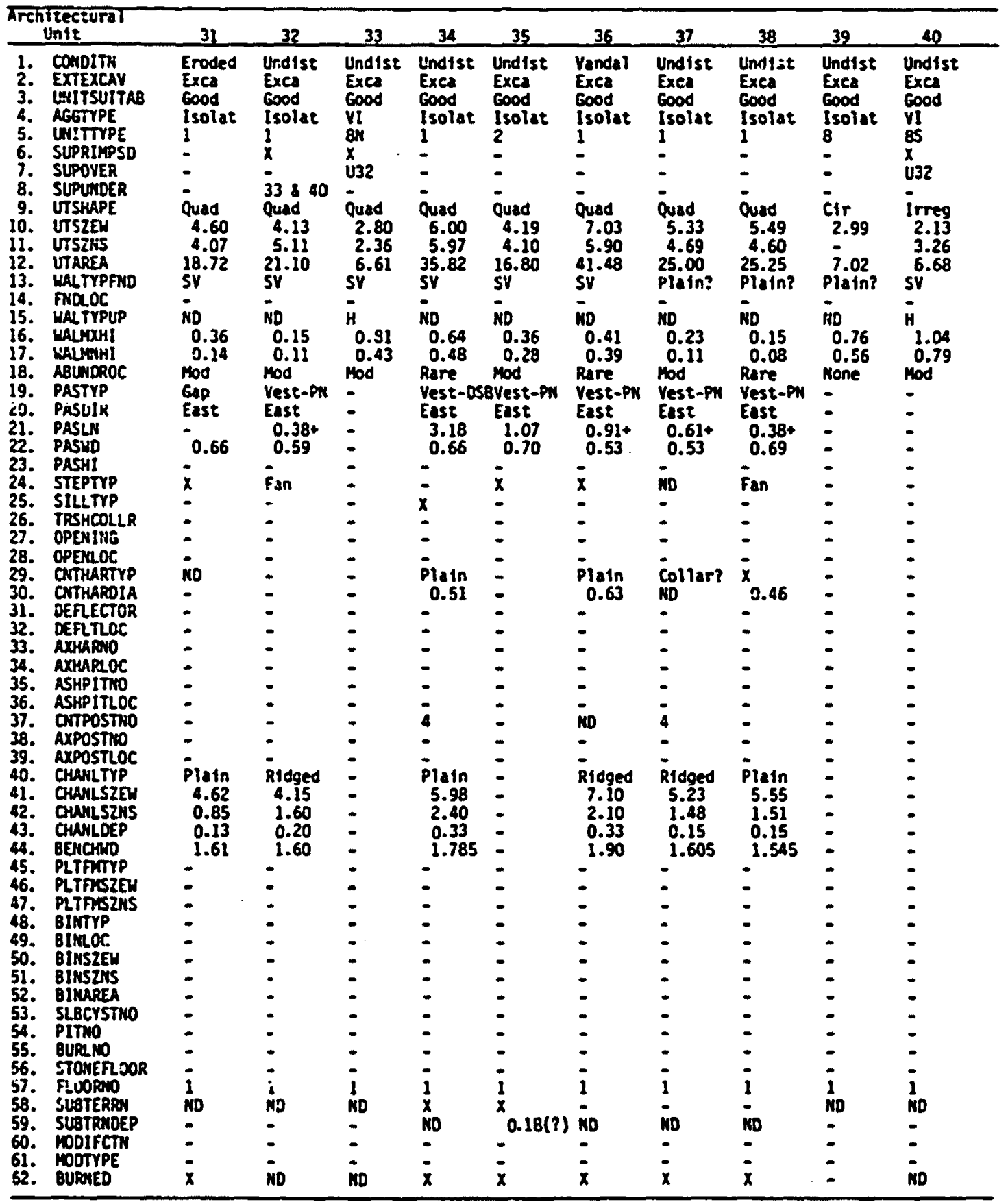


Table 56, Continued.

Sice: Alibates 28-11

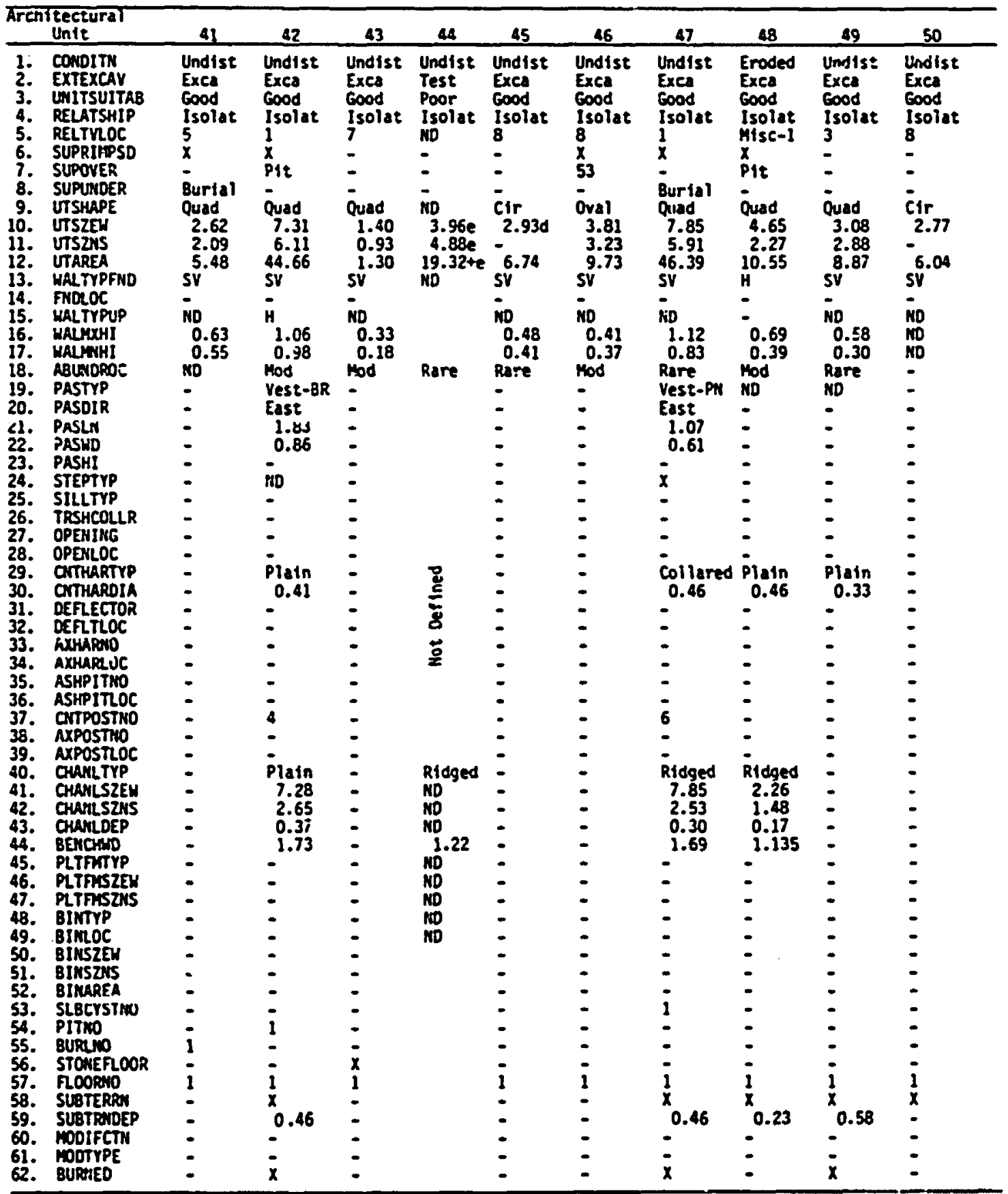


Table 56, Continued.

Site: A! tbates 28-11, I

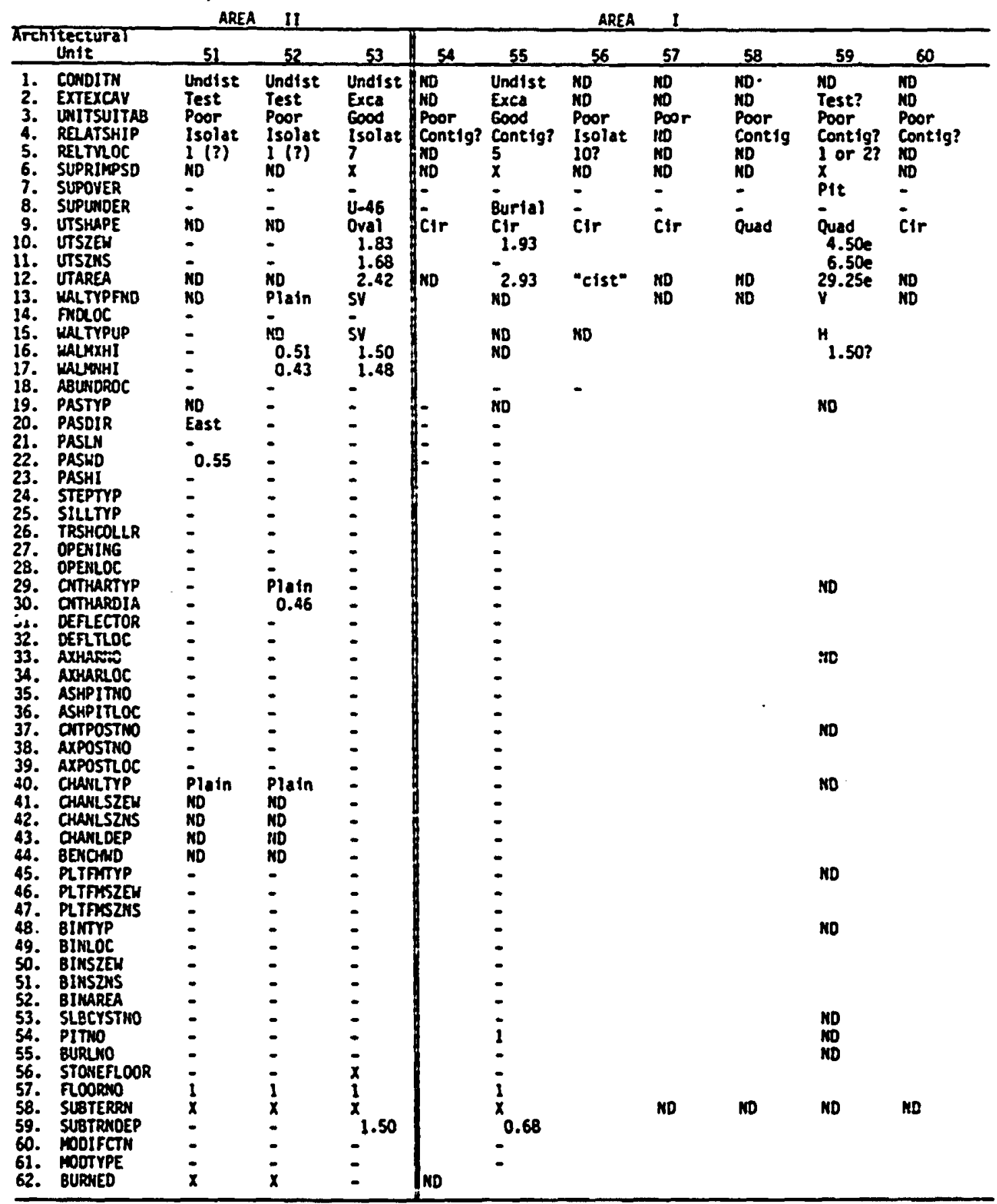


Table 56, Continued.

Site: Allbates 28-II, 28A, 30

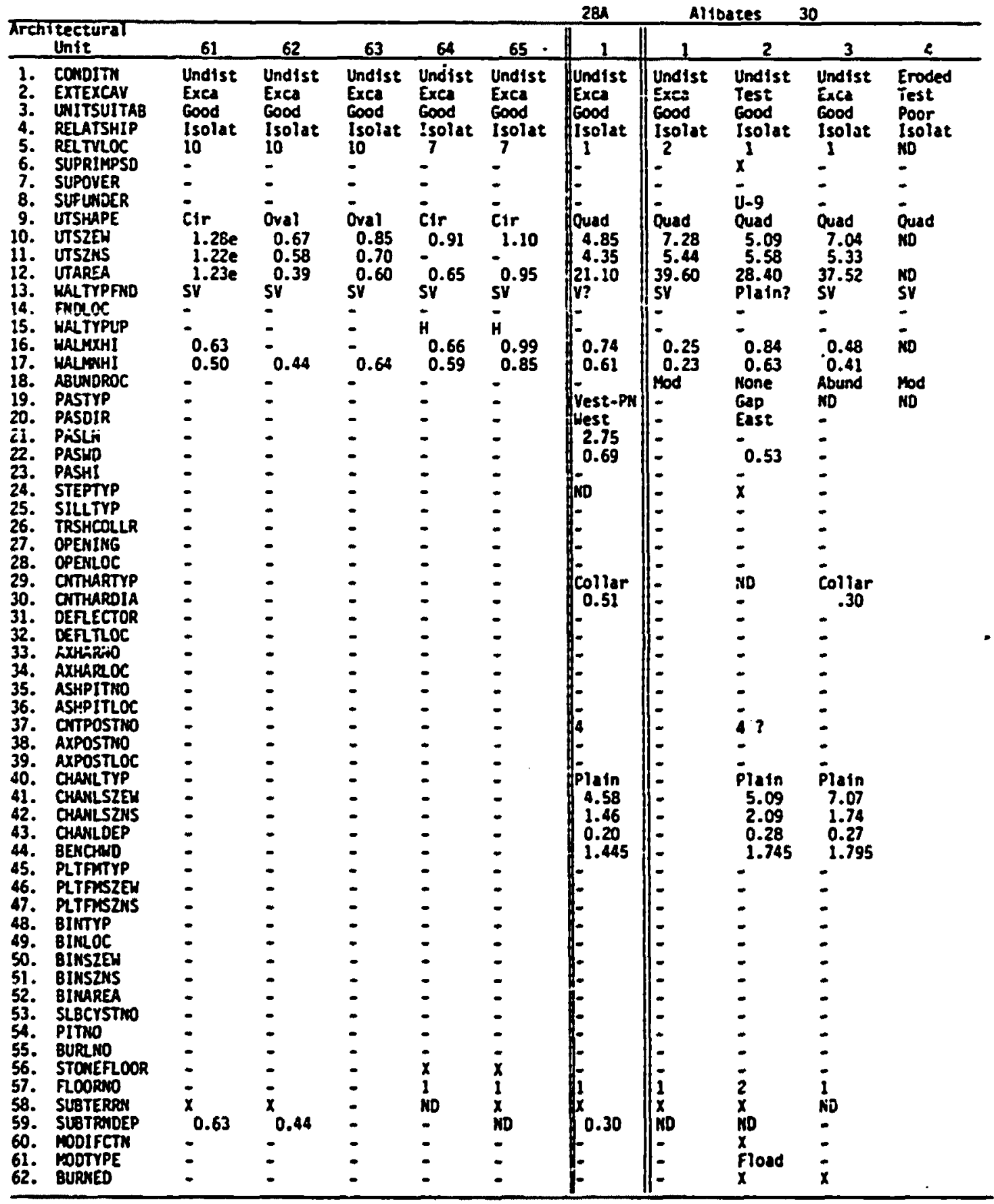


Table 56, Continued.

S1te: Allbates 30, Antelope Creek 22

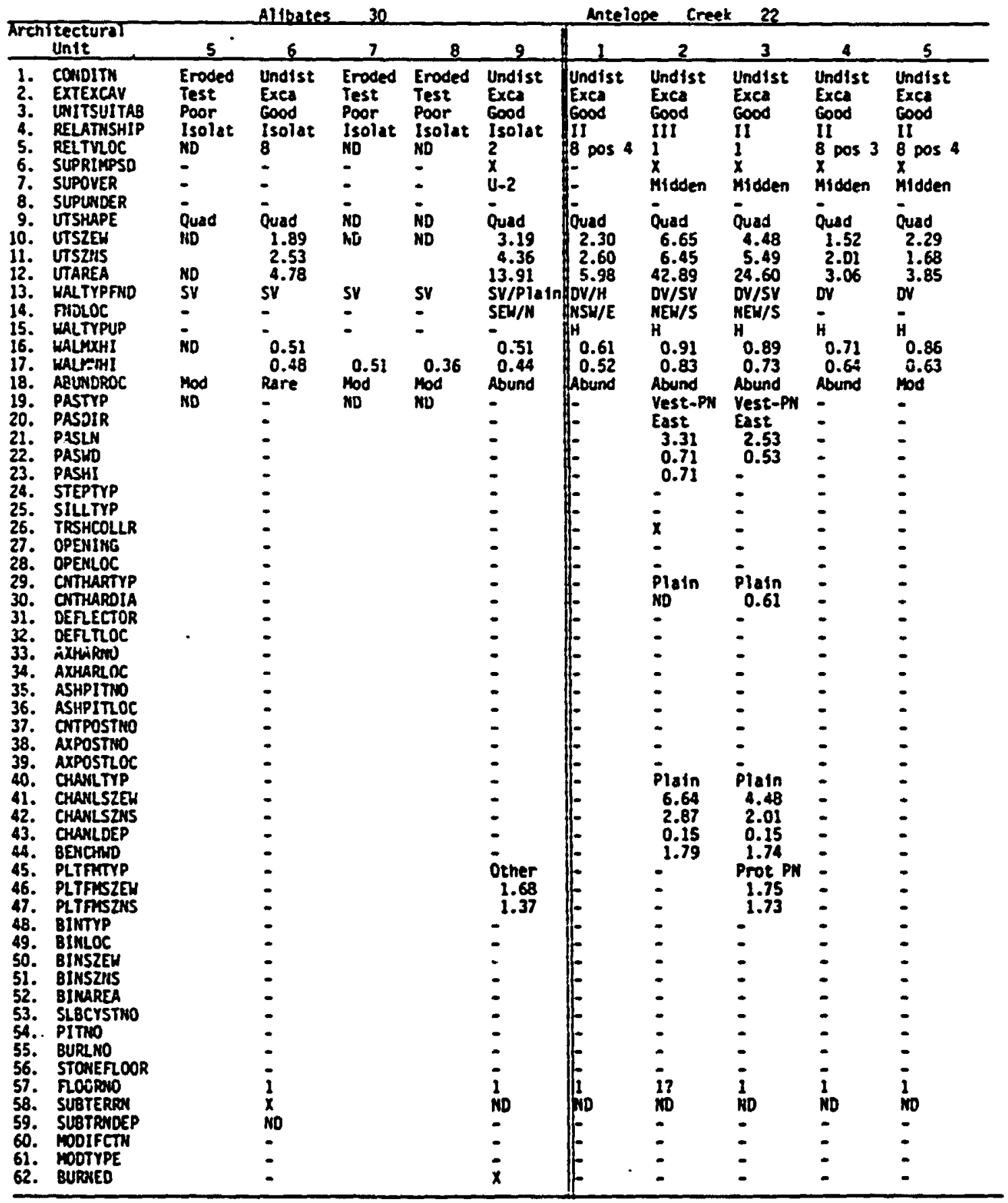


Table 56, Continued.

Site: Antelope Creek 22

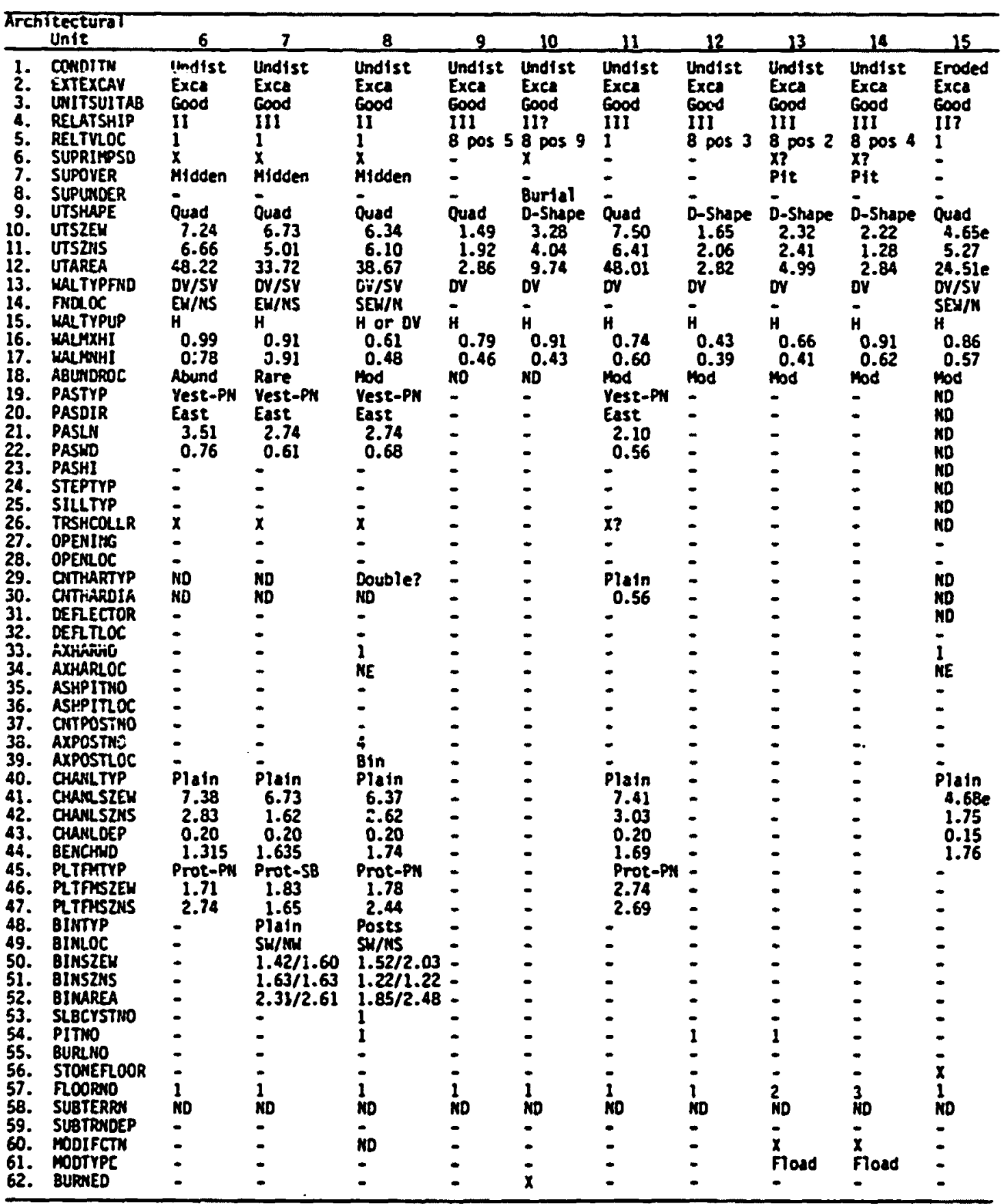


Table 56, Continued.

Site: Antelope Creek 22

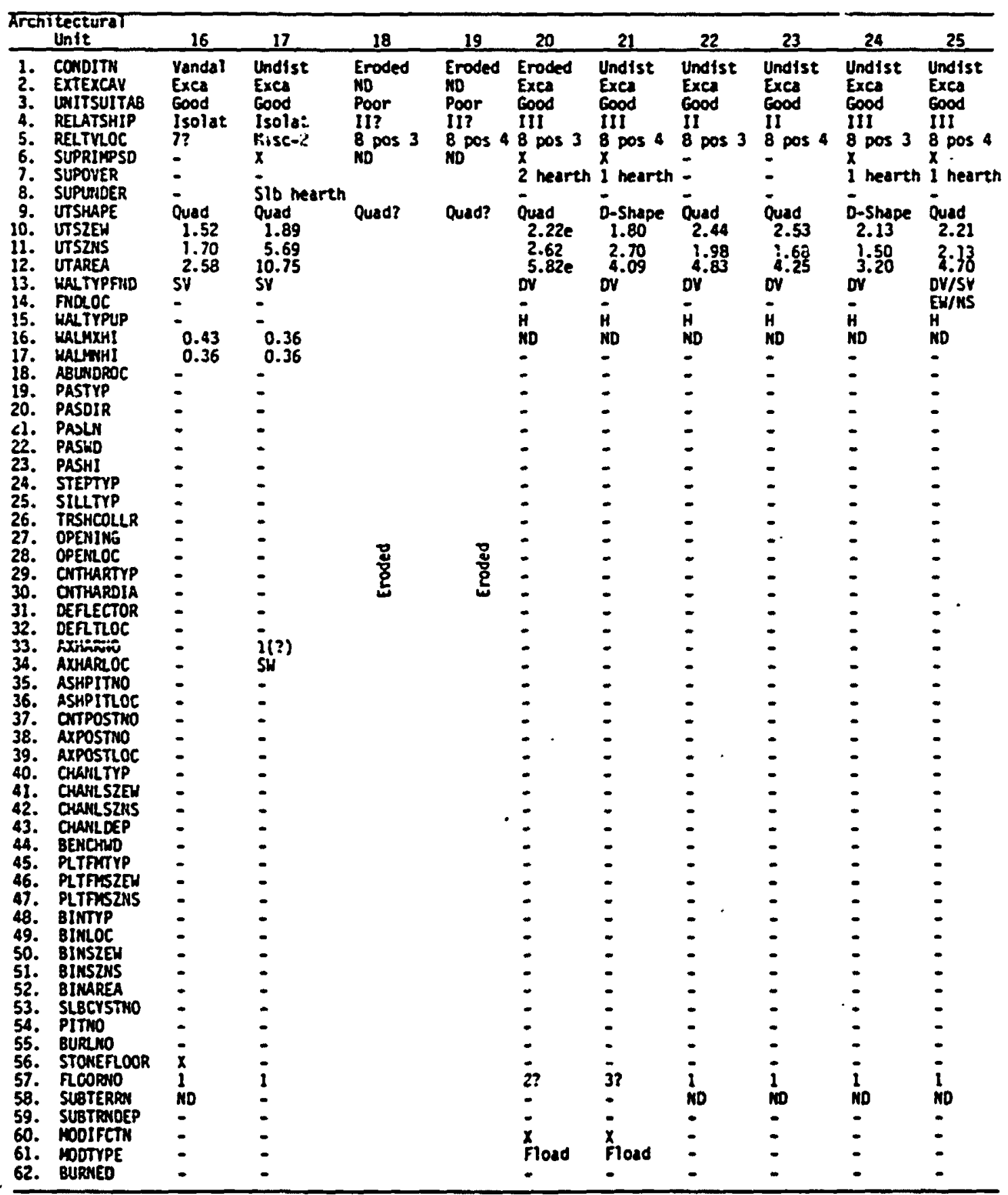


Table 56, Continued.

Site: Antelope Creek 22, $22 \mathrm{~A}$

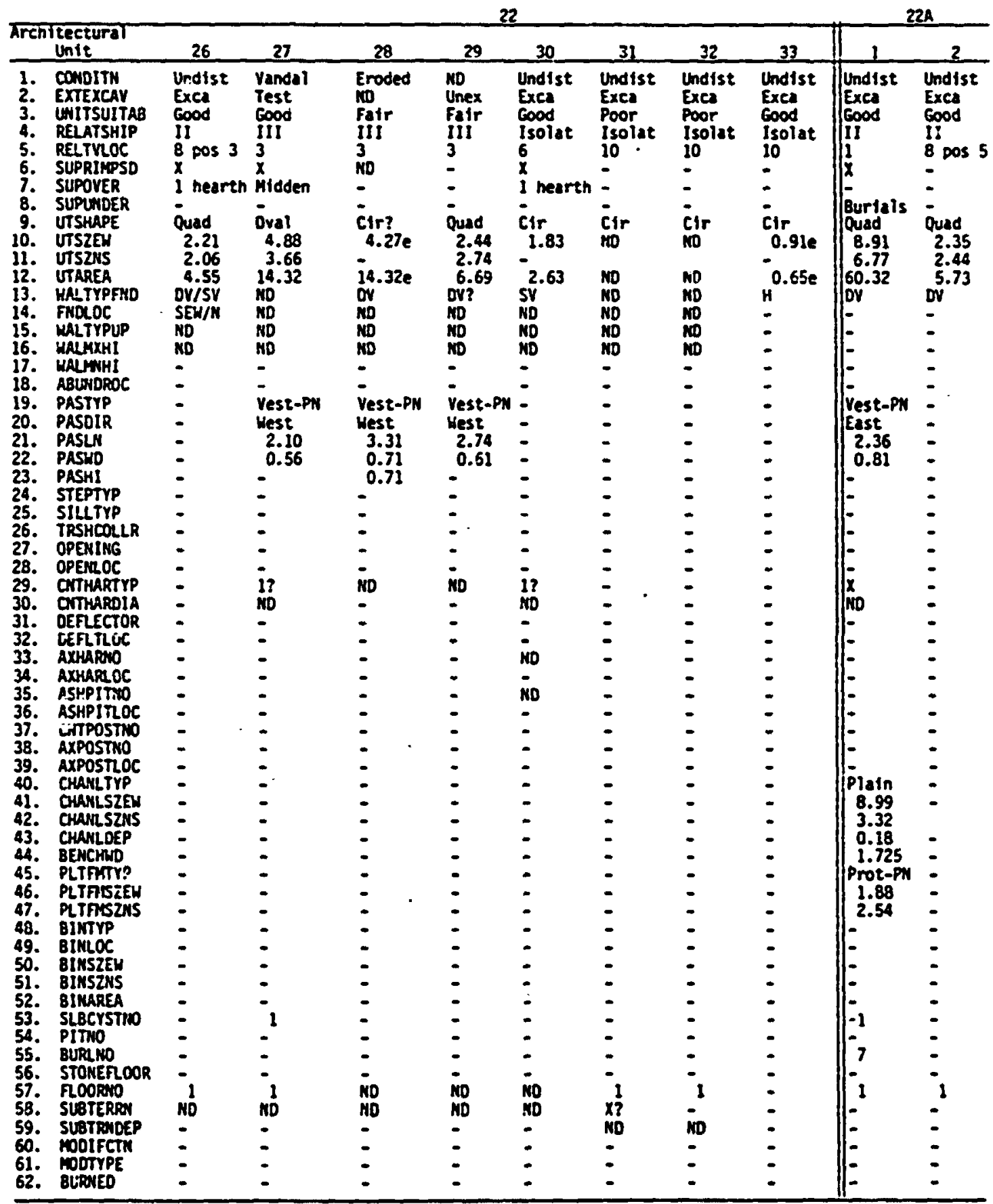


Table 56, Continued.

Site: Antelope Creek 22A, 23, 24

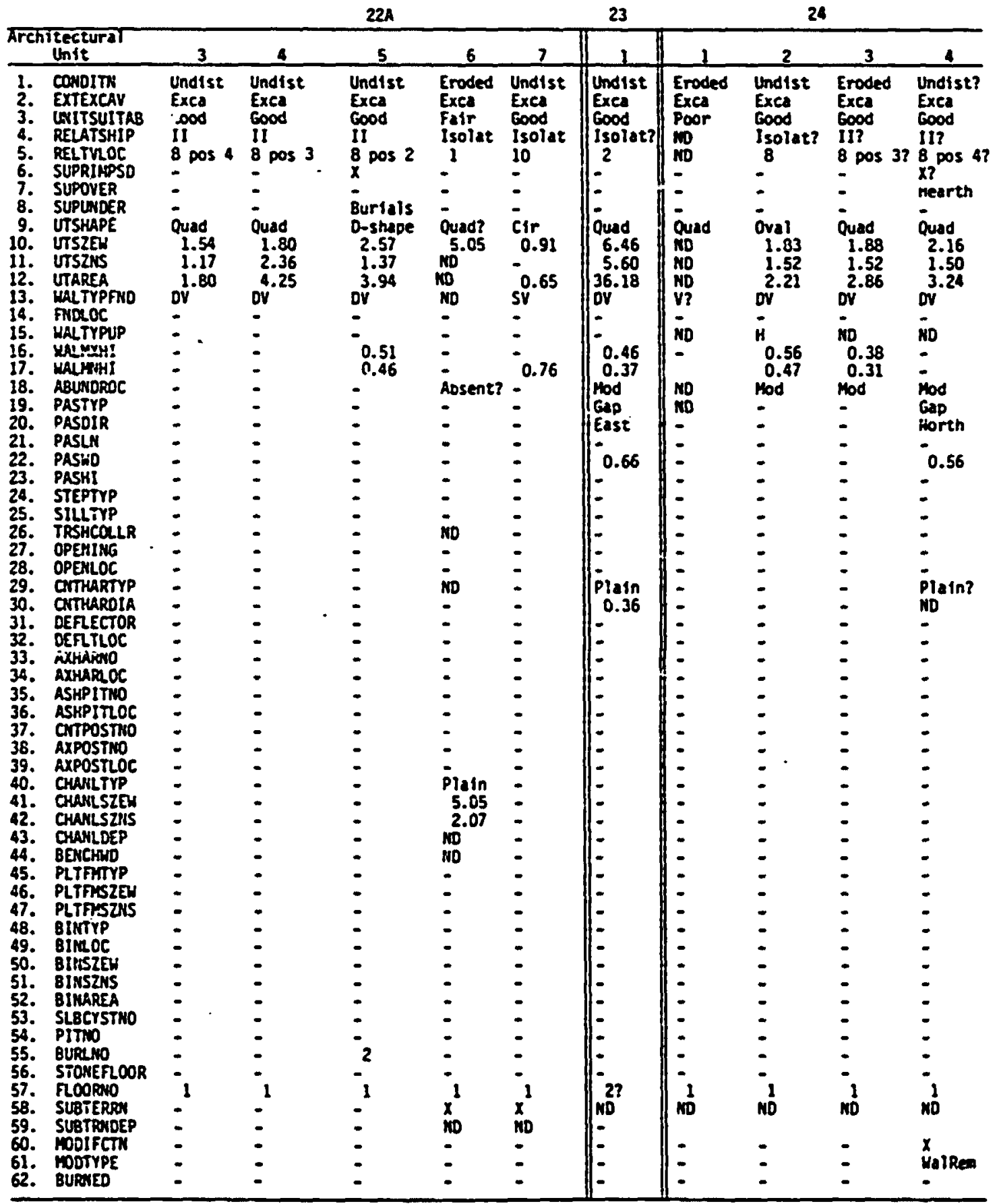


Table 56, Continued.

Site: Antelope Creek 24

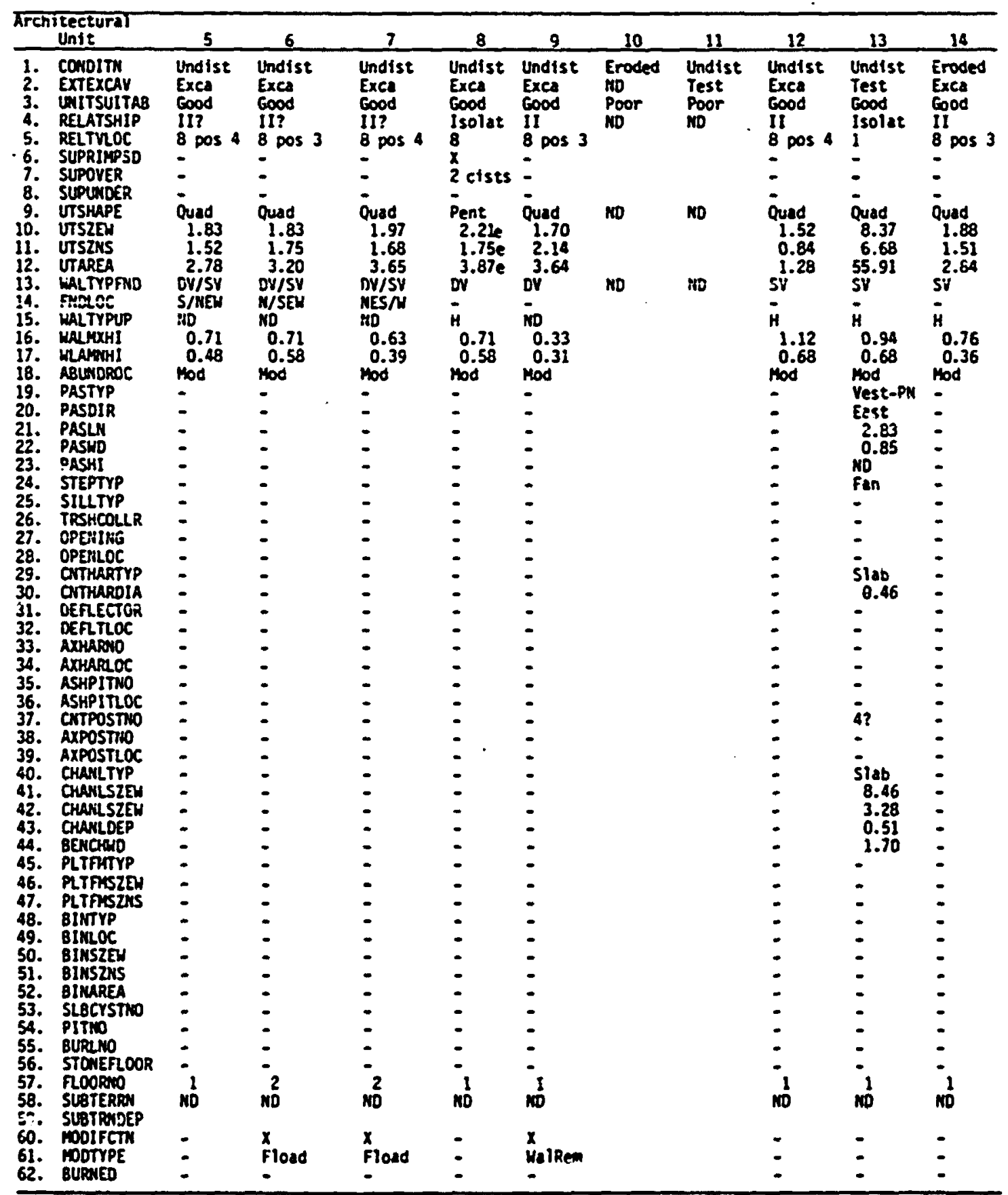


Table 56, Continued.

Site: Antelope Creek 24, Chimey Rock 51. 514

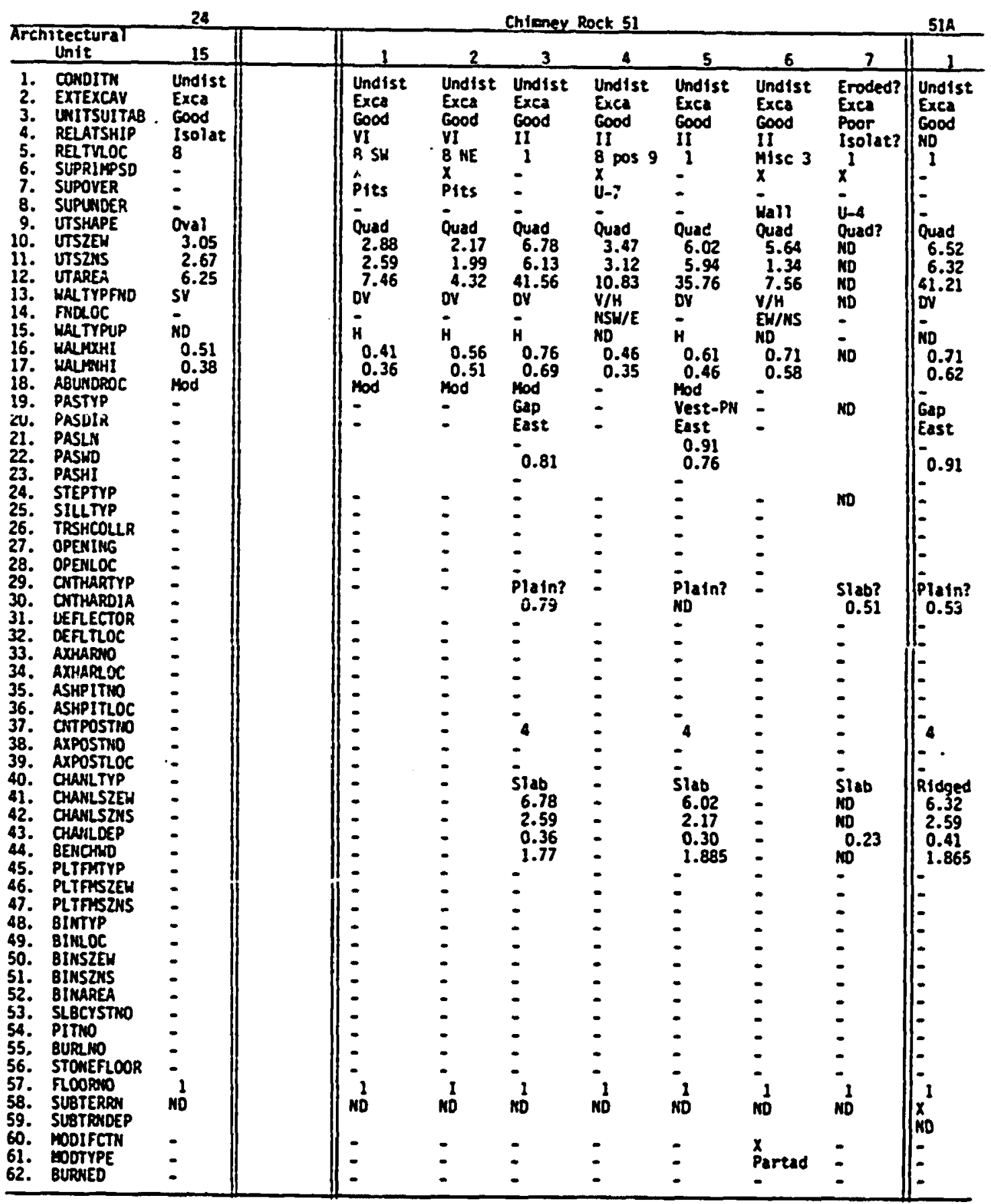


Table 56, Continued.

Site: Tarbox Rufins

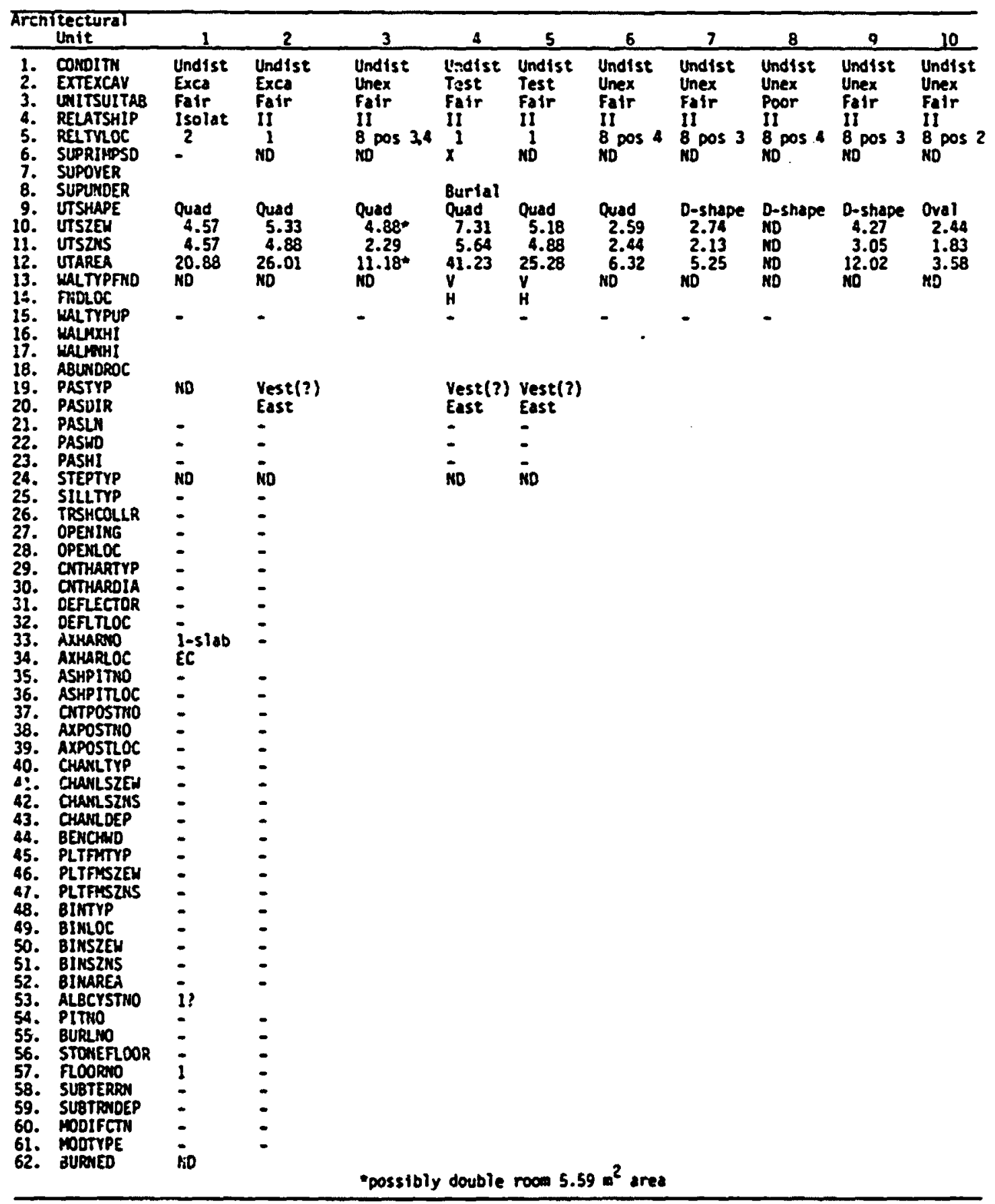


Table 56, Continued.

Site: Tarbox Ruins

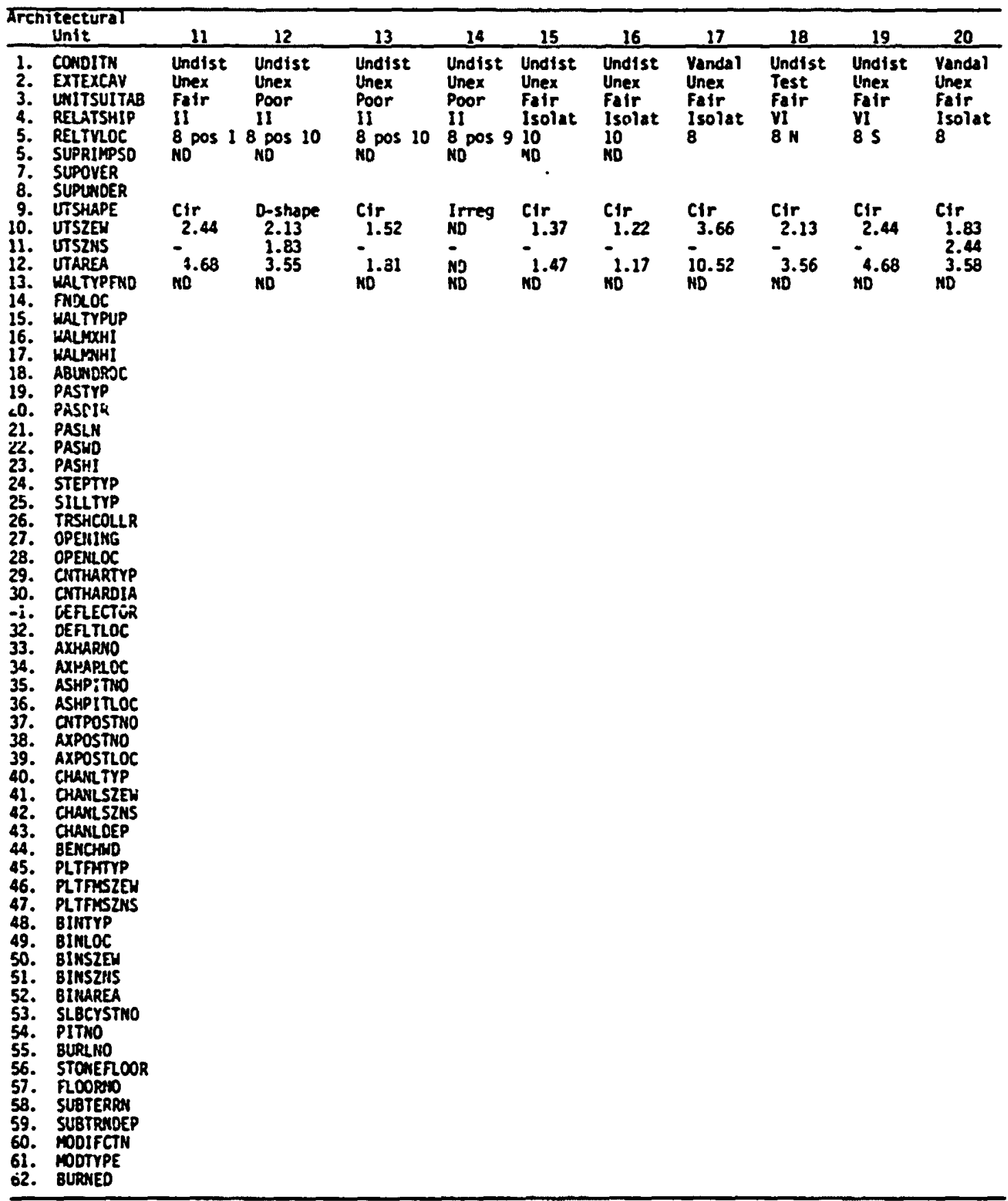


Table 56, Continued.

Site: Lookout Ruin, Coetas Ruin, Conner

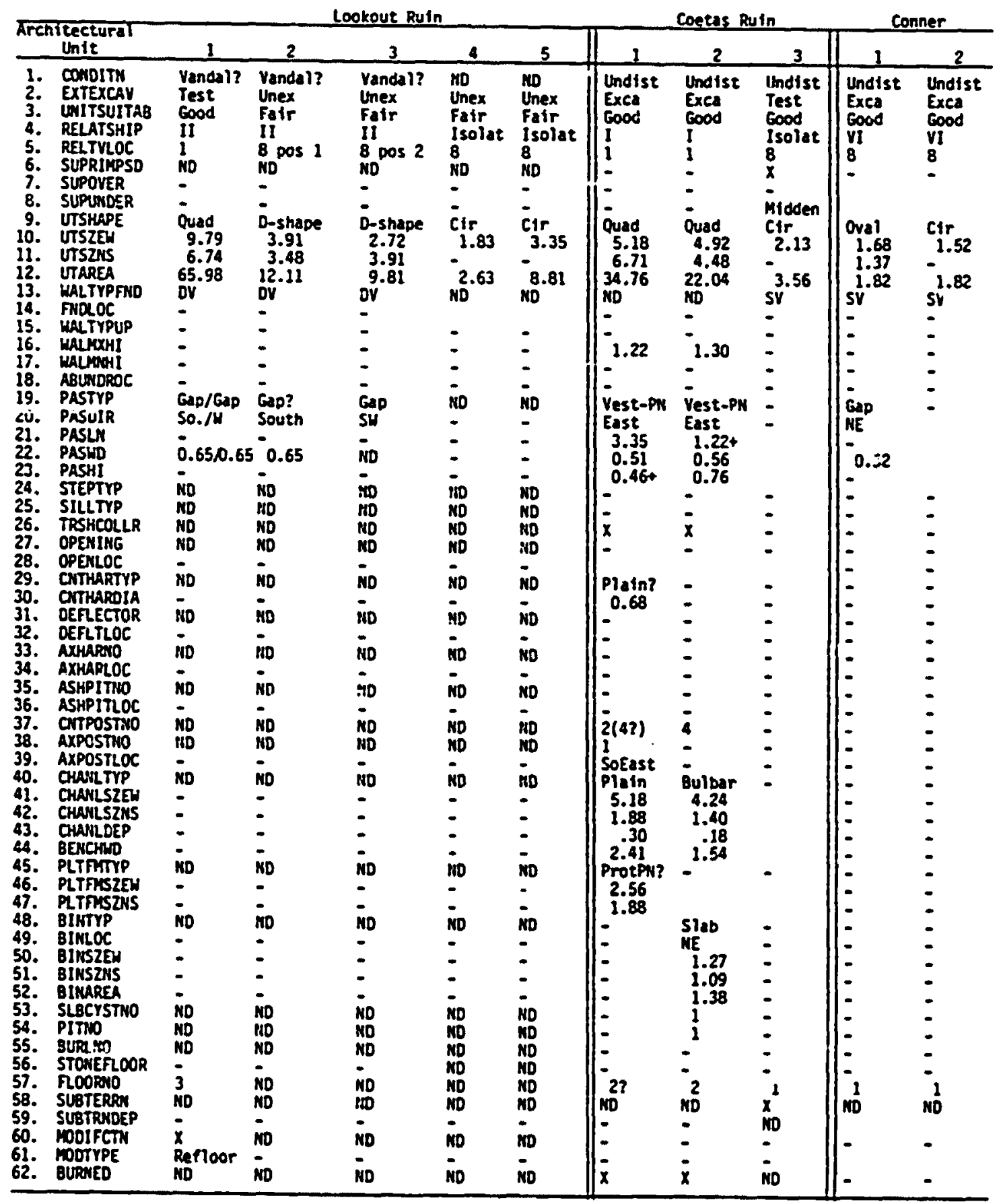


Table 56, Continued.

Site: Spring Canyon, Medford Ranch

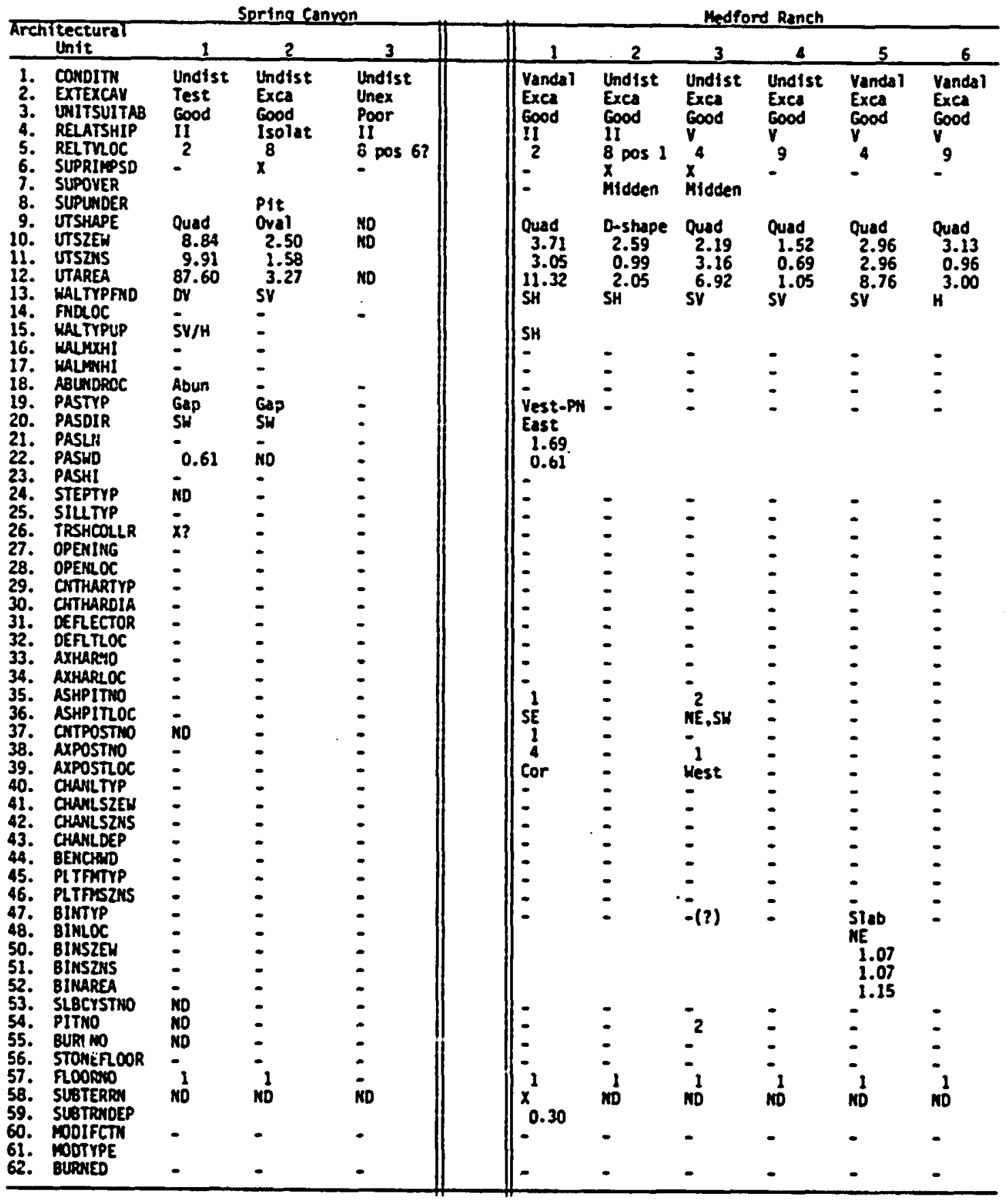


Table 56, Continued.

Site: Roper. PIckett, Cottomood Creek, Marsh Sites

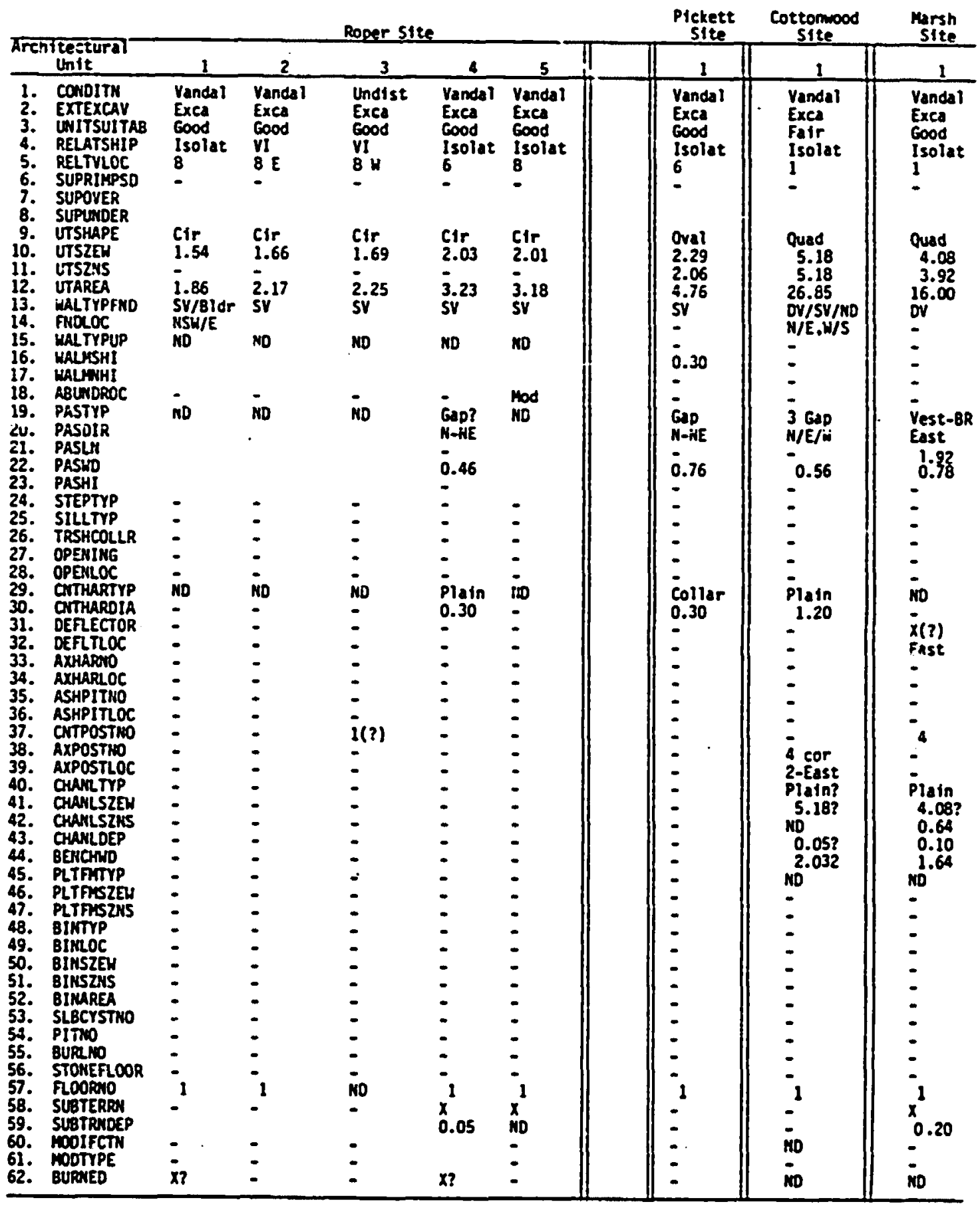


Table 56, Continued.

Site: Sanford Ruins

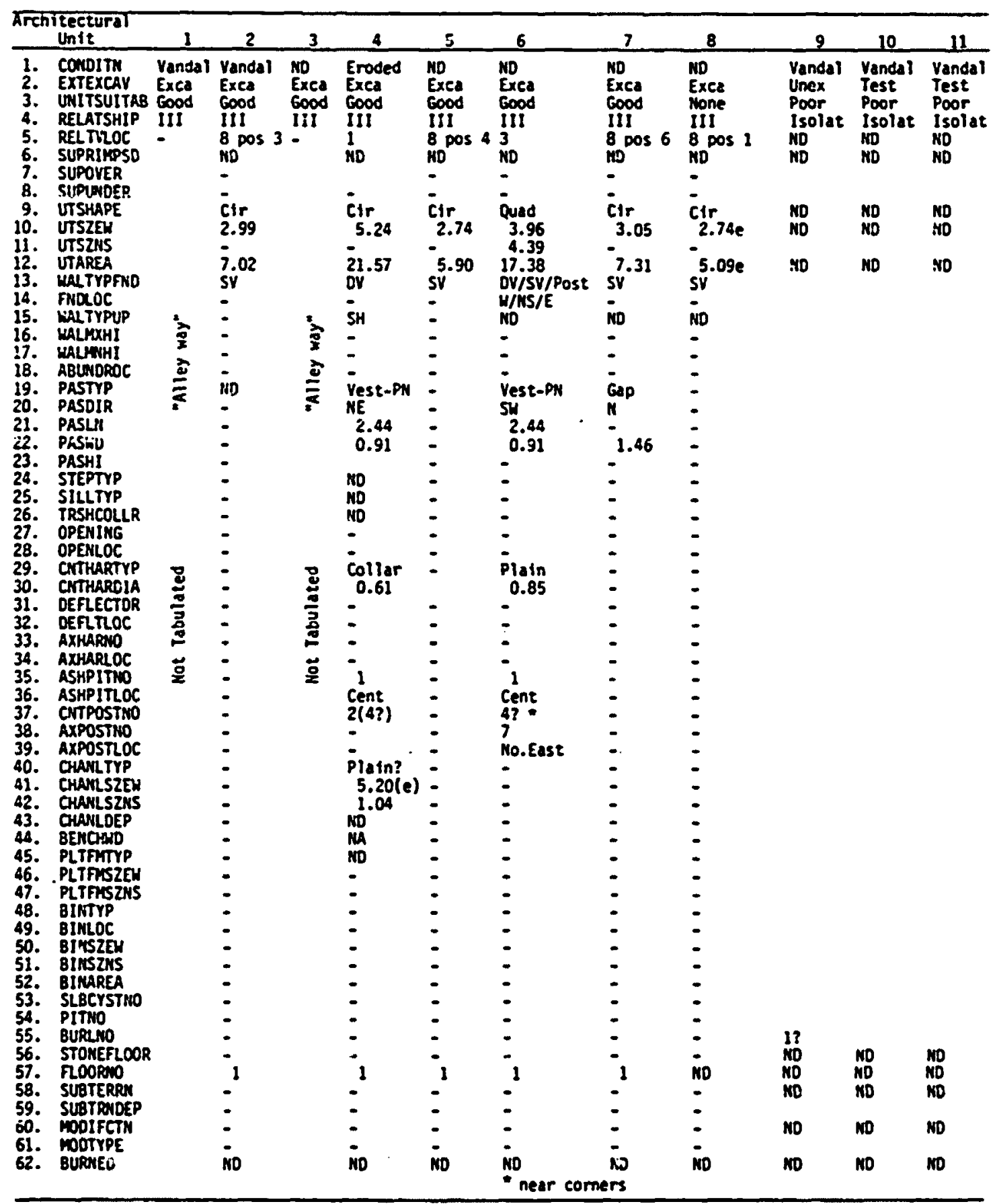


Table 56, Continued.

Site: Jack Allen, Zollars

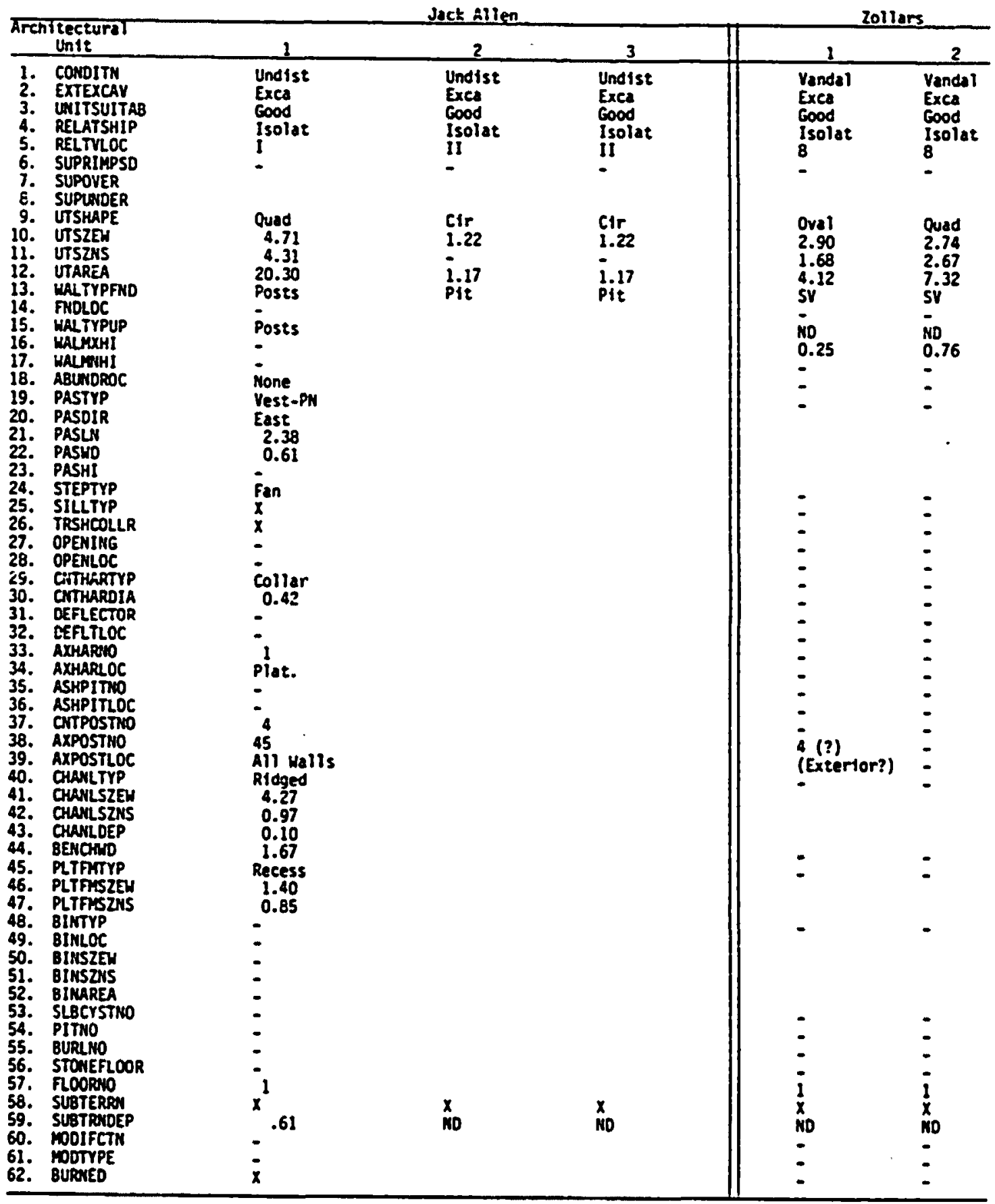


Table 5ó, Continued.

Sice: Arrowtiead Peak

\begin{tabular}{|c|c|c|c|c|c|c|c|c|c|c|c|}
\hline arch & $\begin{array}{l}\text { itectural } \\
\text { Unit }\end{array}$ & 1 & 2 & 3 & 4 & 5 & 6 & 2 & 8 & 9 & 10 \\
\hline $\begin{array}{l}1 . \\
2 . \\
3 . \\
5 . \\
6 . \\
6 . \\
8 .\end{array}$ & $\begin{array}{l}\text { CONOITH } \\
\text { EXIEXCA } \\
\text { WNISLIIT:B } \\
\text { RELATSHIP } \\
\text { RELTIROC } \\
\text { SUPRIMPSO } \\
\text { SUPOVER } \\
\text { SUPWWDER }\end{array}$ & $\begin{array}{l}\text { Vandal? } \\
\text { Exca } \\
\text { Good } \\
1 ? \\
2 \\
x^{2} \\
\text { in } \\
?\end{array}$ & $\begin{array}{l}\text { Vandal? } \\
\text { Exca } \\
\text { cood } \\
1 \\
1 \\
\vdots \\
\vdots\end{array}$ & $\begin{array}{l}\text { Yandal? } \\
\text { Exca } \\
600 d \\
1 \\
2 \\
x^{2} \\
u 4,5,6\end{array}$ & $\begin{array}{l}\text { Yandal? } \\
\text { Exea } \\
\text { Good } \\
\text { VI } \\
\text { Bil } \\
x \\
\text { U3 } \\
-\end{array}$ & $\begin{array}{l}\text { Vandal? } \\
\text { Exca } \\
\text { Good } \\
\text { vI } \\
\text { 8-Nitd } \\
\text { X } \\
\text { U3 } \\
-\end{array}$ & $\begin{array}{l}\text { Vandal? } \\
\text { Exca } \\
600 \text { d } \\
\text { VI } \\
8-5 \\
x-5 \\
i 3 \\
-\end{array}$ & $\begin{array}{l}\text { Vanca i? } \\
\text { Exca } \\
\text { Good } \\
11 \\
1 \\
x\end{array}$ & $\begin{array}{l}\text { Und1st? } \\
\text { Exca } \\
\text { Good } \\
\text { II } \\
8 \text { pos } 7 \\
-\end{array}$ & $\begin{array}{l}\text { Undist } \\
\text { Exca } \\
6000 \\
\text { Isolat } \\
2 \\
-\end{array}$ & $\begin{array}{l}\text { Undist } \\
\text { Exca } \\
\text { cood } \\
\text { Isolat } \\
11 \\
x \\
\text { Midden }\end{array}$ \\
\hline $\begin{array}{l}9 . \\
\text { 10. } \\
\text { i1. } \\
12 .\end{array}$ & $\begin{array}{l}\text { UTSHAPE } \\
\text { UTSZEW } \\
\text { UTSZHS } \\
\text { UTAREA }\end{array}$ & $\begin{array}{l}\text { D-shape } \\
3.51+ \\
3.66 \\
12.85+\end{array}$ & $\begin{array}{l}\text { Quad } \\
4.27 \\
48.27 \\
18.23\end{array}$ & $\begin{array}{r}\text { Quad } \\
4.88 \\
5.33 \\
26.01\end{array}$ & $\begin{array}{l}\text { Quad } \\
1.65 \\
1.62 \\
2.67\end{array}$ & $\begin{array}{l}\text { Quad } \\
2.13 \\
1.37 \\
2.92\end{array}$ & $\begin{array}{l}\text { Quad } \\
1.83 \\
2.74 \\
5.01\end{array}$ & $\begin{array}{r}\text { Quad? } \\
3.73 \\
4.50 \\
16.79\end{array}$ & $\begin{array}{c}\text { D-shape } \\
3.66 \\
2.97 \\
9.05\end{array}$ & $\begin{array}{l}\text { Quad } \\
5.74 \\
5.20 \\
29.85\end{array}$ & $\begin{array}{c}\text { Oval } \\
1.10 \\
0.76 \\
0.84\end{array}$ \\
\hline $\begin{array}{l}36: \\
13 . \\
14 .\end{array}$ & $\begin{array}{l}\text { WALTYPFNO } \\
\text { FHDLOC }\end{array}$ & $\begin{array}{l}\text { SVISH } \\
\text { N.E/S }\end{array}$ & $\begin{array}{l}\text { oY/ROA/SV } \\
E / W / 5\end{array}$ & $\begin{array}{l}\text { SYYOH } \\
\text { NEW/S }\end{array}$ & siv & sv & sv & & $\begin{array}{l}\text { OVISV } \\
\text { SE/N }\end{array}$ & sV? & $\begin{array}{l}\text { plain } \\
-\end{array}$ \\
\hline $\begin{array}{l}15 . \\
16 .\end{array}$ & WALTYPUP & & No & no & ND & ND & NO & MO & & ND & no \\
\hline 17. & WALWHI & - & $=$ & - & $=$ & - & $=$ & $=$ & $=$ & & $=$ \\
\hline $\begin{array}{l}\text { lo. } \\
19 .\end{array}$ & $\begin{array}{l}\text { ABLis0ROC } \\
\text { PASTYP }\end{array}$ & : & $\bar{v}_{\text {Vest-pn }}$ & $\Xi$ & Gap? & - & - & Vest-PN & & Vest-PW & \\
\hline . نَّ & PASDIR & - & East & - & East & - & - & & & East & - \\
\hline 22. & $\begin{array}{l}\text { PASLY } \\
\text { PASHO }\end{array}$ & : & 0.73 & : & 0.84 & : & : & אo & : & $\begin{array}{l}1.28 \\
1.07\end{array}$ & - \\
\hline 23. & $\begin{array}{l}\text { PASHI } \\
\text { STEPTYP }\end{array}$ & 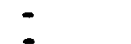 & 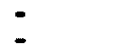 & : & - & E & $=$ & - & $=$ & & $=$ \\
\hline 25. & SILITYP & 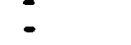 & & $=$ & $=$ & 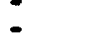 & - & - & - & & - \\
\hline 26. & $\begin{array}{l}\text { TRSHCOLLR } \\
\text { OPEYING }\end{array}$ & : & - & - & : & : & : & : & 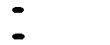 & & $\vdots$ \\
\hline 28. & OPEALOC & : & & Dinde & - & - & - & & - & & - \\
\hline 30. & CNTHAROIA & : & 0.49 .0 .68 & 30.30 & $=$ & 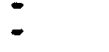 & $=$ & $0.68 \mathrm{e}$ & & 0.300 .30 & \\
\hline 32. & $\begin{array}{l}\text { DEFECTOR } \\
\text { DERTLOC }\end{array}$ & : & $\begin{array}{l}x \\
\text { East }\end{array}$ & $:$ & $:$ & $=$ & : & $:$ & 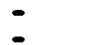 & ${ }_{\text {Hest }}^{X}$ & : \\
\hline 33. & AXXuRevo & $=$ & & - & - & 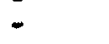 & & - & & & 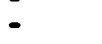 \\
\hline $\begin{array}{l}\text { 34. } \\
\text { 35. }\end{array}$ & $\begin{array}{l}\text { AXHARLOC } \\
\text { ASHPITMO }\end{array}$ & $i$ & 1 & : & : & : & $=$ & - & $=$ & $i$ & : \\
\hline 36. & $\begin{array}{l}\text { AshPIIIOC } \\
\text { CNTtOSto }\end{array}$ & Non & HC & $=$ & $=$ & : & : & i(20res) & : & $\dot{r i}$ & $=$ \\
\hline 38. & Axpostno & $1(20 \mathrm{r} 4 !)$ & $(4)$ & $\overline{-}$ & 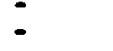 & - & ? & I & $=$ & $=$ & 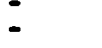 \\
\hline $\begin{array}{l}39 . \\
40 .\end{array}$ & $\begin{array}{l}\text { AXPOSTLOC } \\
\text { CHANLTYPP }\end{array}$ & - & Plain & - & $=$ & E & $\overline{-}$ & Prain? & 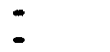 & & \\
\hline 4. & $\begin{array}{l}\text { CHANLSZEH } \\
\text { CHALLSEILS }\end{array}$ & & $\begin{array}{l}4.50 \\
1.22\end{array}$ & & & & & & ! & : & \\
\hline 43. & CHANLDEP & & 0.20 & & & & & no & & : & \\
\hline 年. & BEMCAD & & .1 .525 & $:$ & $:$ & : & $:$ & no & - & $\Xi$ & - \\
\hline 46. & PLIFASzEN & : & - & - & & 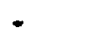 & & & & & \\
\hline 48. & $\begin{array}{l}\text { PLTFFSZNS } \\
\text { BLTYP }\end{array}$ & - & : & : & 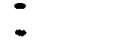 & - & & : & ? & : & \\
\hline 49. & BIMLOC & - & - & - & & - & & - & & - & \\
\hline 50. & BIAS2E & - & $=$ & $=$ & $\therefore$ & - & & $=$ & : & $:$ & \\
\hline $\begin{array}{l}51 . \\
52 .\end{array}$ & $\begin{array}{l}\text { BIMSIMS } \\
\text { BIMREA }\end{array}$ & : & $=$ & $:$ & - & & & $:$ & & 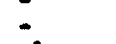 & \\
\hline 53. & SLBCYSTNO & & - & - & & & & 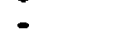 & - & 1 & \\
\hline 54. & & & - & $=$ & & & & & $=$ & & \\
\hline & $\begin{array}{l}\text { BURANO } \\
\text { STONEFLOOR }\end{array}$ & 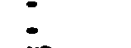 & & - & & & & & & & Bedr \\
\hline 57. & $\begin{array}{l}\text { FLOOFHO } \\
\text { SUBTERPY }\end{array}$ & ND & No & ND & no & No & No & & MD & & \\
\hline 59. & SUSTPNDEP & $\theta^{\circ}$ & & - & - & $=$ & & & - & & 1.22 \\
\hline $\begin{array}{l}60 . \\
61 .\end{array}$ & $\begin{array}{l}\text { Poofrctur } \\
\text { nOOTPE }\end{array}$ & & & & & & & $\begin{array}{l}x ? \\
\text { Chenf } 11\end{array}$ & & Martad & \\
\hline 62. & BUPGED & - & & - & - & - & - & - & - & & - \\
\hline
\end{tabular}


Table 56, Continued.

Site: Turkey Creek, 4110-7

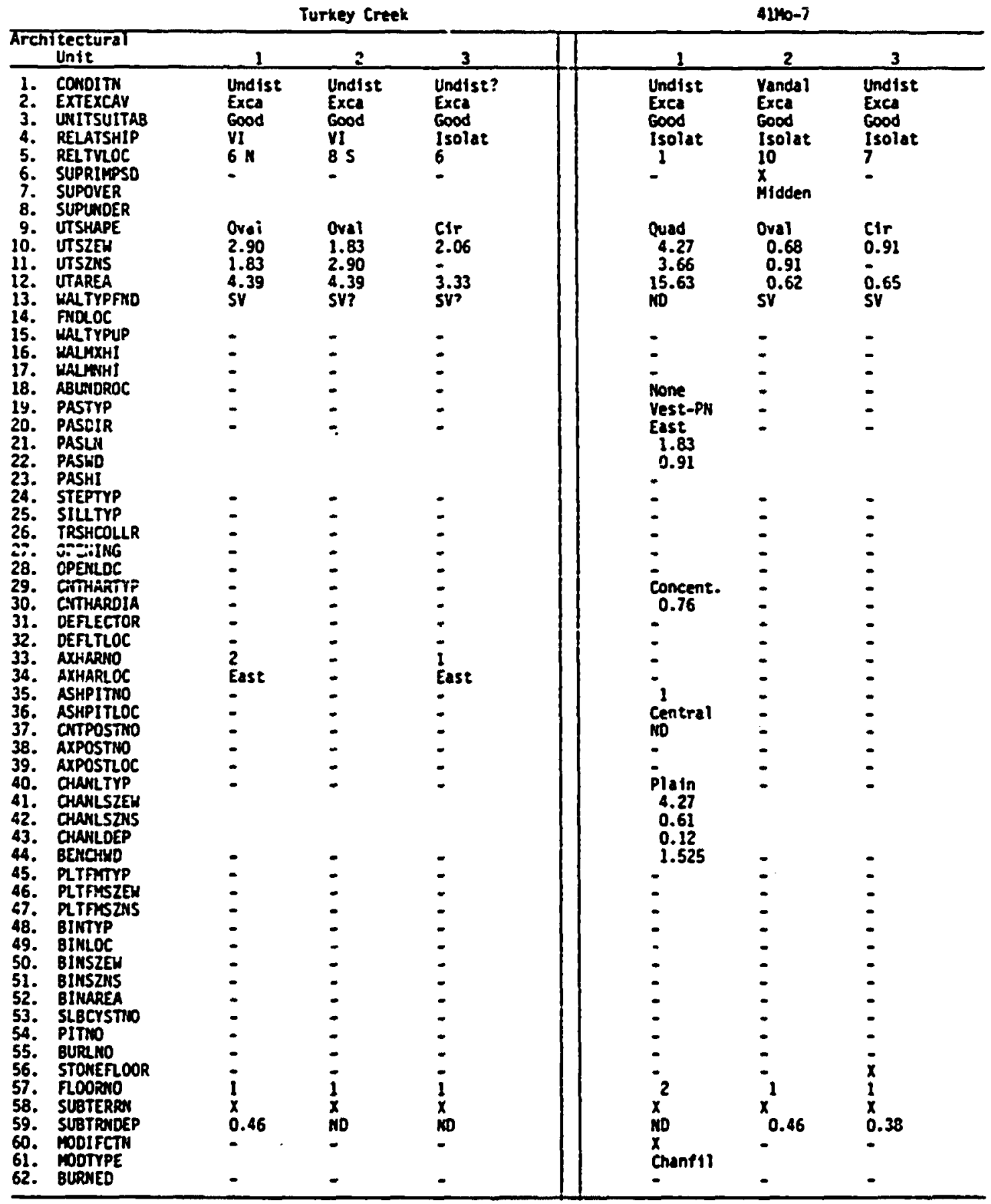


Table 56, Continued.

Site: Footprint

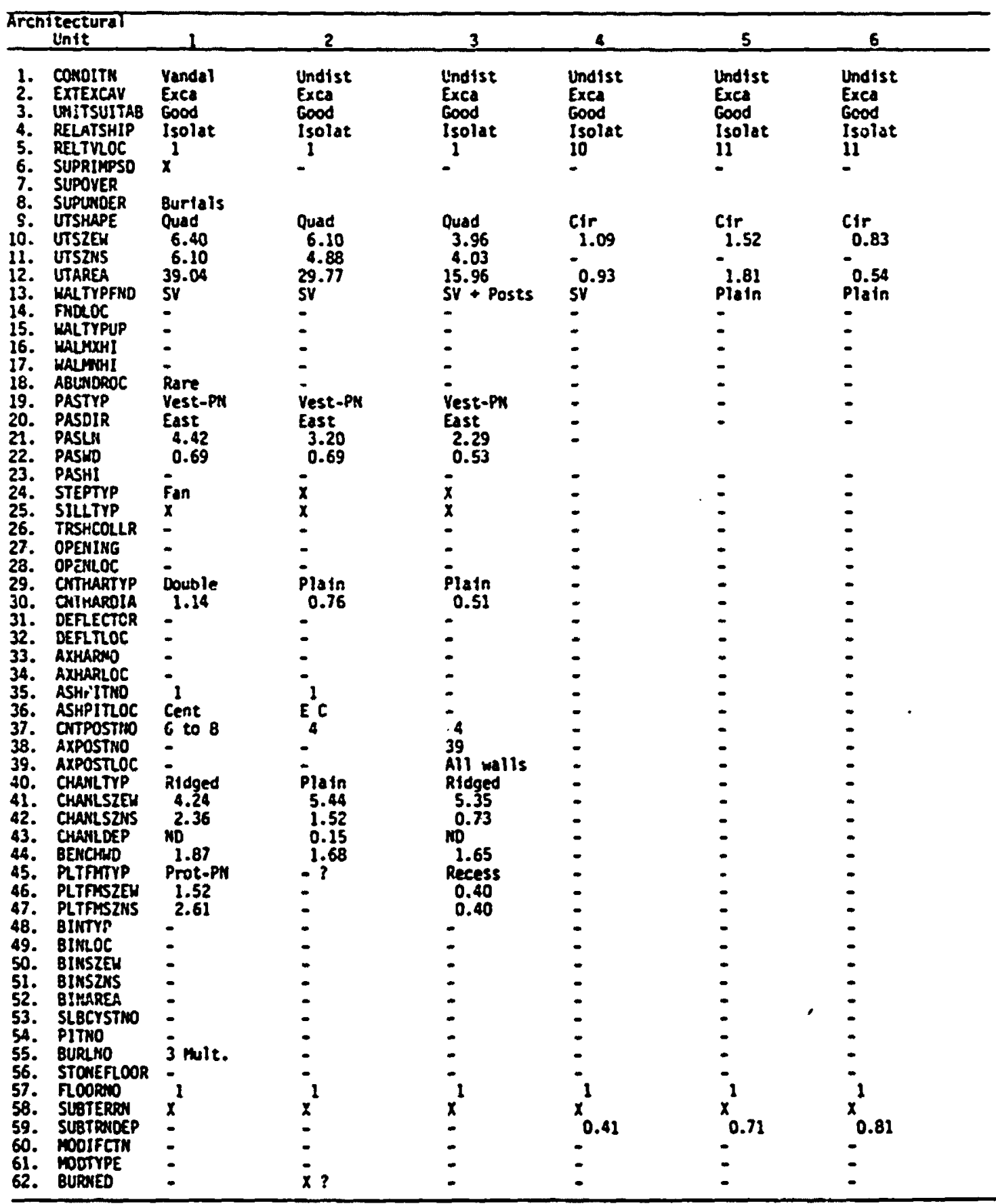


Table 56, Continued.

Site: Black Dog Village

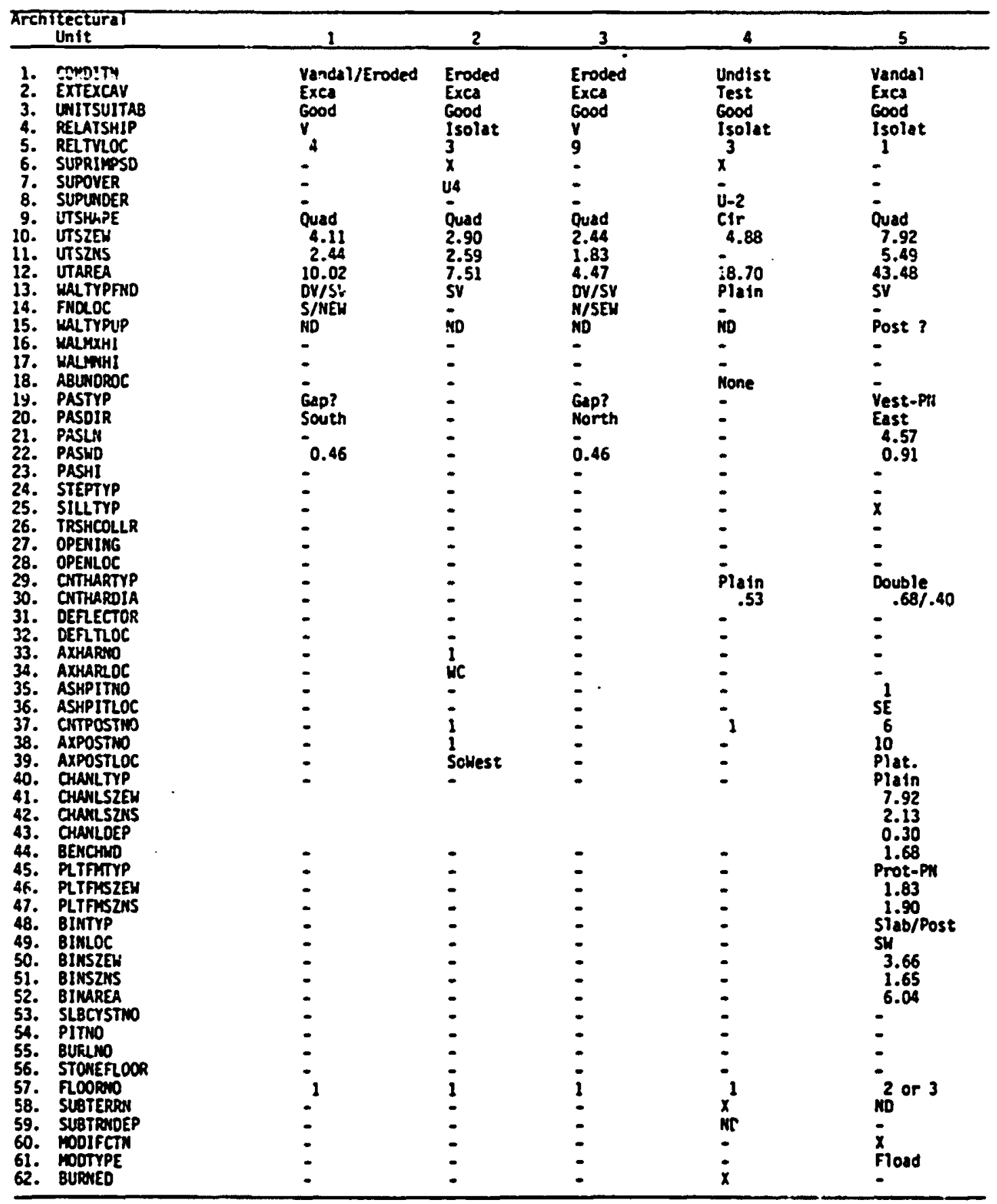


APPENDIX C

ARCHITECTURAL UNIT REFERENCE SOURCES

This appendix provides the major reference sources for architectural units and sites used in the present study. The list is included as an aid to other researchers seeking the primary literature sources and is deemed necessary for three reasons:

1) Different observations even on a single feature were collected by izchaeologists on expeditions sponsored by different institutions.

2) The WPA projects maintained multiple record sets as quarterly and final reports. Occasional discrepancies were encountered within the various record sets.

3) The records for some sites excavated by studer, sayles and the IFA have become widely scattered among several institutions.

In as attempt to circumvent future difficulties in locating the WPA records, copies of the extant documents were reassembled by site designation, and sent to the Texas Archaeological Research Laboratory, Austin Texas, The Panhandle-Plains Historical Museum, Canyon Texas, and Lake Meredith Office of the National Park Service in Fritch Texas. In addition, the Texas Archaeological Research Laboratory is attempting to consolidate Sayles' records, some of which were available only through the Arizona State Museum, Tucson, Arizona.

Corroborating information, sketches and diagrams from Floyd Studer's field work are on file at the National Park Service office at Fritch, Texas, and at the archives and the archaeological laboratory at the 
Panhandle-Plains Historical Society, Canyon, Texas. Also, extensive handwritten field notes alli maps amassed by J. Alden Mason during his 1929 excavations at Alibates Ruir 28 azc on file at the University of Pennsylvania Museum, Pittsburg. Copyright restrictions have prevented Mason's important records from being more widely circulated. Finally, Jack Hughes' daily field logs, which are on file at the Panhandle-plains Historical Museum, Killgore Research Center, Canyon, Texas, and the Texas Archaeological Research Laboratory, Austin, provide important observations on most sites included in this study.

The information presented in the body and appendices of this study reflect an integration of data from these various sources. In some cases, information from an obscure record anc used in this study may seemingly conflict with specific observations from more readily available reports. Consequently, future researchers should consult the range of reports indicated and evaluate the chronology of the reports. 
Sites

Alibates Ruin 28
Unit Number Major References

$$
\begin{aligned}
& \text { 1-13 Baker and Baker i94̄la; Studer } 1942 \\
& 14 \text { Baker and Baker 1939a, 1941b; Studer } 1942 \\
& 15 \text { Baker and Baker 194la; Studer } 1942 \\
& \text { 16,17 Baker and Baker 1939a, 1941b; Studer } 1942 \\
& 18 \text { Baker and Baker 1939b, 1941b; Studer } 1942 \\
& 19 \text { Baker and Baker 1939b, 1941b; Studer 1942; } \\
& \text { Mason nda, ndb; 07son } 1929
\end{aligned}
$$

Alibates Ruin 28A

1 Baker 1940b; Baker and Baker 1941b; Studer 1942

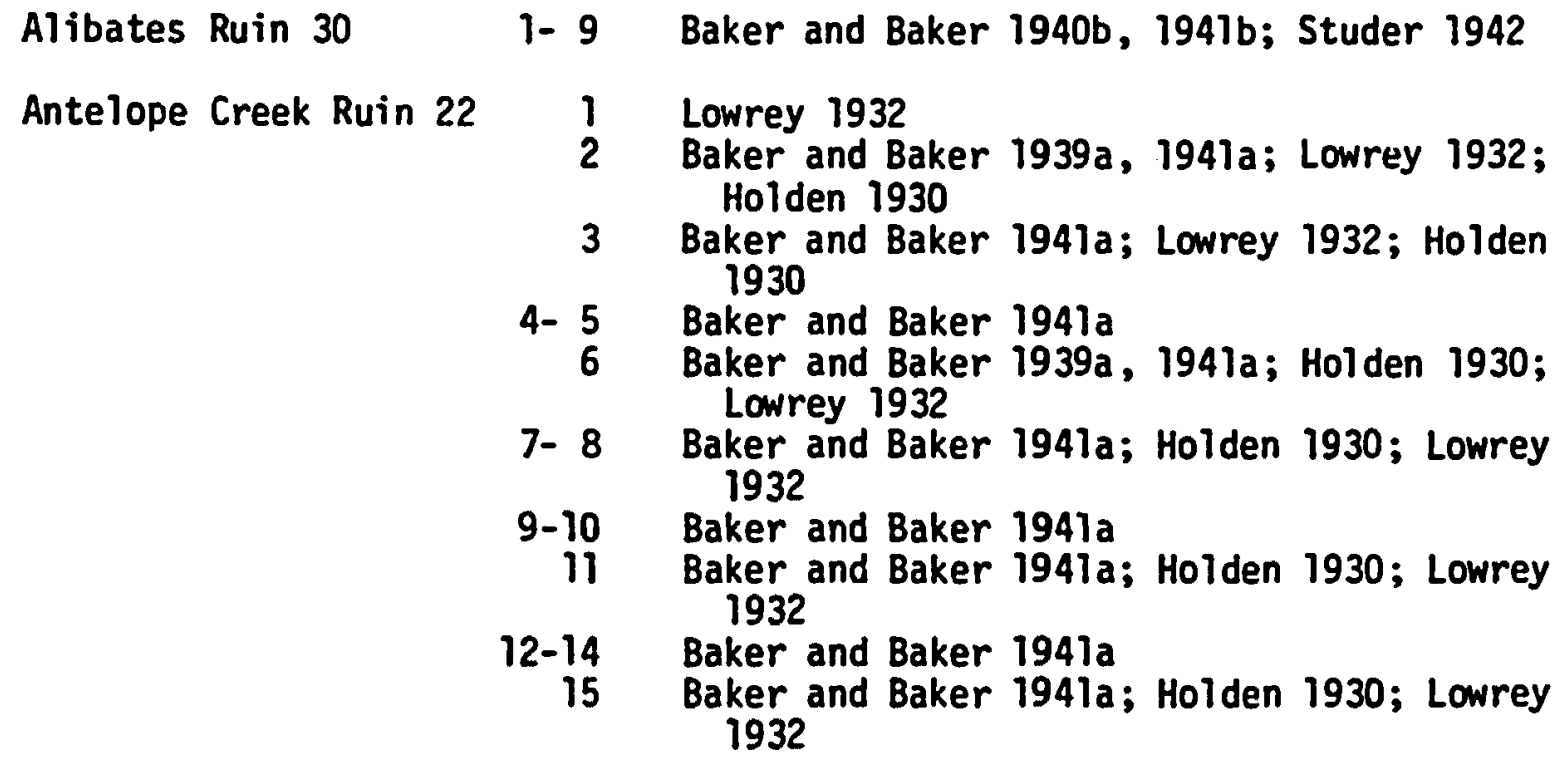


Sites
Unit Number

630

Antelope Creek Ruin 22

$$
\text { (continued) 16-19 }
$$

22-26

30-32

33

Antelope Creek Ruin 22A 7- 4

5- 7

Antelope Creek Ruin 23

Antelope Creek Ruin 24 1-11

$$
12
$$

13-15

$1-10$

1- 5 Keller 1975

Black Dog Village

1- 7 Baker and Baker 1941d; Studer nda

Chimney Rock Ruin 57

1

Baker and Baker 1941d; Studer nda

Coetas Ruin 55

1- 3 Studer 1934, ndb

Conner Site

1- 2

Duffield 1964, 1970

Cotturiwood Creek Ruins

Footprint Site

1- E

Carter 1959; Moorehead 1931

Jack Alien Site

1- .3 Harrison nd

Lookout Ruin

1- 5 Lowrey 1932

Marsh Site

Madford Ranch Site

4lmo- 7

Pickett Ruin

Roper Site

Sanford Ruins
1 Hughes 1967

1- 6 Duffield 1964, 1970

1- 3 Green 1967

1 Carter and Carter 1958; Duffield 1970

1- 5 Dumas nd; Duffield 1970

1-11 Hughes 1953; Duffield 1970 
631

Sites

Spring Canyon

Tarbox

Turkey Creek

Zollars Site

Big Blue Cemetery
Unit Number Major Reference

1- 3

Duffield 1964, 1970

1-20 Holden 1929

1- 3 Green 1967; Bandy 1976

1- 2 Smith and Smith 1982

none Texas Archaeological Society nd

* refers to a box of loose notes at the Panhandle-Plains Historical Soceity. 


\section{APPENDIX D}

\section{Burial Attributes and Variables}

This appendix presents the basic information for Antelope Creek phase burials. A minimum of 22 observations were collected for each interment (Table 57). Each column represents one burial. In those instances of multiple interments, each individual is listed separately. The burial numbers assigned by the field archaeoiogists are retained in this appendix. The rows record the field archaeologist's name, six provenience observations and fifteen observations on the burial feature. In addition, specific grave goods are quantified. The age, maturation stage, and sex are based on information as originally repcrted. However, most burials from Alibates Ruin 28, Antelope Creek 22 and 22A, and the Footprint Site have been reexamined by physical anthropologists (David K. Patterson 2974; Deborah E. Patterson 1974). These subsequent analyses occasionally disagreed with the original age or sex assignment by the field archaeologist. In instances where differences arise, both interpretations are presented. Those offered by the physical anthropologists are indicated by "(P)." All dimensions are reported in meters, and directions are abbreviated. Other abbreviations occasionally used are: " $x$ " denotes the presence of an attribute; "-" indicates absence; "ND" indicates no data; and "NA" denotes a "not applicable" observation. 
Table 57. Antelope Creek Phase Mortuary Information.

Site: Alibates 28 , Unit I

\begin{tabular}{|c|c|c|c|c|c|c|}
\hline Burial No.: & 1 & 2 & 3 & 4 & 5 & 6 \\
\hline Field Archaeologist & Baker & Baker & Baker & Baker & Baker & Baker \\
\hline $\begin{array}{r}\text { Location: Interior } \\
\text { Exterior } \\
\text { Exterior. Adjct to }\end{array}$ & $x$ & $x$ & $x$ & $x$ & $x$ & $x$ \\
\hline Feature No. & $\operatorname{Pon} 11$ & $\operatorname{Pin} 11$ & $\operatorname{Ros} 11$ & $\operatorname{Pon} 11$ & Ren 11 & Rom 11 \\
\hline Unit Type & 1 & 1 & 1 & 1 & 1 & 1 \\
\hline Location Inside Unit & E & ENE & atie & HSH & WhN & ENE \\
\hline Unit size $\left(\mathrm{m}^{2}\right)$ & 23.42 & 23.42 & 23.42 & 23.42 & 23.42 & 23.42 \\
\hline $\begin{aligned} \text { Stratig. Pos. (m) Ov. Fl. } \\
\text { On Fi. } \\
\text { Un. Fi. }\end{aligned}$ & $\bar{x}$ & $\begin{array}{l}x-0.89 \\
-\end{array}$ & $\begin{array}{l}\times 0.15 \\
= \\
=\end{array}$ & $\begin{array}{l}\times 0.28 \\
= \\
=\end{array}$ & $\begin{array}{l}x 0.41 \\
= \\
=\end{array}$ & $\begin{array}{l}\times 0.15 \\
= \\
=\end{array}$ \\
\hline Burial Type & Primary & Primary & Primary & Primary & Primary & Primary \\
\hline No. Individuals & 1 & 1 & 1 & 1 & 1 & 1 \\
\hline cody Position & Flexed & Flexed & Flexed & MD & Flexed & Flexed \\
\hline Placed on & Back & Right & Front & MD & Back & Back \\
\hline Orientation (head toward) & $x$ & $\boldsymbol{n}$ & E & ND & $\mathbf{M}$ & $\mathbf{S}$ \\
\hline Facing & $\boldsymbol{H}$ & $\boldsymbol{u}$ & Down & ND & $\mathbf{H}$ & $\mathbf{E}$ \\
\hline Sex & Female & Fenale & Female $P$ & - & $-\quad \cdots$ & - \\
\hline Maturation & Adoles. & & Adult & Infant & Child & Infant \\
\hline Age Estimate & $\begin{array}{l}16 y \\
14 y p\end{array}$ & $20-25 \mathrm{yr}$ & $30-35 y r$ & $2-3000$ & 10-12yr & $6-8 m c$ \\
\hline Charred/Burned & - & - & - & - & - & - \\
\hline Violent Death & - & - & - & - & - & - \\
\hline Supernumerary Remains & - & - & - & - & - & - \\
\hline Rock Covered & - & $x$ & $x$ & ND & - & - \\
\hline Pit Size $(m): \begin{array}{l}\text { Length } \\
\text { Width }\end{array}$ & $\begin{array}{l}1.07 \\
0.61\end{array}$ & $\begin{array}{l}0.91 \\
0.61\end{array}$ & $\begin{array}{l}1.07 \\
0.61\end{array}$ & $\begin{array}{l}\text { ND } \\
\text { ND }\end{array}$ & $\mathrm{nD}_{\mathrm{NO}}$ & $\begin{array}{l}0.6 i \\
0.46\end{array}$ \\
\hline $\begin{array}{l}\text { Grave Goods } \\
\text { Points } \\
\text { Knives } \\
\text { Scrapers } \\
\text { Pipes (eltow) } \\
\text { OEtiry } \\
\text { Basketry } \\
\text { Bone Awils } \\
\text { Antier Tools } \\
\text { Turquoise Beads } \\
\text { Shell pise Beads } \\
\text { Olivella Beads } \\
\text { Shell Pendants } \\
\text { Conch Shell } \\
\text { Mussel Vaive } \\
\text { Tibla Digging Stick } \\
\text { Other }\end{array}$ & - & - & - & - & - & $1-$ \\
\hline
\end{tabular}


Table 57, Continued.

Site: Alibates 28, Unit I

\begin{tabular}{|c|c|c|c|c|c|c|}
\hline Burial Ne: & 7 & $B$ & 2 & 10 & 11 & 15 \\
\hline Field Archaeologist & Baker & Baker & Baker & Baker & Baker & Studer \\
\hline $\begin{array}{c}\text { Location: Interior } \\
\text { Exterior } \\
\text { Exterior, Adfct to }\end{array}$ & $x$ & $x$ & $x$ & $X$-NE & Area $2-57$ & $x$ \\
\hline Feature No. & $\operatorname{Ron} 11$ & Pon 11 & Pon 11 & $\operatorname{Pon} 21$ & NA & $\operatorname{Ros} 55$ \\
\hline Unit Type & 1 & $\mathfrak{l}$ & 1 & 8 & MA & 5 \\
\hline Lisision Inside Unit & NE & NWW & MH & - & $M$ & $s$ \\
\hline Unit Size $\left(w^{2}\right)$ & 23.42 & 23.42 & 23.42 & - & $M A$ & 2.90 \\
\hline $\begin{aligned} & \text { Stratig. Pos. (m) Ov. Fl. } \text { On Fl. } \\
& \text { Un. Fi. }\end{aligned}$ & $\begin{array}{l}x 0.46 \\
-\end{array}$ & $\begin{array}{l}x-0.30 \\
=\end{array}$ & $\dot{x}$ & $\begin{array}{l}- \\
-\end{array}$ & $\begin{array}{l}\text { MA } \\
\text { MA }\end{array}$ & $\begin{array}{l}x \\
-\end{array}$ \\
\hline Burial Type & Primary & Pritary & Primary & Primary & Primary & Primary \\
\hline No. Individuals & 1 & 1 & 1 & 1 & 1 & 1 \\
\hline Body Position & Flexed & Flexed & Flexed & Flexed & Flexed & Flexed \\
\hline Placed on & Right & Back & Back & Right & Right & Right \\
\hline Orientation (head toward) & $\mathbf{E}$ & E & N & N & iit: & N \\
\hline Facing & $\boldsymbol{N}$ & Up & $\omega$ & Up & $M$ & - \\
\hline Sex & - & - & Male? P & Female & Male & ND \\
\hline Maturation & Chitid & Cntld & Adult & Adult & Adult & Adult \\
\hline Age Estimate & Ilyr & $10 y r$ & $40-45 y r$ & $35-40 y r$ & $40 y r$ & - \\
\hline Charred/Burned & - & - & - & - & - & - \\
\hline Violent Death & - & - & - & - & - & - \\
\hline Supernumerary Remains & - & - & $-=$ & - & - & - \\
\hline Rock Covered & $x$ & $x$ & $x$ & $x$ & $x$ & - \\
\hline Pit Size (m): $\begin{array}{l}\text { Length } \\
\text { Width }\end{array}$ & $\begin{array}{l}0.91 \\
0.61\end{array}$ & $\begin{array}{l}1.07 \\
0.55\end{array}$ & $\begin{array}{l}1.37 \\
0.71\end{array}$ & $\begin{array}{l}1.07 \\
0.61\end{array}$ & $\begin{array}{l}1.50 \\
1.14\end{array}$ & $\begin{array}{l}\text { MD } \\
\text { ND }\end{array}$ \\
\hline $\begin{array}{l}\text { Grave Goods } \\
\text { Points } \\
\text { Knives } \\
\text { Scrapers } \\
\text { Pipes (elbow) } \\
\text { Pottery } \\
\text { Basketry } \\
\text { Bone Awis } \\
\text { Antler Tools } \\
\text { Turquoise Beads } \\
\text { Shell Disc Beads } \\
\text { Olivella Beads } \\
\text { Shell Perdants } \\
\text { Conch Shells } \\
\text { Mussel Volve } \\
\text { Tibia Digging Stick } \\
\text { Other }\end{array}$ & - & 10 & - & - & - & $\begin{array}{l}x \\
1 \\
1\end{array}$ \\
\hline
\end{tabular}


Table 57, Continued.

Sites:

Alibates 28, Unit II

Antelope Creek 22

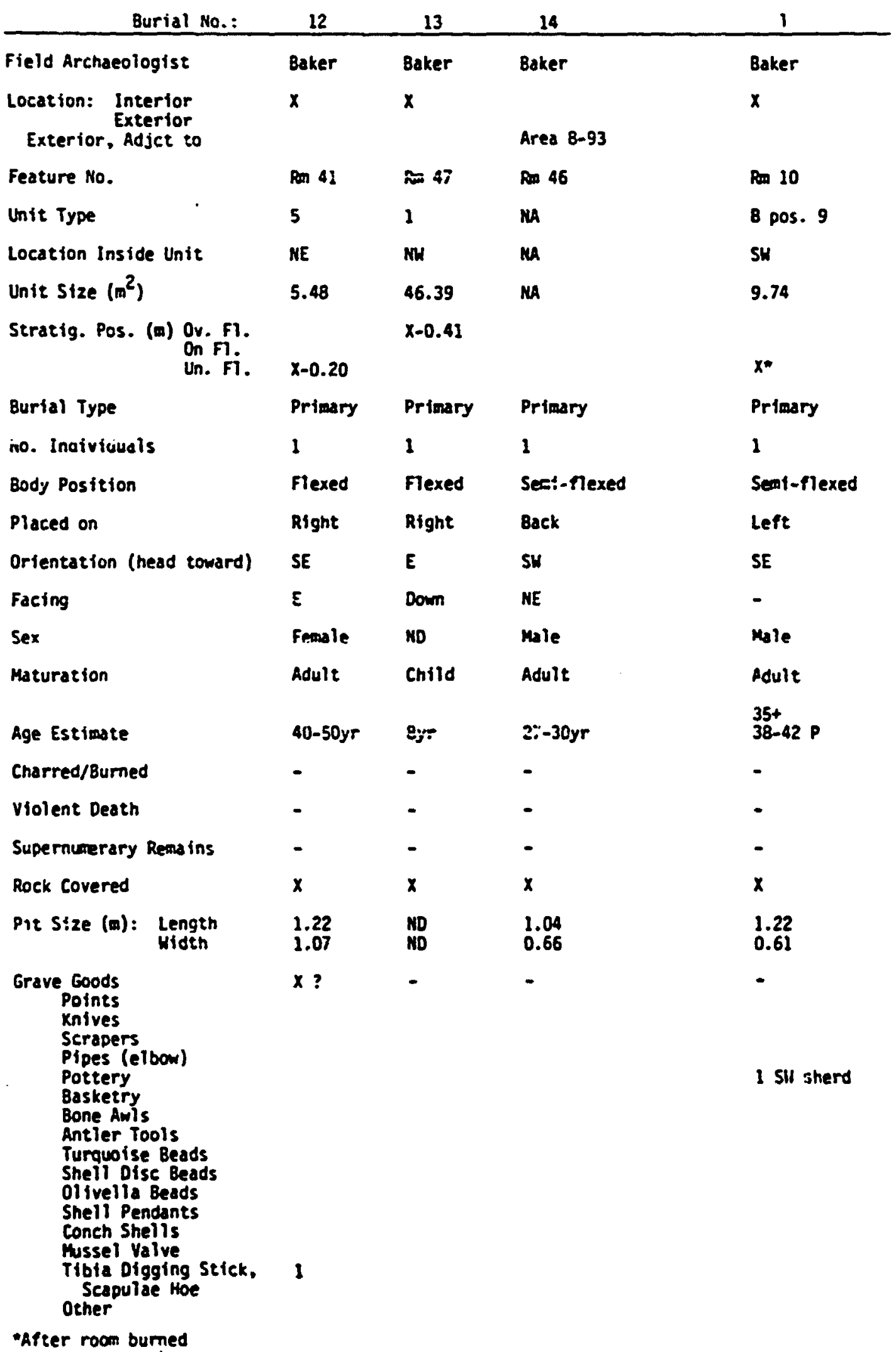


Table 57, Continued.

Site: Antelope Creek 22A

\begin{tabular}{|c|c|c|c|c|c|c|}
\hline Burial No.: & $2(7 P)$ & 3 In & 4 In & 5 In & 6 In & 7 In \\
\hline Fielo archaeologist & Baker & Baker & Baker & Baker & Baker & Baker \\
\hline $\begin{array}{c}\text { Location: } \begin{array}{l}\text { Interior } \\
\text { Exterior }\end{array} \\
\text { Exterior, Adjent to }\end{array}$ & $x$ & $x$ & $x$ & $x$ & $x$ & $x$ \\
\hline Feature No. & Ren $1 A$ & $\operatorname{Pon} 1 A$ & $\operatorname{Pon} 1 A$ & $\operatorname{Ron} 1 \mathrm{~A}$ & $\operatorname{Ron} 1 A$ & $\operatorname{Rm} 1 A$ \\
\hline Unit Type & 1 & 1 & 1 & 1 & 1 & 1 \\
\hline Location Inside Unit & SE & SH & M & MU & Center & NE \\
\hline Unit size $\left(m^{2}\right)$ & 60.32 & 60.32 & 60.32 & 60.32 & 60.32 & 60.32 \\
\hline $\begin{array}{c}\text { Stratig. Pos. (m) Ov. Fl. } \\
\text { On Fi. } \\
\text { Un. Fi. }\end{array}$ & $x-0.10$ & $x$ & $x-0.30$ & $\times 0.61$ & $\times 0.46$ & On wail \\
\hline Burial & Primary & Primary & Primary & Primary & Primary & Primary \\
\hline No. Individuals & 1 & 1 & 1 & 1 & 1 & 1 \\
\hline Body Position & ND & Semi-nexed & Sent-nlexed & Flexed & Flexed & Seni-flexed \\
\hline Placed on & - & Left & Back & Rlght & Back & - \\
\hline Orientation (head toward) & $\mathbf{E}$ & $n$ & $N$ & N & N & $N$ \\
\hline Facing & ND & E & $\mathbf{E}$ & MO & $\mathbf{E}$ & $\mathbf{E}$ \\
\hline Sex & ND & Male $\mathrm{P}$ & ND & Male P & Male P & ND \\
\hline Maturation & Infant & Adule & Child & Adult & Adinte & Child \\
\hline Age Estimare & lyr & $\begin{array}{l}\text { 30: } \\
\text { 35-45 P }\end{array}$ & $8-10$ & 50: & $\begin{array}{l}30: \\
40-46\end{array}$ & $\begin{array}{l}10: \\
12-14 p\end{array}$ \\
\hline Charred/8urned & - & - & - & - & - & - \\
\hline Violent Death & - & - & - & - & - & - \\
\hline Supernumerary Remains & - & - & - & - & - & - \\
\hline Rock Covered & $x$ & $x$ & $x$ & $x$ & $x$ & $x$ \\
\hline Pit Size $(m): \begin{array}{l}\text { Lengeh } \\
\text { Width }\end{array}$ & $\begin{array}{l}0.61 \\
0.46\end{array}$ & $\begin{array}{l}1.83 \\
0.61\end{array}$ & $\begin{array}{l}1.22 \\
0.61\end{array}$ & $\begin{array}{l}0.91 \\
0.61\end{array}$ & $\begin{array}{l}0.91 \\
0.61\end{array}$ & $\begin{array}{l}0.91 \\
0.61\end{array}$ \\
\hline $\begin{array}{l}\text { Grave Goods } \\
\text { Points } \\
\text { Knives } \\
\text { Scrapers } \\
\text { Pipes (elbow) } \\
\text { Pottery } \\
\text { Basketry } \\
\text { Bone Awls } \\
\text { Antier Tools } \\
\text { Turquoise Beads } \\
\text { Shell Disc Beads } \\
\text { Olivella Beads } \\
\text { Sheil Pendants } \\
\text { Conch Shell } \\
\text { Mussel Valve } \\
\text { Tibia Digging Stick } \\
\text { Other }\end{array}$ & - & $\begin{array}{l}x \\
4 \text { edge } \\
1 \text { leaf }\end{array}$ & - & - & - & - \\
\hline
\end{tabular}


Table 57, Continued

Site: Antelope Creek 22A

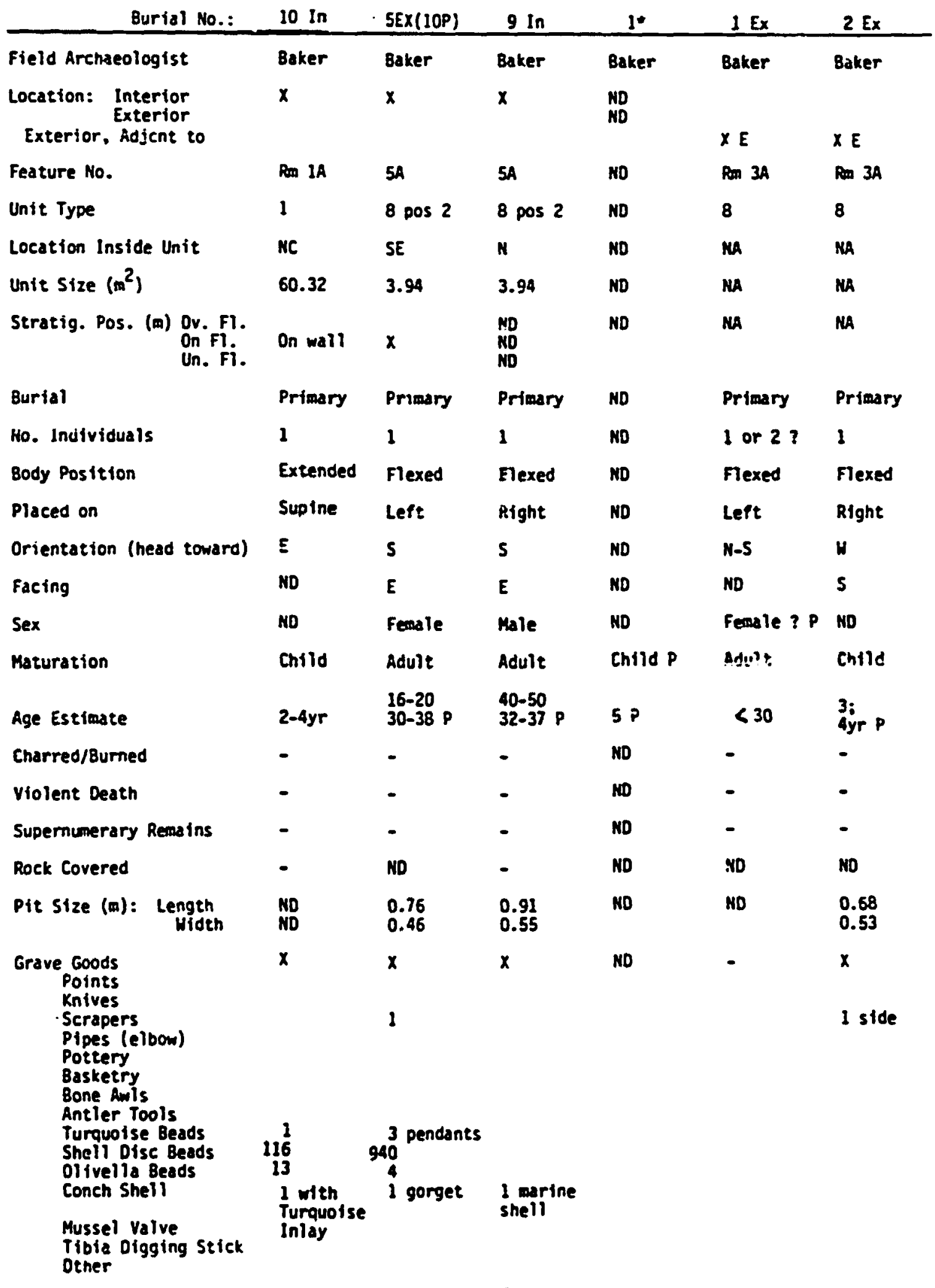

- Separate burial identified by physical anthrodologist. 
Table 57, Continued.

Site: Antelope Creek 22A

\begin{tabular}{|c|c|c|c|c|c|}
\hline Burial No.: & 3 Ex & $4 E x$ & $65 x$ & $7 \operatorname{Ex}(5 P)$ & $8 E x$ \\
\hline Field Archaeologist & Baker & Baker & Baker & Baker & Baker \\
\hline $\begin{array}{c}\text { Location: Interior } \\
\text { Exterior } \\
\text { Exterfor, Adjcnt to }\end{array}$ & $X$ SE & X SH & $\times \mathrm{NC}$ & $\mathbf{N}$ & HC \\
\hline Feature No. & $\operatorname{Pen} 1 \mathrm{~A}$ & $\operatorname{Pin} 1 A$ & $\operatorname{Rom} 19$ & Ren $5 A$ & $\operatorname{Ron} 1 A$ \\
\hline Unit Type & 1 & 1 & 1 & 8 & 1 \\
\hline Location Inside Unit & MA & NA & MA & MA & MA \\
\hline Unit size $\left(m^{2}\right)$ & MA & MA & MA & MA & MA \\
\hline $\begin{array}{c}\text { Stratig. Pos. (m) Ov. Fi. } \\
\text { On Fi. } \\
\text { Un. Fi. }\end{array}$ & MA & NA & MA & MA & \\
\hline Burfal Type & Primary & Primary & Primary & Primary & Primary \\
\hline No. Individuals & 1 & 1 & 1 & 1 & 1 \\
\hline Body Position & Semi-flexed & Flexed & Flexed & Flexed & Flexed \\
\hline Plesed on & Back & Right & Left & ND & ND \\
\hline Orientation (head toward) & $\mathbf{E}$ & H & $\mathbf{S}$ & MH & $\mathbf{E}$ \\
\hline Facing & 5 & 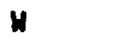 & $\mathbf{E}$ & ME & $\mathbf{s}$ \\
\hline Sex & Fenale $P$ & male & $\begin{array}{l}\text { Male } \\
\text { Female P }\end{array}$ & ND & Male \\
\hline Maturation ' & Adult & Adult & Adule & Child & Adult \\
\hline Age Estimate & $\begin{array}{l}35: \\
30-26 P\end{array}$ & $\begin{array}{l}40-50 ; \\
29.35\end{array}$ & $\begin{array}{l}40-50 ; \\
30-40\end{array}$ & $\begin{array}{l}3-5 ; \\
10-11 p\end{array}$ & $\begin{array}{l}50-60 ; \\
30-35 p\end{array}$ \\
\hline Charred/Burned & - & - & - & - & - \\
\hline Violent Death & - & - & - & - & - \\
\hline Supernumerary Renains & - & - & - & - & - \\
\hline Rock Covered & ND & NO & $x$ & ND & x. \\
\hline P1t Size $(m): \begin{array}{l}\text { Length } \\
\text { Width }\end{array}$ & $\begin{array}{l}1.25 \\
0.91\end{array}$ & $\begin{array}{l}1.02 \\
0.88\end{array}$ & $\begin{array}{l}1.07 \\
0.68\end{array}$ & $\underset{\text { MO }}{\text { MD }}$ & $\begin{array}{l}1.17 \\
0.79\end{array}$ \\
\hline $\begin{array}{l}\text { Grave Goods } \\
\text { Points } \\
\text { Knives } \\
\text { Scrapers } \\
\text { Pipes (eloow) } \\
\text { Pottery } \\
\text { Basketry } \\
\text { Bone Awls } \\
\text { Antier Tools } \\
\text { Turquoise Beads } \\
\text { Shell Disc Beads } \\
\text { Olivella Beads } \\
\text { Shell Pendants } \\
\text { Conch Shell } \\
\text { Mussel Vaive } \\
\text { Tibid Digging Stick } \\
\text { Other }\end{array}$ & $\begin{array}{l}4 \text { rounded } \\
\text { coal }\end{array}$ & - & - & - & - \\
\hline
\end{tabular}


Table 57, Continued.

Sites: Antelope Creek 23. Tarbox, Coetas Ruin (across creek to ME) Antelope Creek 23 Tarbox

\begin{tabular}{|c|c|c|c|c|c|c|}
\hline & Burial No.: & 1 & 1 & 2 & $\mathbf{l}$ & 2 \\
\hline Field Archi & eologist & Baker & Holden & Holden & Studer & Studer \\
\hline $\begin{array}{l}\text { Location: } \\
\text { Exterior }\end{array}$ & $\begin{array}{l}\text { Interior } \\
\text { Exterfor } \\
\text { Adjent to }\end{array}$ & $X N E$ & $x$ siab cist & $x-E$ & $x$ & $x$ \\
\hline
\end{tabular}

\begin{tabular}{|c|c|c|c|c|c|}
\hline Feature No. & $\operatorname{Rm} 1$ & $\operatorname{Pon} 3$ & & MA & MA \\
\hline Unit Type & 2 & 4 & & MA & MA \\
\hline Location Inside Unit & MD & WC & & MA & MA \\
\hline Unit size $\left(\mathrm{m}^{2}\right)$ & NO & 2.01 (cist) & & MA & MA \\
\hline $\begin{aligned} & \text { Stratig. Pos (m) Or. Fl. } \text { On Fi. } \\
& \text { Un. Fi. }\end{aligned}$ & No & ND & & MA & MA \\
\hline Burtal Type & NC & Ho & Primary & Primary & Primary \\
\hline No. Individuals & No & 1 or 2 & 1 & 1 & 1 \\
\hline Body Position & ND & No & Flexed & NO & ND \\
\hline Placed on & NO & No & Left & ND & No \\
\hline Orfentation (head toward) & ND & No & 5 & $\mathbf{E}$ & E \\
\hline Facing & ND & NO & ND & ND & ND \\
\hline $\operatorname{sex}$ & ND & No & ND & ND & ND \\
\hline Maturation & 190 & Child & Nn & Chilid & chtld \\
\hline Age Estimate & NO & 2 & ND & - & - \\
\hline Charred/Burned ND & ND & - & - & - & - \\
\hline Violent Death & NO & - & - & - & - \\
\hline Supernumerary Reeains & MD & Extr: skull & - & - & - \\
\hline Rock Covered & MD & $x$ & $x$ & $x$ & $x$ \\
\hline Pit size $(m): \begin{array}{l}\text { Lengeh } \\
\text { Width }\end{array}$ & $\begin{array}{l}\text { ND } \\
\text { ND }\end{array}$ & $\begin{array}{l}2.01 \\
2.01\end{array}$ & $\begin{array}{l}\text { ND } \\
\text { ND }\end{array}$ & ND & ND \\
\hline $\begin{array}{l}\text { Grave Goods } \\
\text { Points } \\
\text { Knives } \\
\text { Scrapers } \\
\text { Pipes (elbow) } \\
\text { Pottery } \\
\text { Basketry } \\
\text { Bone Amls } \\
\text { Antler Tools } \\
\text { Turquoise Beads } \\
\text { Shell Dise Beads } \\
\text { Oifvella Beads } \\
\text { Shell Pendants } \\
\text { Conch Shell } \\
\text { Mussel Vaive } \\
\text { Tibia Digging Stick/ } \\
\text { Scapulae Hoe } \\
\text { Other }\end{array}$ & NO & NO & - & 56 & HD \\
\hline
\end{tabular}


Table 57, Continued.

\begin{tabular}{|c|c|c|c|c|c|c|}
\hline \multirow[t]{2}{*}{ Sanford Ruin an } & \multicolumn{2}{|c|}{ id Footprint } & \multirow{2}{*}{$\begin{array}{l}\text { Footprint } \\
\text { Pit A }\end{array}$} & \multirow[b]{2}{*}{$1 \mathrm{~A}$} & \multirow[b]{2}{*}{$2 \mathrm{~A}$} & \multirow[b]{2}{*}{$3 A$} \\
\hline & 1 & 2 & & & & \\
\hline Field Archaeologist & Hughes & Hughes & Green & & & \\
\hline $\begin{array}{c}\text { Location: } \begin{array}{l}\text { Interior } \\
\text { Exterior } \\
\text { Exterior, Adjent to }\end{array}\end{array}$ & $x ?$ & $\times 46 \mathrm{mE}$ & $x$ & & & \\
\hline Feature No. $\quad \ln 1$ & 9 & & $\operatorname{Ren} 1$ & & & \\
\hline Unit Type & 8 & ND & 1 & & & \\
\hline Location Inside Unit & ND & MA & NH & & & \\
\hline Unit size $\left(\mathrm{m}^{2}\right)$ & ND & MA & 39.04 & & & \\
\hline $\begin{array}{l}\text { Stratig. Pos. (m) Ov. Fl. } \\
\text { On Fl. } \\
\text { Un. Fi. }\end{array}$ & ND & MA & $x$ & & & \\
\hline Burfal Type & ND & Prizary & Multiple & & & \\
\hline Mo. Individuals & ND & 1 & $7-10$ & & & \\
\hline Body Position & ND & Sear-flexed & & Supine & ND & Serri-flexed \\
\hline Placed on & No & ND & & ND & ND & Right \\
\hline Orientation (head toward) & no & E & & ND & ND & ND \\
\hline Facing & HD & Down & & ND & No & ND \\
\hline Sex & HD & Female & & NO & ND & ND \\
\hline Maturation & NO & Adult & & Infant & Infant & Juvenile \\
\hline Age Estimate & MD & ND & & ND & ND & ND \\
\hline Charred/Burned & KD & - & & MD & ND & ND \\
\hline Violent Death & MD & NO & & - & - & - \\
\hline Supernumerary Rena ins & NO & NO & Uncersain & & & \\
\hline Rock Covered & ND & $x$ & - & & & \\
\hline Pit Size (m): $\begin{array}{c}\text { Length } \\
\text { Width }\end{array}$ & NO & ND & $\begin{array}{l}1.98 \text { bell } \\
1.98\end{array}$ & & & \\
\hline $\begin{array}{l}\text { Grave Goods } \\
\text { Points } \\
\text { Knives } \\
\text { Scrapers } \\
\text { Pipes (elbow) } \\
\text { Pottery } \\
\text { Basketry } \\
\text { Bone Awls } \\
\text { Antlei- Tools } \\
\text { Turquotse Beads } \\
\text { Shell Disc Beads } \\
\text { Olivellia Beads } \\
\text { Shelil Pendants } \\
\text { Conch Shell } \\
\text { Mussel Valve } \\
\text { Tibia Oigging Sticks } \\
\text { Oener }\end{array}$ & ND & $x:$ & $\begin{array}{l}x \\
2 \\
1\end{array}$ & & & \\
\hline
\end{tabular}


Table 57, Continued.

Site Footprint

Pit A

Burtal No.:

Field Archaeologist

Location: Interior

Exterior, Adjent to

Feature No.

Unit Type

Location Inside Unit

Unit S:ae $\left(\mathrm{m}^{2}\right)$

4A

$5 A$

$6 A$

$7 A$

Stratig. Pos. (m) Ov. Fi.

On Fl.

Un. Fl.

Burtal Type

ilo. Individuals

Body Position

Plased on

Orientation (head toward)

Facing

Sex

Maturation

Age Estimate

Charred/gurned

Violent Death

Supernueerary Remains

Rock Covered

Pit size (m): Length Width

Grave Goods

Points

Knives

Scrapers

Pipes (elbow)

Pottery

Basketry

Bone Awis

Antier Tools

Turquotse Beads

Shell Disc Beads

oltuella Be .

Shell Pendants

Conch Shell

Mussel Valve

Tibla Digging Stick

Other
$\operatorname{Ron} 1$

1

NE

39.04

P1t B

Green

$x$

$x$

Multiple

$7+$

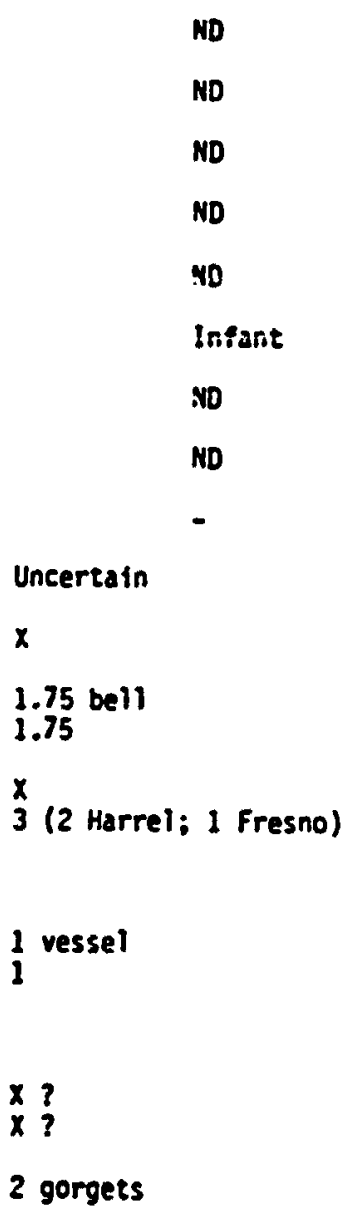


Tabie 57, continued.

Site footprint

Pit B

\begin{tabular}{llllllll} 
Burial No.: & 28 & 38 & 48 & 58 & 68 & 78 \\
\hline
\end{tabular}

Field Archaeologist Location: Interior

Exterior, Adjent to

Feature No.

Unit Type

Location Inside Unit

Unit size $\left(m^{2}\right)$

Stratig. Pos. (m) Ov. Fl.

Un. Fi.

Burial Type

No. Individuals

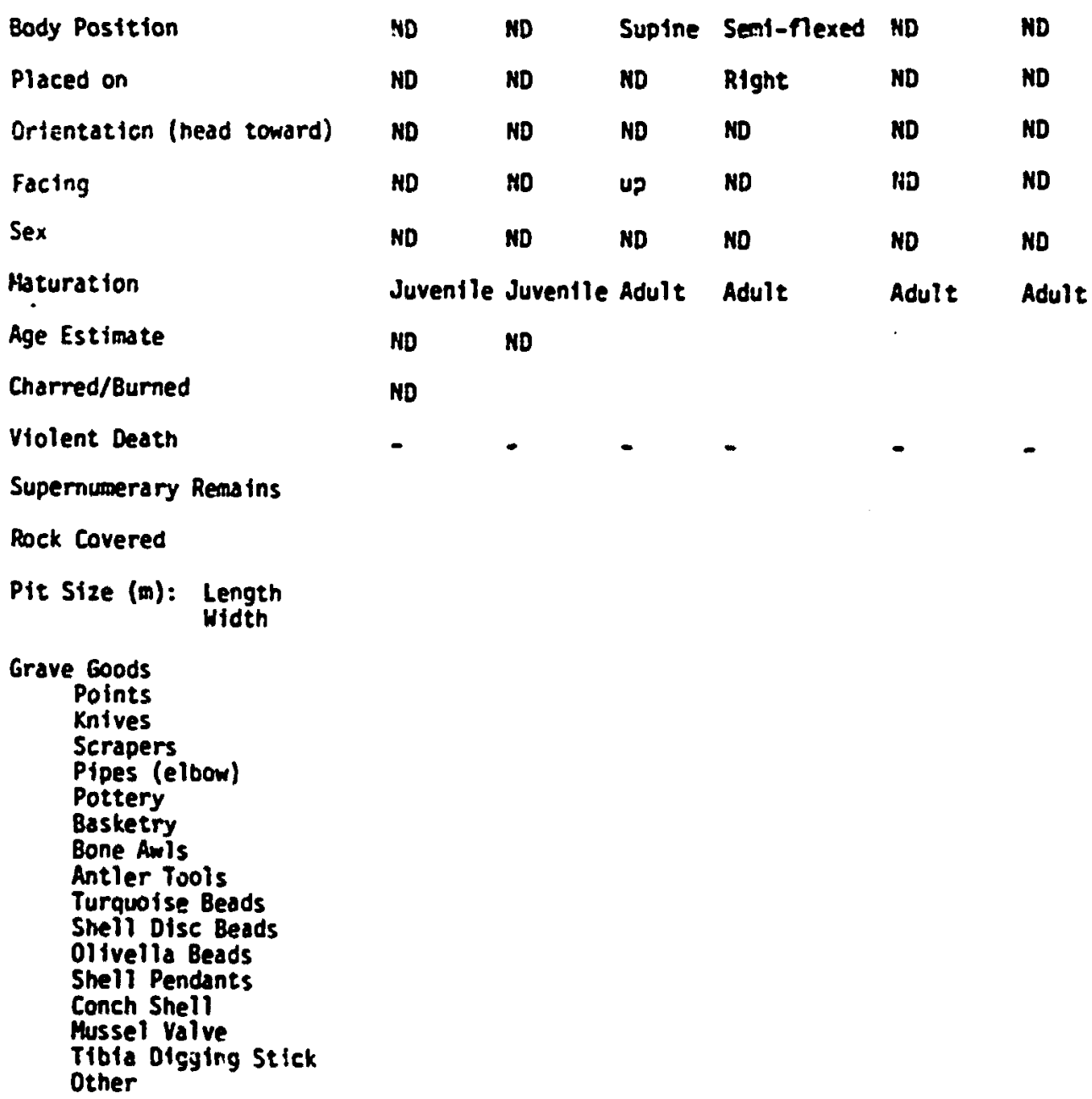

$\begin{array}{llllll}\text { ND } & \text { ND } & \text { Supine Sent-flexed ND } & \text { ND } \\ \text { ND } & \text { ND } & \text { ND } & \text { Right } & \text { ND } & \text { ND } \\ \text { ND } & \text { ND } & \text { ND } & \text { ND } & \text { ND } & \text { ND } \\ \text { ND } & \text { NO } & \text { UP } & \text { ND } & \text { ND } & \text { ND } \\ \text { ND } & \text { ND } & \text { ND } & \text { ND } & \text { NO } & \text { ND } \\ \text { Juventle Juventle Adult } & \text { Adult } & \text { Adult } & \text { Adult } \\ \text { ND } & \text { NO } & & & & \end{array}$

ND 
Table 57, Continued.

Site: Footprint

Pit C

Burial Mo.:

$\begin{array}{lllll}1 C & 2 C & 3 C & 4 C & 5 C\end{array}$

$6 \mathrm{C}$

\begin{tabular}{|c|c|c|c|c|c|c|c|}
\hline Field Archaeologist & Green & & & & & & \\
\hline $\begin{array}{c}\text { Location: Interior } \\
\text { Exterior } \\
\text { Exterior. Adjent to }\end{array}$ & $x$ & & & & & & \\
\hline Feature No. & Rn 1 & & & & & & \\
\hline Unit Type & 1 & & & & & & \\
\hline Location Inside Unit & S. Cent. & & & & & & \\
\hline Unit size $\left(m^{2}\right)$ & 39.04 & & & & & & \\
\hline $\begin{array}{c}\text { Straig. Pos. (m) Ov. Fl. } \\
\text { On Fl. } \\
\text { Un. Fi. }\end{array}$ & $x$ & & & & & & \\
\hline Burial Type & Hultiple & & & & & & \\
\hline Ho. Incivicuals & 7 & & & & & & \\
\hline Body Position & & ND & Prone & Prone & Supine & Sent-nexed & Sent-flexed \\
\hline Placed on & & ND & (Tw1s.) & (Twis.) & ND & Right & Sitting \\
\hline Orientation (head soward) & & พอ & ND & HD & ND & NO & ND \\
\hline Facing & & ND & KD & ND & ND & ND & ND \\
\hline Sex & & No & ND & ND & ND & NO & NO \\
\hline Maturation & & infant & Juven. & Juven. & Juven. & Adult & Adult \\
\hline Age Estimate & & No & Ho & Mo & ND & MD & ND \\
\hline Charred/Burned & $x$ & ND & NO & ND & ND & NO & NO \\
\hline Violent Death & & ND & ND & no & ND & no & ND \\
\hline Supernumerary Remains & Uncertain & & & & & & \\
\hline Rock Covered & - & & & & & & \\
\hline Pit Size (w): $\begin{array}{l}\text { Length } \\
\text { Wideh }\end{array}$ & $\begin{array}{l}1.90 \\
1.90\end{array}$ & & & & & & \\
\hline $\begin{array}{l}\text { Grave Goods } \\
\text { Points } \\
\text { Knives } \\
\text { Scrapers } \\
\text { Pipes (elbow) } \\
\text { Pottery } \\
\text { Basketry } \\
\text { Bone Awis } \\
\text { Antler Tools } \\
\text { Turquoise Beads } \\
\text { Shell Disc Beads } \\
\text { olivella Beads } \\
\text { Shell Pendants } \\
\text { Conch Shell } \\
\text { Mussel Vaive } \\
\text { Tibia Digging Stick } \\
\text { Other }\end{array}$ & 1 leather? & & & & & & . \\
\hline
\end{tabular}


Table 57, Continued.

Site: Footprint

$$
\text { Burial No.: }
$$

Pit $C$

7C Skull Pile

Scattered Elements

Field Archaeologist

Location: Interfor

Green

Green

Exterior, Adjent to

Feature No.

Rm 1

Rer 1

Unit Type

1

1

Location Inside Unit

ENE

Scattered

Unit size $\left(m^{2}\right)$

39.04

39.04

Stratig. Pos. (m) Ov. Fl. On Fl.

$x$-shallow pit

$\mathrm{x}$

Un. Fi.

Burlal Type

11 skulls

4 mandibles, 1 femur, 2 "I imb fragments". 2 articulated tibla

Ho. Inciviusals and fibula, 1 articulated foot

Body Postition

Placed on

No bodies

Orientation (head toward)

ND

NA

Facing

ND

NA

Sex

No

ND

NA

Maturation

\section{Adult}

ND

Age Estfesste

Charred/Burned

ND

ND

Violent Death

$x$

ND

Supernumerary Remains

No

No

$x$

$x$

- ?

Uncertain

Uncerta in

Rock Covered

Pit Size (m): Length

ND

$$
\text { - }
$$

ND

NA

$x$ ?

MO

1

Knive

Serapers

pipes (elbow)

Pottery

Basketry

Bone Awis

Antler Tools

Turquise Beads

Shell Disc Beads

Ulfuella Beads

Sneil Pendants

Conch Shell

Mussel Valve

Tibta Digging stick

other 
Table 57, Continued

Site: B1g Blue Cemetery

\begin{tabular}{|c|c|c|c|c|c|c|}
\hline Burtal No.: & 1 & 2 & 3 & 4 & $5 d$ & 6 \\
\hline Field Archaeologist & Calhoun & Caihoun & Calthoun & Calhoun & Calthoun & Calhoun \\
\hline $\begin{array}{c}\text { Location: } \begin{array}{c}\text { Interior } \\
\text { Exterior }\end{array} \\
\text { Exterior, Adjent to }\end{array}$ & $x$ & $x$ & $x$ & $x$ & $x$ & $x$ \\
\hline Feature No. & NA & MA & NA & NA & MA & NA \\
\hline Unit Type & NA & MA & NA & MA & MA & MA \\
\hline Location Inside Unit & MA & MA & NA & MA & NA & $\mathrm{Ma}$ \\
\hline Unit size $\left(m^{2}\right)$ & NA & NA & NA & MA & NA & NA \\
\hline $\begin{array}{l}\text { Stratig. Pos. (m) Ov. Fi. } \\
\text { On fl. } \\
\text { Un. Fi. }\end{array}$ & NA & MA & MA & MA & NA & MA \\
\hline Burial Type & Primary & Primary & Primary & Primary & ND & ND-Vandalized \\
\hline No. Individuais & 1 & 1 & 1 & 1 & - & ND \\
\hline Body Position & Sent-flexed & Flexed & Flexed & Flexed & & ND \\
\hline Placed on & & & & & & \\
\hline Orientation (head toward) & SE & $\mu$ & E & NW & & ND \\
\hline Facing & SW & SE & $\mathbf{s}$ & NE & & ND \\
\hline Sex & - & - & - & male & & - \\
\hline Maturation & Infant & Infant & Juventle & Adult & & no \\
\hline Age Estifrate & No & ND & ND & ca. 20y & & ND \\
\hline Charred/Burned & - & - & - & - & & - \\
\hline Violent Death & - & - & - & $-?$ & & \\
\hline Supernumerary Remains & - & - & - & - & & ND \\
\hline Rock. Covered & $x$ & $x$ & $x$ & $x$ & $x$ & $x$ \\
\hline Pit Size $(m): \begin{array}{l}\text { Length } \\
\text { width }\end{array}$ & $\begin{array}{l}0.49 \\
0.37\end{array}$ & $\begin{array}{l}1.07 \\
0.45\end{array}$ & $\begin{array}{l}1.22 \\
0.91\end{array}$ & $\begin{array}{l}0.85 \\
0.61\end{array}$ & & $\begin{array}{l}1.14 \\
0.91\end{array}$ \\
\hline $\begin{array}{l}\text { Grave coods } \\
\text { Points } \\
\text { Knives } \\
\text { Scrapers } \\
\text { Pfpes (elbow) } \\
\text { Pottery } \\
\text { Basketry } \\
\text { Bone Awls } \\
\text { Antier Tools } \\
\text { Turquoise Beads } \\
\text { Shell Disc Beads } \\
\text { olivelia Beads } \\
\text { Sheli Pendants } \\
\text { Conch Shell } \\
\text { Mussel Valve } \\
\text { Tibia Digging Stick } \\
\text { Other }\end{array}$ & 2 sherds & - & - & \multicolumn{2}{|c|}{ Broken vessel } & ND \\
\hline
\end{tabular}

